\title{
Himalayan Dreaming: Australian mountaineering in the great ranges of Asia, 1922-1990
}





\title{
Himalayan Dreaming: Australian mountaineering in the great ranges of Asia, 1922-1990
}

\author{
Will Steffen
}

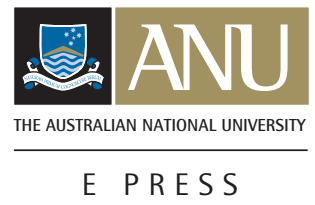




\section{ANU}

E PRESS

Published by ANU E Press

The Australian National University

Canberra ACT 0200, Australia

Email: anuepress@anu.edu.au

This title is also available online at: http://epress.anu.edu.au/himalayan_citation.html

National Library of Australia

Cataloguing-in-Publication entry

Author: Steffen, Will.

Title: Himalayan Dreaming: Australian mountaineering in the great ranges of Asia, $1922-1990$.

ISBN: 9781921666162 (pbk.) 9781921666179 (pdf)

Notes: Includes bibliographical references.

Subjects: Mountaineering --Himalaya Mountains--History.

Mountaineers--Australia.

Everest, Mount (China and Nepal)

Other Authors/Contributors: Will Steffen

Dewey Number: 796.522095496

All rights reserved. No part of this publication may be reproduced, stored in a retrieval system or transmitted in any form or by any means, electronic, mechanical, photocopying or otherwise, without the prior permission of the publisher.

Cover design and layout by ANU E Press

Front cover image: John Finnigan and Theo Hooy at the base of the west face of Baruntse, 1988. Photo by Ken Baldwin

Author Photo: Carrie Steffen

Back cover: Greg Mortimer on the summit of Mt Everest, 1984. Photo by Tim Macartney-Snape

Printed by Griffin Press

This edition (C) 2010 ANU E Press 


\section{Contents}

Preface ....................... . . . .

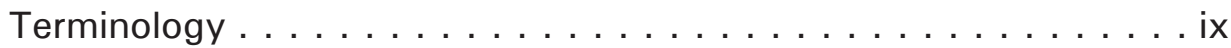

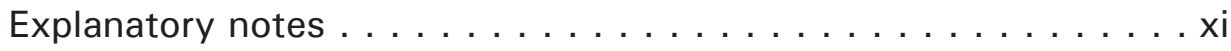

Acknowledgments. . . . . . . . . . . . . . . xiii

Part 1: Deep history - the early days

1. Unlikely mountaineers . . . . . . . . . . . . . . 1

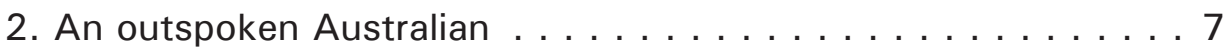

3. Quiet years. . . . . . . . . . . . . . . . . 25

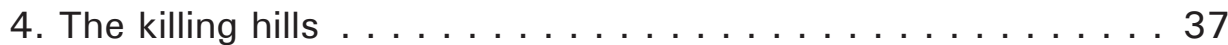

Part 2: On top-first major Aussie triumphs

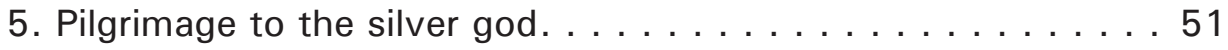

6. Upwardly mobile young men. . . . . . . . . . . . . 67

7. Long necks on Dunagiri . . . . . . . . . . . . . . . 85

\section{Part 3: Everest I-success against all odds}

8. A powerful partnership. . . . . . . . . . . . . . . . . 109

9. Everest apprentices . . . . . . . . . . . . . . 125

10. Tough trials . . . . . . . . . . . . . . . . 139

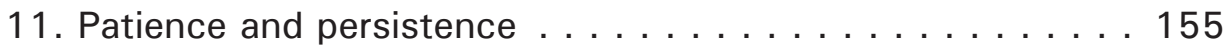

12. An unforgettable face $\ldots \ldots \ldots \ldots \ldots \ldots$

$\begin{array}{ll}\text { Maps } & 187\end{array}$

$\begin{array}{ll}\text { Images } & 191\end{array}$

Part 4: Combat zone-soldiers in the mountains

13. A colonel's dream . . . . . . . . . . . . . . . . . . . . . . 249

14. Ordered to climb . . . . . . . . . . . . . . . 263

15. By the book . . . . . . . . . . . . . . . 273

16. An arranged marriage. . . . . . . . . . . . . . 287

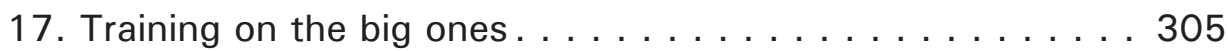


Part 5: Team building-mail-order mountaineers

18. Climbers wanted . . . . . . . . . . . . . . . . . 327

19. Turkeys on ice . . . . . . . . . . . . . . . 337

20. Innocence lost. . . . . . . . . . . . . . . . . 351

Part 6: Everest II-the bicentennial ascent

21. A strained relationship . . . . . . . . . . . . . . 365

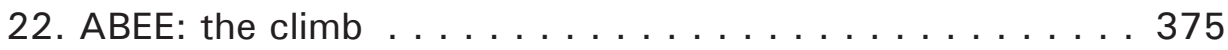

23. ABEE: an analysis . . . . . . . . . . . . 393

Part 7: Peak performance-tough climbs on big mountains

24. Master of all trades . . . . . . . . . . . . . . . . . 415

25. An even score. . . . . . . . . . . . . . . . . . . . . 437

26. A quiet achiever . . . . . . . . . . . . . . 451

Part 8: New summits-beyond the trade routes

27. Small is beautiful. . . . . . . . . . . . . . . . . 463

28. Where are the women? . . . . . . . . . . . . 483

29. A Himalayan grand slam . . . . . . . . . . . . . . . . . 503

Epilogue . . . . . . . . . . . . . . . . . 521

Bibliography . . . . . . . . . . . . . . . . . . . . . . . 529

Appendix: Record of Australian

mountaineering in the Himalaya . . . . . . . . . . . . . 553 


\section{Preface}

The title 'Himalayan Dreaming' for this history of Australian mountaineering in the great ranges of Asia reflects a major theme of the book: the emergence of world-class Himalayan mountaineers from the world's flattest, hottest continent, a land better known for its gentle, time-worn landscapes and its rich heritage of Aboriginal culture.

The history begins with the British expedition to Mt Everest in 1922 and continues through to the magnificent Australian successes in 1990 on four of the world's highest mountains. The book is not organised in a linear chronological fashion but rather is composed of strands woven together as a large tapestry. The strands are composed of groups of mountaineers who have climbed together for a number of years in the Himalaya, sometimes drawing in sub-strands for attempts on major peaks and at other times splintering to form offshoot groupings. The ebbing and flowing of these strands and their intertwining in the period 1975-90 forms the tightly woven tapestry of Australian Himalayan mountaineering described in this book.

Two major focal points - one in time and the other in space-dominate the tapestry. The first is the year 1975, in which so much of Australian activity in the Himalaya had its start. The second is Mt Everest. Every major Australian Himalayan mountaineer has, at one time or another, been involved in an Everest attempt. Thus, most of the strands are linked at some point to this most magnetic of Himalayan summits.

Although I have tried to be rigorous in my presentation of the facts, much of the material presented in the book is opinion - either my own or that of the climbers I have quoted. In addition, the ways in which I have presented the events and the relative emphases I have placed on them are generally my perceptions. For example, many of the climbs that I organised around an eventual major attempt on Mt Everest were not, in fact, at the time specific training climbs for Everest but were objectives in their own right. For these and other value judgments by organisation and emphasis, I take full responsibility.

Many of the chapters contain excerpts from the climbers themselves - usually tales of a particularly humorous or dramatic nature. They are set out in boxes so as not to interrupt the flow of the story itself, but they do give an immediacy and first-person perspective not often found in a historical work.

I have not attempted to recount every Australian ascent in the Himalaya (although most get at least a mention), but rather have attempted to tell a coherent and 
interesting story based on the major players and their ascents and attempts. For a more thorough listing of Australian climbing in the Himalaya, including all ascents and all attempts on major peaks during the period covered in this book, please refer to the table prepared by Zac Zaharias, which appears in the appendix of this book. The table was compiled primarily from five such tables that have appeared over the years in Wild magazine: nos 40 (Autumn 1991), 55 (Summer 1995), 80 (Autumn 2001), 92 (Autumn 2004) and 100 (Autumn 2006).

Finally, the book presents a glimpse into the lives - the successes, failures, tragedies, motivations, fears, conflicts, humour and compassion-of a most remarkable group of Australians as they push themselves to the ultimate limits of survival in the most spectacular and demanding mountain arena of all: the high Himalaya. 


\section{Terminology}

Three important matters of terminology deserve comment. The first is the word 'Himalaya', which quite frequently appears, incorrectly, as 'Himalayas' in English-language publications. 'Himalayas' is a double plural, as explained clearly by Professor Ram Rahul, quoted in the editorial of Volume 32 of the Himalayan Journal:

I have used the collective name Himalaya (Him, snow, plus alaya, home) in place of the commonly used Himalayas, which is a double plural and a grammatical monstrosity. Indeed, to use the word Himalayas is as absurd as referring to Englishmen as Englishes or using the word alphabets for two or more letters and characters of an alphabet. Moreover, Himalayas jars on ears accustomed to the euphony of Sanskrit words and phrases. It is curious that it is only in English that the name suffers a corruption. In all other languages of the world, including other Western languages like French and Russian, it is what we in India have called it from time immemorial.

The second matter concerns the name for the highest mountain in the world. It is now preferable around the world to use the local, indigenous names for mountains rather than those given later by Western explorers. For example, the highest peak in North America is now called Denali (Mt McKinley). Most agree that Chomolungma is probably the best local name for Mt Everest, although Sagamartha is often used on the Nepalese side of the mountain. Climbers, however, almost exclusively use Everest to refer to it, partly because of tradition and partly because it is simply shorter and easier to say than either of the local names. In this book, I have mostly stuck with the common usage of the mountaineers themselves - that is, with Mt Everest.

The final point concerns the geographical definition of the term 'Himalaya'. Strictly speaking, the Himalaya are the narrow range that curves in a great arc from Bhutan in the east to near the India-Pakistan border in the west. I have, however, used the term as a short version of 'Greater Himalaya', which includes - in addition to the Himalaya itself - the Pir Panjal, the Karakoram, the Pamir and the other great ranges of Asia. 



\section{Explanatory notes}

In some chapters, I have included phrases and passages designed to explain mountaineering terms to the uninitiated. I have tried to keep such passages to a minimum, but feel that they are necessary at a few points.

I have used mixed units for height. Although metric units are now the only official units of height and distance used in the Himalaya, many Western mountaineers, particularly those from English-speaking countries, still use imperial units at some times. In fact, mountaineers quite happily swap from one set of units to the other, referring to a camp at 6800 metres in one breath and discussing tactics for a 5000-foot face in the next. I have retained this mixed usage, especially in the earlier climbs when imperial units tended to be used more frequently than now. In most cases when I have used imperial units, I have given the metric equivalent in parentheses. The conversion factor is roughly 3.3, so that to convert in one's head from metric to imperial, multiply by three and add another 10 per cent. For example, a 7000-metre mountain is $3 \times 7000=$ 21000 plus another 10 per cent of that, or about 23000 feet. 



\section{Acknowledgments}

There are many people to whom I owe much in the preparation of this book.

First, there are Australia's Himalayan climbers themselves, who have spent much time telling me their stories. Those with whom I talked-either in person or over the telephone - with whom I corresponded or who commented on early drafts of the manuscript include Brian Agnew, Peter Allen, Don Baldwin, Ken Baldwin, Paul Bayne, Geof Bartram, Austin Brookes, Dorothy Brown, Dot Butler, John Cashman, Jonathan Chester, Greg Child, Peter Cocker, Steve Colman, Pat Cullinan, Warwick Deacock, Michael Dillon, John Finnigan, Jo Flood, Peter Gration, Michael Groom, Lincoln Hall, Andy Henderson, Graeme Hill, Theo Hooy, Richard Howes, Peter Lambert, Mark Lemaire, Geoff Little, Tim Macartney-Snape, Roddy Mackenzie, Terry McCullagh, Rob Mitchell, Colin Monteath, Rick Moor, Peter Morris, Greg Mortimer, Brigitte Muir, Jon Muir, Bill Packard, Phil Pitham, Colin Putt, John Retchford, Michael Rheinberger, Andrew Rothfield, Ben Sandilands, Fritz Schaumburg, James Strohfeldt, Jim Truscott, Jim van Gelder, Ray Vran, John Wanless, Geoff Wayatt and Zac Zaharias.

The following climbers provided the photographs reproduced in this book: Peter Allen, Ken Baldwin, Dorothy Brown, Graham Budd, Warwick Deacock, Michael Groom, Tim Macartney-Snape, Brigitte Muir, Jon Stephenson, Geoff Wayatt and Zac Zaharias.

Special thanks go to Zac Zaharias, who has carefully compiled the tables of Australian Himalayan climbing that appear in the appendix at the end of this book. These tables represent the most complete, up-to-date record of Australian mountaineering in the great ranges of Asia. Furthermore, I am grateful to Wild magazine for their permission to use in these tables information that first appeared in Wild.

In addition, thanks go to six climbers who helped me with the description and analysis of the Australian Bicentennial Everest Expedition (ABEE). This was a particularly difficult expedition to write about and I am grateful to Pat Cullinan, Peter Lambert, Terry McCullagh, Michael Rheinberger, Jim Truscott and Zac Zaharias for taking the time to give me detailed comments on an early draft.

Two other climbers-Lincoln Hall and Greg Child-deserve special acknowledgment for their writing as well as their climbing abilities. Both are superb writers - the equal of any climbing authors anywhere in the worldand I can highly recommend their books as excellent accounts of Himalayan 
mountaineering. I am grateful to them, and others, for allowing me to quote extensively from their works at several points in this book. This has given the book an immediacy and liveliness it otherwise would have lacked.

Also, I am grateful to Chris Baxter, editor of Wild magazine, for allowing me to use several extensive quotes from articles that have appeared in Wild over the years. Wild is an excellent source of information on Australian Himalayan climbing; its breadth of coverage and accuracy of reporting have made my research task easier.

Finally, and most importantly, I thank my wife, Carrie, and my daughter, Sonja. Carrie played a large part in the development of the initial idea for this booksomething she has no doubt regretted on many occasions! She has had to endure many evenings with a house full of climbers spinning yarns and emptying bottles of wine and many hours with an uncommunicative husband hunched over a keyboard. In addition, she has put in many hard hours herself turning my assaults on the word-processing system into something legible. 


\section{Part 1: Deep history-the early days}





\section{Unlikely mountaineers}

It was mid-September 1984 and high winds scouring the North Face of Mt Everest had pinned the American climbers in a camp high on a ridge bordering the massive wall. The American expedition had been continually plagued by the gales - winds so strong that they had blown away 20-kilogram bags of food and torn a side shield off one climber's goggles, freezing the exposed tissue in his eye and leaving him temporarily blind. The Americans, however, methodically pushed on, establishing a string of camps up the mountain, fixing permanent ropes between the camps to act as a safety line and stocking the camps with food and fuel.

The team consisted of the elite of America's alpine climbers and they were slowly putting themselves into position to snatch one of the last great unclimbed routes left on Everest. The mountain was first climbed in 1953 and since then climbers from around the world have continued to find challenges on Everest by climbing ever steeper and more difficult routes and by tackling the peak without the aid of supplementary oxygen — a feat not accomplished until 1978. One of the greatest challenges - the one driving the Americans on through the vicious winds and frequent snowstorms - lay on Everest's northern side.

The target of the first serious attempts on Mt Everest in the 1920s, the North Face is a great pyramid rising more than 3500 metres above the Tibetan Plateau. British climbers attempted the mountain by the most obvious line of weakness on the northern side: a series of ridges and shoulders that bordered the wall on the east. They and subsequent mountaineers, however, could not help but notice a striking feature: a long couloir or ice gully that split the face vertically from about mid-height to just below the summit. It is what mountaineers call a 'classic line': a route that is aesthetically pleasing in its directness and simplicity, albeit one that is also steep, physically demanding and fraught with considerable danger.

There was no incentive for climbers to attempt the Great Couloir, as it was known, in the 1920s and 1930s, since, as long as Everest had not been climbed, mountaineers would naturally concentrate on the least difficult route to the top. With the closing of Tibet to foreigners in 1950, there was no possibility of access to the northern side of Everest, so the Great Couloir was, as far as mountaineers were concerned, gone, although it certainly was not forgotten.

In 1979, the northern side of Everest was opened again to foreign mountaineers. Three years later, a large, experienced and talented American team took on the 
Great Couloir - and just missed making the first ascent of Everest's imposing North Face. They quickly regrouped and organised another expedition to Everest's north side in 1984. Their objective again was the Great Couloir but this time there was a bureaucratic obstacle as well. Chinese authorities controlled climbing on their side of Everest by issuing permits; only one group was allowed to attempt a particular route at a time. In 1984, the Americans had been beaten to the punch for the Great Couloir route by an Australian team.

This was not much of a problem in the Americans' view. Who ever heard of Australian mountaineers competent to climb Mt Everest? Australia was the world's flattest and hottest continent, it had no tradition of alpine climbing and its handful of mountaineers, with only a few expeditions to the Himalaya under their belts, had managed to climb only four $7000 \mathrm{~m}$ peaks and none of the world's 14 peaks of more than $8000 \mathrm{~m}$. To top it off, the Australian team of five climbers - tiny by Everest standards - would attempt the unclimbed Great Couloir route without the help of supplementary oxygen. No route on $\mathrm{Mt}$ Everest had ever been climbed - not even by the world's best mountaineers - for the first time without oxygen. The Americans, then, were still in a commanding position to make the first ascent of the North Face. They would set up camps part-way up the early British route, wait patiently for the Australians to throw in the towel and go home, then traverse into the Great Couloir and snatch the prize. $^{1}$

Throughout September, the American plan seemed to be working to perfection. Undaunted by the frequent spells of bad weather, they had set up several camps on the North Ridge and were poised to move into the Great Couloir. The Australians, meanwhile, were having their problems. They had made very little progress at all on the vast face and, with a high point of only $7300 \mathrm{~m}$, were a long way from making a summit attempt. Furthermore, they seemed to retreat at the first sign of bad weather and spend their time skiing on the upper Rongbuk Glacier rather than forcing the climb up the couloir.

Confirmation of the Americans' view came from the local staff attached to the Australian base camp. They visited their colleagues with the American expedition and reported that the Australians were a group of no-hopers - very nice young lads but lacking the drive and determination needed to force a route up a mountain as formidable as Everest. They would probably ski around for another week or two and then return to the golden sand, warm waters and sunny skies of Australia, content to have banged their crampons and ice axes into the lower slopes of Everest's north wall.

1 Krakauer, J. 1985, 'Return to the North Face', Outside, February, pp. 29-32, 68. 
It was not surprising that the crack team of American climbers had trouble taking the virtually unknown Australians seriously. Even Australian mountaineers' own countrymen know little of their exploits and often question the sanity of their desire to climb in the Himalaya. Well-known writer Thomas Keneally expressed that typical attitude succinctly:

I remember a day when Lincoln Hall was sitting at his ease on the sundeck of my house in Sydney and chatting about his experiences as a member of the first Australian party ever to climb Everest. All of us there on the sundeck were dressed for a summer's day. I noticed the damage which several seasons of Himalayan frost-bite had done to Lincoln's feet and hands. As non-climbers always do, I wondered about the compulsion which makes an Australian, born in the sun in a country of ancient, worn-down mountains, seek the transcendent cold and height of the highest mountains of all. ${ }^{2}$

Keneally's comment points out the two commonly mentioned factors that work strongly against would-be Australian Himalayan mountaineers: Australia's climate and culture of sun, surf and sand and its total lack of any substantial mountain range on which to train.

Mention Australia to a North American or European and they will almost surely conjure up images of a vast desert of red sand and bouncing kangaroos rimmed by a coastline of pristine beaches, coral reefs and tropical fish. Many of Australia's sportspeople most well-known overseas come from activities associated with sun and sea: golf, tennis, swimming, surfing and sailing. Australia was the first country to take sailing's most coveted prize - the America's Cup - from the United States. Its Ironman competition - a spectacular display of strength and endurance in a setting of crashing surf and broad beaches - could become Australia's biggest sporting export.

From an early age, Australian boys and girls are introduced to the leisure culture of sun and sea. The standard Australian family holiday is a trip to their favourite coastal park: set up the tent, stoke up the barbecue and head for the water. Advertising reinforces this mind-set. We are constantly shown images of healthy, attractive young adults cavorting on a golden beach at sunset and older couples enjoying a quiet drink at a posh seaside resort. The sound of waves rhythmically crashing on a rocky headland, the smell of the salty seaside air and visions of bright sunshine glinting off golden sand are indelibly etched onto the Australian psyche.

2 Keneally, T. 1989, 'Foreword', The Loneliest Mountain, Simon \& Schuster, Sydney, p. v. 
And what of mountains? Behind the coast are rocky escarpments and rolling, wooded hills; there is no range of jagged, snow-clad mountains to challenge adventurous young Australians or fire the imagination of armchair climbers. When it comes to the continental mountain sweepstakes, Australia is dead last.

A quick examination of the international literature of mountains and mountaineering leaves one in no doubt as to just where Australia stands. The forward to National Geographic's book Mountain Worlds, which profiles 18 of the world's mountainous regions, clearly sets out the situation — naturally from an American point of view:

Mountains. They span the globe, swell the oceans and rise on all continents and major islands. They are the Sierra Nevada, Cascades, Coast Ranges, Alaska and Brooks Ranges, the Appalachians-and the Rockies, with more than a hundred different ranges large enough to have their own names. They are the peaks of the Antarctic, and the Andes and the Sierra Madres. They are island mountains like Tahiti, Hawaii, and the Azores, and mountainous islands like New Zealand and Greenland. They are the Himalayas, buttressing the thousand-milewide Tibetan Plateau that averages 15,000 feet - higher than anything in the contiguous United States. They are the Atlas and Kilimanjaro and Kenya. They are the Pyranees, Caucasus, the Alps that dominate western Europe, and the Urals, the traditional boundary between Europe and Asia.

Their names sing of wild places and unfenced spaces-Ruwenzori, Tetons, Hindu Kush, Dolomites, Uinta, Sangre de Cristo, Bitterroot, Allegheny, Gallatin, Karakorams. Mountains command the eye and enlarge the being. They dominate the globe like no other natural thing except the oceans. ${ }^{3}$

Australia does not receive a mention - nor do any of its diminutive mountain ranges. Obviously, no Australian range is featured in the body of the book.

In the mountaineering literature, Australia is even more conspicuously absent. In Francis Keenlyside's Peaks and Pioneers. The story of mountaineering, he quite properly focuses on the Alps and then the Himalaya. In a chapter entitled 'Further afield', he looks at developments in North and South America, New Zealand and European ranges other than the Alps. He introduces his short section on the history of African mountaineering with 'Mountainwise Africa is a disappointing continent' ${ }^{4}$ He could well have added that mountainwise, Australia is a nonexistent continent.

3 Sedeen, M. (ed.) 1988, Mountain Worlds, National Geographic Society, Washington, DC.

4 Keenlyside, F. 1975, Peaks and Pioneers, Paul Elke, London. 
At least middle-aged American adventurers Dick Bass and Frank Wells had to pay lip-service to Australian mountains. Disgruntled executives, they decided to solve their midlife crises by climbing the highest mountains on each of Earth's seven continents. That required them to scale Mt Kosciuszko-a feat that received a scant nine pages in the book on their adventure, Seven Summits. And much of that brief chapter, entitled 'Kosciusko: a walk in the park', is devoted to planning their attempt on remote Mt Vinson, the largest peak in Antarctica. After coping with storms, extreme altitude, dangerous snow conditions and remote access on the highest summits of the other continents, their main problems on Kosciuszko were organising the champagne for the top and fighting off the hordes of tourists out for a weekend walk. ${ }^{5}$

The last word comes from John Cleare, a professional mountaineer/photographer who has travelled the world filming and participating in adventurous activities. He has jumped out of hot-air balloons over Texas, hung off the north wall of the Eiger filming Clint Eastwood in precarious positions and climbed and photographed wild sea-stacks along the British coast. His survey of the world's ranges and peaks, simply called Mountains, is a highly respected guide to mountaineering around the world. He does devote a section to Australia, with a most appropriate introduction on the Australian climbing scene:

Seen from space, Australia must appear as a vast, dull grey and red expanse, with only a green fringe on the east coast to break the monotony. A closer examination of this belt would reveal an almost continuous chain of mini-mountains. Mt Kosciusko, the continent's highest point, barely tops 7,000 feet. Mostly wooded (the timber line extends to 4,000 feet), the Great Dividing Range is the preserve of the 'bushwalker' rather than the mountaineer. Its mountains have been well described as being '...so old that time has rounded them to resemble sleeping dinosaurs, with here and there a skeleton showing ribs and vertebrae...' Australia has no permanent snowfields and few mountains you can't walk up, or drive up.

Australian mountaineering is confined to a small but growing band of rock-climbing devotees who live in the cities of the south-east. It is a lucky coincidence that the 'mountainous' south-east is also the centre of gravity of this flat continent's sparse population. Elsewhere vast distances, searing heat and inferior potential have combined against any significant mountaineering activity. ${ }^{6}$

Interestingly, Cleare's perceptive comments on Australian climbing were published in 1975, the year the first Australian expedition went to the Himalaya

5 Bass, R. and Wells, F., with Ridgeway, R. 1986, Seven Summits, Pan Books, London, pp. 269-77.

6 Cleare, J. 1975, Mountains, Macmillan, London, pp. 235-9. 
and the year in which many strands of Australian mountaineering beganstrands that would eventually twine together to produce some astonishing results. It was undoubtedly the most significant year in the history of Australian mountaineering.

That realisation was to come much later. For the Americans dug in on Everest's North Ridge in 1984, Australian mountaineers were still very much unknownindeed, a novelty. The Americans could be forgiven for thinking that the Australians should be at Bondi instead of base camp. Just a week or so after the weather finally settled, however, the American mountaineers-poised to capture one of the great remaining prizes on Everest - were suddenly reduced to spectators witnessing one of the most remarkable climbs Everest had ever seen. The climb intensified the Americans' curiosity and raised questions that were increasingly asked by experienced mountaineers as more and more Australians ventured into the Himalaya and came away with more than their share of successes: just who were these most unlikely of mountaineers, coming from the world's flattest, hottest continent? With no tradition of mountaineering and no significant mountains in their homeland, how did they get the skills to tackle Everest and other Himalayan giants? And, as Thomas Keneally so lucidly queried, what would make Australians - from the most equable of climates and the most comfortable of lifestyles - risk their lives in the extreme dangers and discomforts of Himalayan climbing? 


\section{An outspoken Australian}

The first Australian connection with Himalayan climbing goes back to very nearly the beginning of Himalayan climbing itself and in location to Mt Everest, to the precise area of the mountain's northern aspect where the AmericanAustralian drama of 1984 unfolded. In 1922, the second major British expedition to Mt Everest made the first serious attempt to reach its summit. The British climbers of 1922, using the North Col/North Ridge route that the Americans would follow 62 years later, climbed higher than any human had previously climbed. In setting that record, the second British summit team avoided high winds on the ridge by traversing across the North Face to a point very close to the Great Couloir - the line of the 1984 Australian climb. Ironically, the leader of that group of British climbers in 1922 was in fact an Australian, George Ingle Finch.

Finch was a man of many and varied talents. In addition to being one of the most accomplished snow and ice climbers of his era, Finch was a well-respected scientist, a clever innovator and an exacting and, at times, witty writer. Although he was a member of only the 1922 British Everest expedition, Finch exerted an important and often controversial influence on Everest attempts for decades.

It was a scramble up a rocky little peak on his family's sheep and cattle property near Orange, New South Wales, that first sparked thirteen-year-old George Finch's enthusiasm for high places. He wrote in his autobiography, The Making of a Mountaineer:

[O]n a dewy spring morning in October, I urged my panting pony towards a hill-top in the Australian bush, the better to spy the whereabouts of a mob of wallaby. The last few feet of the ascent being too much for the pony, I dismounted and, leaving him behind, scrambled up a short, rocky chimney to the summit. The wallaby were nowhere to be seen; but my wondering eyes were held spell-bound by such a vision as I had never even dreamed of. Miles and miles away the white-washed roofs of the township of Orange gleamed brightly in the clear morning sunshine; the main roads converging upon the town showed sharp and distinct from out [of] their setting in the rolling bush. The picture was beautiful: precise and accurate as the work of a draughtsman's pen, but fuller of meaning than any map. I was just thirteen years old, and for the first time in my life the true significance of geography began to dawn upon me; and with the dawning was born a resolution that was to colour and 
widen my whole life. Before returning to my pony after this, my first mountain ascent, I had made up my mind to see the world, to see it from above, from the tops of mountains. ${ }^{1}$

Young Finch did not have to wait long to begin his life's odyssey to see the world from above. A year later, the Finch family travelled to Europe, and in no time George and his brother, Max, found something to climb. After scrambling up a steep, dangerous sea-cliff at Beachy Head in England, they scaled-much to their parents' consternation - the Notre Dame Cathedral on their first visit to Paris.

They would have many more opportunities to climb in Europe. It was decided that the boys would be educated on the Continent, looked after by their mother, while their father returned to Australia to manage the property. After tutors in Paris accomplished his secondary education, George Finch settled on the Eidgenossische Technische Hochschule (ETH) in Zurich for his tertiary education.

He decided that the physical sciences were exacting and challenging enough for him, so he pursued a course in chemical engineering, gaining his diploma in 1911 and winning a gold medal as the best student in his year (which he quickly sold to finance one of his climbing trips). After short sojourns in Germany and Geneva, he settled in England and built his considerable scientific reputation with more than 40 years of research there.

For nearly all of that period, he was on the staff of the Imperial College of Science and Technology in London, rising to Assistant Professor in 1927 and then to the Foundation Professor of Chemical Engineering in 1936. His major interest lay in surface physical chemistry and he was a pioneer in using the technique of electron diffraction to study the properties of surfaces. His work was widely recognised throughout the scientific world and he was accorded its highest honours. He was elected a Fellow of the prestigious Royal Society, received an honorary Doctorate of Science from the University of Brussels, was created a Chevalier of the Legion of Honour in France and was made a Companion of the Order of Leopold II in Belgium. Throughout his distinguished scientific career, he presented numerous invited lectures in England and on the Continent. ${ }^{2}$

George Ingle Finch's mountaineering career was equally illustrious. A member of the Academic Alpine Club of Zurich, he was soon recognised by his peers for his climbing prowess and for his rather unusual personal style. Italian climber Count Aldo Bonacossa, on visiting Zurich in 1909 and meeting the leading mountaineers of the area, remarked:

1 Finch, G. I. 1924, The Making of a Mountaineer, J. W. Arrowsmith, Bristol, England, ch. I.

2 Russell, S. 1988, George Finch-The mountaineer. A memoir, J. W. Arrowsmith, Bristol, England, ch. 4. 
But the recognised number one mountaineer and the most outstanding personality among them by far was George Finch. He was tall and wore his hair long and untamed, quite unlike other men in Switzerland...this gave him an exotic look. Moreover he came from the Antipodes and as a result was nicknamed 'The Australian'. ${ }^{3}$

At the time of Finch's development as a climber, the mountaineering world was centred on the European Alps. The Himalaya were certainly known to climbers and Mt Everest had already been established as the highest peak in the range, and indeed the world. The problem, however, was access. The Kingdom of Nepal, which lay to the south of the great range of the Himalaya that contained Everest and seven other of the world's $8000 \mathrm{~m}$ peaks, was definitely off limits to outsiders. The northern approach to the range, through Tibet, was only slightly more accessible. It was the British who gained the inside track to the northern route primarily through their covert support of Tibetan autonomy in a threeway tussle with Russia and China for control of the arid plateau. Although China was officially recognised by the other powers as having sovereignty over the region, the Tibetans, when they eventually gained autonomy in 1913, did not forget the unofficial help they received from the British.

With the possibility of gaining access to the Himalaya growing year by year, the attention of the British mountaineering community quickly focused on $\mathrm{Mt}$ Everest - the logical first target of ambitious climbers. Finally, near the end of 1920, the Dalai Lama gave permission for a British expedition to travel to Mt Everest. The scramble was immediately on to organise the venture, choose the climbers, equip them and get the entourage to the mountain the next year before the fickle politics of the region had a chance to slam the door shut again.

George Finch was an obvious choice as one of the Everest climbers. He was by then one of the leading alpinists in Britain and the Continent, he was available for the expedition and in many other ways he was simply impossible to ignore. Even his physical appearance, though not quite as 'Australian' as in his earlier climbing days, commanded attention from all who met him. As his son-in-law Scott Russell wrote:

At first sight he seemed rather formidable. Over six feet two inches tall, broad-shouldered and very erect, he made the rest of us look rather puny, but it was his strong finely drawn features which impressed me most, especially his expressive cold-blue eyes, which inspected me, rather dauntingly, at our first meeting. Later I came to realise that they were an excellent barometer of his mood, which sometimes changed rapidly. Interest, amusement, suspicion, or disapproval were unmistakably 
conveyed with an appropriate change in voice; silence and a blank, rather stern, expression indicated that he was deep in thought. It was no surprise that he inspired great friendships and equally great enmities for his personality and his appearance made it scarcely possible for him to be ignored in any company. ${ }^{4}$

Finch's experience and climbing skill were certainly recognised by Percy Farrar, president of the British Alpine Club, who recommended Finch and his brother, Max, as the summit party. They would be joined by Marcel Kurz, a strong Swiss climber, to form the nucleus of the climbing team for the 1921 expedition.

Unfortunately for Finch, Farrar could not make the selection alone. Soon after the Dalai Lama granted access to Everest, a committee was formed to organise and oversee the venture. Although the Mount Everest Committee had equal representation from the Alpine Club and the Royal Geographic Society (RGS), the group was quickly dominated by A. R. Hinks, the secretary of the RGS and a man with no mountaineering experience. Almost immediately, mountaineering considerations were pushed to the background and, try as they might, Farrar and the other Alpine Club members were virtually powerless to influence the committee's decisions on most aspects of the expedition.

The first to go was Kurz, as it was decided that the expedition should be all English. Next to get the axe was Finch, whose outspoken and unconventional behaviour did not sit well with the staid RGS, and particularly Hinks. Indeed, although Farrar supported him vigorously, Finch had made a few enemies within the Alpine Club with his frank comments on the quality of British climbing.

Everest historian Walt Unsworth attributed much of Finch's trouble with the Mount Everest Committee to his 'Australian unorthodoxy'. ${ }^{5}$ It was, however, undoubtedly not his Australian upbringing, but rather his own, often abrasive, personality, his questioning, analytical scientific mind, his background as a Continental rather than British climber and his outspokenness, particularly when challenging traditional values, that got him into trouble with the committee.

Finch's problems with the Alpine Club itself stemmed from his pointed comments on two strongly held values of club members: the importance of rock climbing and the necessity of guided climbing in the Alps. British climbers' emphasis on rock climbing was understandable. The British Isles are liberally endowed with small to medium-sized crags of sound rock; but apart from a few Scottish hills with steep gullies that are covered in ice in winter, there are no ranges on which climbers can hone their alpine skills.

4 Ibid., ch. 2

5 Unsworth, W. 1981, Everest, Penguin Books, Middlesex, England, ch. 3. 
In Finch's home range of the Alps, he had learned to contend with a variety of conditions, from hard polished ice to soft, almost bottomless snow into which climbers sometimes sunk to their chests. He had to devise routes through mazes of glaciers, snow basins, ridges and gullies, and sometimes carry out the climbs in raging storms or thick fog. He had to be alert to dangers: the stability of a moderately angled snow slope against avalanching, the possibility of a rock fall from an unstable ridge above or the likelihood of hidden crevasses in a glacier. To Finch, rock climbing was just another weapon, and not a terribly important one at that, in the rather considerable arsenal of the alpine climber - and he was not afraid to say so publicly.

In The Making of a Mountaineer, he wrote:

Rock-climbing, particularly on good, sound rock, has never held any great charm for me. I have always regarded it as but one of the simplest, most easily learnt and less important branches of a wider art, and, as it is met with on almost any big snow-and-ice expedition, I have never felt disposed to go out of my way in search of it for its own sake. ${ }^{6}$

Earlier he had contended that 'the novice who is sound in mind and limb can do well on rocks even at his first attempt...even the greatest rock-climb becomes in time a gymnastic feat, a trial of purely physical strength'. ${ }^{7}$

Despite this attitude, Finch was, at one time, induced by devotees of rock climbing to scale the Grepon, one of the great rock pinnacles near Chamonix in the Alps. After the col below the peak itself, the climb was purely on rock and at the end of it an unimpressed Finch remarked, 'One could not help feeling that a baboon would have acquitted himself throughout with much more distinction than any of his human brothers. ${ }^{\prime}$

Finch, however, saved his most vitriolic attacks for those, including some Alpine Club members, who pontificated about the danger of amateurs climbing in the Alps without the services of a professional guide. At the time, the conventional wisdom was that the strongest mountaineering party consisted of keen amateur climbers, who provided the idea and the driving force for the venture, and professional guides, who supplied the technical expertise required for long routes up complicated mountains over a variety of snow and ice conditions. In addition, the guides would do the hard physical labour of cutting steps in steep ice slopes. Moreover, climbing without professional guides was considered downright dangerous, and the inevitable accidents would give mountaineering a bad name.

6 Finch, The Making of a Mountaineer, ch. XVII.

7 Ibid., ch. V.

8 Ibid., ch. XVII. 
Although Finch was not the first climber to challenge this idea, he was the most outspoken proponent of guideless climbing. He believed that only by climbing without a guide could a mountaineer develop the true love of mountain adventure that came from tackling and solving problems using only one's own resources and experience the supreme joy that unaided achievement brought. When Finch and others began extolling the virtues of guideless climbing in public, the establishment fought back vigorously, calling the new ideas suicidal, wicked and immoral.

The clash over guided climbing was typified best by Finch's remarks when he was chastised by traditional climbers in Zermatt after having arrived by crossing the Furggjoch by himself:

Zermatt is filled with non-climbing trippers and crowds of hoary headed Alpine Club has-beens who seem to delight in discouraging would-be climbers...I was rude to two most important members of the A. C. who said I should not have come over the Furggjoch alone. I wound up by asking one of them point-blank if he measured my capacity as a climber by his own. ${ }^{9}$

Despite George Finch's sharp clashes with his more traditional peers, his mountaineering achievements themselves were so outstanding that the Everest Committee could not exclude him from the 1921 expedition without some more solid grounds. The clever Hinks was up to the task and soon found an iron-clad reason for tossing the troublesome Finch off the team.

The committee required all prospective climbers to undergo an extensive medical examination - quite a reasonable proposition since they would be subject to the most extreme physical stress on the Everest attempt. The committee chose the doctors and Finch was found unfit for the expedition, probably because he had contracted malaria during the war and had undergone drastic treatment in France. He was occasionally subject to weight loss, but that minor problem never interfered with his climbing in the Alps.

The decision to exclude Finch was controversial and the hand of Hinks was often suspected as the real reason for the negative medical report. More concrete evidence for this suspicion came to light only in 1986, when Scott Russell was researching his 'memoir' on the life of George Finch. Just after Finch had undergone his medical examination, and before he had been officially excluded from the expedition, he and an engineer travelled to Oxford to investigate the performance of stoves at low pressures. To do their tests, they used a lowpressure chamber constructed by Professor George Dreyer to study the reaction

9 Russell, George Finch-The mountaineer, ch. 6. 
of airmen at high altitude to the use of supplementary oxygen. Before the pair could use the chamber for their stove tests, they had to undergo an exhaustive medical examination. The summary of the report on Finch states:

1. Captain Finch is slightly under weight at present, otherwise his physique is excellent.

2. He has an unusually large vital capacity. This indicates a high degree of physical fitness, and he should therefore be able to stand great exertion at high altitudes better than most persons.

3. Furthermore, the tests in the low pressure chamber proved that Captain Finch possesses quite unusual powers of resistance to the effects of high altitudes. Among the large number of picked, healthy, athletic young men we have examined, more than 1000 in all, we have not come across a single case when the subject possessed the resistance power to the same degree. ${ }^{10}$

The committee, by a majority decision, had excluded Finch from the expedition by the time it had received Dreyer's report. Farrar, who had backed Finch all the way, was furious when he saw Dreyer's report and fumed to Hinks, 'This is the weakling whom we have flung out!'11 The decision stood, however, and Finch was relegated to climbing in the Alps that season. He wasted no time in climbing Mt Blanc by a particularly difficult route, prompting Farrar to write to Hinks that 'our invalid Finch took part "in the biggest climb done in the Alps this summer"'. ${ }^{12}$

The 1922 Everest expedition was quite a different story. The 1921 team had thoroughly explored the approaches to the mountain but had made little real progress in solving the problem of attaining its summit. It was clear that the next group would need to pay far more attention to the climbing aspects rather than exploration. The committee realised that the climbing team had to be strengthened and reluctantly agreed to invite George Finch to join the four other climbers: George Leigh-Mallory, Henry Moreshead, Edward Norton and Edward Somervell. The leader was General Charles Bruce.

Finch's reputation was very well known - as a climber and as an outspoken eccentric. While the former commanded respect from his colleagues, the latter encouraged them to hold him at arm's length and make him feel not particularly welcome on the trip. Even General Bruce, one of whose jobs as leader was to encourage harmonious relations among the expedition members, wrote of Finch:

10 Ibid., ch. 7.

11 Ibid.

12 Ibid. 
'Cleans his teeth on 1 February and has a bath the same day if the water is very hot, otherwise puts it off until next year. Six months' course as a lama novice in a monastery would enable one to occupy a Whymper tent with him.' ${ }^{\prime 3}$

The problems were compounded by Finch's insistence that supplementary oxygen was necessary to climb Everest. The oxygen question sparked another bitter row between traditionalists, who thought that using supplementary oxygen was unsporting and un-British, and those, like Finch, who thought that oxygen, like an ice axe or a stove, was just another aid to the climber tackling a very formidable problem. Other climbers objected to the use of oxygen not on philosophical grounds, but because the weight of the apparatus itself more than negated the benefit of breathing the pure gas. Initially, Finch was himself against the use of oxygen for this reason, but his meeting with Dreyer, who was a recognised expert on the use of oxygen by airmen, convinced him that oxygen would be useful for Everest climbers and, indeed, that the mountain could not be climbed without supplementary oxygen.

Farrar and Finch managed to convince the Everest Committee that the dispute over the usefulness of oxygen could be resolved only by testing the idea on the mountain itself, so Finch was put in charge of the supplementary oxygen apparatus and its use. Finch's enthusiasm for oxygen, however, and his nightly 'oxygen drills' on the voyage to the subcontinent and the march to base camp quickly turned the rest of the climbing team against oxygen. One of them penned a sarcastic poem and handed it to Finch:

The anchor was weighed at the Port of Marseilles

When we started to verify travellers' tales.

The weather was fine and we all were at ease

And prepared for a fortnight's good rest on the seas.

But Hark? What is that? It's six bells without doubt

And soon all our holiday's gone up the spout,

For whether we're resting, or reading or ill

We're ruthlessly summoned to Oxygen Drill.

Have you theories precise on the subject of gas?

Respiration, and so on and action in mass?

The exactest of thought will appear rude and boorish

Compared with the latest in science from Zurich.

Do you think you know about altitudes high,

And what kind of glass keeps the sun from your eye?

On such questions your ignorance really is crass,

But you'll soon be made wise when George Finch starts to gas. ${ }^{14}$

13 Monteath, C. 1986, 'The man who brought English air to Everest', Geo, vol. 8, no. 4, pp. 40-51.

14 Russell, George Finch-The mountaineer, ch. 8. 
By the time the expedition finished its long journey across the Tibetan Plateau and established base camp along the Rongbuk Glacier, the group dynamics had ensured that Finch was well and truly excluded from the main climbing group and, indeed, that the objectives of the expedition had subtly changed from climbing Everest to seeing how high climbers could get without using supplementary oxygen. This tacit change of direction rankled Finch, who was determined himself to get to the summit if at all possible. The possibility of severe and open conflict between Finch and the other climbers was removed somewhat when Finch contracted a mild form of dysentery and was forced to remain at base camp while the other four climbers made the expedition's first attempt to climb Everest.

The mountain was a long way from base camp, so the climbers had to pass through three additional camps along the East Rongbuk Glacier before they could tackle their objective. The route they chose on the mountain itself was judged to be - and was subsequently proven to be - the least difficult on the northern side of Everest. They gained the upper reaches of Everest by climbing the steep snow slope that stretched from the neve of the glacier to the North Col-a saddle between Everest and Changtse, its northern outlier. From there they would climb the broad ridge from the col, at 23000 feet $(7000 \mathrm{~m})$, to a shoulder at $27400 \mathrm{ft}(8350 \mathrm{~m})$ where the ridge from the col joined the long North-East Ridge. They then hoped to climb the latter for the final $1600 \mathrm{ft}$ (480 m) to the summit. The plan was to establish camp four on the North Col and put in one additional camp high on the ridge above the col before going for the summit.

By the time Mallory, Norton, Moreshead and Somervell had retired beaten from their attempt on the mountain, Finch had moved up to camp three below the North Col and had greeted the climbers on their return. He reported them to be 'practically at the end of their tether and were hardly able to speak coherently'. ${ }^{15}$ Still, the four had made a tremendous effort, climbing to $25000 \mathrm{ft}(7620 \mathrm{~m})$ before establishing the last camp, from which Mallory, Norton and Somervell pushed to nearly $27000 \mathrm{ft}(8230 \mathrm{~m})$ before the effects of cold and altitude forced a retreat.

Finch, now recovered from his bout of dysentery, still had two formidable problems to solve before making his own bid for the summit. The first was a lack of climbing partners. The other four members of the climbing team had just returned exhausted from their attempt and obviously none would be in condition to accompany Finch. He was forced to settle for Geoffrey Bruce (see image 2.1), the cousin of General Bruce, and Gurkha Tejbir, one of the non-commissioned officers attached to the expedition. Neither had any mountaineering experience.

15 Finch, The Making of a Mountaineer, ch. XX. 
It would be hard to imagine a more bizarre team to attack Mt Everest: a skilled but eccentric climber who periodically suffered from the effects of malaria and who had just recovered from a bout of dysentery, the expedition's transport officer whose only experience in mountains had been to chase game in Kashmir, and a Gurkha porter whose main attribute seemed to be that he grinned a lot. Nevertheless, Finch, who was undoubtedly disappointed at not having any of the climbing team to accompany him, was not unduly worried about his partners' lack of climbing experience. In fact, he had often climbed with novices in the Alps, sometimes on difficult routes, and considered a man's character, fitness and mental attitude to be as important as his climbing experience. In choosing Bruce and Tejbir for his Everest attempt, his judgment proved to be flawless.

The second major problem was the condition of the oxygen apparatus, which had taken quite a battering on the rough trip to base camp. Many repairs were needed and since Finch's reputation was staked on the efficacy of the apparatus, he threw himself into the task during his days at camp three. Joined by the hardworking Bruce, who had become an enthusiastic convert to the oxygen cause, Finch set up a workshop outside the tents at the camp. The pair, interrupted at times by snowstorms, worked tirelessly with hacksaws, pliers and soldering iron to seal metal joints, replace dry washers, check valves and design and construct a new mask. The hard, often uncomfortable work paid off. The trio was about to embark on one of the most remarkable efforts on the world's highest mountain.

On 22 May, Finch, Bruce and Tejbir set out for the North Col. Using the oxygen apparatus with the redesigned mask, the climbers made short work of the task and arrived at camp four just three hours after their start. Of that time, 45 minutes had been taken by stops, so the $2000 \mathrm{ft}(610 \mathrm{~m})$ of altitude had been gained in little more than two hours. That rate was comparable with a good rate in the Alps; Finch had proved his point about the usefulness of oxygen.

Furthermore, Finch's knowledge of snow conditions had come to the fore in the climb to the col. He led his inexperienced partners directly up the treacherous slopes; a zigzagging route would have risked loosening snow shields or triggering avalanches. Near the top of the slope, Finch cleverly found the buried lip of a small bergshrund on which to safely traverse to a point where the ice cliffs guarding the col itself could be breached. It was a masterful performance by all three and it suddenly appeared that Everest would have a strong challenge.

The three climbers dropped their loads, had a look around the col and then descended to camp three to rest for a day before starting their push for the summit. They completed the descent in just 50 minutes, including frequent stops for Finch to take photographs. The other four climbers, resting at camp 
three, were startled by the performance of Finch's party. It looked like Finch was about to turn the tables on those who had mocked him and his oxygen on the trip to base camp.

The success of the team's carry to the North Col had convinced John Noel, the expedition's official photographer, of the value of oxygen and Noel accompanied the group on their second climb to the col on 24 May. The next morning, Finch sent the porters away at 8am for the carry up to the next camp. The three climbers themselves, however, were in no hurry as Finch was confident that, with the help of oxygen, they would quickly overtake the porters. At 9.30am, they left camp four and, about $1500 \mathrm{ft}(460 \mathrm{~m})$ above the col-about $24500 \mathrm{ft}$ $(7470 \mathrm{~m})$ high - they overtook the porters on the broad snow ridge leading to the shoulder. Above lay a steepening snow slope, so Finch set to work cutting deep, closely spaced steps to aid the porters' ascent. The party progressed steadily, but as they gained the rocky terrain above the snow ridge, the weather broke and they were buffeted by wind and snow. Finch pushed the party on, but as they reached $25500 \mathrm{ft}$ (7770 m), he realised that to push further into the storm would unjustifiably risk the lives of the porters, who were to return to the col after dumping their loads at the high camp.

The camp was pitched precariously on a little ledge on the crest of the ridge; it hung above precipitous drops into the Rongbuk and East Rongbuk Glaciers. As Finch, Bruce and Tejbir settled in for the rest of the day, the storm intensified. At times it lifted the tent, with its three occupants, off the ground and threatened to toss it off the ridge. The three climbers took turns crawling outside to resecure the guy wires, and during the worst gusts Finch reported that the 'wild flapping of the canvas made a noise like that of machine-gun fire, and, what with this and the shrieking and howling of the gale round our tent, it was well-nigh impossible to converse with each other except by shouting, mouth to ear' ${ }^{16}$ To make matters worse, a flying rock cut a hole in a panel of the tent.

After a short lull in the morning raised hopes of the storm's abatement, it returned in full fury. There was no possibility of the climbers moving either up or down. By early afternoon, the storm finally began to wane and the trio had an opportunity to abandon their precarious perch and return to the relative safety of the col. Finch, however, would not entertain the thought. He had come to Everest to climb the mountain and he would give it his best shot. When the porters, carrying flasks of hot tea prepared by Noel at camp four, arrived in late afternoon, they were amazed when Finch and his partners refused to return with them. 
Although the storm had cleared, the second night at $25500 \mathrm{ft}(7770 \mathrm{~m})$ was little better than the first. They had virtually run out of food and the bitter cold was beginning to penetrate their bodies. Even the optimistic Finch began to worry about the real possibility of severe frostbite and even about their ability to survive the night. Then he remembered the oxygen, hitherto used only for climbing, and dragged a set in from outside the tent. The three took whiffs of oxygen in turn. The effect was instantaneous, as Finch described:

Tejbir took his medicine without much interest; but as he inhaled, I saw with relief that his face brightened up. The effect of the oxygen on Geoffrey Bruce was particularly visible in his rapid change of expression: the hitherto drawn, anxious look on his face gave place to a more normal one. ${ }^{17}$

The oxygen probably saved their lives.

In the morning, the unlikely trio set their sights on the top. With Finch in the lead and oxygen sets on their backs, they climbed steadily up towards the shoulder. About $500 \mathrm{ft}(150 \mathrm{~m})$ above the camp, however, Tejbir collapsed; he simply could not push himself any further. Finch and Bruce split his load and, after ensuring that he could descend safely on his own, sent him back down to the camp.

The wind came back in considerable force as Finch and Bruce pushed up towards the shoulder. Finch soon decided, with the icy wind howling across the ridges in increasingly powerful gusts, to abandon the ridge-tops and traverse out onto the somewhat sheltered North Face. The tactics, however, led to more difficult climbing as the strata on Everest dipped to the north so that the slabs of rock overlapped to present to the climbers small overhangs rather than small ledges. In addition, new snow had covered much of the rock. To save time, Finch had decided not to tie a rope between himself and the novice Bruce, thus showing considerable confidence in his partner's ability to handle the tricky conditions.

At an altitude of $27000 \mathrm{ft}(8230 \mathrm{~m})$, Finch decided to change the attack and angle up directly towards the summit. A few minutes later, he heard Bruce give a panicked cry, 'I'm getting no oxygen!' and turned just in time to grab Bruce's shoulder before he tumbled backwards down the North Face. ${ }^{18}$ Finch sat his companion down and, sharing oxygen with him, systematically went to work to find the fault. It turned out to be a broken glass tube in the mask. The methodical Finch had carried a spare tube, so he quickly repaired the mask and the pair was on their way again. 
The delay had, however, taken too much out of them, particularly Bruce. With Finch's vast experience in the mountains, he was alert to the condition of his companion and realised that Bruce was near to a breakdown like Tejbir's. It was a brutal blow to Finch, who wrote: 'Never for a moment did I think we would fail; progress was steady, the summit was there before us; a little longer, and we should be on the top.' ${ }^{19}$ Finch had the strength and determination to continue, with a good chance of reaching the summit, but he had no choice. To continue would have endangered Geoffrey Bruce, so, despite Bruce's protestations, Finch ordered a retreat. The first serious attempt on Mt Everest was over.

Although Finch was deeply disappointed at not reaching the summit, he and Bruce had achieved much. They had climbed to $27400 \mathrm{ft}(8350 \mathrm{~m})$ - higher than anyone had climbed before. In doing so, Finch had safely guided two completely inexperienced companions up difficult and dangerous snow slopes, across treacherous rock slabs and through the perils of cold, storm and high altitude. And he had proved, on Mt Everest itself, that supplementary oxygen was definitely a benefit to climbers. That aspect of the debate was over.

Despite all of those achievements, Finch's difficulties with the Everest Committee continued, and even increased during the next year or two. When the climbing team was selected for the 1924 Everest expedition, he was not included. Much of the new trouble stemmed from a European lecture tour that Finch gave on the 1922 Everest expedition. According to the agreement that Finch and all the other climbers had signed with the committee, all photographs were to become the property of the committee and only lectures organised by and for the benefit of the committee could be undertaken. Finch was a keen amateur photographer, even taking his own mobile darkroom with him on the 1922 expedition, and, quite understandably, he did not want to part with his negatives. Apart from that, he did his best to help the committee. He and George Mallory lectured extensively in Britain and Finch subsequently suggested that he lecture, using his own photographs but sharing the proceeds with the Everest Committee, in Europe. Hinks refused to grant permission and when Finch went ahead with the tour anyway, the committee had had enough. His relationship with the committee had been strained beyond repair; Finch would never climb in the Himalaya again.

George Finch's influence on future attempts to climb Everest was not finished, however, as the Everest Committee was not above seeking his advice and help on the design of oxygen equipment. Although many modifications and improvements to the equipment were made through the years, Finch's basic design remained unchanged. When Sir Edmund Hillary and Tenzing Norgay finally climbed Everest in 1953, they used oxygen sets of Finch's basic design. 
Ironically, that first successful Everest expedition met George Finch, then Director of the National Chemical Laboratory of India, in Delhi on their way home. The leader of the expedition, John (later Lord) Hunt, wrote of their meeting:

It was a particular delight in Delhi to meet again George Finch, veteran of the 1922 Expedition and pioneer in the use of oxygen for climbing purposes. His presence among us was the more welcome in that we were so anxious that the tributes with which we were being showered should be shared with those who had shown the way. As one of the two outstanding climbers on the first expedition to make a definite attempt to reach the summit of the mountain in 1922 - the other was George Mallory - and as the strong protagonist of oxygen at a time when there were many who disbelieved in its efficacy and others who frowned upon its use, no one could have better deserved to represent the past than George Finch. We saluted him. ${ }^{20}$

Although the traits that made George Finch such an excellent climber and at the same time such a controversial figure probably had little to do with his early upbringing in Australia, he did share some characteristics with Australian climbers who ventured to the Himalaya much later. Prominent among these was an ability to take a fresh look at the traditional approaches to mountaineering, an openness to adapting new techniques to old problems and a knack for improving climbing equipment and modifying old methods for coping with high altitudes.

With his quick, analytical mind and training as a physical scientist, Finch was, not surprisingly, a very innovative mountaineer, always ready to question traditional wisdom and test new ideas. Nowhere was this more evident than in his simple but brilliant design of the mask for the oxygen apparatus used during the 1922 Everest expedition.

The requirements for an effective oxygen apparatus for mountaineering were sometimes conflicting, particularly regarding the mask. To make the use of the rather heavy oxygen apparatus worthwhile for the climber, every possible litre of the gas had to be breathed in by the climber and metabolised; the least possible amount should be lost to the atmosphere. This necessitated some sort of system to reuse the expired air so that the maximum amount of oxygen could be extracted from it. In addition, however, the mask had to be simple, robust, reliable and not prone to malfunction under the severe climatic conditions at high altitudes. The reliability of the system was of utmost importance, as it was believed at the time, especially by experts such as Dreyer, that if the oxygen

20 Monteath, 'The man who brought English air to Everest'. 
supply was suddenly cut off, even for a very short time, the climber would likely die. Even if he could somehow survive for a few minutes, he would be so incapacitated that he could not effect a repair.

The preferred mask was called the 'Economizer' and was designed to store the expired air so that oxygen not absorbed by the lungs in the first breath would be recycled for use in subsequent breaths. The major problem with the system concerned two critical valves that, unfortunately, were prone to freezing, thus rendering the entire system useless. Many modifications were tried, but the Economizer was never considered reliable enough to use on the mountain.

Finch was keenly interested in the problem and brought his considerable talents as an experimental physical chemist to bear on it. The result was an ingenious design: simple, robust, reliable and effective (see image 2.2). Finch threw out the complicated valve system and attached a rubber hose to the outlet from the oxygen cylinders. To this, he connected a T-shaped glass tube; the other two ends of the $\mathrm{T}$ were connected to a toy football bladder and to another piece of rubber tubing, which was inserted into the mouth of the climber. Finch described the use of his mask succinctly:

On inhaling, the oxygen flowed through the rubber tube into the mouth of the climber, there mixing in with the indrawn air. On exhaling, the climber had to close the end of the tube in his mouth by biting it, and thus prevent the flow and consequent waste of oxygen. During this latter operation the oxygen, which was still flowing from the apparatus, was stored up in the expanding football bladder. On re-inhaling, the climber simply released the pressure of his teeth upon the tube, and the bladder, collapsing slowly, gently forced the oxygen into his mouth where it mixed with the inhaled air. The correct closing and opening of the rubber tube by alternating biting and releasing the pressure of the teeth upon it became, after a few minutes' practice, a perfectly automatic subconscious process. $^{21}$

The design was ridiculously simple yet extremely effective, as Finch and Bruce subsequently proved in their record-breaking attempt on Everest.

The oxygen mask was not the only innovative contribution Finch made to the design of mountaineering equipment. For the 1922 expedition, he made a jacket insulated with eiderdown - one of the first duvet jackets ever made and a vast improvement in warmth and weight over the heavy tweed jackets normally worn by climbers of that era (see image 2.3). The shell of Finch's jacket was made of waterproofed balloon cloth with the feathers quilted within. At first,

21 Finch, The Making of a Mountaineer, ch. XX. 
Finch's colleagues ridiculed his dress, but they were quickly put in their place when the weather turned cold and Finch functioned in far more comfort than they did. John Noel reported:

Finch, who had a scientific brain, invented a wonderful quilted eiderdown suit of aeroplane fabric, doped. Not a particle of wind could get through. Underneath he used to wear a suit of silk underclothes, then one of wool, then another, then a fourth of thicker wool, then a fifth of the thickest substance he could find - then he really began to dress in earnest, when he was to go up to the highest camp with the wind reaching a velocity of 100 miles per hour. ${ }^{22}$

Curiously, Finch's duvet jacket seemed to have been quickly forgotten and did not become standard equipment for Himalayan mountaineers until decades later.

Because of his record of distinction as a scientist and the crucial role oxygen played in the first successful ascent of Mt Everest in 1953, George Finch is justifiably well known as an innovative mountaineer. Much less known is Finch's keen interest in helping younger, less experienced climbers improve their skills in alpine techniques. Although he did not suffer fools gladly and often verbally chastised climbers who made fundamental errors of judgment in the Alps, he nevertheless took great delight in leading determined, bright but inexperienced young climbers up challenging climbs on their first trip to the mountains.

Much of his instruction was in connection with the Academic Alpine Club of Zurich. Scott Russell recalled a typical situation in which Finch made quite a vivid impression on John Case, an American visiting Zurich in 1911:

George was then President of the Zurich Academic Alpine Club, and although the Club was very democratic, the President took rather dictatorial powers. Aspirant climbers were expected to display their skills on a climbing wall near the club hut, and to maintain standards George periodically knocked off popular holds. Notwithstanding this, Case climbed the wall, and the next weekend George and Marcel Kurz put him through his paces on a nearby mountain. Case passed, was admitted to the Club, and some weeks later George took him as his second in climbing the Marinelli Couloir on Monte Rosa. The crux of the climb came, in total darkness before dawn, on very steep grooved ice. So that George could see to cut steps Case kept very close behind him, holding a candle-lantern aloft on his ice axe. So they proceeded until dawn came, reaching the summit in eight hours from the Marinelli 
Hut, a record time. Case later wrote that during the climb the lantern had fallen from his ice axe but he had caught it; George's only comment had been 'Don't do many things like that, man' $^{23}$

Although Finch's sharp rebuke might have seemed inconsiderate, Case, who followed Finch on several other major climbs, had the utmost respect for his mentor and later remarked that Finch's instruction had been so unobtrusive and tactful that he was not at first aware of the extent of the 'systematic training of a varied nature' that he received..$^{24}$

The classic example of Finch's willingness to take novice mountaineers on difficult climbs, and to patiently help them over the rough spots, was his partnership with the totally inexperienced Geoffrey Bruce in the 1922 attempt on Everest. Bruce was extremely grateful afterwards to Finch and wrote to him, 'I can never thank you enough either for electing to take me with you on the climb, or for the perfectly astonishing way you pulled me through it all. It was wonderful. ${ }^{25}$

Thus, Finch's reputation for abrasiveness notwithstanding, he was, as Russell recorded, 'sympathetic to those whose skill or physical ability was below his standards and to those who had an unavoidable accident - or perhaps a moment of carelessness' ${ }^{26}$ In this willingness to help the less experienced or less fortunate, Finch perhaps started to build the reputation Australian mountaineers - and indeed Australians in general — now have for helping others in need.

Although he shared these characteristics of inventiveness and helpfulness with later Australian climbers, Finch's connections with Australian mountaineering appear most tenuous. He always considered himself to be every bit an Englishman and as a climber his background was almost entirely Continental. His basic motivation for climbing, however, undeniably goes back to his upbringing in rural New South Wales. As Finch recalls:

The love that Max and I have for the mountains I cannot but attribute to the fact that we were possessed of a father who taught us from our earliest days to love the open spaces of earth, encouraged us to seek adventure and provided the wherewithal for us to enjoy the quest and, above all, looked to us to fight our own battles and rely on our own resources. ${ }^{27}$ 
So, despite his close connections with the traditional climbing community of Switzerland and the staid British Alpine Club, George Finch's most important mountaineering attribute - the basic motivation to climb mountains - and even his attitude towards life in general were firmly rooted in the wild and open Australian bush. 


\section{Quiet years}

George Finch, outstanding and well-known climber that he was, never had an impact on Australian mountaineering. His lecture tours were confined to Britain and the Continent; in fact, he never returned to Australia after leaving in 1902. His climbing career was focused firmly on the Alps and to a lesser extent Britain. He went to the Himalaya only once, as a member of the 1922 British expedition to Mt Everest.

Finch's book The Making of a Mountaineer, which interspersed vivid accounts of his climbs in Corsica, the Alps and on Everest with instruction, often in considerable detail, on climbing techniques, was read avidly by New Zealand mountaineers but had no impact in Australia. The reason was simple. There was no history or tradition of climbing in Australia, there was no active or vigorous Australian climbing community and there was little contact between outdoors-oriented Australians and climbers elsewhere, even their cousins across the Tasman.

Further Australian connections with Himalayan climbing followed the Finch model: they were the result of isolated individuals joining British expeditions or of British expatriates resident in Australia launching their own efforts in the Himalaya. Even these sporadic and unrelated trips were, however, to come more than three decades after Finch's 1922 Everest expedition.

Indeed, for Himalayan mountaineering in general, the 1930s and 1940s were quiet years - the result of economic factors and problems of access. Most climbers simply could not afford the costly trip to the subcontinent for such a frivolous activity as mountaineering, particularly during the Great Depression of the 1930s. Even if they could afford it, lack of access was an insurmountable barrier for much of the Himalaya. Nepal was still closed to all foreigners and only the British were allowed to climb from the Tibetan side of the main Himalayan range. Apart from a succession of unsuccessful British attempts on Everest, Himalayan mountaineering was confined largely to attempts on Kanchenjunga, accessible through Sikkim; exploration and some climbing attempts in the spectacular Karakoram Range; and a series of German attempts on Nanga Parbat, a massive $8000 \mathrm{~m}$ mountain to the south of the main Karakoram Range.

All of this changed after World War II. Nepal opened its doors to foreigners in 1950 and an increasing number of suddenly affluent Western mountaineers mounted climbing expeditions to the once forbidden kingdom. Annapurna was the first $8000 \mathrm{~m}$ peak to fall—climbed in dramatic fashion by Maurice Herzog's 
French expedition in 1950. A British expedition finally succeeded on Everest in 1953, with Edmund Hillary and Tenzing Norgay reaching the summit just in time for the coronation of Queen Elizabeth II. Activity was not confined to the giants. Expeditions from Japan, North America and New Zealand joined those

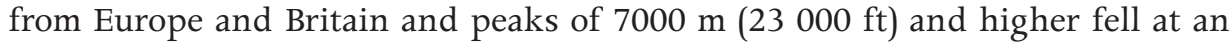
exponential rate. In addition, there were still plenty of remote areas to explore for those with a geographical curiosity and a desire to climb a virgin 'lower' peak of 6100-6700 m (20 000-22000 ft).

It was on one of these exploratory expeditions in 1957 that the next Australian set foot on a Himalayan mountain. In that year, the Imperial College Exploration Society sent an expedition to a remote area of the Karakoram, centred on a series of glaciers draining into the Siachen Glacier south-east of the area of high peaks dominated by K2, which was second only to Everest in height. With experts in geology, glaciology and surveying as members, it was one of the typical exploratory trips that were so valuable in accurately mapping previously unknown areas of the Himalaya (see image 3.1). In addition, the expedition hoped to make the first ascent of Peak K36 (Saltoro Kangri, 7740 m [25 $400 \mathrm{ft}$ ]) via the K36 glacier.

The leader was Eric Shipton, who with Bill Tilman had elevated the exploratory/ climbing expedition to a fine art. In addition to Shipton, five other English members and a Pakistani surveyor, the expedition included two Australians: Grahame Budd, an Australian doctor who was working in London, and Tasmanian Geoffrey Bratt, a surveyor (see image 3.2). Interestingly, the trip owed a little to the first Australian Himalayan mountaineer, George Finch, for it was Finch who first established the Imperial College Exploration Society in the early 1930s.

The club's 1957 Karakoram expedition was beset by problems from the outset. First, the Suez crisis threatened to scuttle the entire trip and in the event delayed by three weeks the arrival of the expedition's equipment. Then, Shipton's wellknown preference for frugal expeditions that 'lived off the land' had several members wondering what they had got themselves into. Englishman Keith Miller reported some disquiet about the food just two weeks into the trip: At this stage the local food was not tasting too good but who dared grumble when we could see the porters nibbling away at boiled chicken heads?' ${ }^{1}$ Budd, on the other hand, found the food excellent - on the approach march and in the mountains.

1 Miller, K. J. 1958, 'The Imperial College Karakoram expedition, 1957', Himalayan Journal, vol. 21, pp. 71-9. 
Australians Bratt and Budd distinguished themselves by escaping from a couple of dangerous positions - one of their own making and one definitely not. Miller recalls Bratt's bravado in doing a survey from the top of Tawiz Peak, a $6400 \mathrm{~m}$ $(21000 \mathrm{ft})$ mountain they had just climbed:

The summit was heavily corniced which necessitated volunteer Geoff, sitting on its very edge, complete with phototheodolite equipment, so that a 360 degree vision could be achieved. Whilst the cornice groaned Geoff did a first-class piece of work, and his sin of mishandling the loose rock during the ascent was readily forgiven. ${ }^{2}$

Budd, as well as Keith Miller, had narrow escapes from close encounters with hidden crevasses. Budd's accident occurred on the return journey to the Siachen base camp. As Miller noted, 'Reuniting with the party on the Lolofond we were told of Budd's lucky escape from a crevasse-long outstretched hands had saved him...From now on, everyone moved in pairs with a rope between them wherever they went.' ${ }^{3}$

\section{Escape from a black hole \\ Grahame Budd}

My own mishap occurred when, at the start of our return journey from Siachen Base near the end of the expedition, Shipton and I were breaking trail for six laden porters to lay a dump four hours' march up the Lolofond Glacier. Recent heavy snowfalls had so effectively filled the lower crevasses that we were travelling unroped. A few minutes before the end of my final lead, my right foot suddenly broke through into a hidden crevasse. I found myself sitting on my left leg, which was doubled under me on the near edge of the crevasse. My right leg was dangling down the crevasse and my body was sprawled across a large black hole, on the far side of which my right forearm and my ice axe spread my weight over the unbroken remainder of the snow bridge. Both crevasse walls were vertical and faded into blackness 40 feet below me. For the moment, I was secure enough, but any attempt to extricate myself would have broken the remnant of the snow bridge and sent me to the bottom.

I called to Shipton for help, and in the 10 seconds or so until he could reach me I gazed at the opposite wall 8 feet away, and pondered the vast airiness of the crevasse. Then Shipton arrived, I grabbed his extended ice axe with my left hand, and in a moment I was out. The porters arrived and dumped their loads, I photographed the hole, and we returned down the glacier-securely roped together.

For Geoff Bratt, the expedition had a most interesting fringe benefit. He and the veteran Shipton hit it off instantly, as both were very much interested in the exploration of unknown mountain ranges. Later in 1958 the pair was off to the wild mountains of Patagonia in South America.

2 Ibid. G. Budd noted that Geoff would have been standing and was not on the very edge of the cornicejust close enough to see the required trig points.

3 Ibid. 
Of the other members of the Imperial College expedition, Keith Miller was the most fascinated and intrigued by the spectacular Karakoram mountainsenough so to organise another trip to the same region in 1960. A mountain called K12 had fired Miller's imagination. He and the two Australians had climbed a $22500 \mathrm{ft}(6860 \mathrm{~m})$ mountain they called Island Peak and from the summit they could see the northern flanks of K12-24 $370 \mathrm{ft}(7430 \mathrm{~m}) \mathrm{high}$ - and a large basin that sat below it. Miller was fascinated by this huge snow basin and the walls that retained it. His party was unable to explore it fully in 1957, so it and K12 became two of the primary objectives of the 1960 trip.

The 1960 Saltoro expedition, as it was called, again had an Australian connection, as Jon Stephenson, later Associate Professor in the Department of Geology, James Cook University, Townsville, was its leader. Like its 1957 predecessor, the Saltoro expedition nearly did not make it even to the Karakoram. The Pakistan Government initially denied permission for the expedition on the grounds that enough expedition permits had already been issued and the region's resources could not sustain another group. Miller's persistence paid off, as Stephenson recalled: 'as a result of Miller's insistence, every known string was being pulled and ten weeks later, through the support given to our re-application by the Australian High Commissioner in Karachi, we obtained a permit. ${ }^{4}$ It would not be the last time Australian Government officials used diplomatic pressure to ensure that a permit was granted to Australian climbers.

For organiser Miller, the Saltoro expedition was not a very happy one. Shortly after leaving Skardu, the jumping-off point for the expedition, he contracted a severe case of dysentery and had to return to the Skardu Hospital. After recovering, he rejoined the main body of the expedition but was later knocked unconscious by a block of ice while receiving packs being lowered into a crevasse during a difficult crossing. He luckily escaped serious injury but was again forced to return to Skardu.

Stephenson, on the other hand, was having a most enjoyable and productive trip. In addition to his satisfying geological work (see image 3.3), he was thoroughly enjoying the spectacular scenery of the Saltoro Gorge, with its row upon row of magnificent rock towers and spires. As one of the two experienced mountaineers in the party, Stephenson had his share of climbing as well, particularly on the route to the pass north-west of $\mathrm{K} 12$, a route made difficult by an enormous crevasse that spanned the entire width of the glacier. It was in this chasmthe crossing of which was pioneered by Stephenson-that Miller suffered his unfortunate accident. 
With the departure of Miller, Stephenson was left without an experienced partner for his attempt on K12. Nevertheless, he, American anthropologist J. P. Hurley and two porters, taking advantage of an unusually fine spell of weather, made an attempt on K12. After re-establishing themselves on the pass, they set to work on the south-west ridge, which rose towards the summit in a series of snow and ice buttresses. The initial climbing was made difficult by the fact that neither of the porters had crampons, so Stephenson had to painstakingly cut steps in the ice under the overlying crusted snow. They pushed on to nearly $20700 \mathrm{ft}(6310 \mathrm{~m})$, where space was found for their one small tent. Just before reaching that point, the inexperienced Hurley had decided to descend with one of the porters and leave the other, Mohammed Choo, to continue in his place. Choo and Stephenson were rewarded with a magical sunset: 'The view was fantastic, the wilderness of peaks, spires and ridges being picked out in their incredible succession by the setting sun. ${ }^{5}$

The next morning the pair continued up, sometimes traversing out onto the icefields of the upper part of K12's west face. By late morning, however, Choo was feeling the effects of altitude and exertion and decided to wait while Stephenson continued on alone. From that point - about $22000 \mathrm{ft}(6710 \mathrm{~m})$-Stephenson continued up the firm snow of the face for another four hours. By then, though, he had reached only $23000 \mathrm{ft}(7000 \mathrm{~m})$ and had nearly 1500 more feet $(450 \mathrm{~m})$ to go. It became obvious that he would not reach the summit for some time. As he later said, 'I ran out of support (and energy!) — the technicalities were passed.' Still Stephenson was not unhappy with his effort:

I had the thrill of looking down into the south and southeast sides of K12 which I believe no one has previously seen, and to my delight observed that the published map details of much of this country are entirely incorrect. It was easy to turn back for I was extremely tired and the summit would still have been four hours away. ${ }^{6}$

In an uncanny similarity to George Finch's attempt on Everest in 1922, Jon Stephenson had teamed with an inexperienced climber and a porter to mount a serious attempt on K12. He very nearly became the first Australian to climb a major Himalayan peak and he was the first Australian to climb to $7000 \mathrm{~m}$ without the aid of supplementary oxygen (see image 3.4).

Another three years passed before Australia was again linked with the Himalaya, but this time the roles were reversed. The expedition was mounted from Australian shores, but its leader was an Englishman, Peter Taylor. His was one of the more bizarre expeditions ever to travel to the Himalaya. It was undoubtedly the smallest and quickest expedition to make a first ascent, its 
training program had been conducted on the sand dunes and in the searing heat of the Australian outback and its execution was bedevilled by logistical headaches of the nightmarish proportions usually associated with large Everest expeditions.

Taylor was an itinerant geologist, a man short of stature but blessed with an engaging personality that charmed the ladies and got him into, and subsequently out of, predicaments of varying seriousness with officialdom around the world. He had done some mountaineering in Europe and Canada, but his only experience with high altitude came when, working in Brazil, he managed to talk his way onto a 1961 German expedition to Aconcagua - at nearly $23000 \mathrm{ft}$ (7000 $\mathrm{m})$, the highest mountain outside the Himalaya. By the time Taylor reached base camp at $14000 \mathrm{ft}(4270 \mathrm{~m})$, however, bad weather had forced the Germans off the mountain.

The abortive Aconcagua trip had nevertheless sown the seed of high-altitude mountaineering in Taylor's mind, so, when he was transferred from Brazil to Australia a few weeks later, he firmly set his sights on a Himalayan trip in 1963. He wisely used his 1962 Christmas break to make a climbing trip to New Zealand, where even his considerable gift of the gab was not enough to convince the head ranger at Mt Cook National Park to allow him to attempt Mt Cook itself. Taylor settled for some of the lesser snow and ice climbs in the Cook region, and even then he was impressed with the seriousness of the undertakings compared with the climbs he had done in Europe and Canada. It was those difficult, and often dangerous, conditions of New Zealand's Southern Alps that had so thoroughly prepared Edmund Hillary and the climbers of his generation for the Himalaya and would play a crucial role in the development of Australia's Himalayan mountaineers.

Nearly all of Taylor's preparation, however, took place at his work site along the Birdsville Track at the southern edge of the Simpson Desert. It would be hard to imagine a more inappropriate place to train for a Himalayan climb. As Taylor himself remarked: 'here I am in a country that's dead flat, so hot that even the birds have quit flying, and we're about two hundred feet above sea-level. It's a great combination. ${ }^{7}$ Of his training regime on the dunes of the Simpson Desert, he said:

I loaded seventy pounds of the stuff [sand] into my pack, and the first time out I managed to stagger about four hundred yards with it. A week later I was able to manage a couple of miles without too much exhaustion. At five o'clock every evening it became a ritual. Pack hoisted, I set off across the flats to the same old dunes every night. At the same half-

7 Taylor, P. 1964, Coopers Creek to Langtang II, Rigby, Adelaide, ch. 3. 
way mark I stopped for a few minutes, wiped off the perspiration, and swatted away at the clouds of flies. Then the march back, a quick shower, and into the mess trailer for tea at six. ${ }^{8}$

Taylor's choice of mountain in the Himalaya was dictated by timing. He had six weeks of leave, beginning on 20 April, which would put his expedition just near the end of the normal climbing season in the Nepalese Himalaya. That season is dictated by the monsoon, which dumps snow on the mountains from June through to September and makes climbing difficult and dangerous during that period. The generally warm period leading up to the monsoon, during April and May, is considered the best in which to attempt the higher peaks. A further constraint was the length of time; six weeks was long enough only for an attempt on a relatively low peak close to Kathmandu. Taylor settled on a 21 $592 \mathrm{ft}(6583 \mathrm{~m})$ mountain in the Langtang region just north of Kathmandu. He later learned that it was called Langtang II.

Difficulties immediately arose when Taylor discovered that Langtang II was not on the Nepalese Ministry of Tourism's list of peaks officially open to foreign expeditions. That was an insurmountable problem for an ordinary mortal, but the slick Taylor was equal to the challenge. A few letters with just the right amounts of authoritative presumptuousness, gentle pleading and demurring politeness and that tough nut was cracked.

In comparison, the other major problem - Taylor had no-one to climb withwas trivial. He simply mounted a one-man expedition and, through a contact in Kathmandu, organised Sherpas to climb with and porters to carry the loads to base camp.

Theoretically, a one-man expedition should be the easiest of all to organise. Even Shipton and Tilman, those paragons of parsimony, might have considered it just a bit small. When April 1963 finally arrived, however, the one-man Langtang II expedition was beset with a series of bureaucratic bungles from which even the fast-talking Taylor had trouble extricating himself.

He arrived in Kathmandu on 25 April, just as planned, but found that his gear had not followed him:

One of my travelling-bags had been unloaded by error in Rangoon and had been impounded by Customs there. A case containing my few items of equipment was still in the Port of Calcutta, as my agent there had omitted to tell me of such refinements as import licences, bonds and the 
like. He assumed I knew it all. I assumed he knew it all. I returned to Calcutta to untangle this lot while my Sherpas went sight-seeing in the Kathmandu Valley. ${ }^{9}$

Taylor's 'lamentable catalogue of follies and frustrations' continued when he tried to clear his supplies through Nepalese customs:

The customs officer at the airport in Kathmandu shook his head and looked apologetic. 'I am very sorry, Mr Taylor, but I cannot permit you to bring this food into Nepal.' He was referring to some of my high altitude rations, clearly marked DEHYRATED BEEF STEW. I had forgotten that the eating of beef is contrary to religious custom in Nepal. My faux pas would require delicate handling...In the end I got my rations, but only after signing - under bond - a lengthy declaration to the effect that not in any circumstances would I offer the beef stew to the Nepalese. ${ }^{10}$

After clearing that hurdle, Taylor quickly tried to patch over the problem by chatting up the customs officer, but the camaraderie was short-lived; a few minutes later he [the customs officer] plunged his hand into a pile of sweatersand also into a gooey mess of honey, which had run out of a damaged carton'. ${ }^{11}$

Somehow Taylor survived the problems of Nepalese officialdom-usually the most severe encountered on an expedition to Nepal-but he lost valuable time in the process. He had planned to be at base camp about 1 May, but did not even get away from Kathmandu until 18 May. The march in took only four days, but even at that he was starting his expedition dangerously close to the time that the monsoon could break.

After his previous tribulations, his successful ascent of Langtang II was almost anticlimactic. He had no choice but to attack the mountain in a single, immediate push with no prior period of acclimatisation; he climbed from the valley floor at $6000 \mathrm{ft}(1830 \mathrm{~m})$ to the $21592 \mathrm{ft}(6583 \mathrm{~m})$ summit in a remarkable five days. Not surprisingly, he suffered badly from altitude sickness. Fortunately, the route was technically straightforward, although Taylor had one tense moment when 'I wandered on to the South ridge by mistake. The visibility was poor and the sudden realisation that I was near the sheer west face made me draw back in a hurry. There was a nasty void in the swirling mist a few feet ahead.' ${ }^{12}$ Taylor was suffering badly, possibly from the first symptoms of pulmonary oedema, on the morning of 23 May when he and Pasang Sherpa climbed from a high camp to the summit. He was barely able to descend the mountain under his own steam.

9 Taylor, P. 1964, 'Langtang Himalaya', Himalayan Journal, vol. 25, pp. 69-76.

10 Taylor, Coopers Creek to Langtang II, ch. 1

11 Ibid., ch. 1.

12 Taylor, 'Langtang Himalaya'. 
On his return to Kathmandu, Taylor quickly found himself on the expedition cocktail circuit. Before leaving for Langtang, he had befriended Sally Dyhrenfurth, wife of the leader of a large American expedition that succeeded in making the first traverse of Mt Everest - that is, climbing the mountain by one route and descending by another. Mrs Dyhrenfurth appeared more excited by Taylor's one-man show than by the history-making achievement of her husband's team and invited Taylor to the big American celebration. Taylor was impressed:

It was a great evening; an evening of cigars, Scotch and sodas, gin and tonics, handsome and intelligent men, and their attractive wives. The smoke bothered my lungs a bit, and I had a few coughing fits. The ladies clucked with sympathy, and I felt like a wounded soldier back from the front. ${ }^{13}$

As usual, Peter Taylor had landed firmly on his feet.

Buoyed by his success on Langtang II, Taylor was back in the Himalaya in 1964. He had many of the same Sherpas who had been with him the previous year and also Graham Homan, who had been his base camp manager. He boosted the climbing strength of his party by adding Mary Boyle and George Petley, the latter whom Taylor described as 'an Australian of the "let's 'ave a go" school'. ${ }^{14}$ This time the objective was Langtang Lirung: at $23770 \mathrm{ft}$ (7247 m), the highest peak in the Langtang Himal. Taylor and his party were, however, clearly out of their depth. They quickly retreated after making a short trip up the lower sections of the daunting South-West Ridge and returned to Kathmandu without making any further attempts on the mountain.

More than a decade passed before another Australian was a member of a Himalayan expedition. By then the Himalayan climbing game had changed dramatically. All of the $8000 \mathrm{~m}$ peaks had been climbed and many of those between $7500 \mathrm{~m}$ and $8000 \mathrm{~m}$ had also succumbed to the onslaught of expeditions. In many ways, however, the challenge of climbing in the Himalaya had just begun. Most of the giants had been climbed, but, quite naturally, by the easiest route possible. There still remained an almost limitless number of knife-edged ridges, mixed rock and ice buttresses, massive faces and long high-altitude traverses to be done. By the 1970s, it was this group of 'problems' that increasingly received the attention of ambitious climbers.

The 1975 New Zealand Jannu expedition was a trip very much in the modern mould, as its objective was a route up the steep North Face of Jannu, a $7710 \mathrm{~m}$ peak near Kangchenjunga in eastern Nepal. The expedition marked the entry

13 Taylor, Coopers Creek to Langtang $\Pi$, ch. 12.

14 Taylor, P. 1966, 'Langtang Lirung, 1964', Himalayan Journal, vol. 27, pp. 141-3. 
into Himalayan climbing of a new generation of New Zealand mountaineers, following about 10 or so years after a number of Sir Edmund Hillary-led expeditions had made first ascents of several smaller mountains in the Everest region. The Jannu team, led by veteran guide Peter Farrell, comprised many of the best young New Zealand climbers. One of these was Geoff Wayatt, who, despite having lived in New Zealand for a number of years and having been closely associated with New Zealand mountaineering, was in fact an Australian.

Born and raised in Tasmania, Wayatt got his start in climbing on the Organ Pipes, a rock outcrop high on the slopes of Mt Wellington overlooking Hobart. The mid-1960s found him in New Zealand, where he teamed with some other Tasmanians to climb the north buttress of Mt Darwin, a big-rock route in the Mt Cook region. After his first New Zealand trip, however, Wayatt did not retreat to the warm Australian rock, as did many of his countrymen, but rather stayed on more or less permanently and quickly established himself in the Mt Cook climbing scene.

In the late 1960s, he worked as a guide for Alpine Instruction Limited Mt Cook, one of the first of the professional mountaineering schools and guiding services that were being established in New Zealand. Even in those days, Wayatt took a keen interest in skiing and anticipated by several years the acceptance of ski-mountaineering as a sport in its own right in New Zealand. By 1973, he had established his own school, Mountain Recreation, based in Wanaka and operating in the Mt Aspiring region. He did not, however, confine his activity to New Zealand. He also worked as a heli-ski guide in Canada, picking up valuable experience in judging snow conditions and the susceptibility of slopes to avalanche, and also made the first ascent of the east face of Nevado Huascaran, the highest mountain in the Peruvian Andes. By the time the Jannu team was selected, Wayatt had become so well known as one of New Zealand's leading alpinists that hardly anyone suspected him of being an Australian!

The Jannu team had certainly taken on an enormous task with the North Face route: two vertical kilometres of steep, dangerous and difficult climbing. The bottom section up the face - a rock buttress dubbed the 'Wall of Shadows' was difficult enough, but above it lay extensive fields of steep ice and snow, interrupted about halfway by a line of ice cliffs that frequently sent blocks of ice crashing down the face. The danger was severe enough that some climbers decided not to go above the buttress and in fact the whole expedition reached something of an impasse as the team's morale plummeted when faced with the ice cliffs.

Wayatt and partner Jim Strang broke the crisis by making an 'alpine-style' push virtually all the way up the North Face. Alpine-style climbing-rapidly increasing in popularity in the Himalaya - is the antithesis of the siege-style 
attacks used in earlier Himalayan expeditions. In an alpine-style ascent, climbers simply put everything they need-tents, food, fuel, clothing and climbing gear - on their backs and set out from the bottom of the mountain to push for the summit in one concerted effort. It is much quicker and requires much less gear and supplies than the siege approach, but it also means that there is no string of camps already set up in case something goes wrong high on the mountain. It therefore places much more emphasis on the skill, determination and stamina of the individual climbers.

An alpine-style approach to Jannu's North Face made sense. Wayatt and Strang were both very strong climbers and making a single push for the top meant that they would have to pass under the menacing ice cliffs only once on the ascent and once on the descent, rather than having to make repeated carries under them. Despite some dangerous moments, the tactic nearly worked. The pair reached a point near the bottom of the cliffs the first day and traversed under them as quickly as they could on the morning of the second (see image 3.5). By the end of that day, they were well above the cliffs and onto the upper part of the face. On the third day, Strang made a solo climb to within $100 \mathrm{~m}$ of the summit ridge but, with Wayatt still back in the tent suffering from fatigue and a sleepless night, Strang wisely backed off and the pair descended.

Although Wayatt and Strang did not reach the summit, they had broken the psychological barrier. A second team then made an attempt, taking a somewhat different line up the face, but they ran out of steam on the summit ridge as cold wind threatened them with frostbite, so they retreated. The New Zealanders did not reach the summit of Jannu, but they had shown plenty of courage and determination in scaling the North Face.

Geoff Wayatt's climb on Jannu was harder, steeper and more dangerous than any Himalayan climbing previously undertaken by Australians. It marked Australia's first link with the new style of severe technical climbing in the Himalaya. In many other respects, however, it followed the earlier pattern of Australian involvement in the Himalaya, particularly that of George Finch: a climber of Australian birth who lived and climbed in another country and who was the lone Australian in a foreign expedition.

If Wayatt's only contribution to Australian climbing in the Himalaya had been his participation in the Jannu expedition, he would have had no more impact than Finch or Peter Taylor. Through the training of many novice Australian climbers in his Mountain Recreation School in Wanaka, however, Wayatt was to have an important influence on Australian Himalayan mountaineering. 


\section{On the North Face of Jannu Geoff Wayatt}

Jim led the way, clawing up steep gullies of ice and endless ridges of powder snow. The wind gusts would pin us to the face, then after a momentary lull it would swing and attempt to whip us away. Our faces were continually battered by ice pellets. It was 4.30 p.m. when we hauled ourselves onto the first flat spot in nine hours (see image 3.6). We'd eaten nothing all day and were exhausted. With a lot of effort we levelled a site, pitched the tent and stumbled inside. Jammed inside our sleeping bags and cramped by equipment, we found our stove failed to ignite. Brand new and tested $750 \mathrm{~m}$ lower, the faulty stove now meant we were without hot liquids. We drank some water which we had carried, ate some sardines and dozed off to sleep. The night for me was sleepless, resulting from fatigue, the altitude and the strong winds battering our tent.

In the morning, all I could think of was more sleep, so I swallowed two sleeping tablets. Disturbed by my snoring, Jim decided to look for a better campsite. Six hours later he returned after a solo climb to within $100 \mathrm{~m}$ of the summit ridge. While he was away, I spent two hours fiddling with the primus and managed one and a half cups of warm water. Our dehydration was becoming serious, for without liquid we could eat no food.

That night the storm increased in intensity and threatened to collapse the tent. The air space became so restricted I was forced to sleep with my head in the tent entrance; in the morning I was covered with snow.

It was suicidal to remain high on the face any longer. We had to retreat.

Getting dressed for temperatures of -20 degrees C was an ordeal, and I eventually had to wait outside the tent for Jim. Already my hands were becoming numb; the delay was unbearable but I resisted hurrying him. Finally, stiff with cold, I led off, trailing the rope. Three metres from the tent I tripped and plummeted towards the valley. Jim had yet to tie on and watched me slide helpless through our toilet area down the steepening snow slope. Suddenly my leg jammed in a crevasse and I was spun headfirst downhill, screaming in agony and struggling to relieve the tension from my leg. Jamming my ice axe into the slope for balance I regained my footing then without hesitation I turned and clambered out of sight around a steep ice bulge. Thinking that I'd become deranged, and that I might trip again, Jim thrust his ice axe into the slope and belayed me.

For the first few rope lengths we moved singly until our muscles had loosened. We only had one set of mitts each. Jim's had become wet, so I lent him my spare pair. We backed down the face steadily, gripping the axes firmly while the ever-present wind poured snow onto our hands, feet and faces. Two hours later we ran the gauntlet under the ice cliffs to the sunny calmness of the crevasse camp.

From 'Then the mountain took control...', New Zealand Alpine Journal, vol. 29 (1976), pp. 16-17. 


\section{The killing hills}

The 1950s were a turning point in the history of Himalayan mountaineering. As noted in the previous chapter, improved access to many regions and the increased affluence of Westerners after World War II led to a rush of expeditions arriving to make first ascents of scores of virgin Himalayan peaks.

During the same period, the factors of access and affluence were also at work in Australia to greatly broaden the outlook of its outdoor enthusiasts. Bushwalking enjoyed a surge in popularity. Unlike many other Western countries, Australia was blessed with large wilderness areas near most of its major population centres, so with increased income and, perhaps more importantly, increased leisure time Australians were exploring their unique bush in greatly increased numbers.

Another outdoor activity - rock climbing - came onto the Australian outdoor scene after the war. Although Australia has no large mountain ranges that hold permanent snow, it is liberally sprinkled with a large number of rocky crags of a variety of shapes, sizes and composition. There are the freestanding volcanic plugs of the Glasshouse Mountains near Brisbane and the Warrumbungle Mountains of western New South Wales; the sandstone cliffs of the Blue Mountains near Sydney; the vast faces of metamorphosed sandstone of Mt Arapiles in western Victoria, destined to become the mecca for Australian rock climbing; the granite gorges of Victoria's Mt Buffalo and the sweeping granite slabs of Booroomba Rocks near Canberra; the massive quartzite cliffs of Tasmania's Frenchman's Cap; and countless other crags and cliffs scattered throughout the south-east. Like its good bushwalking areas, most of Australia's rock-climbing venues are not far from its population centres.

The sport of rock climbing appeared on the Australian outdoors scene as early as the late 1920s and early 1930s, when Dr Eric Dark, Osmar White and others of the Blue Mountaineers were taking 32-millimetre yacht manila or heavy sashcord to the sandstone cliffs west of Sydney to do a bit more than just scramble around them. After the war, more local climbers - with David Roots and Rus Kippax being particularly active - found their way into the Blue Mountains. Later hard-climbing newcomers Bryden Allen and John Ewbank from England added further impetus to the sport. Rock climbing was also becoming popular in Victoria and it soon flourished throughout the eastern states. The sport's devotees eventually appeared in Perth and Adelaide as well and by the 1970s, rock climbing was truly a national sport. 
For groups of bushwalkers and rock climbers of the 1950s and 1960s, increasing affluence also meant access to wild areas further afield. New Zealand quickly became a popular destination. Not only was it relatively close to Australia and easy and inexpensive to travel around in, the South Island had the long range of rugged, snow-capped mountains that Australia so obviously lacked. Bushwalkers revelled in the open valleys rimmed by high peaks, the spectacular pass crossings and the large tracts of temperate rainforest-so different from Australia's sparse, mostly sclerophyll forests. Rock climbers traded vertical rock for steep snow and ice and $100 \mathrm{~m}$ crags for $3000 \mathrm{~m}$ mountains.

The lure of New Zealand's Southern Alps, however, led some unsuspecting and inexperienced Australian walkers and climbers into a number of nasty traps. First, there is the weather. Storms appear in the South Island's mountainous regions with a speed and ferocity virtually unknown in the Australian hills. Unprepared walkers find themselves pinned down on high passes by gales and driving snow. At the onset of rain or snow, slopes of snow grass quickly become perilous slippery slides to the valley floor.

For unwary rock climbers, the traps are even more insidious. Snow is a far more variable and inconsistent medium than rock on which to climb. It can vary from soft, sugary slush in which climbers sink to their knees or thighs to hard green ice barely penetrable by crampon points, and anything in between. There are patches of windslab snow on the lee of ridges and layers of fresh wet snow over a hard base - both ripe for avalanching, particularly on the moderately angled slopes that look so inviting to the novice climber. There are cornices on the knife-edged snow ridges and icefalls hanging above popular access routes. Even the rock is vastly different - usually shattered and loose and sometimes coated with a thin invisible layer of ice. Belaying - or attaching oneself to the mountain or cliff while one's partner climbs - requires far more judgment, skill and experience on snow and ice. Finally, when conditions turn bad, climbers cannot simply retreat to a nearby pub and have a beer; they sometimes find themselves so pinned down by a quick storm that even the closest hut is days away.

Walkers and climbers face perils on the broad glaciers that appear to be smooth highways to the high passes or give easy access to steep rock buttresses or snow slopes. Often there are hidden crevasses in the glaciers and a fall into one by an unroped climber or walker is usually fatal. Even if roped to a partner, the unfortunate climber could still be in serious trouble if the pair is not skilled in crevasse rescue techniques. In the broad valleys, away from the glaciers, ice and snow, walkers and climbers still are not out of danger. River crossings are notorious killers in New Zealand and a side-stream that can be crossed with 
a hop and a jump on the way in to a mountain can, after a sudden rainstorm, quickly become a boiling torrent that might sweep away an impatient walker or climber heading back to civilisation.

These dangers are manageable by mountain-people of sufficient experience and with the proper training. New Zealanders have coped with the perils of their mountains for years and they have learned their mountain craft from their older and more experienced countrymen. Before World War II, only a very few Australians went to New Zealand to walk or climb. They nearly always climbed with guides or joined groups of locals so they learned mountain skills in the New Zealand fashion. The situation changed dramatically in the 1950s as scores of Australians made annual trips to New Zealand and some of these went into the mountains uninitiated, without the help of guides, New Zealand friends or groups organised by the New Zealand Alpine Club (NZAC).

The results soon became obvious and gave Australians an unenviable reputation. As Colin Putt, a New Zealand mountaineer who moved to Australia in early 1950 and was secretary of the Sydney Bushwalkers in 1953, recalls:

[O]verseas travel was becoming possible for the average young Australian and at the same time rockclimbing was becoming a significant sport in Australia. Increasing numbers of Australians, usually with considerable bushwalking and rockclimbing experience but with little understanding of alpine conditions and techniques started to go into the New Zealand mountains, often with absurdly ambitious plans and aspirations. By 1956, the number of serious and fatal accidents was quite out of proportion to the number of Australians climbing. Australians quickly achieved a reputation for being unsafe on mountains; most New Zealanders were therefore unwilling to climb with them, so they never got an opportunity to learn except by bitter experience. There were exceptions of course, but this was the pattern as seen by the New Zealand mountaineers. ${ }^{1}$

The problem was not the lack of skill of some Australians but their lack of experience. As Putt put it:

$[\mathrm{T}]$ hey tended to be rather faster and more agile than the New Zealanders, but they did rush in where angels feared to tread. They just didn't know about the weather of real mountains, avalanches, rockfall, the coefficient of friction of snow and ice, suitable and unsuitable clothing, river crossings, or crevasses. ${ }^{2}$

1 C. Putt, Personal communication, 16 September 1989.

2 C. Putt, Personal communication, 15 January 1991. 
Putt recalled a few representative incidents. 'There was a man who set off to glissade down some snow slopes above the Mueller Glacier, head-first and on his stomach. He went over the high bluff at the bottom of the snow, non-stop. It would be funny if it wasn't tragic.' ${ }^{3}$

There was also the well-publicised incident of the 'Three Johns', in which John Young, a very able, experienced Englishman, perished with two inexperienced Australian climbers. No-one knows precisely what happened, but it is probable that Young was somehow put in a position by his partners from which none could escape.

'There were also a number of occasions,' Putt pointed out, 'where an Australian survived an accident (sometimes more than one accident) in which somebody else was killed.' ${ }^{4}$

The view of Australians as unsafe mountaineers became widespread throughout New Zealand mountaineering circles. The NZAC received numerous letters from Australian would-be mountaineers, which exposed profound ignorance of New Zealand conditions by asking questions such as 'could Mount Cook be climbed the first season and was a tent required'. The secretary of the Canterbury/ Westland section of the NZAC noted that 'such a letter... almost required a book in reply'. ${ }^{5}$ M. J. P. Glasgow, editor of the 1955 New Zealand Alpine Journal, wrote:

One of the most significant features about the accidents of the last year or two is the number of climbers from beyond New Zealand (chiefly Great Britain and Australia) who have been involved. It is probable that they have not been aware of the severity of the climbs they have undertaken, nor of the dangers brought about by the peaks being out of condition (as they so often are in New Zealand), nor of the unsettled weather usually encountered in the Southern Alps. In some cases it is clear that they have not realised the difficulty of adapting rock climbing techniques (however useful in their own field) to New Zealand's snow and ice peaks, and to its mixed snow, ice and rock (often glazed) peaks. ${ }^{6}$

Australians' unfortunate reputation even became part of New Zealand's tourist promotion. A guide who took tourists up the Franz Josef Glacier used to tell his clients that 'this glacier comes down from 9000 feet to sea-level, it has about 3,000 crevasses and there's an Australian down every one of them!' ${ }^{7}$ It appeared that New Zealand's Southern Alps had become Australia's killing hills.

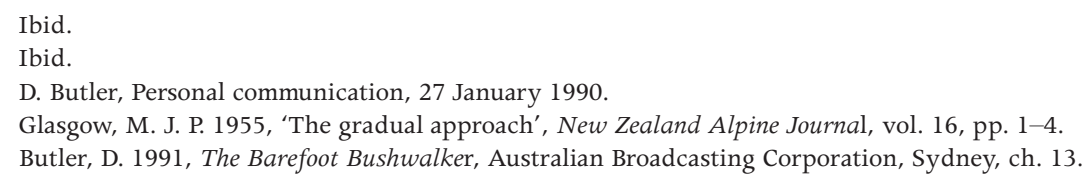


Was that perception - so prevalent among New Zealand mountaineers of that time and built on anecdotal evidence-backed up by the statistics? G. H. Hasell reported in the NZAC Bulletin ${ }^{8}$ that the total number of fatalities in the New Zealand mountains for the period 1945-62 was 88: 46 by climbing accidents, 24 by drowning, 15 by exposure and three by illness. No breakdown by nationality was given, although most of those killed by drowning would almost surely have been New Zealand shooters and fishermen.

The rate of total accidents of all nationalities was thus just more than five a year. That was fairly high, but even if Australian fatalities amounted to half of the total (which they probably did not), it would not have been the horrific rate sometimes implied by those critical of early Australian climbers. Nevertheless, as outlined earlier, there were enough Australian fatalities and enough serious accidents involving Australians that most experienced climbers, including many of the Australians who had become safe and very competent alpine climbers, recognised that a problem existed. For the sake of Australians' reputation, and more importantly for the sake of those inexperienced Australians who could easily come to grief in New Zealand, something had to be done.

A small group of Sydney-based mountaineers, including New Zealanders such as Colin Putt and Ian Wood, and Australians such as Dot Butler, Marie Byles and Lionel Lever, with close connections to New Zealand mountaineering, recognised the problem and approached the NZAC to form an Australian section of the club. The driving force behind this move was Butler, who had climbed in the Southern Alps since the late 1930s and had been an NZAC member since 1940.

The idea had been discussed in early 1956 by Butler, Colin Putt and Ian Woodwho, like Putt, was a New Zealand mountaineer resident in Australia - on a bushwalk in the Endrick River region of New South Wales. They talked around the campfire about the accident rate of Australian climbers and concluded, as Putt said, 'that what many Australians needed, desperately, was some elementary training in snow-and-ice climbing when they first went to New Zealand, and that this could best be organised and provided by NZAC, through its Australian Section, which we then proceeded to invent' ${ }^{9}$

Butler wrote to longstanding NZAC member Whaka Newmarch asking that an Australian section be formed. There was considerable urgency in her letter:

Those of us who have climbed in New Zealand know that there is no alternative to actual experience under New Zealand conditions, if one is planning to climb in New Zealand; but if we could see that prospective

8 D. Butler, Personal communication, 14 January 1991.

9 C. Putt, Personal communication, 16 September 1989. 
visitors to your country were properly equipped, physically, materially and mentally, to meet the different conditions over there, we will have gone a long way towards making for safer climbing and happier associations with your mountaineers. We all feel very seriously that something must be done, and soon, before the next wave of visitors goes over at Christmas. ${ }^{10}$

The NZAC looked favourably on Butler's request and the Australian section, based in Sydney, was established in mid-1956. The Sydney group soon became an information and advisory centre for Australians planning a climbing trip to New Zealand. It had a library of mountaineering books and New Zealand Alpine Journals. More importantly, it organised annual instruction courses in New Zealand, with some of New Zealand's best mountaineers and guides as instructors. Butler organised the first trip in the 1956-57 Christmas period and accompanied instruction trips for nearly 30 years thereafter.

It was most fitting that Dot Butler was the leading light in turning around Australians' reputation as incompetent and dangerous alpine climbers. She is undoubtedly one of the most remarkable people ever to appear on the Australian outdoor scene. Long before bushwalking was the popular recreational activity that it is today, Butler was charging around the Blue Mountains and areas further afield as one of 'The Tigers' - a small group of enthusiastic walkers who specialised in marathon weekend walks.

For example, Butler and fellow walker Max Gentle began one of their weekend dashes on a Saturday lunch-time. They bought a copy of the Sydney Morning Herald, caught a train to Blackheath in the Blue Mountains and then raced down to the Blue Gum Forest in the Grose Valley by mid-afternoon. It must have been a particularly weighty edition of the Herald (perhaps an election campaign was in full swing), as Butler used the paper for a sleeping-bag that night! The next day, Butler and Gentle took off down the Grose River and reached Richmond, 50 miles ( 80 kilometres) away, by the end of the day, thus completing the long trip in a day and a half. As was her custom, Butler walked barefoot.

She was a skilled rock climber as well and preferred to climb - as she walkedbarefoot. She remarked, 'Rocks are my friends and I caressed them as I climbed. They told me what I could and couldn't do. People who climb in boots and overalls are cutting themselves off from that contact.'11 One of Butler's most memorable climbs was her first ascent in 1936 of the spectacular Crater Bluff in the Warrumbungle Range.

10 D. Butler, Personal communication, 27 January 1990.

11 Coote, G. 1989, 'The rocks are her friends-Dot Butler', Australian Geographic, no. 16 (OctoberDecember), pp. 112-13. 
Even at home Dot Butler did some rather remarkable things. In her tribute to Butler as Australian Geographic's 1988 Adventurer of the Year, Gillian Coote related a trip that surpassed even her 'Tiger' weekends:

Dot married Ira Butler, a fellow bushwalker, in Australia during the war. He had been posted to Melbourne and proposed by letter. Unable to get a seat on an interstate train, Dot rode her bike to Melbourne to marry him. On her return journey she rode from Melbourne to Albury on the NSW border before she could get a seat. She estimates she cycled 32,000 km during the war. ${ }^{12}$

It was in New Zealand that Butler made her biggest contribution to Australian mountaineering. Arriving in the Southern Alps in 1939, she spent most of the next three years climbing and became the first Australian to climb in New Zealand without a guide. In fact, she worked part of that time as a guide herself for the Mt Cook National Park. She was therefore in an ideal position to instigate the instruction courses for aspiring Australian mountaineers: she had intimate, firsthand knowledge of New Zealand climbing conditions, her considerable alpine skills were useful in the instruction courses themselves and she was well known in and respected by the New Zealand climbing community.

The courses proved to be extremely popular and very effective (see image 4.1). A group of Australian participants wrote about their experiences in the 1959 course in the next year's edition of the New Zealand Alpine Journal. The very thorough course was led by Norman Hardie, one of the most well-known and experienced New Zealand mountaineers of Sir Edmund Hillary's era. His instruction began on the train ride from Christchurch, during which he lectured on the use of the rope.

When the group arrived at the Crow Hut in the Arthur's Pass region, the course became even more intensive.

From this stage onward, the intensely practical course kept us on rock, snow and ice for practically all our waking hours, and quite long hours at that. Everybody plugged and cut steps, belayed, and climbed across, into, and out of crevasses in the Crow Icefall under Hardie's watchful eye, and each member had enough personal experience of getting out of crevasses to make him very anxious never to get into them...to add to the general experience, a sudden electrical storm had been arranged, with hail, wind and cloud, and the party watched aghast while 'dinkum' blue sparks played about the heads of their axes. ${ }^{13}$

12 Ibid.

13 New Zealand Alpine Journal, vol. 18 (1960), pp. 358-60. 
The Australian writers concluded by affirming that the 'New Zealand Alpine Club's efforts... have already made a tremendous difference to the Australians' approach to climbing' ${ }^{14}$

This was particularly evident when many course participants began to return later to help train the next generation of climbers. Australians began to provide a large number of rescue teams that operated in the Southern Alps, as evidenced by an incident related by Colin Putt:

In 1962 on New Year's Eve a party of Australian walkers managed to escape our net and thus the training courses, got themselves mislaid on Mt Avalanche in Arthur's Pass and got one of their number injured; the Australian training course in the nearby Crow Valley had sufficient trained members of the NSW Federated Bushwalking Club's Search and Rescue Section present to carry out unaided the rescue of fifteen people off a high mountain! $!^{15}$

By the 1970s, the Australian alpine climbing scene had begun to change. The Australian section of the NZAC, based in Sydney, had grown geographically with the formation of a strong nucleus of Melbourne-based climbers. There had always been at least a few Melbourne climbers in the club, with one of them acting as an unofficial representative for the Melbourne group. In the 1970s, Rob Mitchell, an expatriate New Zealand climber resident in Melbourne, became the representative. He soon realised that the lines of communication between the Sydney and Melbourne groups had become too long, slow and cumbersome, so, with the active core of the Melbourne group up to 20-30 climbers, he proposed in 1976 that their group become a separate section of the NZAC. After 18 months of negotiations, the southern Australian section of the NZAC was officially formed in late 1977.

Much like its Sydney-based parent, the southern Australian section held well-attended monthly meetings, put on slide shows and acted as a source of advice for Melbourne climbers going to New Zealand. In addition, the more experienced members of the southern section held instructional climbing trips for beginners, primarily at Mt Feathertop in the Victorian Alps, but also further afield at Blue Lake in the Snowy Mountains of New South Wales. Although these weekend courses could provide some instruction in the basic techniques of snow and ice climbing, they were no substitute for New Zealand courses set in the Southern Alps with their crevasse-riddled glaciers, unpredictable weather and treacherous rivers.

14 Ibid.

15 C. Putt, Personal communication, 16 September 1989. 
By the late 1970s, the alpine climbing scene in New Zealand had changed considerably as well. With the appearance of professional guiding and instruction schools - most notably Alpine Guides Limited in 1967 and Mountain Recreation in 1973 - there was no longer the need for the specialist NZAC training courses that Dot Butler had organised. So, by the late 1970s, both Australian sections of the NZAC were referring many of the increasing numbers of New Zealand-bound Australians to the commercial guides for instruction courses. The Australian sections had done a magnificent job, not only in reducing the accident rate of Australian climbers to an acceptable level, but in generating an indigenous Australian mountaineering community. For the first time, there was an active group of Australians, drawn from the ranks of bushwalkers and rock climbers, with the desire and skills to climb ice and snow mountains.

Throughout the 1970s and 1980s, the commercial instruction courses continued to build the community of Australian alpine climbers. Of these schools, Alpine Guides, centred on the Mt Cook region, and Mountain Recreation, operating in the Mt Aspiring area further south, were undoubtedly the most popular with Australians. Both continued the tradition of teaching basic alpine skills that was established earlier in the Australian section's training courses and both were most valuable in preparing climbers for the rigours of the Himalaya.

Geoff Wayatt's attitudes and mode of operation are typical of both mountaineering schools. He was a guide with Alpine Instruction Limited, the forerunner of Alpine Guides, in the late 1960s and, as noted earlier, founded Mountain Recreation in 1973. As an Australian, he was undoubtedly in a good position to anticipate the needs of Australians climbing in New Zealand for the first time. Furthermore, as the introduction to the interview of Wayatt in Wild magazine noted, 'Geoff Wayatt's philosophy towards alpinism and equipment has significantly influenced the amateur Australasian climbing community as well as many trainee instructors working for Mountain Recreation, perhaps more than any other individual ever to work in New Zealand's Southern Alps'. ${ }^{16}$

Perhaps some of Wayatt's ability to design courses around the needs of Australian rock climbers and bushwalkers comes from his own introduction to the Southern Alps:

My first major climb in New Zealand was the Northwest Ridge of Mt Aspiring during a New Zealand Alpine Club meet. I was teamed up with the local 'Doberman Pinscher', a very fit and aggressive New Zealander. He charged full-speed over rocks in his massive Eckenstein crampons, dragging me tottering along behind. His humour did not improve when he could not follow me up a rock step and he had to detour. We reroped

16 Monteath, C. 1986, 'Interview with Geoff Wayatt', Wild, no. 21 (Winter), pp. 38-41. 
on the snow in the dawn, and again he took off at speed. I yelled 'Hold on!' Instantly he flashed in a boot-axe belay, and turned to see me still finishing my chest coils. 'Don't say that again unless you're falling,' he spat. (We were standing on dead flat snow!) My second ascent of the peak two days later, with Australian friends, was a good deal more fun. ${ }^{17}$

The eight-day Mountain Recreation courses, as well as the Alpine Guides courses, continued the tradition of teaching basic alpine skills that was established earlier in the Australian section's training courses. Much of the emphasis in the professional New Zealand mountaineering courses, however, is on philosophy and attitudes towards mountaineering in general-characteristics that are probably more important than technical ability in determining success or failure in Himalayan climbing. Their approach is very similar to the tried-and-true New Zealand way, as Wayatt points out:

Mountain Recreation is based on the simple formula of a novice being taken into the mountains by an experienced friend. I have simply substituted a professional instructor for the experienced friend, who these days seems hard to find. Mountain Recreation is concerned about specialist skills, but more importantly, it is concerned about the attitudes and values that give them their worth, such as personal aspirations, group communication and spirit, using the mountains to find an inner sense of well-being, and learning to live for extended periods in a sometimes bleak and hostile environment. ${ }^{18}$

The Alpine Guides instructors also impressed on their students attitudes and values that would lead to safe climbing practices and intensely enjoyable and satisfying experiences in the mountains. Several then-novice climbers of the Army Alpine Association, later to become one of the major strands in the Australian Himalayan story, recalled vividly their Alpine Guides course in the late 1970s. Their instructor, a rather gentle, laidback New Zealander, gave them the feeling for the mountains - the ability to understand the mountains on their own terms - which would see them through some difficult climbs in the 1980s.

The values that the Mountain Recreation and Alpine Guides instructors instil in their students for safe and successful New Zealand climbing - a lightweight approach, the importance of good food and safety through judgment rather than equipment - are those that are so crucial to the success of a Himalayan expedition. In fact, add the importance of group communication and spirit mentioned above and you have a pretty good formula for a safe and successful Himalayan trip. 
Much of Wayatt's philosophy comes from his own climbing experiences (see images 4.2, 4.3):

During the Huascaran expedition [in the Peruvian Andes] we saw Poles, Americans, Germans, and Norwegians all burdened down with huge tents, imported foods, deck chairs, and so on. It took little imagination to realise that the implements of comfort were impediments to climbing. The lightweight, live-off-the-land approach is flexible, fun to organise and requires no committing sponsorship. High mobility can only be achieved through the use of lightweight tentage and improvised shelters such as bivvy sacks, bivvy rocks and snow caves. ${ }^{19}$

Alpine Guides and Mountain Recreation courses make copious use of natural shelters. Often accommodation is under rock overhangs, in snow caves or even simply on rock slabs on top of a broad ridge. Despite the decided lack of comfort, using 'passive' shelters does have an advantage, as Wayatt points out:

$[\mathrm{M}]$ ore time is spent in closer contact with the environment we are trying to understand. An intimate knowledge of mountain weather is vital to successful climbing, and from under a bivvy rock you can sense the quickness of the storm building up, the fickleness of a westerly flow, and the suddenness of a southerly snowfall. ${ }^{20}$

Being able to make the correct judgments in difficult situations such as deteriorating weather is the essence of safe mountaineering. Having the latest fancy equipment is of little value; having sufficient training, an unfailing alertness of mind and plenty of experience are vital. As Wayatt says, 'safety and judgement are in your head. Successful mountaineering does not rely on technological advances, but on a number of hard earned factors which can be loosely bundled under the title "judgement"...the only way to get them is to go climbing. ${ }^{21}$

And go climbing is just what Australians did. First in Dot Butler's NZAC training courses and later in the professional training courses, large numbers of Australians began climbing safely and successfully in New Zealand. By the mid to late 1970s, the Australian mountaineering community had grown to the point where new climbers were learning from their more experienced countrymen, in the traditional fashion. Australians began to undertake some of the most difficult ice climbs as well as repeating many of the classics in the Southern Alps. They even climbed several significant new routes. The days of the hordes of inexperienced Aussies were over. They were ready to have a go at the Himalaya in their own right. 



\section{Part 2: On top-first major Aussie triumphs}





\section{Pilgrimage to the silver god}

The year 1975 was undoubtedly the most important in the short history of Australian mountaineering in the Himalaya - not only for the first Australian expedition to the Himalaya but for the beginnings of ideas and careers that would eventually lead to stunning Australian successes. In Melbourne, a small group of climbers was heading for New Zealand's Southern Alps but dreaming of bigger things. In Canberra, enthusiastic students at The Australian National University, beginning the long build-up to launching an overseas climbing trip, were slowly changing their objective from Alaska or the Andes to a major Himalayan peak. In Perth, a young officer was made commander of a Special Air Service (SAS) unit and was ordered to climb; he took the task very seriously. In Nepal, a colonel in the Australian Army, on the classic trek to Everest base camp, sat on top of the hillock called Kala Pattar, looked up at the summit of Everest and dreamed of Australian soldiers standing there in the bicentennial year. And in Sydney, at Kingsford Smith Airport in August 1975, the first truly Australian expedition to the Himalaya was departing for India.

Australia's first home-grown expedition was, fittingly, a national affair, with climbers from Sydney, Melbourne and Canberra making up most of the 14-person team. It also had an international flavour, with a woman from Britain and a man from France joining the trip. Their objective was Mulkila, the 'Silver God' mountain, a $6517 \mathrm{~m}$ (21 $382 \mathrm{ft}$ ) peak in the Central Lahoul region of the Indian Himalaya.

The leader of the Mulkila expedition was Warwick Deacock, a retired major in the British Army. In 1975, there was no-one else in Australia more ideally suited to lead a Himalayan expedition than Deacock. With a background in British rock climbing, he had made climbing trips to diverse places around the world, including the Alps, the Pyrenees, Alaska, Lapland, the Atlas Mountains and Japan. From 1953 to 1956, he commanded British troops in the Ski and Mountain School at Schmeltz in Austria and in 1959 he set up the British SAS climbing wing.

In 1958, Deacock was the founder, secretary and botanist of the British Pakistani Forces expedition to Rakaposhi, one of the giants in the Pakistani portion of the Himalaya. The expedition made the first ascent of the $25500 \mathrm{ft}(7770 \mathrm{~m})$ mountain, but Deacock, in the second summit team, had to descend when his partner, Tom Patey, a well-known Scottish ice climber, got frostbite. Deacock had reached $24500 \mathrm{ft}$ (7470 m). 
After establishing the SAS climbing wing, Deacock immigrated to Australia in 1959 to become the first permanent warden of the Australian Outward Bound School, which he set up on the Hawkesbury River from 1959 to 1962. In 1961, he sailed across the Tasman Sea in a $28 \mathrm{ft}$ sloop and then attempted to climb New Zealand's Mt Tasman. Perhaps his most well-known exploits, however, were several trips to Heard Island, a sub-Antarctic island under Australian jurisdiction. Those trips featured sailing and mountain-climbing components. Big Ben, a $9000 \mathrm{ft}(2740 \mathrm{~m})$ snow-covered volcano and the highest peak in Australian territory, is located on Heard Island.

The 1964-65 trip was perhaps the most memorable. Although Deacock was the overall leader of the expedition, the commander of the schooner Patanela, which transported the party from Sydney to Heard Island, was none other than Bill Tilman, Eric Shipton's intrepid companion on many a mountain exploration, who had become an avid sailor. Tilman got them to Heard Island in good shape, but landing the mountaineering party was another matter as there was no decent harbour on the island. Getting the five climbers ashore through the pounding surf turned out to be quite an epic, as the landing craft capsized three times and dumped its crew into the freezing water. The incidents prompted Colin Putt, one of the climbers, to remark that 'the climb was the only one started below sea level!'.1

After establishing a camp at $4000 \mathrm{ft}$ (1220 m), the climbing team, which included Grahame Budd, a member of the 1957 Imperial College Karakoram expedition, pushed on to the summit of Big Ben in late January, which was the first time the mountain had been climbed. The ascent was not, however, trivial. The climbers were frequently buffeted by blizzards and slowed by white-outs and they often found themselves down slots in the treacherous, crevasse-riddled slopes. Getting back on board the Patanela after the climb was, if anything, more difficult than the landing; most of the expedition's gear had to be left behind. The Heard Island trip was, however, a resounding testament to the effectiveness of small, lightweight, privately funded expeditions and to the skill of Deacock's leadership.

Although the 1958 Rakaposhi trip was Deacock's only climbing expedition to the Himalaya, he considerably strengthened his links with the region after coming to Australia. His old friend Colonel Jimmy Roberts, a Kathmandu-based retired officer from the Gurkha Regiment of the British Army, decided in the mid-1960s to promote walking holidays in Nepal. Roberts institutionalised the British expedition tradition of Sherpa staff, palatable food and a leisurely pace. He thus

1 Temple, P. 1969, The World at Their Feet, Whitcombe \& Tombs, Christchurch, New Zealand, ch. 16. 
changed the style of Himalayan trekking from the spartan, uncomfortable test of endurance that the march to Rakaposhi had been to the enjoyable mountain holidays that thousands have come to enjoy.

Deacock got in on the ground floor. In 1965, he founded the company Ausventure to provide special-interest adventure holidays for Australians with an emphasis on Himalayan trekking. A year later, he teamed up with Roberts' in-country trekking company, Mountain Travel, to send six Australians to Everest base camp. Throughout the next 10 years, Deacock made numerous trips to the Himalaya, leading Ausventure treks, pioneering new routes and opening up new areas for trekking. During that period, he also sent aspiring mountaineers to the Himalayan Mountaineering Institute courses at Darjeeling and Manali and others to Sherpa Wangdi's School of Mountaineering at Manali; and even contrived, 'by some devious means', ${ }^{2}$ to get a few into the Tibet Frontier Course. From 1977 to 1987, he was the Honorary Royal Nepal Consul-General to Australia and he also became the Honorary Secretary for the Australia-New Zealand Section of the Himalayan Club.

By 1973, Ausventure was organising some very adventurous treks - for example, a trip in heavy snow over the Tesi Lapcha Pass, a technically difficult and high (19 $000 \mathrm{ft}, 5790 \mathrm{~m}$ ) link between the Rolwaling Valley and the Khumbu. Returned trekkers from arduous trips such as that began to express a desire to learn more about the high Himalayan peaks. Deacock judged that Australians might be ready to do more than just walk through the mountains. The idea for the first Australian expedition - like the beginnings of many good adventures - came at a social gathering, as Deacock recalled: 'the idea was generated over a beer at the International Mountaineers' Meet at Darjeeling in 1973 to which I was a delegate. Australian climbers seemed about ready to launch upon the Himalaya and Mulkila at 21380 feet [6518 m], seemed to suit the bill.' ${ }^{3}$

Deacock knew the Himalaya inside out and was thus in a perfect position to select a suitable peak for a first Australian attempt. Mulkila, or Mulkila IV as it is more accurately known, is the highest of a group of 10 or so peaks in the Central Lahoul region of the Indian Himalaya. It had been climbed several times previously - first in 1939 by a British/Austrian expedition - and presented no great technical difficulties for first-timers in the Himalaya. The base camp for the mountain was located in a valley surround by seven peaks $18000-20000 \mathrm{ft}$ (5500-6000 m) high of varying difficulty, a couple of which were, at that time, unclimbed. There was something for everyone.

But where would the climbers come from? Deacock was well aware of Australian climbers' earlier reputation, as he pointed out in his Himalayan Journal article

2 W. Deacock, Interview.

3 Deacock, W. 1975, The fifth silver god, Report on Mulkila expedition. 
on the trip: Australians hit the mountain scene with a rather unfortunate bang after the War when transmitting their competitive aggressions from the sports field and proceeded to kill themselves on Mount Cook, the biggest peak in the New Zealand Alps.'4

He was, however, also aware of the training courses that the Australian section of the NZAC had established and he had met many of their graduates on Ausventure outings. By passing the word around the Ausventure fraternity and their connections via a series of 'seldom newsletters', Deacock assembled a heterogeneous team of 14 climbers, with an age span of 38 years and including three women (see image 5.1).

The youngest was twenty-one-year-old Adrian Blake of Killara, New South Wales, and the oldest fifty-nine-year-old Harry Eldridge of Strathfield, New South Wales. By far the most experienced member of the team was Josephine Flood (nee Scarr), who in the early 1960s had teamed with Barbara Spark as a two-person expedition to make first ascents of several $19000-21000 \mathrm{ft}$ (5800$6400 \mathrm{~m}$ ) peaks in the Kulu area of India and then took part in an all-woman British expedition that made the first ascent of Kanjiroba (21 $035 \mathrm{ft}, 6413 \mathrm{~m}$ ) in western Nepal. As described in more detail later (Chapter 28), Flood was one of the first Australian women to climb in the Himalaya, although her Himalayan career did not extend beyond Mulkila. The other women on the Mulkila trip were Canberra schoolteacher Dorothy Brown, who was asked by Deacock to lead the first Ausventure trek to Everest base camp, and Terri Jack of Britain.

The strong Victorian contingent on the trip included Mike Richards, John Ryder, Garry Ash and Keith Seddon. In addition to Deacock, Blake and Eldridge, Derek Lucas, Jim Dorrington and Peter Morris, the expedition doctor, were from New South Wales. John Wanless, along with Dorothy Brown, was from Canberra. Completing the team was Frenchman Michel Altermann, who was born in Cognac. On learning that fact, Deacock immediately advised him that a bottle or two from his hometown would be most welcome on the trip.

The expedition was approached in vintage Deacock 'rumdoodle' fashion. He firmly believed in a less serious attitude than was often found among younger, more competitive Himalayan climbers. The enjoyment comes more from the adventure of the journey itself - from seeing new places, experiencing different cultures and travelling through wild and beautiful places - than from simply getting to the top of a mountain. He summed it up by saying:

To some it [an expedition] signifies a worthy conglomeration of people with an august patron and committee which undertakes at considerable expense a ponderous attempt to 'conquer' some natural hazard - often a

4 Deacock, W. 1975, 'The Silver God mountain (Mulkila) 1975', Himalayan Journal, vol. 34, pp. 156-7. 
peak. Success does not always ensue; death frequently does, and this is accepted by the uplift school of thinkers as inevitable and glorious and by media sponsors as a bonus... Our journey to climb Mulkila IV, the 'Silver God' peak, was seen as a fun thing, a light-hearted rebellion by a party of people who enjoy high places. ${ }^{5}$

Deacock also shunned extensive sponsorship by external sources. 'An expedition,' he said, 'is when you get together with a group of friends, sell the family car, and go off into the unknown for a good time. ${ }^{6}$ Every member of the Mulkila team paid his or her own way, including Deacock himself, who admitted to the team in a newsletter that 'I gave up grog for a year to save up and pay my own way'. ${ }^{7}$ His philosophy was that the expedition should have 'no letterhead, no publicity and no free milk powder'.

In addition to simply having a good adventure with a group of friends, Deacock had a further purpose in organising the Mulkila expedition: to train the first large group of Australian climbers to handle the conditions of Himalayan mountaineering or, as he put it, 'to expose climbers from Down Under to the needs of Up Yonder'. ${ }^{9}$ Although Deacock was an old hand at Himalayan climbing and trekking, most of the rest of the team were novices. They would be getting their first taste of Himalayan expedition climbing, with its vagaries of local transport, base camp food, weather, group dynamics and snow conditions on the mountain.

There is nothing better to introduce a novice to the Himalayan expedition scene than an extended trip on a local bus. The Mulkila team was not disappointed. One of the advantages of choosing Mulkila was its relative ease of access; the walk to base camp took only three days. Before that, however, came a bus ride of the type only the Himalaya could produce, with its mixture of narrow, potholed, winding, landslide-prone roads, dilapidated vehicles and determined, bordering on maniacal drivers.

For the Mulkila newcomers, their bus journey through Lahoul was a real eye-opener and probably the most dangerous thing they did on the entire expedition. Threatened by rock avalanches, tossed about by a head-on collision and delayed by punctures and mechanical failures, they reached base camp only by the perseverance of their driver. Determined to let absolutely nothing stop him, he won the admiration of the trip members, particularly that of the doctor, Peter Morris. Morris's admiration, however, quickly turned to horror when, in

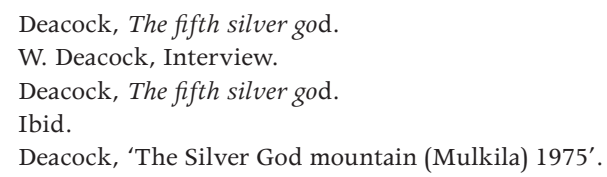


the very best tradition of expedition doctors, he contracted a case of diarrhoea during the journey and could not convince the driver to stop for him. After all, if you can get through avalanches and survive collisions, why stop for a little discomfort experienced by one of the members? It was a most memorable journey for Morris.

\section{Through Lahoul by bus \\ Peter Morris}

The trip in on the bus for two days was an extraordinary adventure in itself. The bus went over mountain passes that are swept by avalanches so that the road has to be continually rebuilt. At one stage on the trip in, there was a tremendous rainstorm and, sure enough, there was an avalanche, a rock fall, which had come right across the road in front of us. We had a small Sikh driver who would stop at nothing. We reached this rock fall where the road was blocked and we thought that the expedition would be over and we would be back in Delhi. But nothing stopped this driver!

He took his turban off, put it on the steering wheel-he didn't want to get it wet-and leapt out of the bus. In the rain, with rocks whizzing down like cannon shot and bouncing all around him, he pulled the biggest rocks off the road so he could get his bus through. I've never seen such dedication! We all sat inside, and he was working out there all on his own in the rain. So half a dozen of us put on our climbing helmets and went out and started helping him move the big rocks. We eventually got the worst of them out of the way, and he gradually eased the bus over the rubble and on we went.

Further on that day, we came to another narrow piece of road with a sharp corner. As we came around the corner, what should we meet but another bus! We had a head-on collision. People were thrown all over the place. The radiator broke on the other bus, but our bus surprisingly kept going. Later the rear suspension completely broke to the extent that the people sitting over the arch on the back wheels started to feel a tremendous vibration and smell burning rubber. Then they started to see the rubber of the wheel coming through the arch! In fact, we were running on the chassis! The driver didn't stop. We pointed to it, he said, 'Yes, yes', and just kept on driving.

He eventually pulled into a construction site where there was engineering work. We were taken off and shown something for half an hour or so while the bus was descended on by about 30 Indians, who jacked it up, made the right brackets and things on the spot, bolted them all in place, and the bus went on!

Nothing would stop this driver. Some of the turns on that road were so sharp he couldn't make it in one go. So he would go into the corner as far as he could and then back around a bit, with the back of the bus hanging right over the edge of the gorge. One wheel of the dual wheels on the back would be hanging in air about 200 feet straight above the river. We reached one of these corners and I got off. I had had enough! I wasn't going to sit in this bus. I've heard many reports since then of buses rolling into the gorge. Everyone would have been killed in that situation; it was extremely dangerous.

But that driver was quite extraordinary. If you had him for a bus driver, he would drive from here to the North Pole and not stop! Nothing would stop him!

Base camp life was enriched considerably by the inclusion on the trip of the Frenchman Altermann, who was a chauvinist in more ways than one. Despite the fact that he was on an Australian expedition, he refused to speak anything but French. This necessitated that he share a tent with Jo Flood, who had lived 
in Paris and spoke French. Morris was the third inhabitant of the tent. Altermann thought it peculiar that there were women on the expedition and informed Flood, who was undoubtedly the most experienced high-altitude climber of the team, that she should be at home doing the shopping and looking after the kids. Flood is, as Morris describes, not 'a woman who can be taken lightly'10 and the altercations between Altermann and Flood-conducted in French at the tops of their voices - kept Morris awake into many a long night at base camp.

The approach to Mulkila IV from base camp - a long march up the Milang Glacier - provided the climbers with a good sampling of Himalayan conditions: searing heat and blinding solar radiation during the day, bitter cold at night, $25 \mathrm{~kg}$ loads to carry through soft snow and the breathlessness and headaches of altitude. As compensation, however, it also provided views of a spectacular mountain basin ringed with soaring peaks. With Wanless and Blake in the lead much of the time, three camps were established along the glacier before a steep slope was climbed to gain the main ridge leading to the summit. Fixed ropes were placed on some nearly vertical sections of mixed snow and rotten rock; the climbing was more difficult than had been anticipated.

The team established camp four at $19400 \mathrm{ft}$ (5900 m) in a precarious position on the main ridge, but several attempts to complete the steep traverse to the summit were repulsed by treacherous snow conditions, described as 'silky snow lying on stacked saucers' ${ }^{11}$ The climbers, however, did not return empty-handed as six of them climbed Mulkila V, a nearby peak of $20000 \mathrm{ft}(6000 \mathrm{~m})$.

Although the primary objective of Mulkila IV was not climbed, the trip was judged a success. Six of the climbers ascended a $20000 \mathrm{ft}(6000 \mathrm{~m})$ peak and all gained valuable experience climbing and living in Himalayan conditions. In fact, the team was defeated in their attempt on Mulkila IV by two of the more common conditions that confronted Himalayan climbers: unstable and often dangerous snow conditions on the mountain and a rapid deterioration of physical strength, often due to problems with food.

The first problem is invariably present to some extent on mountains of $7000 \mathrm{~m}$ (23000 ft), which are too high for the snow to melt and refreeze to consolidate into a firm pack. It could sometimes occur on lower peaks as well, as it did in the Mulkila region in 1975. Trying to push through soft, bottomless snow is not only physically exhausting, it can be quite dangerous, particularly when combined with a sharp ridge, cornices or moderately angled slopes. There is always a chance that by trying to push on through such unstable snow

10 P. Morris, Interview.

11 Deacock, 'The Silver God mountain (Mulkila) 1975'. 
conditions, climbers will trigger an avalanche or collapse a cornice and be swept to their deaths in the process. Faced with such conditions, it is usually wise to retreat, just as the Mulkila climbers did.

Perhaps even more important, however, in stopping the Mulkila team were problems with food and drink. It seems utterly basic and obvious that adequate food and drink should be provided on a climbing trip, but delivering the goods in a remote area of the Himalaya is much easier said than done. More than a few expeditions have been considerably slowed or stopped in their tracks by problems with food.

The culinary hardships that the Mulkila team suffered were not of their own making, as Deacock was knowledgeable enough about this aspect of Himalayan climbing to have planned for adequate provisions. Rather, the problem was in the execution. It seemed that the Indian outfitter the expedition had contracted was untrustworthy or, as Deacock put it, 'a rogue if there ever was one'. ${ }^{12} \mathrm{He}$, or his porters, apparently stole a significant amount of the expedition's supplies, including a large portion of the kerosene. Without fuel for cooking, it was difficult to use many of the supplies, particularly the rice, which the team had counted on as a staple. Perhaps more importantly, it soon became difficult to obtain enough liquid at high altitude when the fuel had to be rationed, as the only way to obtain water was to melt snow. Just when the climbers were in position to go for the summit, the fuel had virtually run out. Dehydration was then a severe problem and, as Wanless pointed out, the performances of many climbers were adversely affected.

Nevertheless, Deacock and many of the expedition members were pleased with the trip. 'We had climbed the fifth Silver God instead of the fourth,' Deacock said, 'had a lot of fun, and no one suffered serious injury - so I suppose it was a success.' ${ }^{13}$

Deacock happily 'misused' the facilities of his company Ausventure to help arrange the administrative details of the Mulkila trip. In that regard, the Mulkila expedition was an antecedent of the commercial mountaineering trips that would start to play a role in Australian Himalayan climbing in the late 1980s.

As a result of the Mulkila experience, however, Deacock concluded that he would not in future offer expeditions within a commercial framework. His reasons were based on ethical and practical considerations. As for the former, he was well aware of the risks of Himalayan mountaineering, having lost six companions in mountaineering accidents over the years, and he believed that

12 Deacock, The fifth silver god.

13 Ibid. 
it would be difficult, if not impossible, to vet applicants. There was therefore a chance that a 'paying customer' could perish. That was a responsibility that Deacock did not wish to assume.

On the more practical side, Deacock had been involved in the organisation of seven Himalayan expeditions and was very familiar with the amount of drudgery needed to get a trip off the ground. He judged that to cost properly the administrative time required to launch a Himalayan expedition of whatever size would make it commercially untenable. His chief reservation, however, remained the ethical one of a climber's responsibility for the safety of his companions on the mountain.

It was another five years before Deacock organised his next expedition to the Himalaya, but by that time much had changed in the Australian Himalayan scene. As described in later chapters, during the late 1970s, more and more Australians were travelling to the Himalaya to climb. Some of these expeditions, especially those to Changabang and Dunagiri, were far more ambitious undertakings to mountains higher and technically more difficult than Mulkila. The ante in Australian Himalayan mountaineering had been raised considerably.

In keeping with these trends, the tenor, objectives and organisation of Deacock's second trip were very different from those of the Mulkila expedition. The goal was Annapurna III, one of the many daunting summits of the massive Annapurna Range, a $20 \mathrm{~km}$ long massif of ice and snow hanging above the tropical lowlands of central Nepal. Over its entire length, the range never falls below $7000 \mathrm{~m} \mathrm{(23}$ $000 \mathrm{ft}$ ). Annapurna I, the highest summit of the Himal, was the first $8000 \mathrm{~m}$ mountain to be climbed, but it - and indeed the entire Annapurna massif - has since gained the reputation as one of the most dangerous Himalayan areas in which to climb. The death rate of climbers attempting Annapurna I is higher than that for any other $8000 \mathrm{~m}$ peak. For the Australian team of 1980, Annapurna III — one of the 'Givers of Life' — would prove to be just the opposite: a deity of far more treacherous and lethal nature than Mulkila, the Silver God.

By the late 1970s, after the success of the Mulkila expedition and the impressive Australian performances on Changabang and Dunagiri (cf. Chapters 6, 7 and 9), Deacock thought it appropriate for Australian mountaineers to go for something about $25000 \mathrm{ft}$ (7600 m). His choice of $24859 \mathrm{ft}$ (7582 m) Annapurna III seemed ideal. It was just the right height and its northern flanks provided snow slopes of reasonable but not excessive steepness and were free of any great technical difficulties. Furthermore, the trek in to base camp, on the northern side of the Annapurna massif, would be a fascinating walk through a remote corner of the Himalaya. Although that trek is now part of the well-trodden Annapurna circuit, the area north of the range had just been opened to Westerners in 1980 and was still a somewhat out-of-the-way region. 
In keeping with Deacock's decision not to arrange expeditions commercially, the Annapurna III trip was organised privately with its own committee and delegated responsibilities. To obtain the considerable financial support required, Deacock went around to many of his friends and acquaintances in business to obtain sponsorships, but in the end much of the necessary $\$ 100000$ came from individuals who contributed small sums. In addition, many of the trip members were given fundraising tasks, such as holding film shows or giving lectures. Another source of support was a series of three treks to the Annapurna III base camp. The 36 trekkers got to meet the climbers and enjoy a professionally arranged trek while, by doing so, contributing towards the expedition expenses. The same idea was used successfully eight years later to raise some support for the Australian Bicentennial Everest Expedition.

Geoff Wayatt, the well-known New Zealand guide, was originally selected as the climbing leader, but, because of other commitments, he was forced to withdraw before the trip's departure. Wayatt's replacement was Colin Monteath, another climber with Australian and New Zealand connections. Originally from Scotland, Monteath moved to Australia with his family at the age of nine. He spent the rest of his childhood and early adulthood in Australia, where he took up rock climbing. Soon after graduating from Sydney University in 1972, he moved to New Zealand and quickly became an accomplished alpine climber. He worked as a mountain guide at Mt Cook National Park and as a field operations officer for the New Zealand Department of Scientific and Industrial Research (DSIR) Antarctic Division. His mountaineering experience included not only extensive time in the Southern Alps, but climbing trips to Peru, Canada and Antarctica.

Deacock and Monteath's team included several others with professional connections with mountain activities. Geof Bartram, originally from South Australia, had become a mountain guide based in the United States and Steve Colman had just set up Wilderness Expeditions, an outdoor adventure company centred on trips in the Snowy Mountains. Jonathan Chester, who was establishing himself as an adventure writer/photographer, also joined the trip. One of the most experienced alpine climbers of the team was Faye Kerr, a nextgeneration Dot Butler who had stacked up an impressive record of climbs in the Southern Alps and had become a ranger in Mt Cook National Park.

Other team members included Ray Johnston, a retired lawyer; Jack Higgs, from the Maritime Services Board of Sydney; Canberra student Stafford Morse; Adrian Blake, a radio technician; and Melbourne barrister Nick Reeves. Steve McDowell, Richard Schmidt and doctors Ken Bowes and Brian Fearnley completed the group. Although the Annapurna III team had an abundance of alpine climbing experience, only Blake, a member of the Mulkila expedition, had been on a Himalayan mountaineering trip before. 
The Annapurna III venture was beset by extraordinarily bad luck from the start, as it nearly came undone by a bizarre accident in Bangkok well before it had reached the Himalaya. Colman recounted the incident:

In the morning, after staying in some cheapish hotel, we were all heading back to the airport in taxis. We had a van in which we stacked all our gear-it was absolutely full.

On the way to the airport the back door of the van flew open and it left all our luggage strewn through the streets of Bangkok for a couple of kilometres. The van driver finally realised that the door had flown open, closed it, and managed to get some of the luggage to the airport. But it was quite tense at the airport as we went through the gear to see what we had lost. Some people's rucksacks, with all their climbing gear, had gone missing.

But we were fortunate in that an enterprising taxi driver, who had been following us, had stopped and picked up all the gear on the road. We managed to get it all back. ${ }^{14}$

Although that incident was a bad omen for the trip, the next stages went smoothly. Everyone, and the gear, arrived safely in Kathmandu and the 10-day trek up the Marsayandi Valley lived up to its expectations as a pleasant walk in a remote part of the Himalaya.

Base camp was established near the village of Manang, in an idyllic grassy glade among trees at an altitude of $3850 \mathrm{~m}(12600 \mathrm{ft})$. The pleasant surroundings and low altitude meant that base camp would be an excellent place to recuperate mentally and physically after extended bouts with the mountain.

The team immediately went to work organising gear for the siege-style assault on Annapurna III. Equipment had to be unpacked and checked, food sorted into packets suitable to be carried up the mountain and kerosene filtered and decanted into sturdy, small containers. And most importantly, the team had to get the blessing of the local Buddist monk, as Nick Reeves reported:

Inside a hall, with the walls lined with golden buddhas and large leatherbound prayer books, we stood together as the lama chanted his blessing, accompanied by cymbals and drums. We prayed to the god of Annapurna III. Incense spread throughout the room. We each made an offering and were told that the lamas would spend an hour each day 
praying for our well-being. Returning from the temple, we passed a row of Buddhist prayer wheels. Each expedition member loudly spun the wheels while silently making a prayer for success and safety. ${ }^{15}$

The route the team decided on was essentially one that a Swiss group had followed a few years earlier. The only real difficulty was an icefall at $20000 \mathrm{ft}$ (6000 m), below which the climb was a slog up glaciers and easier-angled snow and above which a series of 45-degree snow slopes led directly to the summit. The moderately angled slopes, however, were also something of a trap, as they often held snow ripe for avalanching. The avalanche-prone nature of the route was a concern expressed earlier by several other Australian climbers who had seen photos of the northern aspects of Annapurna III.

With the gear sorted and packed and plenty of time up their sleeves, team members methodically moved food and equipment up to a dump on the glacier at about $14500 \mathrm{ft}$ (4420 m) and then to a provisional camp at $16000 \mathrm{ft}(4880 \mathrm{~m})$. Very early in the load-carrying phase of the expedition, however, Annapurna III sounded a terrifying warning to those who would tread on even its lower slopes. Colman recalled the incident vividly:

I was carrying a load up the ridge towards the storage dump. Some of the others had gone ahead and were out on the glacier, sort of ahead but down below me. They had dropped down off the ridge so they were probably a couple of hundred feet below me, about four or five hundred metres away.

There was an almighty roar, and a huge bit of the icefall at 20000 feet broke off. It seemed to drop five to six hundred feet and then hit a series of very steep slopes. It exploded over the whole mountain into an absolutely enormous powder avalanche. There was a $1000 \mathrm{ft}$ wave of airborne powder roaring down. It was absolutely stunning!

There were three of us paralysed on the ridge watching the two or three others on the glacier. They were in deep, heavy snow. You could see them turn around and start to run backwards, but after two steps they just slowed and stopped. The powder then poured between us and them. When it settled, we could see that the avalanche had finished two or three hundred metres away from them. It was quite daunting to see the power of the mountain. ${ }^{16}$

Although the avalanche had emphasised the danger of the north face of Annapurna III, it had also given the team some encouragement. The icefall

15 Reeves, N. 1980, 'We prayed to the god of Annapurna', The Australian Women's Weekly, 14 May 1980, pp. $2-5$.

16 S. Colman, Interview. 
appeared to be very stable and there was little debris below it to indicate that it calved seracs - or pillars of ice - frequently. Perhaps that was the icefall's one avalanche of the year and the route below it would be safe for quite some time.

The provisional camp was moved another 100-300 m up the glacier, to a more sheltered site, and subsequently well provisioned to form an advanced base camp from which the assault on the mountain could be staged. Alternating teams of load carriers moved up to the camp to spend a few days to acclimatise for the higher altitudes.

During one such acclimatisation stay, heavy snowfalls triggered another avalanche, and this time the camp was in the path. Fortunately, it was a much smaller avalanche than the first and, although one tent, with two occupants, was tumbled $150 \mathrm{~m}$ down the slope and another tent destroyed, no-one was killed or seriously injured. The seven climbers at the camp-Bartram, Bowes, Blake, Chester, Morse, Reeves and Schmidt - spent a most uncomfortable night crammed into one tent.

It was obvious, however, that the heavy snows had put the slopes above the camp in a very dangerous condition, so at first light the party began to descend. The first part of the climb back down to base camp went smoothly, as the team crossed the glacier and gained the ridge before the mountain sent any more avalanches crashing down. They had apparently escaped the clutches of Annapurna III.

Just before the climbers reached the safety of base camp - in fact, only 400-500 $\mathrm{m}$ above the camp - they had to traverse a small cirque that had recently been covered with snow from the storms. Often the cirque was completely bare of snow-a small grassy bowl with slopes of about 30-degree steepness. This time, as the line of climbers crossed the slope, it cracked right back to grass level and the whole slab of snow gave way. The resulting avalanche, in comparison with the ones that had thundered down the north face of Annapurna III, was trivial. Colman said, 'I've seen bigger avalanches in the Snowy Mountains. ${ }^{17}$ Its consequences, however, were devastating.

Six of the seven climbers were in the cirque when the slab gave way. Jonathan Chester, who had stopped to take a photograph, was still on the ridge above. Geof Bartram managed to dive off the back of the slab and directly onto the grass, thus avoiding the slide down the cirque. The other five were taken in the avalanche. Ken Bowes, one of the expedition doctors, was only partially buried and was able to dig himself out . Adrian Blake was buried but had a hand still visible. The three who had escaped saw Blake's hand almost immediately and pulled him out of the snow, but there was no sign of the other three. 


\section{Avalanche on Annapurna Jonathan Chester}

At first I thought I was dreaming - the side of the tent was caved in. Then I felt around me and there was nothing but snow. What was this doing inside the tent? Richard's feet, which were at my head, were kicking frantically. I began to panic and struggle for breath. I tried to make a space for some air around my head by winding my hand over my face. More snow fell down and I panicked again but somehow managed to regain control. By continuing to wind my arms upwards in search of air, more snow fell down onto my face, choking me. Suddenly my hand broke through the surface and I gulped the life giving oxygen. The realisation that I was close to the surface gave me the strength to break through and stand up in the small hole I had made. Once on top I saw that our tent was completely buried and the tunnel tent nowhere in sight. Only Stafford and Adrian's tent was still standing unscathed.

Adrian and Stafford were probing with ski stocks in search of the buried tunnel tent and when I emerged they turned their efforts to helping me dig out my tent mates. A muffled cry of 'I can't breathe, I can't breathe,' came from Geoff's direction. The weight of snow on the tent poles and fabric was crushing his chest. Stafford went to work to free him while I frantically dug for Richard. As soon as I reached his head some moans and gasps told me he was alive and I returned to help extricate Geoff. With both Stafford and myself burrowing and clawing at the snow he was soon free and popped up like a chorus girl out of a giant cake. Richard, although his body was now mostly exposed by my digging, was still lying prone and struggling to get up. I couldn't work out what was restraining him. Then I saw an inch diameter aluminium tent pole lying across his throat. At first I feared he may have had a broken neck but then I remembered how strongly he'd kicked me when we were lying side by side. With the strength of a frightened man I was able to lift the pole that pinned him and we embraced, showing great relief and joy to be alive.

All of us were clad only in thermal underwear and it was snowing and blowing. Geoff and Richard were suffering from the shock and trauma of those minutes under the snow, so they sought shelter in the remaining tent. Stafford, Adrian and myself began to dig and probe for the third tent. We found nothing, but not wishing to believe they were dead I kept on burrowing frantically. My bare hands were now senseless. Time seemed to stand still, and yet the more I dug the less chance I felt of seeing them alive. About half an hour had elapsed since I had been buried and gradually reason entered my thinking. Frostbite was a distinct possibility so I staggered back to the tent in search of some gloves and boots. Clad only in Damart underwear and socks the adrenalin must have been sufficient to keep me going in the wind and the snow. But slowly the chilling reality of it all began to creep through me. Adrian was also back in the tent looking for boots, Geoff and Richard were snug in sleeping bags and Stafford was still out searching.

Several minutes later we heard shouts and screams in the distance. I had given up hope of seeing the others alive but I hurried out of the tent just in case. It was dark and down the hill I saw a torchlight and voices could be heard. I lurched down the slopes through thigh-deep snow. Could they still be alive? My heart thumped in anticipation. When Stafford cried out, 'They are safe', 'It's OK,' I couldn't believe my ears. It was heavy going but the thought of seeing Nick and Ken alive drove me on. My mind was racing over the events of the last hour. Everything had been so sudden and unexpected, and that they should also survive after being swept downhill was simply incredible. My mind must have drifted for I suddenly found myself wandering back uphill. I turned around and started back down and was soon faced with Nick and Ken, both very much alive, and Stafford guiding the way. 
Back at the tent the problem was how to squeeze seven people into a $7^{\prime} \times 7^{\prime}$ pyramid. But the pure joy of seeing everyone safe and well more than compensated for the discomfort of cramped quarters. As we clad ourselves in duvets or sleeping bags, Nick described their miraculous escape. Their tunnel tent had been bowled downhill like a balloon before coming to rest on top of the avalanche. They simply had to unzip the door of the tent and step outside. The process of gathering boots, sleeping bags and torches accounted for the length of time we had searched with no sight or sound of them.

The celebration of life that followed our reunion was deep and emotional. Time and again Nick broke the silence with, 'I can't believe I'm alive.' It was hot and stuffy in the pyramid and Richard and I called to Adrian to let in some fresh air. We were the furthest from the door and after our temporary burial we were feeling a little claustrophobic.

From 'Annapurna tragedy', Australian Rock, vols 3-4 (1981), no. 19.

While Chester, Bartram and Bowes continued the search, Blake was sent down to base camp for help. He first appeared as a dot above camp, then as a wildly waving figure as he moved closer. It did not take long to raise a rescue party as some of the climbers had intuitively sensed that something had gone wrong on the mountain and had begun preparations for a trip up to the higher camp.

Climbers buried in an avalanche could not survive for long, so it soon was painfully obvious that the rescue operation had become a search for bodies. Over the next few hours after the base camp party had arrived, the bodies of Stafford Morse, Richard Schmidt and Nick Reeves were found, one by one, buried in the snow. The avalanche - ridiculously small by Himalayan standards - had carried them down the cirque and into a gully, which had funnelled the snow just deep enough to bury them.

For the first time, Australians had experienced the all-too-frequent Himalayan occurrence: the sudden shock of losing climbing companions and good friends. There was no question about the attempt to climb Annapurna III. It was finished. Not only had much equipment been lost in the avalanches, the loss of three companions had knocked the psychological stuffing out of the rest of the team. After a simple ceremony in which Morse, Schmidt and Reeves were buried near base camp, the expedition departed.

The tragedy of the Annapurna III expedition was not, however, quite over. After the attempt was called off, Faye Kerr went on a painting/trekking trip to the Garhwal region of the Indian Himalaya. A short while later, she died of a stomach complaint in India.

Deacock later admitted that 'maybe we bit off more than we could chew. I thought we were ready for a 25000 footer, but things went terribly wrong. ${ }^{.18}$

18 W. Deacock, Interview. 
There is no doubt that routes on the north side of Annapurna are fraught with danger from avalanches. In all fairness to Deacock and his team, however, they were well aware of those dangers and were evacuating the mountain after the first serious snowstorm. It was an extraordinarily freak avalanche that took the lives of the three climbers. Mike Cheney, a veteran of the trekking/climbing business in Nepal, wrote in his summary of the 1980 season, 'The Annapurna III accident was particularly tragic and a severe blow to Australian mountaineering. It was an exceptionally well organised and carefully planned expedition.' ${ }^{19}$

The Annapurna III tragedy convinced Deacock that leading serious Himalayan mountaineering expeditions was no longer for him. It was the last time he was directly involved in a major Himalayan climbing expedition. By then, however, he had already had a lasting influence on Australian climbing in the Himalaya in two ways.

First, his company, Ausventure, continued to provide Himalayan trekking holidays for hundreds of Australians and he and his company provided logistical support for several other Australian expeditions. In addition, by the late 1970s and early 1980s, other trekking companies, such as Australian Himalayan Expeditions, Peregrine Expeditions and Wilderness Expeditions, had come onto the scene to provide hundreds more Australians the opportunity to walk in the high Himalaya. Some of these trekkers, introduced to the Himalaya by an organised trek through one of these companies, would later return as members of Australian climbing expeditions.

Second, Warwick Deacock made a most significant direct contribution to Australian mountaineering in the Himalaya. With his Mulkila expedition in 1975, he started the ball rolling (see image 5.2).

19 Cheney, M. J. 1980, Nepal Himalayan expedition report premonsoon 1980, Unpublished ms. 


\section{Upwardly mobile young men}

It is hard to imagine a lifestyle further removed from the rigours, dangers and deprivations of high Himalayan climbing than the genteel academic existence of Canberra's Australian National University. Bordered by the native bush of Black Mountain and by Lake Burley Griffin's picturesque West Basin, The Australian National University is a haven of tranquillity near the centre of the nation's capital. Erudite professors discuss the nuances of John Locke's political philosophy over a cup of coffee in the leafy Fellows Garden; chemists huddle over their lab benches for long hours in the search for newer, more useful compounds; and students earnestly struggle with the latest in macroeconomic theory to prepare themselves for the heady life of high finance. Even sport takes on a rather elegant feeling. One of the major sporting events, the annual 'Town versus Gown' contest, is based on a cricket match, that most civilised of sports in which the players interrupt the battle for orderly tea breaks and favoured spectators spend a day being wined and dined under comfortable pavilions.

Yet it was within the academic atmosphere of The Australian National University that an unlikely group of Australians coalesced to conceive of, organise and mount the most significant of the early Australian expeditions to the Himalaya, a trip that produced a remarkable success on a difficult mountain and that led eventually to the first Australian ascent of Mt Everest. It was a happy mixture of students and non-students, of novice and experienced climbers and of people with energy, imagination and organisational skills - the sort of mixture that produced a whole that was much greater than the sum of its parts. The pot in which this curious mix of people was brought together and stirred was the ANU Mountaineering Club (ANUMC).

Again, it was during that most eventful year of 1975, the year in which Warwick Deacock led the first Australian expedition to the Himalaya, that the ANUMC began to lay plans for its milestone trip to the Himalaya. The club was the ideal vehicle for launching such an ambitious project as it represented not only ANU students and staff but the Canberra area climbing community in general.

In the early 1970s, it was the university community that was poorly represented in the ANUMC; there was a core of rock climbers from the Canberra region but only one or two undergraduate student climbers. One of that non-university core, Peter Cocker, decided that something had to be done about the lack of student participation. 
Cocker, like several of the other Canberra rock climbers, was an Englishman who had done a considerable amount of climbing in the mother country before migrating to Australia. He was familiar with the activity of the British climbing clubs and their importance to the development of new talent. 'When I joined the ANUMC,' Cocker said, 'I was very surprised about the fact that there was only one undergraduate climber. I resolved to do something about it.'

By February 1974, Cocker had become the president of the ANUMC and had decided to put a big effort into the club's Orientation Week presentation. During O-Week, the various clubs associated with The Australian National University set up stalls near the Student Union and vie with each other to attract new members from the ranks of incoming students. In 1974, Cocker went beyond a simple stall; he organised films and lectures on mountaineering and even set up demonstrations of climbing on the campus. The extra effort paid off. The club signed up 30 new undergraduate students.

The very successful O-Week recruitment drive was quickly followed by a climbing meet at Booroomba Rocks, the local ACT rock-climbing cliff. Cocker rounded up nine of the local rock climbers as instructors to take the new recruits out for introductory climbs. The meet was phenomenally successful by almost any standards. Nineteen of the 30 new members came to the event and 16 of those 19 continued to climb on a regular basis thereafter.

In addition to the rock-climbing meets, Cocker organised frequent film, slide and lecture evenings to inspire the new members and to introduce them to other types of climbing and to other mountainous regions of the world. Soon their horizons were stretched beyond the local crags to New Zealand's Southern Alps, to the Andes of South America, to Mt Blanc, the Matterhorn and the other great European peaks and to the Himalaya itself - the greatest mountain range on Earth. Warwick Deacock showed films of Alaska and of Rakaposhi, and later Canberran John Wanless told the story of the 1975 Mulkila expedition, which sowed another seed in fertile minds already filling with plans for a climbing trip to high mountains in a remote part of the world.

Simultaneous with Cocker's emergence as an enthusiastic leader of the nonuniversity segment of the ANUMC was the arrival at The Australian National University of a group of energetic, outdoors-oriented young undergraduates who were extremely receptive to the club's new high-profile approach. Ken Baldwin, Andrew Blakers, Keith Burns, Theo Hooy and Martin Stone formed the nucleus of that group, but they were quickly joined by others, such as Andrew Bond and Lincoln Hall, a Canberran who had begun rock climbing while in secondary school.

1 P. Cocker, Interview. 
By early 1975, the ANUMC's nucleus of climbers had reached critical mass and the sweeping granite slabs of Booroomba were abuzz every weekend with groups of ambitious young students impatient to climb higher and harder (see image 6.1). It was the perfect blend, however, of that youthful drive with the more cautious approach of the experienced rock climbers that produced a rapid rise in climbing standards as well as a much larger Canberra climbing community. Veterans such as Norm Booth, Ray Lassman, Dick Curtis, John Smart and Chris Larque gladly gave their time to the young ANUMC recruits and not only taught them the basic methods of climbing, but showed them all the rope-handling and other techniques and attitudes that were essential for safe climbing. As Baldwin put it, 'They provided a bit of sanity amongst all this energy.'2

Booroomba Rocks could not contain the energy for long. When the winter months arrived, the ANUMC climbers were up in the Snowy Mountains, learning to climb ice and snow on the short but steep frozen waterfalls on the bluffs above Blue Lake (see image 6.2). New Zealand was the next step and soon groups were travelling to the Southern Alps to learn mountaineering in the now well-established schools at Mt Cook and Mt Aspiring. Indeed, a few, such as Baldwin, had already made climbing trips to New Zealand.

Again, Peter Cocker was one of the primary driving forces as he actively encouraged as many young climbers as possible to build up mountaineering experience in New Zealand. He realised that although the students were becoming proficient rock climbers, they would need several seasons in New Zealand before they could tackle larger snow and ice-clad mountains elsewhere in the world.

With the active program of slide and film nights within the ANUMC, the young climbers had already begun to think and talk about a trip further afield. There were plenty of areas to think about: the Andes Mountains of Peru; the European Alps with their classic, well-known routes; the great volcanic peaks of eastern Africa; the snow-covered mountains of tropical New Guinea; and, of course, the great Himalayan Range of Asia, the highest mountains of them all.

Climbers often dream and talk of trips to remote mountains overseas, particularly to the Himalaya, but the dreams usually remain just that, until some particular event triggers a core of climbers to begin turning the dreams into reality. For the ANUMC group, that event was a social occasion, as it had been for Warwick Deacock, who launched the 1975 Mulkila expedition over a few beers in Darjeeling.

The location was not as remote for the ANUMC climbers, nor was the occasion as formal as a Himalayan Club meeting. A few of the Canberra group got together

2 K. G. Baldwin, Interview. 
over a cup of coffee in a cafe just down the street from an outdoors-gear shop in Civic, Canberra's downtown area. They had been browsing in the shop and, as usual, conversation had quickly turned to an overseas expedition.

Present at that very casual get-together in the cafe were Peter Cocker, John Finnigan, one of the veteran climbers who had been an instructor on that first ANUMC rock-climbing meet and had since become Cocker's regular climbing partner, Lincoln Hall and another of the younger climbers. This time their talk of an expedition to the Himalaya took on a sense of purpose and commitment that lifted it above the level of an idle dream.

By mid-1975, their idea of a Himalayan expedition had gathered momentum and indeed had taken on a life of its own. Vague ideas now gained a bit more substance and practicalities, rather than just wishes, began to dominate conversations among the wider ANUMC membership. Very early on, two major questions came to the fore: where and what type of expedition?

Although it had been agreed that the expedition would go to the Himalaya, that still left a lot of possibilities. The Himalaya stretch for $2700 \mathrm{~km}$ in a great arc through Asia and contain countless peaks, climbed and unclimbed, of varying height, steepness and accessibility. The ANUMC group went about the task of choosing an area or a peak in a most systematic fashion. Subgroups were formed to thoroughly investigate likely regions and then report back to the main group. Serious contenders for the target area included the Langtang region just north of Kathmandu in Nepal; the Rolwaling Valley, a little-visited region west of $\mathrm{Mt}$ Everest; the very remote Kanjiroba Himal in the west of Nepal; the Garhwal region of the Indian Himalaya; and regions further to the north-west, such as Kashmir and the Hindu Kush.

The final choice of an objective depended very much, however, on the style of the expedition. The original idea, the one Peter Cocker had favoured, was for a low-key trip, an expedition into an area where there were a number of peaks of various sizes and difficulties rather than a single, major objective.

'We would set up a base camp and stock it with good food,' he said, 'and then go off and climb. The idea was to take a bunch of relatively inexperienced climbers into some high mountains and get them some high-altitude experience. ${ }^{3}$ In that regard, Cocker's idea was very similar to Warwick Deacock's notion of getting climbers from 'Down Under' used to the needs of 'Up Yonder'.

Several of the areas under consideration would meet the needs of a 'climbingcamp' style of expedition and in the end the Garhwal region of the Indian Himalaya was chosen. It seemed to be the ideal area. Its major attraction was

3 P. Cocker, Interview. 
the Nanda Devi Sanctuary, a spectacular high, hidden valley surrounded by a rim of imposing snow, ice and rock peaks and dominated by India's highest mountain, Nanda Devi $(7817 \mathrm{~m}, 25647 \mathrm{ft})$, which rose majestically from the centre of the sanctuary. Apart from very high and difficult glaciated passes, the only access to the sanctuary is via the gorge of the Rishi Ganga, a short but arduous and rather dangerous trek. The Nanda Devi Sanctuary offered just what the ANUMC team was looking for: they could attempt several of the impressive peaks on the northern rim of the sanctuary and climb in a spectacular setting in a remote and seldom-visited part of the Himalaya.

Only one problem remained: gaining permission for their plans from the Indian authorities. They quickly discovered - as many other Himalayan expeditions had and would find out - that getting to the mountain often proved more difficult and frustrating than climbing it. They were denied access to the wide range of peaks they had hoped to attempt and were offered instead a single peak, Dunagiri, on the outer rim of the sanctuary.

That decision by the Indian authorities forced a subtle change to the nature of the expedition. Although several members had always preferred an expedition with only one large mountain as an objective, the fact that they could obtain a permit for Dunagiri only meant that the expedition would no longer be a trip primarily to climb a number of lesser peaks but rather a venture with a single, major, difficult objective.

Dunagiri was undeniably a formidable target. Although it had been first climbed in 1939 by a Swiss team led by Andre Roche, it had, by the mid-1970s, been climbed only one other time and, more ominously, had claimed a disconcertingly large number of lives in the intervening years. Furthermore, the ANUMC team decided to tackle Dunagiri by a route not previously tried - a move that would add to the significance of the attempt but would increase the difficulty and possible danger of the climb. Finally, Dunagiri was $7066 \mathrm{~m} \mathrm{(23} 184 \mathrm{ft})$ high, a Himalayan giant by any standards and particularly so for a team of primarily young university students.

Indeed, no-one in the ANUMC group had been on a climbing expedition to the Himalaya before, so they set about getting advice wherever they could find it. Cocker sought information from many other groups and talked to literally dozens of people, including Deacock and Wanless from the Mulkila trip. In the end, the most important of these advisors was Bill Packard, a New Zealander who had moved to Canberra in 1961 and was the warden at Bruce Hall at The Australian National University.

Packard's connection with Himalayan climbing went right back to 1950, when Nepal was just opening its doors to foreign expeditions. The previous year, 
the Nepalese Government had yielded to considerable British pressure and allowed a single exploratory expedition, led by the veteran mountaineer Bill Tilman, into the Langtang region north of Kathmandu. The Nepalese had, however, put a condition on the trip - much to the annoyance of Tilman - that the expedition must have a strong scientific component. Tilman revelled in extremely lightweight mountain travel and abhorred any encumbrances added by scientific pursuits. He barely tolerated biologists and particularly disliked geologists, who would invariably burden the expedition with rucksacks full of rocks.

The Himalayan Committee of the British Alpine Club secured Nepalese permission for another Tilman-led climbing expedition in 1950 and, from the British point of view, one of the purposes of the trip was to introduce younger climbers to Himalayan mountaineering conditions to build up personnel for future Everest attempts. Packard was a geography research student at Oxford University at the time the 1950 trip was being organised. With a background in science and some seasons of New Zealand climbing under his belt, he turned out to be the right person in the right place at the right time. After a chance meeting with Tilman at a dinner, Packard was invited on the expedition. He secured his place perhaps not so much by his scientific or mountaineering experience but rather by his extreme economy of words. Tilman hated verbose people nearly as much as he did pick-wielding geologists.

Tilman's 1950 expedition headed for central Nepal with the aim of making the first ascent of a $26000 \mathrm{ft}(8000 \mathrm{~m})$ peak. They first looked at Manaslu and then made an attempt from the north on Annapurna II, later accurately surveyed to be slightly less than $26000 \mathrm{ft}$ (8000 m). 'Being a characteristic British expedition,' Packard quipped, 'we didn't get to the top of anything, but we didn't lose our fingers or toes either. ${ }^{4}$

Unfortunately, Packard contracted poliomyelitis on the expedition and that ended his career as an active mountaineer. He remained in Britain for several years, however, and served as a technical advisor to the successful 1953 British Everest expedition and as the London agent for Sir Edmund Hillary's 1954 New Zealand Barun Valley expedition. (The highest peak climbed during that 1954 trip, Baruntse, would be the target of an Australian team in 1988.) When the ANUMC group started looking around for advice on Himalayan mountaineering, there was no-one in Canberra more suited to the task, or more willing to help, than Bill Packard. He was officially appointed technical advisor to the Dunagiri expedition. 


\section{Dinner with the great man Bill Packard}

In the late 1940s and early 1950s, one of the wishes of the Royal Geographical Society and the Alpine Club was for Bill Tilman to take a small group of younger climbers into Nepal so that there would be a cadre of younger people with Himalayan experience. The Maharajah-Prime Minister still required scientific work - none of these useless expeditions - so Tilman decided he would take a botanist, as plants didn't weigh very much, but, in his own whimsical way, expressed his general disapproval of rock-collecting geologists.

He had come to speak to the Oxford University Mountaineering Club about his 1949 Langtang trip. I was then at Oxford and very keen in the Mountaineering Club. We heard the great man give his absolutely magnificent lecture, and afterwards, as was the club's wont, the great man was entertained to supper by the inner core of the climbers. I was one of those people, but more on the fringes, I think.

Tilman, having given this wonderful lecture, didn't say a word. We were trying to get him to talk, and all we got were monosyllabic grunts. Somehow it came out I was a New Zealander, and he initiated his first and last question of the evening.

'You know Dan Bryant?' he snapped. Mercifully, I knew Dan Bryant, who had been with Tilman in 1938 on Mt Everest. I started talking about Dan Bryant, and suddenly he cut me quite short, 'Bloody fine bloke!' And that was that.

I had indicated, as had quite a number of other people there, that we were very interested in his sort of lightweight exploratory expeditioning. I was at the university doing postgraduate studies in geography at the time, a fact that he somehow found out.

So I got a letter from him some three weeks later saying, 'Dear Packard, Would you care to join me in the Himalaya this year to wield a phototheodolite. Yours, W. Tilman.'

I, for once, was able to be even briefer than he. 'Dear Tilman. Yes. Yours, Packard.' I then had to go off and find out what a phototheodolite was and how to wield one.

The Dunagiri aspirants needed much more than just advice, however, to get the expedition off the ground. Mounting a major attempt on a large peak such as Dunagiri would require a large amount of resources: climbing equipment, tentage, ropes, fuel, stoves, food and the transport to get it all to the base of the mountain. Most of the team members were university students, who were in no position to fund the trip themselves. Not only was the objective much more formidable than that of the 1975 Mulkila expedition, much more outside support would have to be found to get the trip off the ground. It certainly could not be the 'no free milk powder' style of expedition that Deacock preferred.

The Dunagiri team had one big advantage in their fundraising efforts: they were associated with a university and, in the best tradition of many earlier Himalayan expeditions (Tilman notwithstanding), they could combine scientific experiments with mountaineering activities. The scientific component of the trip could then attract support, in the form of tax-deductible donations, from 
quarters that would otherwise not be interested in a mountaineering venture. Furthermore, many of the team had backgrounds in the physical or biological sciences and were thus ideally placed to carry out the experiments themselves.

To attract this type of support, the ANUMC group incorporated itself and published a high-quality colour brochure outlining the expedition's objectives scientific, exploratory and climbing. Eventually, in collaboration with staff at The Australian National University, the group organised three scientific experiments to be carried out during the expedition: an estimation of the rate of uplift of the Himalaya from the tiny tracks left in rock crystals by disintegrating uranium atoms; the collection of tree-ring samples for dating purposes; and a rather bizarre way of determining the mobility of plant seeds - by having members of the team wear socks on various stages of the march in to base camp and then, back at The Australian National University, placing the socks in a sterile potting mixture and allowing them to germinate. The last experiment was thwarted in the end by the thoroughness of Australian quarantine officers.

The continuing organisation of such a complex enterprise as the Dunagiri expedition entailed a lot of hard work. As Bill Packard put it, "There had to be a "burning light" to keep it going. ${ }^{5}$ That burning light was undoubtedly Ken Baldwin. Although he received plenty of help - principally from Keith Burns but also from several others-Baldwin was the organisational driving force behind the Dunagiri trip.

'No matter what else happened,' Packard recalled, 'no matter who dropped out or whatever else went wrong, Ken Baldwin was going to get himself to the Himalaya.' ${ }^{6}$ And, as it turned out, he would get everyone else there as well.

It must have been a very busy year for Baldwin in 1977. In addition to carrying a very heavy Dunagiri workload, he was doing his honours year in physics at The Australian National University. 'My supervisor looked aghast when I told him I was organising this Himalayan expedition as well,' Baldwin said. 'To some extent, he was right. ${ }^{\prime 7}$ Baldwin, however, still managed a first-class honours that year.

There were many other possible sources of support apart from the sciencerelated ones and Baldwin went to work hunting them out. 'In many regards, funding support wasn't that hard as we were working with a virtually untapped 
market then,' he recalled. 'We were the first major Australian expedition to the Himalaya, or certainly the first one to seek large-scale support, and we found some very receptive sponsors, particularly food companies.' ${ }^{8}$

The real breakthrough, however, came when Baldwin engineered a \$10 000 package with the Sydney Morning Herald newspaper. The possibility of support from the newspaper had initially been raised by the expedition patron, the university's Pro-Chancellor, Dr H. C. Coombs, who knew the Fairfax family. With the backing of such a large media group, the expedition achieved an even higher profile and thus found obtaining additional support considerably easier.

In addition to the direct financial support, the Sydney Morning Herald provided a reporter, Ben Sandilands, to accompany the expedition and paid for his share of the expenses. The much higher media profile that the deal ensured, however, meant another significant change to the nature of the expedition. First, the trip had changed from a 'climbing-camp' style of venture in which members went off in small groups to attempt a variety of peaks to an expedition attempting a single, high mountain by a new route. Now that attempt would be in full public view, on the front pages of major Australian newspapers.

Such a major shift in the nature of the expedition was bound to create some problems. Peter Cocker, for one, was very uneasy as the trip grew in complexity and particularly as the publicity aspect grew in importance: 'The character of the expedition changed completely. I thought of pulling out, personally. Now a lot of money was involved. Now we had to go and we had to perform. I wasn't very happy about that. ${ }^{9}$ The uneasiness about the media situation, at least in Cocker's mind, was never very far from the surface and perhaps contributed to tensions later in the expedition.

Cocker undoubtedly felt most strongly about the potential problems with media sponsorship, as he had become the expedition leader. He was the obvious choice. Although he was a non-student and some 15 years older, his very youthful appearance, engaging personality and supportive and encouraging attitude towards novices made him very popular with the younger climbers. Furthermore, it was largely Cocker - always fired with enthusiasm for grand ideas - who had got the Himalayan trip going in the first place.

In addition to the personal attributes needed for effective leadership, Cocker had a considerable amount of overseas climbing and trekking experience. With the usual Englishman's background of rock climbing in England and Wales and ice climbing in Scotland, he had made climbing trips to the sea-cliffs of Cyprus, to Arctic Norway, where he had a close call when he nearly had a

8 Ibid.

9 P. Cocker, Interview. 
long and fatal fall, and to the north-eastern corner of Turkey, where he and his climbing partner were caught by police in an illegal zone near the border with the Soviet Union but managed to talk themselves out of the delicate situation and complete the trip. On an overland journey from Britain to Australia, Cocker stopped by the Himalayan Mountaineering Institute in Darjeeling, where he met Tenzing Norgay, Hillary's companion on the first ascent of Everest. Later, Cocker returned to the Himalaya for an 'extended walk' in the Helambu area north of Kathmandu.

Bill Packard, the expedition advisor, judged that Cocker had just the right qualities for leader and was most enthusiastic in his support: 'As leader, Peter was ideal. He had a lot of experience, and he had the right amount of inner good sense and daring. You need a bit of daring. If you're going to do everything absolutely perfectly, you'll never get up anything!'10

Cocker, however, had the young team's safety utmost in his mind: 'I was determined before anything else, including reaching the top, that we would eliminate as many risks as possible.'11 Cocker received considerable help in dealing with potential problems such as a high media profile, as well as with the planning stages of the expedition in general, from two other experienced members, John Finnigan and Charlie Barton.

'The worry about media sponsorship was only amongst the older people,' Finnigan pointed out. 'We were concerned about being driven to do something we didn't want to do. But we recognised that, so it wasn't likely to happen.' ${ }^{12}$

Finnigan brought more overseas experience and a good deal of talent to the expedition team. In fact, he was widely acknowledged to be the most proficient ice climber of the group and one of the best rock climbers. Overall, he was probably the best technical mountaineer of the group.

Like Cocker, Finnigan was originally from England, where he had taken up climbing at an early age through school outings. He remembered one extended trip in particular, where he and his schoolmates were dragged up severe climbs by an overly ambitious instructor: 'We were terrified on various crags all over Snowdonia.'13 Later Finnigan himself became an instructor for the British Mountaineering Association and led novices up classic rock routes around the British Isles.

His first overseas trip in 1966- to the Dolomites in the Italian Alps - proved an introduction to 'epics', which seemed to become Finnigan's trademark in

10 W. Packard, Interview.

11 P. Cocker, Interview.

12 J. J. Finnigan, Interview.

13 Ibid. 
succeeding years. The journey began when, after a heavy night on the grog, Finnigan managed to get his right hand smashed in a closing train door. Undeterred, the party continued into the Alps but was stopped on the wrong side of the Brenner Pass by floods. After salvaging a bit of climbing on Austria's Kaisergeberge Wall, they finally made it to the Dolomites, where Finnigan, with a right hand that still looked like a boxing glove, led a steep, exposed climb up one of the Vajolet Towers, a group of spectacular limestone pillars.

The next year, he was in Norway attempting the Trolltind Wall, Europe's largest vertical rock face and one that rivalled the great granite walls of the United States' legendary Yosemite Valley. Again, Finnigan was immediately involved in an epic, as he and his partner were bailed up partway up the wall by a nasty storm of sleet and snow. They were in a position, legend had it, from which descent was not possible and the storm-fed waterfalls above prevented them from completing the climb. There was no way out; they had had it. The resourceful pair, against all odds, somehow managed to down-climb the wall the next morning and escape the clutches of the Trolltind. Buoyed by their Houdini-like escape from death, the pair then raced up the wall in record time when the weather cleared.

Finnigan's next epic did not have such a happy ending. In 1969, he was in the Alps to attempt some hard, mixed ice and rock climbs in the Mt Blanc region. He and his partner were on the very steep west face of the Petit Dru, the most dramatic of the granite aiguilles near Chamonix. Again, a snowstorm had forced a retreat from high on the face. After exiting the rock face into a snow couloir, Finnigan was swept off a stance by a rock fall and tumbled hundreds of metres to the bottom of the couloir. He was extremely lucky to escape death, but suffered severe damage to his left knee. The early prognosis was not good: the end of a promising climbing career and probably the end of any athletic or sporting activity.

By the early 1970s, Finnigan had moved to Australia and, after extensive rehabilitation on his knee, was climbing again. Still, he could not bend the knee more than 90 degrees and, as he put it, he 'had to learn to climb again with one and a half legs' ${ }^{14}$

Even with one and a half legs, Finnigan was counted on to be the main driving force of the Dunagiri climbers and the one who could overcome any severe technical difficulties the group might encounter. Packard recognised Finnigan's importance and his penchant for getting involved in epics. 'John Finnigan,' 
Packard said, 'is a man who must have broken his bones on almost every mountain range in the world. But he was terribly important to the expedition. He was really prepared to give things a go.' ${ }^{15}$

In addition, every expedition must have a 'hard man' and for the Dunagiri trip, Finnigan was it. On the frequent winter training trips to Blue Lake in the Snowy Mountains, Finnigan was renowned for his desire - after an arduous ski trip to the lake through gales and driving snow when all any sane person wanted to do was crawl into a sleeping-bag with a hot cup of tea-to cajole someone out of a tent and climb the hardest ice cliff on the crag. Finnigan's drive to climb hard was, however, balanced by his bizarre, Monty Pythonesque sense of humour, which could defuse tense situations and made him a most entertaining companion in the mountains.

The third of the trio of English climbers who formed the backbone of Dunagiri's old guard was Charlie Barton. Barton's climbing background was considerably different from that of Cocker and Finnigan; most of his overseas experience was in Africa, where he lived for a decade. Barton had climbed the classic volcanic peaks of eastern Africa-Mounts Kenya and Kilimanjaro - but had also climbed in the snow-covered Ruwenzori Range of Uganda and the Hoggar Mountains in the Sahara Desert.

Barton brought many other qualities to the expedition. His long experience in Africa prepared him well for living in the vagaries of Third World societies. Indeed, he revelled in local bazaars, where his uncanny ability at bargaining for everything from a washer for a stove to gallons of kerosene could prove most useful. Perhaps his most important attribute - particularly in a group primarily of young, energetic, but inexperienced university students - was his steadiness. Nothing seemed to ruffle Barton and he could always be relied on to provide that bit of sensible, sane advice that could break an impasse.

Another of the more experienced of the team was Charlie Massy, an Australian who ran a property near Dalgety in New South Wales. Massy was the group's most experienced climber in New Zealand, with four trips to the Southern Alps, and the expedition's deputy leader and treasurer.

The bulk of the climbing team, however, was that group of young, energetic undergraduate students who had come to The Australian National University in 1974 and had revitalised the ANUMC. Most were in their early twenties, had varying amounts of ice and rock-climbing experience and had one or two trips to New Zealand under their belts. 
Ken Baldwin, as described above, played the major role in organising and coordinating the trip. Also prominent in the organisation were Keith Burns, originally a New Zealander and at twenty-one the youngest member of the group, and Martin Stone, a Tasmanian and a recent graduate of the ANU Forestry Department.

Indeed, the Forestry Department was well represented on the Dunagiri team, with three other students: Andrew Bond, Theo Hooy and Tim MacartneySnape, who was the best skier of the team. Like Macartney-Snape, Hooy was a Victorian and he was heavily involved in the scientific as well as the climbing aspects of the trip.

Ken Bell, a grazier from Goulburn, New South Wales, added a breath of fresh air to the otherwise sometimes heavy academic atmosphere of the group and lightened things with a sense of humour as zany as that of Finnigan. Another honours physics graduate, Andrew Blakers, a very keen runner, skier and bushwalker, was probably the fittest member of the expedition.

Lincoln Hall and John Armstrong completed the climbing team. Hall promised to be one of the strongest climbers on the trip; he was arguably the best rock climber of the team and, even though he was only twenty-two, had already managed three climbing seasons in the Southern Alps. Armstrong, the oldest climber of the group at forty-three, added another large dose of good sense and willing labour as well as 28 years of climbing experience.

Medical officer for the expedition was Mark Podkolinski, who was no stranger to working in harsh conditions. Before the Dunagiri expedition, he spent 13 months as medical officer at Davis Base in the Australian Antarctic Territory. Finally, getting the news back to Australia was Ben Sandilands, the reporter from the Sydney Morning Herald.

Officially on the trip as a reporter, Sandilands had a strong background in rock climbing and mountaineering. He began climbing in the Blue Mountains in the early 1960s and followed that with numerous trips to New Zealand, where he climbed Mt Cook no less than four times, two of them being traverses of the three summits. He had climbed in the Dolomites and the French and Bavarian Alps in Europe, the North Cascade Range in the United States and even on the massive vertical granite walls of Yosemite Valley. In many regards, Sandilands was more experienced than several of the Dunagiri climbing team.

By early 1978, with the team composition settled, the scientific program in place, the sponsorship found and funds raised, the transport arranged and the hard training over, everything was in place to send the largest and most wellpublicised Australian expedition to the Himalaya. Or was it? 
In the early months of 1978, a series of events nearly knocked out most of the experienced climbers and threatened to leave the expedition leaderless. First, Charlie Barton had to pull out at the last minute. Barton was working on a PhD in geophysics at the ANU Research School of Earth Sciences and the demands of the last stages of his academic program forced him to retire from the expedition. John Finnigan, too, was working towards a $\mathrm{PhD}$ and, in addition, his wife, Margaret, was expecting their second child about the time the expedition was due to leave for India. His participation began to look shaky. Losing Barton was a severe setback, but losing Finnigan, with his drive and depth of experience, would be a crippling blow to the team's chances of climbing Dunagiri.

Then, in the final weeks before the team was due to depart, it looked as if Cocker might pull out as well. Although he had been instrumental in getting the Dunagiri trip off the ground-and indeed had played a leading role in rejuvenating the ANUMC and had become a pillar of the club-Cocker, in the months leading up to the departure, was beset with personal problems that greatly affected his participation in the final planning stages.

Cocker had separated from his wife. In addition, he was experiencing severe financial problems; he was working long hours in real estate sales to make ends meet and, in the end, had to sell his car. Just meeting his financial commitments to the expedition posed almost insurmountable problems. 'Everything was against going on the expedition,' Cocker said, as he remembered those difficult times:

It was probably difficult for the students to understand how you could be working seven days a week, 10 hours a day and not earn a penny! No-one seemed to understand that it was a real crisis for me, emotionally and consequently financially. Perhaps I should have pulled out from the expedition from the beginning but uppermost in my mind was the safety of the students and the mountain was secondary. Of course, this would put me on a direct collision course with the media expectations for the expedition. I was unable to commit any time or money to the organisation of the expedition. ${ }^{16}$

As the organisational duties multiplied towards the end of the planning stages, Cocker, the expedition leader, was nowhere to be seen at the frequent meetings. 'Just when he was absolutely needed to keep things going, he was suddenly not around,' Finnigan recalled. ${ }^{17}$

Things nevertheless had to be kept going and most of the tasks fell into the capable hands of Ken Baldwin. Already burdened with obtaining sponsorship

16 P. Cocker, Interview and correspondence.

17 J. J. Finnigan, Interview. 
and organising many of the other expedition details, Baldwin found that the additional duties placed on him during the final months taxed even his considerable energy and organisational skills. Somehow he managed to get everything done, but not without a lot of stress and more than a few sleepless nights. Cocker's absence inevitably caused some degree of friction between him and the overworked Baldwin.

The toughest talk, however, came from Finnigan, Cocker's closest friend on the expedition team. Just before the expedition was departing, Cocker confided to Finnigan that he had decided not to go and asked for Finnigan's advice. In typical fashion, Finnigan minced no words: 'You can't pull out,' he told Cocker, 'you would lose all credibility. If you drop out, you'll never have any respect around the climbing community again. And you would always regret it yourself if you didn't go. ${ }^{\prime 18}$

That was enough to convince Cocker that he could not drop out. His decision to continue as leader, however, if anything, complicated his role in the expedition because in his absence, Baldwin had taken over many of his functions. 'It had very much become Ken's show,' Finnigan said, 'and he did it bloody well.' ${ }^{19}$ With the re-emergence of Cocker just before the expedition's departure, it was Cocker, and not Baldwin, who received much of the attention and accolades in the splash of press coverage the expedition received on departure.

Cocker made efforts to include Baldwin more than others in the subsequent decision making and Baldwin encouraged Cocker to remain leader during his period of personal difficulties. At the expedition's celebratory formal dinner, Cocker as leader was asked to speak but when he stood up, he said, 'This honour goes to Ken Baldwin in recognition of his outstanding efforts to make this expedition a reality.' Cocker said, 'I am sure that Ken has a speech ready.' ${ }^{20}$ It is much to the credit of both that they each had the welfare of the expedition as their ultimate goal and, although friction came to the surface once later in the expedition, it was never really a factor in the conduct of the trip in any significant way.

It is worthwhile here to digress briefly to consider the nature of conflict in mountaineering expeditions. Most Australian expeditions have been largely free of divisiveness, but, as we shall see later, it was an important factor in one large Everest expedition.

Conflict among climbers is one of the most fascinating aspects of Himalayan expeditions, particularly to outsiders. Indeed, some American climbers 
have made a thriving cottage industry of reporting, in lurid detail, all of the interpersonal squabbles and fights that occur during an expedition. It seems they have had no lack of material from large American expeditions, particularly those to K2, the world's second-highest mountain. On one such trip, fighting broke out over who was going to get a window seat on the flight to Skarduwell before the team even reached their base camp. On another, one group of climbers hid oxygen cylinders so that rival team-mates could not reach the summit.

The same types of conflict - sometimes very bitter-have also been part of several Australian expeditions. The reporting of the conflicts, however, whether it be of Australian or other expeditions, often gives the wrong impression - that of a group of childish, immature, egocentric misfits who simply do not get on together. Often it seems that personality conflicts are the cause. To be sure, often rather trivial personality traits trigger an outburst or start a fight, but it should never be forgotten that Himalayan climbers are operating in what is often compared with a war zone, in conditions of extreme physical deprivation and hardship and under significant psychological stress, with death never far away. Under those conditions, the more petty personality traits latent in all of us can easily come to the fore.

Usually, however, there are precursors to conditions that eventually cause problems on an expedition. There can be subtle differences in climbing philosophies, genuine disputes over styles of leadership or varying assessments of or responses to risk and danger, all of which feed undercurrents of discontent that can burst into the open given appropriate triggers. Keeping these sorts of potential conflicts under control is often more important to the success of an expedition than is the climbing ability of the members.

Large expeditions are naturally more prone to interpersonal conflict than are ones composed of a small, closely knit group of friends. Two of the first Australian expeditions to the Himalaya - those to Mulkila and Dunagiri - were quite large but both avoided any major conflict. In the Mulkila trip, the low-key nature of the venture, the modest objective and Warwick Deacock's selection of the members all led to a harmonious expedition. The potential for problems was undoubtedly greater for the Dunagiri expedition, with its more difficult and dangerous objective, but serious conflict did not eventuate.

To a large extent, the friction between Cocker and Baldwin was probably due to the pressures that had already built up for them before they even got close to the mountain; for Cocker, it was his personal problems, and for Baldwin, it was the extraordinarily heavy workload of honours year at The Australian 
National University and the organisation of a big Himalayan expedition. For both, the end of the organisation and of the pre-trip publicity was a decided relief. As Baldwin recalled, 'Now that the organisation was over, I could sit back and enjoy the ride.' ${ }^{21}$ The responsibility had now shifted onto Cocker's shoulders as climbing leader, which to him must have seemed lighter than the personal pressures before the trip. As Cocker vividly remembered, 'I got on the plane and shut my eyes. That was it. A fait accompli. I was going. ${ }^{\prime 2}$ The agony of indecision was over. Now he was leading a group of Canberra climbers, none of whom had ever climbed in the Himalaya before, to a big and dangerous mountain. Cocker summed up his feelings: 'I was aware that there were two other experienced mountaineers who could have led the expedition; however, I was convinced that I was the best person to ensure the safety of the expedition members, which was always my priority.' ${ }^{23}$ 



\section{Long necks on Dunagiri}

On arriving in India, Peter Cocker almost immediately proved his value as leader of the Dunagiri expedition. An advance party of three, with Charlie Massy in charge, had travelled to New Delhi in early April, a few days ahead of the main party. One of their tasks was to clear all of the expedition's equipment through Indian customs and prepare it for the truck journey to the Himalayan foothills. When the main party arrived, however, the gear had not moved from the customs hall and the frustrated Massy - used to dealing with such matters in a straightforward and honest way — was at his wit's end. Cocker, an old hand at the Asian way of doing things, diagnosed the problem instantly, greased the appropriate palms, the underpaid customs officers suddenly worked furiously and the gear flowed freely from the hall.

The next obstacle was the formidable gorge of the Rishi Ganga, the only access to the southern side of Dunagiri. For years, the gorge had repelled explorers trying to penetrate the Nanda Devi Sanctuary and it was not until 1935 that Eric Shipton and Bill Tilman finally forced their way up the gorge and into the sanctuary. Their route was a hair-raising combination of precarious river crossings, steep slogs up slippery gullies and delicate traverses across narrow, slabby ledges perched high on the gorge walls. It was not a walk for the fainthearted.

If anything, the trip up the Rishi Ganga was worse for the Dunagiri team, as the high-level route that Shipton and Tilman had used to avoid the first section of the gorge was closed because of heavy, late-winter snowfalls. There were reports of avalanches plunging down into the forests well below the snowline. The situation forced the team into the bed of the gorge, where the precipitous walls necessitated frequent crossings of the fast-flowing Rishi Ganga.

The fact that other expeditions had earlier gone up the gorge was of little use; the afternoon floods caused by snowmelt in the sanctuary washed away the temporary log bridges they had built. To expedite this aspect of the journey, Cocker sent an advance party of Charlie Massy, Ken Baldwin, Ken Bell, Martin Stone, Tim Macartney-Snape, Lincoln Hall and Sher Singh, the sirdar or leader of the local staff, out in front to lessen the difficulty and danger for the heavily laden porters by securing the river crossings before the arrival of the main party.

There were other dangerous parts of the trek to base camp. When the route finally left the treacherous riverbed, it led up steep, muddy cliffs where a slip would be fatal. It did little good for the morale of the party when the porters 
frequently pointed out places where people had fallen to their deaths. All in all, it was an arduous trip to base camp - probably as difficult as any in the Himalaya.

There was at least one close scrape with death on the walk in to base camp. Cocker, who was coming up at the rear of the party to look after stragglers and deal with porter strikes or any other unforeseen event, nearly went into the Rishi. '[T]o fall into this torrent was certain death,' he recalled. 'Rocks could be heard rolling along the bed; it was icy and moved with crushing force... While catching up to the others, I had a close call when part of a bridge traversing a small cliff collapsed. I fell through the middle but caught a support on either side of me.'

Fortunately, the team did not have to follow the Rishi Ganga all the way into the sanctuary. Access to the Dunagiri area was via the Ramani Glacier, to the north of the gorge. Base camp was established on a grassy patch of moraine along the glacier and, after a period of sorting gear and setting up tents, the group began a reconnaissance of the unclimbed East Ridge. They had originally planned to attempt the North Ridge, but it had been climbed by a Japanese expedition a year earlier.

The first thing to impress the ANU climbers was the enormous scale of the Himalaya (see images 7.1, 7.2 and 7.3). It was a long, hard push of several kilometres just to get from base camp to the start of the East Ridge, and the ridge was just as nasty as they had expected from photos taken by Australians who attempted nearby Changabang the previous year (cf. Chapter 9). The ridge was very long, laced with cornices, even double cornices in places, and was guarded by a number of rocky gendarmes - outcroppings of steep rock that barred a direct route along the top of the ridge. These features, combined with the logistical difficulties of moving gear and supplies up the long glacier, meant that the East Ridge would be a very serious proposition.

Leading the reconnaissance were Lincoln Hall and Tim Macartney-Snape. To get a better look at the ridge, the pair made an attempt on Purbi Dunagiri, a $6600 \mathrm{~m}$ outlier of Dunagiri. Even though they were not yet fully acclimatised to higher altitudes, they pushed to within $300 \mathrm{~m}$ of the summit of the difficult granite peak. Their efforts raised some anxiety in base camp when they missed their regular radio call during the climb. The tension was relieved at 9pm when the radio crackled with the tune of Waltzing Matilda played on a mouth organ, their self-devised identification call for the daily radio schedules.

Cocker had quickly seen and heard enough of the East Ridge to decide that it was too difficult and dangerous for his inexperienced crew. With little hesitation, he

1 P. Cocker, Interview. 
switched the attack to the South-West Ridge, a variant of the route by which Dunagiri had first been climbed by the Swiss in 1939. In that ascent, Roche approached the ridge from the north, whereas the ANU team would be taking a route from the south to gain the ridge itself. There was little cause for relaxation, however, because of the change of routes. Access to the start of the South-West Ridge was still long and arduous and a steep headwall topped by a difficult mixed ice and rock step was the only way to get from the glacier to the ridge.

The route the Australians were now concentrating on had been climbed the previous year by an American expedition, but its triumph almost immediately turned to tragedy when all four climbers fell to their deaths on the descent. Sher Singh, who had been the sirdar for the American expedition, recounted the incident and impressed on the team the seriousness of the South-West Ridge. Evidence of the American saga was constantly around the ANU team as they climbed. Martin Stone reported being aware of "the "presence" of our luckless American precursors in the gaping burial crevasse, our minds constantly jogged by chopped and bleached fixed ropes draped on ledges and projections and appearing out of ice bulges'. ${ }^{2}$

Another idea quickly abandoned was that of a quick, lightweight alpine-style ascent in which a few climbers, carrying everything they needed on their backs, climbed a mountain in a single concerted push. Dunagiri was far too big and difficult for that-something that even the ambitious young climbers recognised very quickly.

Lincoln Hall's first impression of Dunagiri was typical of their reaction:

Research had revealed that the Garhwal Himalaya in India was a region well suited to expeditions with modest ambitions. Our mistake was that we selected Dunagiri rather than any of the other peaks nearby...At just over 7,000 metres Dunagiri is the highest mountain between Nanda Devi and Kamet. As it makes up part of the outer wall of the Nanda Devi sanctuary access is difficult from the south. And the northern side...3,000 metres of steep ice and rock which speaks for itself. Add to this description the mountain's record with mountaineers - six deaths and two severe cases of frost-bite against only four ascents. All in all a formidable picture. What were a bunch of Australian rockclimbers doing there in the first place ${ }^{3}$

As Cocker noted, however, the 'choice' of Dunagiri had not been a choice at all:

2 Stone, M. 1979, 'On the shortcomings of Kodachrome', New Zealand Alpine Journal, vol. 32, pp. 60-1.

3 Hall, L. 1979, 'Dunagiri', New Zealand Alpine Journal, vol. 32, pp. 57-9. 
Dunagiri was never on our list of possible mountains. It was allocated to us by the Indian authorities. There was no consultation with the expedition regarding the suitability of this mountain. Dunagiri is a big mountain; it's an impressive mountain. Its west face is one of the biggest precipices in the world. It is a climbers' mountain with many fantastic challenges. The Tasker-Renshaw route was described by them as being two Walker Spurs, one on top of the other, six thousand feet of extreme climbing...I would never have chosen Dunagiri as an objective for an expedition of this level of experience. It took us so long to get permission to climb in India that as a result there was no question of changing the mountain allocated by the Indians. ${ }^{4}$

The first task facing this bunch of Australian rock climbers as they approached the formidable peak was load carrying. To climb the mountain in the traditional fashion, a string of camps had to be established and supplied and to safeguard the passage of load carriers, ropes had to be fixed over the more difficult sections of the route. Although the load carrying was simply hard work, lead climbers had to negotiate some difficult terrain to fix the ropes for the subsequent carries.

The first part of the route proceeded straightforwardly. A 'dump' camp was established partway up the Ramani Glacier and then a 'cave' camp, in which tents were erected in a natural rock cave, at the top of the glacier. Beyond this, a steep headwall of snow, requiring some fixed ropes, led to the third camp on a col. Bell and Massy led the bottom section of the headwall and Baldwin and Sher Singh finished off the work to the col.

Above col camp, the climbing became even more difficult. A buttress - first of moderately angled snow and then of very steep rock-led towards the SouthWest Ridge. Beyond the steep rock, the angle of the buttress eased somewhat and it became a series of ice fields with patches of broken rock. Teams of climbers went up above col camp to systematically fix ropes up the buttress. Hooy and Stone fixed the snow slopes just above the camp and Hall and Macartney-Snape pushed the route through the steep rock band before retiring to base camp for a rest. Above the steep rock, however, the climbing bogged down. Several teams, including Bell and Massy and a rested Hooy and Stone, had a go, but none could make much headway up the ice fields. The fixed ropes stopped at about $6500 \mathrm{~m}$, a few hundred metres below the South-West (summit) Ridge. An impasse had been reached.

With time inexorably rolling on towards the onset of the monsoon and the climbers banging their heads against a virtual altitude barrier at $6500 \mathrm{~m}$,

4 P. Cocker, Correspondence. 
the prospects for success looked dim. Most climbers blamed the weather but expedition leader, Peter Cocker, realised that a lack of time for proper acclimatisation was probably a bigger factor:

Delays of almost a week in Delhi and further delays in Joshimath over the availability of porters had eaten into our schedule. The team launched themselves vigorously into the assault well before they had acclimatised. Many of the team pushed themselves to their limits. Ken Bell blacked out while fixing ropes at 18000 feet. He was lucky to have had Charlie Massy as his partner; Charlie was able to hold his unexpected fall. ${ }^{5}$

Cocker, however, still had an ace up his sleeve. John Finnigan, one of the team's most experienced, motivated and skilled climbers, had missed the departure because of the pressures of his PhD studies and the birth of his daughter, but had arrived just about the time the climbers had established col camp and were beginning the push up the buttress. Hopefully, Finnigan, the acknowledged 'hard man' of the team, could break through the impasse.

Finnigan's solo trip through India and his rushed trek to base camp had not been easy. He had been left some administrative tasks to tidy up with Indian authorities, one of which was to complete the paperwork for the importation of the radios. It took all the cleverness the crafty Finnigan could muster to get the radios, which had already been sneaked in, officially approved.

'I had to rewrite the laws of physics to get the radios approved,' he recalled:

I dictated a long letter to some clerk in the Communications Administration explaining how we could change the frequency of the crystals in our radios by tuning them. I invented a whole new science of electronics to do it. This guy wrote it down religiously and it went onto a pile of correspondence stacked on his desk to the height of his shoulder. On the other side of his desk was a pile of the same height, and, to each side of those, were other piles, which started at the floor and reached the same height. Correspondence slowly moved across his desk, and my letter went to the far pile. It would probably be another 10 years before my letter reached the out tray. ${ }^{6}$

That was not the end of Finnigan's troubles with the Indian authorities. In the few weeks between the main group's and Finnigan's arrival, a diplomatic row had erupted over allegations of misconduct by an American mountaineering expedition to the Nanda Devi Sanctuary some years earlier. The Indian Government alleged that the American mountaineers were in fact Central

5 P. Cocker, Interview.

6 J. J. Finnigan, Interview. 
Intelligence Agency (CIA) agents and had planted a nuclear-powered listening device on the summit of Nanda Devi or Nanda Kot, a nearby mountain, to monitor China's nuclear weapons testing program. The device had subsequently been avalanched off the mountain and into the headwaters of the holy Ganges River, where alleged nuclear contamination was causing a national uproar. The Indian Government placed a ban on all expeditions going into the areafortunately just after the main ANU team had left Joshimath, their jumping off point for the trek. Finnigan eluded the ban by claiming that he was not part of an expedition but simply an individual mountain walker.

Finally out of the clutches of the Delhi bureaucracy, Finnigan hired a car and driver and compressed the normal two to three-day trip to Joshimath into 18 bone-rattling hours. 'I had my first view of Himalayan mountains,' Finnigan remembered fondly, 'when I got out along the side of the road for a vomit.'

Trying to save more time, he pushed the trek into base camp as hard as he could and finished it with a two-day push from $1500 \mathrm{~m}$ on the riverbed to nearly 4600 $\mathrm{m}$ at base camp. If ever there was a sure recipe for altitude sickness, that was it.

I felt all right at first. Then I went to sleep in one of the tents and woke up a few hours later with an unbelievable migraine headache. It was one of the most miserable nights of my life: bouts of vomiting and a paralysing headache. It was an early introduction to altitude sickness. I remember hauling myself out of the tent in the early hours of the morning and propping myself up between two rocks, just below base camp, which had a convenient hole to one side so I could lean over when I became ill. Every time I vomited it felt like the top of my head was blowing off. ${ }^{8}$

That episode slowed the ambitious Finnigan and he adopted a more moderate schedule of acclimatisation for the next few weeks. By the time he was able to climb comfortably to col camp, he had done so much load carrying that he was in need of a rest, not a round of hard climbing above $6500 \mathrm{~m}$. The impasse remained.

It was getting on towards the end of May and things were getting desperate. Virtually no progress had been made for many days. Cocker pushed up to col camp to see whether he could break through the upper icefields and onto the summit ridge. Up at the high camp, he discovered that an important factor contributing to the impasse was that most basic of high-altitude problems-lack of adequate food and drink — which slowed and stopped so many Himalayan expeditions. 
The group had taken only one type of stove - a kerosene-burning one - to use high on the mountain and they proved to be extremely difficult to keep going. The problem was most likely due to the combination of small fuel jets and low-grade kerosene. Even Macartney-Snape, somewhat of an expert at stove maintenance, could not get the stoves to work reliably. As a consequence, it was virtually impossible for climbers resident in col camp to get adequate fluids and they invariably had to climb the most difficult part of the mountain in a dehydrated state. 'Only the ingenious Martin Stone was able to get regular use out of the stoves,' Cocker recalled. ${ }^{9}$

Other factors affected the team's health. The glacial water, unless it was boiled religiously, would play havoc with even the toughest digestive system. The heavily processed foods imported from Australia could also have contributed to ill health and there was some evidence that those who opted for the local fare of chappatis and curry remained healthier (or at least did not suffer from constipation!).

Some members, however, claimed that their health was compromised by the cooking arrangements at base camp. The expedition had hired a well-known and well-respected cook, but, on joining the trip, he decided that he would rather be the mail runner. One of the kitchen boys was elevated to cook and he proved to be a disaster. Not only was his food barely edible, according to some of the members, his hygiene left much to be desired. The team eventually persuaded him that he needed to regularly wash and dry the plates, bowls and cutlery, but then discovered that he used the tea towel as a turban between meals! Climbers descending to base camp for a rest sometimes became sick instead.

At one point, all expedition members at base camp reported that they were suffering from violent stomach upsets. Cocker, who was up the mountain, quickly descended. The chef explained that the sahibs were insatiable and had overindulged in the onion pakoras that he could not turn out fast enough. As a result, the onions were undercooked. Constipation was not a problem! The next day, they had all recovered so there was no real Delhi belly on this particular occasion.

The final straw was the increasing occurrence of heavy afternoon snowfalls, which were consistent with reports that the monsoon had arrived early. It looked as if the mountain had won. Physical exhaustion and the arrival of porters to carry the expedition gear back out prompted an extensive afternoon radio conference in late May. The group reluctantly had to admit that they had given Dunagiri their best shot and it was time to pack up and go home.

9 P. Cocker, Interview and correspondence. 
At the end of the meeting, Macartney-Snape and Hall contacted Cocker from base camp and a further discussion ensued. Macartney-Snape and Hall volunteered to go back up the mountain to retrieve gear and rope, but the pair had also discussed going up to the summit ridge and exploring further towards the summit if the weather looked good.

Cocker further suggested that if they came up the mountain and were able to progress further to the summit ridge, he would then ask expedition members to volunteer to support one final attempt on the summit. Macartney-Snape and Hall readily agreed. Cocker added, 'They were rested, fit and raring to go. They had acclimatised and really wanted to go for something. There was no way that they wanted to go back empty-handed. ${ }^{10}$

Cocker continued:

If Lincoln and Tim climbed to the summit ridge and then returned to col camp that day, I planned to ask for support from base camp (more food, working stoves plus fuel). As the support climbers raced up, Tim, Lincoln and I would return to the summit ridge, Tim and Lincoln would go for the top, I'd stay on the ridge and dig an ice cave and prepare for their return, and, if needed, help them down. ${ }^{11}$

Early on the morning of 29 May, Macartney-Snape and Hall set out from cave camp to climb up onto the buttress and hopefully to the summit ridge. They stopped briefly at col camp for breakfast and a quick chat with Cocker, who had decided to remain in camp for the day. They then climbed higher up to the top of the fixed ropes. For once, the afternoon snow squalls stayed away and they began to think about the last-ditch push for the top.

Hall said:

When Tim and I left camp at 5:30am, we had no intention of going for the summit, but when we reached the top of the fixed rope, the weather was better than it had ever been before, so we decided to push on up to the summit ridge. As we climbed, the idea of continuing to the summit became firm in our minds, but the decision to go for the top was not made until we were at the start of the summit ridge. ${ }^{12}$

Even then, there was no possibility of reaching the summit that day as it was still more than $1 \mathrm{~km}$ away and a few hundred vertical metres above. They would have to spend the night out in the open on the ridge - something they were

12 Sheppard, T. 1984, 'Lincoln Hall, Everest mountaineer', in Australian Adventurers, Angus \& Robertson, Sydney, pp. 3-14. 
barely equipped to do. They had brought with them sleeping pads, down jackets and bivvy bags, but no tent, stove or sleeping-bags. They had one water bottle each and minimal food - some energy bars, chocolate and a tin of cherrieswhich they shared. It was a most uncomfortable night for the pair, as their feet had become wet during the day's climbing due to interior condensation in their leather boots. Hall warmed his feet on Macartney-Snape's stomach during the night, and vice versa, which probably staved off frostbite.

In the morning, the weather still looked good, but the decision to go for the summit was not clear-cut. Hall knew that his feet were in trouble and he would very likely suffer frostbite if he continued on towards the summit. Furthermore, they had no water and no means of obtaining it. It would be a long, hard, dry day. Not only would they have to climb a long, dangerous ridge in a severely dehydrated state, they would have to find the stamina to somehow get themselves back down. Despite these odds, they went for the top.

The alarm bells started to ring for Cocker immediately he realised that MacartneySnape and Hall were going for the summit. He was responsible for this group of young university students, a group that had become much closer than most large expedition teams. A tragedy would have shattered the team.

Cocker said:

I was astounded when they went directly for the summit, and was aghast that they were making the attempt so ill prepared. It was a very risky, really a very foolhardy thing to do. I was even more concerned because a previous night I had dreamt about two going to the summit and not coming back. ${ }^{13}$

Cocker immediately radioed Charlie Massy expressing his concerns:

These guys are really gutsy but the risks are enormous. I am really concerned about what is happening. They are probably already dehydrated, Charlie. Choose whoever you want as a partner and please come up with a working stove and some food. I think we may need to be prepared for a rescue. ${ }^{14}$

Massy set off with Theo Hooy, bivvying that night at the site of the already dismantled dump camp. Massy, who was deputy leader of the expedition, was, in Cocker's mind, the perfect support: 'During the entire expedition, I could rely on Charlie 100 per cent.' ${ }^{15}$

13 P. Cocker, Interview and correspondence.

14 Ibid.

15 Ibid. 
Nevertheless, there was plenty of enthusiasm for the attempt, as Cocker recalled: 'When they came out from the bivouac and headed for the summit, there was this massive cheer on the radio. The excitement was tremendous. All day the reports were coming up...moving slowly...can't see them...can see only one of them now...moving very slow. ${ }^{16}$

The reports were coming from base camp, where the other climbers had binoculars trained on the summit ridge all day. What they were really seeing, however, was not a person but a 'rainbow' - a point of diffraction, where the sun hit thin clouds of snow crystals kicked up by the climbers. On occasion, when a strong gust of wind swept across the ridge, larger plumes of snow indicated the climbers' position.

Up on the ridge itself it was hard going for Macartney-Snape and Hall (see images 7.4 and 7.5). Soft snow covered hard ice on both sides of the ridge and the north side was periodically corniced. After a tortuous morning negotiating the tricky ridge and the occasional cornice or rock that forced them off it, the two climbers reached the last snow slope leading to the summit itself. Hall was exhausted and decided to rest while Macartney-Snape continued on alone to the summit. Just after midday on 30 May, the ANUMC expedition had managed to put one climber on top of Dunagiri, after it appeared a few days earlier that the situation was beyond hope.

There was still the descent, however, and many of the team were haunted by the American tragedy on the same route just a year earlier. Anxieties rose further when the weather turned bad. By the late afternoon, the summit ridge was hit by a violent electrical storm followed by high winds that reduced visibility. Macartney-Snape and Hall, racked by exhaustion and dehydration, doggedly pushed on and reached the end of the summit ridge just as darkness was setting in. A few harrowing abseils later, the pair was at the top of the fixed ropes, where they separated as it would be safer to descend the fixed ropes individually.

Meanwhile at col camp, Cocker was becoming increasingly anxious about the fate of the two young climbers. It was already dark. They were into their second night out on the mountain and they had no tent, sleeping-bags or stove. And worse, they had not had any water for at least 36 hours. About 11 pm, MacartneySnape arrived, with news that he had made the summit and that Hall was just behind. The time went by, however, and Hall still did not appear. Cocker feared the worst. Undeterred by a blizzard that was raging on the col, Cocker went out at 1.30am to search for Hall. After a slow but very eventful trip up the fixed ropes, Cocker found an exhausted Hall progressing very slowly down the fixed 
ropes. He had spent some time in the open on rocky ledges above the ropes and was very slow in changing over his descender at the anchor points. The pair then descended to the safety and relative comfort of the tent.

In a dramatic, last-ditch effort, Dunagiri had been climbed, but not without cost. Although Macartney-Snape escaped with a minor case of frostnip, Hall was in much worse shape. In addition to some blistering on his fingers, he had sustained major frostbite to several of his toes during the slow descent through the night. Many of the other climbers watching the dramatic summit attempt from base camp realised almost immediately that the pair would likely need help on the descent. Most aware of the potential problems was the experienced Cocker and he had already organised a rescue operation as the two summiters were slowly working their way back along the summit ridge and down the fixed ropes.

\section{To the top of Dunagiri \\ Lincoln Hall}

The next morning was cloudless but windy. We realised we were not to have a repeat of the previous day's perfect weather. The first problem for the day (apart from the absence of breakfast) was a huge cornice. We floundered through thigh deep snow on the southern slope until it was safe to regain the ridge. My feet gave up the struggle against the cold, and went completely numb. My oxygen-starved mind worried only about the climbing and forgot about my feet.

The hardest section of the ridge followed. Granite boulders blocked the crest, and turning them was a slow and often frightening process. Shortly after midday we reached the bottom of the big summit dome formed by the intersection of the mountain's four main ridge systems. We decided to unrope and proceed at our own pace. After staggering a few steps I collapsed for a rest. We were dehydrated and exhausted, and I was beginning to doubt whether I would have the energy to return along the ridge. The only choice was to sit where I was, and recover as best I could. Tim plodded on, up towards the summit. Exactly an hour later he returned. He had succeeded but was too exhausted even to speak.

Storm clouds were gathering in the north, so we could only afford fifteen minutes rest. Fortunately we climbed the most difficult section before the storm hit us. Static electricity literally immobilised us - whenever we tried to move we crumpled up in pain from electric shocks. We were very frightened, imagining that at any moment we would be roasted by lightening [sic]. After a few minutes the electric part of the storm moved on and we were able to continue our descent. The wind blew snow from the ridge into our faces so that we couldn't see anything. We had to feel for the ridge with our ice-axes, all the while crouching to avoid being blown off the ridge completely.

Just on dark we reached the end of the summit ridge. Luckily we had no trouble finding the spare rope we had left there for abseiling. The four abseils to the fixed ropes took several hours. We could not find anchors in the rotten rock. The ropes became jammed twice, my fingers were clumsy with frost-bite, and our minds worked at quarter-speed because of the cold, the altitude, and the lack of food, water and sleep. Tim reached the fixed ropes first, and he began to abseil while I pulled down the climbing ropes and coiled them. He arrived at the top camp at 6,000 m some hours before I did. It was 7:00 am before I dragged my body with its frost-bitten hands and feet into the warm, sheltered, soup-containing Omnipotent.

From 'Dunagiri', New Zealand Alpine Journal, vol. 32 (1979), pp. 57-8. 


\section{Midnight search \\ Peter Cocker}

By $10.30 \mathrm{pm}$, I'd given up hope of seeing Tim and Lincoln that night. The storm was intensifying and was roaring across the rock prow. I stored bottles of melted snow inside my sleeping bag. I spoke to Charlie [Massy], bivvying $3000 \mathrm{ft}$ lower down. We agreed that at first light I'd go up to find Tim and Linc and he and Theo [Hooy] would move up at full steam.

I found it impossible to sleep. The whole scenario was identical to a dream I'd had in which two climbers failed to return from a summit bid-not a rare event in the Himalaya. The tension I felt made me feel sick; a second night out would, at the least, mean some frostbite...I said a short prayer. Imagine saying a prayer for a couple of heathens like Tim and Linc! Well, it worked for me, as I fell asleep.

I awoke to hear the furious jangling of the aluminium snow stakes hanging from the other tent. I couldn't believe it. The storm was now hammering col camp in spite of its superbly protected location.

The clashing of the snow stakes continued, yet something didn't gel. The noise was too erratic. Pulling on my boots, I crawled outside expecting to find a lynx trapped in the other tent. It was too dark to see anything, so I grabbed a torch. Its beam picked up a large creature, six-foot-three, standing silently behind the spare tent.

'Tim! Am I glad to see you!'

'Not half as glad as I am to see you!'

He later explained that on arriving at the col, the tents had apparently disappeared. (They were buried under a foot of snow.) He thought he and Linc had been abandoned. This was an indication of the grimness of the ordeal he'd just been through.

He assured me Linc was close behind. In the tent I gave him a drink, took off his boots and radioed Charlie at dump camp and the team at base camp with the good news. Charlie wanted to know if they'd reached the summit. It had never entered my head to ask! Tim replied that they had, but he was hesitant. He found it difficult to explain that Linc's frozen feet had prevented him from climbing the last slope to the summit. For Tim, this was the only thing that seemed to mar their inspiring achievement.

No sign of Linc. I yelled and whistled, no reply. I started climbing the fixed ropes to meet him, but my hands became so cold they would not function. I couldn't grip the ascenders; my thumbs were locked in a painless cramp. I returned to the tent. Tim pointed out that there was little I could do if I did find him. My fear was that Linc may have stopped to rest and then fallen asleep. I put on more clothing and strapped on my crampons, ensuring that the straps went under the laces, as the straps supplied were not the ones specified by the makers.

This time I moved up the fixed ropes quickly. I was surprised at how far the rope hung away from the rock face. My headlamp provided the only light, but most of the time its beam was lost in the void.

Then my left crampon came off, dangling from the strap and spinning wildly in the storm. As I bent down to retrieve it, a rope sling I was using slipped down, only to be snared by the furiously gyrating crampon. In a matter of seconds I was looking at an incredible tangle, the sort of thing that happens only in a Tom and Jerry cartoon. My first reaction was amazement, then embarrassment, [and I was] thankful that no-one could see my predicament. Dangling upside down and spinning in space, I finally appreciated the humour of the situation. All climbers should carry a pocketknife. Never know when you need to cut the rope! No single slash for this Gordian knot, but surgical snips with the greatest of care (Linc would never forgive me if I cut the wrong rope). 
The higher I progressed the more I was impressed by the skill of the team who fixed the ropes. I rarely touched the rock. I lost sense of time. The storm eased a little. The stars began to fill the sky. As always, I was surprised that a million stars give no real light.

There was an unreal feeling about ascending a free-hanging rope in the dark, and it was easy to become disorientated. This feeling was enhanced when I caught a glimpse of a fiery light high above me. I lost sight of it as I rotated on the rope. When I got a better look, I was mesmerised; I was looking at a 'volcano'. The summit of Nanda Devi glowed like the inside of a furnace. The rock was molten. I searched the sky but found not a hint of dawn; the rest of the world was in darkness. I turned back to look at Nanda Devi. Seeing is believing. The summit was of 'burning lava'. I again searched the sky for signs of dawn, for this was the only explanation for this incredibly beautiful illusion, but there was not even a tinge of dawn light. I felt aggravated knowing that what I could see couldn't exist. Nanda Devi means Goddess of Joy in Hindi, and this was the mountain she had chosen as her throne. That I could understand.

The next time I looked, the summit had turned to burning gold and dawn light started to douse the stars. Streaks of green light preceded the sun's emergence. It was as though I was hanging on the edge of space. Kalanka emerged from the night, followed by the monolithic Changabang. The mountains turned from grey to shades of pink, blue and gold. At that precise moment I was convinced that no other being on our planet was in a more spectacular position and privileged to view such a magnificent spectacle. Base camp was still buried in the dark of night $6000 \mathrm{ft}$ below.

Nearing the top section of the prow, I glanced upwards to see that the rope had become snagged some five metres to the left of the line of ascent. It was caught in a small niche on a large overhanging shelf. To continue up would force the rope to free itself and run across the sharp edge of the overhang, damaging the rope, and perhaps even severing it. I took stock of the situation and was quite comfortable about my decision. I didn't want to be anywhere else; I didn't want to be doing anything else. I just wanted up.

When the rope did free itself, I was unprepared and surprised at how far I fell before stopping. For the next minute or so I bounced up and down on the rope, but it appeared undamaged. Waiting for the yoyoing to stop, I amused myself by calculating where I would have ended up had the rope been severed. The spectacular trip would have ended $4000 \mathrm{ft}$ down the mountain in a huge crevasse. It was [in] this crevasse that Dick Renshaw and Joe Tasker had buried the four luckless American climbers from the previous expedition. During our stay on Dunagiri, they were often in our minds, and some of us felt a special affinity towards them.

After about three hours of jumaring, I reached the top of the prow. There was no sign of Linc, but I could hear a strange mumbling. I whistled and he appeared from nowhere. The mumbling was Linc 'talking to his fingers'. 'Cool hand Linc' in more ways than one! He was smiling. Same Linc, unflappable.

I watched him, trying to assess his condition. He appeared quite normal except for his actions, which were very slow but precise. Lincoln later told me he thought I was Ken Bell.

I made sure that Linc attached his abseil device correctly to the fixed rope. He was on. Lincoln then abseiled slowly into the void. I gave him a few minutes to make sure that he was safely off this section of rope before I proceeded down. I then attached myself to the rope and abseiled after Lincoln.

By the time I reached the anchors Lincoln was descending down the second abseil. During the third abseil, I paused beneath an overhang and could see that the section of rope immediately in front of my face had a deep gash in it exposing its core. I then realised that the incident when the rope was caught in the niche on my ascent was a closer call than I had realised. It was a good thing ours was the last trip down the fixed rope! 
We continued down the remaining fixed ropes without incident and were soon back at the tents where I found Tim giving Lincoln his first drink in well over 36 hours. As Linc sat in the entrance of the tent, I removed his boots and later invited him to place his frostbitten feet under my jumper and against my stomach. I am not sure it helped much.

Within an hour, Charlie and Theo arrived with the new stove and more food. As soon as Andrew Blakers and Dr Mark arrived, Tim, Theo and I set off down the fixed ropes to cave camp. We then roped up for the descent down the Ramani Glacier, moving with care as the crevasses were just beginning to open up. Some of the advance rescue group were already on the way up to bivvy at cave camp that night and were at dump camp by the time we arrived. They were in high spirits and cheered Tim for his remarkable ascent and survival.

It was a great day, a great feeling, everyone was smiling. Tim swore he was finished with mountaineering and was sticking to his beloved cross-country skiing! Still no sign of Ben's early monsoon. Dunagiri is a very beautiful mountain, I must come back.

When Cocker and Hall arrived back at the tent at col camp early on the morning of 31 May, the rescue operation was already well under way (see image 7.6). First up, arriving about $1 \mathrm{lam}$, were Charlie Massy and Theo Hooy, followed two hours later by Andrew Blakers and Mark Podkolinski, the expedition doctor, who had climbed all the way from base camp to the col in a single day.

Hooy saw firsthand the evidence of Macartney-Snape and Hall's desperate 49-hour push to the summit and back down: 'These guys were totally, totally exhausted. And Lincoln was obviously frostbitten. We let Tim have a sleep for another two hours and then Peter and I escorted him down to cave camp. ${ }^{17}$

Soon after the first of the rescue party arrived at col camp, more of their colleagues, including John Finnigan, Martin Stone and Ken Baldwin, followed. Finnigan and Stone had improvised a makeshift stretcher/sled device from rucksack frames and, while the others stripped the col camp, they carefully strapped Hall, still in his sleeping-bag, to the sled.

With Finnigan lowering from the belay points above and Stone guiding the sled down the slope, Hall began the final leg of his trip down the mountain. The lowering operation down the fixed ropes went surprisingly smoothly, so smoothly, in fact, that the relaxed Hall was spouting a steady stream of the puns and one-liners for which he was so well known among the others. In jest, Baldwin and a couple of the other climbers threatened to cut him loose and let him slide down the mountain on his own if he continued cracking these appalling jokes. Banter like that was undoubtedly useful in relieving some of the apprehension that had built up during the previous two days.

Cocker realised the importance of getting Hall to a hospital as soon as possible, so he had organised a series of relay rescue teams. Cocker was determined to get Hall down to base camp in a single day, no matter what. 
At the bottom of the fixed ropes, reinforcements were at hand. Nearly every member of the Dunagiri team had climbed back up onto the mountain to assist in the rescue. And, as it turned out, they were needed. Below the fixed ropes, the operation, if anything, became more difficult. The slope was nearly as steep and there were no ropes in place to assist in the control of the sled. Down they went, still having to put in belays but also on occasion having to help drag the sled down the slope. The final segment of the journey to cave camp was even more tortuous, as they had to manhandle the sled over rocky moraine.

At cave camp, the exhausted climbers - many of whom had not fully recovered from their own stints on the mountain - were met by a group of able-bodied porters whom Cocker had organised to finish the operation. For triple pay, they were to get Hall down to base camp as quickly as possible. With an incentive like that, the strong men of the Garhwal raced Hall, who had been transferred to a proper stretcher, all the way down the Ramani Glacier to dump camp by the end of the day.

McCartney-Snape and Cocker had arrived at dump camp where McCartneySnape received a rousing reception. Cocker still feels the moment: 'The morale was incredibly high. Everyone was over the moon. It was a highly charged and emotional scene. We had the spare climbers and porters ready to carry Lincoln down the last and longest leg to base camp.'18

All of the climbers arrived at base camp by dark, thus completing a remarkable day in which they not only got Hall down all the way from col camp at just more than $6000 \mathrm{~m}$, they completely stripped the mountain of most of the gear. Somehow they found the energy to celebrate their triumph.

The next day, about 4pm, Cocker and Sher Singh were literally running down the mountain to Joshimath, and 26 hours later had arrived at their destination. Cocker made his way to the army base where he met the commanding officer and explained that a helicopter was required for the rescue of Lincoln Hall. The brigadier advised them that he would not be able to act until he was authorised by his superiors and that they would not act until an official request was forthcoming from the Australian High Commission.

Cocker was extremely surprised when an Indian sergeant knocked at his door at 7 that evening and instructed him, 'Sahib, please be ready at 7 o' clock sharp tomorrow morning. A jeep will pick you up.' With that, he saluted, turned on his heel and disappeared.

The next morning, Cocker jumped into the jeep and was driven to a flat piece of ground where a party awaited him. The brigadier, two army surgeons, two

18 P. Cocker, Correspondence. 
bearers - one serving tea and the other holding a silver tray of delicately cut sandwiches - greeted the elated Cocker. The brigadier informed him that the helicopter was on its way.

Cocker suspected that H. C. Sarin, President of the Indian Mountaineering Foundation and a close friend of Arthur Tang (the former Australian High Commissioner to India), was responsible for the prompt arrival of the rescue helicopter. Tang, who was a personal acquaintance of Cocker's, had previously contacted Sarin from Australia and asked if he could keep an eye on the Australian expedition and assist them if they needed it.

The helicopter arrived and landed on the tee-off for hole one on the tiny Joshimath golf course. The pilot, a towering Sikh with a big grin on his face, was famous throughout India for his daring rescues. The brigadier, Cocker and the pilot then discussed the situation, the pilot expressing his concern that he would not be able to find base camp because the weather was closing in and that he would return the next day. Cocker hastened to assure the pilot that he could guide him in to base camp.

Cocker jumped into the helicopter, the engine roared and the machine lifted off, tipping into a hair-raising dive into the Ganges Gorge before picking up speed in one thrilling swoop up the Ganges. A short while later, the helicopter landed at base camp, where Hall was waiting with Macartney-Snape and the liaison officer and his porters. Hall and his gear were loaded in and the helicopter returned immediately to Joshimath.

The sympathetic and attentive local surgeons examined Hall and decided that he required expert treatment at the Bareilly military hospital south-east of Delhi. Hall was summarily transferred back into the helicopter and whisked off for the hospital - only four days after he had been struggling along the summit ridge of Dunagiri. A few months after his return to Australia, Hall lost parts of two toes to frostbite.

The expedition was over and the Dunagiri success was splashed across the front pages of Sydney and Canberra newspapers. In fact, during the lead-up to the trip and during the expedition itself, the team's activities were covered very heavily in the press; some 46 major articles appeared in newspapers and magazines around Australia.

Such heavy media sponsorship was essential for the penniless students in getting the Dunagiri expedition off the ground. As noted earlier, however, such sponsorship does not come without strings attached. There is always the potential for climbers, particularly inexperienced ones, to be tempted into trying something they should not. 
It was a problem that had confronted even Peter Taylor, the solo climber of Langtang II in 1963. Even though the publicity for his trip had been modest by Dunagiri standards, he felt somewhat threatened by it.

Taylor recalled:

There were newspaper interviews; this was much easier [than television]. The only thing that bothered me was the fact that I might start trying to live up to my publicity. I might be tempted to try the impossible if I felt public attention focussed on me. It was an uneasy feeling. ${ }^{19}$

Although the potential for such problems was certainly there, they never materialised on Dunagiri. Despite a few minor misunderstandings, and one major one between the reporter Sandilands and Cocker late in the expedition, the trip was generally free of serious troubles caused by the journalistic obligations. As for the students being sucked into attempting the impossible, Baldwin reported that they felt no pressure whatsoever: 'We were quite happy to take the money and run.' ${ }^{20}$

Sandilands was an experienced, dedicated and hardworking journalist, as the number of detailed reports he sent to Australia testified. In doggedly pursuing some of his stories, however, he did not always see eye-to-eye with Cocker on some aspects of the expedition, which prompted Cocker to quip at one point: 'Ben's interests were not always the same as my interests. As a companion, he was bloody great; as a journalist, he was bloody devious.' ${ }^{21}$

For his part, Sandilands seemed to relish the odd run-in with one of the climbers: 'I just don't seem to notice personality problems; I have very thick skin...I greatly valued the company and respect of the other climbers. Perhaps Peter [Cocker] and I did have an occasional harsh word, but we parted good friends at the end of the trip.' ${ }^{22}$

The young Dunagiri climbers were also guinea pigs in a medical research experiment. Although Diamox, a diuretic, is now often used to alleviate the unpleasant symptoms - nausea, headache, loss of appetite, lethargy - of altitude sickness, in 1978, the notion of using a drug to prevent or reduce altitude sickness was still relatively novel. To help the research along, the Dunagiri climbers volunteered to test a promising drug, such as Diamox. Half of the climbers were given the diuretic and the others a placebo.

19 Taylor, P. 1964, Coopers Creek to Langtang II, Rigby, Adelaide, p. 101.

20 K. G. Baldwin, Interview.

21 P. Cocker, Interview.

22 B. Sandilands, interview. 
This medical experiment did a great deal to enhance what Theo Hooy called 'the cult of the pee bottle' ${ }^{23}$ Basic bodily functions, such as urination - which most of us take for granted in our daily lives - become important, and often dreaded, events in the world of high-altitude mountaineering. There is nothing worse than having to crawl out of a warm sleeping-bag in the middle of the night during a blizzard and then, while trying to keep from being blown off a high ridge, fumbling through innumerable layers of bulky clothing with frozen and clumsy hands just to relieve oneself. To avoid such uncomfortable situations, climbers often urinate into 1-litre plastic bottles and then empty the contents in the morning. Pee bottles have become standard equipment, as Hooy points out: 'I'm personally convinced they're one of the most important pieces of equipment a climber can have. ${ }^{24}$

The experimental use of diuretics on the Dunagiri trip added a new dimension to the use of pee bottles. Hooy remembered:

Martin Stone was sharing a tent with me...we used to lie in our sleepingbags and wait for the sun to melt the hoarfrost, and then we could go outside without getting a shower. Early one morning the sun was just on the tent and I was quite enjoying the sun's rays warming the air, when there was a muffled scream from Martin and this thing went hurtling out of the tent like a grenade. His pee bottle had frozen and split during the night, and the solid contents were becoming liquid. ${ }^{25}$

Stone was obviously one of the test group, although the climbers were not told what they had been given. 'None of us knew who was in what group,' Ken Baldwin explained:

except that some of us peed and the rest of us didn't. Not only that, but some of the ones that peed a lot had quite erotic dreams in full colour. I remember being in a tent with one of the people that were peeing a lot. We were given 1-litre pee bottles, and that's a lot of pee. You'd, of course, start with them empty in the evening. I can remember him sitting up in his sleeping bag one night and I could hear the sound of the pee bottle filling up, the pitch getting higher and higher and higher... until all of a sudden the sound stopped with a cry 'Oh my God!' ${ }^{26}$

Hooy added:

In fact, it became a bit like the International Everest Expedition in the early Twenties where people frequently discussed various bodily

23 T. Hooy, Interview.

24 Ibid.

25 Ibid.

26 K. G. Baldwin, Interview. 
functions. The topic of our discussions became 'how many ccs?', and how many people broke the 1-litre barrier. You almost started to classify people in terms of whether they were musical or practical. You had the ones who judged by the change in the pitch as the volume increased or the ones who worked from the dipstick principle. ${ }^{27}$

The diuretic experiment had its serious side as well. Although it was hoped the drug would improve a climber's performance by reducing the debilitating symptoms of altitude sickness, it probably retarded performance by flushing even more fluids out of bodies already prone to dehydration.

As a postscript to the Dunagiri expedition, John Finnigan's casual remark that it would take 10 years for a piece of correspondence to move from an Indian clerk's in-tray to his out-tray was uncannily close to the mark. More than nine years after Lincoln Hall was flown to the hospital at Bareilly, the ANUMC received a bill from the Indian Government for the helicopter rescue.

\section{Showing the way}

So how significant was the ANUMC's Dunagiri climb to the development of Australian mountaineering in the Himalaya?

In many ways, the Dunagiri expedition was clearly the most important of the early Australian expeditions to the Himalaya. Perhaps the most important contribution the ANUMC team made to Australian high-altitude climbing was to break a psychological barrier - that of the ability of young Australian climbers to organise and carry out a major, difficult Himalayan expedition (see image 7.7).

The importance of psychological barriers in climbing cannot be overestimated. Anyone who has led rock climbs - that is, gone up first with the rope behind him - knows that it is far easier to cope psychologically with a climb, even a hard one, if it has been done before compared with a first ascent. Eric Shipton noted this phenomenon on the first ascent of Mt Kenya, when certain segments of the climb or sequences of moves seemed much harder to Shipton than they would have ordinarily simply because he did not know what lay ahead.

In Himalayan mountaineering, the biggest psychological barrier was undoubtedly the use of artificial oxygen to ascend Everest. Although the necessity of supplemental oxygen was debated vigorously in the 1920s and 1930s, the oxygen-assisted ascent in 1953 by Hillary and Tenzing put up an enormous psychological barrier that was not broken until 1978, when Rheinhold Messner 
and Peter Habeler fought their way desperately up the 1953 route without the aid of bottled oxygen. Soon thereafter more and more climbers battled their way to the top of Everest without the help of oxygen. Once they knew it was possible, once that tremendous mental barrier had been broken, it became more manageable, although still terribly demanding physically.

Although the ANUMC Dunagiri expedition was not the first Australian expedition to the Himalaya, it was the one that showed the way for many groups of young Australian climbers. With its extensive publicity and its team primarily of young university students, it invited other climbers to ask themselves, 'If a group of young students can go climb in the Himalaya, why can't we?' People who had perhaps considered going to the Himalaya realised that you did not have to be a well-known Continental, British or American climber to go there.

In that way, the effect the Dunagiri trip had on Australian Himalayan climbing was much like the impact Bill Packard's inclusion on Tilman's 1950 trip to Annapurna had on New Zealand mountaineers. Despite being very accomplished climbers in their home ranges, many New Zealanders had previously considered themselves not quite up to Himalayan mountaineering standards. Then, as Packard recalled with some amusement, several of his New Zealand colleagues said, 'Look at Packard. He's been invited on a Tilman expedition, and Packard's not a crash-hot climber. ${ }^{28}$

In addition to its psychological effect, the Dunagiri expedition was noteworthy simply for its achievement. Dunagiri is a big mountain, difficult and dangerous by any route, as its record of successful ascents and accidents proves. Indeed, Peter Cocker reiterated after the trip that

Dunagiri is not a good mountain to start out on. That ridge - the SouthWest Ridge - is too long and exposed and the faces are steep and difficult. And so many people have been killed on Dunagiri.

In the Himalaya, ascent routes rarely follow sky-line ridges. These long ridges make the descent as arduous as the ascent, never offering the option to abseil and exposed to the weather with often no chance of shelter. The big ridges of the Himalaya are the equivalent of the big north faces of the European Alps. That is why they are usually the last routes to be climbed. ${ }^{29}$

The young ANU climbers, however, met the challenge to make only the fourth ascent of the mountain. Their climb of Dunagiri stood for five years-despite

28 W. Packard, Interview.

29 P. Cocker, Interview. 
a rapidly increasing number of Australian expeditions to the Himalaya during that period - as the highest mountain, and the only one more than $7000 \mathrm{~m}$, climbed by an Australian expedition (see image 7.8).

Finally, the Dunagiri expedition launched the Himalayan careers of two remarkable Australian climbers: Tim Macartney-Snape and Lincoln Hall. From the large group of ANU students, Macartney-Snape and Hall stood out - first climbing high on the technically difficult Purbi Dunagiri and then overcoming the long and dangerous summit ridge of Dunagiri itself in a 49-hour display of daring and determination. Their Dunagiri success propelled them into a series of Himalayan climbs that led in just six years to one of the most spectacular ascents ever of Mt Everest. In doing so, they took the status of Australian climbing in the Himalaya from one of curiosity to one of high regard, as recognised by some of the most well-known and respected Himalayan mountaineers. 



\section{Part 3: Everest I- success against all odds}





\section{A powerful partnership}

The emergence of Tim Macartney-Snape and Lincoln Hall from the Dunagiri expedition as a potent climbing partnership followed a long-established Himalayan pattern - that of a well-matched pair pulling off remarkable mountaineering feats. In 1978, the same year that Macartney-Snape and Hall succeeded on Dunagiri, the Austrian combination of Rheinhold Messner and Peter Habeler stunned the international mountaineering community by climbing Everest without artificial oxygen. A strong English partnership, Joe Tasker and Peter Boardman, got their start on Changabang, a mountain just next-door to Dunagiri, and went on to achieve a string of impressive successes. Well before any of those pairs was established, Eric Shipton and Bill Tilman, in nearly 20 years of climbing together, had become arguably the most prolific mountain explorers of all time.

Thus, in mountaineering, two is the optimal number. Although many of the highest Himalayan peaks, including Everest, have now been climbed solothat is, by climbers operating entirely on their own - it is far more common for mountaineers to rope together in pairs. Even in the largest expeditions, where the climbers might number 15 or 20 , the climbing itself is often done by pairs climbing in turn, not by larger groups.

The reason for the predominance of twosomes is partly practical. When mountaineers encounter difficult or dangerous terrain where a fall becomes more than a remote possibility, they usually climb one at a time, one out in front and the other, anchored to the mountain, paying out the rope while always alert to hold a possible fall. In such situations, a solo climber has absolutely no margin of safety while three climbers on a rope are considerably slower than two. On big mountains, speed, without undue haste, means safety.

In the case of the most successful and long-lasting partnerships, the psychological reasons are undoubtedly more important than the practical ones. Roping up with someone else on a big and potentially dangerous mountain is not a decision to be taken casually. You are literally putting your life in someone else's hands. A mistake by one of a roped pair often means the death of two climbers instead of one.

In Himalayan climbing, there is another side to the psychological aspect. Just the harshness of the day-to-day existence at high altitude can strain any relationship. Having to endure days of stormy weather in a cramped snow cave, to fiddle with a recalcitrant stove when you are dehydrated and exhausted and 
it is your turn to cook and to face together the very real dangers of avalanche or altitude sickness will test the best of friendships. It is when two competent climbers share a similar outlook and philosophy on mountaineering but have complementary personality traits that the most dynamic and successful partnerships are formed.

Messner and Habeler were an example of a pair that achieved some phenomenal successes but broke apart prematurely because they clashed with rather than complemented one another in one important personality trait: they were both extremely competitive. In fact, even on the trek to the base of a mountain, they would often become involved in quite serious foot races over the steep paths. That might have been good for conditioning, but it probably added considerable unwanted pressure to a relationship that would be stressed enough just from the rigours of Himalayan climbing. So, although Messner and Habeler did some brilliant climbing together - in addition to Everest, they made a lightningquick 10-hour ascent of the infamous north wall of the Eiger in the Alps - they split apart soon after their 1978 success.

Tasker and Boardman, on the other hand, were the ideal team. At the time they got together for their first Himalayan trip as a partnership - to Changabang in 1976-Boardman was much better established than Tasker as a high-altitude climber. Nevertheless, Tasker sensed Boardman was the right person when he was looking for a partner for the Changabang trip:

But it was not these things [his climbing record] which made Pete in my eyes the right person to ask about Changabang. It was not the record of achievements that I saw in him but the attitude of mind that I sensed. With some people it is not necessary to have climbed in their company to know that they are of the same inclination and share the same spirit as oneself. ${ }^{1}$

Tasker's intuitive choice of Boardman as the ideal climbing partner proved to be the right one. Although their plans to climb the west face of $6864 \mathrm{~m}$ Changabang - an unrelentingly steep wall of granite often made even more treacherous by coatings of ice and snow - were considered outrageously difficult by many in the mountaineering community at that time, they nevertheless pulled it off. The partnership quickly blossomed, as they climbed together in British expeditions to K2, the world's second-highest mountain, in 1978 and 1980, and were members of small groups that made first ascents of Kongur, a 7719 m peak in western China, and the North Ridge of Kangchenjunga, the world's thirdhighest mountain. In all these expeditions, the complementary personalities of the outgoing and gregarious Boardman and the taciturn Tasker, who had

1 Tasker, J. 1982, Savage Arena, Methuen, London, ch. 4. 
studied to become a monk before he took up climbing, were undoubtedly crucial in getting them through many days and nights of danger, discomfort and extreme deprivation. Tragically, the Tasker-Boardman partnership ended abruptly in 1982 when the pair disappeared on the then unclimbed North-East Ridge of Everest. They were last seen at a height of more than $8200 \mathrm{~m}$ on a push for the summit.

The quintessential mountaineering partnership, however, has to be that of Eric Shipton and Bill Tilman. The two first climbed together in 1930 in East Africa, where Shipton had established himself as an immigrant farmer. In addition to the well-known volcanic peaks of Kilimanjaro and Kenya, they climbed in the iceclad Ruwenzori Range. Then, over the next 18 years, they climbed and explored in some of the most spectacular and least-known mountainous areas of the world: trips into the Nanda Devi and Badrinath Ranges in the Indian Himalaya, two expeditions to the Tibetan side of Everest, an exploratory journey through remote areas of the Karakoram Range in Pakistan and China, and several trips to the high mountains of western China while Shipton was the British Consul at Kashgar.

During many of those journeys, they were undoubtedly under considerable mental stress as they were operating in areas that had not been mapped and, indeed, had not been visited by any previous explorers. Often they set out up gorges for which no exit was known and headed for high, glaciated cols that sometimes offered only hideously steep, broken ice cliffs for the descent on the other side. The physical deprivations were just as severe. On one trip, they ran out of food while still deep in the mountains and had to subsist on bamboo shoots for days before forcing their way through thick forest to the nearest village. Through 18 years of this sort of travel, there was reportedly only one serious disagreement between the two, which broke out when Shipton wanted to take two shirts instead of one on a four-month expedition and Tilman thought it an unnecessary extravagance.

The partnership of Tim Macartney-Snape and Lincoln Hall showed elements of these other, more well-known Himalayan pairings. In addition, they clearly represent the two strands of outdoor activity from which Australia's highaltitude mountaineers are drawn. Macartney-Snape was an 'all-rounder', an outdoorsman competent in a wide range of activities, including bushwalking, canoeing and skiing. For him, climbing was almost an extension of bushwalking, just on steeper and more difficult terrain. Hall, on the other hand, was a dedicated and highly skilled rock climber before broadening his horizons to include alpine climbing. 
Hall was something of a rarity on the Dunagiri expedition of the ANU Mountaineering Club (ANUMC): he was one of only two Canberra-born and bred members of the team (the other was Ken Baldwin). It was in secondary school in Canberra that Hall had his start in rock climbing:

A friend had been rockclimbing once or twice with the Phys. Ed. teacher at school. One day he suggested that I join them. I didn't know anything about it. It was a case of not having anything better to do. So why not?

I certainly didn't take to it naturally. Gymnastics I had done as a kid helped but didn't stop me from being scared silly. What was I scared of? The usual thing. Death. Here I was in my jeans and T-shirt and jeans jacket dressed as if I was going for a stroll in the bush. And there in the mist was this wall of granite hundreds of metres high. Awe-inspiring. Well anyway, quite enough to start with.

The climb we did in the morning was straightforward enough, but the afternoon's problem was a different story. We did three pitches [ropelengths, climbed first by the leader and then the beginner at the other end of the rope]. On the last pitch we went up a vertical face that fortunately had very big hand holds. It started to rain, and my hands very quickly became cold and nearly useless, while the rock became dangerously slippery. I was more or less hauled up, which meant putting my faith in the rope. That's when I decided that I would stick to hockey.

The following weekend this same friend wanted to go rockclimbing again. Again I went along, just because I wasn't doing anything else. Once at the cliff we heard that only the day before someone had fallen off this same rockface and been killed.

We did some good climbs, the weather was good and I enjoyed myself. If I hadn't gone that second time, I don't think I would ever have done it again. ${ }^{2}$

Hall was only fifteen at the time and the physical education teacher who took him on his first climb was Norm Booth, a talkative, elf-like character who clambered over rocks as though he was born to climb them. Booth was one of the veterans of the ACT rock-climbing scene and he knew all the cliffs and crags of the territory as well as anyone.

After those first few weekends, as Hall recalled,

2 Sheppard, T. 1984, 'Lincoln Hall. Everest mountaineer', Australian Adventurers, Angus \& Robertson, Sydney, pp. 3-14. 
it was a matter of going as often as we could talk Norm into it. He was our transport. Before long I was climbing at the same standard as Norm, which was good because this meant that he was no longer having to climb below his ability in order to encourage beginners. ${ }^{3}$

Not much later, Hall was able to do first ascents, which most rock climbers aspired to as the ultimate stage in their development. A beginner climber usually climbs as a 'second' - that is, he climbs up on the end of a tight rope being taken in by the leader, who has already climbed the pitch and is firmly attached to the rock above. Thus, a fall is of little consequence; the second simply dangles on the end of the rope, rests a bit and has another go.

After a climber has become comfortable seconding climbs, it is time to begin leading them. A lead climber ascends the rock first, taking the rope up behind. A leader arranges 'protection' in case of a fall by slotting metal nuts into cracks in the rock and attaching the rope via carabiners (snap-links) to create a pulleylike system. Placing protection depends on natural weaknesses in the rock and the skill of the climber. Obviously, places for protection are not always available precisely where the climber would like to place nuts, so leading a climb can be a serious business. A fall by a leader, if well above the last piece of protection, can result in severe injury or occasionally death.

The final step in a rock climber's development is to do 'first ascents' - that is, to climb a patch of rock that no-one else has climbed. First ascents are much more difficult mentally than recognised climbs, for which a guidebook provides a description of the route and a judgment of the difficulty. No such psychological crutch is available on a first ascent, where the lead climber can suddenly find himself in a delicate situation when he runs into unexpected difficulties. That Hall so quickly became competent at doing first ascents was testament to his skill as a rock climber.

Many of the first ascents that Hall and his partners put up were on Orroral Ridge, in the mountainous country south-west of Canberra. Orroral Ridge is a long, heavily wooded ridge littered with a number of small granite outcrops and a few single, free-standing monoliths. Its climbs are noted for their short but very steep character and its rock for its very course, sharp and crystalline nature, which often makes the climbing rather painful. The names of some of the climbs with which Hall was involved were indicative of the toughness of Orroral Ridge climbing: 'Manic Depression', 'Psychadelia', 'Lincoln's Lament' and the spectacular crack line 'Vertigo'. All in all, Hall had a hand in 26 first ascents during the early 1970s. 
By the time he entered The Australian National University, Hall had become one of the best climbers in the Australian Capital Territory. Academic life did not, however, seem to slow his very active climbing lifestyle. In addition to climbing at Booroomba Rocks and other ACT crags virtually every weekend, Hall found novel ways to train during the week.

$[\mathrm{M}] \mathrm{y}$ friends and I would practise on buildings on campus. I started on the library and the shop next to it and moved on to the back of the post office. That was good, with plenty of difficult problems. Unfortunately sometimes there were cars parked right up against the bottom of the wall that prevented me from starting. Also, I tended to get an audience and that was a trifle distracting. The retaining wall of the physics building down by Lake Burley Griffin was my favourite. It posed some very hard problems. $^{4}$

Hall joined the ANUMC and it was through the club that he was introduced to alpine climbing: 'A few of my friends in the club had gone over to New Zealand to climb mountains and came back saying that they'd had a good time and that I should go too. Again it was a matter of, well, why not? Nothing better to do. So off I went. ${ }^{5}$

The many pitfalls of making the transition from Australian rock climbing to New Zealand alpine climbing were by then very well understood, so Hall followed the established pattern and did a week-long course with Geoff Wayatt's Mountain Recreation at Mt Aspiring before attempting a few of the standard, less-difficult climbs in the Mt Cook region.

I had rather the same reaction to my first attempts at mountaineering as I did to the rockclimbing. When I came back to Australia, I thought about it and decided that I would at least give it another go. This I did the following season. By then I had finished uni and I was able to spend about three months climbing in New Zealand. In between I cycled around in the country. I made three attempts to climb Mt Cook, and I enjoyed it all apart from one near disaster that taught me twice as much as the climbing course had the year before. ${ }^{6}$

For two of those attempts on Mt Cook, Hall's partner was John Finnigan, a veteran Canberra climber and one of Australia's best all-round mountaineers. The pair had planned a very ambitious outing: starting from Plateau Hut, they would first ascend Mt Cook by the seldom-climbed Bowie Ridge, traverse the mile-long summit ridge, descend to Empress Hut on the other side of the mountain, then 
climb the steep South Face of Mt Hicks - one of the most demanding ice climbs in the Southern Alps. The plan required that they carry heavy packs with all their gear as they climbed the difficult Bowie Ridge, traversed the summit ridge and then descended.

Finnigan recalled:

We climbed the Bowie Ridge all right, but when we got to the summit icecap, we met Gary Ball [a New Zealand mountain guide] and his client, who had turned back. Gary said that the ice was soft and treacherous and also it looked like the weather was about to break, so we turned back.

A few days later we attempted Cook again, this time by the East Face/ Zurbriggen's Ridge route. Again we got to the top of the ridge and were just below the summit when the weather broke. This time it was a fullblown nor' wester, and as we came down the Linda Shelf, gusts of wind would literally lift us up and blow us across the snow. It was a pretty frightening descent. ${ }^{7}$

After that second New Zealand trip, Hall had a very good idea of what alpine climbing was all about:

Climbing mountains is different from climbing rocks. I enjoy the technical difficulties of rockclimbing. The applied gymnastics. But with mountains, because it's more dangerous, there has to be more commitment. You can't just go out for the weekend and if the weather turns nasty, abseil off and go to the pub. When there's a thousand metres of steep ice in every direction and you start having second thoughts you just have to push them out of your mind. ${ }^{8}$

Lincoln Hall was well on his way to making the transition, in skills and attitude, from rock climber to alpine climber. By the time the ANUMC was planning its expedition to Dunagiri, Hall was perhaps the most promising of the young climbers and almost certainly the most skilled rock climber of the entire team. For Tim Macartney-Snape, on the other hand, the journey to Dunagiri took a very different path.

Born in 1956 to Australian and British parents, Macartney-Snape spent the first 12 years of his life on a farm in the southern highlands of Tanzania, which was then the British colony of Tanganyika. Almost from its very beginnings, his life

7 J. J. Finnigan, Interview.

8 Sheppard, 'Lincoln Hall. Everest mountaineer', ch. 1. 
in East Africa was shaping Macartney-Snape's attitudes towards adventure and risk and was equipping him with the mental toughness that later served him so well in many long and dangerous sojourns in the mountains.

I spent the first 12 years of my life in Africa's south-east highlands in what was an idyllic setting. I would not have swapped that part of my life for anyone else's; yet I was to gradually find out that it was quite different from the lives of other kids of my race and generation. In fact it was much more like the lives of their parents and grandparents.

I found out that we lacked many things that others took for granted. For a start, we had no electricity or plumbing. Snakes and spiders used to regularly drop out of the grass ceiling of our house. At night we heard the noises of wild animals, some of them certainly dangerous to little boys. The nearest hospital was a four-hour drive along a gravel road. We had no telephone or radio and no medical insurance.

These would no doubt be thought of as disadvantaged conditions, but I can assure you they were quite the opposite. I was being brought up in about as natural a way as a settled existence could allow, well supplied with attention from my parents and, thanks to modern medical knowledge, free from most illnesses. It was an upbringing very close to that which has accompanied the evolution of the human species over millions of years.

My father was a lover of trees and planted over half a million eucalypts on our farm. I was an avid climber of trees... and given quite regularly to falling out of them. Doing things like climbing trees was as important to my development as having my mother teach me to read. It made me rely on myself, and raw experience was a far more effective teacher than any number of words. It was an upbringing that encouraged me to take responsibility for myself and taught me the value of taking calculated risks, elements I think are sadly missing from the way most children are brought up today. ${ }^{9}$

Although Macartney-Snape's climbing experience as a boy in East Africa was limited to trees, he soon had his sights set on much bigger things: 'Our school was right below a 14,000-foot volcano. I used to look out the window at it. I always wanted to see what it was like on top, but, unfortunately, I never got the

9 Macartney-Snape, T. 1990, 'Taking personal responsibility', Australian Geographic, no. 17 (JanuaryMarch), p. 31 . 
chance. ${ }^{\prime 10}$ Like the first Australian Himalayan mountaineer, George Ingle Finch, Macartney-Snape decided from an early age that he would like to see the world from on top.

When Tim was twelve, his parents migrated to Australia. He was enrolled in Geelong Grammar School and, when he was fifteen, he spent a year at Timbertop, Geelong Grammar's outdoor education centre in the Victorian mountains. That sort of educational environment suited Macartney-Snape perfectly and, in addition to developing skills such as bushwalking and cross-country skiing, his year's experience at Timbertop reinforced his self-reliance and sense of personal responsibility.

It was a stroke of genius on the part of the school to let students loose in some of Australia's most rugged mountain terrain. We all grew tremendously from that year in the bush. One of the most important lessons was that we could actually look after ourselves, virtually independent of the sheltered world we were brought up in. Being responsible for ourselves made us feel more alive, gave us a sense of purpose and gave more meaning and enjoyment to what we did. It was amazing how much easier it was to coax aching muscles to keep on climbing a steep hill, when going to that hill was our own idea. ${ }^{11}$

A few years later, Macartney-Snape enrolled as a forestry student at The Australian National University. During Orientation Week, he found his way to the stall of the now-rejuvenated ANUMC.

'I walked past the Mountaineering Club display and saw some photos of people climbing and stopped to have a look. It was something I had always wanted to try. A very enthusiastic, very young-looking bloke started telling me about climbing and I signed up. ${ }^{12}$

The young bloke was Lincoln Hall, who was already becoming one of the top rock climbers in the Canberra region.

It was not in rock climbing, however, that Macartney-Snape first made his mark in the club. Rather, he quickly established a reputation for generous amounts of energy and enthusiasm, as Steve Colman, another of his good friends in the ANUMC and a future partner in the outdoor adventure company Wilderness Expeditions, recalled:

The ANU Mountaineering Club used to run beginners' ski trips. We organised one of these trips up to the Snowies [Snowy Mountains]. With

10 T. Macartney-Snape, Interview.

11 Macartney-Snape, 'Taking personal responsibility'.

12 T. Macartney-Snape, Interview. 
the typical heavy nights that one would have, early morning starts were often neglected. There we were, after a late night at the pub, sunrise at Island Bend, and suddenly there was this noise of someone walking through camp banging a billy. It was Tim, with his Timbertop-style approach to things, trying to get us up to go skiing. The howls of abuse had him sulking back to his tent. ${ }^{13}$

Macartney-Snape's remarkable stamina and energy, for which he was later very well known, were also evident, according to Colman, in the early ANUMC days:

The thing about Tim is that he has a superb physiology. On skis or walking, he's a dynamo. He doesn't know the meaning of the words 'slow down'. I found it good, as amongst the people I skied with, I was probably the strongest and most able-bodied skier. Tim's coming onto the scene allowed me to push a bit harder, as Tim and I used to find quite severe slopes to ski down. That opened up a whole new era of skiing at Kosciuszko, in terms of telemark skiing and cross-country/ downhill skiing.

Out of that core network from the Mountaineering Club emerged the renaissance of the telemark in Australia as a functional turn. We were doing things that made people think twice - we were skiing down the pipeline at Guthega Power Station and off Watsons Crags. This was the era when the general feeling about cross-country skiing was that you just walked around on the skis. If you did a stem-christie, then that was about it. It was bushwalkers heading out on skis, whereas we saw ourselves as skiers. We had discovered a way of putting a lot of excitement into it.

As for Tim's energy, it nearly got us into trouble once. One of the first times we went out to ski Watsons Crags, Tim and I had arranged to meet at Blue Lake. He said, 'I'll bring all the food and stoves, and we'll meet at mid-afternoon.' So I skied in about mid-afternoon, but there was no Tim. All I had was a bar of chocolate, nothing else. I didn't bring a tent, as Tim said he would supply that too. Luckily I had a shovel, so late in the day I dug a snow cave. Tim just didn't turn up. The really difficult thing was that the whole place was frozen over, so I was starting to get quite thirsty. I was eventually able to chip through the ice and get some water out of the lake. It came on dark, and I thought, 'Bastard, where is he?' Sometime later in the evening, when it was quite dark, this head poked through the opening. It was Tim. He had done a bit of skiing on the way. He had left Dead Horse Gap early in the morning all right

13 S. Colman, Interview. 
but he couldn't refrain from skiing every conceivable patch of snow between there and Blue Lake. Not only had he carried all the gear in, but he had skied at least 12 hours on the way in as well!

We spent a lot of time camping in the snow, and became totally comfortable in it. It really honed up our wilderness skills. Also, I learned that Tim was a great talker in his sleep. On one skiing trip he entertained us all night with his talking. At one point he sat straight up and said, 'Don't worry! Don't worry! I'm going to organise all the transport.' Of course, it bore no relevance to the fact that we were up in the Snowies. That earned him the nickname 'The Minister for High Alps Transport', and he travelled under that name for quite a while at the university. ${ }^{14}$

In addition to being a skilled bushwalker and skier, Macartney-Snape had become a competent rock climber by the mid-1970s. His approach to that sport, however, was somewhat different to that of Lincoln Hall, who enjoyed the gymnastic aspects of climbing and had become one of the hard rock climbers of the ACT scene. Macartney-Snape, on the other hand, enjoyed rather more just climbing with a friend or two on a wild, isolated crag away from the more crowded and competitive popular cliffs where many of the leading climbers were continually trying to outdo one another by putting up harder and harder routes.

Macartney-Snape later described his attitude towards rock climbing in terms of the highly competitive scene of the 1980s, when he wrote about a remote crag he had found in the desert of Western Australia:

There was just the cliff. The only white marks were those of guano from falcons and kestrels. There were no white blotches of desperately smeared chalk to mark the past struggles of human climbers. No bits of steel bustled from any rock. What I liked best of all though was that there was no one strutting around in their latest kaleidoscopic finery. The nearest funny earring was horizons and horizons away...it was nice to see a place where we could climb on untainted rock for the anonymous joy of doing it. Where fashion had no significance and we could climb for the sake of the physical experience, for the sake of seeing the world around with the clarity which a hard climb brings, not for the sake of telling the world how good we were, that is a job for the alienated world of the city not the natural world of the wilderness. ${ }^{15}$

14 Ibid.

15 Macartney-Snape, T. 1989, 'Desert climbing', Outside (Mountain Designs newsletter), vol. 2, no. 3 (December), p. 3. 
With Macartney-Snape's strong background in bushwalking, skiing, snowcamping and rock climbing, it is not surprising that he found his way to New Zealand soon after arriving at The Australian National University and joining the Mountaineering Club. In early 1976, he took a basic mountaineering course in the Southern Alps and a year later he was back in New Zealand, in the Mt Cook region, to climb some classic routes, including Mounts Elie De Beaumont, Malte Brun and Green. His second New Zealand journey was most notable, however, for his trip to the Olivine Ice Plateau, a remote, rugged mountain wilderness south of the Mt Aspiring area. Because of the Olivines' remoteness, climbing there is serious business, requiring fitness, stamina, good route-finding skills and a large dose of confidence and self-reliance. It was perhaps typical of Macartney-Snape that he would search out challenges of that nature rather than sticking solely to the more well-trodden climbs of the Cook and Aspiring regions.

Although Macartney-Snape was not one of the original group of young ANUMC members who had been involved in the Dunagiri plans from the start, he quickly joined that group and, as a result, began to climb more often with Lincoln Hall on the rolling granite slabs and steep buttresses of Booroomba Rocks. As they climbed together more frequently, they began to realise that, even though they came into climbing from quite different backgrounds, they shared a common desire to drive themselves harder and harder. With the ANUMC's plans to mount a major Himalayan expedition coming to fruition, they had a further reason to push their skills to the highest possible level.

In early 1978, a few months before the ANUMC group departed for India, Hall and Macartney-Snape made another climbing journey to New Zealand-the third for each but the first together as a team. It was on this trip that their partnership began to flourish and to produce some remarkable results. As Macartney-Snape said, 'I was finally paired with somebody else who really wanted to climb.'16

And climb they did. They tackled the south face of Mt Hicks, a daunting wall of $2000 \mathrm{ft}(610 \mathrm{~m})$ gullies of hard, green ice - the test piece for the hard men of the New Zealand ice-climbing scene (see image 8.1). Even more impressive was their ascent of the MacInnes Ridge, a hard rock route, on Nazomi followed without a break by the climb up the long, technically difficult ridge that connected Nazomi with the southern summit of Mt Cook. It was a marathon mountaineering effort that made the New Zealand climbing establishment sit up and take notice and one of the first of the long, demanding traverses that still

16 T. Macartney-Snape, Interview. 
provide the biggest challenges to Southern Alps mountaineers. What made the Nazomi-Cook traverse even more remarkable was that two young, unknown Australians pulled it off.

So, with a season of truly hard New Zealand climbing just completed, Hall and Macartney-Snape, as mountaineers liked to say, 'hit the hills running' when they arrived in the Indian Himalaya. Their near-ascent of Purbi Dunagiri- a very difficult peak - so early in the expedition confirmed their position as the top climbing pair of the ANUMC team and their eventual climb of Dunagiri itself showed beyond any doubt that they had the skills, strength and determination to cope with high-altitude climbing in the Himalaya.

Just a year after the Dunagiri trip, Macartney-Snape and Hall were back in the Himalaya again, but this time in very different circumstances. They were part of a very small, low-key expedition, with Canberra climber Phil Cullen completing the climbing trio, and their target was the Manikaren Spires area of the Kulu Himal. Macartney-Snape's sister, Deb, joined the expedition as a non-climbing member.

Even though the Manikaren Spires and Dunagiri are both in the Indian Himalaya, they appear as though they are worlds apart. In fact, the spires look like they hardly belong in the Himalaya at all. Unlike the towering peaks covered in snow and ice that typify the majority of the Himalayan ranges, the Spires - a small cluster of granite ridges and peaks - are of moderate height, from 5000-5500 $\mathrm{m}$, and hold only isolated, very small patches of permanent snow. To climb in them requires rock-climbing skills, so the Manikaren Spires are a particularly attractive objective for Australian climbers, particularly those strong on rock such as Lincoln Hall and Phil Cullen.

Almost from the start, however, the trio ran into trouble, as Hall and Cullen developed severe stomach complaints that necessitated a walk back out of the mountains for treatment before they could even begin to climb. MacartneySnape, on the other hand, was already proving that he was as immune to local illnesses as he was to the effects of high altitude.

Hall recovered in time to walk back into the mountains and rejoin MacartneySnape to attempt at least a few climbs; Cullen was knocked out of the rest of the expedition. Their first efforts resulted in a gem of a climb: an aesthetic ridge route on Geru, a $5100 \mathrm{~m}$ unclimbed peak. From the summit, they could clearly see Ali Ratni Tibba, a beautifully tapered $5500 \mathrm{~m}$ high pyramid of rock that was the highest mountain in the Spires.

With little time remaining, they set out on Ali Ratni Tibba's South-West Ridge and made short work of the route, finding it technically easy enough that they did not require a rope. The ascent was made interesting by a sudden storm that 
caught the two climbers partway up, forced them into a bivvy under a rock overhang and then complicated the final climb to the summit by coating the rocks with fresh snow. The descent was probably more exciting than the climb, as Hall and Macartney-Snape abseiled down the precipitous West Face.

The mini-expedition to the Manikaren Spires was nowhere near the previous year's Dunagiri trip in terms of the danger, the severity of the climbing or the magnificence of the achievement, yet it was further proof that the blossoming Macartney-Snape/Hall partnership had the drive and determination to overcome serious obstacles - this time, illness - to get to the summit. Perhaps more importantly, it forced the two, because of the small size of the team, to spend a lot of time together; they could not develop the other relationships possible in a much larger group to release built-up tensions. It was therefore a good test of compatibility, a test that Macartney-Snape and Hall passed with flying colours.

At the beginning of the 1980s, then, Australia's first durable climbing partnership had formed. Macartney-Snape and Hall had demonstrated the strength and intense desire to succeed of the Messner/Habeler team without the direct competitiveness and the two Australians were as well matched in temperament and personality as the Tasker/Boardman and Shipton/Tilman teams.

Just after their expedition to Mt Everest in 1984, Hall wrote of his partner:

Tim's lanky build and quiet manner belied his physical and mental stamina. Projects of his were never half-hearted affairs, though sometimes rushed as he tried to achieve more than time allowed. Things were done today instead of tomorrow to leave room for whatever tomorrow would present. If a stove needed maintenance or a candle-holder improvised it would be Tim who fiddled away by torchlight. He had definite ideas on everything and a stubbornness for what he felt to be right. Decision making on our expeditions was always a process of talking until we agreed upon the best alternative. Often it was Tim's plans we carried out because his practical mind was quick to solve the problems we faced.

For Tim part of the attraction of high mountains was their continual ability to demand more energy than one's body and mind could supply. No other sphere of activity offered that to him. Accordingly, it was when the mountains drew the utmost from us that he felt satisfied. The pleasure was not one of masochism or displaying bravery but of feeling his body and mind working efficiently when his life depended upon it. Tim always seemed to know where he was in terms of both selfconfidence and geography. His skill in finding the best route in a storm or at night was little less than magical. 
Away from the mountains the fierceness of his determination remained hidden behind his politeness and modesty. Self-control and self-reliance were the foundations of his self-respect. As a consequence he kept his ambitions, needs and emotions to himself. Though he had many friends it was difficult for anyone to know him well because the different facets of his life existed independently of each other. Only within himself did they come together. ${ }^{17}$

Many of Hall's personality traits complemented those of Macartney-Snape beautifully. Whereas the latter was so brimming with energy and enthusiasm that he would spend his 'rest' days skiing, fiddling with stoves or in some other active pursuit, Hall was given to meditation, yoga and similarly contemplative activities. It was during these quiet times in the mountains that Hall developed his views not only towards climbing, but towards the inhabitants of the areas he climbed in. He wrote after the Dunagiri trip:

It was not until I visited India in 1978 for my first Himalayan climb that the self-indulgence of my activity occurred to me. The challenge for so many people in the world is simply to survive. There is no need for Indians to invent frightening games in order to prove themselves to themselves. India made me realise the narrowness of my outlook. I began to share my life with other interests. Climbing has remained my avenue of experience, but these days I spend more time looking around me. No longer is my head down in a beeline for the summit. ${ }^{18}$

Though Macartney-Snape, too, had developed rather similar philosophies towards the peoples of the Himalayan region and towards wilderness and the natural environment, the two would likely express their feelings in quite different ways. Ask them the same question and Macartney-Snape would respond with a careful, well-thought-out line of reasoning. Hall, on the other hand, would make the same point instantly with one of his classic, penetrating one-liners.

In one other extremely important characteristic the two were again very complementary. Macartney-Snape possesses an almost unbounded enthusiasm and a knack for problem solving that generate an air of optimism, which is often essential to carry climbers through the physically demanding and psychologically draining conditions of a big Himalayan climb. There are so many difficult and unpleasant aspects of climbing in the Himalaya-lack of food and water, long periods of storms and bad weather, the debilitating effects of high altitude - that without someone with Macartney-Snape's enthusiasm, an expedition could simply grind to a halt before the mountain is climbed.

17 Hall, L. 1985, White Limbo, Weldons, Sydney, pp. 48-52.

18 Ibid. 
Caution was probably the key theme in Hall's approach to Himalayan climbing. 'Usually suggestions of soft options and words of caution come from me because of my healthy awareness of my own mortality,' Hall wrote of himself. ${ }^{19}$ A good dose of caution is the perfect antidote to an overabundance of enthusiasm. Too much caution and nothing is ever climbed, but too much enthusiasm and a fatal accident can result. Macartney-Snape's enthusiasm and Hall's caution were, as it turned out, perfectly matched to produce a remarkable string of Himalayan successes that culminated, sooner than anyone had expected, in the first Australian ascent of Mt Everest. 


\section{Everest apprentices}

Mt Everest is an irresistible magnet to most mountaineers. It is certainly not because Everest is seldom climbed. Between 1953 and 1990, about 200 people have climbed the mountain, by at least eight different routes and in all three climbing seasons, and the number of ascensionists has risen sharply since 1990. Its magnetism also does not lie in its beauty. A hulking black pyramid set amid more shapely snow and ice-clad peaks, Everest is not one of the more aesthetic Himalayan peaks. Ama Dablam and Machapuchhare would have to take those honours and, amongst the $8000 \mathrm{~m}$ giants, K2 and Makalu are more beautiful. Everest is also not one of the most difficult $8000 \mathrm{~m}$ peaks; K2, Dhaulagiri and Makalu are all technically harder to climb. Simply because its summit is the highest point on the face of the Earth, however, Everest is a lure that few mountaineers can resist.

At the beginning of the 1980s, Everest had another strong attraction for Australian climbers: no Australian had ever stood on its summit, and, apart from George Ingle Finch in 1922, no Australian had ever attempted to climb the mountain. No doubt the thought of eventually climbing Everest crept into the back of the minds of a few young ANU students preparing for Dunagiri, and perhaps occasionally one young climber would say to his friend, 'If we go well on Dunagiri, maybe we'll have a go at Everest in a few years.'

For most of the ANU team, however, Dunagiri was a sobering experience. Although all members contributed to the eventual success, most found trying to climb a 7000 m mountain on a difficult route in their first Himalayan trip just a bit too hard physically and psychologically. Everest would be several times more difficult. Furthermore, for many, family ties and careers would prevent the commitment of time and resources needed to build a Himalayan climbing career to the stage where an ascent of Everest was a real possibility.

Still, Dunagiri was a first big step for Australians towards Everest. The ANU team was met on their return to Australia by Sir Edmund Hillary, who commented that 'Dunagiri is a formidable mountain and obviously they struck difficult conditions on their final ascent. I think they should be complimented.' He added that he thought the Dunagiri expedition 'was a step in the right direction for an Australian ascent of Mount Everest' ${ }^{1}$ Of the 15-member Dunagiri team, the two who were obviously in the best position to build on the successful ascent were Tim Macartney-Snape and Lincoln Hall. Before even that formidable partnership

1 'Dunagiri - a step towards Mt Everest', The Canberra Times, 15 June 1978. 
could contemplate an assault on Everest, however, they would have to serve a much longer Himalayan apprenticeship and, along the way, find a few more likeminded Australian mountaineers to form a strong team for an Everest attempt.

After their trip to Dunagiri in 1978, Macartney-Snape and Hall began to spend more and more time in the Himalaya. There was a climbing trip to the Kulu Himal the next year and then frequent journeys to Nepal to lead treks for Australian adventure-travel companies. Although the treks involved no climbing, they still proved valuable experiences for the pair. They were able to learn more about the culture and customs of the Nepalese people, particularly the Sherpas; to become accustomed to the local food, which they would use to advantage on later expeditions; and to observe close up several of the mountains they would eventually climb.

It was climbing experience, however, that Macartney-Snape and Hall really needed to prepare for tackling bigger mountains. Their next opportunity came in 1981, when they were asked to join an expedition to $6856 \mathrm{~m}$ Ama Dablam, in the Everest region of Nepal. This time the trip was not their idea, but rather that of Ken McMahon, a Sydney rock climber who had made several trips to New Zealand and had done some hard climbing in the Southern Alps.

Like quite a few Himalayan trips, the 1981 Australian Ama Dablam expedition was started by climbers bailed up by bad weather in a New Zealand mountain hut. McMahon was climbing in the Mt Cook region in 1978 with American Dave Pluth when the pair decided that perhaps the weather was a little better, or at least a bit more predictable, in the Himalaya, so a climbing trip there would not be a bad idea. The idea gradually gained substance and Ama Dablam was chosen as the objective at the suggestion of Geoff Wayatt, who, in yet another contribution to Australian mountaineering, had learned that the mountain had just been released for climbing to foreign expeditions and passed that information to McMahon.

The team was organised in the best of traditions, as McMahon did a quick ringaround of his friends and acquaintances in the climbing community. American Hooman Aprin joined his countryman Pluth, Sydney climber Andy Henderson, resident in London at the time, was enlisted and Macartney-Snape and Hall, well known from the high-profile Dunagiri expedition, completed the climbing team. Support was provided by Karen Robins, Leo Ertsler and Canberra climber Damien Jones, who contributed much to the rock climbing on the lower sections of the mountain.

With the climbing team scattered all over the world, the first major obstacle was to get them all together in Kathmandu at approximately the same time. This was 
no problem for Macartney-Snape and Hall, who were leading treks in Nepal just before the expedition, but for Aprin, the journey to Kathmandu proved nearly as dangerous as the climbing, as McMahon recounted:

Waylaid in a Bangkok hotel room by two girls, Girl-1 kept him occupied in the shower, while Girl-2 cleaned out his wallet and travellers cheques. Hooman, sensing something was amiss, came out of the shower to see Girl-2 running out the door. Disregarding his totally naked state, he chased her out into the street and jumped onto the bonnet of the getaway car. Holding onto the windscreen wipers, he tore off a wing mirror and proceeded to smash in the windscreen. The terrified Girl-2 rammed the front end of the car, then the back end, but got away in the crowd that had gathered.

Hooman stalked off to get his clothes. Girl-1 had disappeared, but in her haste had left her watch behind, so Hooman had an 'expensive' watch for his troubles. The Bangkok police were highly amused, and they all naturally assumed that Hooman was Clint Eastwood's brother. I'm afraid Hooman suffered a lot of ribbing over this incident and the watch was eventually given to our sirdar. ${ }^{2}$

A few days later, in Kathmandu, Hall provided more amusement for the climbers, albeit in a less spectacular fashion. While shopping for food in a popular tourist area, he was accosted by a beggar who waved a misshapen hand in front of him and demanded a rupee. Hall responded by removing his shoe, exposing his feet with bits of toes missing and demanding two rupees. The beggar was stunned by this rejoinder and simply stared at Hall's feet in silent amazement.

Wayatt's suggestion of Ama Dablam turned out to be a stroke of genius. It was, in the words of Andy Henderson, 'the perfect expedition for a small grouplovely walk-in, beautiful mountain, steep and interesting route' ${ }^{3}$

As any trekker to the Mt Everest region will affirm, Ama Dablam is a stunningly beautiful mountain, one of the loveliest anywhere in the world. Seen from the Buddhist monastery at Thyangboche, Ama Dablam stands above the Imja Khola Valley as a giant spire of ice with two long, steep ridges spreading out like enormous arms to embrace the monastery. Sometimes called the 'Terrible Tooth', Ama Dablam in fact means 'mother's charmbox' and is so named for the prominent ice cliffs hanging like charms on the west face below the summit.

2 McMahon, K. 1981, 'Captain Cruch. The Australian Ama Dablam expedition, 1981', New Zealand Alpine Journal, vol. 34, pp. 63-7.

3 A. Henderson, Interview. 
With the black, rocky summit of Everest peering over the Nuptse-Lhotse wall in the background, the view up the Imja Khola towards Ama Dablam is one of the world's classic mountain scenes.

The Australian-American group had booked the North-East Ridge, which is behind the mountain when viewed from Thyangboche and accessed from a pleasant base camp on a grassy patch in the Chukkung Valley. There is no easy route to the top of Ama Dablam; like the other ridges, the North-East Ridge is unrelentingly steep and of considerable technical difficulty.

Illness and injury slowed the expedition at the start. McMahon contracted a chest infection and had to descend to Thyangboche for a week to recover. Meanwhile, Hall had run into problems as well, according to McMahon:

Lincoln's acclimatisation trick was to fall seven metres off a boulder into a bunch of smaller ones, and survive. He did need nine stitches in his leg, and we all held him down while Tim, our expedition 'doctor' (having spent time stitching up livestock on his parents' farm) gave him his injections and sewed him up. ${ }^{4}$

The steepness and difficulty of the ridge, combined with the fickle weather, slowed progress and forced the establishment of four camps on the mountain. The climb was roughly divided into thirds, with the first third being predominantly sound rock, which prompted one of the climbers to say that it was 'just like Booroomba [the ACT granite crag] at $5330 \mathrm{~m}^{\prime} .^{5}$

Because the route was so steep and loads had to be carried to establish and supply the camps, fixed rope was placed on much of the ridge (see imge 9.1). In addition, a ladder remaining from a French expedition aided the ascent of a $5 \mathrm{~m}$ overhanging section.

With the weather deteriorating as the season wore on, the second third of the climb became even more difficult. It was often mixed climbing on snow and ice of dubious firmness and on rock of not quite the same firm quality as that lower down. Progress was frustratingly slow, with a camp placed on a ledge at $6000 \mathrm{~m}$ and a further camp only $400 \mathrm{~m}$ higher.

At this point of the expedition, McMahon was forced to retire with a recurrence of his chest infection and Aprin and Pluth, concerned about the safety of the fixed ropes, also returned to base camp. That left Hall, Henderson and Macartney-Snape at the high camp to go for the summit. Although the top was only $550 \mathrm{~m}$ above them, it took several days to climb that last section of the ridge, as McMahon recalled:

4 McMahon, 'Captain Cruch'.

5 Ibid. 
For two days they fixed ropes to the top of a large ice-tower that marked the end of the second third of the climb. On the 14th of May they left the camp and made an alpine-style bid for the top. After some nerveracking and exhausting climbing they put in a snow-hole at 6,550 $\mathrm{m}$ where they spent the night. On the 15th of May they reached the summit, at midday (see image 9.2). Lincoln was responsible for the only incident of note- he dropped their chocolate bar down the south side of the mountain. That night, at 10:30 pm, they regained the high camp, a tremendous effort of endurance and commitment. ${ }^{6}$

Hall's recollection of the climb gave some clues about the nature of the 'nerveracking and exhausting climbing' that McMahon referred to. Much of the upper section of the ridge was double-corniced - that is, overhung on both sides of the ridge - leading to dangerous and exceedingly tense climbing. Also, the snow on the ridge was soft and unconsolidated and at times the climbers had no choice but to put their weight onto ropes tied to aluminium stakes driven into the untrustworthy snow.

Hall, Henderson and Macartney-Snape's ascent of Ama Dablam was another big step for Australian mountaineering. Not only did it mark the second significant achievement for Hall and Macartney-Snape, it was the first Australian success on a mountain in Nepal since Peter Taylor's ascent of Langtang II in 1963. And, most importantly, it pushed Everest from the back of Hall and MacartneySnape's minds to the front. That was not too surprising given the position of Ama Dablam's North-East Ridge: directly across the Chukkung Valley from the Nuptse-Lhotse wall and the summit pyramid of Everest. As Hall remarked, 'we were looking over at the bloody thing very often' ${ }^{7}$ so the idea of attempting Mt Everest moved from the realm of daydreams to that of constructive planning. Even at that point, Macartney-Snape had begun to think about doing a new route on Everest without artificial oxygen.

Also significant for the eventual Everest attempt was the inclusion in the Ama Dablam summit trio of Andy Henderson. Any realistic Australian attempt on Everest would require more than just two climbers, no matter how strong or competent, so the discovery of Henderson - an easygoing, compatible yet very competent mountaineer - added more strength and skill to the powerful nucleus of Macartney-Snape and Hall.

Henderson's development as a Himalayan climber followed a fairly typical Australian pattern. A Sydneysider, he became interested in outdoor sports through bushwalking at school and then became involved with rock climbing

6 Ibid.

7 L. Hall, Interview. 
Himalayan Dreaming

in the Blue Mountains. That eventually led to a trip to New Zealand in 1975, when he took an Alpine Guides instruction course and climbed in the Mt Cook region.

A year later, Henderson was back in New Zealand, this time climbing in the Mt Aspiring region with his friends Adrian Cooper and Martin Hendy. As often happens in New Zealand, bad weather forced the climbers into a hut for an extended period and their thoughts turned to climbing big mountains somewhere else, such as the Himalaya, where the weather might be better.

Independently, Sydney climber Gary Mathew had the same idea and he acted on it by booking $6864 \mathrm{~m}$ Changabang in the Indian Himalaya for the postmonsoon season (September-October) in 1977. Just next-door to Dunagiri, Changabang is a striking mountain dominated by two extraordinary rock faces that drop precipitously from just below the summit to the base of the Nanda Devi Sanctuary. Most mountaineers consider it, like Ama Dablam, to be one of the most charismatic peaks in the world.

Mathew quickly recruited Henderson and Hendy - already keen to go to the Himalaya - and added Malcolm Noble and Charlie Cuthbertson to complete the five-man team for the first of many Australian attempts on Changabang. At the time Mathew was planning the 1977 Changabang trip, very little Australian climbing had taken place in the Himalaya and, indeed, the Sydney climbers were unaware of the large ANUMC Dunagiri expedition - by then well advanced in planning and publicity - which would follow them to the Garhwal a few months later. Henderson, however, knew of Warwick Deacock's 1975 Mulkila expedition and of his trekking business, so obtained some advice from him. Most of their information specifically on Changabang, on the other hand, came from Colin Read, a British climber who had attempted the peak in 1976.

The 1977 Australian attempt on Changabang could be accurately described as very low key and run on an extremely low budget. Their equipment, of course, was limited by their pocketbooks. 'We were kitted out in our old New Zealand gear-ex-Army woollen trousers and the like,' Henderson said, 'and everyone lashed out for a good sleeping-bag and maybe one other item, perhaps a duvet, but that was all.'8

The shoestring quality of the trip continued on arriving in India, as Noble wrote:

[T] he merchant sits comfortably, surrounded by neat piles of grain and lentils of all description. He tips the last of the measures of freshly milled flour into one garbage bag and starts to total up the list of figures.

8 A. Henderson, Interview. 
Charlie flashes out his miniature calculator to check but the merchant, seeing this, utters a few words to his assistant and from the depths of the ancient store produces a calculator with at least twice as many functions. Amidst the laughter Charlie quietly pockets his and the merchant, with infinite patience, taps out the figures.

Our ridiculous pile of gear had forced Andrew, Charlie and me out of the tiny hotel room and into the corridor where we were trying to stuff an amazing array of biscuit tins with an even more amazing array of goodies. Struggling to remove the lid from a particularly stubborn tin, I fell backwards through the flimsy door of the next room accompanied by a resounding avalanche of tins and hardware. Seated in lotus position were two New Zealanders, up to that moment deep in meditation. Slowly one of them turned his head and glared at me with his eyes closed. Something told me that I wasn't the presence they were looking for and by the next day they had disappeared. ${ }^{9}$

The misadventures continued on the trek into the sanctuary:

Arrival at Base Camp was celebrated by Kunwar [the cook] exploding a pressure-cooker full of dahl all over the place and the paying of all but two of the porters. These two kindly agreed to be paid if and when we returned as we had run out of money. This factor, along with a sugar shortage and Charlie's habit of bludging fags from them, finally convinced the porters that we really were not millionaires. ${ }^{10}$

Changabang's imposing rock walls looked a bit too imposing to the five Australians, so they opted for a variant of Chris Bonington's 1974 original route of ascent: a rising traverse up the south face of Kalanka to a col in the ridge joining it to Changabang, then along the East Ridge to the summit. The route is still an exciting and challenging mountaineering proposition, but without the severe and sustained technical difficulty of the face routes.

The team, after a minimal period of acclimatisation, made a single, alpine-style push for the summit, partly because they did not have the equipment and supplies to set up a string of camps and partly because, as Henderson said, they 'didn't know any other style'. Despite none of them having had any previous Himalayan experience, they pushed through sometimes difficult climbing conditions to within 50 vertical metres of the summit before bad weather forced them back. Henderson added that they had simply 'run out of food, fuel, and energy'.11

9 Noble, M. 1978, 'Changabang', New Zealand Alpine Journal, vol. 31, pp. 54-8.

10 Ibid.

11 A. Henderson, Interview. 


\section{Changabang 1977 \\ Malcolm Noble}

Charlie arrived in good spirits from Base and dawn on the following morning saw the five of us plodding up the approach to the long gully. Well, you can read about high altitude plodding pains in any number of expedition books so suffice it to say that after this first day we were stuffed. For Gary and Charlie it was worse. Charlie was forced back, his ankle flaring into agony on the steeper ground, then Gary found that he wasn't acclimatising well and he, too, sadly moved down. After ages in the gully we soloed over some exposed mixed crud to emerge low on the Kalanka face. By dusk we had the tent perched on a miniature platform and I resigned myself to lying in a hammock formed by the tent floor over the edge of the platform. Andrew did wonders with the tuna and freeze-dry but this first night above 6000 $\mathrm{m}$ was awful so we gladly declared the next day a rest. Despite improvements the second night wasn't much better.

We treadmilled through deepening snow towards the col encountering only one nasty slot. This slot holds a special memory for me after I attempted to jump it during our descent and sped off down the slope in what I cannot claim to be an entirely controlled descent.

Camp 2 was thankfully level, sheltered by a small ice wall and commanding a superb view of the glacier with Nanda Devi dominating the whole show. In the evening we could look across to the light brown granite of Changabang's South face plunging startlingly out of sight. Behind, the dark Earth shadows slowly drowned the mountains.

Breakfast of tea and biscuits took the usual one-and-a-half hours and the sun had hit the tent by the time we staggered out to claim our bits of frozen gear and struggled into harnesses. We rose onto the col from where we had the first good view of the East ridge. It looked quite a buzz but honestly the word narrow just didn't do it justice. Dunagiri showed up splendidly isolated against a backdrop of endless Tibetan ranges. Casting our gaze further we were moderately astounded to see foot-prints leading from the steep north side of the col and up the west ridge to the summit of Kalanka. Regrettably the tracks didn't belong to a Yeti but were those of a Czechoslovakian team that we' $d$ missed by about ten days.

Andrew led onto our ridge, complaining about exposure as the loop in the rope dropped out of sight beneath us. Despite the effort, we raved in each other's ear at every belay about the fantastic position we were in. Time slipped by. At 3 p.m. while trying to negotiate an awkward gendarme we realised the summit wouldn't be reached before dark, so started digging a bivy [sic] cave. The usual afternoon cloud closed in, chilling us as we waited our turn to dig. By a stroke of foresight someone had brought a snow shovel but hard ice forced the tunnelling sideways until a diffuse light indicated the other side of the ridge coming up fast. So digging ceased and we grovelled into contorted positions, blocked up the entrance and discovered how dark it was inside.

I didn't bother asking Andrew [for a torch]-in a moment of chronic poverty he had sold his to a porter. Another strenuous rummaging session produced a 2 -penlight, $1 / 2$ candlepower device that cast a sick yellow glow for a few seconds then died. This was my torch. Dinner was a few banana chips and it was not a good night.

Morning, and we stumbled, blinking, out of our humble hole, forcibly realising what a home away from home it was. Ice runnels speared down, away, out of sight below. Looking up wasn't any better-high cloud, rising wind and spectacular forbidding cloud plumes off Kalanka and its mates. Breakfast-fudge and banana chips.

Leaving the sacks, the three of us moved off slower than ever, the summit cornice only just over there. We never made it. With a blizzard building up rapidly and each ropelength taking an age we simply had to get back along the ridge to the tent before dark. No disappointment, just mild relief, a strange pleasure in being where we were and the logic of having no real alternative. 
The wind tried to buffet us out of our steps, gusting, driving showers of snow up the side of the ridge, over the cornices, filling the duvet hood with noise. We moved together slowly, balls of snow crusting our mitts, every little hair a line of white frost. The satisfaction of having been so high on a beautiful mountain with a small alpine party bloomed later.

From 'Changabang', New Zealand Alpine Journal, vol. 31 (1978), pp. 54-8.

The 1977 Changabang expedition was, in many ways, a prototype for many Australian Himalayan expeditions of the 1980s. It was a trip organised by a group of friends and acquaintances with little fanfare and virtually no sponsorship. It attempted a significant mountain and it achieved as much or more than could have been expected from the climbers' previous experience. Not surprisingly, however, the Changabang expedition did not have the impact of the Dunagiri climb, which it preceded by six months.

At that time, there was no regular reporting of Australian climbing in the Himalaya, in either Australian outdoor magazines (Wild, for example, did not exist at the time) or overseas climbing magazines. Furthermore, the contact between groups of climbers in Sydney, Canberra, Melbourne and other centres was much less than it is now. Any publicity for an expedition in the 1970s had to be self-generated, which the Dunagiri team did to great effect and the Changabang team did not do at all. Or, as Lincoln Hall put it, "The Changabang expedition was just as "major" as our Dunagiri climb, but they didn't beat their chests as much as we did.'12

The Changabang climb was particularly significant as the start of Andy Henderson's Himalayan career. Henderson's efforts on the Changabang and Ama Dablam expeditions obviously impressed Hall and Macartney-Snape, and at the conclusion of the latter trip they invited him to join them on a climbing trip to China later in 1981 - an expedition they had organised before the Ama Dablam climb. Henderson accepted immediately.

The expedition, which left Australia just a few months after the conclusion of the Ama Dablam climb, was to the Anyemaqen Range in central China, to the north-east of the Himalayan chain. Although not part of the Himalaya, the main peaks, between 6000 and $6300 \mathrm{~m}$ high, provided Himalayan-like conditions in a remote and little visited mountainous region.

Hall, Henderson and Macartney-Snape were joined by Charlie Massy of the ANUMC Dunagiri expedition and by Geof Bartram, a very experienced 
Australian climber and mountain guide. Well-known British mountaineer Doug Scott was also to have been a member of the expedition but withdrew before the team's departure for China.

The trip was another success for Hall and Macartney-Snape, although the climbing was not as difficult as they had done on Dunagiri and Ama Dablam. In just a few days of real climbing, the pair, along with Henderson and Bartram, climbed a new route to the $6152 \mathrm{~m}$ eastern summit, from which Hall and Macartney-Snape traversed to the main summit $-6282 \mathrm{~m}$ high. All four climbers then descended via the $6 \mathrm{~km}$-long North Ridge. Massy had to leave the expedition early because of commitments in Australia and missed the climb to the summit. Three other smaller peaks in the range were also climbed during the course of the expedition.

Far more significant than the climbing were the contacts that the Australians made with the Chinese Mountaineering Association (CMA), which controlled all mountaineering activity in that country, including attempts on Himalayan peaks from the Tibetan side. Those talks with the CMA were the first chance for Hall and Macartney-Snape to sound out the prospects for an eventual Australian attempt on Mt Everest. What happened in the talks, as Henderson explained, surprised everyone:

In China you have to pay for everything at the end of the expedition. You just collect the bills as you go along and, at the end of the trip, CMA officials come along with an accountant and an abacus, a case of beer and some coke, and you sit down and work out how much you owe.

The CMA officials are mainly old climbers - with teeth, toes and bits of noses missing. So, though there were lots of arguments about how many yaks we really used and that sort of thing, there was also a lot of storytelling going on. In the midst of all this, Geof asked them what was available on Everest. 'Nothing' was the immediate reply. ${ }^{13}$

Macartney-Snape, however, had done some homework on the issue. While in Kathmandu after the Ama Dablam expedition, he obtained some information from a Japanese climber who had been on Everest's North Face in 1980. The North Face appeared to be a good possibility, as it was a very direct route to the summit. At base camp on Amyemaqen, Macartney-Snape asked the liaison officer about the availability of the North Face and the liaison officer subsequently contacted Beijing for further information. The response from the CMA officials was that a French expedition had just cancelled their permit for the North Face/ West Ridge in 1984, so Macartney-Snape and Hall grabbed the opportunity.

13 A. Henderson, Interview. 
Suddenly an Australian attempt on Everest had become a reality. And more than that, there was relatively little time to prepare for it. In that sense, Hall and Macartney-Snape would have preferred an attempt in 1986 or 1987, but Everest was booked so far in advance (at that time, with very few exceptions, only one team was allowed on a particular route during a climbing season) that they jumped at the one chance they had, even if it meant that they would have less than three years to get everything ready. Furthermore, waiting a few more years increased the risk that another Australian expedition could have been mounted to Everest or that an American team would succeed on the North Face route that Macartney-Snape and Hall were contemplating for their expedition.

In addition to getting a booking for Everest, their Anyemaqen expedition had uncovered an enthusiastic third member of the Australian Everest team in Geof Bartram. If Andy Henderson's development as a Himalayan mountaineer followed a fairly typical Australian pattern, Geof Bartram's was more unusual. Born in Port Augusta, South Australia, he spent much of his youth in the Northern Territory; he went to high school in Darwin and then worked for five years in Alice Springs. At that time, there was virtually no rock climbingand of course no alpine climbing - in the Northern Territory, so a career as a professional mountaineer would never have entered Bartram's mind.

After his stint in Alice Springs, Bartram travelled to the United States and was quickly attracted to the big snow-clad peaks of the Rocky Mountains. At the age of twenty-seven, he began his climbing career in the Rockies. He then travelled south to climb first the high volcanic mountains of Mexico and then peaks of the northern Andes in Bolivia and Peru. Unlike most other Australian mountaineers, he began alpine climbing immediately with no apprenticeship as a rock climber, and even later, despite a career as a professional mountaineer since 1978, he had done very little rock climbing.

Bartram's professional career began when he became a guide for the American Alpine Institute in Bellingham, Washington. For the next six years, until 1983, his life was almost totally devoted to mountaineering and he lived nearly all of that time on some of the biggest mountains in the world. He spent four to five months of every year guiding in the Andes of Bolivia and Peru and much of the remainder leading Himalayan treks for an Australian trekking company. After 1983, he devoted even more time - more than half of every year - to guiding in the mountains of South America. With scores of ascents of $6000 \mathrm{~m}$ peaks under his belt, Bartram was, by the early 1980s, Australia's most experienced highaltitude climber.

Geof Bartram brought much more than his considerable experience and skill to the Everest team. Despite the fact that climbing had become his work and that he spent most of his time in the mountains, he retained the enthusiasm and 
excitement for mountains of a keen beginner. He was not at all jaded by the professional aspects of his mountaineering adventures; in fact, he approached his trips like an experienced climber taking a group of younger friends into the mountains for a holiday. Bartram exudes that rarest of qualities: contentment with what he is doing with his life. Many of the things that drive people in our society - financial rewards, status, power, fashion and the like - are alien to Bartram. He is simply happy to spend his time climbing mountains. Such a mature, well-adjusted personality is a big asset on a long, difficult Himalayan expedition where danger is always present and tensions are often high.

Bartram's work as a guide endowed him with one other invaluable quality: judgment, or what many like to call 'mountain sense'. When taking paying clients up a high mountain-people who often have an intense desire to reach the summit but do not have the experience to match their ambitions - a guide must temper their enthusiasm and drive with his own ability to judge conditions as the climb progresses, conditions such as snow and ice stability, weather, his clients' strength and fitness and possible dangers such as rock falls or avalanches. Above all, the guide has to keep his clients alive and that often requires making more conservative decisions than a group of experienced climbers might make in a given set of circumstances. Such conservative decision making, which becomes second nature to an experienced guide, is particularly important for the Himalaya, where the enormous scale of the mountains and their potential dangers mean that decisions that would be prudent in New Zealand or the European Alps might not necessarily be so in the Himalaya.

So, at the end of 1981, where did the first Australian expedition to Mt Everest stand? The first big step, and sometimes the most difficult, had been taken. The mountain had been booked. Not only that, the Australians had the good fortune to land one of the last great routes on Mt Everest: the classic line directly up the North Face.

A second major obstacle - that of assembling a group of climbers with the skill and experience to have a reasonable chance of making the ascent-was well on its way to being overcome. The veteran guide Bartram had joined Hall and Macartney-Snape to form a trio of strong, experienced alpinists. With the possible addition of Henderson - who was definitely interested in, but not yet firmly committed to, the Everest trip - the group would be further bolstered. One or two more suitable climbers would complete a team of the ideal size to attempt a lightweight, alpine-style ascent of Everest's north wall.

One large gap in the group's preparation remained - that of experience on the very highest of the world's mountains, those $8000 \mathrm{~m}$ or higher. Bartram had plenty of experience on $6000 \mathrm{~m}$ Andean mountains, but his only attempt on a Himalayan peak ended very low on the mountain, just above base camp, 
with the tragedy on Annapurna III in 1980. Henderson had been on two Himalayan trips, Changabang and Ama Dablam, neither of which was even 7000 $\mathrm{m}$ high. And Hall and Macartney-Snape, the most experienced in Himalayan mountaineering, had climbed only one $7000 \mathrm{~m}$ peak with their last-minute push up Dunagiri in 1978. Everest, however, is nearly $2000 \mathrm{~m}$ higher than Dunagirian enormous difference by any standards. Conditions near Everest's summit would be far more difficult, dangerous and exhausting than anything they had ever experienced. They were fully aware that they needed considerably more high-altitude experience before tackling Everest. So, at the end of 1981, they found themselves with just two years not only to organise and finance the Everest expedition, but to climb mountains higher and harder than Dunagiri, Ama Dablam or Changabang_ideally at least one peak $8000 \mathrm{~m} \mathrm{high}$. 



\section{Tough trials}

The run-up to the 1984 Australian Everest expedition began modestly. Early in 1982, Tim Macartney-Snape, Lincoln Hall and Geof Bartram were back in the Himalaya, this time in the Garhwal region of India. This expedition, however, promised few of the tough conditions they would need to experience before attempting Everest. Their objective was Changabang, only $6864 \mathrm{~m} \mathrm{high,} \mathrm{and}$ they would be acting as guides for six clients from Australia and the United States. They would attempt the original route of ascent across the Kalanka Face and then along the East Ridge - the route that Andy Henderson and his Sydney mates had attempted in 1977. It would be a challenging and exciting climb for the novices, but hardly Everest-preparation material for Macartney-Snape, Hall and Bartram. They soon discovered, however, that well-laid plans could go very wrong in the Himalaya.

Access to their route on Changabang was via the inner Nanda Devi Sanctuary and the only feasible access to the sanctuary was the arduous trek up the gorge of the Rishi Ganga. In early 1982, heavy winter snows made a passage through the upper Rishi Gorge impossible until later than usual. Indeed, as Hall reported, 'One Czech climber [Thomas Gross] was stranded by the heavy snow for a month inside the sanctuary. He survived by following the vultures around looking for something to eat.' ${ }^{1}$ Gross eventually escaped by making an epic descent of the upper gorge in wintry conditions - a trip he described as harder than any climbing he had ever done. ${ }^{2}$

Fortunately, the Australians had not penetrated the upper gorge, but they were nevertheless forced to abandon their plans to attempt Changabang. They diverted instead to Trisul, a peak on the rim of the outer sanctuary that could be accessed without having to traverse the upper Rishi Gorge. At 7120 m, Trisul offered a bit more altitude than Changabang and a straightforward snow route to the summit would give appropriate climbing for a commercial expedition.

At first, things went much as planned, with a series of three camps - the highest at about $6500 \mathrm{~m}$ - putting the team in position for a summit attempt. As they occupied the top camp - a group of three tents - another of the season's intense snowstorms built up during the night and pinned the group to the side of the mountain for three days. Then followed a chain of events, triggered by the increasing intensity of the storm, which nearly led to disaster.

1 L. Hall, Interview.

2 T. Macartney-Snape, Correspondence. 
First, in an effort to get some sleep through the third night of the storm, some of the clients had taken large doses of sleeping tablets and were sufficiently drowsy to impair their ability to cope with the storm. While the three guides hung on to poles and reinforced their own tent, one of the other two tents disintegrated around some of the sleepy clients and tore to pieces. Just getting to the neighbouring tent was an ordeal for the novices as they were blown over repeatedly while crawling across the snowfield.

The situation soon deteriorated further. Despite the weight of six climbers in a three-person tent, the violent gusts of wind literally lifted the tent, forcing the climbers to dive for the back end to keep the tent on the ledge. That proved a futile exercise as that tent collapsed, leaving the beginners on the side of a big mountain in a storm in the middle of the night enveloped in a flapping, formless tent.

There was little the guides could do but provide shelter for as many as possible and try to prevent the onset of panic. Descent was out of the question with no light and an intense storm raging. With a slight drop in wind speed early in the morning, Macartney-Snape, Hall and Bartram ordered an immediate retreat.

The descent itself was fraught with danger, as the heavy snows had obliterated the tracks of ascent and had made the slopes avalanche prone. It was MacartneySnape's uncanny knack to pick his way to safety through a storm - an ability for which he had become well known among his colleagues - that saw a disaster narrowly averted and the battered group safely down to camp two.

From there the team continued the descent to camp one, with the guides allowing one client to ski the easier terrain down to the camp on the condition that he came behind and stuck to their tracks. Bartram and Macartney-Snape set off with the rest of the group, leaving Hall to bring up the rear. On arrival at camp one, both Hall and the client on skis were missing. After an hour's search in the mist, Hall was located but not the skier; it was assumed that he had gone all the way to base camp.

There was no improvement in the weather the next day so the guides decided that the team should stay at camp one another night to allow the exhausted clients time to recover from the ordeal of the storm at camp three. On the rest day, Macartney-Snape set out for base camp to check on the missing skier, but only half an hour out of camp he turned back due to the threat of travelling alone in what he perceived to be dangerous avalanche conditions. Nearing camp, Macartney-Snape heard a faint cry and further yelling led him to the lost climber, who had dug himself into a hole in the snow. He had sustained some frostbite and seemed to be suffering from mild cerebral oedema, which could be fatal if the victim could not be lowered quickly. As he was incapable of walking well, he was helped down the mountain. 
What had begun as a straightforward commercial expedition - one with, on the surface, little potential for rigorous Everest training - had turned out to be a surprisingly tough trial. Macartney-Snape, Hall and Bartram had been forced to deal with violent storms, altitude sickness and frostbite-conditions that often occurred on Everest. One ingredient, however, was still missing: extreme altitude. For that they would have to return to the little Himalayan kingdom of Nepal, which had the highest concentration of the range's $8000 \mathrm{~m}$ peaks.

Hall and Macartney-Snape had spent much time in Nepal leading treks for Australian adventure-travel companies in addition to participating in their own mountaineering ventures. The most popular of all the treks in Nepal, and one they had often led, was the circumnavigation of the great Annapurna massif.

In a land of spectacular mountains, Annapurna stands out as one of the most impressive of all. Set immediately to the north-west of the central Nepalese town of Pokhara - a decidedly tropical community just $850 \mathrm{~m}$ above sea level- the Annapurna Himal rises precipitously in a $20 \mathrm{~km}$-long crest of icy peaks $7000 \mathrm{~m}$ high and higher. Nowhere else on Earth does such a massive line of mountains rise so abruptly from such a low base.

On just the first or second day out from Pokhara, even the most casual of trekkers cannot fail to be impressed by a beautiful black rock pyramid soaring above the eastern end of the Annapurna Range (see image 10.1). Experienced mountaineers are equally taken by a clean spur that drops directly from the mountain's summit down the South Face. It is one of the classic, direct lines that climbers so admire.

The mountain, Annapurna II, was thus well known to Hall and MacartneySnape, who had often walked under it and looked up at that prominent spur on the South Face. As they thought more and more about preparing for Everest, Annapurna II looked a most attractive proposition. It was $7937 \mathrm{~m} \mathrm{high,} \mathrm{nearly} \mathrm{at}$ the $8000 \mathrm{~m}$ mark and much higher than anything they had previously attempted. In addition to giving them the much-needed extreme altitude experience, it had seldom been climbed and none of the previous ascents had been by the striking South Face route. They would get a good degree of hard, technical climbing and the challenge of the unknown thrown in with extreme altitude-just the right sort of preparation for attempting a new route on Everest.

Bartram was unavailable for the expedition, set for the second half of 1983 , but Andy Henderson was available. By that time, Henderson had decided to go on the Everest expedition and was therefore keen to join Hall and MacartneySnape for the warm-up on Annapurna II (see image 10.2). To that trio were added Mike Groom, one of the clients from the Trisul expedition the previous 
year, and Greg Mortimer, who, like Bartram, was a very experienced and highly competent Australian climber. Though experienced in the Andes, the European Alps and New Zealand, Mortimer had been on no previous Himalayan trips.

The Annapurna II expedition turned out to be quite an introduction to Himalayan climbing for Mortimer. In addition, it was a very tough Everest test indeed for the entire team - a trial by exceptional danger, even by Himalayan standards - and provided extreme discomfort from the very start of the trip.

For most expeditions, the walk in to base camp is an enjoyable and relaxing experience. Most Himalayan climbing trips begin with a ramble through the foothills, where the weather is mild and the colourful Nepalese village life makes the journey an interesting experience in its own right. Altitude is usually gained at a gradual, comfortable rate - just the sort of acclimatisation needed before the rigours of climbing. There are invariably spectacular views of the mountains as the climbers approach, creating an air of excitement and anticipation. Finally, the trek leads up to high, open valleys about 4500-5500 $\mathrm{m}$ in altitude, tucked under the high mountains, where a grassy meadow can often be found as an ideal site for a base camp. The trek usually takes a few weeks and provides an ideal transitional period from the rush of the last-minute organisational tasks to the isolated, monastic life in a high-altitude climbing camp.

The five Australians heading for Annapurna II, however, were denied virtually all these pleasantries of the standard approach march. Not only was their trek unusually short - about a week long - because of what Hall described as a place where 'the geographical formality of foothills has been forgotten', ${ }^{3}$ they had no choice but to follow a deep, jungle-choked gorge to the foot of Annapurna II. There simply was no gradual gain of altitude and no high, grassy alp from which to base their attempt on the mountain. Their base camp, established in a clearing at the end of the gorge, was at the ridiculously low altitude of 2600 m-not much higher than Mt Kosciuszko. That meant more than 5000 vertical metres of climbing to the summit.

The week-long march itself was generally unpleasant, with Hall making reference to 'oppressive...muggy heat', 'sidestreams dangerously swollen by the monsoon rains', 'struggling through giant stinging nettles' and 'plucking dozens of leeches from our bodies'. ${ }^{4}$ Thrashing through dense jungle instead of strolling along mountain paths was bad enough, but having to do it during the heavy rains of the monsoon made the situation almost intolerable. As with the route, however, they had little choice as to the timing. The best weather for a post-monsoon attempt on a big Himalayan mountain is immediately after the

3 Ibid.

4 Hall, L. 1985, White Limbo, Weldons, Sydney, ch. 3. 
rains clear and before the high winds and intense cold of winter set in, so the walk in has to be completed during the monsoon so that the team is in position to begin climbing just as soon as the weather stabilises.

For Hall, Macartney-Snape, Henderson, Mortimer and Groom, the climbing began during the monsoon, for the only way to progress beyond base camp was to struggle up through the steep jungle at the end of the gorge. It was not the start to an expedition that Macartney-Snape was accustomed to:

We had just climbed a 1,000 metre cliff overgrown with bamboo and a rich variety of other exotic herbage that grew in the black soil which clung in patches to the near-vertical mountainside. Being in the wettest region of Nepal during the monsoon means that it rains a lot, and the cliff face was the wettest place any of us had ever been. If it wasn't raining from the clouds, it was raining from the sodden vegetation, so we got used to being wet all the time.

It was a week since we had left Kathmandu and it seemed ludicrous that climbing had already begun. The previous day, we had arrived at a small clearing in the jungle and the porters had made it clear that it was indeed Base Camp. Base Camp? But we were still in low altitude moss forest, warm, humid and crawling with every imaginable insect. That night one of them crawled into my ear. It was probably minuscule, but it felt like an irate crocodile. ${ }^{5}$

One benefit at least of having a very low, uncomfortable base camp was that it encouraged the group to climb immediately out of the jungle at the end of the gorge and set up an advanced base camp much higher in the cirque at the head of the river - a camp much more practically located from which to stage the high-altitude climbing. With the help of a local porter, they promptly found a way up the vegetated cliffs and, in a series of stages, climbed out of the dense vegetation, up precipitous bluffs and across alpine herb fields to set up advanced base camp on a grassy meadow at $4700 \mathrm{~m}$.

The climb to advanced base was not a trivial exercise, as Hall remarked that 'carrying loads of food and equipment up to the depot was done in perpetual mist. It was almost a protective cloud, preventing us from seeing the extent that the cliffs rose above us and the doom that awaited us should we slip during the muddy climb'. ${ }^{6}$

It was a hard two weeks of work to establish and supply advanced base camp, but it was a great psychological boost for the climbers to be above the jungle and

5 Macartney-Snape, T. 1984, 'Success on Annapurna II', Wild, no. 12 (Autumn), pp. 38-41.

6 Hall, White Limbo, ch. 3. 
in a position to grapple with the more familiar problems of cold, high altitude and difficult rock and ice climbing. 'We had been mentally preparing ourselves for this stage of the climb for months. It was a relief for us to face these familiar challenges and to leave the rain and mud and leeches behind,' Hall said. ${ }^{7}$

During the load carrying up the head of the gorge, the climbers had a chance to glimpse some of the dangers that Annapurna II had in store for them higher on its flanks. Macartney-Snape recalled:

[W]e had tasted a sample of the awesome character of our surroundings, the most impressive being 'the Generator', a gigantic avalanche chute. What made it special was that several times a day thousands of tonnes of ice would fall down its 3,500 metres, with a cataclysmic roar. In one way or another, the mountain never let us forget how small and insignificant we were. ${ }^{8}$

'The Generator' was a fair warning for what was to come, as the climbers, particularly Hall, were about to experience dangers the likes of which they had never seen, and would never see again. Annapurna II certainly lived up to the reputation of the entire massif as one of the most dangerous places in the Himalaya. Statistically, Annapurna I is the most lethal of the world's $8000 \mathrm{~m}$ peaks, and, as the Australian expedition to Annapurna III learned tragically in 1980, the other peaks in the range are not much safer.

Above advanced base camp, the route on Annapurna II led across a glacier and then up a $300 \mathrm{~m}$-high rock cliff to a long, sloping shelf bedecked with another glacier, flowing parallel with the edge of the shelf. From there, the climbers could either cross the second glacier and ascend directly up a basin to a col below the prominent spur leading up the final rock pyramid or reach the col by a much more circuitous route along the long shelf and then up a small ridge on the adjacent glacier that connected the end of the shelf to the col. Mortimer and Henderson reconnoitred the former but found it too threatened by avalanche so the longer route, despite the extra effort it implied, was chosen.

With that decision made, the climbers, with help from Narayan Shresta and Lobsang Tenzing Sherpa, two of their Nepalese staff, began the tiring task of hauling loads up the long, glaciated shelf to camp one - a pair of snow caves in a hollow at the end of the shelf. As it would be an important staging post for the final assault on the summit pyramid, camp one was made as roomy and comfortable as possible and thus dubbed 'Hotel Annapurna'. The carry to camp one was most demanding, however, as it entailed a gain of 1000 vertical metres in addition to the long climb up the diagonal shelf, which was steep in places.

7 Ibid

8 Macartney-Snape, 'Success on Annapurna II'. 
Beyond camp one there were again two possible routes. One led up a sharp ridge and then dropped to the col, while the other dropped off the ridge and followed a glacier to the base of the col. Following the ridge itself was undoubtedly safer from avalanche threat, but the climbing was more difficult and it involved gaining unnecessary altitude that would have to be lost. The climbers therefore generally opted for the easier glacier route, if they judged the avalanche danger from the flanks of the ridge to be low; otherwise, they were forced onto the ridge route.

Just as camp one was well established and it looked like steady progress could be made higher on the mountain, Annapurna II again showed its deadly nature. The first attempt to reach the col was beaten back by bad weather, forcing the climbers down to Hotel Annapurna. Just before reaching the snow caves, they had to climb a $50 \mathrm{~m}$ rock cliff, which they had descended in the morning to gain the glacier. To expedite their return, they had left a rope in place on the cliff.

Hall was the last person up the rope, and as he began to climb, a rock fall showered down on him from the top of the cliff. He was very lucky to survive. Macartney-Snape described Hall's appearance after the accident:

[H] e staggered into camp looking a frightening sight, with a bloody face and shoulders, his pack covered in rock debris and his helmet cracked like an eggshell. We helped him into our tent and took his gear off to look at the damage. Nothing obviously broken, but plenty of bruising, and he was in a state of shock. ${ }^{9}$

That close call was only the first of several. As Hall recuperated in Hotel Annapurna, the others pushed on to the col at $6600 \mathrm{~m}$ and set up camp two- a snow cave (see image 10.3). Over the next few days, they carried food and fuel to the cave to stock it in preparation for the summit attempt. They then decided to retreat to advanced base camp to rest for a few days before going all the way back up to the top.

On the way down, they stopped at Hotel Annapurna to pick up Hall, who had recovered enough to follow them down to advanced base. Just after they began the last leg of the retreat, Annapurna II unleashed another near-fatal assault and this time Macartney-Snape was the victim:

I got off the crest of the ridge below Hotel Annapurna. It had been snowing heavily and I was really worried about avalanches, particularly at a place 100 metres down the ridge where there was a steep icy base. Suddenly I felt very uneasy on the slope I was descending. The snow was getting deep and heavy. Then, with a heart-stopping, menacingly soft 'crump', 
the snow slope parted from the mountainside. It doesn't take long for a slab avalanche to start breaking up, and if you are standing in soft heavy snow that is vibrating, you soon become inextricably engulfed in it.

\section{In the Annapurna firing line \\ Lincoln Hall}

A few hundred metres below the Col the weather, which had been deteriorating all morning, became so bad that we were forced to dump our loads and head back to Hotel Annapurna. A short way before camp we were faced with climbing a fifty-metre cliff we had descended that morning to reach the glacier. We had left a rope in place, so it was a simple matter of climbing the rock with the rope for safety and as an aid. Only one person could climb the rope at a time. A blizzard was blowing when I, the last of us, began to scramble up the cliff. Because of the bad weather the others decided not to wait for me but to continue to the nearby camp.

A short way up the rock I put my weight on the rope. To my horror it immediately went slack. Before I had time to think I heard the rumble of rocks falling down the cliff. The rope had pulled loose some boulders. I flattened myself against the wall with my arms crossed over my head. Rocks showered around me, large pieces striking my right foot, my arms and my helmet with sickening force. When the dust subsided I checked that all parts of my body appeared as they should be. The pain from my arm and foot was already intense. I realised that I had to get back to camp before the shock wore off and the pain incapacitated me. Only determination got me to the top of the cliff. On the glacier again the wind and snow blew unobstructedly - with darkness approaching it was dangerous weather for an injured person to be away from camp alone. I hobbled back to Hotel Annapurna, already mentally accepting that the climb was over for me. At the snow cave the others were shocked by the sight of me-clothes and rucksack torn, my glasses broken and my face covered with blood. Luckily my injuries were not as serious as my appearance suggested. My helmet had been split, and it was that combined with my quick reactions which had saved my life. On my return to Australia an X-ray confirmed that a bone in my foot had been broken. For the rest of the climb my stiff mountaineering boot acted as a perfect splint.

[About 10 days later, after he had recovered sufficiently to take part in the climbing again, Hall and the others were forced by bad weather to retreat, this time to advanced base camp].

We continued down to the place we had climbed up and down earlier. To our horror we saw that the whole nature of the route had changed because the tremendous weight of the ice pushing the glacier down had pushed it sideways to the edge of the cliff. Huge blocks of ice teetered above our route ready to fall at the slightest nudge from the glacier behind. An ice avalanche had swept away the ropes we had left in place. Fortunately, by abseiling down the one rope we had with us, Tim was able to reach the tangle of ropes caught in the gully lower down. From there he made his way to the bottom of the cliff.

While we were waiting for Narayan to follow, a lump of ice the size of a television set bounced down the slope towards us. I was standing on the edge of the cliff and had nowhere to go. The block bounced straight towards me. I was able to jump over it, but caught a glancing blow to the thigh before it disappeared over the edge. We stared nervously at the blocks the size of trucks that were poised over us.

By the time I abseiled down to the others my thigh was so swollen and painful that I could not walk. My companions pushed, pulled and carried me down the glacier to Advance Base Camp where I spent a second week as an invalid.

From White Limbo, 1985, Weldons, Sydney, pp. 61-3. Re-published in May 2007 by Random House Australia. 
This all flashed through my mind as I struggled to get off an unwanted ride. I was very aware of the 500 metre cliff looming up below me, but it was like trying to run in a dream. I don't really know how serious the situation was, but I managed to get off. To our great relief, the slope we had been worrying about had already avalanched. ${ }^{10}$

Later the same day, it was the luckless Hall's turn to again be in Annapurna II's firing line. When they reached the point on the shelf glacier where they crossed it and descended fixed ropes to advanced base, they were shocked to discover that the entire glacier had moved. According to Macartney-Snape, 'crevasses had opened up where there had been none, the ice had advanced laterally toward the edge of the cliff, and easy-angled slabs had been replaced by crumbling seracs'. ${ }^{11}$

The most horrifying discovery, however, was that the ice had spilled over the edge of the shelf and ripped out the fixed ropes, which had been left as a tangled mass caught in a gully some distance below the top of the cliff. Working feverishly on the end of a climbing rope directly under the threatening seracs, Macartney-Snape was able to retrieve some of the rope and devise a makeshift line down the steep sections of the cliff. It was then the turn of the others to descend.

Narayan Shrestra, one of our two Nepali friends and high altitude Sherpas, was down next. As he was getting to the bottom, small blocks of ice whistled past, one piece glancing off his helmet. Before it had broken into smaller pieces, the same ice block had nearly knocked Lincoln from the cliff top. The sound of everyone scattering had made him look up to see a television-sized piece of ice bouncing straight at him. He jumped it and it glanced off his thigh. When it was his turn to descend, he could hardly move his leg. By the time we were all down the rock and had dragged, pushed and carried Lincoln across the lower glacier to Advance Base, it was well after dark. ${ }^{12}$

The mountain continued to torment them at advanced base. A snowstorm during the night overloaded the kitchen tent. It collapsed under the weight of the fresh snow and pulled a rock down on Tenzing, who was asleep at the time, gashing his scalp. The heavy snow also collapsed Mortimer's tent and soaked his sleeping-bag.

The bad weather continued, forcing a much longer stay at advanced base than the team had planned. It was at this stage of the expedition that the climbers 
could have decided that enough was enough and headed home with everyone still alive. After all, they had learned that Annapurna II was an extremely dangerous mountain, they were repeatedly frustrated by bouts of bad weather and Hall had been injured twice - and was lucky to have escaped death both times. To top it off, the enforced stay at advanced base had exhausted their food supplies. Facing those circumstances, many other expeditions would have called it a day.

Macartney-Snape, Hall, Mortimer, Henderson and Groom, however, did not give in and showed instead a good deal of those old-fashioned qualities of persistence and patience - qualities that would serve them so well on their Everest attempt a year later. The first problem was food and everyone but Hall, who was recovering from his second round of injuries, made the $3000 \mathrm{~m}$ descent to the valley to obtain more food and then the long climb back up in only two days. This was an unusual psychological experience - to descend into the warm, thick air of the green lowlands during the middle of an expedition. As Macartney-Snape admitted, 'the comforts in the land of the living almost tempted us to stay'. ${ }^{13}$

After their return to advanced base and with the clearing of the weather, patience was needed. Time had to be allowed for much of the new snow to avalanche off the mountain and leave their route safe, or at least as safe as any route could be on a treacherous mountain such as Annapurna II.

Finally, after Mortimer had done a difficult and rather dangerous day's climbing to retrieve some of the rope mired at the bottom of the original route up the cliff, the team was ready to push back up again - this time determined to continue until they reached the summit. The deep, fresh snow made the trip up the shelf and then across the glacier to the col extremely exhausting work. It took the group three days to push beyond the col to the $7000 \mathrm{~m}$ level, at the base of the final rock pyramid. There they dug a snow cave - their highest camp-from which they could launch their final push to the top.

At this point, Narayan, Tenzing and Groom headed back down to leave Macartney-Snape, Hall, Mortimer and Henderson to make the summit attempt. It was a blow to Groom to have to descend since he had climbed extremely well in only his second Himalayan expedition, but it had been understood from the start that only two pairs would go for the top and, unless something happened to one of the more experienced climbers, Groom was the one to go down. Nevertheless, the Annapurna II expedition was a most valuable experience for Groom, who a few years later pulled off one of the most remarkable Australian Himalayan successes on an even bigger mountain. 
From the snow cave, it was still nearly $1000 \mathrm{~m}$ to the summit and even the everoptimistic Macartney-Snape realised they could not do that much climbing on steep and difficult terrain in a single day. They therefore set out with food, stoves and sleeping-bags in readiness for the inevitable bivvy.

The rock was friable with virtually no ledges, which meant it was difficult to climb and, with no suitable places to bivvy, the climbers, as much as possible, followed snow leads up the spur. Still, they made frustratingly little progress and at the end of the day with no ledge in sight, they decided to stash the food and extra climbing gear and retreat to the snow cave.

It turned out to be a wise decision, as they were hit almost immediately by a storm first of snow and then fierce winds that pinned them in the cave for five days. It was, as Henderson recalled, 'undoubtedly the low point of the entire expedition. We couldn't even get outside the cave to relieve ourselves. ${ }^{\prime 14}$ In addition to causing extreme discomfort, the stormbound days in the snow cave did little for the climbers' fitness. In fact, it began the process of slow deterioration that came with extended periods at very high altitudes.

When the storm finally abated, there was another opportunity for a quick retreat - an option that many other groups would have taken. Again, however, Macartney-Snape, Hall, Mortimer and Henderson doggedly set out for the topthis time in style: in the darkness and bitter cold of a predawn start.

They made steady progress up the spur, passing their previous high point by mid-morning. By the time they reached $7500 \mathrm{~m}$, however, the pace slowed considerably. Hall remembered the difficulty of climbing at that altitude:

Every step which was in any way awkward required a few extra breaths for concentration. Every pull up was a real exertion. The way to cope with the enormity of the climb and the effort it demanded was to take each small problem as we reached it, and deal with that without worrying about all that lay above. ${ }^{15}$

Nightfall found them well short of the summit and they were forced to dig tiny ledges in the only patch of snow they could find. They tied themselves to pitons driven into cracks in the rock to prevent themselves from sliding off the ledges during the night (see image 10.4). To keep the threat of dehydration somewhat at bay, they cradled the purring gas stoves on their laps and melted snow far into the night.

The next day, they thought, would surely bring the summit and release from the struggle of steep, difficult climbing at lung-bursting altitudes. Just above

14 A. Henderson, Interview.

15 Hall, White Limbo, ch. 3. 
the bivouac ledges, however, a $100 \mathrm{~m}$-high gully of exceedingly steep, loose rock was the only route to easier-angled slopes below the summit. The climbing in the gully would have been difficult at sea level, but above $7500 \mathrm{~m}$ it was utterly exhausting. Only a last-ditch effort by Mortimer got a rope to the top of the gully, but they had used an entire day to climb just $100 \mathrm{~m}$ and were forced to retreat to the makeshift ledges for yet another night.

Again, the temptation to descend must have been strong. They were near the end of their strength, they had made extremely little progress, the summit seemed just as far away as ever and they had little food left. Furthermore, there was always the possibility that the weather, which had been uncharacteristically good for a few days, would break at any time. Even the usually indestructible Macartney-Snape was feeling the effect of their demoralising day in the steep gully:

All through the day I had had lapses of consciousness lasting half a minute or so and had to spend most of it huddled in a windy enclave halfway up the corner. The lapses of consciousness were probably due to an imbalance in my bloodstream caused by the strenuous activity of the day before, the altitude, and by not eating and drinking enough. ${ }^{16}$

Somehow, after another extremely uncomfortable night on the tiny ledges, the foursome dredged up enough energy to climb back up the rope to the top of the steep gully and then struggle on up the relatively easier terrain above. At $2 \mathrm{pm}$, they stood just below the summit cornice, having completed a remarkable first ascent typified by an almost superhuman determination to overcome any obstacles the mountain could throw in their way. There was no time to relax and congratulate one another, however, as they still faced a long, steep descent to get off the summit pyramid.

Just as it had done earlier in the expedition, Annapurna II struck them on the descent with a sudden ferocity. As they were nearing the top cave, the climbers were engulfed in a violent electrical storm. 'We were within clouds that began discharging. There was enormous energy all around us,' Henderson said. 'My glasses were arcing from frame to frame, and there were flashes of lightning on our ice axes.' ${ }^{17}$

The horror descent continued below the snow cave. More wind and snow buffeted them as they climbed down from the col to the shelf. With little food and fuel left, they were weakening rapidly. Avalanches were tumbling around them with alarming frequency and the shelf glacier had again changed beyond recognition. When they finally reached advanced base, they found it deserted; the local staff

16 Macartney-Snape, 'Success on Annapurna II'. 
had retreated to the valley floor. Finally, the four summiters descended the last $3000 \mathrm{~m}$ to the valley floor - much to the relief of Narayan, Tenzing, Groom and the others, who had become extremely anxious about their safety given the long time it took to climb the mountain. Their safe descent was also a relief to friends and relatives in Australia, as an earlier report had reached Australia that Macartney-Snape, Hall, Mortimer and Henderson had been given up for lost and were presumably dead.

\section{Escape from Annapurna}

\section{Tim Macartney-Snape}

Clouds mushroomed around us. Familiar with the mountain's capability for producing surprises, we were now very anxious to get down. We finished the final abseil as darkness fell, and the first signs of electricity became obvious just before we got back to the snow cave. There were metallic tastes and odours in the air, a buzzing and crackling about our equipment and bodies, and the blinding flash of very close lightning. With the weak rays of a headlight, we found the snow cave and bundled in. The thin walls did nothing to lessen the blinding flashes.

We used our second last fuel canister to boil the billy dry. At 1 am thirst woke us, and we all wondered what had happened to the first brew! The next day we stumbled down to the col. We were back to luxury again. The wind shook the tent and spindrift hammered the walls, but they were kept out, and only the sun's warmth came in. As we lay in a disordered heap, our world seemed briefly benign. That night heavy clouds engulfed us and a blizzard began. It was snowing heavily as we left the col next morning. Snow lay menacingly deep on the mountainside. Conditions were exactly wrong to be descending in, but we had no choice: food and fuel were very low and our bodies were weakening. Our fatigue was astonishing; our disinclination to move was almost overwhelming, and all day our nerves were under constant strain. Spindrift avalanches hissed around us, and every few exhausting steps the snow slope settled with that heart-stopping 'thump'. That was the worst day any of us had spent in the mountains. Until the following day...

It continued to snow overnight, and after digging Andy out from the snow cave (we had slept in the tent), we discovered how it was possible to take an hour of hard work to move across 100 metres of level snow. The glacier above the rock barrier had now changed beyond recognition. It was composed of crumbling seracs capped with a metre-and-a-half of soft snow and it overhung the rock barrier. Our progress was ridiculously slow. Hunger, thirst and exhaustion were starting to cramp our style. We spent a wet night above the barrier. In the morning I waded across the top of the serac we were camped on to see what it was like at Advance Base. I peered over the edge and couldn't believe it, I didn't want to believe itAdvance Base was a clean unbroken fold of untrodden snow on the mountainside, no tents, no people, and maybe no food! As we discovered later, the porters had come on time and our Sherpas had decided not to waste money, so everything had been taken down to the nearest village. Maila Tamang, our exceptional cook, had waited for us, together with a local porter, but when it snowed almost a metre, the porter became so frightened that Maila was forced to take him down. However, he did leave the cake he had baked especially for our return.

It is hard to describe the feeling when, after spending days on end during which your survival is questionable, you suddenly know you have got through and are going to survive. The world is suddenly more beautiful than ever. It took us a whole day to reach Advance Base-in better days it had taken just over an hour. Despite still having a gruelling 3,000 metre descent to get off the mountain properly, we knew we had made it, and euphoria, clouded by exhaustion, overcame us. We thought of the conversation we had had back in Kathmandu, while we were staying in the house of our friend, Kunga Sherpa, Greg had described how traumatic it had been to turn 30 and Andy had replied, 'What do you mean, I will be extremely glad to turn 30.' We youngsters looked hard at each other and nodded in agreement. 
In addition to being quite a significant climb in its own right, the ascent of Annapurna II was the perfect trial for Everest. It was much higher than any mountain any of the climbers had previously attempted (in fact, it was the only mountain higher than Dunagiri, ascended by the ANU team in 1978, that an Australian expedition had climbed at that time) and it offered challenging climbing at the highest altitudes. The level of danger and discomfort was very high, even by Himalayan standards, which gave the Australians just the sort of gruelling mental experience they needed before tangling with Everest. Perhaps most importantly, it gave Greg Mortimer, the fifth member of the Everest team, a chance to climb in Himalayan conditions with Macartney-Snape, Hall and Henderson. As noted earlier, it was Mortimer's first Himalayan expedition at all, for although he was asked to join in the 1981 expedition to Anyemaqen, he was unable to participate due to other commitments.

Mortimer's addition to the Everest team added the final touch of experience, ability and compatibility that strengthened the group sufficiently to have a realistic chance of climbing the mountain. Although he was completely unknown in Himalayan climbing circles, and indeed not all that well known among Australian climbers, Mortimer, like Bartram, had quietly become one of the country's best mountaineers - in fact, a very good climber by any standards.

The Boy Scouts was Sydneysider Mortimer's introduction to the bush. By the time he was seventeen, he had become an avid Blue Mountains rock climber and, like many of his climbing friends, he heard casually from others about climbing the snow and ice peaks of New Zealand. From those tales and stories told around the cliffs and campfires of the Blue Mountains, Mortimer developed a curiosity about mountaineering and soon made his way to New Zealand.

Although he wisely concentrated on easy ascents and pass crossings on his first trip, Mortimer became hooked on climbing big mountains and went back to the Southern Alps repeatedly in subsequent years. His big breakthrough in climbing came with a two-year burst of activity in Europe and North America. He climbed almost continuously in the big alpine mountains around Chamonix and in the rugged Dolomites of Italy; he tackled some of the hardest rock climbs England and Scotland had to offer; and he climbed in the mecca of big-wall climbing: the Yosemite Valley of California.

Mortimer also had a flare for the less-frequented and more unusual climbing venues around the world. He travelled to Africa and climbed the Diamond Couloir, a spectacular ice route high on Mt Kenya, and he made the first traverse of Balls Pyramid, an isolated spike of rock jutting out of the Pacific Ocean east of Australia. Antarctica, too, held a fascination for Mortimer, who first made a visit to the continent shortly after joining the New Zealand Antarctic Division as a geologist in 1979. 
Before the Annapurna II expedition, the highest peaks that Mortimer had climbed were in the Peruvian Andes of South America. During a three-month trip in 1980, he and his partners climbed a variety of peaks of varying difficulties from 5700-6600 m high. The highlights were undoubtedly a technically hard ascent of the South Face of Piramide (5885 m) and the climb of $6637 \mathrm{~m}$ Yerupaja, a spectacular mountain in the Cordillera Huayuash. Mortimer described the latter as

a magical journey with all the elements of a 'real expedition' - the uncomfortable truck ride, haggling with the mule owner, the walk through deep, dry valleys with little mud villages — setting up a campreconnoitring a route on the face - up to 6,400 metres and bivy [sic] on the saddle - up to the summit and quickly back down. We ran out of snow stakes rapping [abseiling] back down, so had to saw the last four in half with a Swiss army knife. ${ }^{18}$

It was on one of Mortimer's much earlier trips to New Zealand, in 1974, that he met Hall and established the connection that later would lead to his inclusion on the Everest team. That was Hall's first trip to New Zealand and he recalled climbing with Mortimer: 'Following him up mountains had left me impressed and scared, and determined to restrict myself to the safe warm granite of my home cliffs.' ${ }^{19}$ Of course, Hall did not restrict himself to rock climbing in subsequent years and Mortimer also continued to broaden his climbing skills and experience. Describing the 1984 Australian Everest team, their colleague Geof Bartram, himself a professional mountain guide, remarked, 'Amongst Australian climbers, Greg Mortimer stands apart. He is very, very good technically.' ${ }^{20}$

Just as important as climbing ability to the success of a Himalayan expeditionas has been shown time and time again - is the compatibility of the team members. In this aspect, Mortimer excelled too. Softly spoken and gentle in nature, he was never one to aggressively put forward his point of view or to provoke a confrontation. Hall put it very well:

In every other sphere of mountaineering [outside Himalayan climbing] he was more experienced than any of us. Despite that, in discussions of tactics away from the mountain, he offered his opinions only when invited, as if he were storing his ability to make instant decisions during the climb...The gentleness of his everyday manner was balanced by the

18 New Zealand Alpine Journal, vol. 36 (1983), p. 60.

19 Hall, White Limbo, ch. 2.

20 G. Bartram, Interview. 
aggressive determination of his climbing. This aggression was directed at himself, allowing no space for fear or hesitation to interfere with his judgement. That approach made him a very strong mountaineer indeed. ${ }^{21}$

Mortimer was linked with three other strong mountaineers on the impressive ascent of Annapurna II. That climb showed that the Australian team to attempt Everest would be a formidable one, a group that could overcome all sorts of adversity to persist until they put someone on the summit. The Annapurna II team was, however, only four-fifths of the Australian Everest team; Geof Bartram was absent. Bartram had planned an Everest trial of his own a few months later, leading a guided ascent of $7145 \mathrm{~m}$ Pumori in the Everest region of Nepal.

Like Annapurna II, Pumori is an eye-catching peak along a popular trekking route. A beautifully symmetrical obelisk of ice rising as a sentinel guarding the Khumbu Icefall and Western Cwm of Mt Everest, Pumori stands at the end of the normal trekking route to the Everest region. In fact, Kala Pattar, the hillock most trekkers climb for the classic views of Everest, is a small outlier on the South Ridge of Pumori. This makes access to Pumori, unlike that to Annapurna II, quite easy - ideal for a guided party such as the one that Bartram was leading in early 1984 .

Although Pumori was not as high as Annapurna II, it was still a good test for Bartram, as he had to safely guide six clients up a $7000 \mathrm{~m}$ peak. As he knew from his experience on Trisul two years earlier, taking inexperienced mountaineers up a high Himalayan peak was a very serious business. This time, the trip went smoothly and Bartram not only got all six of his clients to the summit, they climbed the mountain by a new route on the South-East Face. As a bonus, the group was treated to continuous views right up the Western Cwm of Everest as they climbed to the summit of Pumori. So, Bartram too was coming off an impressive success just before the Everest expedition.

It was just six short years since the ANUMC's trip to Dunagiri-a milestone in the development of Australian Himalayan mountaineering. Now, sooner than anyone had dared imagine, and sooner even than the climbers themselves had wanted, an Australian team was on the verge of departing for Everest. It was a strong and talented team with a string of successes-Annapurna II being particularly impressive - in the lead-up to Everest. The group, however, had a total of only nine Himalayan expeditions under their collective belts and no ascents or attempts on any of the 14 peaks of $8000 \mathrm{~m}$ - yet they were about to embark on one of mountaineering's biggest challenges: an attempt, without the aid of artificial oxygen, to climb a new route on the world's highest peak.

21 Hall, White Limbo, ch. 2. 


\section{Patience and persistence}

January 1984 came all too soon and there was still a mountain of work for the members of the first Australian Everest expedition to get through before they even left for China. The team of five was set-Lincoln Hall, Tim MacartneySnape, Andy Henderson, Greg Mortimer and Geof Bartram-but Bartram was busy organising his commercial climb of Pumori and Mortimer had work and family commitments that kept him in New Zealand, so only Hall, MacartneySnape and Henderson were left to tackle the Everest tasks. Much gear still had to be obtained and shipped to China, high-altitude food had to be purchased and packed and sponsorship and financial support still needed to be obtained.

Financial support, in particular, proved hard to find. Even though this would be the first Australian expedition to attempt Mt Everest- the most wellknown and prestigious objective in Himalayan mountaineering - the sport of mountaineering was so little known in Australia that even an Everest expedition attracted little interest or financial support. The team did get some in-kind support from equipment manufacturers, but it was really money that they desperately needed.

Climbing the northern flanks of the Himalaya from Tibet is strictly controlled by the Chinese Mountaineering Association (CMA) and the all-inclusive, in-country organisation, transport and accommodation services the CMA provides are not cheap. Furthermore, unlike the situation in Nepal, where a variety of trekking/ expedition companies compete for clients and there is much more scope for climbers to arrange their own in-country accommodation and transport, there is no alternative to the CMA in China. By the time the team returned from the Annapurna II climb, they had raised less than one-third of the money they needed for the Everest climb, much of it the fees required by the CMA.

Just when it looked like the whole expedition could be in serious financial difficulty, Sydney's Channel Nine television station came to the rescue (see image 11.1). It decided to bankroll the rest of the expedition's expenses in exchange for exclusive film rights to the climb. Although the Channel Nine support was most welcome to solve the expedition's financial crisis, it raised that old Himalayan mountaineering conflict of interest: the need of the climbers to exercise sound, conservative judgment on the mountain and the requirement of the media representative(s) for a good story or film. It was a situation that had created some tension on the 1978 Dunagiri expedition by the ANU Mountaineering Club (ANUMC). 
The potential conflicts that could have arisen in the Channel Nine-Everest arrangement were mostly avoided at the very outset by the choice of an excellent film crew, many of whom had mountaineering experience themselves and all of whom had previous experience working and living in harsh conditions for extended periods.

Mike Dillon was the obvious choice for producer and cameraman. With 11 Himalayan films under his belt, including four with Sir Edmund Hillary, there was no-one else in Australia more experienced in adventure film-making. He was assisted by Colin Monteath, the veteran New Zealand mountaineer who was the climbing leader of the 1980 Australian Annapurna III expedition, and Howard Whelan, an American expatriate with extensive experience in skiing, climbing, photography and writing. Whelan later became the editor of Dick Smith's Australian Geographic journal.

Serving a dual role as soundman and expedition doctor was Jim Duff, an Englishman with a broad mountain background that included climbing in Britain, Norway, the European Alps, North America, New Zealand and Australia. In addition, he had taken part in expeditions to Changabang and K2, the world's second-highest mountain, and was the doctor on the British ascent of the SouthWest Face of Everest in 1975. As will be described later, Duff also played another part in the Australian Himalayan story.

Simon Balderstone, who joined the expedition as a reporter for Melbourne's Age newspaper, completed the auxiliary group. Balderstone had earlier covered environmental and political issues for the Age and also had a strong sporting, bushwalking and trekking background. He quickly developed good rapport with the climbers - a relationship that served as an excellent model for how mountaineers and media people could work together.

The approach to Mt Everest from the north is quite unlike its counterpart in Nepal from the south. The Nepalese approach is invariably on foot and usually takes a minimum of two weeks and sometimes longer if the trek is begun at Jiri rather than Lukla. It is a time for getting the body used to higher altitudes gradually and to carrying heavy loads, and for making the psychological adjustment from urban Western life to an expedition existence. In China, there is no such gradual adjustment. Transport is by every means other than foot and climbers are treated more like well-looked-after tourists than footloose trekkers.

The Australian Everest team left Sydney for Hong Kong on 16 July 1984 and arrived in Beijing four days later. There they were met by officials from the CMA, who not only helped iron out last-minute logistical snags for the expedition, but 
acted as tour guides, interpreters and transport and accommodation agents. The Australians were shown the Temple of Heaven, Mao's Tomb, a Chinese circus performance and, of course, the Great Wall.

After a couple of days of sightseeing in Beijing, the group travelled to the southern Chinese city of Chengdu, where they spent another day as tourists before taking the flight to Lhasa. Although playing the tourist game in China was pleasant enough, it did very little to prepare the climbers either mentally or physically for the challenge of Everest. As Hall said, 'As we travelled through China there was a real sense of biding our time, of twiddling our thumbs until the action started.' ${ }^{1}$

On 25 July, nine days after they had left Sydney, the team was in the fabled Tibetan capital of Lhasa, presided over by the spectacular Potala Palace. Lhasa lay at an elevation of $3500 \mathrm{~m}$ - high enough to cause altitude sickness for some who flew there directly from low-lying cities, so several days were allowed for acclimatisation before continuing the trip to Everest.

Lhasa also means the end of relatively comfortable transport. From there, progress towards the Himalaya is overland by bus or truck and, as Hall notes, 'the roads in Tibet are amongst the worst in the world-an endless succession of pot-holes, fords, washouts, rockfalls and sand-dunes'. ${ }^{2}$ Beyond Lhasa, the road towards Everest rises gradually, crossing a series of passes that link high basins. It seems that the pass crossings are just as tortuous for Tibetan vehicles as they are for humans on foot. Forced to walk over one such pass with the rest of his colleagues while the lightened bus struggled to get over on its own, Hall remarked that the break from bus travel provided the opportunity 'to realign our heads and shoulders after the hours of continuous shaking'.

The route towards Everest had considerable interest and excitement to match the discomfort. Near the end of the first day out from Lhasa, the group's bus was stopped at the flooded Tsangpo River, where the vehicle ferry had not been able to operate for days. They had no alternative but to trust themselves and all the expedition gear to the flimsy-looking yak-skin coracles, the only craft able to negotiate the river. A couple of crossings and the Australian expedition was again safely on its way.

After passing through the towns of Zigatse and Zegar - the latter with the ruins of a fairytale fortress snaking up a long ridge far above the town - the expedition members had their first view of Mt Everest from the north. For Greg Mortimer,

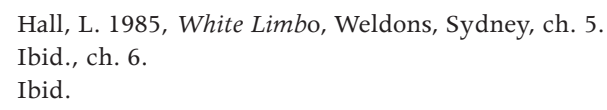


it was his first view ever of the world's highest mountain. 'When we crested the pass we were amazed to see, forty kilometres away, the Himalaya stretched out before us,' Hall recorded:

Cho Oyu, Gyachung Kang, Makalu and, in the middle of them all, Qomolangma-Mt Everest. We stopped the truck and jumped out. The monsoon clouds soon closed in, but not before we were given enough time to appreciate the scale of our objective. The giant mountains of Makalu and Cho Oyu seemed dwarfed. Of all of us, only Greg had not seen Mt Everest before, and he was now adjusting his expectations to the unimaginable reality. ${ }^{4}$

Below the pass lay the entrance to the Rongbuk Valley, which drained the northern aspects of Mt Everest. The Rongbuk was, according to Hall,

appropriately magnificent, gradually narrowing until it was almost a gorge. A thousand metres above us on both sides rose gigantic cliffs. The skyline was a jagged ridge of pinnacles and turrets balanced against the call of gravity - perhaps an example of the power of Mt Everest looming huge somewhere hidden in the clouds at the head of the valley. ${ }^{5}$

Hall's description of the Rongbuk Valley is typical of the many powerful passages in the book White Limbo, his account of the expedition. He achieves a rare combination of colourful and evocative description of the physical scenes around him, riveting accounts of events on the mountain and poignant glimpses of his own thoughts and feelings during his personal struggle with Everest. The three themes are woven effortlessly together. White Limbo is truly a classic of modern mountaineering literature.

Hall and team were, however, still some way from coming to grips with Everest. The entrance to the Rongbuk Valley was a considerable distance from their goal. The expedition's truck crept through the gorge and finally rattled to a stop at a grassy river flat where the defile opened slightly. That was as far as the vehicle could go and so it was, by definition, Everest base camp. It was far too far away from the base of the mountain to be of any use as a climbing camp; in fact, the base of Everest's North Face was still some $20 \mathrm{~km}$ away. Still, base camp was at an altitude of $5100 \mathrm{~m}$ and a few days there sorting and packing gear proved to be useful acclimatisation time.

Although the Australian climbers missed out on the experience of approaching base camp on foot over several weeks, they somewhat made up for it by spending the next few weeks carrying gear and food up the Rongbuk Glacier, first to 
advanced base camp, about $10 \mathrm{~km}$ further up the valley, and then to camp one, set at $5750 \mathrm{~m}$ at the base of Changtse, a northern outlier of Mt Everest. Camp one was still a couple of kilometres from the base of the North Face; anywhere closer would have put the camp in the danger zone for the mammoth avalanches that periodically poured down the face.

The time spent doing all the logistical legwork up the Rongbuk Glacier was certainly not wasted. The climbers were gradually becoming fitter and more acclimatised to working extremely hard at high altitudes. Carrying $30-40 \mathrm{~kg}$ loads over difficult terrain above $5000 \mathrm{~m}$ was exhausting work, but the drudgery was somewhat eased by the immensity of the landscapes they were walking through: the bizarre fin-like formations of the ice on the Rongbuk Glacier, the barren canyon walls near base camp and the magnificent ice peaks that anywhere else in the world would be an impressive range in their own right but in Tibet were just outliers of Everest. Andy Henderson added interest to his spell of load carrying by contriving to have a minor epic on a trip to advanced base camp. His description of the day gives a most realistic account of crossing glacial streams and climbing crumbling moraine walls - the stuff of many a Himalayan expedition.

During the days of load carrying, the team was not losing any valuable climbing time, as to really start climbing on the face would have been suicidal at that time. Monsoonal storms were still dumping snow on the mountain, which it subsequently shed in often spectacular fashion. In one such incident, a huge slab avalanche broke away from a fracture line several kilometres long and slid down the face from $7500 \mathrm{~m}$ to the bottom. The powder snow blown out in front of the avalanche dusted camp one, a couple of kilometres away. That and other such avalanches convinced the team that it would be prudent to work on stocking the glacier camps until the monsoon exhausted itself.

Meanwhile, the large American expedition - the one that had originally wanted the Australians' North Face route and still planned to climb it once the Australians had failed and gone home - was already pushing up the safer North Ridge route. Macartney-Snape visited their base camp, as several of their climbers had attempted the North Face two years earlier: 'Jim Wickwire, one of their leading climbers, was extremely forthcoming with the considerable knowledge he possessed, and was sufficiently impressed to describe our projected route as a Yugoslav or Czech route. In Himalayan terms that is quite a compliment.' ${ }^{6}$

By the mid-1980s, Eastern European climbers, particularly the Yugoslavs, Czechs and Poles, had become well known for their difficult and dangerous ascents of steep face routes; they were the 'hardest' of the hard men who climbed in the Himalaya. 


\section{A day on the Rongbuk \\ Andy Henderson}

Carefully I pulled the 'phones out of my ears, and fumbled numbly with my Walkperson to kill the music which had been filling my head for the past forty minutes. As the chord abruptly cut and the earplugs came out, the subdued sound of the stream in front of me swelled to an intimidating roar.

Upstream, to my left, the water thrashed over a tumble of boulders obscuring any further view from the crossing. The bed of the stream was hinted at by the increasingly steep slopes of mud and rock that flowed up through the layers of cloud, eventually forming the improbable palisades of the East Rongbuk valley, with their shattered rock and hanging gardens of ice.

In front and down stream, the water's behaviour was initially more restrained as it flowed through a series of turbulent pools, before the bed once again dropped steeply, til it was absorbed in the fantastic terrain of the Central Rongbuk. As often happens, the mountain gods had dotted these pools with boulders to ease the passage of travellers, but now the boulders were nearly invisible as soft, grey flakes of snow, untouched by wind, slowly blanketed the smooth rock.

I sighed inwardly, as I recognised all the hallmarks of a developing epic. This little effort, I realised wearily, would confirm my position as expedition bimbo, a role I had been trying to avoid ever since I had managed to con my way onto the trip.

Earlier in the evening I had left Base Camp at the road head after saying farewell to Baldo [Simon Balderston] and our Chinese staff, and headed up to Advance Base Camp with a pack load of food, hoping to reach it without too much drama in about two hours. Actually there was not much really worth calling food at BC, as Baldo had been at some pains to point out, and my pack was, in fact, full of vitamin pills and other dietary supplements. These were all well and good if teamed up with a healthful muesli slice, but were pretty inedible on their own. Baldo, a vegetarian like most of the team, I had left to carry on his lonely struggle with the Chinese, their toilet habits, and telecommunications system, whilst subsisting on a diet of Vitawheats and packet soup. I felt sure his experience as a political reporter, and his proven ability to survive in the surreal atmosphere of the Canberra press gallery, would stand him in good stead.

I decided the normal crossing point was too dodgy, the gazelle-like leaps needed to move from rock to rock being sabotaged by the sludge rapidly accumulating on them. Any unplanned swim at this stage would have been more than embarrassing, so I moved a short way downstream and began to strip below the waist. Whimpering pathetically and wielding a formidable pair of ski-stocks, I shuffled slowly out into the water, feeling a brief flash of pain in the groin, and then a welcome numbness. Flailing desperately with the stocks I fought to remain upright, and finally struggled across the $10 \mathrm{~m}$ to the other bank. It was almost completely dark now, and I was committed to either finding ABC or spending a night out, as recrossing the stream was too risky to make it a going proposition.

At first the falling snow served to outline the path worn by the yaks, making it stand out clearly in the light of my headtorch, but soon the continuing snow obliterated all trace of the track, and I realised with a sinking heart that I would have to rely on instinct in following the trail. As I possess none worth mentioning I felt I had reasonable cause for worry. At this rate I knew I could end up in Nepal if I wasn't careful, but my choices were few, and I ploughed on.

Somewhere, I had to 'turn left' and climb away from the glacier, up onto the lateral moraine where $A B C$ was located. Since I had little chance of finding the actual route, any way up was, within certain limits, as good as any other, so guessing at a likely spot I headed off, up the moraine. 
Within minutes I found myself on a steep slope, loose underfoot, and mushy with snow. Boulders, dislodged by my clumsy feet, rattled down the slope. A period of protracted silliness followed as I ploughed up through the mud and rubble. I continued to entertain a series of guesses as to my location, but none of the options were very pleasant, so I was forced to continue bumbling on, maintaining a steady flow of foul language the whole while. My watch had been broken playing frisbee back in Peking and so I have no idea how long this farce continued, but eventually, to my great surprise and considerable gratification, the slope layed back. Lo! to my complete astonishment a small cairn swam into the light. Stunned by my good luck I plunged smugly forward. Immediately my headtorch, demonstrating a perversity rarely seen in day-to-day life, died, enveloping me in a rich darkness. I stopped moving instantly, fearful of injury, and felt my way to a rocky seat. The silence was wonderful-not total, but with small background noises which contrasted with the stillness, in the same way the stars contrasted with the absolute blackness of the sky. The intensity of the night, as much as the cold, made me shiver a little, so as quickly as possible I replaced two of the three batteries in my headtorch, and watched as a cone of light expanded in front of me.

I was between cairns when the light died again, dwindling rapidly to a misleading glimmer. I could have cried with frustration, as I had no other batteries, but carried on trying to remember the general trend of the track through the heaped moraine. From time to time I would imagine I could see a cairn, only to find it a phantom, or merely a random pile of stones. The idea of spending the night out galled me, not so much because of the cold, which I was equipped to handle, but because of the endless series of jokes I would become the butt of. After four expeditions my greatest attributes were my ability to get lost on glaciers, and an unrivalled skill at rolling joints under adverse circumstances. Would the latter justify sending out a search party? I plodded on, falling down holes now and then to break the monotony, whilst trying to figure out if there was any way I could go badly wrong.

As I crawled out of a particularly nasty hole which I had briefly entertained the idea of bivvying in, a headlamp flashed in the distance, and after much shouting two huge figures homed in on my position. An embarrassed silence settled with the grim snow over our small group.

'Where've you been?' Tim asked.

'Oh, just lost on the glacier again,' I mumbled.

Tim grinned and began fiddling with a Walkie-Talkie he had extricated from the depths of his windsuit.

Jim, flashing a wild and evil smile, proffered a tupperware cup of liquid. I sniffed it suspiciously.

'I didn't think people who had exposure should drink alcohol?'

'You think you're suffering from exposure then lad?' Jim asked.

'Well, not really.'

Jim drained half the mug and passed it to me.

'Finish it off then youth.'

I finished the cup of whisky whilst Tim contacted $A B C$ with our location. Tim replies to a question with 'lost again' and laughter, mixed with static, crackles out of the radio.

'Here we go again,' I think, but it's a warm thought.

From 'Sweet and sour', Mountain, no. 104 (1985), p. 28. 
In addition to being a compliment, however, Wickwire's comment could also have implied that the very small group of unknown Australians was in over their heads.

The line that the Australians had chosen to attempt was certainly a formidable one. Everest's massive North Face is split by two prominent gullies, or couloirs. The narrower couloir on the west side of the face, the so-called 'Super Couloir', was climbed by a Japanese expedition in 1980, but it was the other, larger couloir, the 'Great Couloir', that still attracted mountaineers and had been attempted by a strong American team in 1982. The Great Couloir was one of the last big routes still to be climbed on Everest (see image 11.2).

One of the problems with the Great Couloir route is that only the top part of the couloir can be climbed safely; an ice cliff partway up the gully subjects the bottom half to frequent avalanches and thus makes it extremely dangerous to climb. Getting to the top part of the couloir is not easy, however, and, as the Australian climbers would soon discover, negotiating the bottom part of the face to gain access to the couloir involves some of the most difficult and undoubtedly the most dangerous climbing on the entire face. Everest's considerable defences start at the very base of the mountain.

After much discussion, the Australians opted to breach Everest's lower defences by a steep spur to the right of the ice cliffs. It was more direct but technically harder than the circuitous, easier-angled route to the east that the Americans used in 1982 to gain access to the couloir. Above the spur, the Australians would have to find a way through a rock band and then traverse across a great shelf of moderately angled snow to gain the relatively safer upper reaches of the Great Couloir. It was this shelf of snow, which they dubbed 'White Limbo', that posed the biggest danger. White Limbo was not steep enough to immediately shed new snow, so it was prone, for some time after snowfalls, to send huge avalanches down the face below.

It was late August, three weeks after base camp had been established, and the climbers were finally in position to make their first tentative foray onto the face. They found a cone of avalanche debris to cross the bergschrund, a crevasse that separated the steep face from the relatively flat glacier, and, after years of planning, months of intense preparation and weeks of backbreaking load carrying, finally became the first Australians since George Ingle Finch in 1922 to set foot on Mt Everest.

The climbing was steep - steeper than they had expected-but they soon shook off the tension that came with suddenly finding oneself on steep terrain after months on the level and began to establish the slow, methodical rhythm that was essential to climb at high altitudes (see image 11.3). It was a most productive 
first day. Several hundred metres of rope were fixed up the spur and a few loads were carried up. A second day on the spur pushed the route up another hundred or so metres, where a shallow hole was dug to store the gear that had been hauled up to that point.

Just when it looked like steady progress might be made, the weather broke and heavy snowfalls belted the north side of the mountain. There was no choice but to retreat and the team decided to descend all the way to advanced base camp as it would take several days after the snow stopped for the slopes to become safe again and they did not want to consume the valuable food and fuel stores at camp one.

After so much load carrying on the Rongbuk Glacier, being forced back off the mountain after only two days of climbing could have had devastating repercussions for morale. Hall, Macartney-Snape, Henderson and Mortimer had, however, faced that sort of stop-start climbing on Annapurna II the previous year and had developed the patience to cope with it. They were helped too by the presence of Narayan and Tenzing, who had served them so well on the Annapurna II expedition and had been invited on the Everest trip to help with load carrying lower on the mountain and with camp chores.

'The days passed easily in different combinations of reading, eating, talking and sleeping,' Hall recalled. 'I spent the sunny mornings doing yoga. There was no urgency to do anything. We could afford no room for impatience; attempting to act before the conditions were right would be foolhardy and dangerous. ${ }^{7}$

Conditions had improved enough after a week at advanced base camp that Bartram, Mortimer and Henderson, accompanied by Monteath and Duff of the film crew, moved back up to camp one. On arriving at the tents, they made the first of two nasty discoveries that set back the expedition. The first was relatively minor. The food at the camp had been raided - probably by the furry little rodents called pikas that roamed the Rongbuk - the most serious loss being cheese and some chocolate bars. On the other hand, no-one, particularly Andy Henderson, seemed to lament the loss of some freeze-dried rations: 'I could only hope the freeze-dried macaroni cheese would have the same effect on the little bastards as it had on humans, in which case they would have a short life but a constipated one.'

The second discovery was far more serious. As the three climbers plodded across the neve of the Rongbuk Glacier, they found among avalanche debris bits of the tent and other gear they had stashed at the top of the fixed ropes.

7 Hall, White Limbo, ch. 8.

8 Henderson, A. 1985, 'Sweet and sour', Mountain, no. 104, pp. 28-33. 
That was stark evidence that their route was not safe and that they would have to be extraordinarily careful in returning to the route after snowfalls. Any misjudgment could easily mean the loss of lives as well as of gear.

A further blow came when Bartram, Mortimer and Henderson arrived at the bergschrund at the base of the face. The climbers had left there a stash of gearcrampons, harnesses, ice axes and hammers - that they did not want to haul repeatedly between camp one and the face. The gear had been left on a ledge at the back of the bergschrund, a place they believed to be protected from any conceivable avalanche. The avalanche that obliterated the dump higher on the face had indeed missed the bergschrund in which the gear was stored but after much poking and digging the gear could not be found.

The next day, Hall and Macartney-Snape arrived from advanced base camp and, for the next 48 hours, the scene at the bottom of the face looked more like one from an archaeological expedition than a mountaineering one. A large pit was dug in the most likely spot and subsidiary holes were dug in surrounding areas. Some of the members poked around with ski poles that extended into avalanche probes and Macartney-Snape, acting in desperation on a suggestion from Jim Duff, even resorted to divining for the gear, much to Henderson's amusement:

One of my most enduring memories of the expedition is of Tim solemnly tramping around on this vast cone of avalanche debris 'dousing' for gear with two pack stays lashed together. He had a few problems getting volunteers to work on his random pits, and soon even he had given up. ${ }^{9}$

Nothing worked. After an exhausting spell of digging at $6400 \mathrm{~m}$, the search was called off. Henderson, as usual, saw the light side of the situation: 'In one stroke we went from one of the most hideously over-equipped expeditions ever to leave $\mathrm{Oz}$ to one of the lightest ever to consider Everest.' ${ }^{\prime 0}$

Fortunately, replacements could be found for most of the gear. Some of the climbers had brought spare boots, harnesses could be improvised from nylon webbing and much of the other climbing gear could be borrowed from the film crew, who themselves were climbers and had been equipped by Channel Nine in the hope of ascending partway up the face to do some filming high on the mountain. By then, however, it was obvious that the route, even low on the face, would be too dangerous and difficult for climbers wielding heavy cameras and their accessories. The film crew's climbing gear could therefore be spared.

The one problem that was not readily solved was finding a replacement for Macartney-Snape's climbing boots. None of the film crew's boots came close to

9 Ibid.

10 Ibid. 
fitting his very large feet. He eventually was forced to wear as the inner boots his cross-country ski boots, which just fitted inside a very large pair of 'fabricover boots/gaiters' that Bartram had brought along as spares (mountaineering boots consist of an insulated, flexible inner boot inside a rigid, plastic shell somewhat like a downhill ski boot). Macartney-Snape was able to make them semi-rigid by clipping on an old pair of 'footfang' crampons, thus turning them into serviceable climbing boots. The lack of ankle support, however, gave the boots a tendency to slip off very steep terrain, but once recognised, this problem could be managed. It was far from an ideal solution as it decreased the comfort and increased the risk of frostbite, but Macartney-Snape had no other option.

A period of settled weather followed the cessation of the storm and the big avalanche, so the team made their second foray onto the face. It was an eventful few days, highlighted by some difficult mixed climbing, a case of snow blindness and an unexpected monstrous avalanche that nearly buried camp two before it was even established.

The first priority as the climbers worked their way back up the fixed ropes was to quickly push higher up the wall and find a secure place for the next camp. The one major obstacle - a narrow rock band - was overcome by the skilled Mortimer, who climbed a short gully with one crampon on and the other off to handle the difficult, mixed ice and rock terrain. In climbing the gully, however, Mortimer had taken his sunglasses off for a few hours and consequently contracted snow blindness - a temporary but painful condition that kept him tent-bound for a day or two.

Above the rock band, Hall and Macartney-Snape found a rib of snow that they thought might offer a good spot for camp two (see image 11.4). They decided to put in a snow cave at $6900 \mathrm{~m}$ on the rib. It was a long way from camp one, but there was no feasible place lower. As compensation, the rib had commanding views of the Rongbuk Valley and the peaks to the north and west of Everest. More importantly, being a raised ridge off the face, it gave considerable protection against avalanches; any slide would be split by the continuation of the rib above and would be funnelled into the Great Couloir on one side or onto White Limbo on the other.

Just as Hall was working on the snow cave, an avalanche of truly Himalayan proportions cut loose from somewhere higher on the mountain and poured over the lower face, filling the couloir, scouring White Limbo and blasting right over the top of the rib as well. Hall was nearly buried at the camp two site and Mortimer and Macartney-Snape, who were coming up below, saved themselves by clinging desperately to the fixed ropes. Obviously, nowhere on the lower 
part of the face was completely safe from avalanches of the size that Everest produced, although camp two was hit only by airborne snow, with the more solid snow passing on either side.

\section{Dicing with death on Everest's North Face \\ Lincoln Hall}

The snow was deep and firm, in perfect condition for a snow cave. Tim headed back down to fetch another load and to help Greg, while I set about digging the cave.

The first task was to dig a ledge across the Face, wide enough and long enough for us to sit on while we attached our crampons to our boots, and so that we could lounge about and enjoy our afternoon tea on beautiful days such as this. Having room to move around outside, unroped, did away with the feeling of being trapped by constant danger.

Once I had dug a ledge the size of a single bed, I began to tunnel into the slope at the far end. There was a lot of snow to be shifted, but with the snow-shovel I could carve large blocks which I then rolled down the slope, and so made good progress. Every half hour or so I would take a five-minute rest to have a drink, eat some chocolate and admire the incredible panorama around me. After two and a half hours I had a hole big enough to sit a couple of people. It was an awkward size because there was not enough room to wield the shovel efficiently. I was crouched inside when I heard the familiar 'Whoompf!' of an avalanche.

Sounds like a big one, I thought, I'll have a look at that.

I stepped out onto my narrow ledge and looked across towards the West Shoulder where I expected to see the avalanche. There was nothing. I turned to face the North Col. Nothing there either. With horror I realised the only other possibility. I jerked my head up to see the sky filled with huge clouds of snow, seconds away from sweeping me off the mountain. There was nowhere to go but into my embryo snow cave. As soon as I had flung myself inside, the avalanche hit. Thousands of tonnes of snow poured over the entrance. There seemed to be a real danger of being buried alive. I crawled out onto the ledge I had cut into the slope and pressed myself against the wall. There at least I would be buried less deeply. Snow was forced into my nostrils and my mouth as I breathed so I covered my face with my hands.

'Please don't let the whole slope be swept away,' I said aloud, not so much to anybody or anything, but in the irrational hope that voicing my wish would make survival more likely.

After several minutes the slide of snow lessened and finally stopped. The air was full of snow swirling in the wake of the avalanche. The late afternoon sun glinted from the tiny flakes, reminding me of the facts which at that moment needed no further emphasis - how beautiful is the world, how good it is to be alive.

I gave a whoop of delight, then sobered with worry about the fate of Greg and Tim. I shouted and heard an answering cry. Somebody was alive at least. When I tried to hold my ice-axe I realised that my whole body was shaking with the shock. Not wanting to trust my trembling legs I crawled along our tracks to where I could peer down the steep slope. Greg was only fifty metres below.

'Are you okay?'

'Yeah!' was the feeble reply.

'What about Tim?'

'He was answering nature. His clothes are full of snow.'

Greg's answer told nothing of Tim's safety but his manner implied he must be all right. I lay back in the snow and laughed hysterically. It was the biggest avalanche I had ever seen, let alone been underneath. 


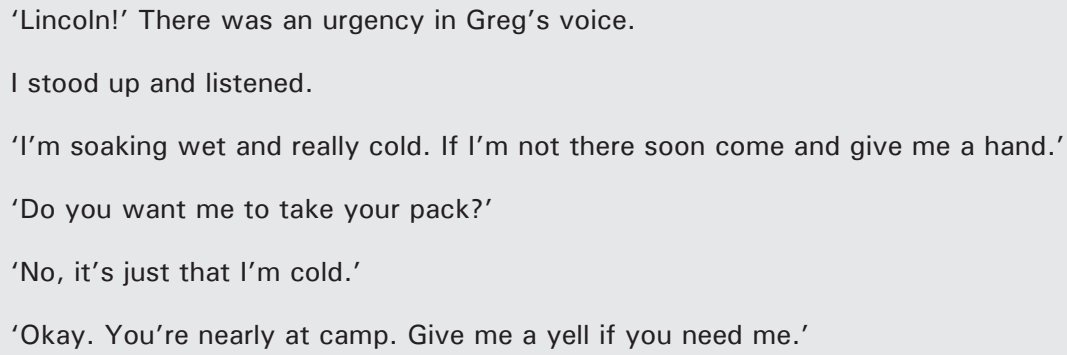

The sun was sinking low in the sky. Time to return to digging the night's shelter. Soon the cave was big enough for me to work in more quickly. When I bulldozed the accumulation of snow off the ledge with my boots Greg was just arriving. He looked worn out and was shivering violently. The snow of the avalanche had worked its way down his neck and sleeves and into his pockets so that now his clothes were quite wet.

He sat down to catch his breath while I pulled dry clothes out of his pack and listened to his story. Both he and Tim had seen the avalanche fly over the ice cliff above and had thought how impressive it would be watching it roar down the Great Couloir. As it tumbled closer and closer they realised it was too huge to be contained in the Couloir. There was nothing they could do but watch it fly over the edge of the rib and bear down on them. Tim, who was in the process of doing up his trousers, threw himself back to the fixed rope where he had attached his pack and hung on with all his might. Greg, who was firmly tied to the fixed rope a little way above, was swept off the slope. The snow poured over him, stretching the fixed rope as the force of the avalanche tried to drag him down. Then it was gone, leaving them stunned but uninjured.

'It took my mind away from my aching eyes for a while,' he said in conclusion. 'Pass me the radio, will you. Camp I has got to hear about this.'

From White Limbo, 1985, Weldons, Sydney, pp. 162-3. Re-published in May 2007 by Random House Australia.

That narrow escape from death for Hall, Mortimer and Macartney-Snape was the last straw for Bartram. A man who had spent much of his adult life living and working in the mountains, he had seen enough of Everest's character to know that the North Face was too dangerous for him. The loss of such an experienced mountaineer was a severe blow to such a small team, but everyone respected Bartram's right to make his own judgment about how much risk he was willing to accept.

Meanwhile back at $6900 \mathrm{~m}$ on the face, Hall and Macartney-Snape, who reasoned that the huge avalanche surely had cleaned the upper face of unstable snow, dug in at camp two and, with Henderson and Mortimer in support, pushed the route out further by anchoring the rest of the fixed rope above camp two onto the creaky slopes of White Limbo. Another day's effort got them to the top of White Limbo, where they dumped some gear and food to be picked up on the summit attempt.

Pleased with their work-five consecutive, energetic days at about $7000 \mathrm{~m}$ Hall and Macartney-Snape then descended to advanced base camp for a rest. 
The retreat was most timely, as another storm was brewing when they began to climb down from the top of the fixed ropes. This time it was not a monsoonal snowstorm, but the first of the winter storms characterised by vicious winds and bitter cold. It was a stark reminder of the life-threatening conditions they would face higher on the mountain. Even more ominously, as Hall noted, a storm with such high winds in September meant that the window of settled autumn weather - the break they needed to climb the mountain - might never come that year.

Winter had arrived at Camp I. Apparently the calm season of autumn had been overlooked. No trees existed; no disposable leaves gave advance notice of change. In Tibet, the rugged lines of the landscape suited the sudden changes in climate. The storms of the monsoon had changed to the clear, cold skies of winter. ${ }^{11}$

Hall paid for his skirmish with the winter-style storm. He developed a severe cough - probably associated with a chest infection and certainly more serious than the normal high-altitude hack that nearly all Himalayan climbers were afflicted with during the course of an expedition. Several days' rest at advanced base camp helped but it was a much weakened Hall who set out with his four colleagues at the first sign of settled weather. This time the climbers were going for the top, using camp two as the staging post for an alpine-style attempt on the summit. There was no selection of a summit team; all five climbers would continue up the mountain together until one or more had to drop back. By this time, Bartram had judged, with the shift to winter weather, that the avalanche risk had diminished enough for him to take part in the climbing again.

Hall's departure from the summit team came frustratingly soon. Just in crossing the neve of the Rongbuk it became painfully clear that he was in no physical condition to go back up onto the face. He lagged far behind the others and when he arrived at a gear dump partway up the neve, he collapsed into a spasm of coughing. His decision was made for him; his body simply could not continue.

His illness was a bitter blow to Hall. He had been with Macartney-Snape from the very beginning of their mountaineering careers - first, that strong New Zealand season followed closely by the last-ditch success on Dunagiri, and then the ascents of Ama Dablam and Anyemaqen, the close call on Trisul and the intense high-altitude struggle to get to the top of Annapurna II. They had been through a lot together and now, with the biggest Himalayan prize of them all in sight, it was heartbreaking for Hall to watch the others, particularly Macartney-Snape,

11 Hall, White Limbo, ch. 8. 
slowly diminish into tiny specks against the vastness of Everest's north wall and to realise that he had been reduced to a spectator for that final, absorbing, exhausting push to the top of the world.

As much as it was an immense personal frustration, Hall's departure from the summit attempt was also a severe blow to the rest of the team. Five was an extremely small team to be attempting a new route on Mt Everest, particularly one as formidable as the Great Couloir, and most of the climb still lay ahead of them. In addition, Hall had shown extraordinary commitment, courage and strength to fight off two serious mishaps on Annapurna II and still climb to the top. Just those qualities often spell the difference between one climber making the last 300 or $400 \mathrm{~m}$ of Everest's rarefied summit pyramid and another falling short.

The other four made the snow cave at camp two by mid-afternoon but the promise of settled weather that the clear, calm morning had brought was receding quickly. It was already blowing again at camp two and a huge plume was flying off the summit. Furthermore, the weather forecast issued from Kathmandu, Nepal, for mountaineers was for cold temperatures and continuing high winds the next day-definitely not good climbing weather. The forecast proved accurate, so Macartney-Snape, Henderson, Mortimer and Bartram were forced to descend the next morning and spend yet another period of waiting, this time at camp one.

There was little point in the climbers waiting out the weather at camp two on the face. In addition to consuming the precious supplies of food and fuel they had worked so hard to haul up to the camp, they would be hastening the process of physical deterioration that occurred with extended periods at high altitude.

Coping with high altitude is very much a matter of trying to optimise two conflicting phenomena. At the beginning of an expedition, when climbers are still relatively fit and healthy, the main impediment to climbing high is lack of acclimatisation. As time passes and increasingly higher trips are made on the mountain, the body adjusts to the lack of oxygen and begins to operate more and more efficiently. After a certain period, however, usually several weeks, at relatively high altitudes (5800 $\mathrm{m}$ or higher), the body begins to deteriorate, slowly at first and then more rapidly, from the chronic shortage of oxygen. Picking the best time to climb a Himalayan mountain is thus a matter of reaching the top of the acclimatisation curve before the inevitable slide down the deterioration curve begins. Of course, many other factors, such as weather and avalanche danger, have a crucial impact on when a summit attempt can be made. 
For the Australian mountaineers making the country's first attempt on Mt Everest, it was the weather that forced them onto the deterioration curve. They had spent nearly two months at base camp and above and had some weeks earlier reached the optimum level of acclimatisation. They could not acclimatise any further no matter how much more time they spent at high altitude. On the other hand, they had almost surely started the slow physical slide; they could not get any stronger, no matter how well they ate and drank. The enforced rest at camp one, on the other hand, at least gave Hall more time to get over his respiratory illness and join the others on another summit bid.

Near the end of September 1984, then, the situation did not look good for the Australian attempt on Mt Everest. Lincoln Hall was struggling to overcome his respiratory problems and all of the climbers were caught in a classic Himalayan catch-22. Each day of waiting meant less strength and more likelihood of the intense cold, windy winter conditions on the summit of Everest. Each day of waiting thus meant a reduced chance of climbing the mountain. To become impatient, however, and push up when the conditions were not right meant almost certain failure, very probably frostbite and possibly death.

The American expedition therefore looked to be in a very good position to snatch the Great Couloir prize. They were well established on the North Ridge, at a point where they could traverse into the couloir above the icefall and were prepared to use supplementary oxygen to climb the mountain. They had not, however, counted on the Australians' extraordinary measure of patience and persistence-qualities that had seen them through a remarkable ascent of Annapurna II and which were being tested just as severely on Everest. If Macartney-Snape had his way, there would be no giving in to the weather, no matter how long it took for the winds to ease.

'The hardest part of climbing a mountain like Everest is the waiting for something that is totally unpredictable and over which you have no control. You have to maintain the burning drive to succeed when doubts can quell the hottest of desires. ${ }^{12}$

12 Macartney-Snape, 'Mt Everest, the Australian ascent'. 


\section{An unforgettable face}

The 27th of September dawned cold and clear at camp one. More importantly, it was not windy. The previous day had been similarly fine but the climbers had decided to stay put. They did not want to waste precious energy to climb to camp two only to be fooled by another brief break in the post-monsoon winds; what they desperately needed was a spell of fine, calm weather lasting several days.

A mixture of excitement and determination pervaded the group as they marched up the neve of the Rongbuk Glacier towards the base of the face and the start of the fixed ropes. The forced rest at camp one had allowed Hall enough time to recover from his respiratory complaint and he was now moving strongly. His return to the team was a great morale booster, as his experience and skill would be essential to such a small, vulnerable team high on Everest.

At camp two, the climbers settled in to the now familiar snow cave for a night's rest before tackling White Limbo and launching themselves into the unknown of the Great Couloir the next day. Yet again, however, their hopes were dashed by the weather. During the night, the wind rose and by morning it was howling across the North Face of Everest. To attempt to climb high on the mountain in such weather would be suicidal.

Again the climbers were forced into a waiting game, this time in the snow cave at camp two. There was a great reluctance to retreat back to camp one now, as there was a limit to how many trips the weakening climbers could make up and down before they dissipated too much energy. They sensed that this time it would be a mistake to descend; if they did, they might not have enough energy left to get back up.

As one enforced rest day dragged into another, morale began to slump. 'Failure to climb a mountain because it was technically too difficult, or because one's reserves of strength were inadequate, was acceptable,' Hall said, 'but to return home without making a solid attempt for the top because the weather conditions did not allow it was intolerable. ${ }^{1}$

1 Hall, L. 1985, White Limbo, Weldons, Sydney, ch. 10. 
By the third day of inactivity in the cramped snow cave of camp two, that 'burning drive to succeed' that must be maintained in the face of adversity was definitely beginning to wane. 'Another day of this and I'll go mad,' Henderson moaned. 'You'll have to improvise a strait-jacket out of my down suit.'

Bartram was more direct, particularly when the prospect of another trip down to camp one was discussed. 'When I go down from here,' he said, 'that's it. I'm not coming up again. We've been here for two months, and that's enough. It's time for me to get on with the other things in my life. ${ }^{3}$ Hall too was not keen on the idea of yet another descent to the glacier. Only Mortimer and MacartneySnape were determined, no matter how long it took for the weather to stabilise, to climb the mountain.

The fierce wind on the north side of Everest seemed to mock the climbers' predicament, as it rose to ever greater intensity during the night. In the morning, however, the gales suddenly dropped and the doubts and frustrations of the previous few days vaporised into the cold, still air as the five climbers prepared to move higher up the mountain.

Above the snow cave, the route followed the ropes previously fixed up White Limbo, the snow on which had consolidated with the onset of the colder autumn weather and now seemed much safer. Even though there were fixed ropes to follow, the climbing was slow and difficult as the weight of the climbers, with their heavy packs, often caused their boots to break through the firm crust into the soft snow beneath.

About halfway up the slope, the summit attempt ended for Bartram. He was suffering from headaches and blurred vision and began to feel dizzy and weak in the legs. The symptoms were most likely those of cerebral oedema, in which fluid collected in the brain. It is a most serious condition and an afflicted climber who does not descend promptly faces extreme risk of dying.

The experienced Bartram was able to diagnose the symptoms in himselfsomething that many other mountaineers have failed to do - and did not hesitate in offloading his communal gear to Henderson and descending to camp two for yet another night in the snow cave. The mountain had already begun the process of choosing the eventual summit team.

As the afternoon wore on, the others reached the end of the fixed ropes at the top of White Limbo, picked up the gear that had been stashed there weeks earlier and one by one began to traverse across the slopes towards the Great Couloir. It had been a satisfying day's climbing. After all the frustrations of 
the weather-induced delays, the climbers had ascended more than $600 \mathrm{~m}$, passed their previous high point and finally entered the Great Couloir itself. The crowning touch was to find a natural snow cave formed by a partially open crevasse. That meant that the four could sleep in far more comfort than their one small tent would afford without the time and effort needed to dig a snow cave themselves.

More fine weather followed the next day. There were a few gentle gusts of icy wind, but nothing like the continuous gales that had buffeted the mountain a few days earlier. It appeared that a period of settled weather had arrived. This was just the break the climbers were waiting for; it was now or never.

Slowly, the four exited the cave and began the exhausting haul up the couloir (see image 12.1). They stepped into a surreal atmosphere as streams of fine snow, sparkling in the early morning sun, meandered down the broad gully and intermittently engulfed their legs. It was as if they were performing a slow, tortured ballet on a vertical white stage.

The climbing, although not difficult, certainly was not without danger. The angle of the face was only about 45 degrees - not steep enough to require a rope and belays - and the snow was firm bordering on icy: perfect conditions for cramponing. The hard snow meant, however, that any slip or fall would almost certainly be fatal; there would be little hope of a sliding climber being able to use his axe to arrest his fall.

Climbing the Great Couloir, despite its spectacular position and awesome views, had very few elements of pleasure, as Hall remembered:

I put the radio away and began to climb again. Half my mind concentrated on keeping my balance and on other fine points of not falling off. The rest of my mind devoted itself to the mechanical movements of climbing. There was not enough oxygen for my mind to cope with more than those few thoughts.

Shortly, the angle of the slope eased to about forty degrees. Looking up, the snow slope seemed endless. Somewhere above the Couloir it merged into steep rock, but that was too far away to worry about. All I could do was to take one step and make sure it was followed by another. Twenty steps then a rest, then twenty steps again.

Every now and then I used the view as an excuse for a longer rest. It was heartening to see the enormous bulk of Changtse fall further and further beneath my feet. My slow pace was getting me somewhere after all. Andy, whom I had passed earlier, was catching up. Above, Tim was 
now ahead of Greg but overall there was not much difference in our speeds. We were all climbing well and felt as strong as one could hope to feel at almost 8,000 metres.

The walls of rock flanking the Couloir began to close in, bringing with them a feeling of hostility. It was no place for humans. There was no air, no water, no hope. I shook my head and fought away the pressure of those negative thoughts. It's just another mountain, I told myself. It's just another climb. ${ }^{4}$

Slowly, the climbers worked their way towards the top of the Great Couloir. As the afternoon wore on and shadows crept across the gully, bringing with them an instant, dramatic drop in temperature, Macartney-Snape and Mortimer began the search for a campsite. This time there was no convenient crevasse to provide a ready-made snow cave; the best the pair could find was a slightly more gently angled spur on which a ledge could be levelled for the tent.

Hall was the last to arrive as his three colleagues fumbled with the tent poles in the bitter cold. The thin pieces of nylon and slender aluminium poles were all that stood between the climbers and the elements high on the side of Everest.

They had climbed to about $8150 \mathrm{~m}$ that day, higher than any of them had ever been before and well within the 'death zone', the region above $8000 \mathrm{~m}$ where physical deterioration is rapid. They coped the best they could with the stoves, the exceedingly cramped quarters and their failing appetites to drink at least some liquids and down a little bit of food. With the oxygen concentration well below half that at sea level, sleep was intermittent and light.

In the morning, the weather again appeared to be stable; there was little wind around the tent and the camp one team reported by radio that no plume of snow was blowing off the summit. It was 3 October 1984, more than 62 years since Australian George Ingle Finch made his desperate push for the top in much the same area. This day would see the only attempt the Australians could make. There was no question of another attempt; they would not have the strength.

Their bodies numbed by the intense cold and their minds slowed by the lack of oxygen, they methodically brewed up some tea and put on their boots, crampons and down suits. At that altitude, there are no 'alpine', or very early morning, starts and there is no possibility of hurrying those routine tasks. The cold and thin air see to that.

Mortimer was the first away from the tent, followed by Macartney-Snape and Henderson. The climbers initially had to traverse across the width of the Great 
Couloir and up towards the rock band that blocked the top of the couloir. Although it was straightforward climbing, it was painstakingly slow at that altitude. The rock band at the top of the couloir was in deep shade, thus very cold, and likely to remain so for much of the day so the climbers opted to traverse over to the so-called Yellow Band, which was in the sun.

By the time they reached the Yellow Band, Macartney-Snape was in front and led up a ramp that formed a natural break in the band. It was mixed climbing on rock and ice or, more accurately, 'bad snow on poor rock', ${ }^{5}$ according to Macartney-Snape. Beyond the ramp, he pushed up through the rest of the band in climbing that would be difficult and dangerous at any altitude, but was even more so above $8000 \mathrm{~m}$. Macartney-Snape dropped a rope to secure Mortimer as he climbed the steep section of rock (see image 12.2), but by the time Henderson had reached that point, the other two were too far above to drop the rope- the only one they were carrying. Henderson had to climb it without protection.

Meanwhile, Hall had turned back. The last to leave the tent, he had slowly traversed across the couloir and then realised that his body, and particularly his extremities, were not warming up with the climbing. Hall had been battling cold hands and feet throughout the climb, more so than the others, and did not want another dose of frostbite. He had lost parts of two toes after his two nights out on the summit ridge of Dunagiri six years earlier. Everest had trimmed the summit team to three.

Above the Yellow Band, Macartney-Snape and Mortimer had passed the major difficulties. What remained was the grim, morale-destroying battle with fatigue, extreme lack of oxygen and fading light. The summit was so tantalisingly close but the day was slipping away so fast.

Macartney-Snape was carrying a small tape recorder and described the tremendous effort required by climbing over even easy ground above $8500 \mathrm{~m}$ :

You do six steps and you're totally exhausted... Breath just can't come out any faster. Your whole being is just absorbed in the task of breathing.

It's a beautiful day, a perfect day. Not a breath of wind, a little bit of high cloud. I suppose it's getting on in the day...must be about three o'clock. Plenty of puffy clouds all over Nepal. 1500 feet to go and it's three o' clock - can we make it in time? Who knows... Watching the sun, since my watch is covered up by clothing, the sun is the only way of telling. Anyway, that's the 'real' time. ${ }^{6}$

Later, he again recorded his feelings:

5 Macartney-Snape, T. 1985, 'Mt Everest, the Australian ascent', Wild, no. 15 (Summer), pp. 26-32.

6 Hall, White Limbo, ch. 11. 
'This...is going to be...the hardest day of my life...physically...and mentally...the summit is somewhere up there...How far? I'm not quite sure... but the sun is sinking fast and we've got to make it before sunset... The view up here is absolutely just incredible. It's hard to believe I'm near the top of Mt Everest...Two to four steps and you're exhausted... but couldn't have asked for a more perfect day. ${ }^{7}$

Just on dusk, Tim Macartney-Snape became the first Australian to stand on the summit of Mt Everest. Greg Mortimer joined him a short while later (see image 12.3). It was a remarkable performance in every respect by the pair, but particularly so by Macartney-Snape. Most climbers, even those breathing bottled oxygen, are so exhausted by the time they reach the summit they are hardly able to speak, and those few who climb Everest without supplementary oxygen are so close to their limits they can barely function. Macartney-Snape not only carried a movie camera and filmed Mortimer climbing onto the summit, he brought along the tape recorder and made a short speech on the summit. His thoughtful and heartfelt words on the environment and nuclear war were more eloquent than most people's utterances at sea level.

The Australian team nearly had a third member on the summit. Henderson stopped just 50 vertical metres short of the top. He had been slowed by a broken crampon, which forced him to stop and effect a repair before he could safely move on. More than costing time and probably the summit, the repair cost Henderson his fingers, as he had to take off his outer, insulating mittens. The intense cold quickly froze his fingers.

Perhaps the hardest part of climbing Everest was yet to come for the trio: getting down safely. Macartney-Snape and Mortimer spent about 20 minutes on the summit before beginning the descent. The two summiters picked up Henderson near where he had stopped to repair his crampon. His hands were useless; Macartney-Snape had to dig Henderson's prescription glasses out of his pack and exchange his sunglasses for them so he could see in the dark. The intense cold and darkness made the retreat difficult, particularly since they had only one weak torch between the three of them.

It was easier and less dangerous in the dark to traverse to the top of the Great Couloir. The $30 \mathrm{~m}$ wall that remained too deep in the frozen shade on the ascent could be descended by abseil; the only problem was an anchor, as they had no snow stakes. Macartney-Snape's inventiveness came to the rescue. He removed one of the aluminium staves from Mortimer's pack and buried it in the snowdefinitely not a textbook anchor but it would have to do. 
At camp four, an anxious Hall was awaiting the arrival of his colleagues. He had the stove purring away during the late afternoon and had two billies full of liquid awaiting the exhausted climbers. The importance of that simple task should not be overlooked. By showing maturity and good judgment and not pushing himself past his limits to attain the world's highest peak - a temptation that other climbers have succumbed to and for which they have paid the ultimate price - Hall was in a position to ensure the survival of his compatriots. He provided liquids and organised them in sleeping-bags - mundane operations that Henderson could not perform because of his fingers, Mortimer could not manage because of his exhausted state and even the indestructible MacartneySnape would have found exceedingly difficult.

\author{
The summit of Everest...nearly \\ Andy Henderson \\ 'Andy...' \\ 'Uhn...' \\ 'Not coming...too cold...too slow...' \\ 'Uhn...OK.' On the day of the summit attempt Lincoln was dropping out.
}

The huddled figure in the shadows of the Great Couloir, bent double with the effort of conversation, looked small and very alone, from my position high on the Yellow Band. Lincoln means many things to me, but I'm not used to thinking of him as either small, or alone-it was unsettling. I had similar feelings two days before, as Geof, after giving me his share of the communal gear, had disappeared down the fixed rope. Geof has the powerful style and finely tuned survival instincts that come from keeping accountants, and the like, alive in the mountains of South America. His decision to retreat in the face of overwhelming altitude problems was unavoidable, and had to be made before leaving the fixed ropes, which ended at about 25,000 ft, but I knew he would be bitterly disappointed. Never a peak bagger, Geof delighted in getting high just to see what he could see, and would have loved to have made it to $8,000 \mathrm{~m}$. I could feel his distress through the thin air.

I had my own problems now and was not able to give Lincoln the sympathy he deserved, and perhaps needed. The gentlest of people, he has a flair for disorganisation which could make others weep with frustration. It never ceased to amaze me, then, how good he was at getting expeditions financed, and then to the bottom of their chosen mountain. Once there he generally contrived to reach the top somehow.

I concentrated on steadying my breathing for a few seconds then shouted down, 'Can you... see Tim?'

'Uhn...above you...on snow.'

More deep breaths, then 'Need a rope...crampon broken.'

'Too far...'

Christ! All thoughts of Lincoln fled from my mind, and I found myself panting furiously. I was too terrified to try and downclimb the shattered limestone of the rock band, and the ground appeared to ease off ahead, so onwards and upwards. But first the crampon. By wedging the pick of my axe between two rocks I was able to tremble down on one leg and take the bloody thing off. 
The binding post had broken, but the damage would be repairable once I was in a less intimidating position. With the crampon off I struggled up to the brow of the rock band, scaring myself badly several times in the process. Suddenly Greg and Tim appeared above me, half hidden by a change in angle of the slope.

'Broke a crampon...need a rope.'

'Too far...keep going.'

'Come down...?'

'No...keep going...nearly there.'

Tim hadn't lied, and soon I had scrambled to the top of the rock. Above me stretched a steep snow slope, and then, where I had seen the others, the ground kicked back. A few minutes later I understood Tim's reluctance to move onto this steep slope again. The snow was rubbishy beyond belief, and I wondered what held it in place, especially as it now had a deep diagonal trench slicing through it.

I held my breath and tottered out across the nauseating junk until I was in striking distance of the top. By lashing out with my axe, and scrabbling wildly with my feet, I was able to flop over on the easier ground, and into a new and wonderful world. I lay, like a beached jellyfish, on the edge of a vast, blazing white shelf. At first this plane of wind-smooth snow appeared to hang suspended in mid-air, but looking behind me I saw the eastern edge of the slope was bounded by the upper extension of the Great Couloir, and the upper edge by a high band of black rock. The right hand end and lower edges ended abruptly in space. The whole arrangement was gently tilted at an angle of about 20 degrees.

Some distance above I could see two figures moving up and towards an obvious ramp between the couloir and the rock band. Moving over to a dry patch of flat pebbles I collapsed, and tried to figure out how to repair my broken crampon. Tim had the only rope, 50m of $9 \mathrm{~mm}$, and there was no way I was going to let myself be separated from it any further than was absolutely necessary. I worked as fast as possible, my hands stripped to a single layer of inner gloves for the job.

Tim, long and gangly on first inspection is, in fact, a nuclear powered magician. Greg is, superficially, a much more human creature - at least he drinks - but disappointingly is a real fiend when it comes to technical climbing, and past experience showed that he had a fair working relationship with any of the local mountain gods, from Tibet to Bolivia. The two of them were moving pretty nicely, given the altitude, and in the twenty minutes it took me to fix my gear and pull my gloves on again they had disappeared.

Above the Black Band I found Greg's pack in a pile of rocks, and dumped my own next to it. Tim had taken no pack, preferring to store everything he needed in the pockets of his windsuit. The two were in sight again, and I took off in hopeless pursuit across another hanging plain, steeper this time, to some desperate moves on [a] few metres of mixed ground, and then diagonally right towards the West Ridge. When I reached it the others had disappearedagain.

I stood on the ridge, huddling against the thin, lazy wind, and saw the long shadow of Gyachung Kang, to the west, reaching out across the glaciers and lesser peaks towards me. I felt lonely, and out of my depth. It would be dark in a few minutes, and I would be left like an idiot, standing $50 \mathrm{~m}$ below the peak of the highest mountain on earth, blind in my prescription glacier glasses, blind without. My rectangular glasses were in the top of my pack, somewhere below, and I was separated from them by several hundred metres of steep slab, and at least one tricky section of mixed ground. I turned immediately, and started retracing my steps, hoping to make it across the mixed ground before it became too dark, hoping that I wouldn't have to wait too long at the packs for the others. 
As it was, Greg nearly cramponed my hand as I removed it from the last of the rock-I doubt I would have felt it. I was unbelievably pleased to see the pair again, but neither appeared to be in significantly better shape than myself. Silently we descended to our packs, our only rope, our only headtorch. I don't think I even asked if they had summited.

At the packs, my hands which had happily clutched the head of my axe now refused to grasp the zippers on the top of my pack. I was puzzled by this, and spent a few moments staring at them whilst my brain attempted communication. They continued to be wilful and disobedient.

'Tim...can't manage the zippers...give me a hand with my glasses?'

Wordlessly he changed my glasses, but by this time the only things visible were what Tim's torch washed over.

Greg and Tim must have talked over the descent route previously, because the only discussion during the following few hours concerned bivvying. The idea was quickly dismissed. Descent by the way we had come up was out of the question as we didn't have enough rope to make it down the Yellow Band in one go, and didn't even have any snow anchors, much less rock gear. The logical route was to descend the Great Couloir, and hope that when we reached rock the rope would be long enough.

Hundreds of metres of down climbing soon thrashed shattered muscles to numbness. The ground was steep enough to warrant facing the slope, and the sight of the headtorch bobbing around below, and between, my feet, combined with the measured, rhythmic movements of my body to paralyse the mind. Tim would be weaving his spells, Greg would be in survival mode, haggling with the mountain over the whys and wherefores of life and death, and I was comfortably numb, and cruising.

Several lifetimes dragged past.

Eventually voices started below, and the light danced about in an unaccustomed pattern. An abseil was being rigged-later I discovered we had abbed off Greg's pack buried in the last margins of snow - and Greg disappeared with the headtorch. Finally a muffled shout drifted up and it was time to move. By the time I reached the end of the rope, which seemed to terminate a distressing distance above anything that might have been called easy ground, my crampon had come off again. Tim appeared from somewhere, worked his magic, and I was soon doing climber impersonations again. It was only a $100 \mathrm{~m}$ or so to our Super Diamond, and the eastern side of the couloir was bathed in an elegant silver light from the moon, but now I was in the grip of a powerful lethargy, and it irked me to have to move at all. Tim and Greg had vanished in the moonlight, and it was a long and lonely journey to the tent.

I collapsed through the tent door, where Lincoln packed me into a pit and fed me hot drinks. Greg was slumped unconscious on one side of the tent, Tim fought impotently with the laces of his ski boots, I dribbled tea over frozen claws and sleeping bags with equal dispassion, and Lincoln was on the radio discussing our condition with Jim, and arranging for Geof to move back up to the snowcave (C2).

It was sometime past three in the morning, 16 hours after we had first left Camp 4 . We were in a small tent, on an even smaller ledge, at 27,000 ft and I couldn't understand why Lincoln looked so worried.

From 'Sweet and sour', Mountain, no. 104 (1985), p. 33. 
One by one, the climbers stumbled into the tent, with Henderson last. There were hugs and tears of joy and relief, but Henderson's severely frostbitten hands took the shine off the celebrations.

Macartney-Snape, Mortimer and Henderson were able to drift off to sleep, but Hall had problems:

At that height I found the dark claustrophobic. Sleep was supposed to be a state of rest but instead, as I dozed and my respiratory rate dropped, I plunged into a frightening world of suffocation. Opening my eyes did not relieve the panic because the darkness continued. There was nothing for my mind to hang on to in the swirling blackness. I breathed violently and deeply until at last I calmed down. Sleep was impossible so I lay in my sleeping bag and considered our situation. ${ }^{8}$

Only in the morning did the team's precarious predicament become fully apparent. Of the three who climbed to the top or nearly so, Macartney-Snape was capable of descending under his own steam but Mortimer and Henderson clearly needed help.

First, Hall and Macartney-Snape packed up Henderson's survival gear, split the rest of his belongings between them and got him ready for the long trip down the Great Couloir and across White Limbo. Henderson's hands had been frozen into a 'gripping' position from the previous night's climbing, so it was an easy matter to insert the ice axe again. Apart from his hands, Henderson seemed to have survived the summit ordeal well and was able to descend without further assistance.

Mortimer, on the other hand, was in serious trouble. He lay semi-conscious in his sleeping-bag while the others got ready to leave and, when roused, was unable to get himself ready to descend. Hall and Macartney-Snape had to attach the crampons to his boots and then, apparently forgetting he had them on, he put a couple of large gashes in the bottom of the tent. He was either suffering from extreme exhaustion or, more ominously, the onset of cerebral oedema. In case it was the latter, he had to get to lower altitude as quickly as possible.

Hall began the descent with Mortimer, who had such well-developed climbing instincts that he was able to put himself in 'automatic' and down-climb securely, although very slowly. Macartney-Snape soon overtook the pair, after he and Hall had agreed that Hall was in the better shape and should stay with Mortimer. Hall had hoped to get Mortimer down to the snow cave at camp two that night. The elevation of $6900 \mathrm{~m}$ should bring considerable improvement if 
he was indeed suffering from cerebral oedema. Mortimer was, however, moving much too slowly to make camp two; they would have to settle for a night in the crevasse just above the ice cliffs that spanned the Great Couloir.

About $100 \mathrm{~m}$ above the crevasse, Hall watched in horror as Mortimer caught one of his crampons on the other leg of his down suit, fell head over heels and began cartwheeling down the slope. The ice cliffs loomed just below and a fall over them meant certain death. Somehow, as he tumbled towards the top of the cliffs, Mortimer flipped onto his stomach and slowed and then stopped his fall by plunging the shaft of his ice axe into the soft snow. Mortimer's climbing instincts had saved him. Both shaken by the near tragedy, Hall and Mortimer made their way into the crevasse and its roomy sleeping ledge.

Mortimer's condition seemed little improved by the descent of $700 \mathrm{~m}$. He was unable to keep any food down and twice he kicked over and spilled billies of water that Hall had painstakingly melted from snow. Hall knew that they were not out of the woods yet.

In the morning, Mortimer was a little better. He was able to dress and prepare himself for the day's climbing and set out before Hall for the traverse across White Limbo to the top of the fixed ropes. This time, the descent went without incident and, after a brief stop at camp two to pack some gear and send it down ahead, the pair continued to the base of the face. By nightfall, Hall was back on the glacier with Colin Monteath and Mortimer was just above on the fixed ropes. Henderson had earlier descended from camp two, with assistance on the abseils from Geof Bartram. Macartney-Snape, in a phenomenal finish to a spectacular performance, had climbed down all the way from camp four to the glacier and camp one in a single afternoon! The ordeal was over for all except Henderson, who was to face the trauma some months later of losing parts of all of his fingers.

\section{Making history in style}

The Australian ascent of Mt Everest was remarkable by almost any measure. Never before had the world's highest peak been climbed in such clean fashion or in such good style. Never before had a new route been climbed without the aid of supplemental oxygen. Rheinhold Messner and Peter Habeler, in their historic first ascent of Everest without artificial oxygen in 1978, followed the standard South Col route, the one by which Hillary and Tenzing first climbed the mountain in 1953. In 1980, Messner again amazed the mountaineering world by climbing Everest solo without artificial oxygen. He scaled it by the North Ridge route - with little doubt the most straightforward and least technically difficult route on the mountain and a route that was climbed frequently. The Australians faced the same tremendous physiological problems of trying to climb to $8800 \mathrm{~m}$ 
without the aid of artificial oxygen, but in addition they had to cope with the psychological stress of climbing into uncharted territory, of facing unknown difficulties at the most extreme of altitudes.

Never before had a new route been climbed on Mt Everest by such a small party. All of the other significant new routes on the mountain had been climbed by much larger teams with much more support in the establishment of camps and the carrying of supplies. The 1953 British South Col and the 1975 British SouthWest Face expeditions are classic examples. Of the five Australian climbers who set out from Sydney to climb Mt Everest, two reached the summit, a third came extremely close and a fourth climbed beyond the highest camp; only one failed to get within striking distance of the summit. Considering the normal Everest attrition rate due to illness, fatigue, burn-out and altitude sickness, that is a phenomenal achievement.

The style in which Macartney-Snape and Mortimer reached the summit was near to the ideal alpine style. With only one camp established on the North Face - the snow cave of camp two at $6900 \mathrm{~m}$ - the five climbers set out on 27 September from the base of the face with most of what they would need for the summit attempt on their backs. Apart from consuming some food and fuel at camp two and collecting a small amount of gear at the top of the fixed ropes, they climbed the face in alpine style. Indeed, they climbed the $2000 \mathrm{~m}$ of the face in virtually pure alpine style, establishing camps as they climbed and carrying all food, fuel and climbing gear on their backs.

Perhaps the most remarkable aspect of all was the extraordinary patience and persistence demonstrated by the Australian team. At several points it would have been easy to say that 'we had given it a good go but the mountain won'. At other points it would have been tempting to push into questionable weather because of impatience and frustration at delays. The Australians, however, maintained the right balance of that burning desire to succeed and the judgment required to minimise the considerable risks from weather and unstable snow.

How did the outside world react to the Australian ascent? The authoritative British climbing magazine Mountain summed it up succinctly: 'It was a major feat by a small expedition, a new route without oxygen by the first Australian group to make the attempt.'

Chris Bonington, the doyen of the British Himalayan mountaineering community, remarked:

It really was a superb achievement. I think I'm right in saying they were the smallest expedition ever to make a new route on Everest

9 'Antipodean triumph and tragedy. Info-Greater Himalaya', Mountain, no. 102 (1985), p. 12. 
and they were also the only expedition to make a first ascent without using oxygen. They also seemed to have got on well together and to have tackled the whole climb in a relaxed and balanced way, by what I should imagine were the most appropriate means. So, yes, it was a superb achievement. Great! ${ }^{10}$

Doug Scott, along with Bonington the most experienced of the British Himalayan climbers, commented:

I think the 1984 Australian Everest Expedition was a particularly good one. I got letters about the trip from Jimmy Duff and it sounded like they had achieved a lot of respect for each other. It seemed that these lads had got it together enough to build up more energy as a group than anyone could produce for himself. With all that collective energy working in one direction, without anything in the way, it was a perfect trip, apart from poor old Andy getting frostbite. ${ }^{11}$

In Australia, Chris Baxter, editor of Wild, described the climb as 'a major new route on the North Face. Achieved without artificial oxygen and under unusually difficult conditions by a small expedition (none of whom had previously been over 8,000 metres), it was a victory over the odds and a landmark for Australian mountaineering.$^{12}$

The Australian popular press also saluted the Everest success. The Sydney Morning Herald's editorial comments are typical:

The Australian expedition has already been described by other climbers on the mountain as an all-time classic...As a direct ascent, the line chosen up the North Face by the Australians was aesthetically pleasing to mountain-climbers and remains the straightest and hardest route on the north face...The first Australian ascent of Mt Everest was achieved with courage, skill and spirit, something of which is summed up by the slogan on the expedition's T-shirt: 'Qomolangma: you might forget the name, but you won't forget the face.'13

The most immediate and perceptive comments came from the American climbers entrenched on the North Ridge, adjacent to the Great Couloir. Their view of the Australian team changed from one of a bunch of no-hopers who were no more than a curiosity to one of great admiration. Two of the most amazed of the Americans were the veterans Jim Wickwire and John Roskelley.

10 Baxter, C. 1985, 'Chris Bonington in Australia. Interview', Wild, no. 16 (Autumn), pp. 26-9.

11 Chester, Q. 1986, 'Doug Scott, the mountaineer's mountaineer. Interview', Wild, no. 20 (Autumn), pp. 38-41.

12 Macartney-Snape, 'Mt Everest, the Australian ascent'.

13 'Australians on Everest', Sydney Morning Herald, November 1984, p. 8. 
Roskelley in particular was in a good position to judge the Australian effort. America's most experienced high-altitude mountaineer, he had had two decades of hard climbing, with expeditions to Himalayan giants such as Everest, K2 and Makalu and successes on lower but extremely difficult peaks such as Cholatse. By the early 1980s, European superstar Rheinhold Messner considered Roskelley to be the strongest Himalayan climber in the world.

Recalling the Australian ascent, Roskelley said:

Damned if one night we looked up and they were at almost 28,000 feet, going really slow. We thought, 'No way are they going to make the summit; they'll back off.' But they didn't. They climbed right on into the night and summited and then started down... The Aussies pulled off the mountaineering coup of the century. ${ }^{14}$

Wickwire remarked, 'It was the most amazing thing I've ever seen..' ${ }^{15}$

As a postscript, the American team subsequently had difficulties with their North Ridge route. Only Phil Ershler, using artificial oxygen, reached the summit and only by ascending hand-over-hand the rope the Australians had left hanging down the $30 \mathrm{~m}$ steep section of rock in the Yellow Band. Presumably, Macartney-Snape had not told them the nature of the anchor!

Finally, how did the Australian climbers themselves react to their stunning success? Their reaction was not one of overt pride or self-congratulation, but rather one of relief and gratitude for having survived such a remarkable adventure in such beautiful surroundings. Hall's thoughts as he descended the last fixed ropes on the face and crossed the glacier were a moving and eloquent account of his feelings:

Despite my wish to hurry, my muscles did not have enough strength left for me to move quickly. I was content to go down slowly. There was time on the long abseils to think about our feat. We had done it, climbed a new route on Mt Everest without oxygen; a first, a real mountaineering coup. But of more importance in my mind was the thought that this was our last day on the mountain. No more painful load-carrying up the fixed ropes, no more cold feet and hands, no more worrying about the fickle mountain weather. From now on, back in Australia or away in the mountains, Mt Everest would never be the same. Gone was the air of mystery which had surrounded the mountain during our years of

14 Krakauer, J. 1985, 'Return to the North Face', Outside, February, pp. 29-32.

15 Ibid., p. 68. 
planning. Gone were the doubts of whether our small team was equal to the challenge. Gone was the fear that I might not return from the largest, most impersonal, but somehow most inviting graveyard of all...

[Back on the glacier] I removed my skis and walked down the slope to where the angle eased again. By then it was completely dark, and already the peaks of Lingtren and Khumbutse were lit with moonlight. I remembered that today or tomorrow was the night of the full moon...I slid to a stop as I crested a small rise. The snow around me was rapidly losing its blackness. The distinct line between the mountain's shadow and the white light of the moon seemed to sweep towards me as I stared. I turned around in time to see the tip of the full moon rise directly over Everest's summit.

I could not believe my eyes, yet the unbelievable was definitely happening. The moon rose huge and bright over the apex of the mountain we had just climbed. The snow around me glistened as particles of ice threw the light up at me. The irritability which had been growing with my tiredness disappeared. How could anything be wrong in this most magnificent of settings? Awe filled my being, not with fear or insignificance, but with the warmth of belonging, of being a part of something so beautiful.

I turned around and skied along the well-lit slope. The moonrise could not have been better timed, nor could I have been better placed to appreciate it. The coincidence of those events left me feeling privileged, because I had survived the impersonal strength of the mountain, and had been given such a breathtakingly beautiful scene for my farewell. No longer did my weariness annoy me. The short rests I took every few minutes were not merely delays between me and the comfort of Camp I, but chances to admire the perfection of the night. ${ }^{16}$

Days later, as the Australian team bounced along the rough road away from base camp, Hall gave Everest a poignant farewell: 'Though Qomolangma dominates the skyline it no longer rules our lives. ${ }^{17}$ (See image 12.4).

16 Hall, White Limbo, ch. 12.

17 Ibid. 


\section{Everest aftermath \\ Tim Macartney-Snape}

The moments following a big climb are the purest and sweetest of all. Months of anxiety, pain and discomfort are suddenly over; the monomania which possessed you at the expense of so many valuable thoughts evaporates and the senses it sharpened are let loose to experience the present without any restrictions.

My mind and body felt cleansed, peace was mine: my attention was at last completely free to see where I was. Khumbutse and Lingtren, those exquisite peaks of wind-sculpted ice, glowed against a multitude of stars. Venus shone like a miniature moon and the cusp of the Lhola greeted the Milky Way in a symbolic transition from earth to the stars.

There is an awesome feeling of power surrounding Qomolangma. I think you can sense it as you approach it from any direction, and that night the feeling was strong. The great valleys that drained the mountain came alive in my mind. From the valleys of the Khumbu I could smell juniper, azalea and the dank earth of the rhododendron forests - and Sherpa villages and monasteries so ingeniously and sympathetically suited to their surroundings; the miraculous peaks, Thamserku, Ama Dablam, Taweche, Kangtaiga-it all came clear in my mind. So did the sharply contrasting features of the valley below me. In the lower Rongbuk the earth's skeleton is exposed in all its colours, textures and patterns. During the day the air is so clear, the light so bright and the sky so dark that the rock-strewn landscape jumps up at you, vividly vibrant and alive. These and other images derive from something that is greater than the sum of its parts, something that really gives reverence to the Mother Goddess of the Earth.

From 'Mt Everest, the Australian ascent', Wild, no. 15 (Summer 1985), pp. 27-8. 


\section{Maps}

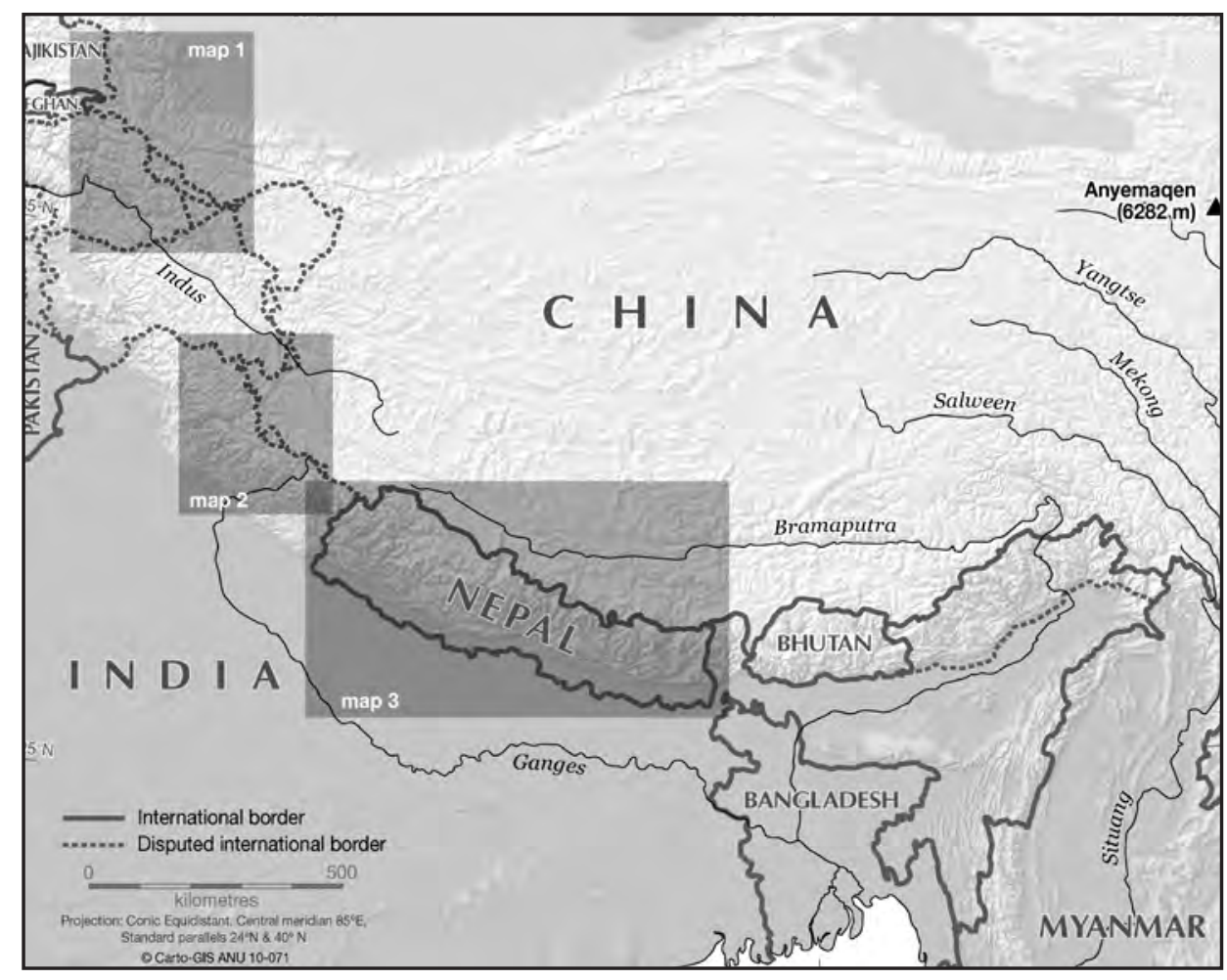

The location of the greater Himalaya, stretching in a long arc through Asia from Bhutan in the southeast to Pakistan, Afghanistan and Tajikistan in the northwest. The shaded areas indicate more detailed maps (following) that show the locations of major peaks climbed or attempted by Australians. Peaks below 6000am are not included. The location of Anyemaqen, a mountain in China that was climbed by an Australian expedition in 1981, is shown on this map. 


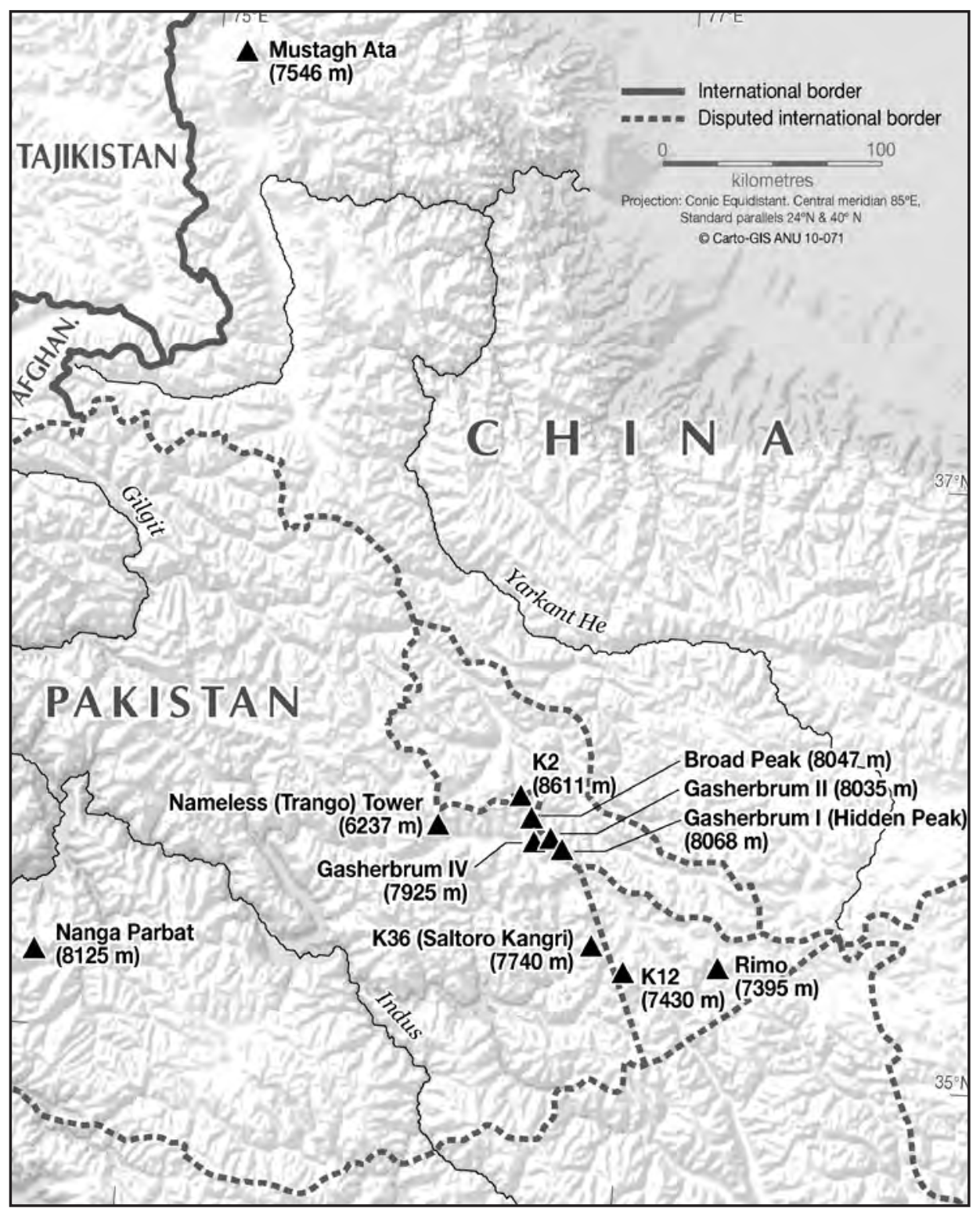

Map 1. The Pakistani Himalaya 


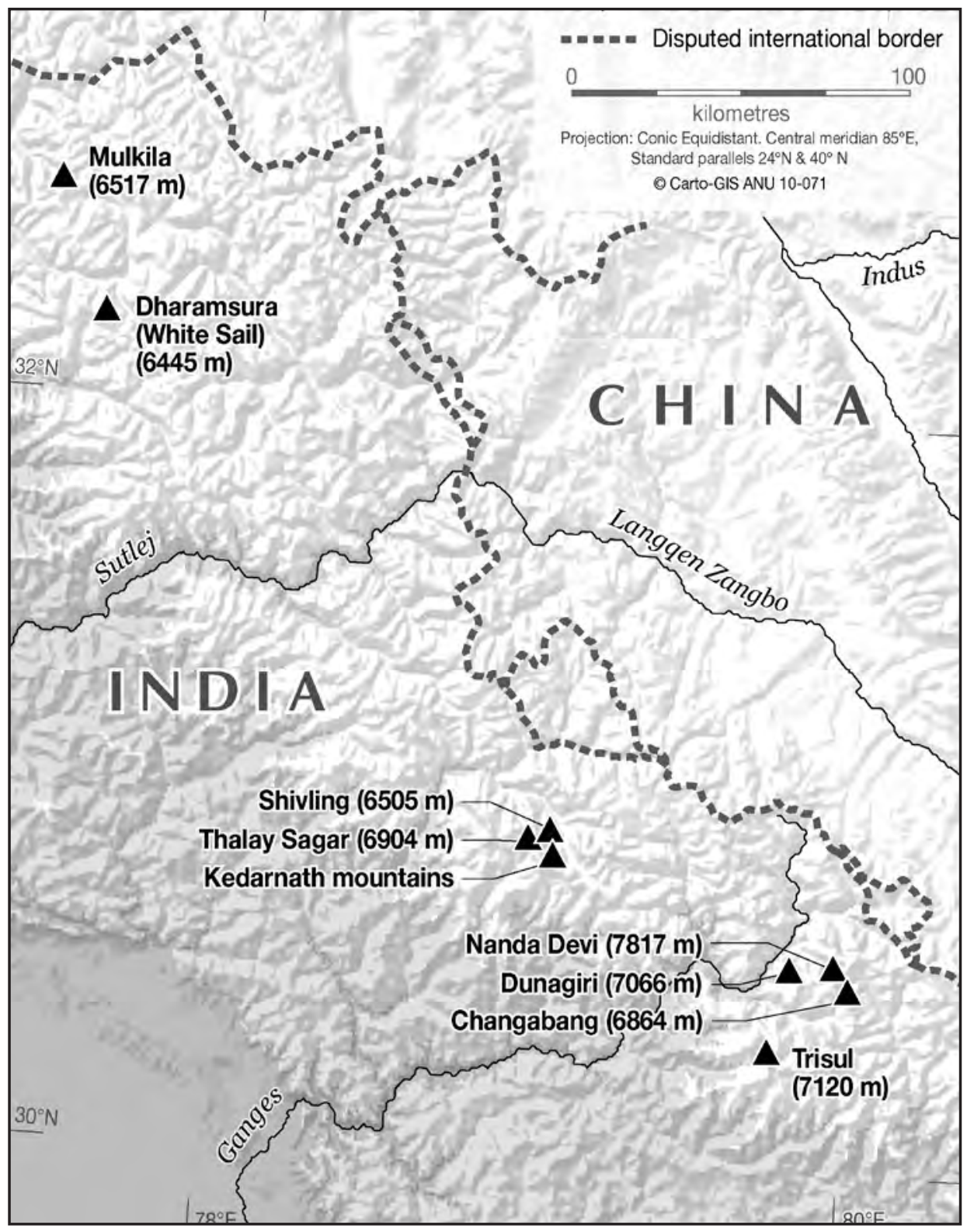

Map 2. The Indian Himalaya 


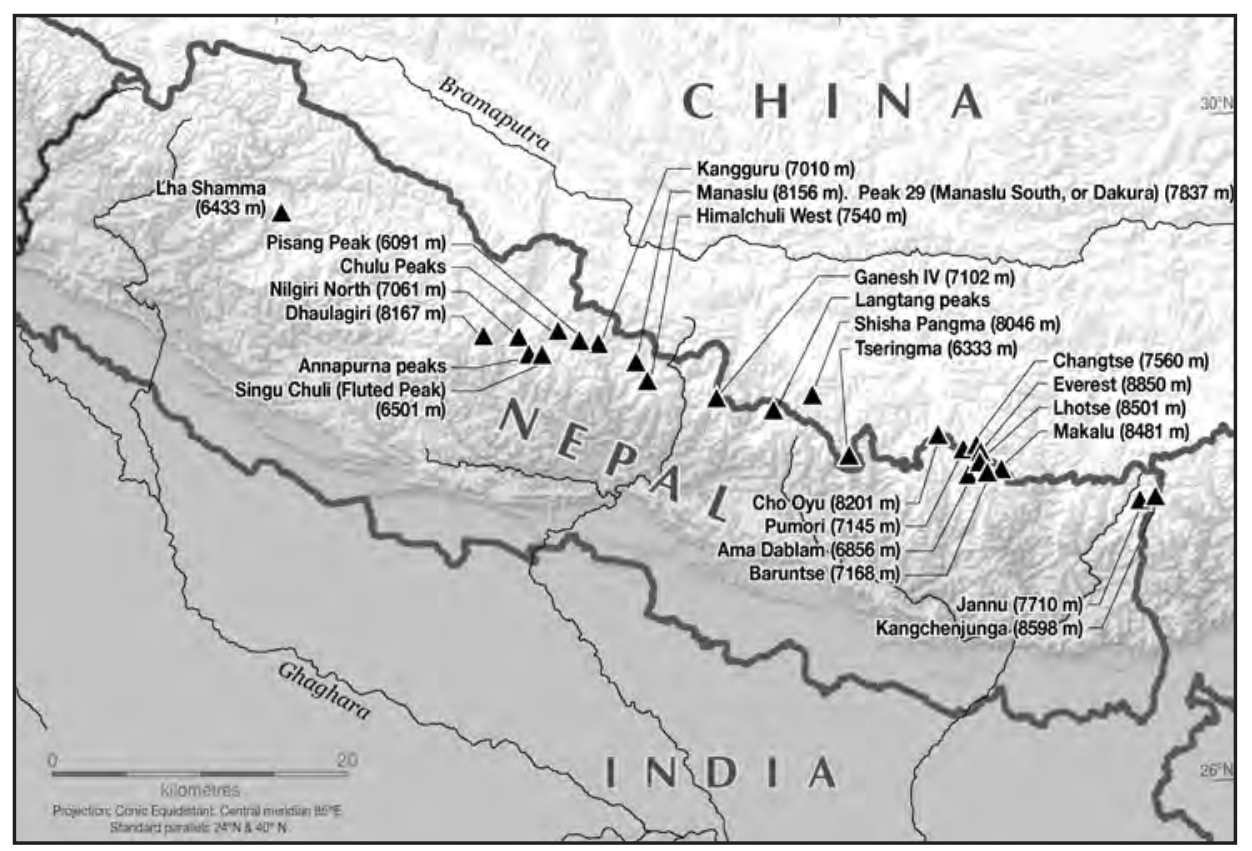

Map 3. The Nepalese and Tibetan (Chinese) Himalaya 


\section{Images}

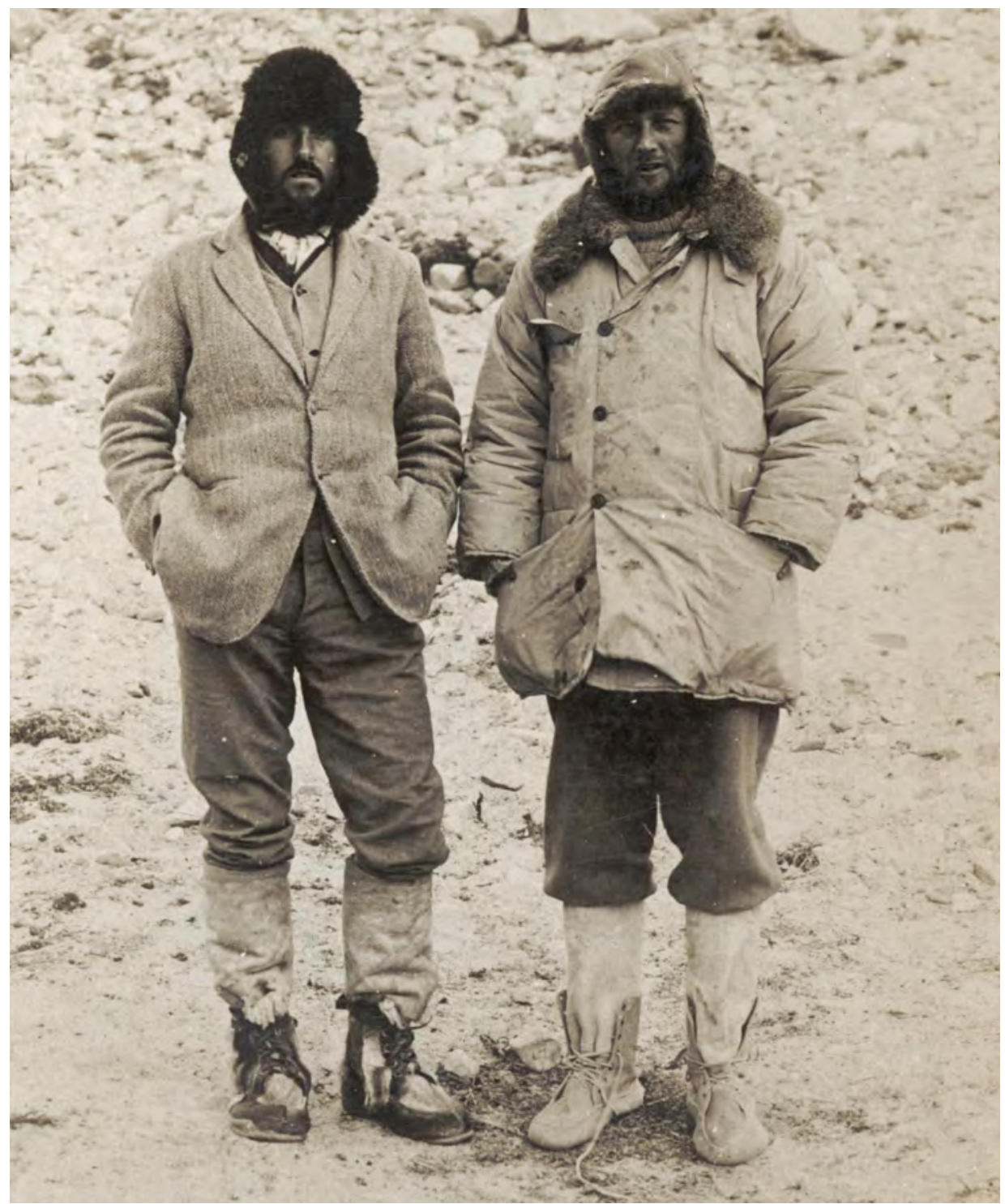

Image 2.1. George Finch (right) and Geoffrey Bruce at base camp, following their attempt on Mt Everest in 1922.

Photo courtesy of the Royal Geographical Society 


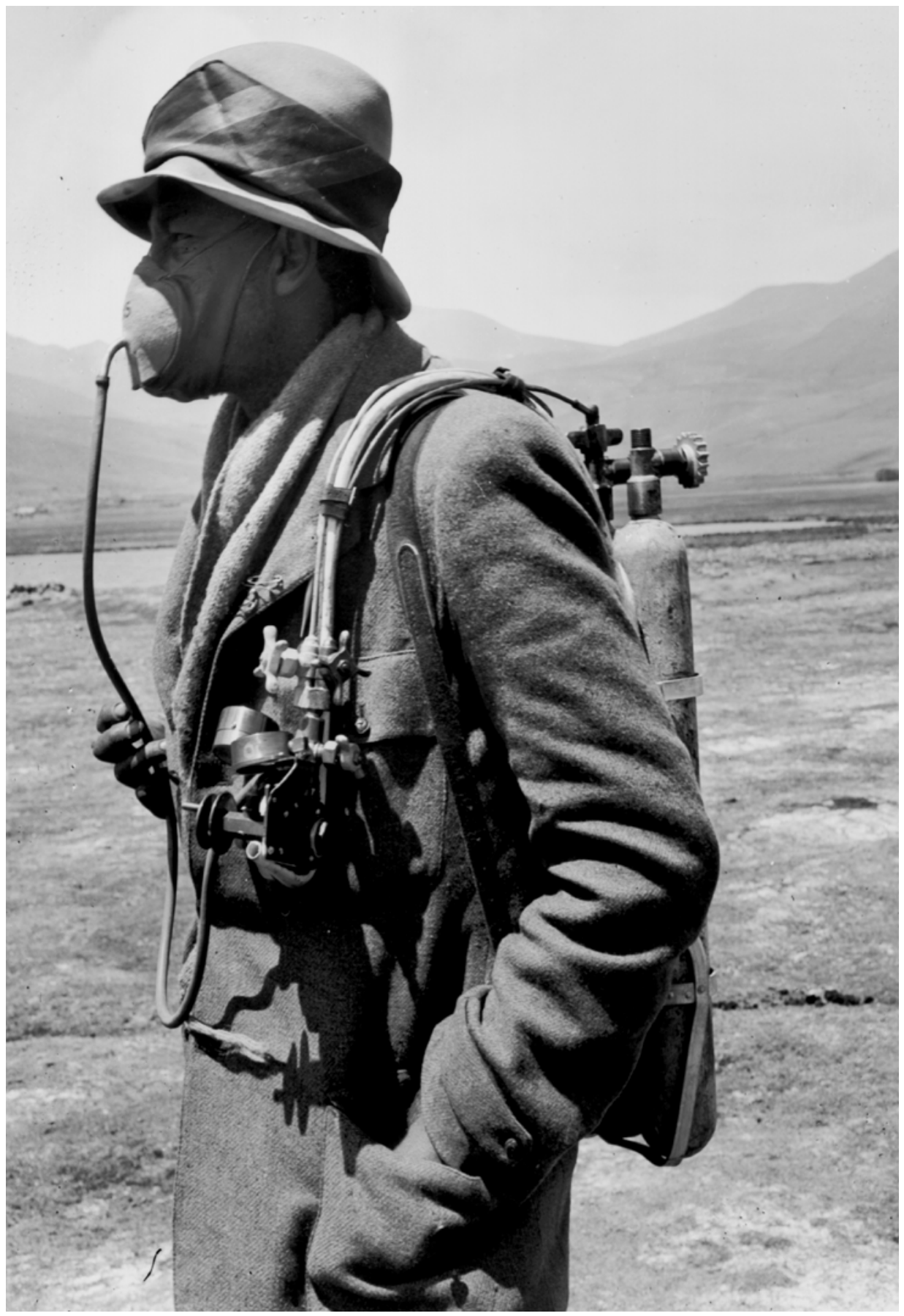

Image 2.2. The oxygen apparatus, invented by George Finch, used on the 1922 and subsequent Everest expeditions.

Photo courtesy of the Royal Geographical Society 


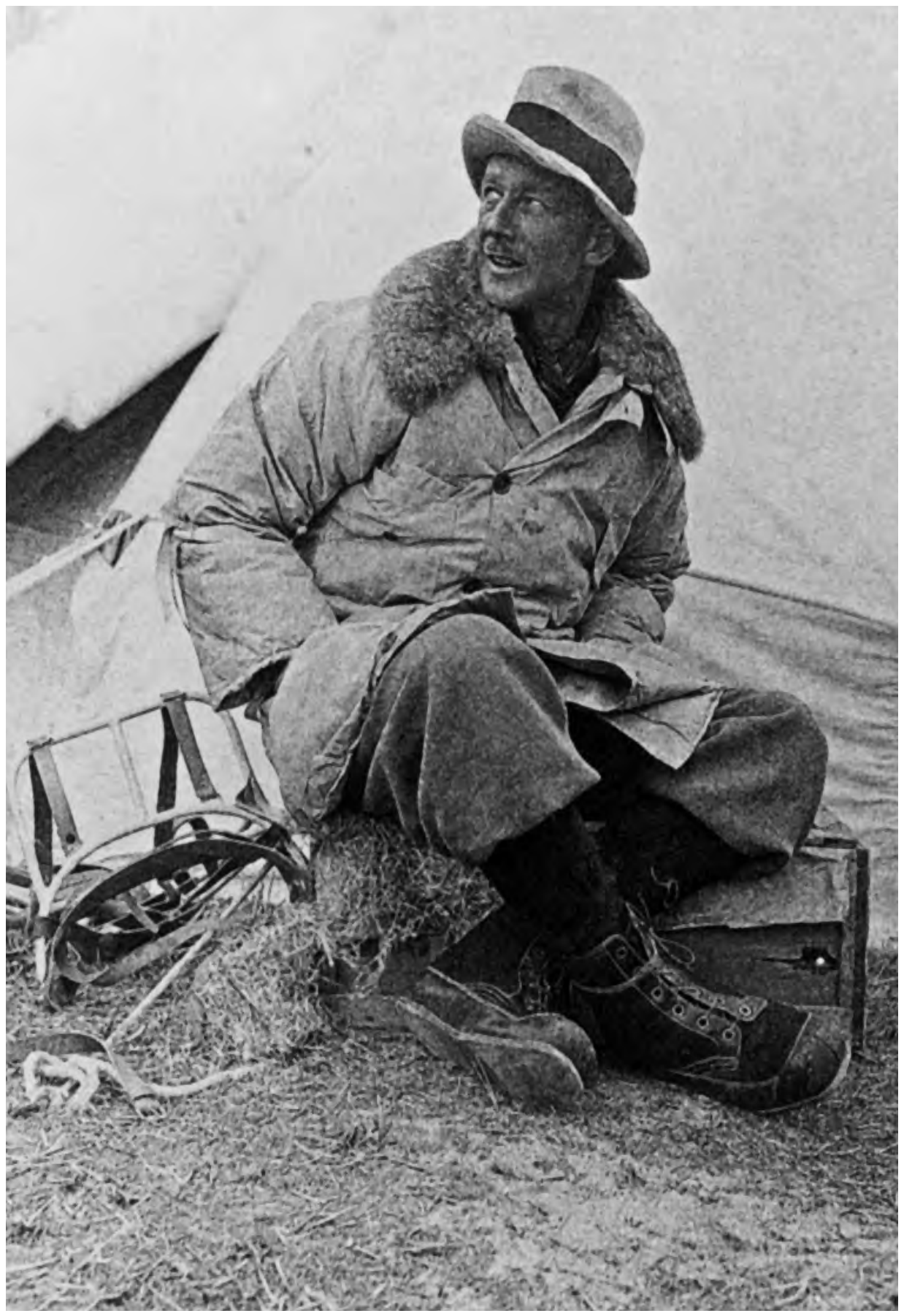

Image 2.3. George Finch on the 1922 Everest expedition, wearing the down-filled jacket that he invented.

Photo from the Finch collection, first published in Finch (1924) 


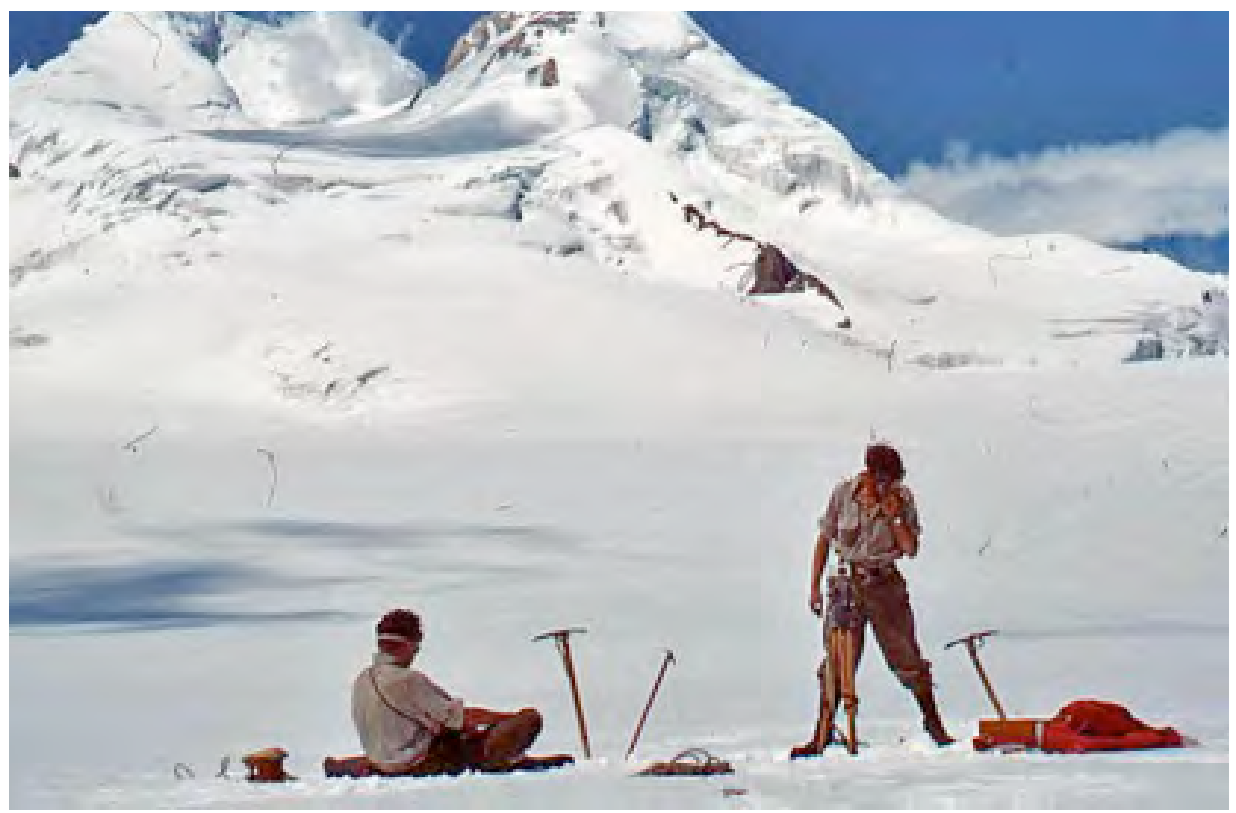

Image 3.1. Surveying on the southern source of the Lolofond Glacier, Imperial College Karakoram expedition, 1957. Grahame Budd (left) and Geoff Bratt, using the theodolite

Photo by Keith Miller

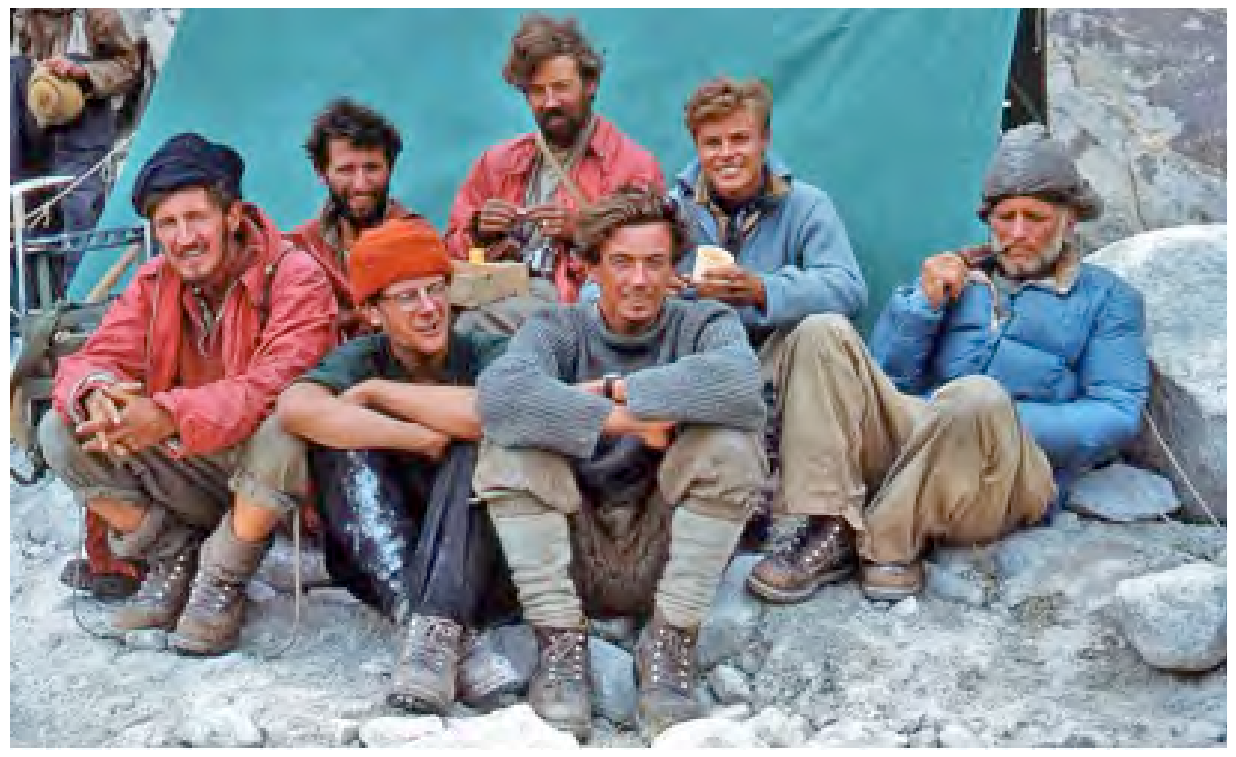

Image 3.2. Members of the Imperial College Karakoram expedition, 1957: From left, back row: Keith Miller, Brian Amos, Peter Grimley, Eric Shipton Front row: Geoff Bratt, Chris Gravina, Roger Cratchley 


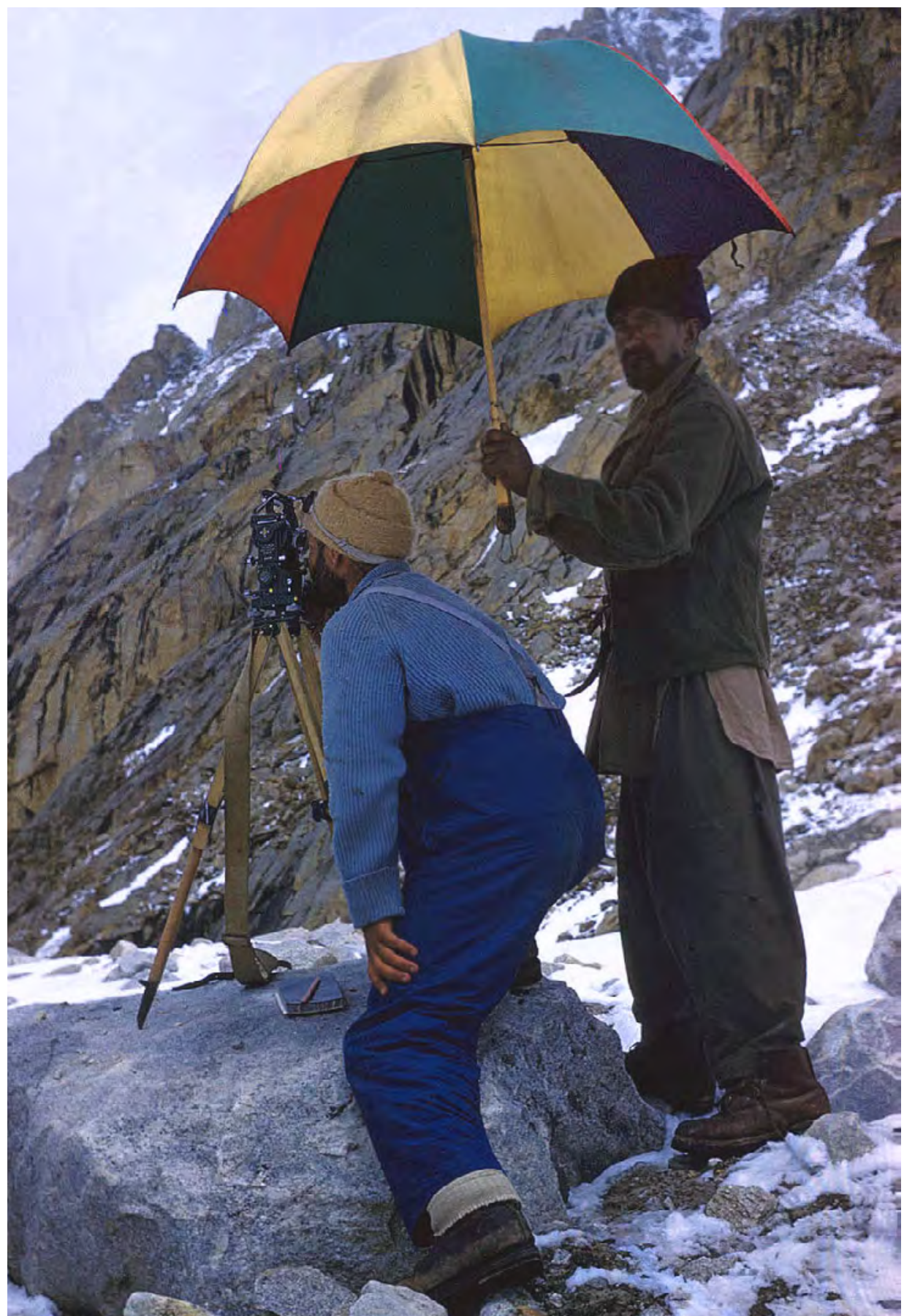

Image 3.3. Jon Stephenson surveying on the 1960 Saltoro expedition, Karakoram, accompanied by Ishmael, a Balti high altitude porter.

Photo provided by Jon Stephenson 


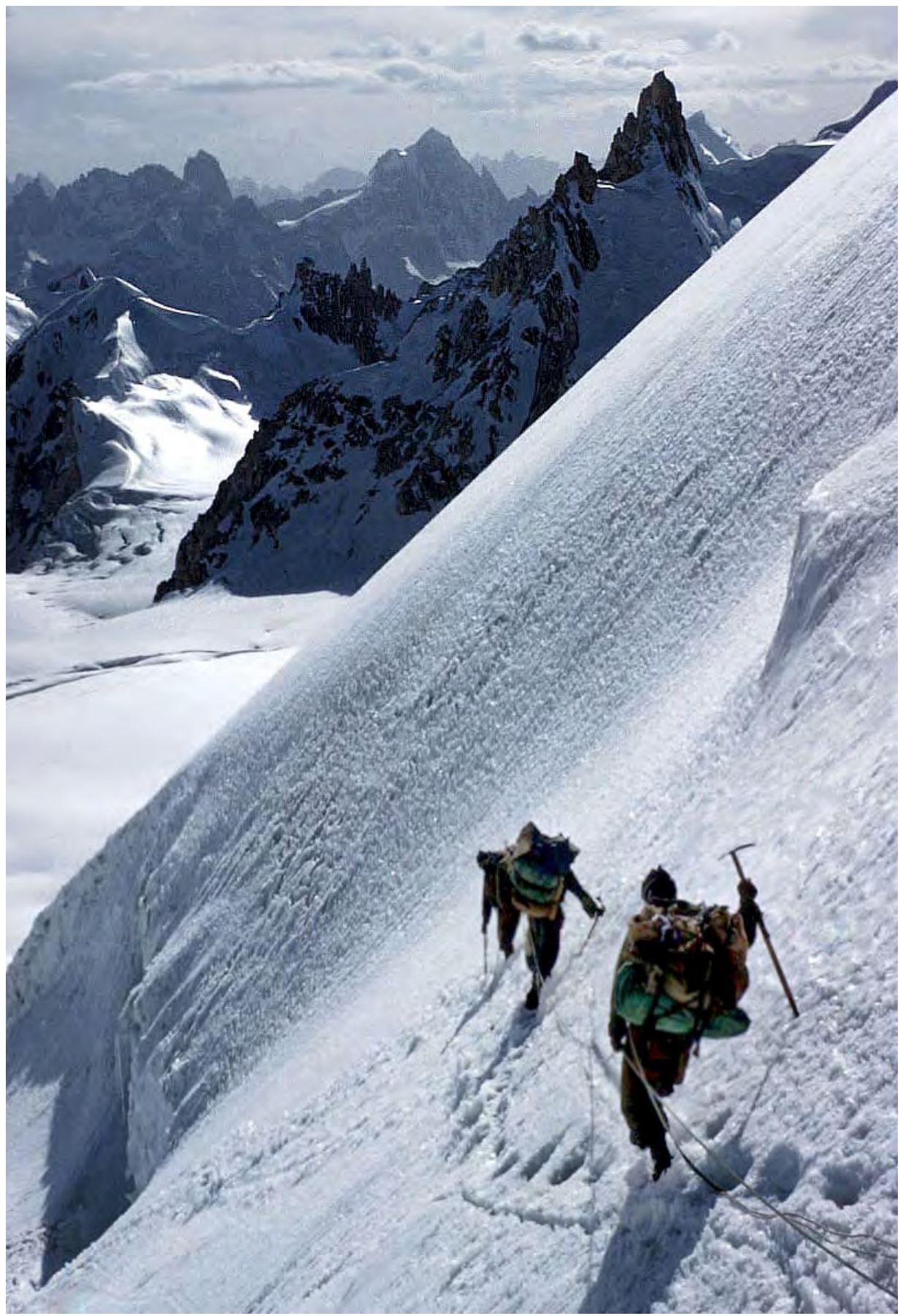

Image 3.4. Descending K12, 1960 Saltoro expedition, Karakoram,

Pakistan.

Photo by Jon Stephenson 


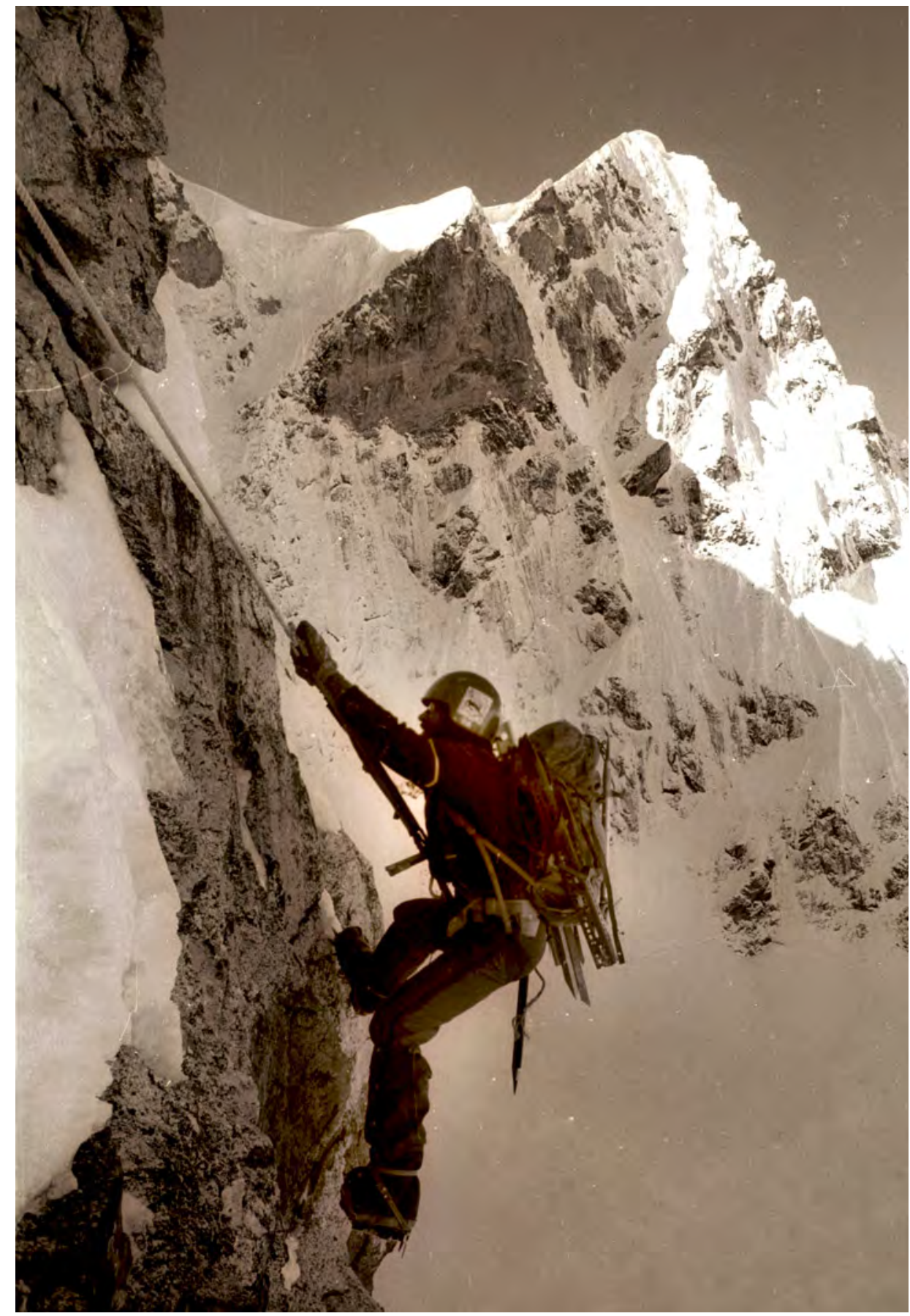

Image 3.5. Geoff Wayatt traversing across the "Wall of Shadows", north face of Jannu, Nepal,1975.

Photo provided by Geoff Waya 


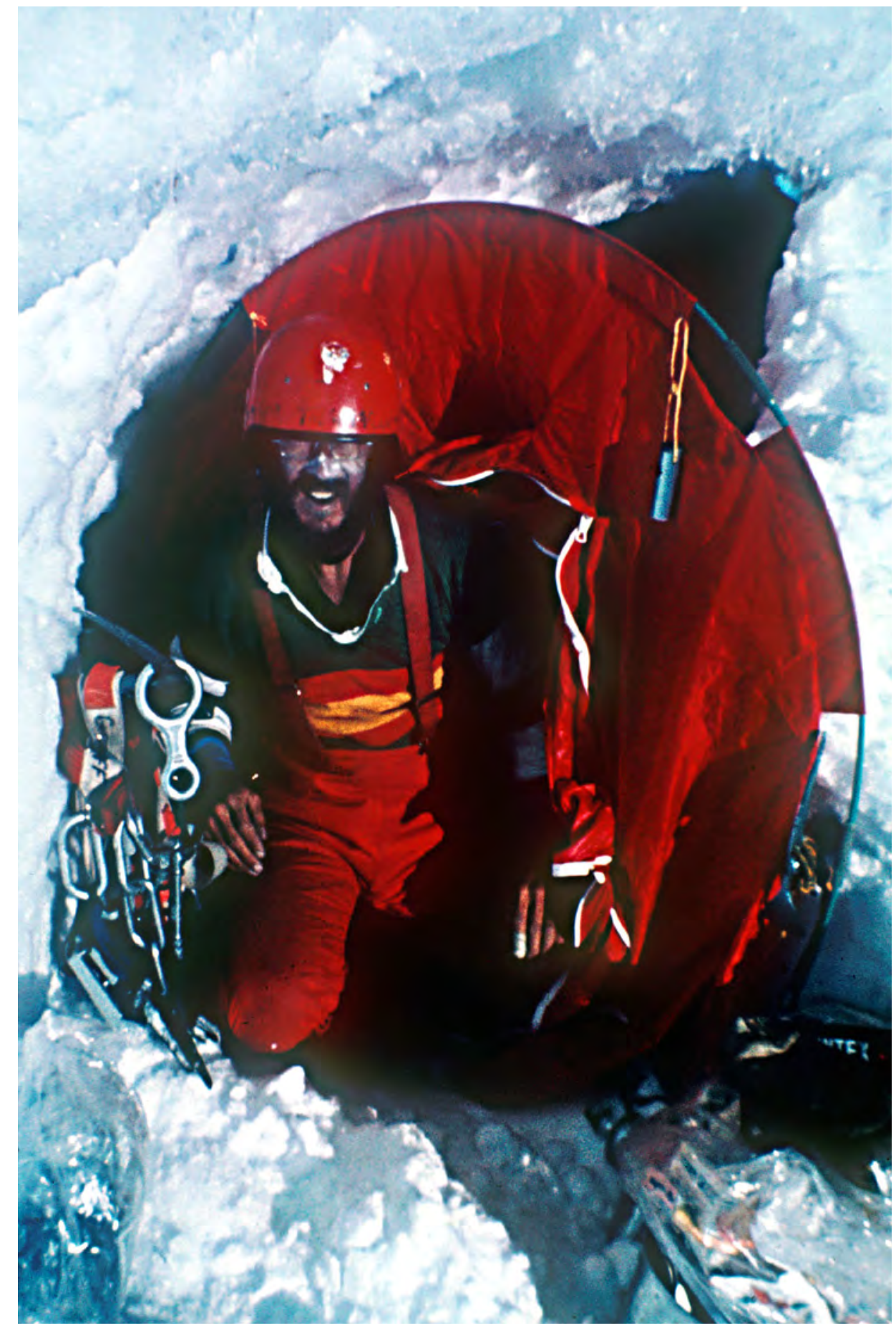

Image 3.6. Geoff Wayatt at camp three on the north face of Jannu, Nepal, 1975. Photo provided by Geoff Wayatt 


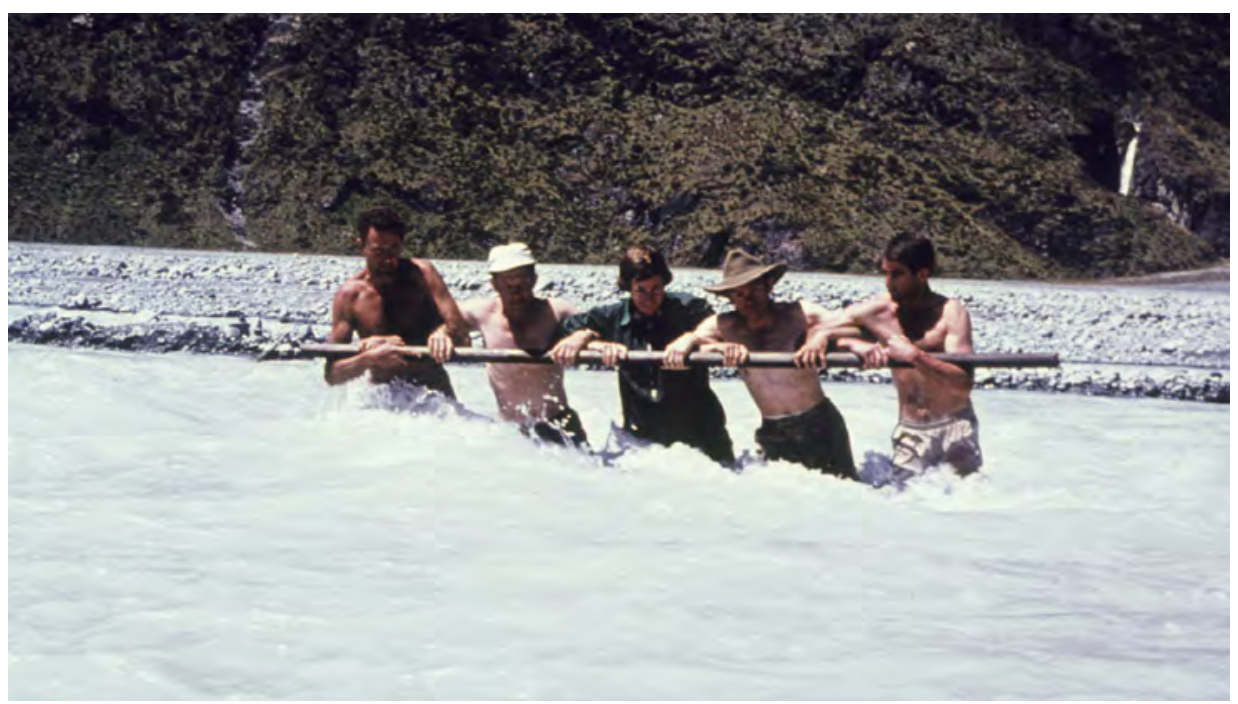

Image 4.1a. : Young Australian climbers on an instructional course in New Zealand in 1965 based at Ball Hut, near Mt Cook: practising (a) river crossing, and (b) crevasse rescue.

Photos provided by Dorothy Brown

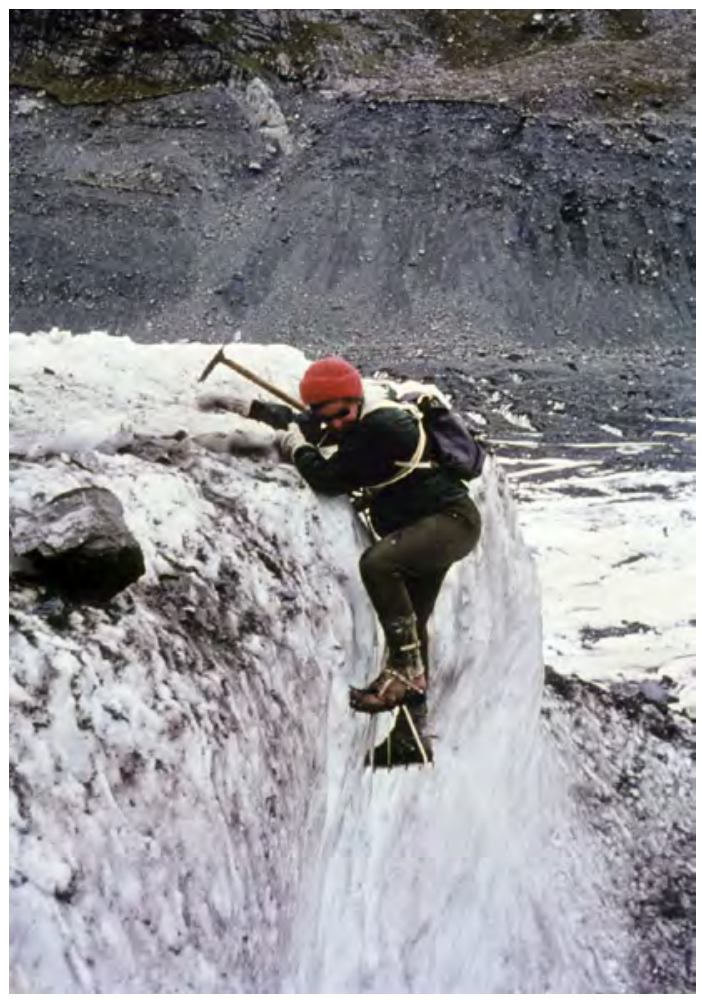

Image 4.1b 


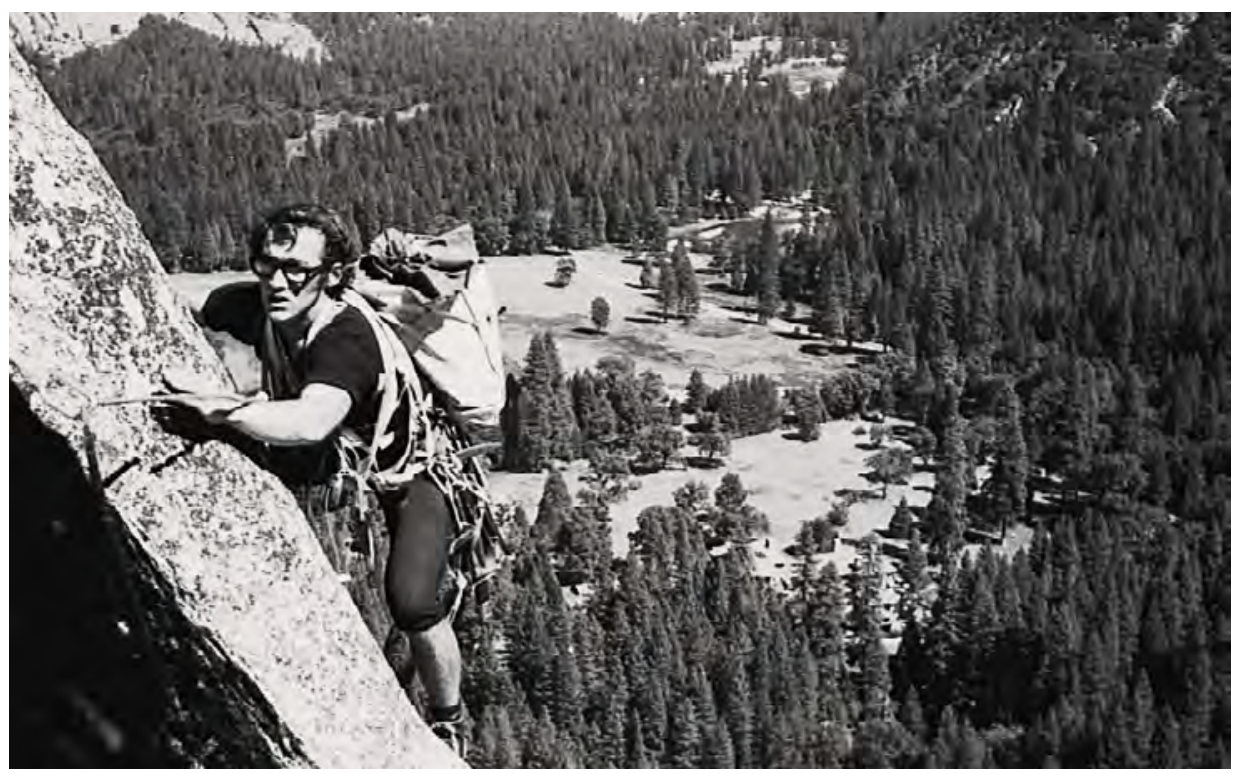

Image 4.2. A young Geoff Wayatt climbing in Yosemite National Park, California, USA, 1969.

Photo provided by Geoff Wayatt

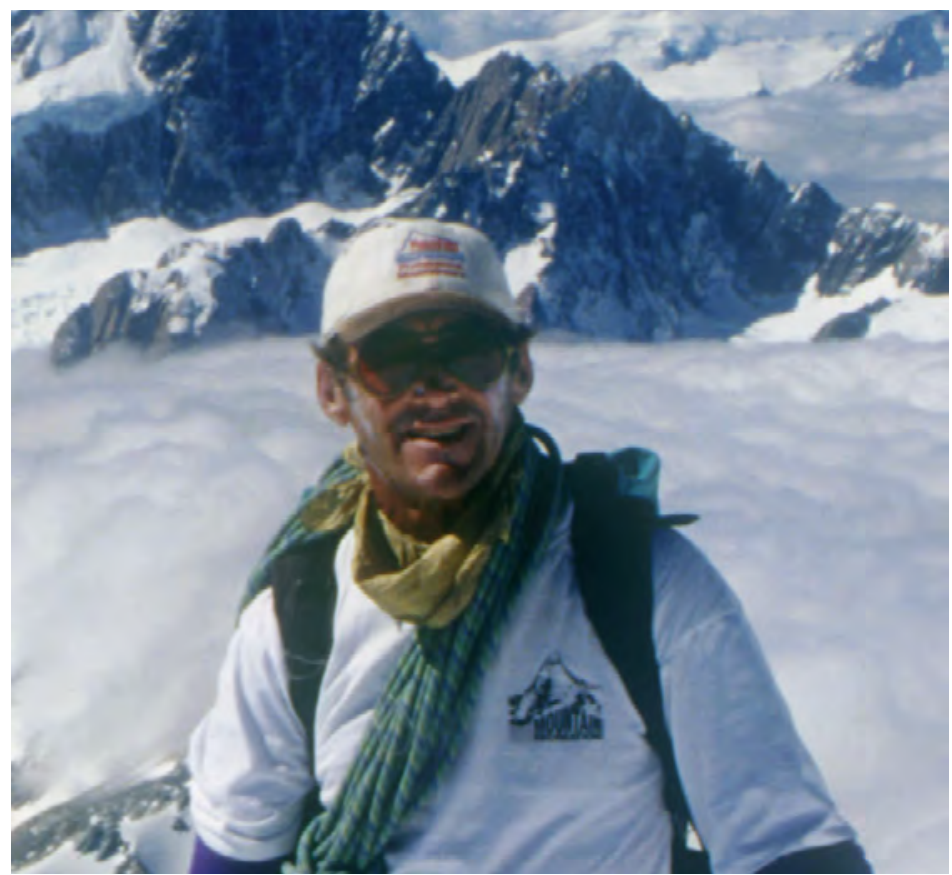

Image 4.3. Geoff Wayatt guiding on Mt Sefton, Southern Alps, New Zealand, 2007.

Photo provided by Geoff Wayatt 


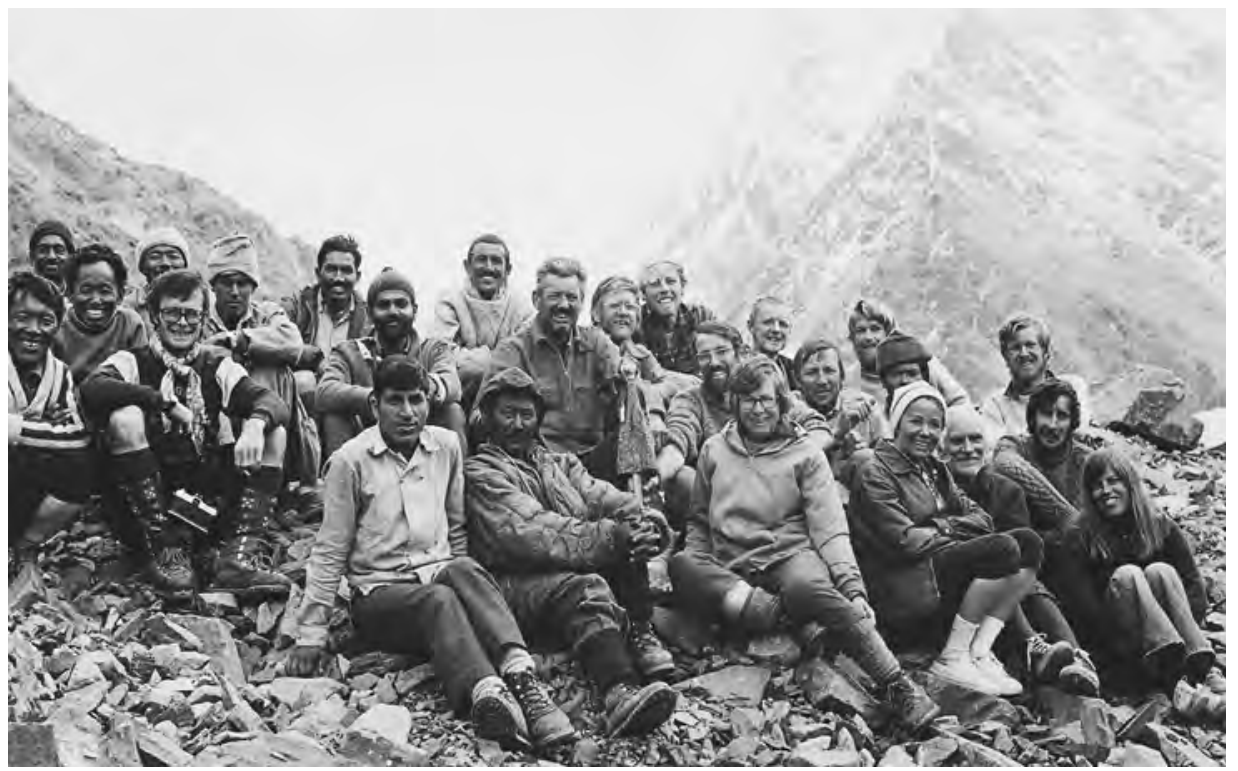

Image 5.1. The Mulkila expedition team at base camp, 1975

Photo provided by Dorothy Brown

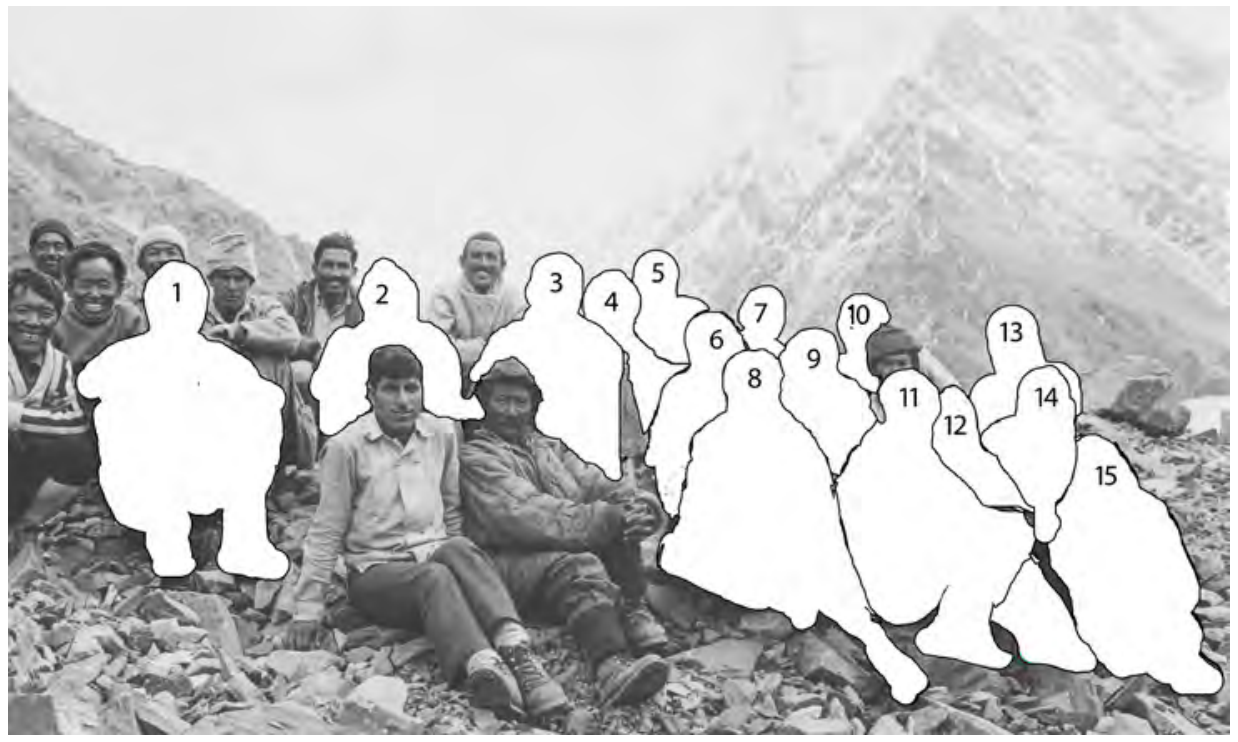

1. Michel Altmann. 2. J.P. Sharma (Indian Army Liaison Officer). 3.

Warwick Deacock. 4. John Ryder (or Gary Ash). 5. Peter Morris (Doctor for trip-now an ACT orthopedic surgeon). 6. Jim Dorrington. 7. John Dorrington. 8. Dorothy Brown. 9. Derek Lucas. 10. Adrian Blake. 11. Josephine Flood. 12. Harry Aldridge. 13. Gary Ash (or John Ryder). 14. Keith Seddon. 15. Terry Jack. 


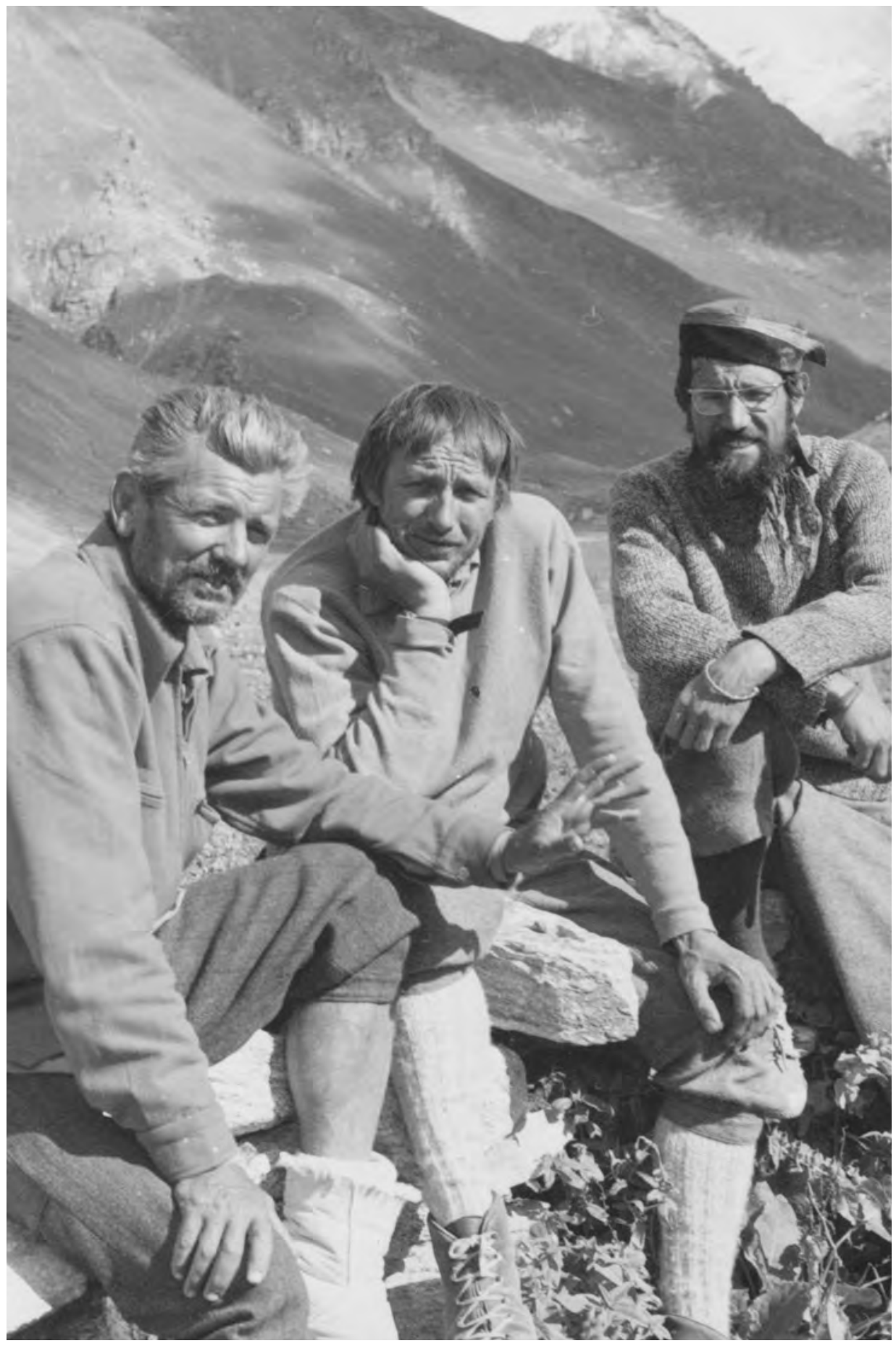

Image 5.2. From left: Warwick Deacock, Derek Lucas and Jim Dorrington at base camp on the glacier, Mulkila, 1975. 


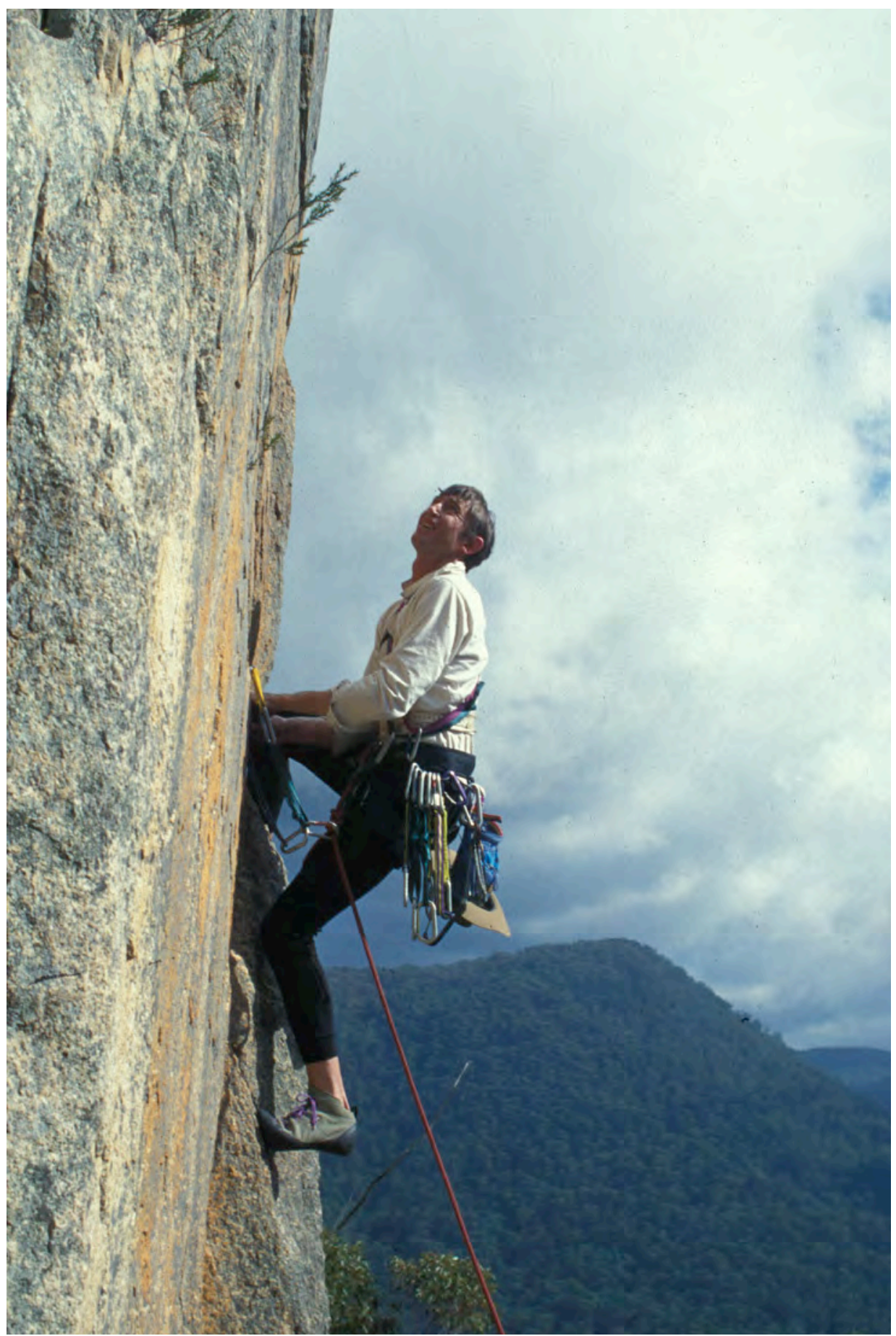

Image 6.1. A training climb at Booroomba Rocks near Canberra. Tim Macartney-Snape on "Morning Thunder".

Photo by James Press 


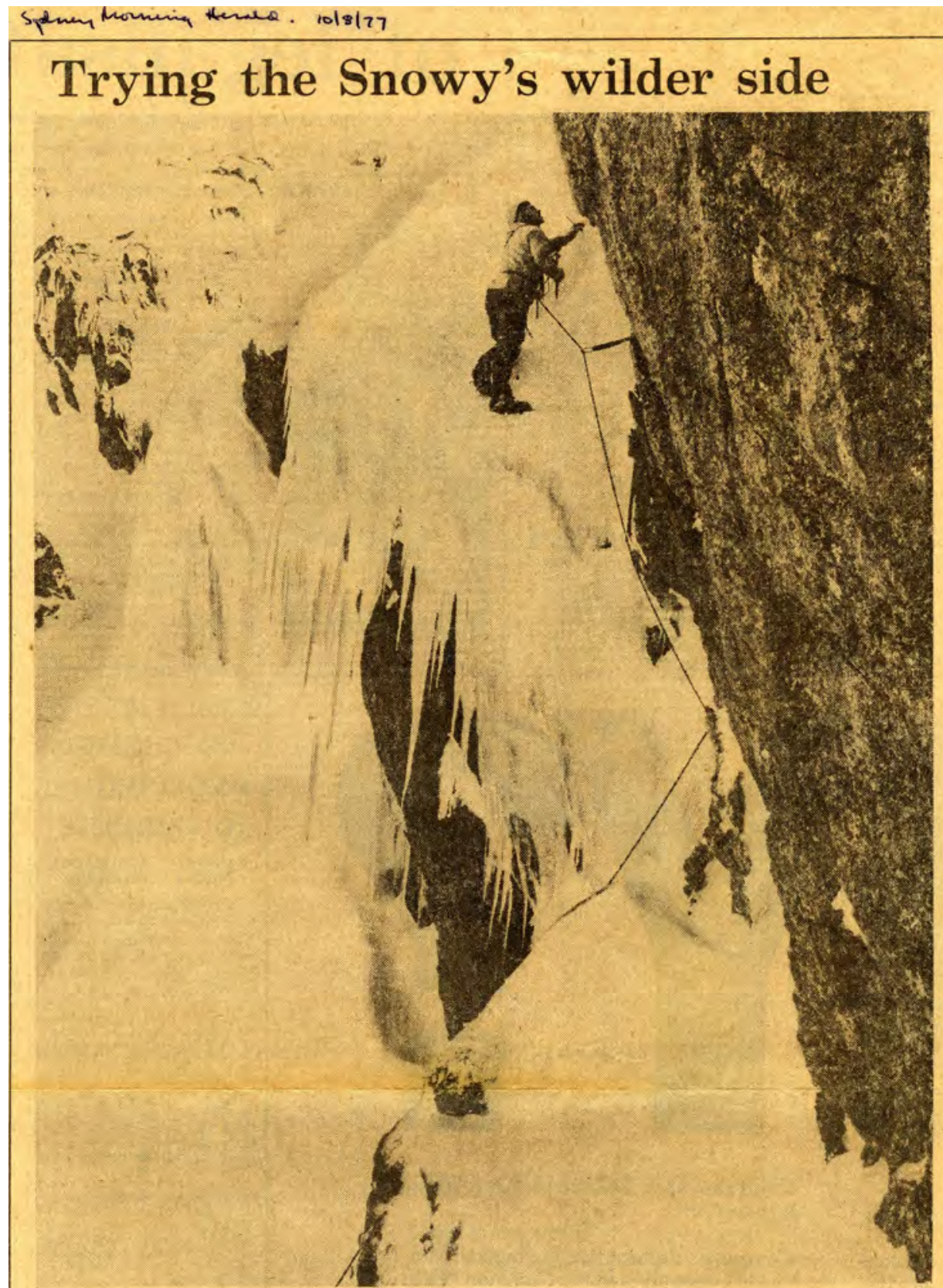

Far from the chic crowds of the Snowy Moun- bitter Blue Lake crags as a chance to sort out gear and tains ski resorts, high above the frozen Blue Lake, a climber tackles a steep shelf of hard ice. techniques before leaving next March,

For a few months, winter turns this wild side of

John Finnigan, 30, a CSIRO scientist, is one of the Snow inte a world apart, a place where the climb-

Image 6.2. Climbing the ice cliffs at Blue Lake, Snowy Mountains, NSW, a training climb for the ANUMC Dunagiri expedition, as reported in the Sydney Morning Herald, 1977.

Photo provided by Ken Baldwin 


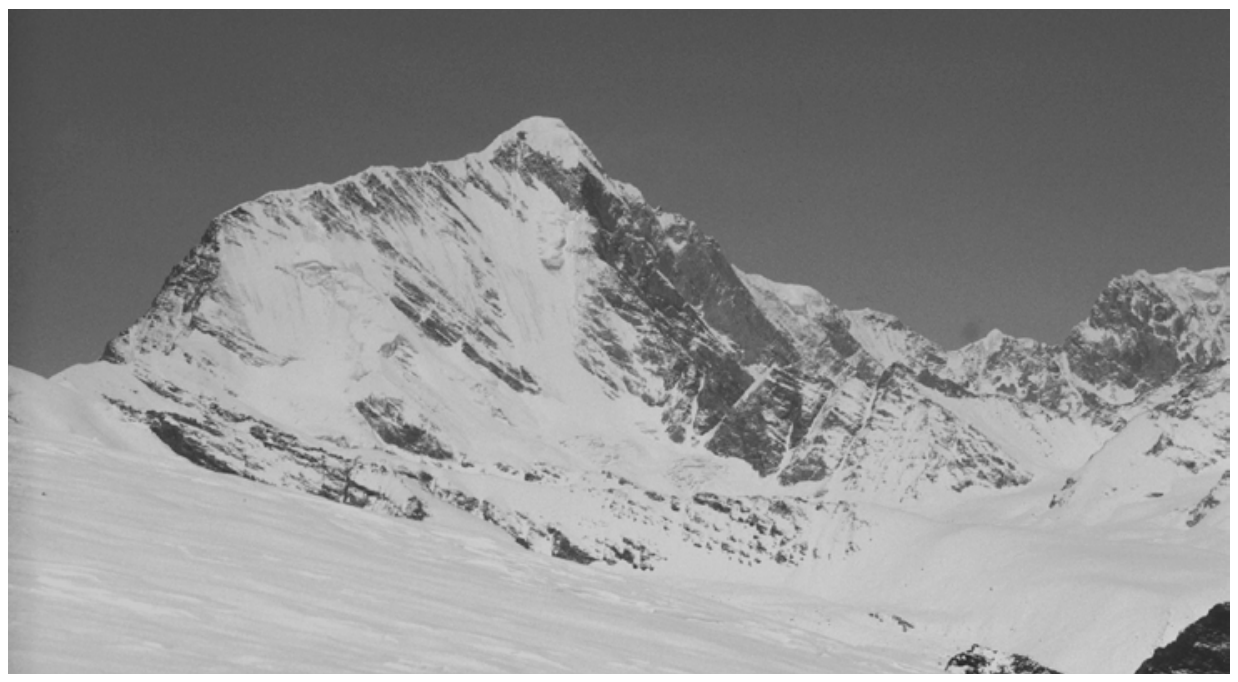

Image 7.1. Dunagiri (7066 m), India, the first major Himalayan peak climbed by an Australian expedition. The route went up to the snowy col at the left of the photo, up the rock buttress, and then along the skyline ridge to the summit.

Photo by Tim Macartney-Snape

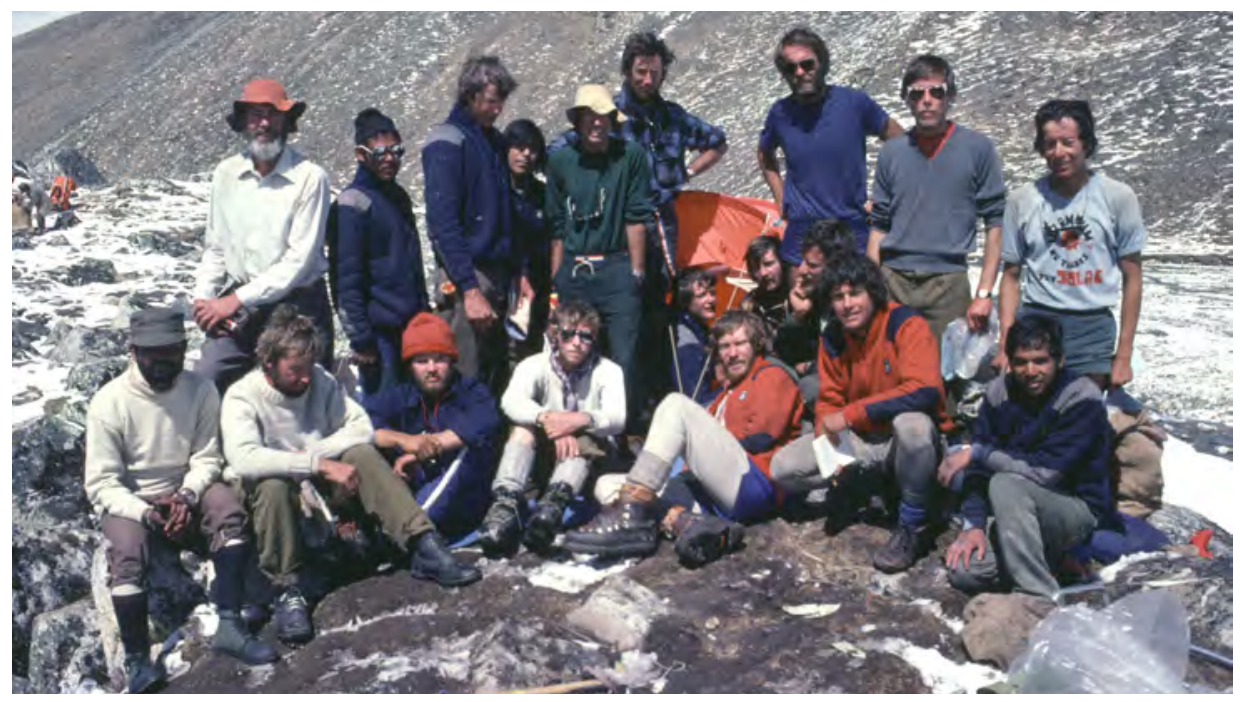

Image 7.2. The Dunagiri team at base camp. Front row, left: Captain Niyogi, Ken Bell, Theo Hooy, John Finnigan, Ken Baldwin, Martin Stone, Kundan Singh. Back row, left: John Armstrong, Sher Singh, Tim Macartney-Snape, Ganga Singh, Peter Cocker, Charlie Massey, Ben Sandilands, Keith Burns, Andrew Blakers. Seated in middle, left: Lincoln Hall, Andrew Bond, Mark Podkolinski.

Photo by Andrew Blakers 


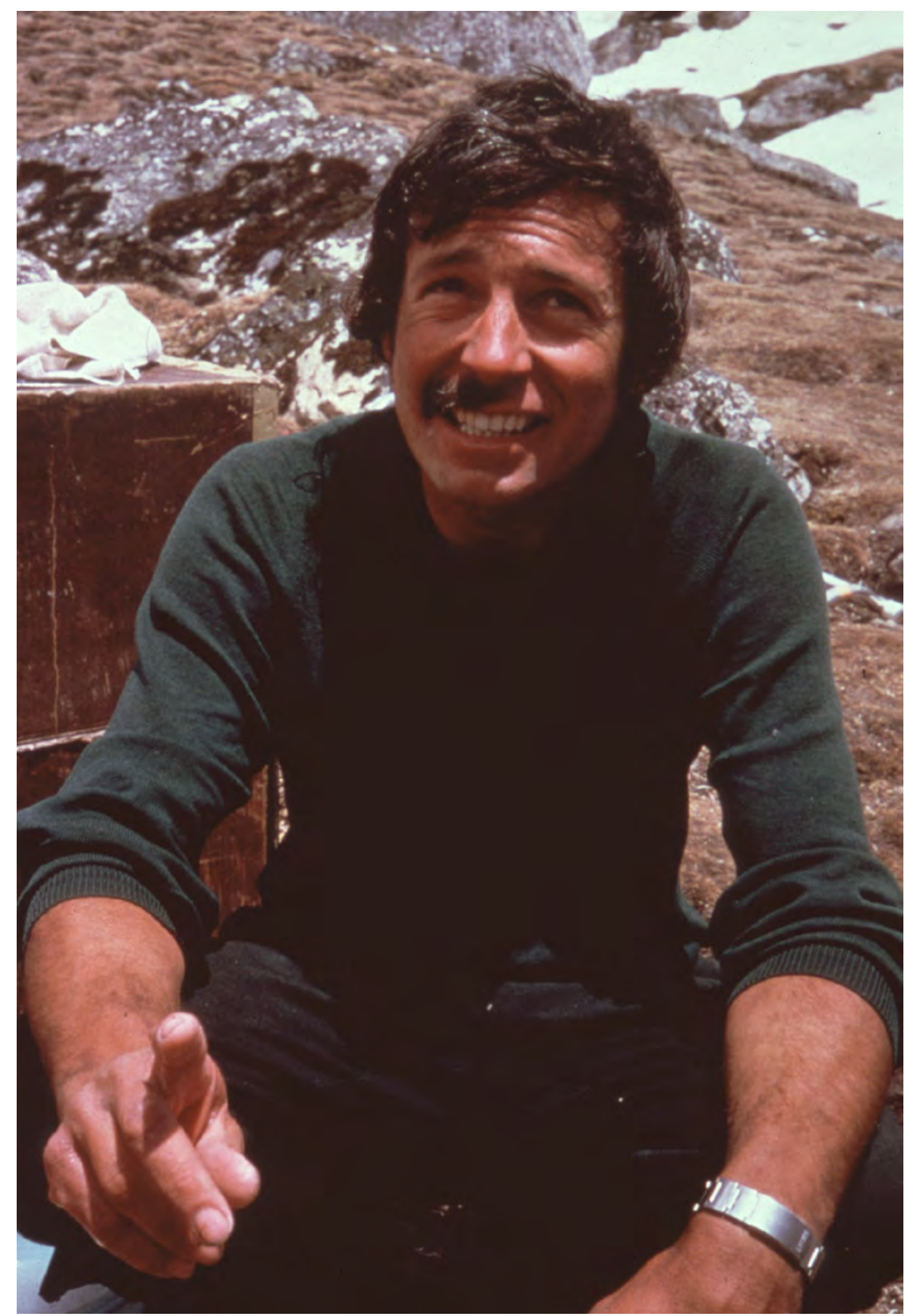

Image 7.3. Dunagiri expedition leader Peter Cocker at base camp.

Photo by Andrew Blakers 


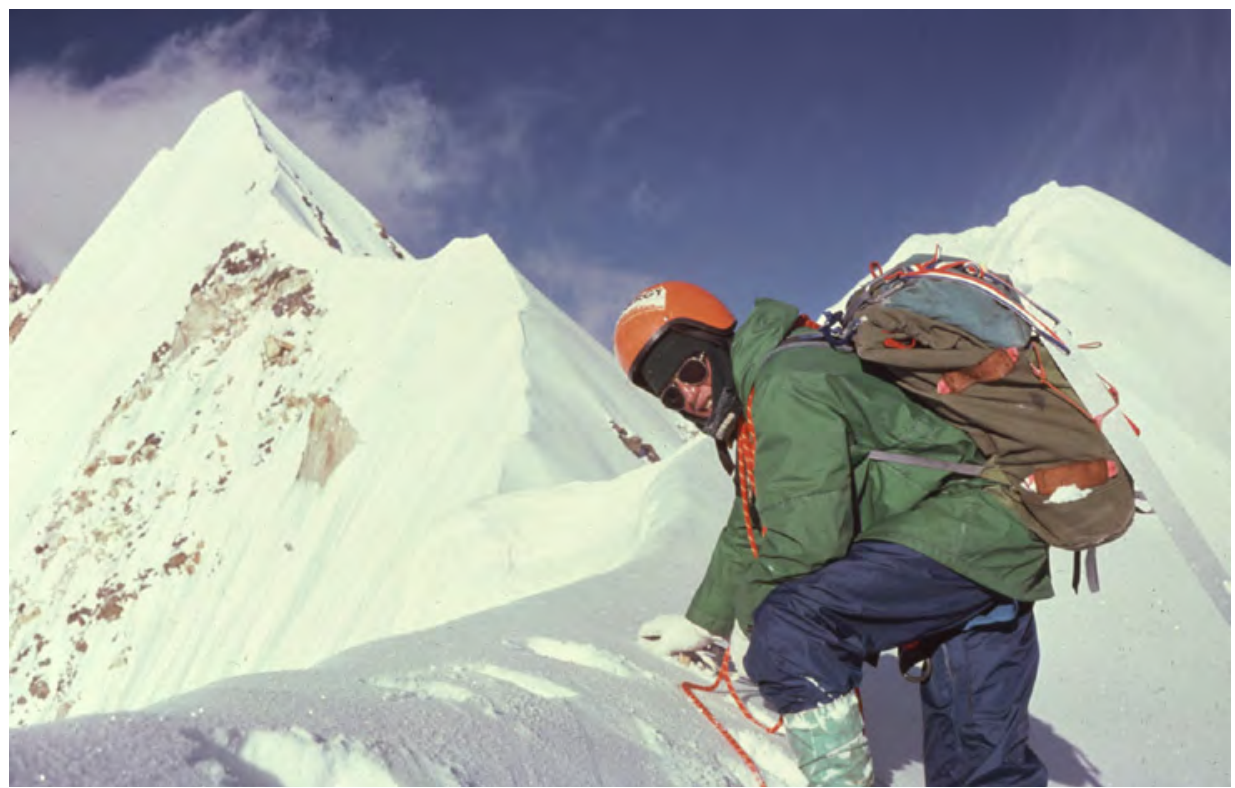

Image 7.4. Tim Macartney-Snape climbing along the summit ridge of Dunagiri.

Photo by Lincoln Hall

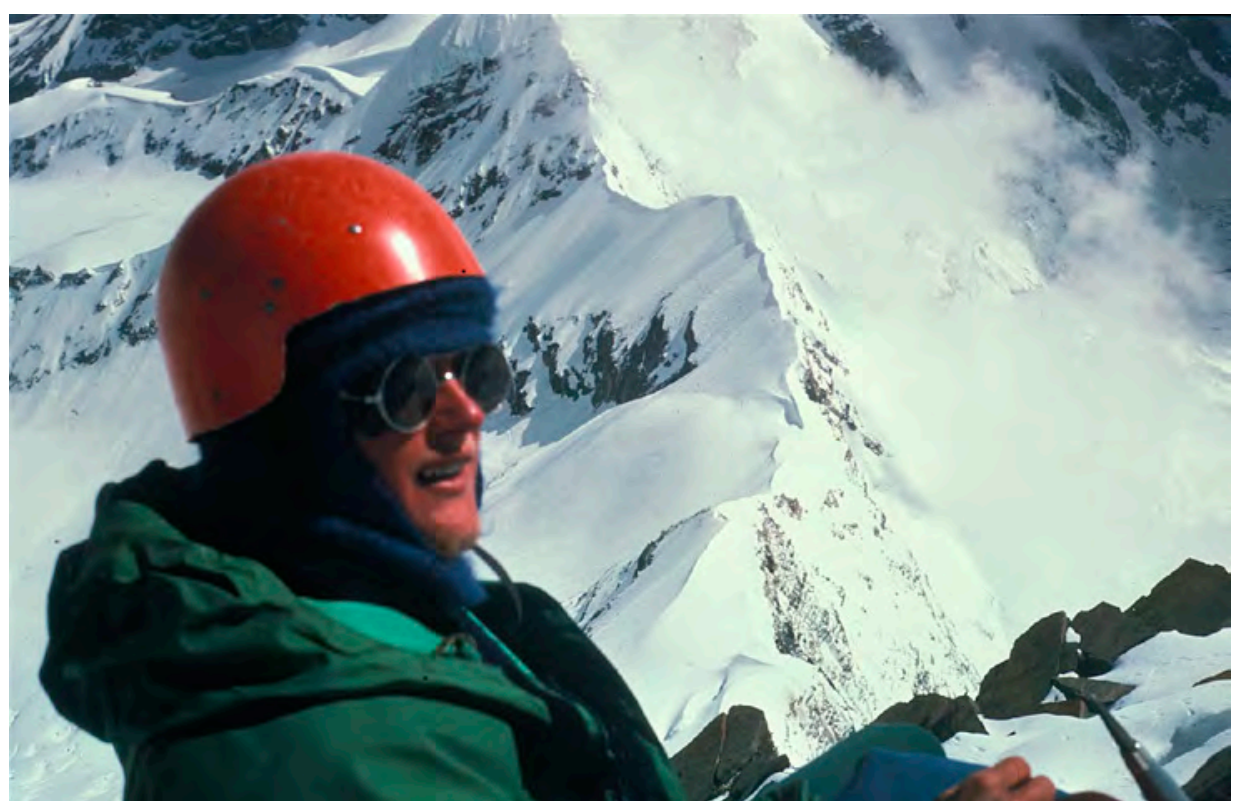

Image 7.5. Lincoln Hall at the start of the summit ridge of Dunagiri, with still almost two kilometres before the summit.

Photo by Tim Macartney-Snape 


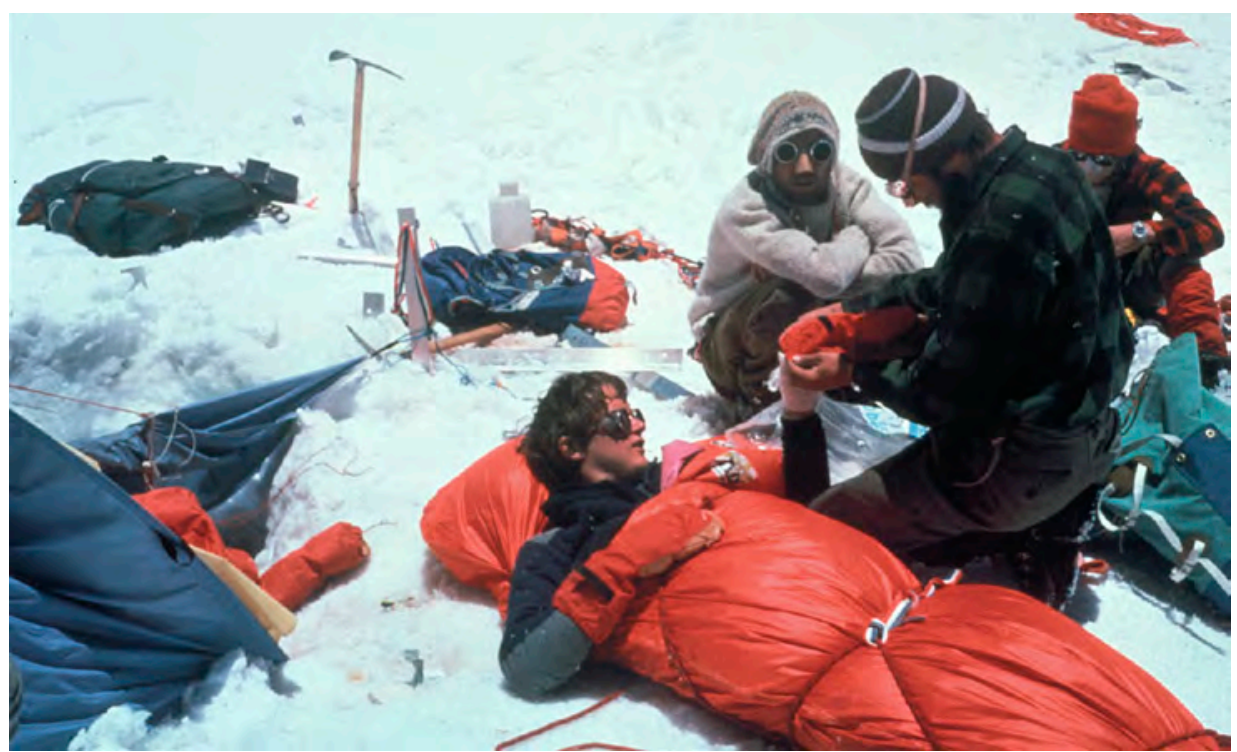

Image 7.6. The rescue of a frost-bitten Lincoln Hall on the lower slopes of Dunagiri. Climbers rendering assistance are Ken Bell, Mark Podkolinski and John Finnigan.

Photo by Tim Macartney-Snape

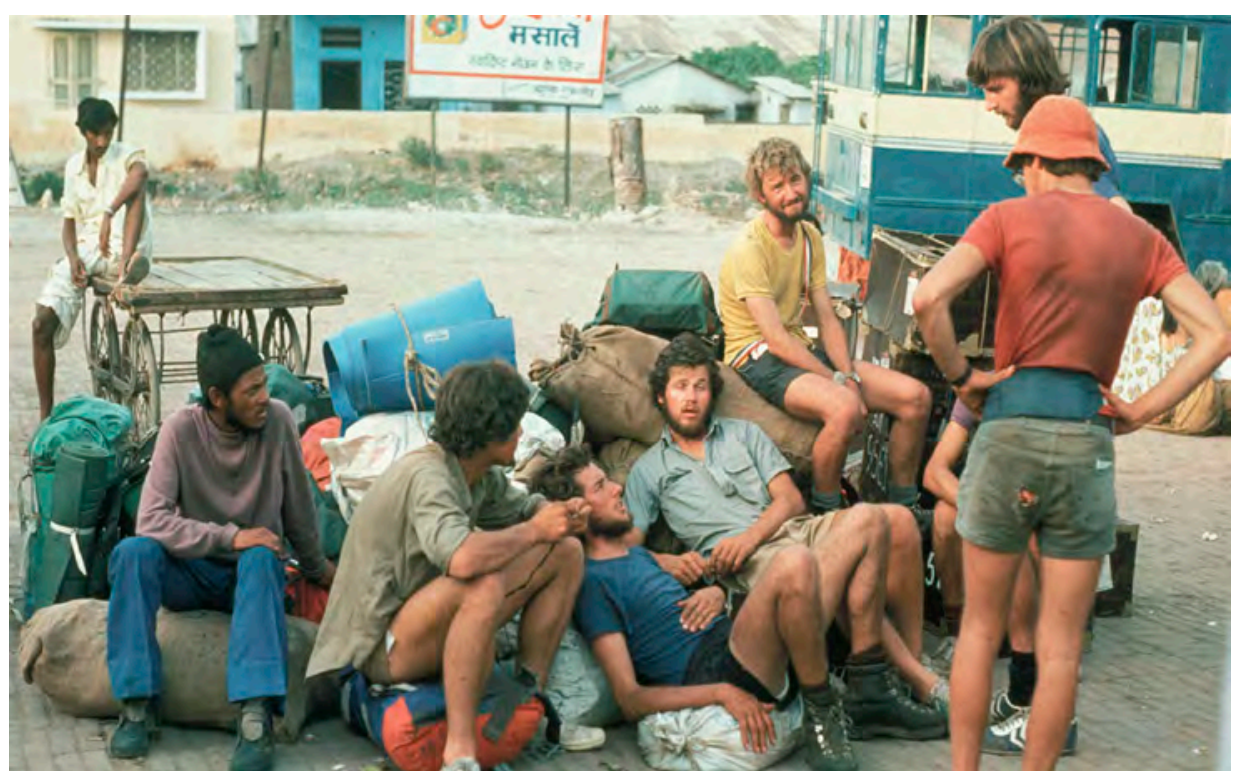

Image 7.7. Weary Dunagiri climbers after the expedition. From left: Sher Singh, Martin Stone, Charlie Massey, Theo Hooy, Ken Bell, Keith Burns (back turned to camera), Andrew Bond.

Photo by Tim Macartney-Snape 


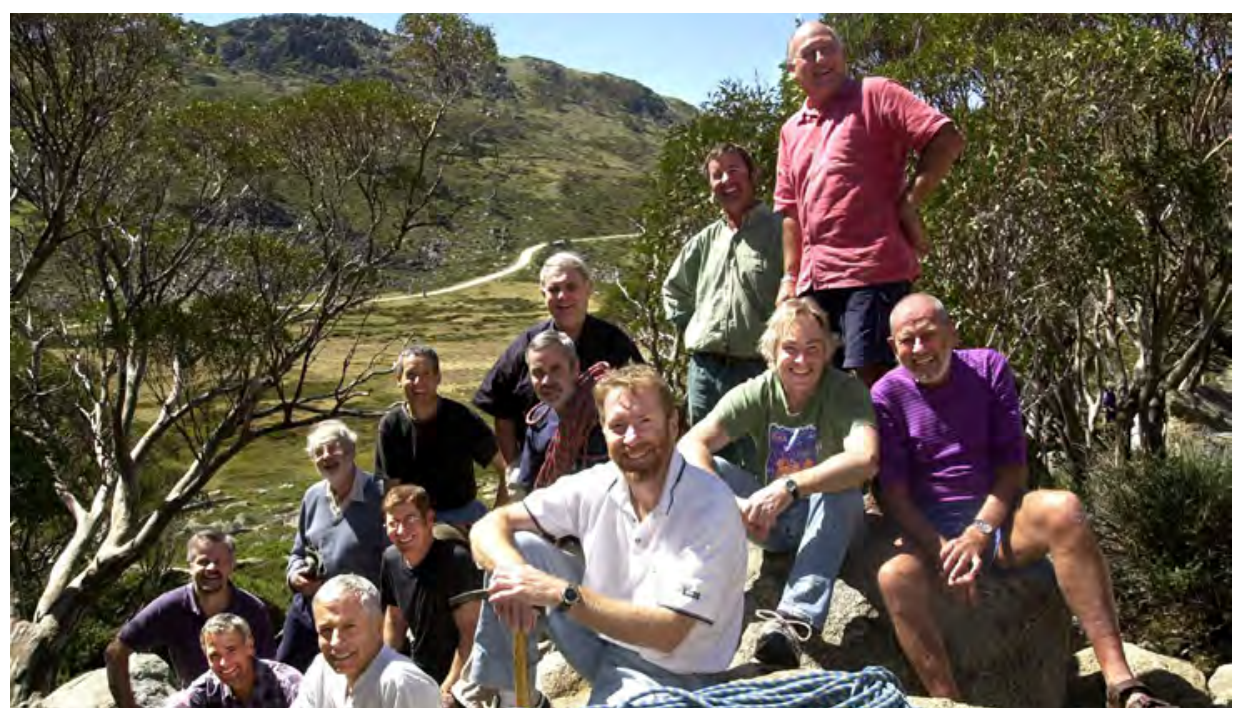

Image 7.8. The 25-year reunion of the Dunagiri expedition, Charlotte Pass, Snowy Mountains, NSW, 2003. Back, from left to right: Theo Hooy, John Armstrong, Andrew Blakers, Ben Sandilands, Ken Bell, Peter Smith. Middle, from left: Martin Stone, Peter Lane, Will Steffen, John Finnigan, Bill Packard. Front, from left: Peter Cocker, Ken Baldwin. Packard was patron of the Dunagiri expedition. Lane and Steffen were members of the 1988 Baruntse expedition; Smith was a member of the trekking party to Baruntse.

Photo by Ken Baldwin

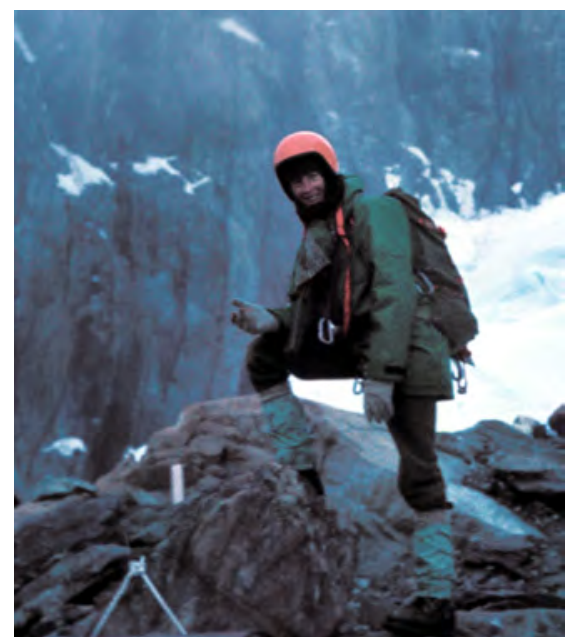

Image 8.1. Climbing in New Zealand's Southern Alps. Tim MacartneySnape at the base of the south face of Mt Hicks.

Photo by Lincoln Hall 


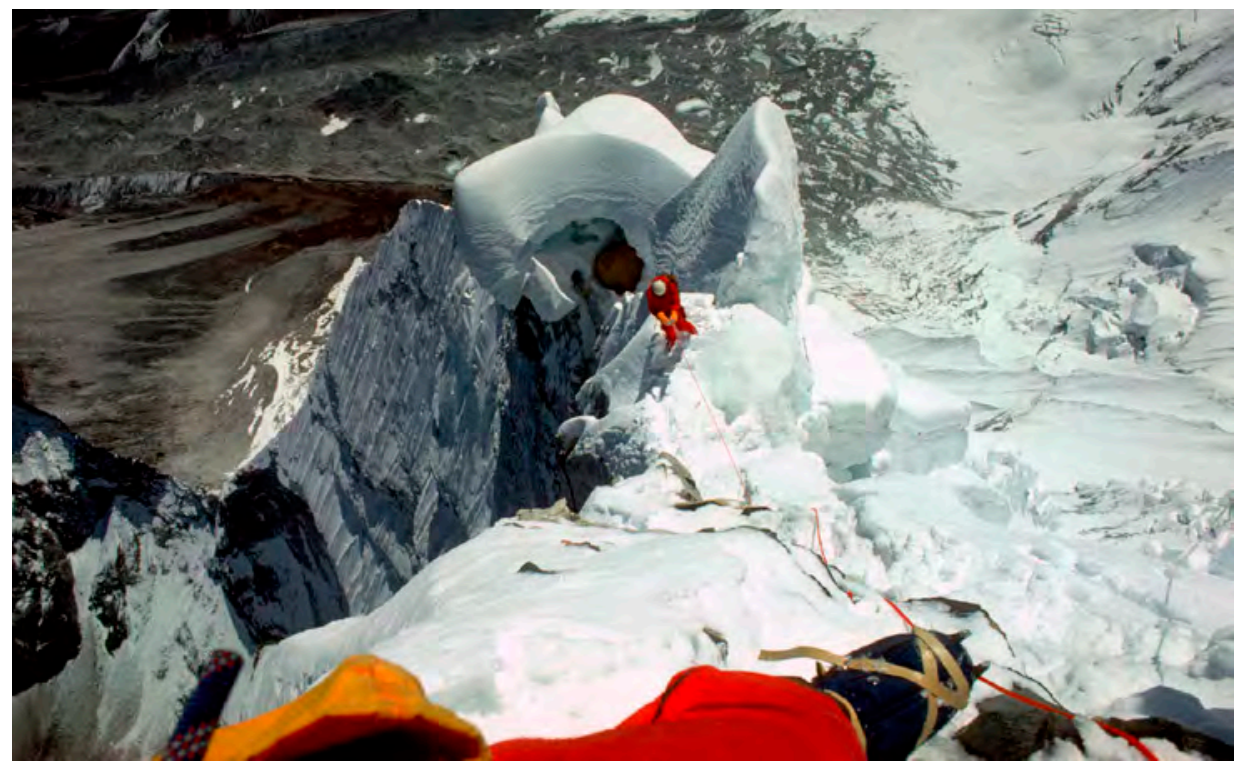

Image 9.1. Andy Henderson climbing on fixed rope high on Ama Dablam, Nepal.

Photo by Tim Macartney-Snape

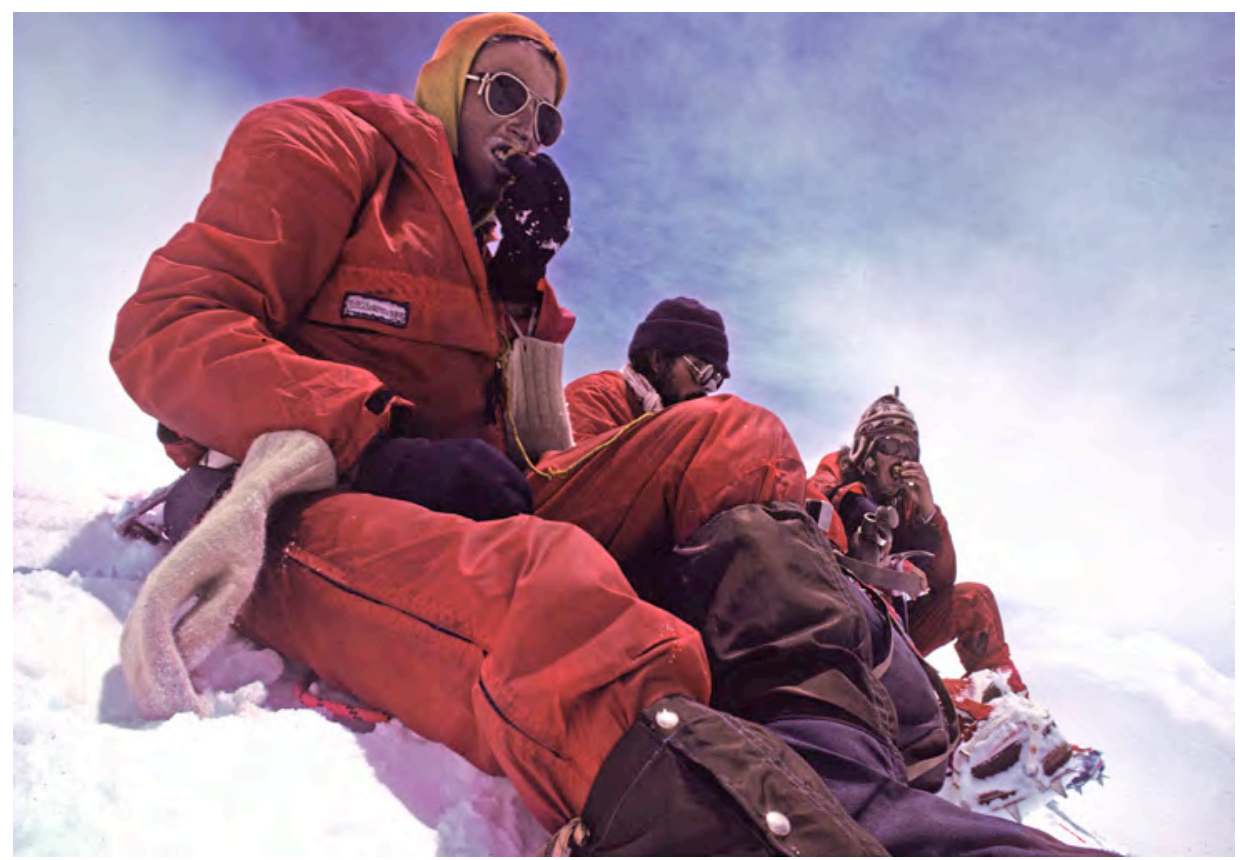

Image 9.2. On the summit of Ama Dablam. From left: Tim MacartneySnape, Andy Henderson and Lincoln Hall.

Photo by Tim Macartney-Snape 


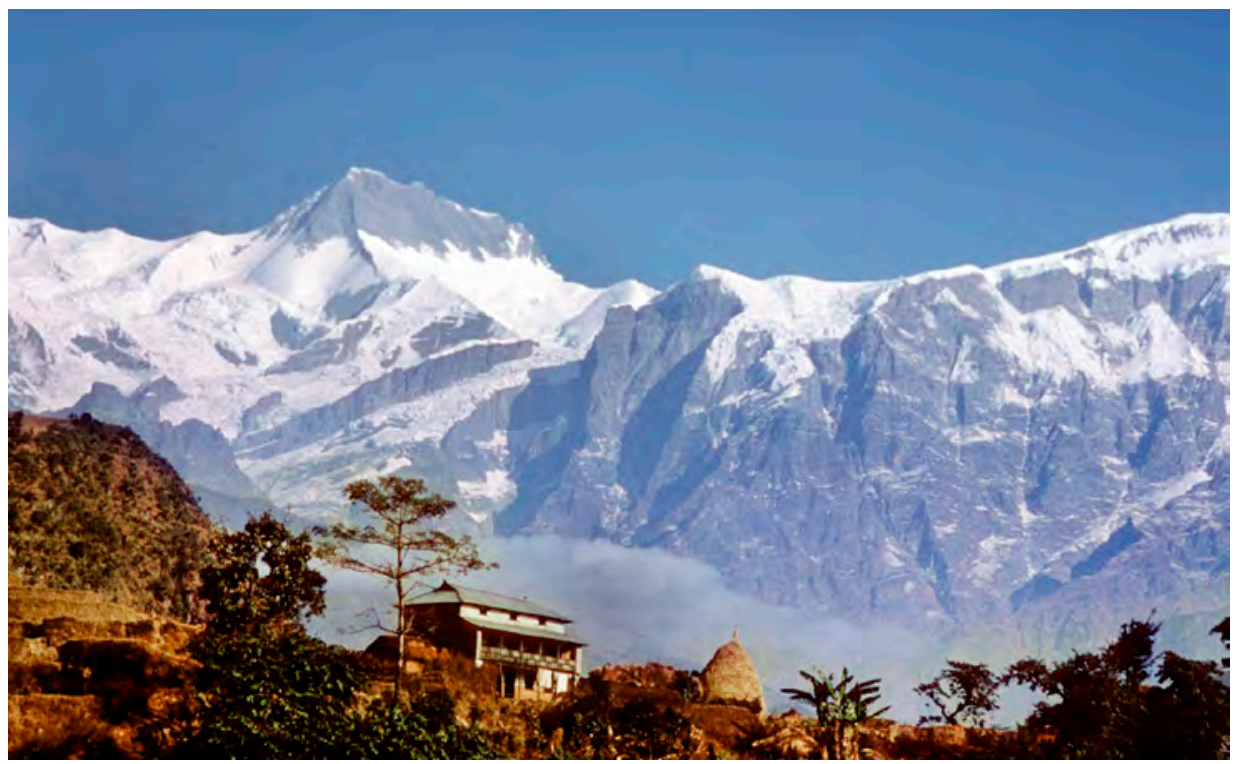

Image 10.1. Annapurna II (7937 m), as seen from low in the foothills near Pokhara, Nepal. The Australian expedition climbed the prominent spur sweeping down to the right from the summit.

Photo by Tim Macartney-Snape

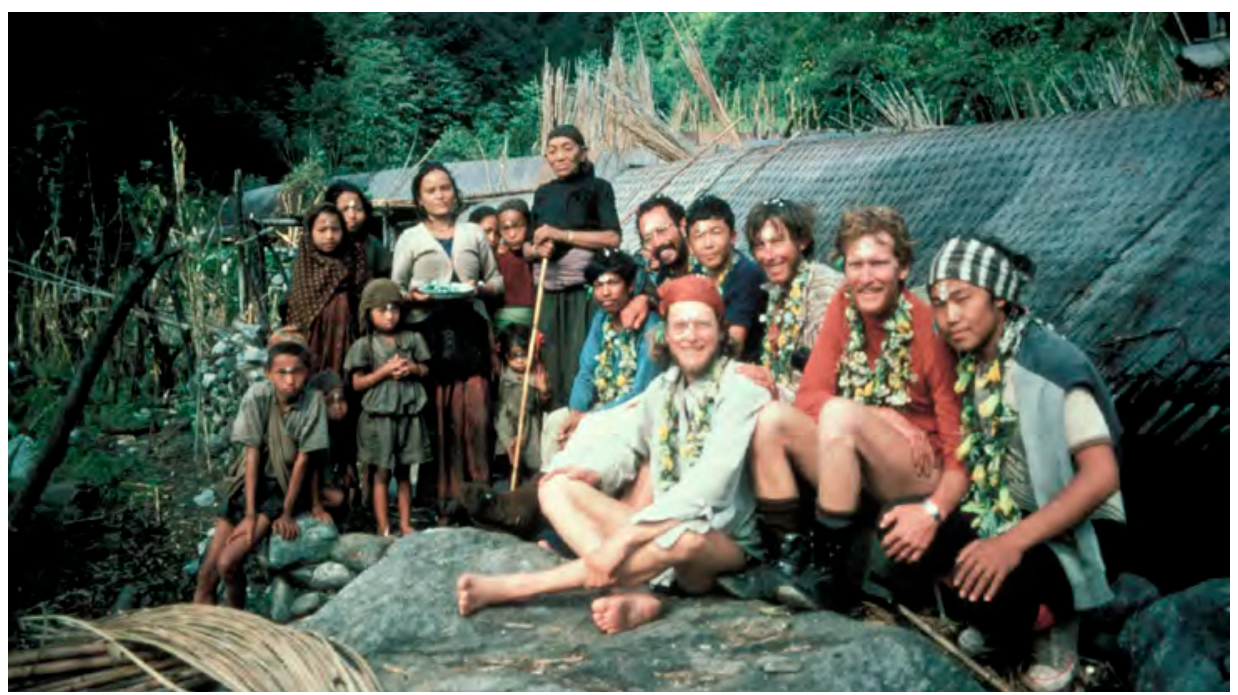

Image 10.2. The Annapurna II expedition team, post-ascent at a jungle settlement below the mountain. From left: Narayan Shresta (in blue), Andy Henderson, Durga Rai, Lincoln Hall, Tim Macartney-Snape, Greg Mortimer and Tenzing Sherpa (Missing: Mike Groom, Ong Chu Sherpa).

Photo from the Tim Macartney-Snape collection 


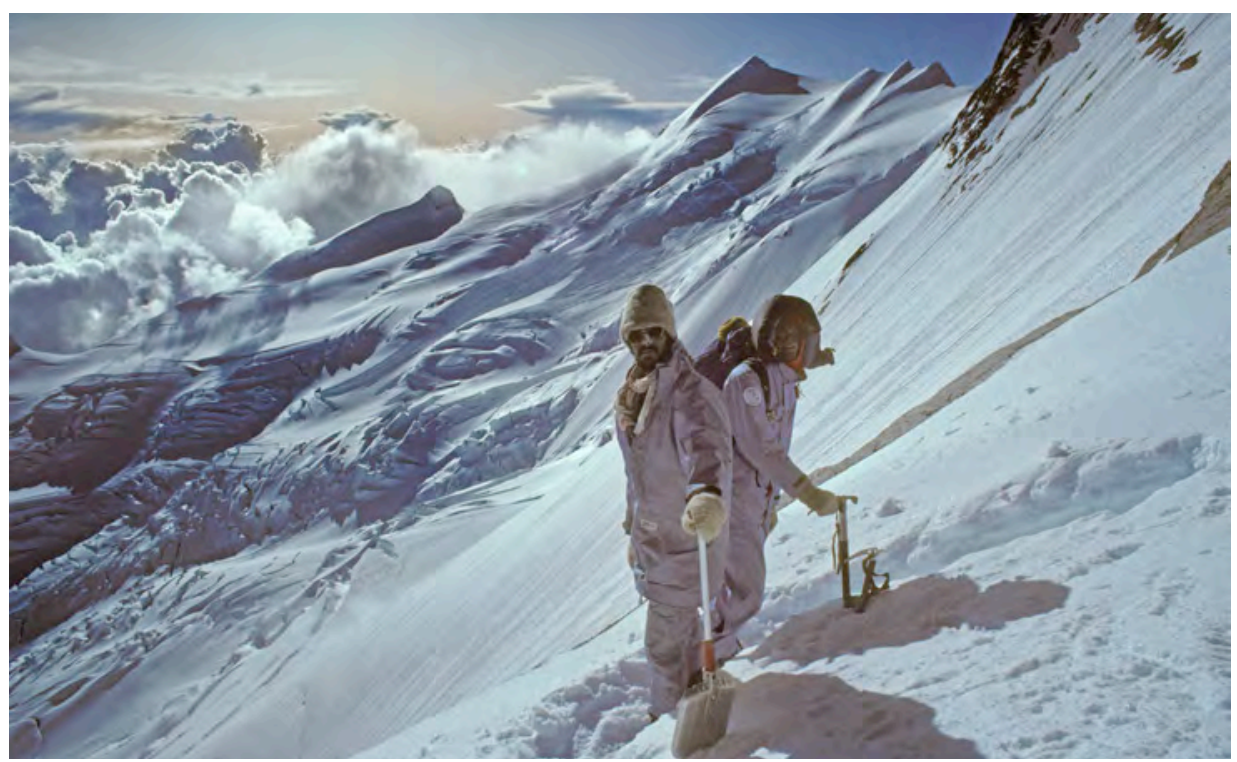

Image 10.3. At the snow cave (camp two) about $6600 \mathrm{~m}$ high on Annapurna II. The two climbers are Greg Mortimer and Andy Henderson (with beard).

Photo by Tim Macartney-Snape

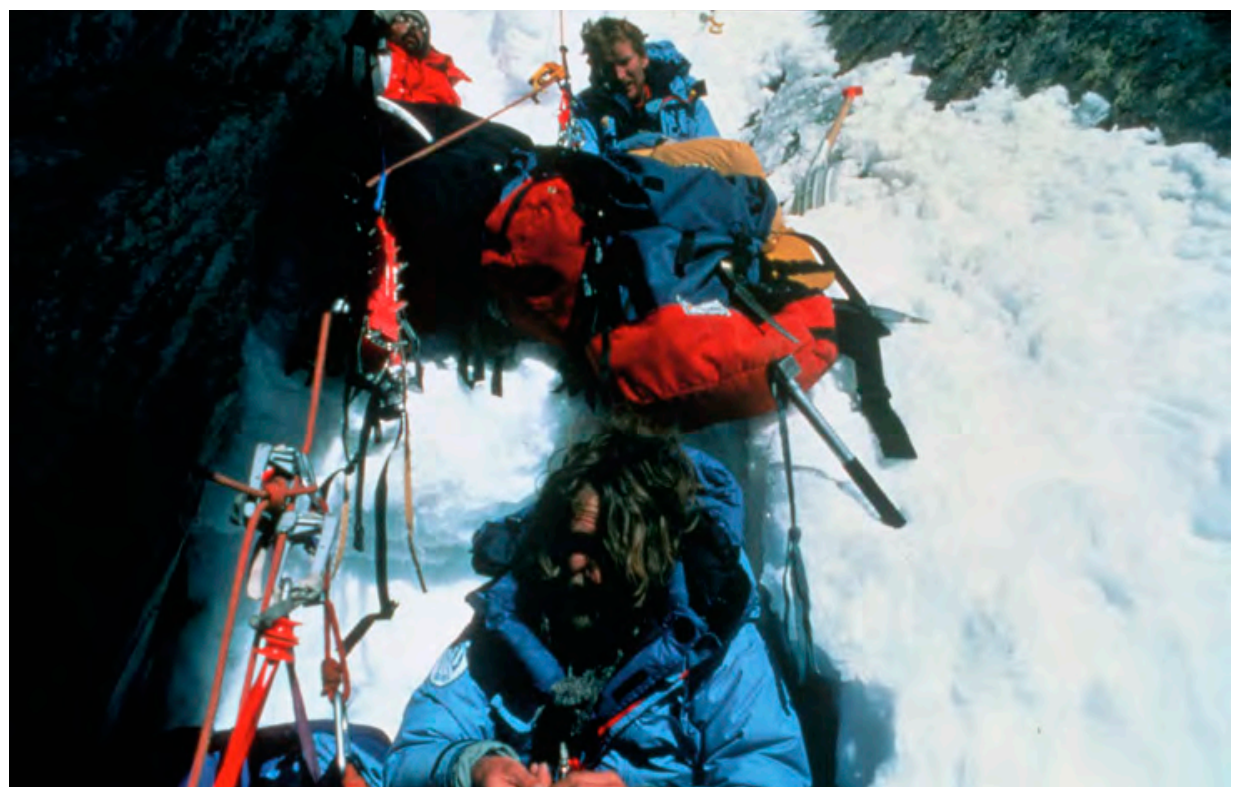

Image 10.4. A bivouac high on the ridge below the summit of Annapurna II. The climbers are Andy Henderson (left) and Greg Mortimer at the top, and Lincoln Hall below.

Photo by Tim Macartney-Snape 


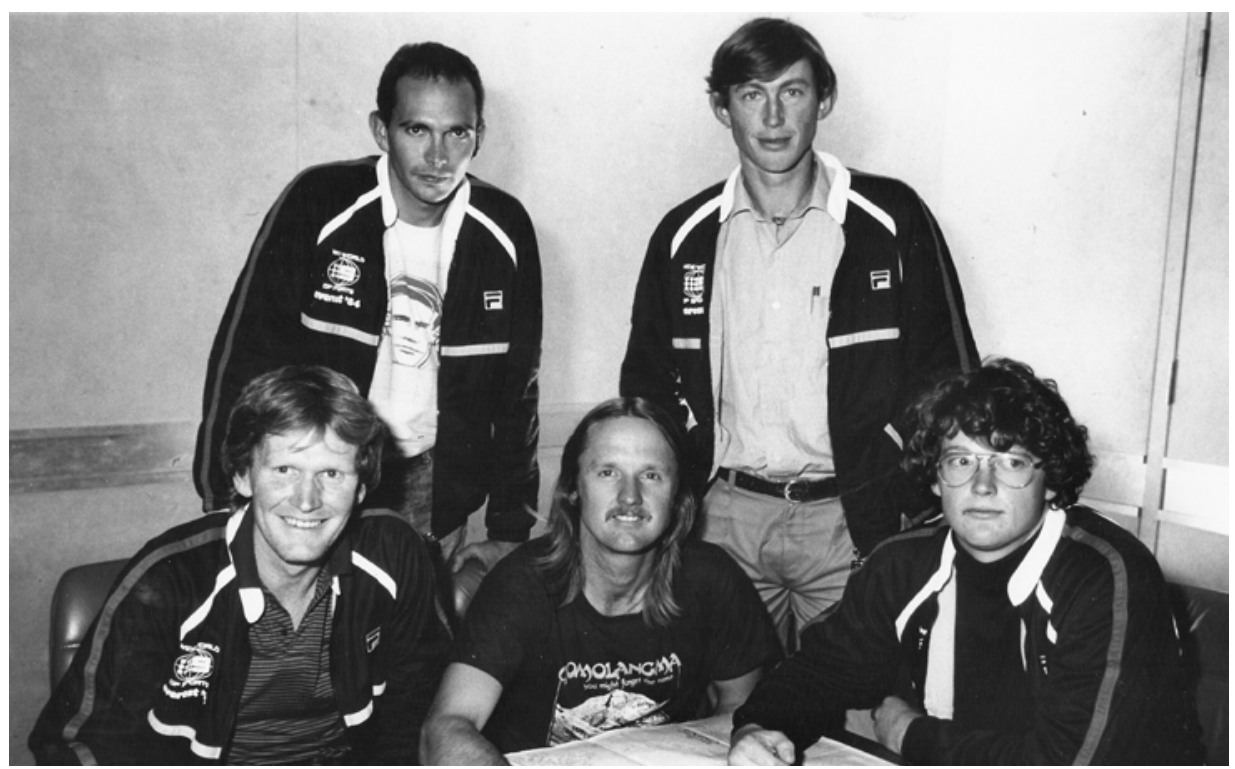

Image 11.1. The team members of the 1984 Australian Everest expedition, at the Channel 9 studios in Sydney prior to the expedition. From left: Greg Mortimer, Andy Henderson, Geoff Bartram, Tim Macartney-Snape and Lincoln Hall.

Photo by Steve White

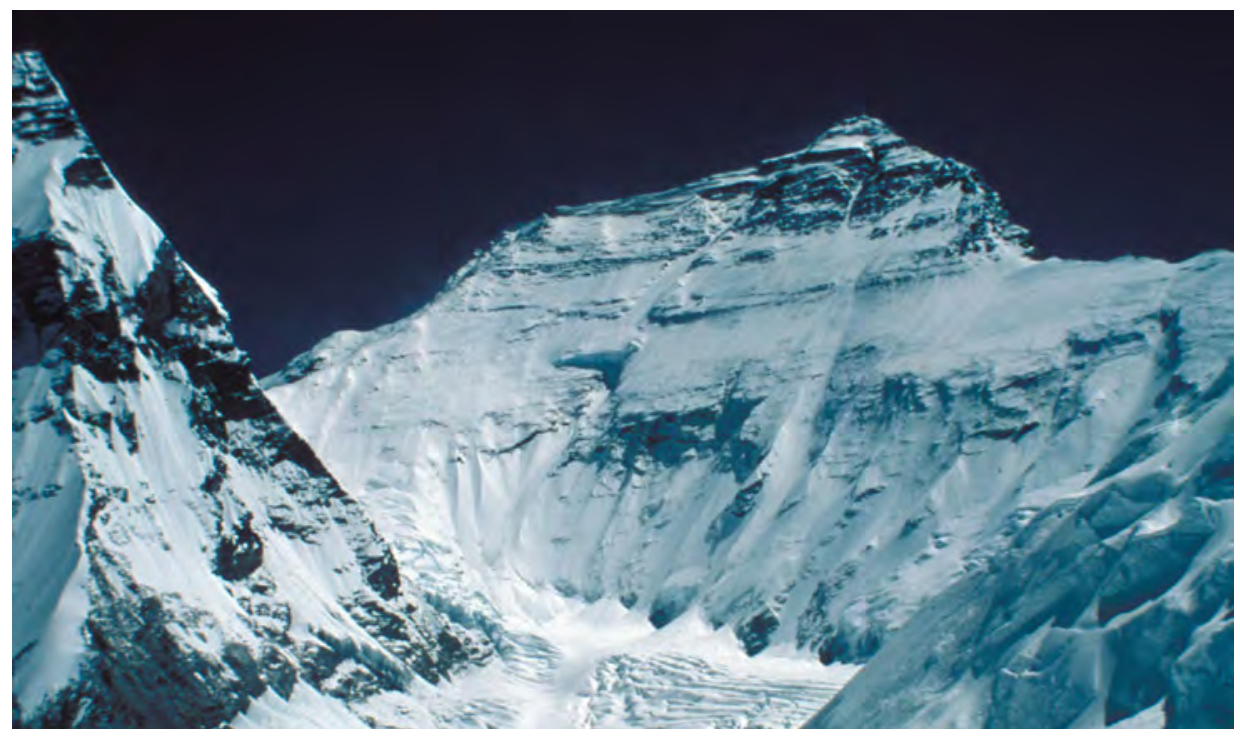

Image 11.2. The north face of Mt Everest $(8850 \mathrm{~m})$, Tibet. The Australian team made the first ascent of the Great Couloir, the prominent gully on the left side of the face.

Photo by Tim Macartney-Snape 


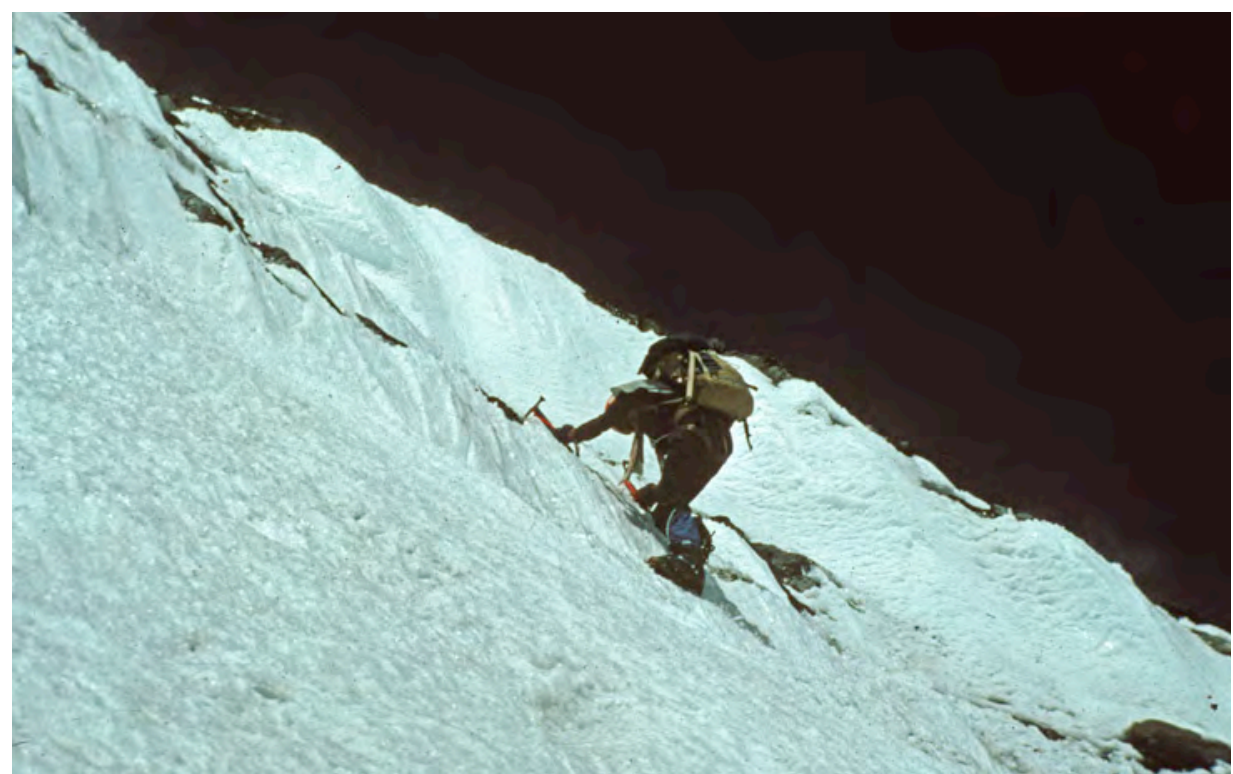

Image 11.3. Greg Mortimer climbing steep snow on the bottom section of Everest's north face.

Photo by Tim Macartney-Snape

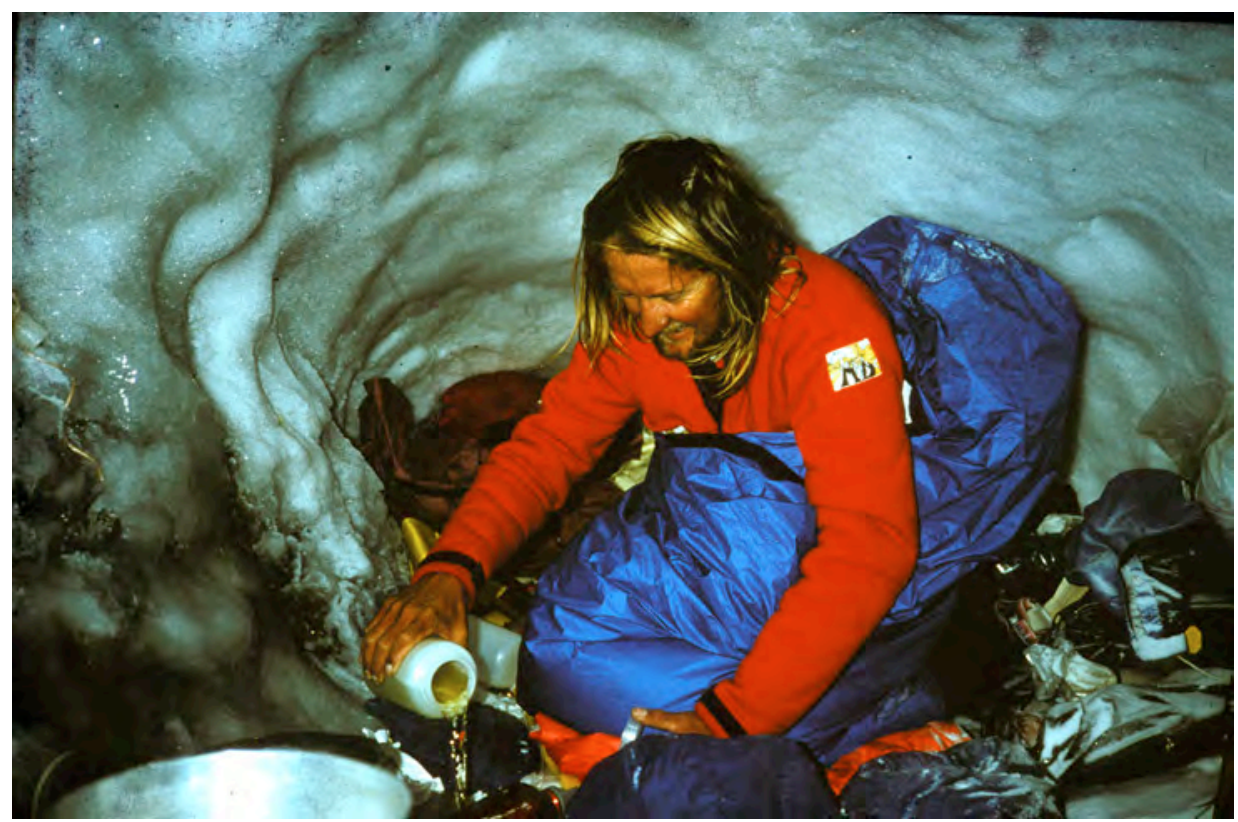

Image 11.4. Geoff Bartram in the snow cave at camp two on Everest's north face.

Photo by Tim Macartney-Snape 


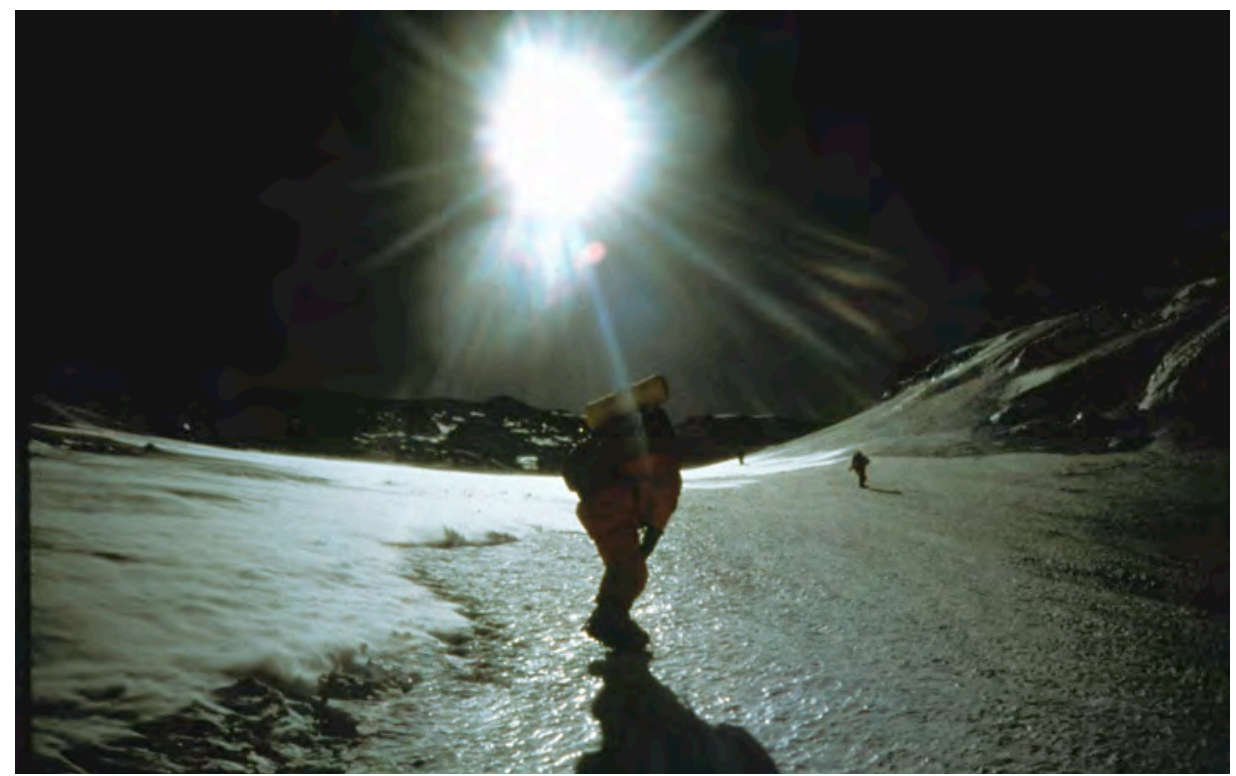

Image 12.1. Slowly climbing up the Great Couloir on the north face of Everest.

Photo by Tim Macartney-Snape

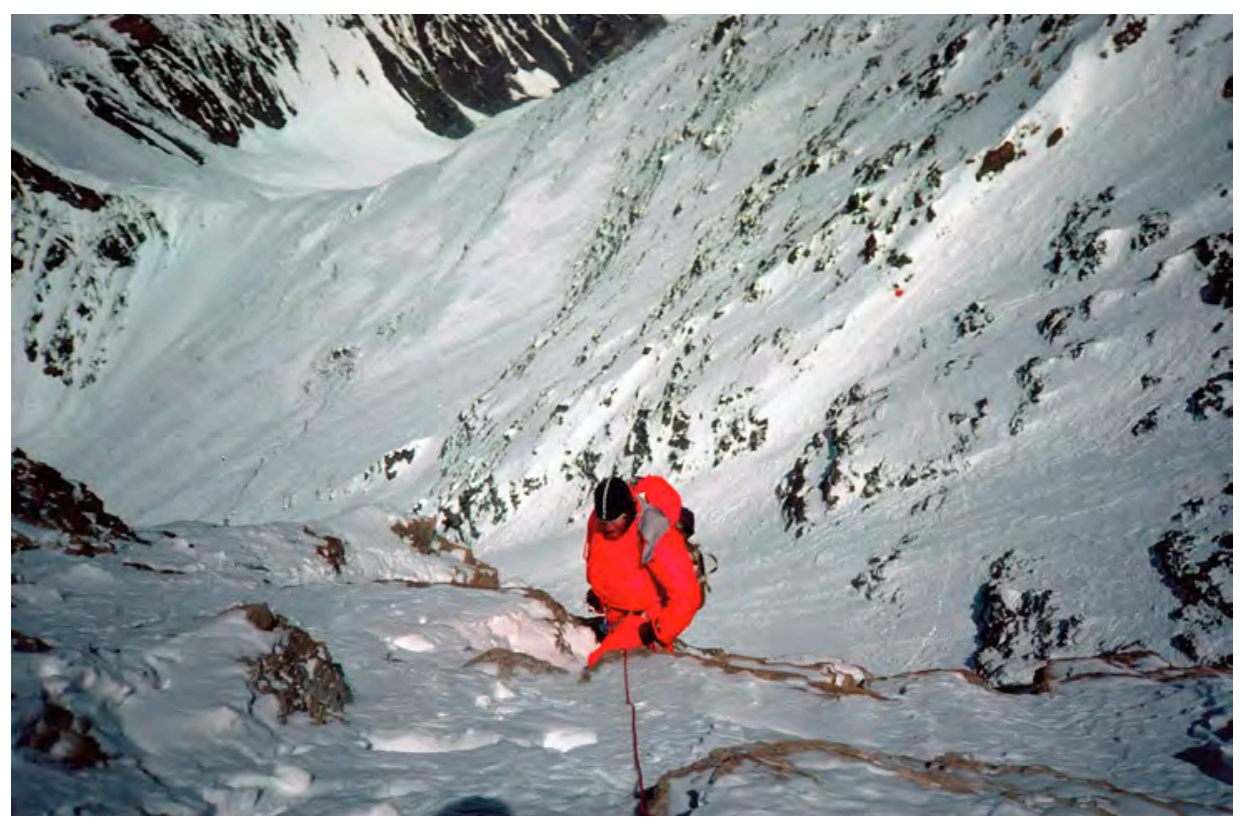

Image 12.2. Greg Mortimer traversing through the yellow rock band high on the north face of Everest.

Photo by Tim Macartney-Snape 


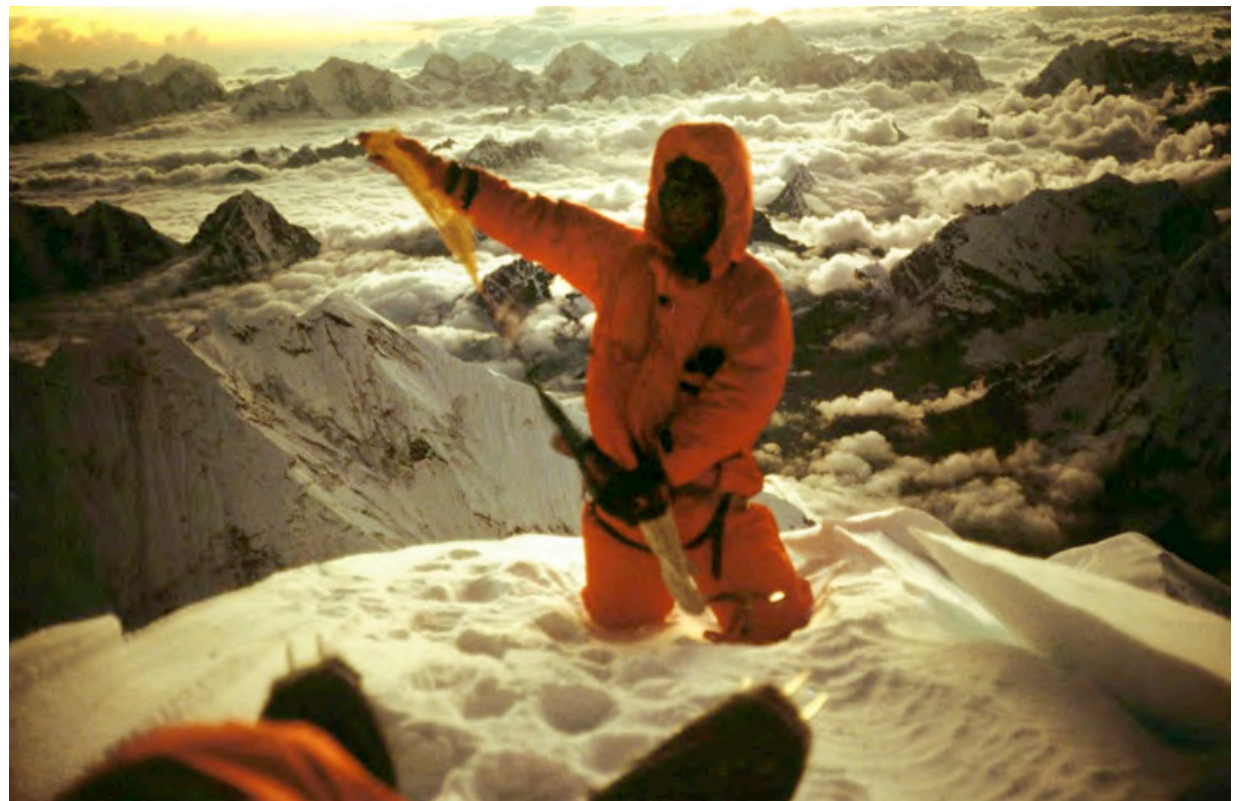

Image 12.3. Greg Mortimer on the summit of Mt Everest, October 1984.

Photo by Tim Macartney-Snape

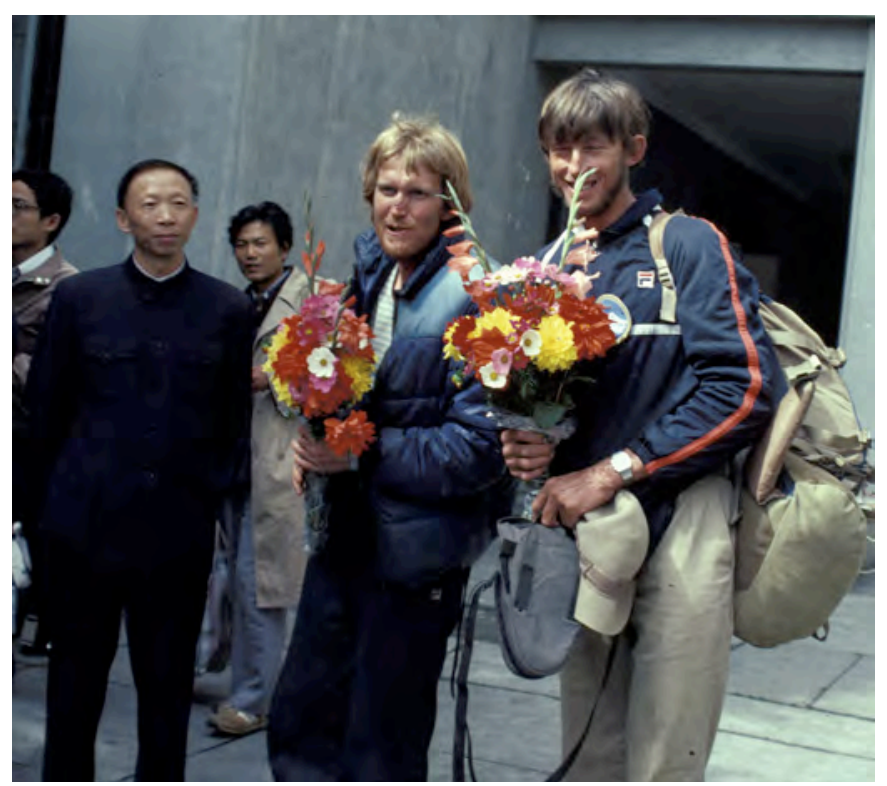

Image 12.4. Greg Mortimer and Tim Macartney-Snape in China after the first Australian ascent of Mt Everest, October 1984.

Photo from the Tim Macartney-Snape collection 


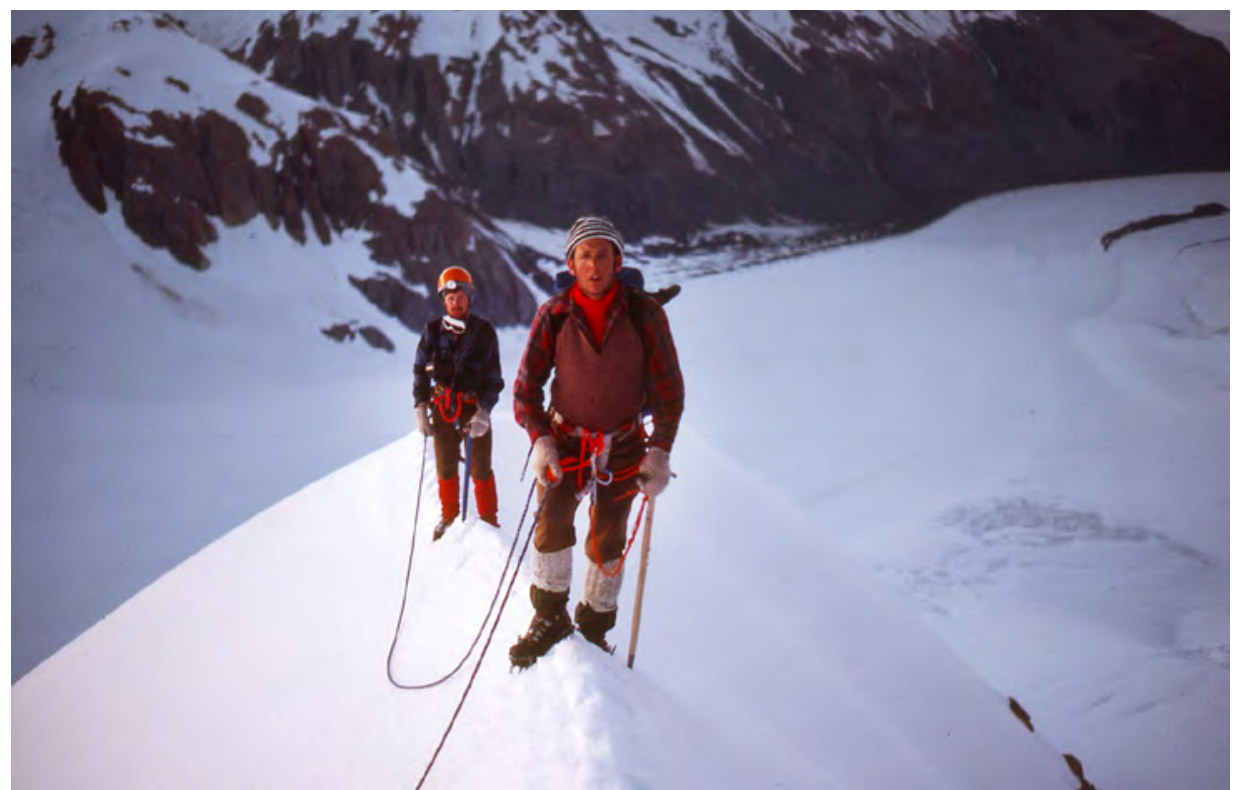

Image 13.1. Bernie McGee and Steve Kennedy on the traverse of the Mt Walter/Mt Green ridge traverse, with the Tasman Glacier below, Southern Alps, New Zealand, 1979.

Photo by Zac Zaharias

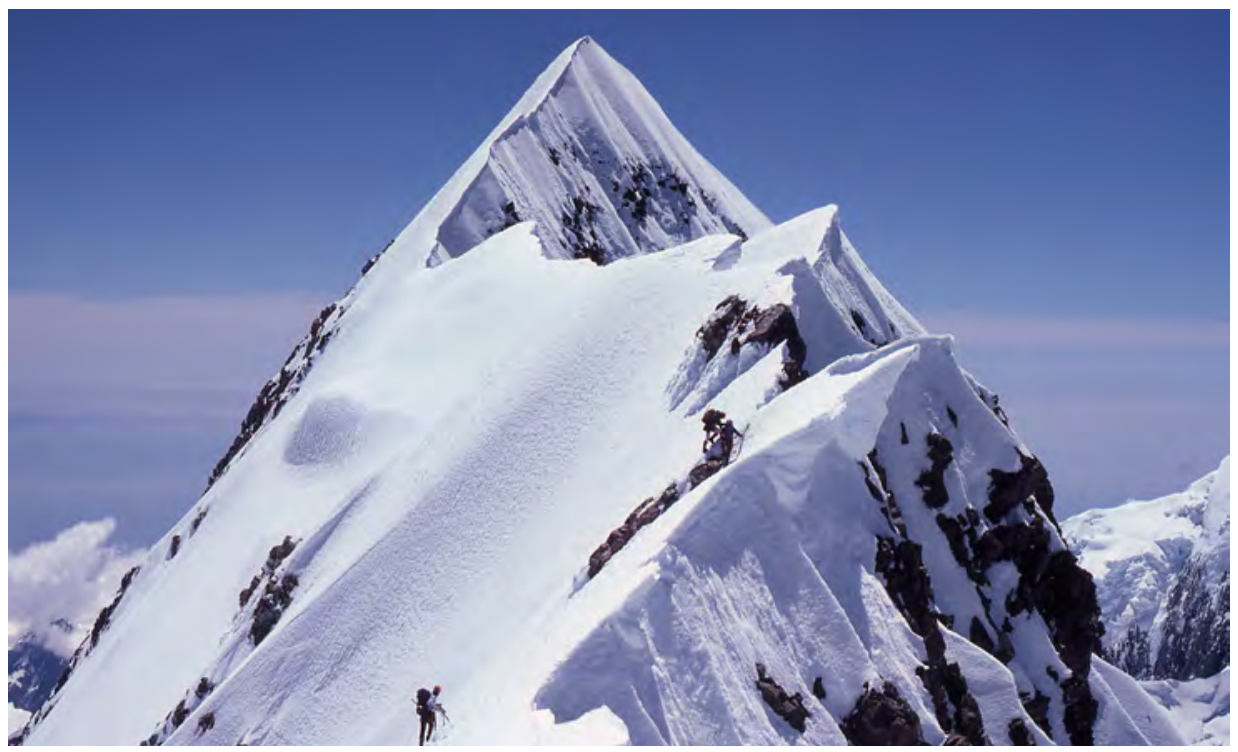

Image 13.2. Brian Agnew, Dave Sloane and Phil Pitham (from left) on a grand traverse of Mt Cook, Southern Alps, New Zealand, January 1981.

Photo by Zac Zaharias 


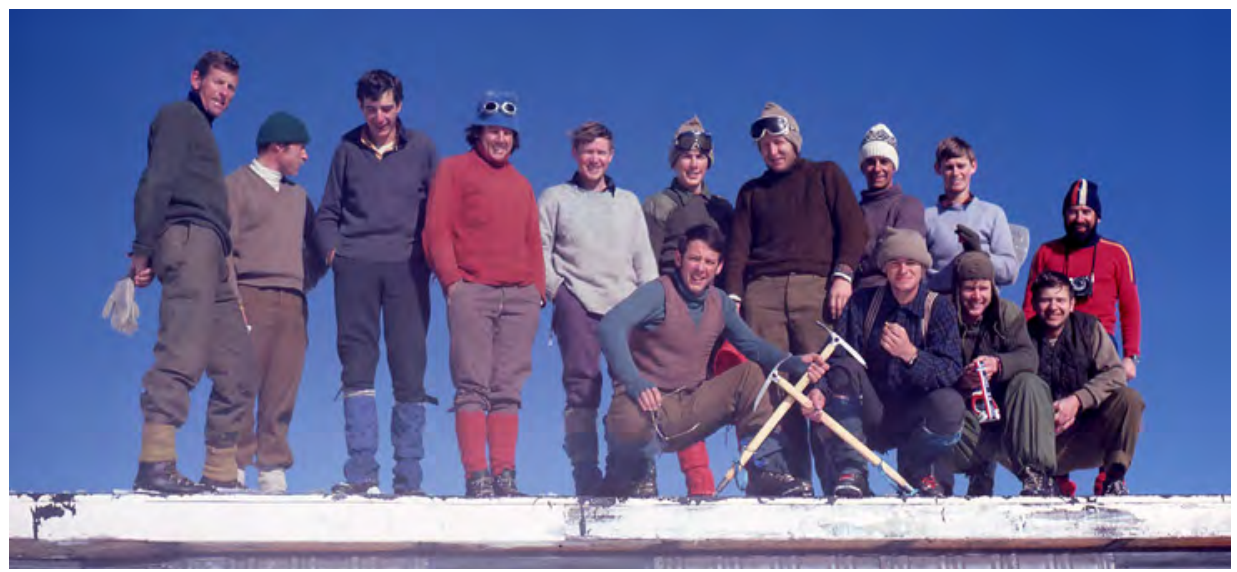

Image 13.3. RMC (Royal Military College) Mountaineering Club adventure training activity, near Blue Lake, Snowy Mountains, 1977, standing on top of the (now demolished) Soil Conservation Hut, below Mt Twynam. Back row, from left: W02 Clem Dwyer (SASR), John Trevivian, Peter Lambert, John Cashman, Lester Cornall, Mal Alexander, Stefan Fuchs, (Unknown), Paul Van den Berg, Fritz Schaumberg; Squatting: Steve Kennedy, Jim Truscott, Bernie McGee, Brian Fuge.

Photo by Zac Zaharias

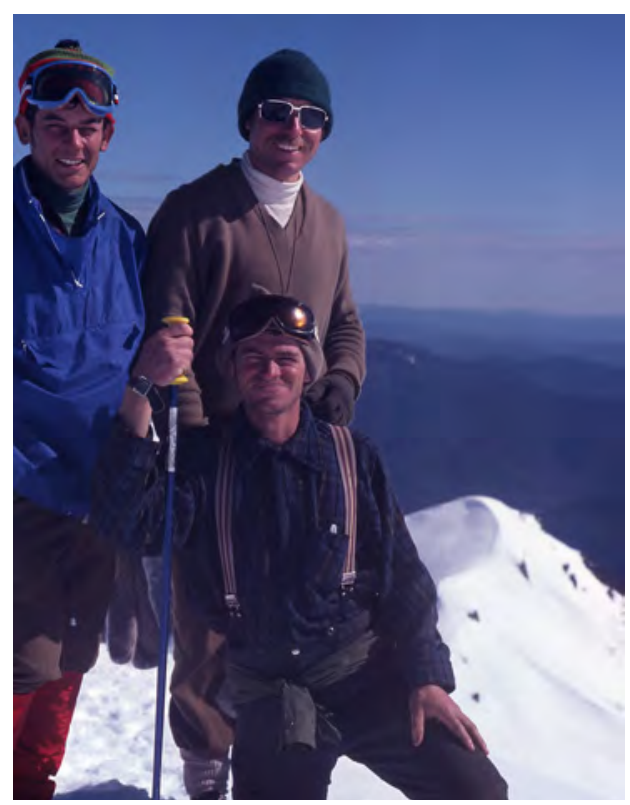

Image 13.4. Zac Zaharias, John Trevivian and Jim Truscott (kneeling) above the Sentinel, Snowy Mountains, during an RMC (Royal Military College) Mountaineering Club training exercise, 1977.

Photo from the Zac Zaharias collection 


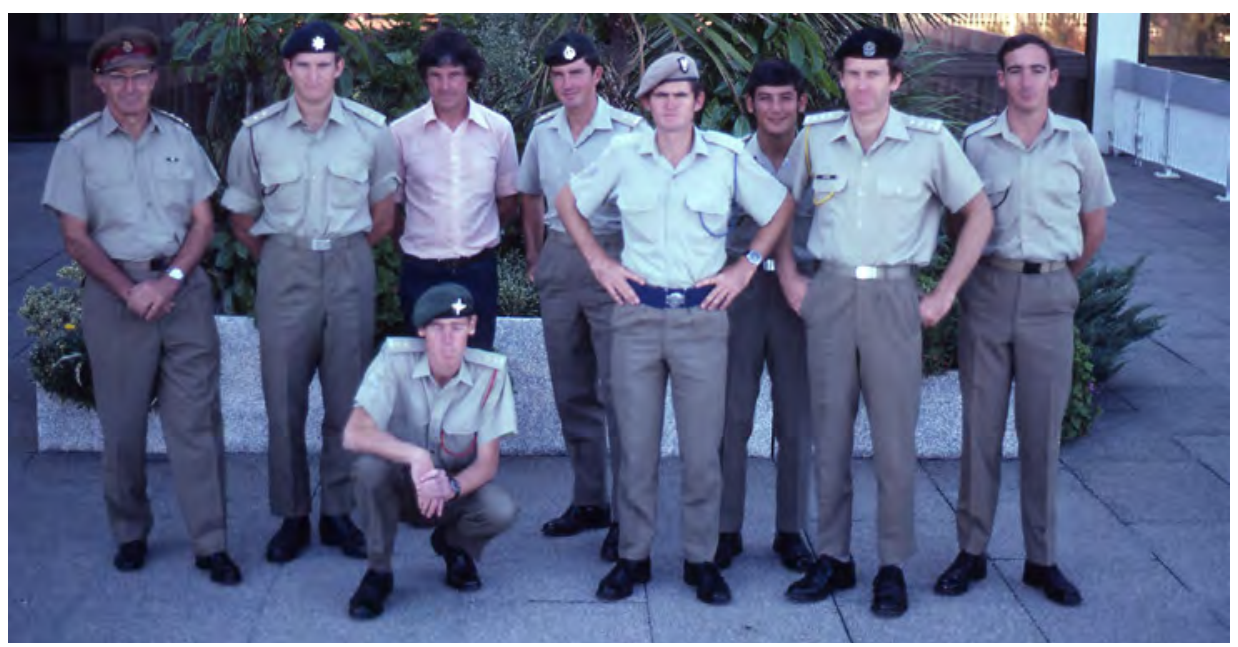

Image 13.5. The Ganesh IV team photo at Kingsford Smith Airport, Sydney, prior to flying an RAAF 707 to Butterworth Air Force base. From left, Colonel Roy Macdonald, LT David Sloane, John Cashman, LT David Simpson, CAPT Jim Truscott, CAPT Zac Zaharias, CAPT Brian Agnew, SPR Phil Pitham and (kneeling) LT Rob Phillpot.

Photo from the Zac Zaharias collection

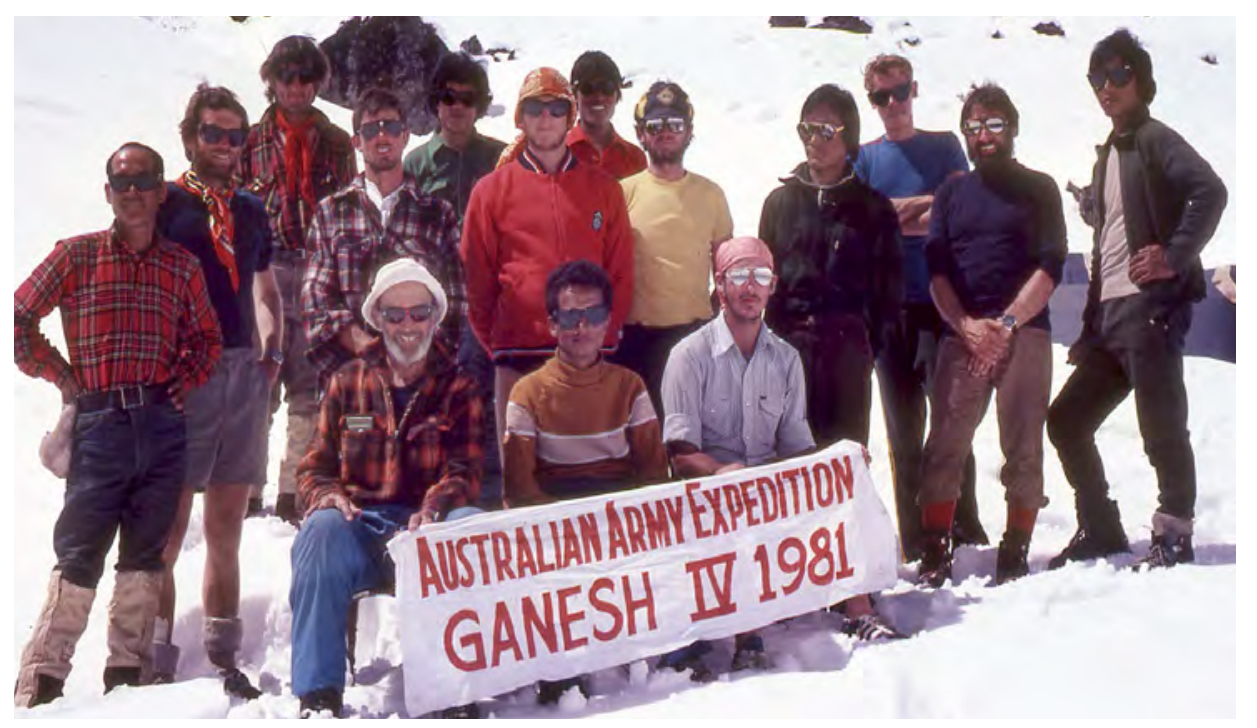

Image 13.6. The Ganesh IV team at base camp. Standing, from left, Temba Sherpa, Brian Agnew, John Cashman, David Simpson, Gyalchen Sherpa, David Sloane, (Unknown), Jim Truscott, Maila Pemba (sirdar), Rob Phillpot, Fritz Schaumburg, (Unknown). Sitting, from left: Dr Roy Macdonald, the Liaison Officer, Phil Pitham. 


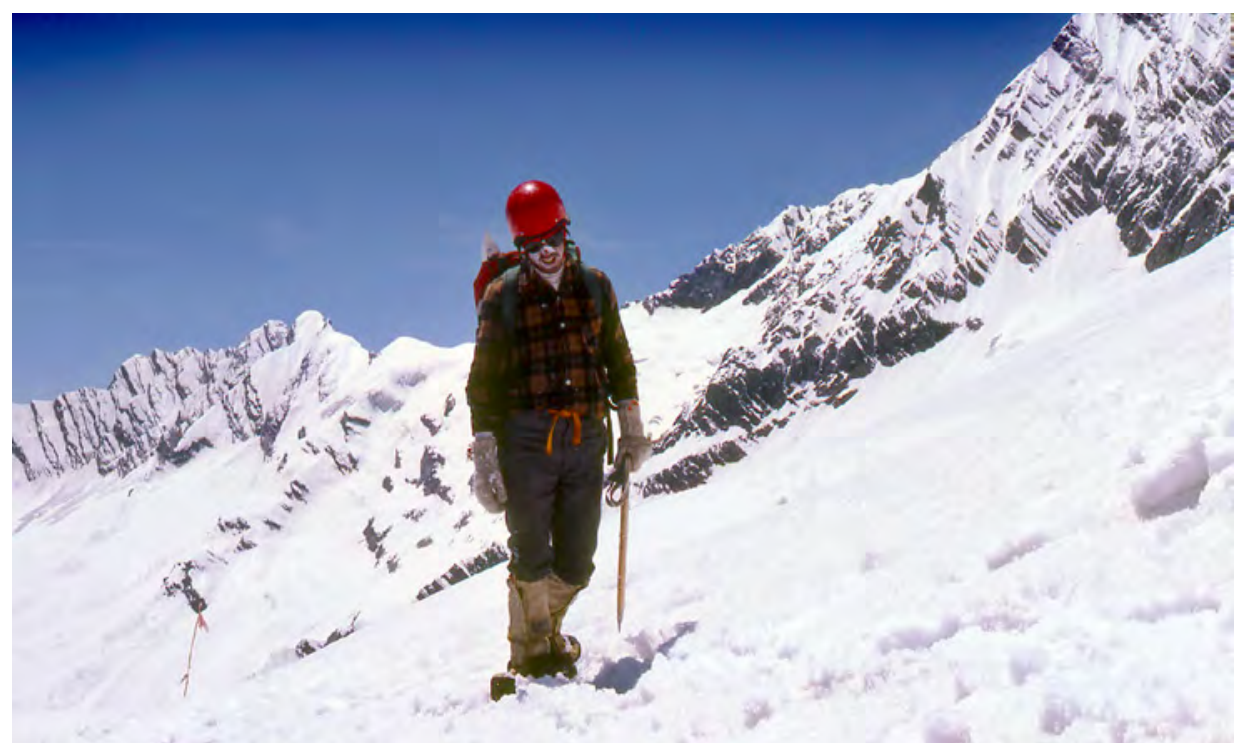

Image 13.7. David Simpson returning exhausted to camp one after a carry to camp two, Ganesh IV.

Photo by Zac Zaharias

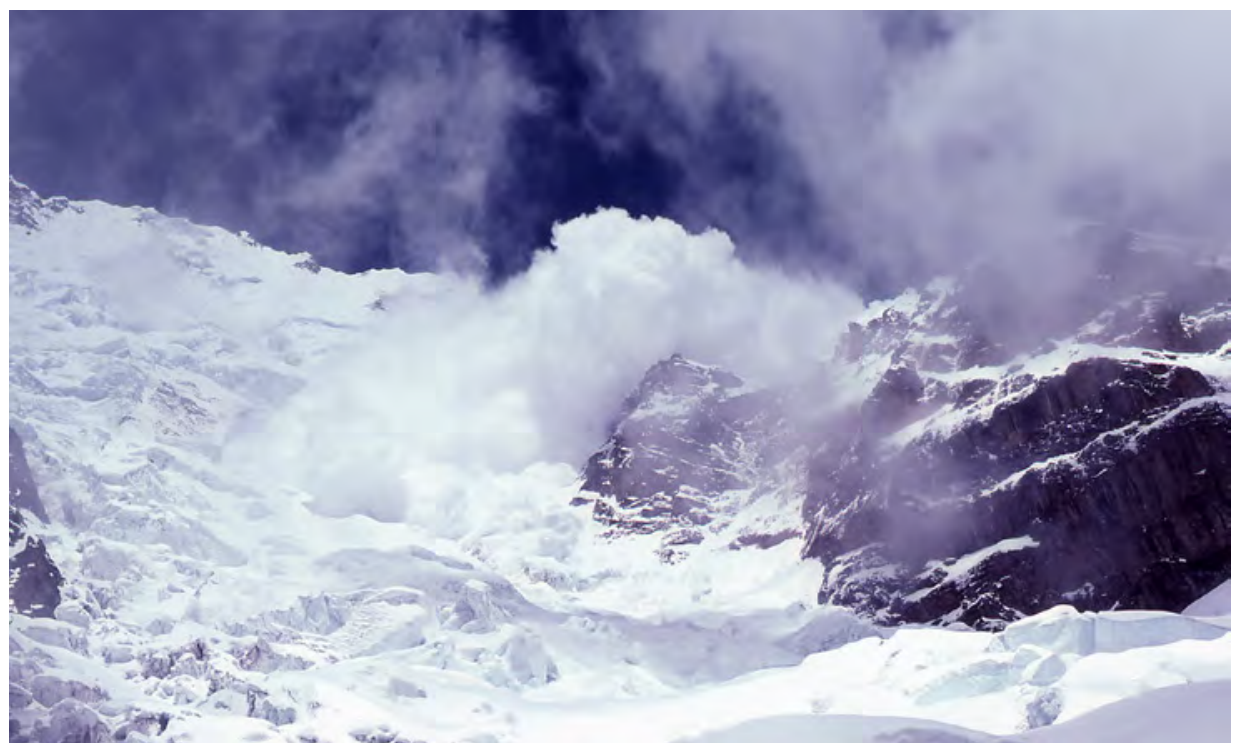

Image 13.8. The fatal avalanche on Ganesh IV, seen from camp one, as it broke and swept over camp two on 23 April, killing David Sloane and destroying the camp, leaving Pemba, Simpson and Truscott stranded without equipment and lucky to be alive.

Photo by Zac Zaharias 


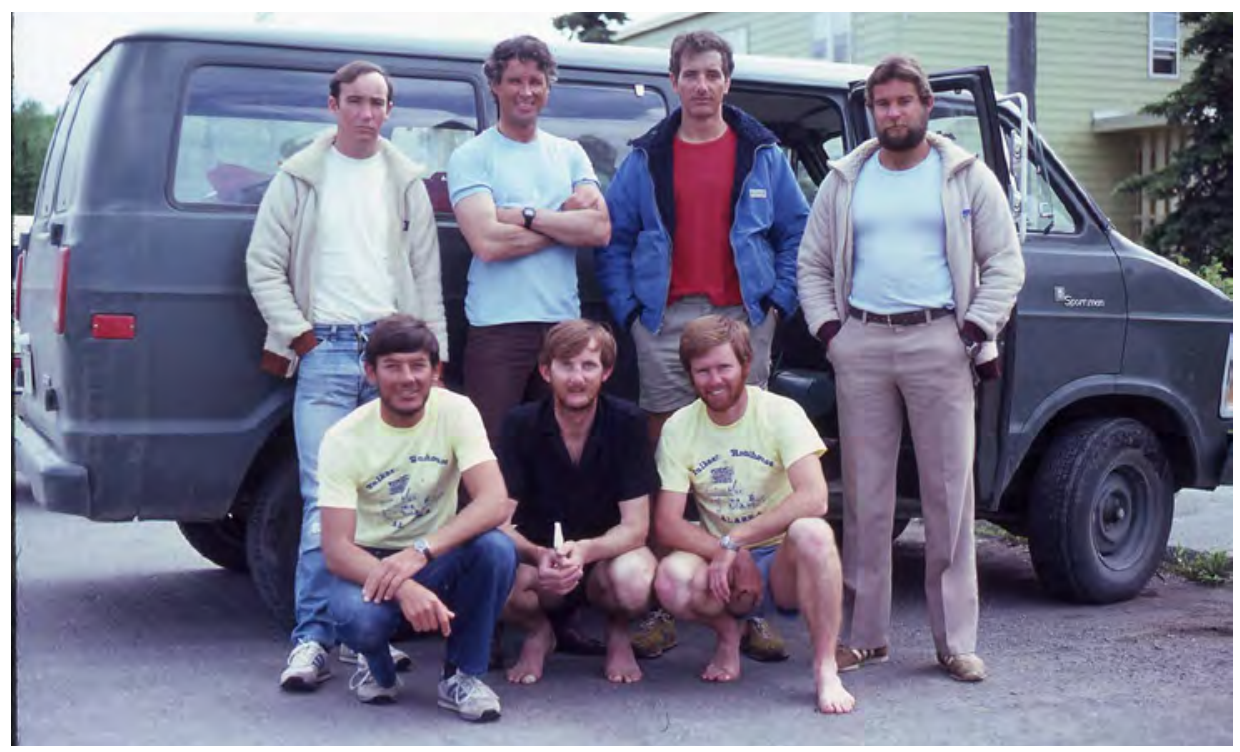

Image 14.1. The team for the AAA expedition to Denali (Mt McKinley), Alaska, USA. Back, from left: Phil Pitham, Dr Tony Delaney, Peter Lambert, Joe Lorincz. Front, from left: Zac Zaharias, David Smith, Bernie McGee.

Photo from the Zac Zaharias collection

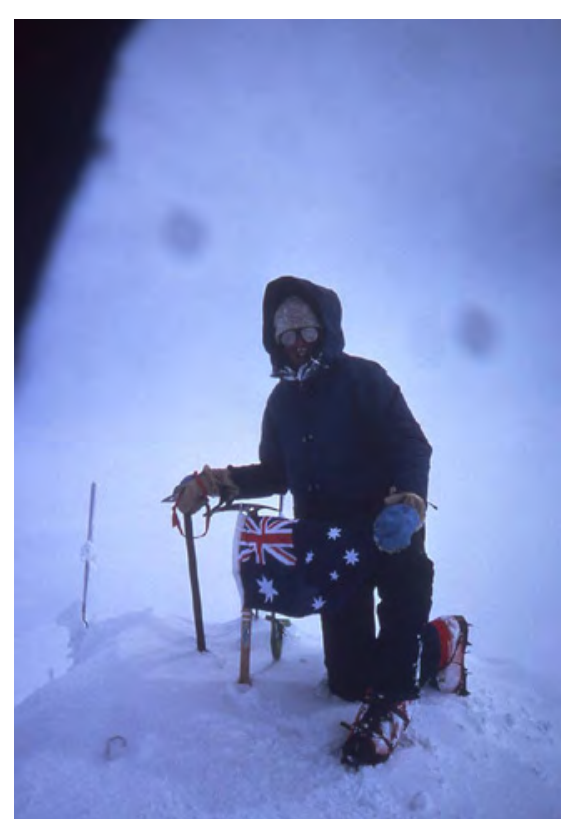

Image 14.2. Peter Lambert on the summit of Denali (Mt McKinley) (6194 m). Photo by Zac Zaharias 


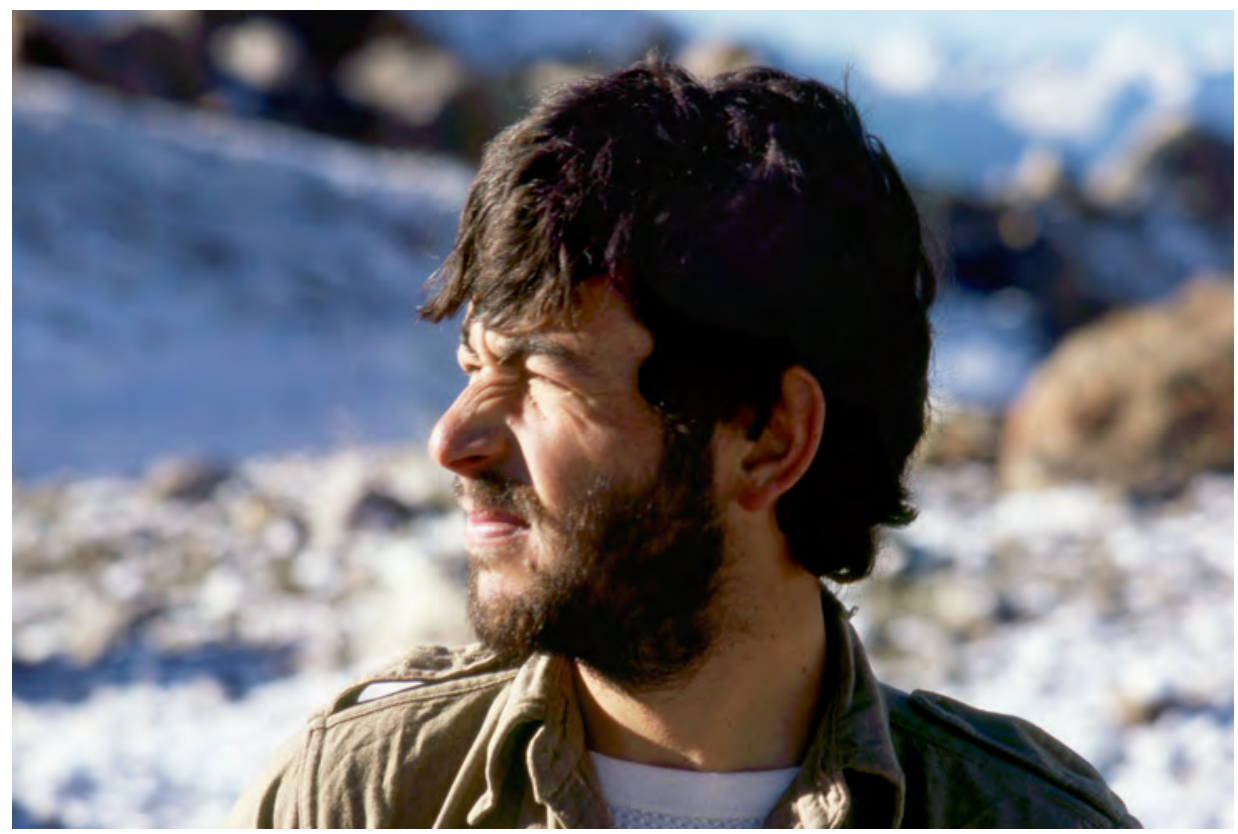

Image 15.1. Andrew Rothfield. White Sail (Dharamsura) expedition, India, 1979.

Photo provided by Peter Allen

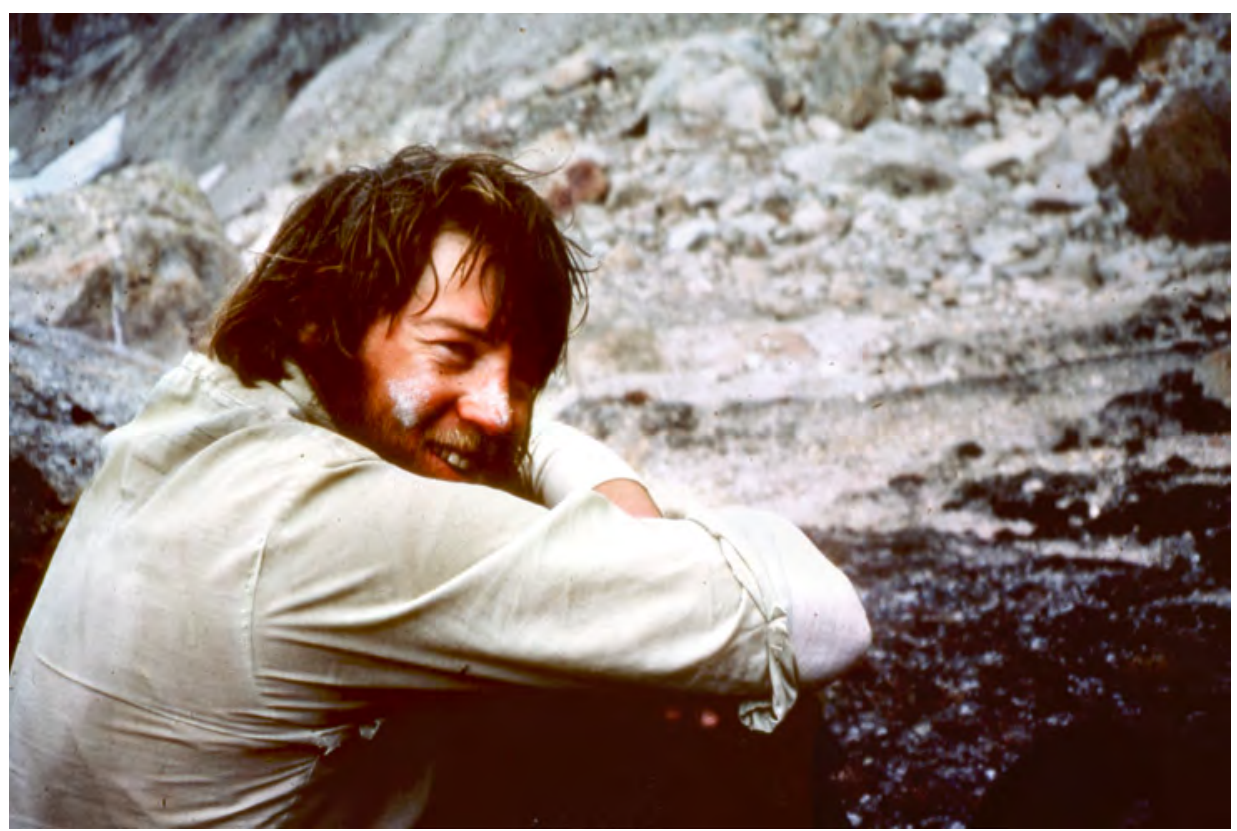

Image 15.2. Gary Wills. White Sail (Dharamsura) expedition, India, 1979.

Photo provided by Peter Allen 


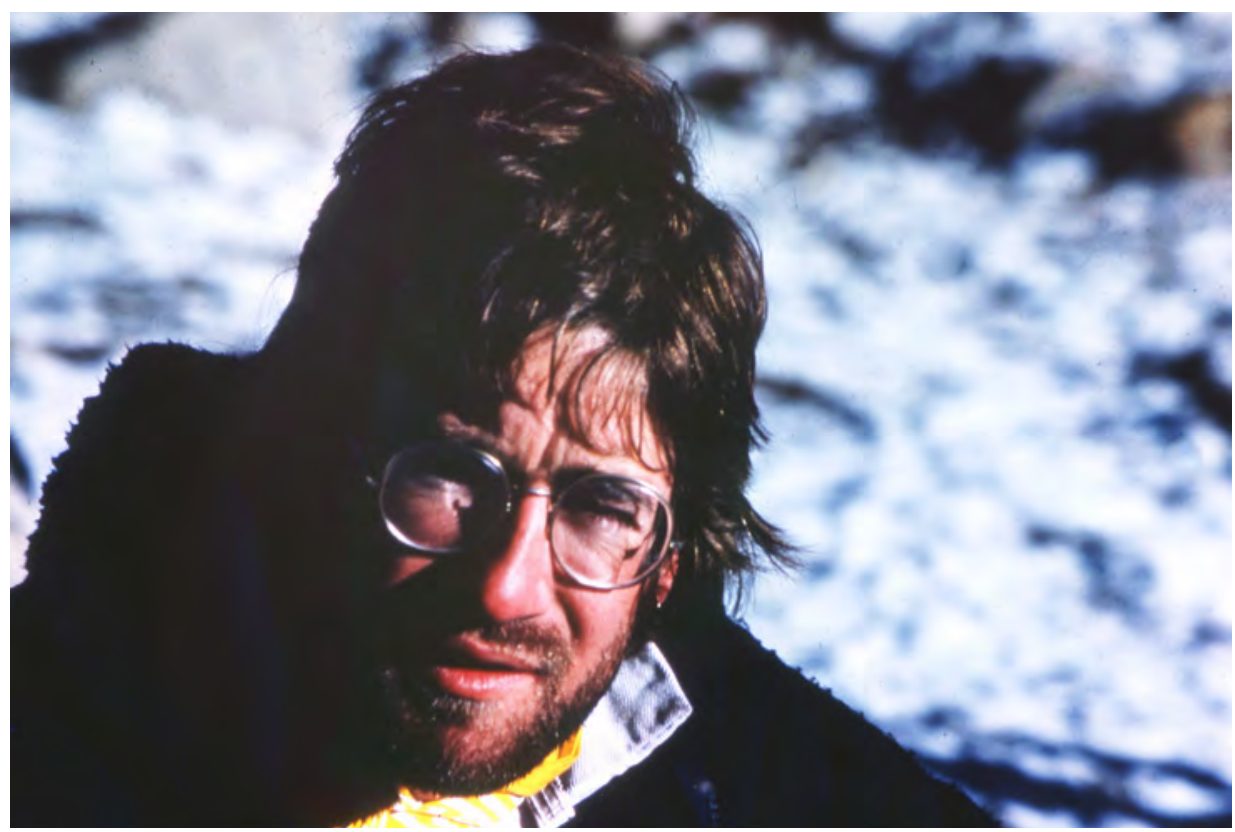

Image 15.3. Peter Allen. White Sail (Dharamsura) expedition, India, 1979.

Photo provided by Peter Allen

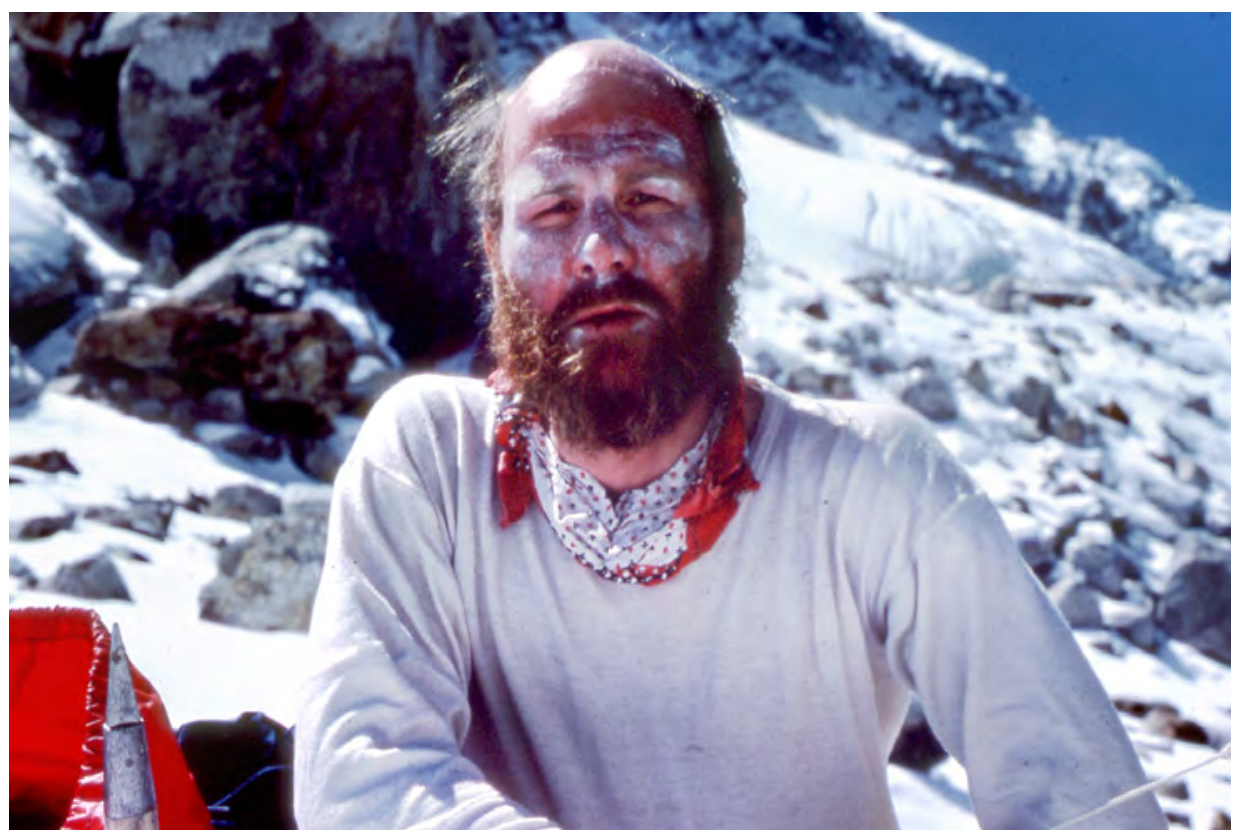

Image 15.4. Mike Rheinberger. White Sail (Dharamsura) expedition, India, 1979.

Photo provided by Peter Allen 


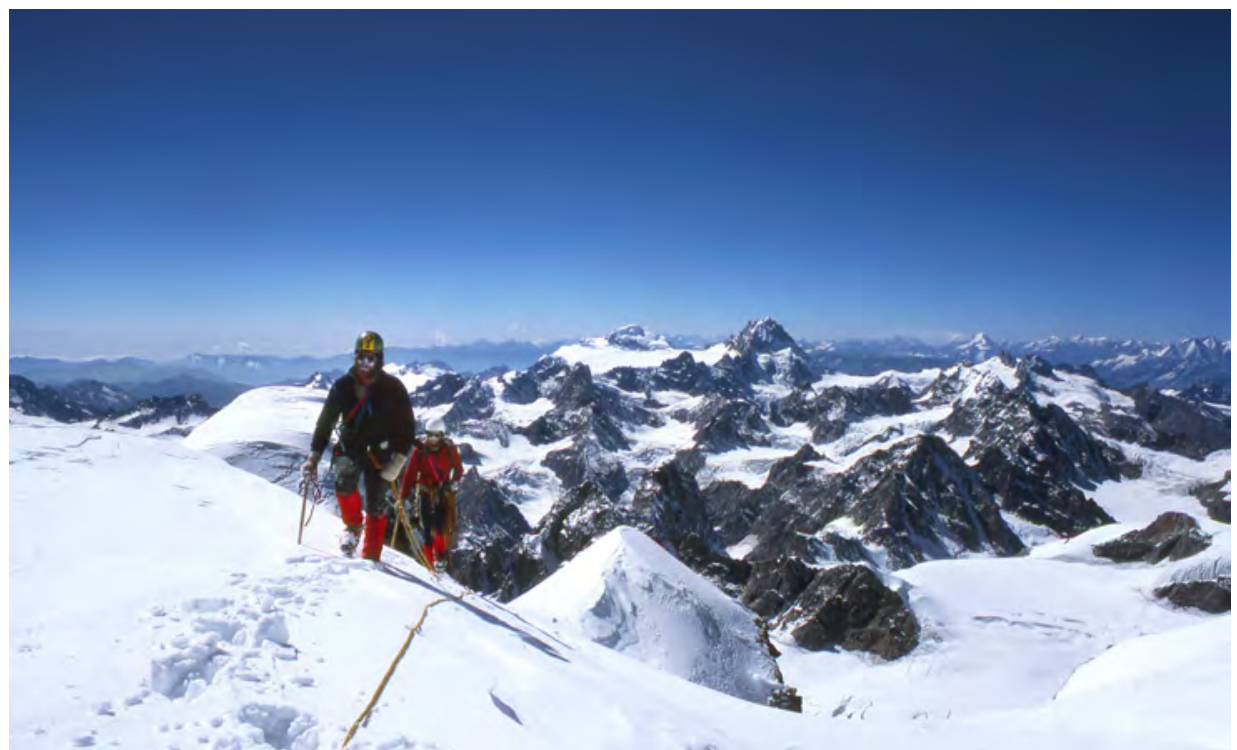

Image 15.5. Gary Wills and Ed Neve near the summit of White Sail, 1979. Photo by Peter Allen.

Photo by Peter Allen

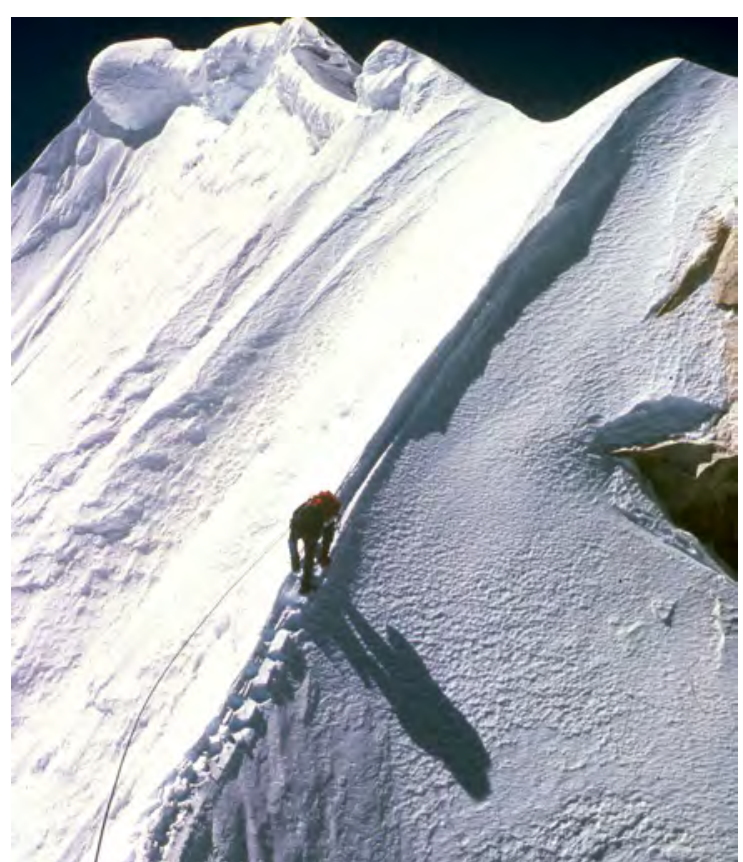

Image 15.6. Andrew Rothfield approaching the summit of Changabang, India, 1980.

Photo by Peter Allen 


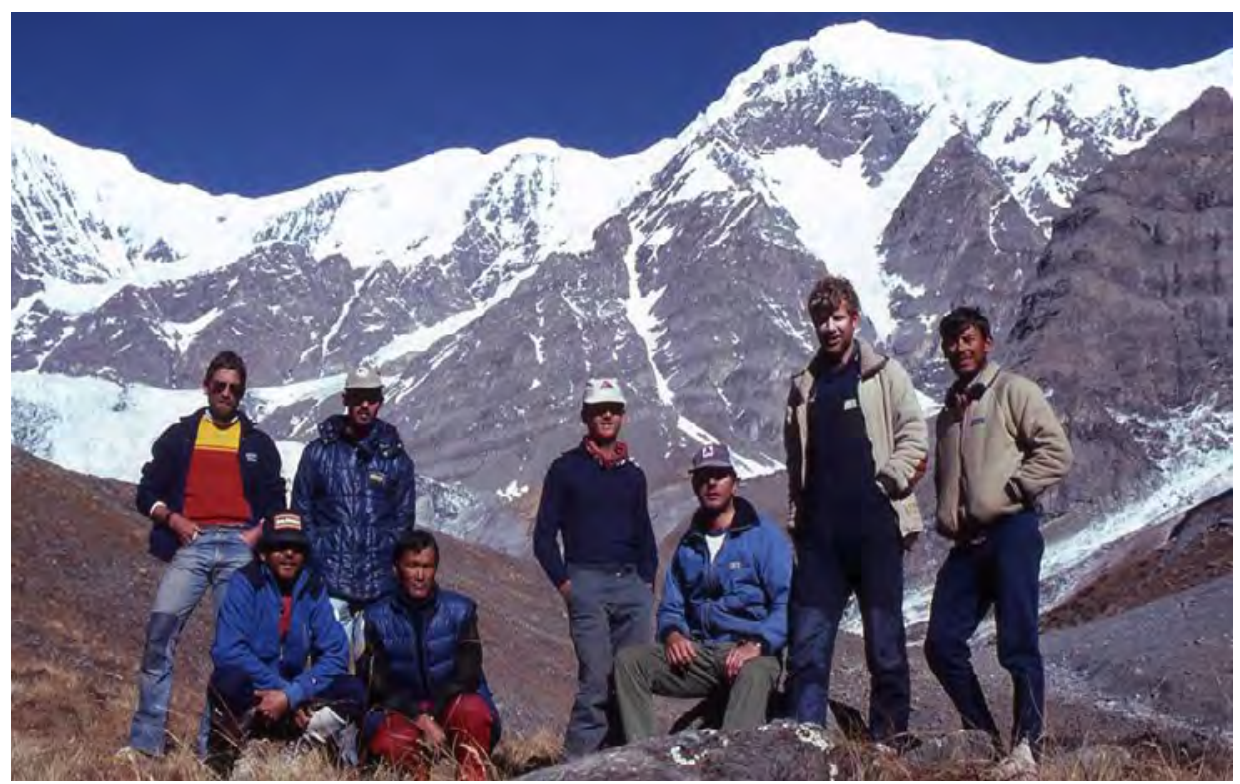

Image 16.1. The team for the expedition to Nilgiri North (7061 m), Nepal. Back, from left, Peter Allen, Phil Pitham, Terry McCullagh, Peter Lambert (sitting), David Evans, Zac Zaharias; Front: Mark Whetu and Maila Pemba.

Photo from the Zac Zaharias collection

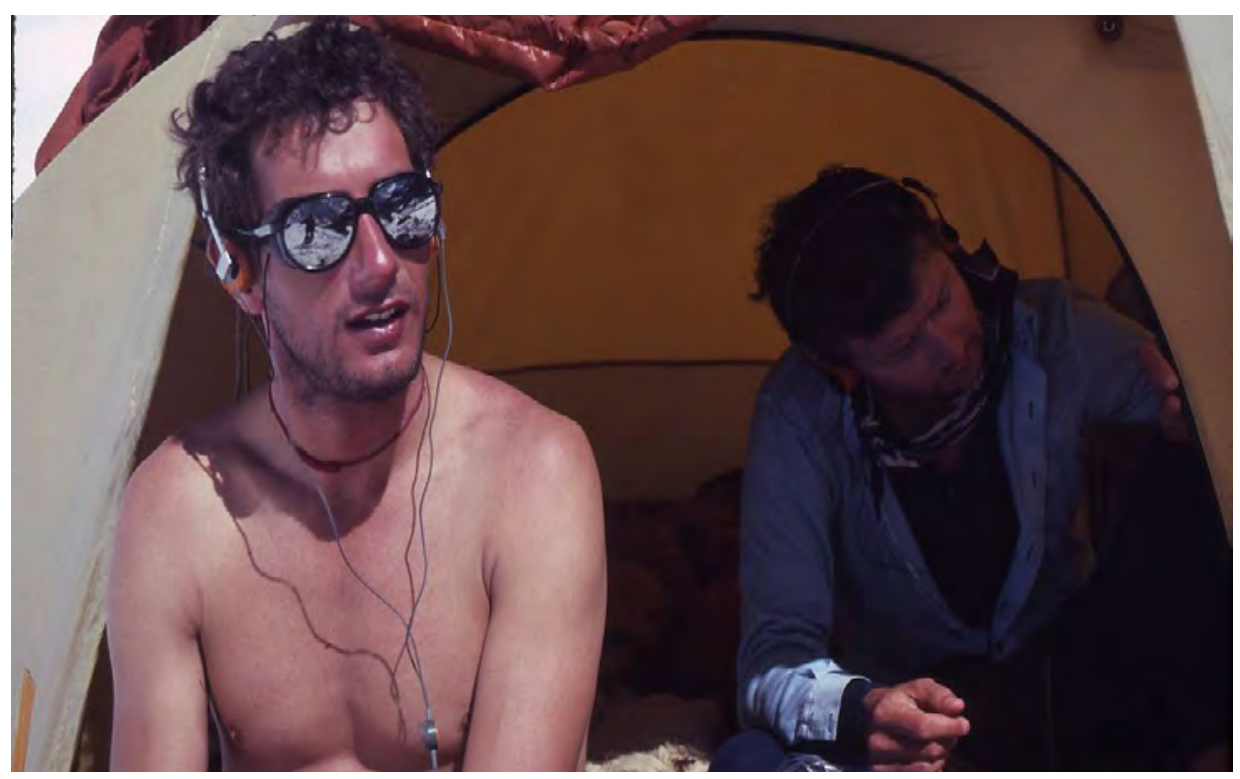

Image 16.2. Peter Lambert (left) and Terry McCullagh at camp one on Nilgiri North.

Photo by Zac Zaharias 


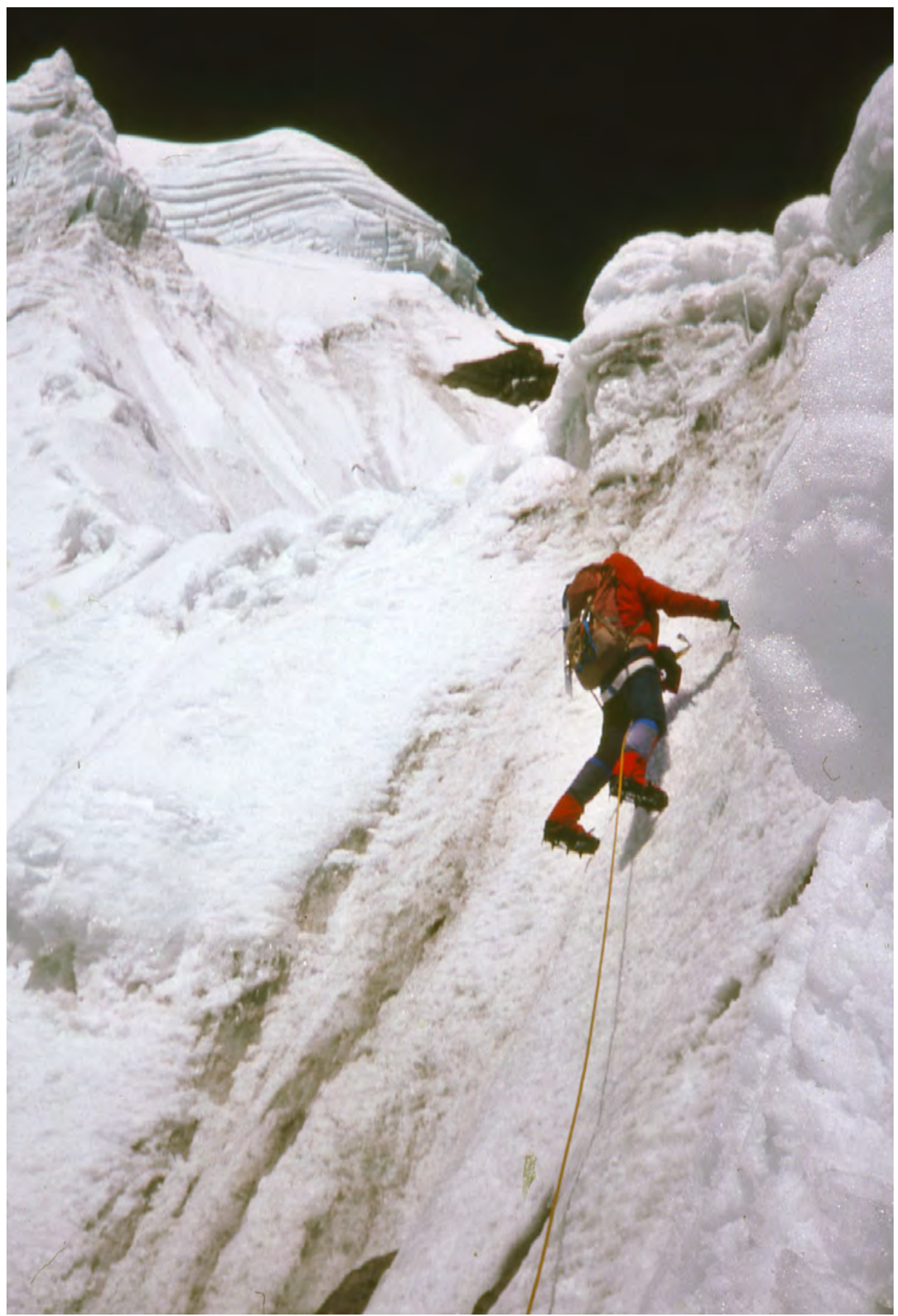

Image 16.3. Steep climbing above camp two on Nilgiri North, 1983.

Photo by Peter Allen 


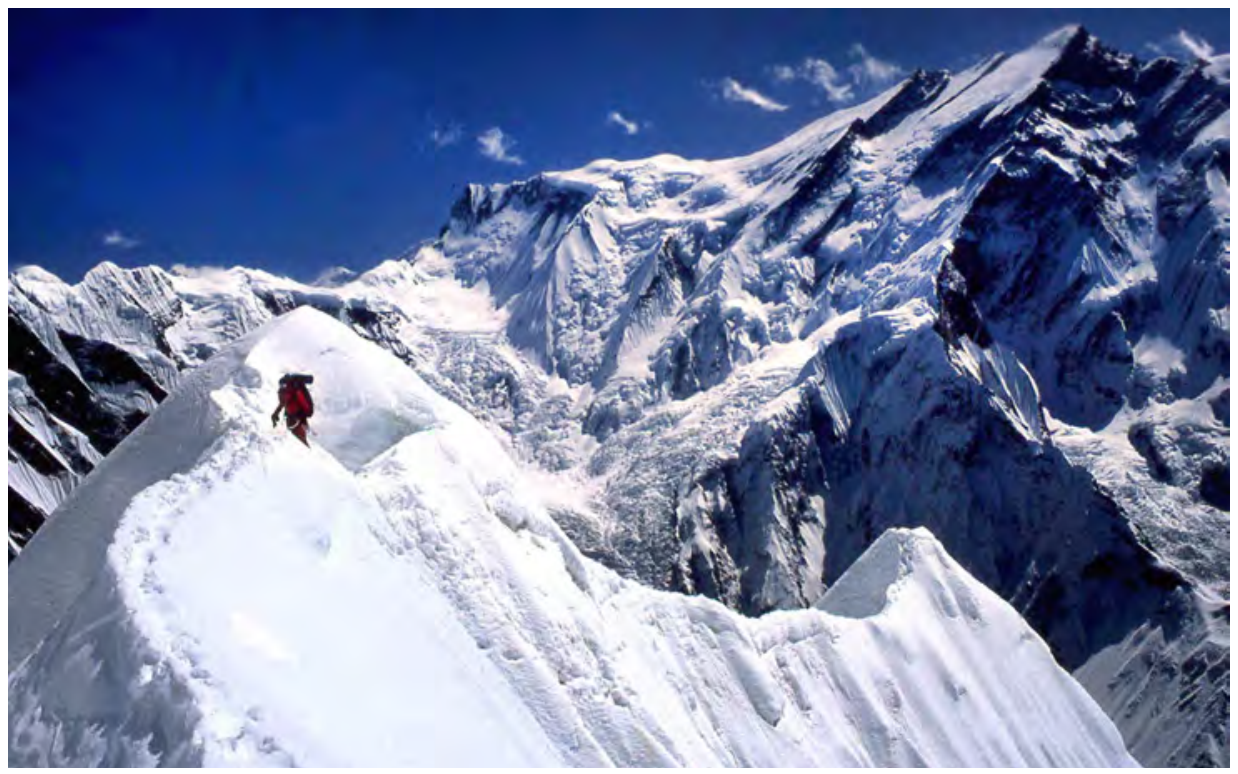

Image 16.4. Terry McCullagh climbing high above camp two on the southeast ridge of Nilgiri North.

Photo by Zac Zaharias

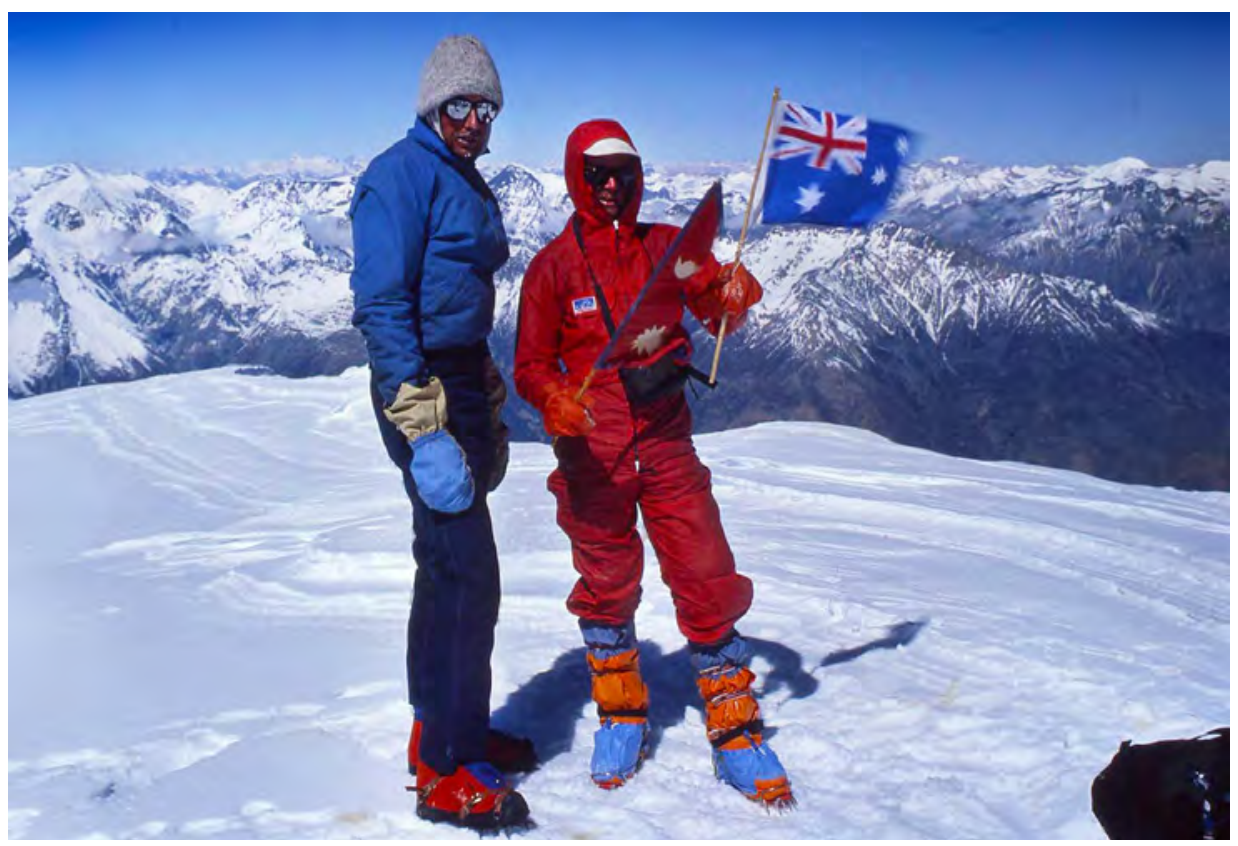

Image 16.5. Peter Lambert (left) and Terry McCullagh on the summit of Nilgiri North.

Photo by Zac Zaharias 


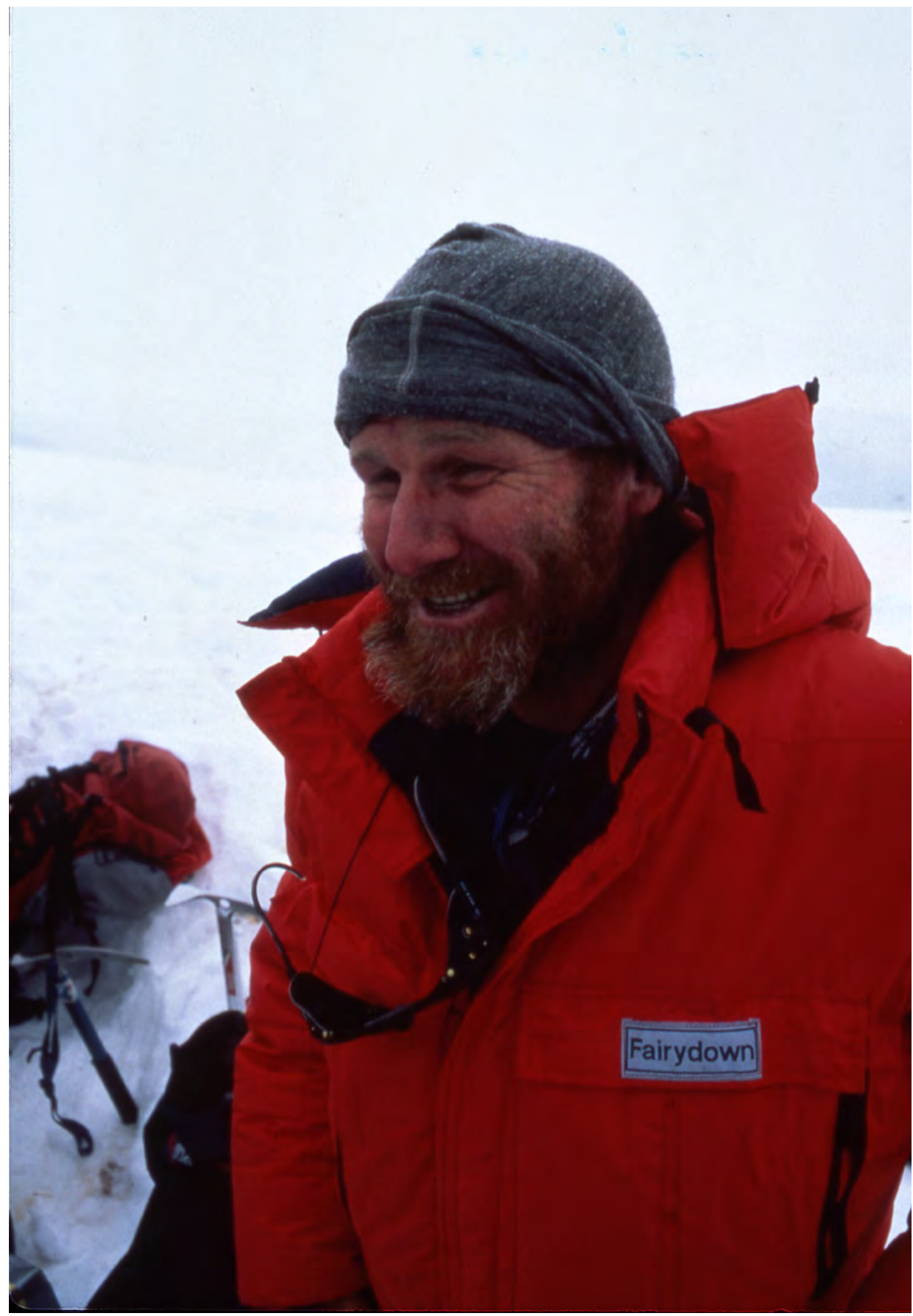

Image 16.6. Mike Rheinberger. Member of the 1985 NZAC Everest expedition. Photo provided by Peter Allen 


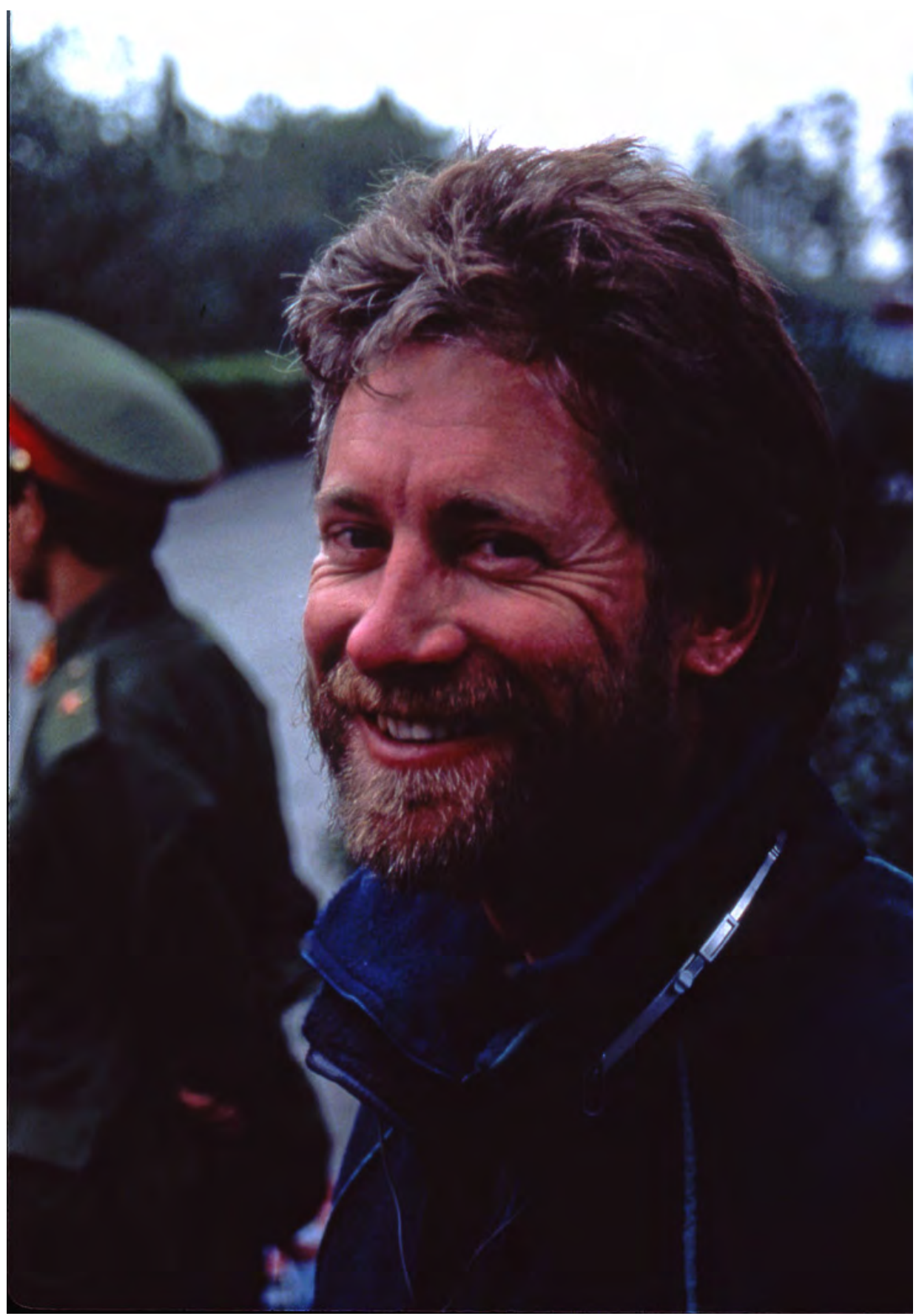

Image 16.7. Peter Allen. Member of the 1985 NZAC Everest expedition.

Photo provided by Peter Allen 


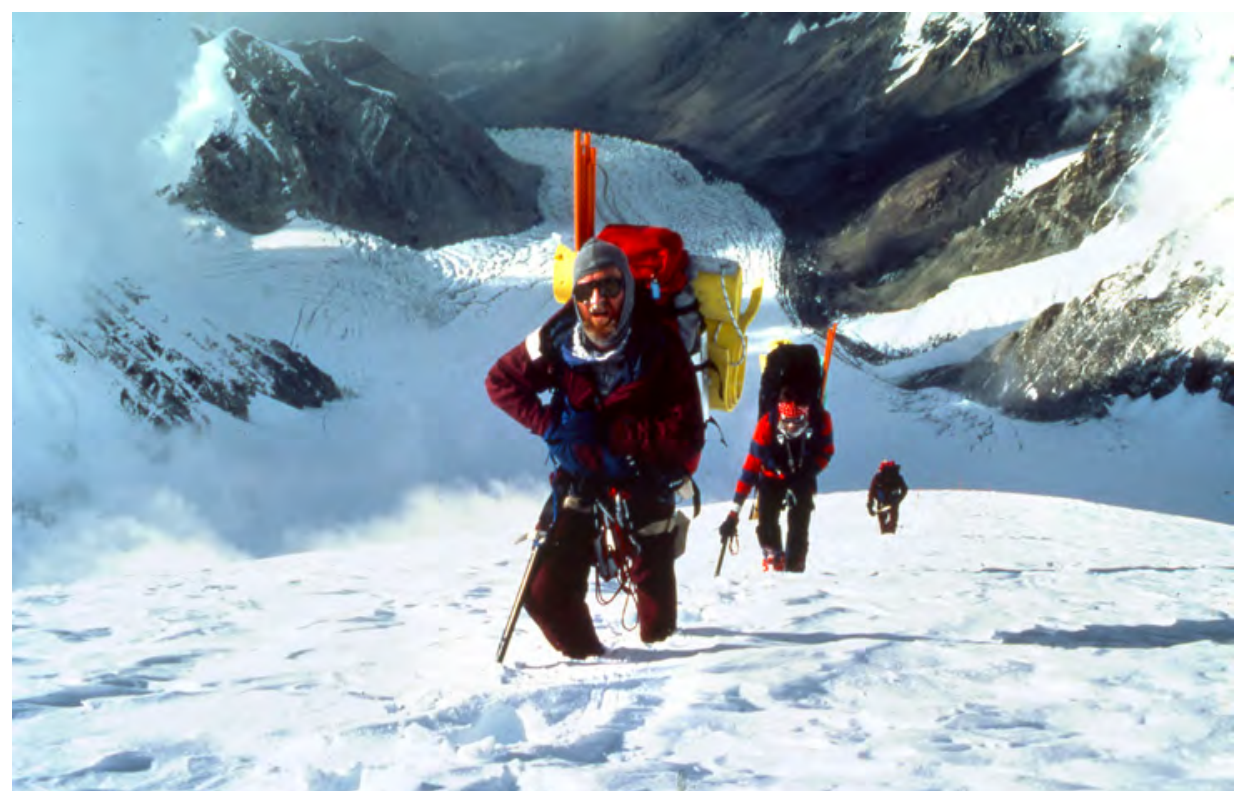

Image 16.8. Mike Rheinberger (front) and Peter Allen climbing on the west ridge of Mt Everest, NZAC expedition, 1985.

Photo by Mike Perry

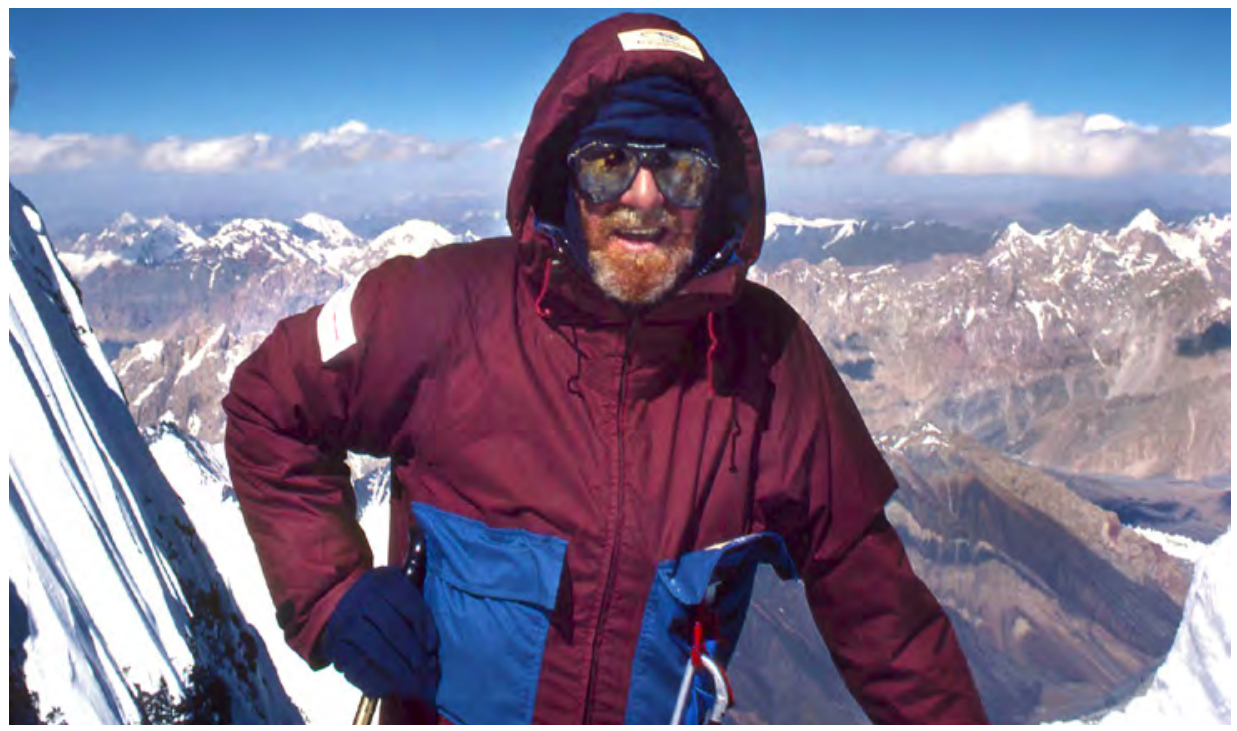

Image 17.1. Close-up of Mike Rheinberger at $7900 \mathrm{~m}$ on his way to the summit of Broad Peak.

Photo by Zac Zaharias 


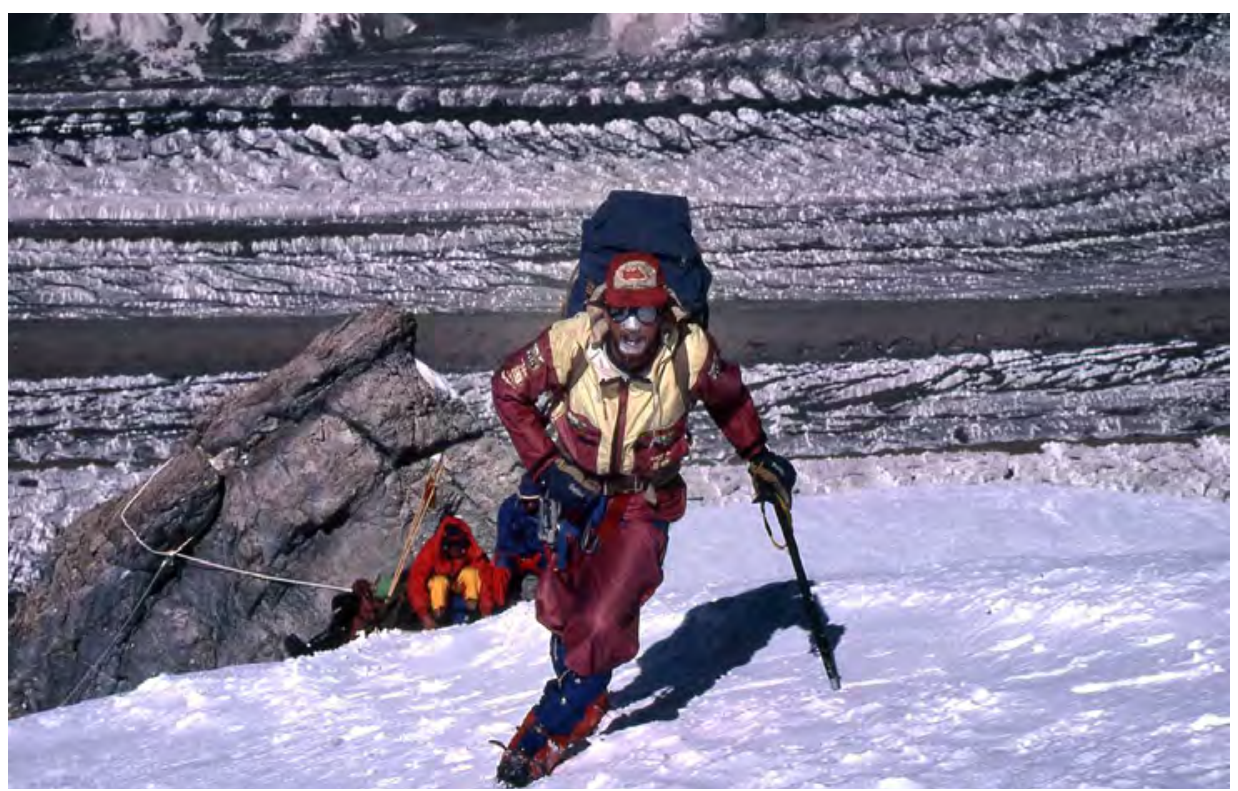

Image 17.2. Peter Lambert climbing above camp two on Broad Peak, Pakistan, during the summit bid.

Photo by Zac Zaharias

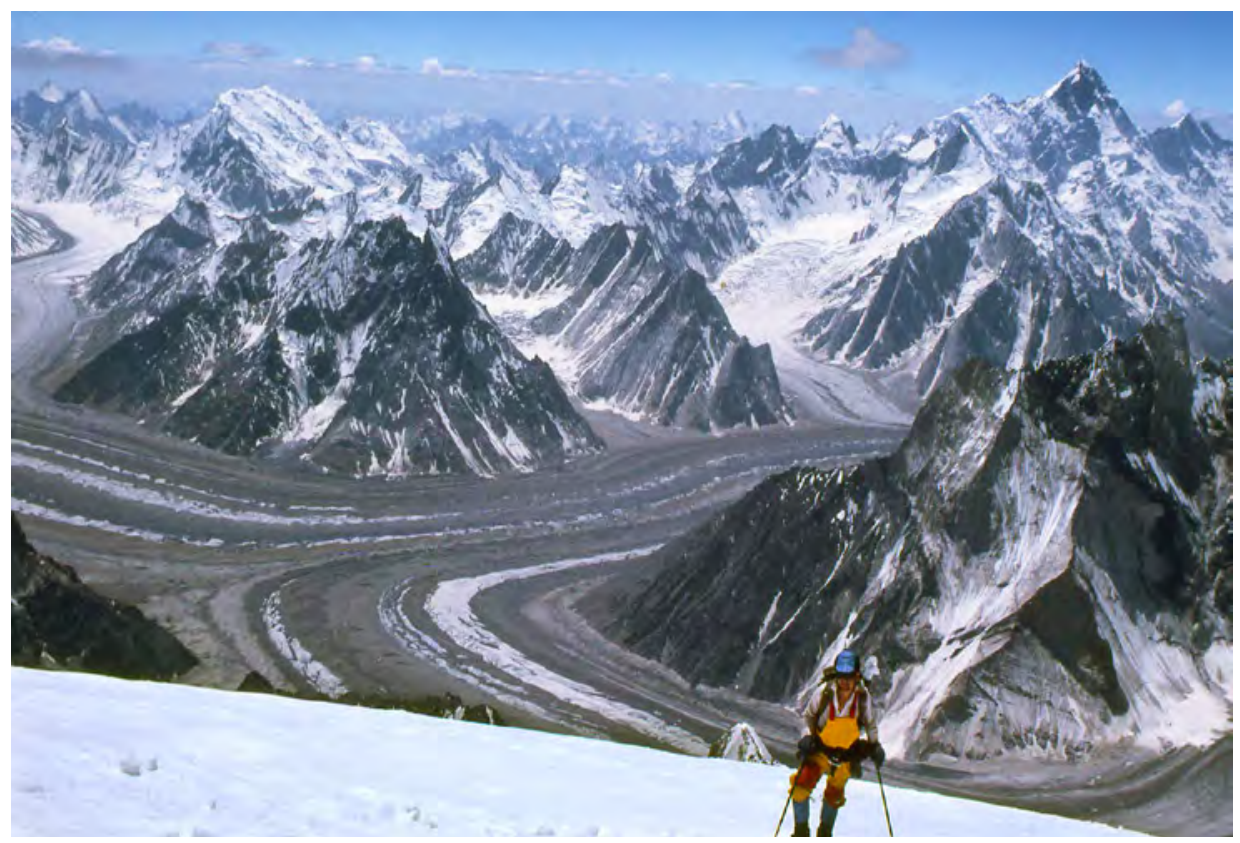

Image 17.3 Terry McCullagh approaching camp three at $7000 \mathrm{~m}$ on Broad Peak, high above Concordia, Baltoro Glacier.

Photo by Zac Zaharias 


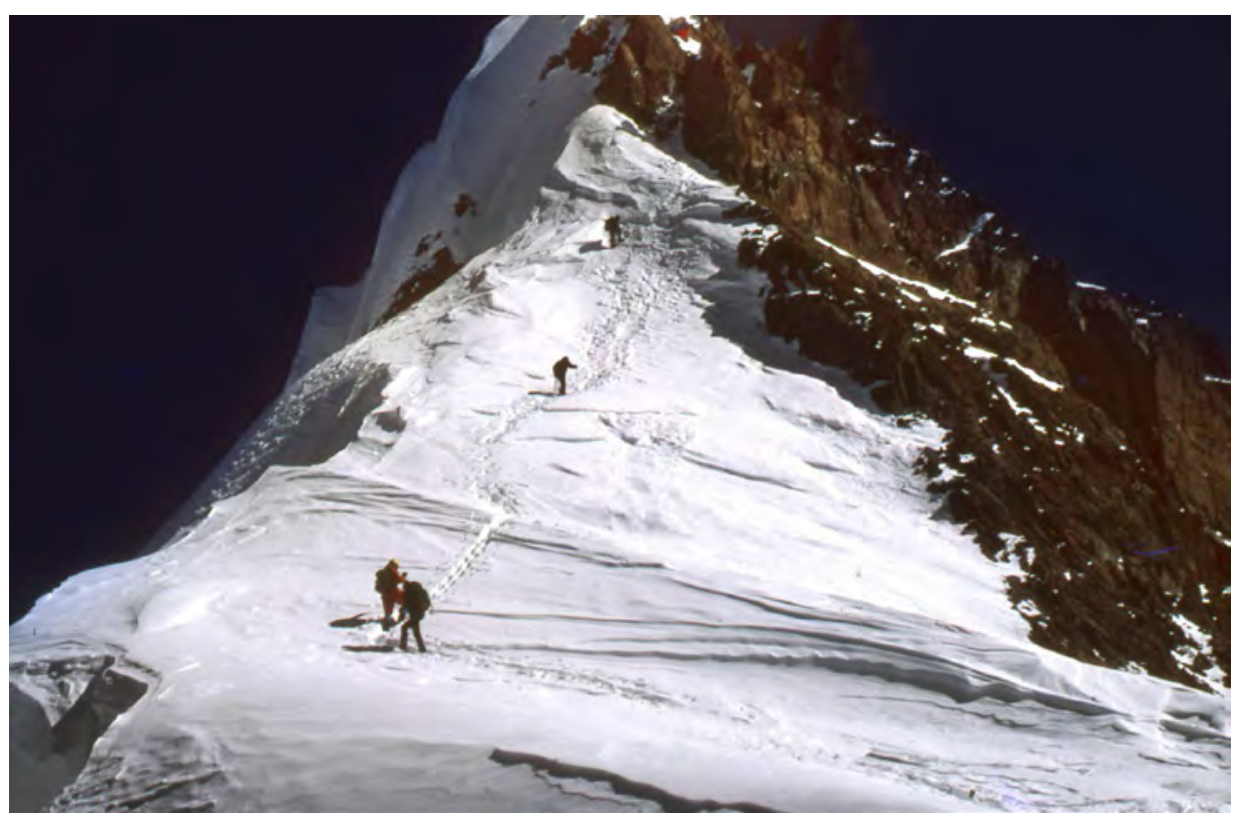

Image 17.4. Climbers at the col leading to summit ridge on Broad Peak. Pat Cullinan is in the red suit with yellow helmet, on the way to the summit with three German climbers.

Photo by Zac Zaharias

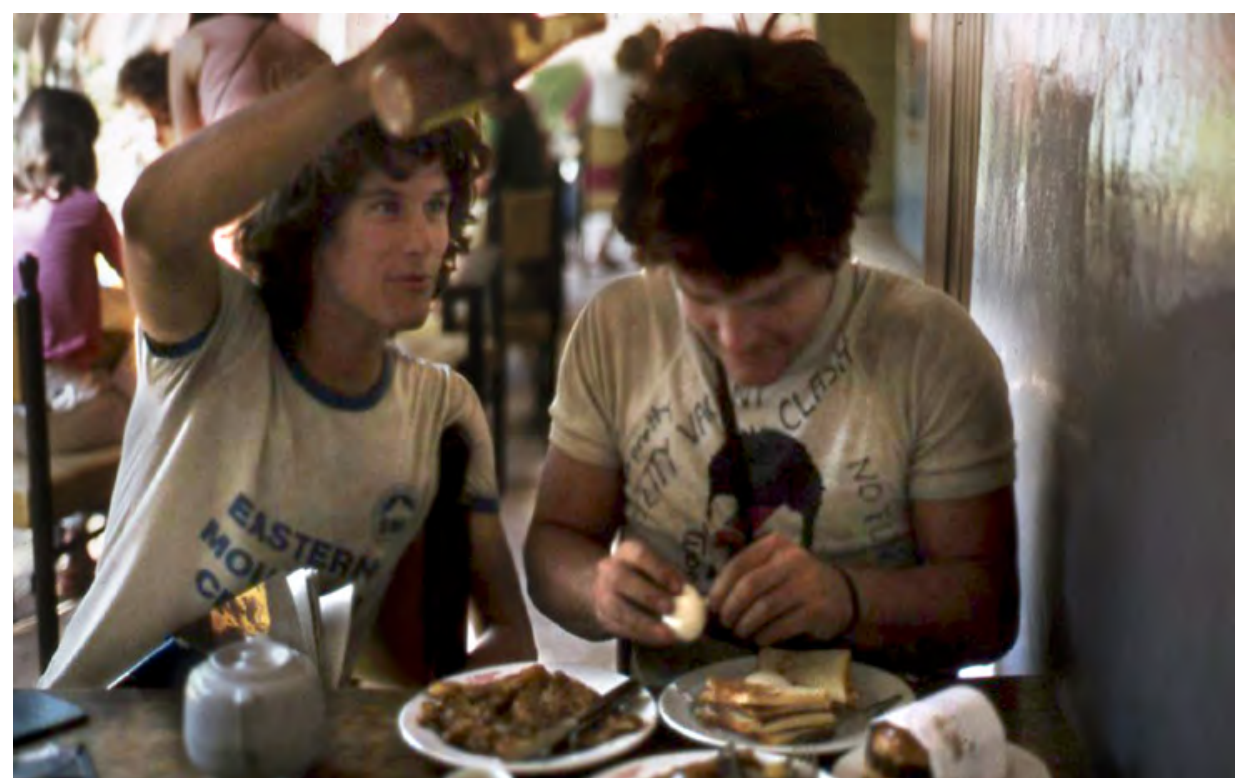

Image 19.1. Craig Nottle (left) and Jon Muir at a tourist camp at New Delhi before the Changabang expedition, 1982.

Photo by Brigitte Muir 


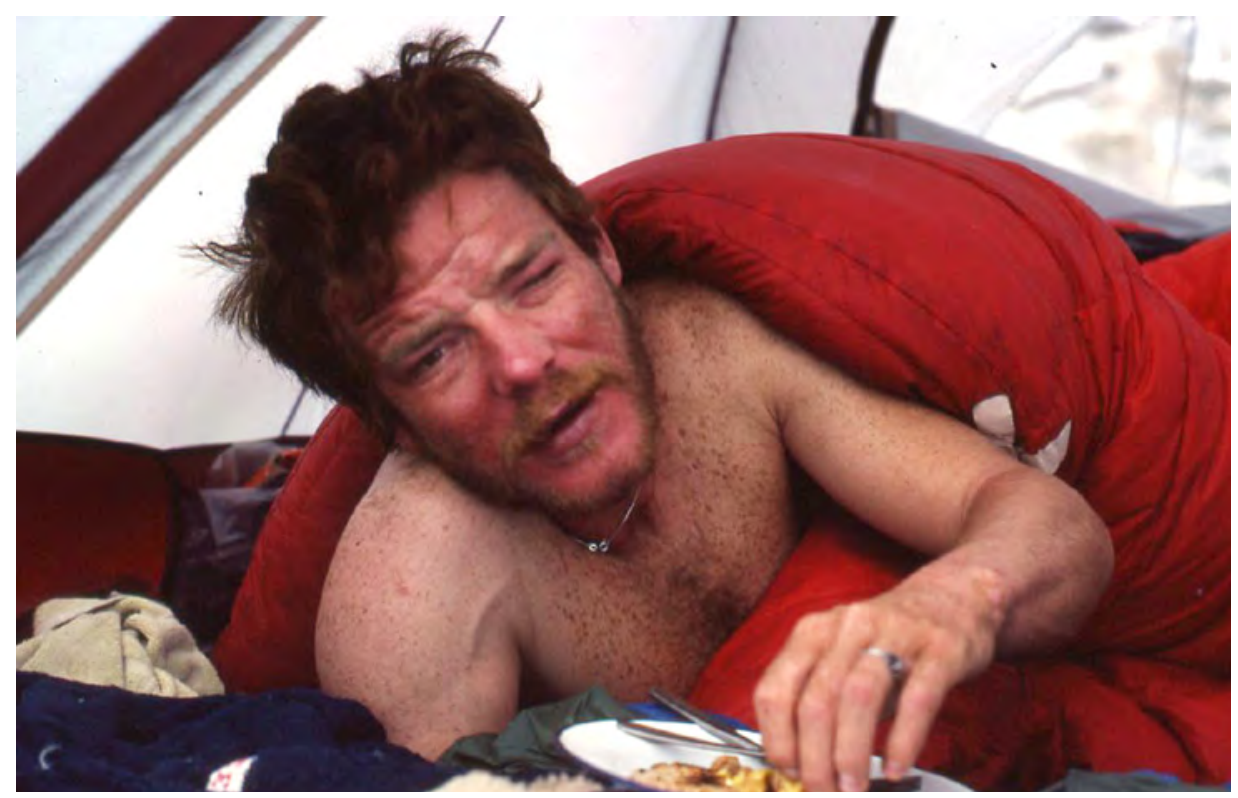

Image 20.1. Jon Muir after descending from the west ridge, Mt Everest, 1984, just after Craig Nottle and Fred From fell to their deaths on the summit day.

Photo from the Brigitte Muir collection

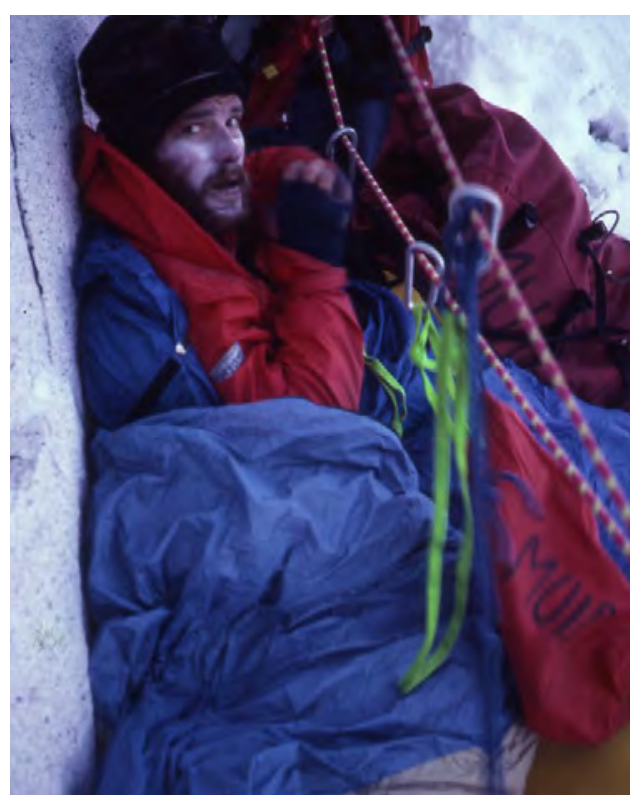

Image 20.2. Jon Muir on the first ascent of the west pillar of Shivling, India, 1986.

Photo by Brigitte Muir 


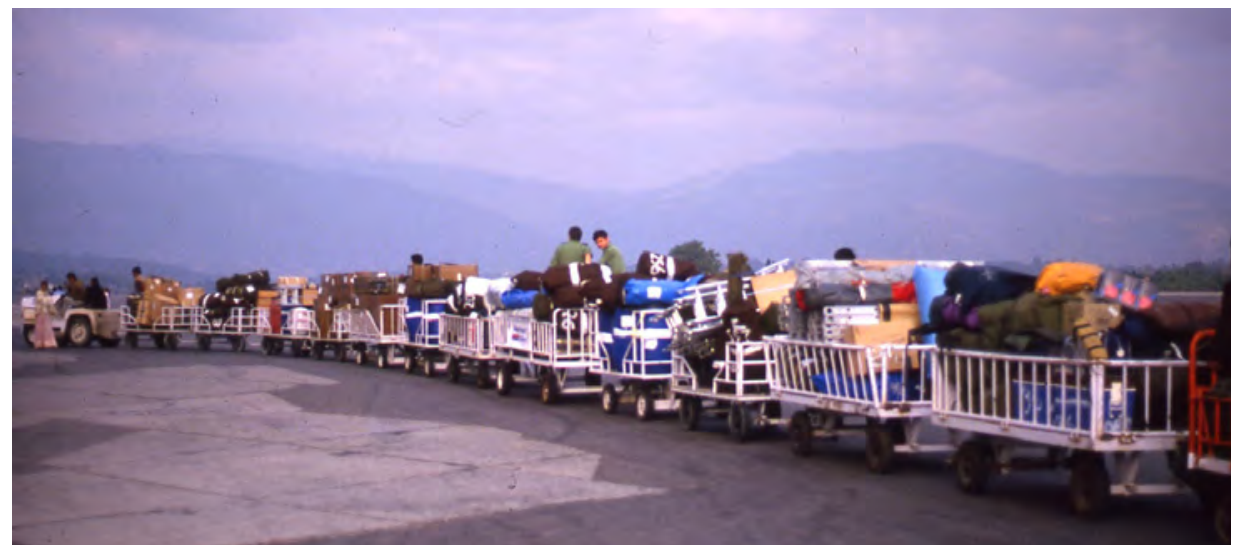

Image 21.1. Carts of ABEE baggage at Kathmandu, Nepal airport (Peter Lambert sitting on the trolley with back to camera) dispatched by RAAF C130 in December 1987.

Photo by Zac Zaharias

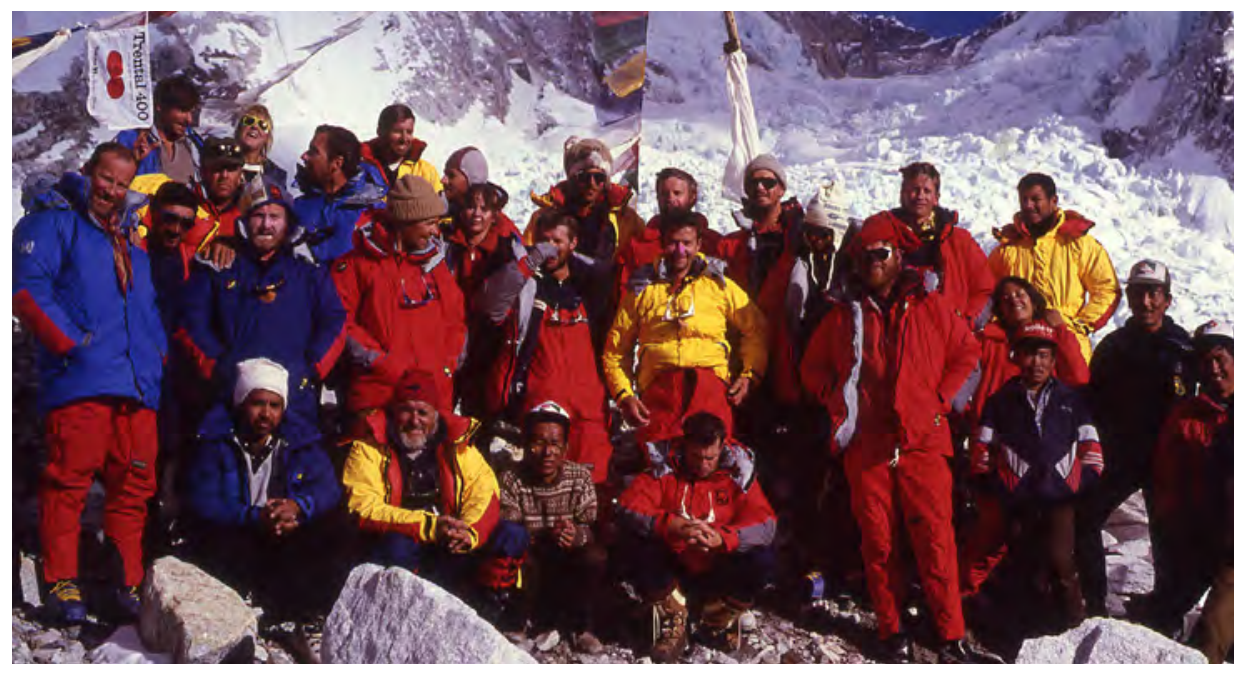

Image 22.1. ABEE team photo at base camp, Mt Everest, 1988. Front row, squatting, from left: Ali Shah, Austin Brookes, Sonam Girme, Jim Truscott. Second row, from left: Bruce Farmer, Terry Tremble, Mike Rheinberger, Charlie Hart, Michael Pezet, Terry McCullagh, Chris Curry, Little Pasang, (and two other base camp staff). Back rows, from left: Jim Van Gelder, Norm Crookston, Di (unknown friend of Terry Tremble and Jon Muir who walked into base camp with the team), Peter Lambert, Pat Cullinan, Richard Moor, Carol Brand-Maher, James Strohfeldt, Brian Agnew, Andrew Smith, Paul Bayne (white beanie), Peter Allen, Jill Trenam, Zac Zaharias, Wanchu.

Photo by Sorrel Wilby 


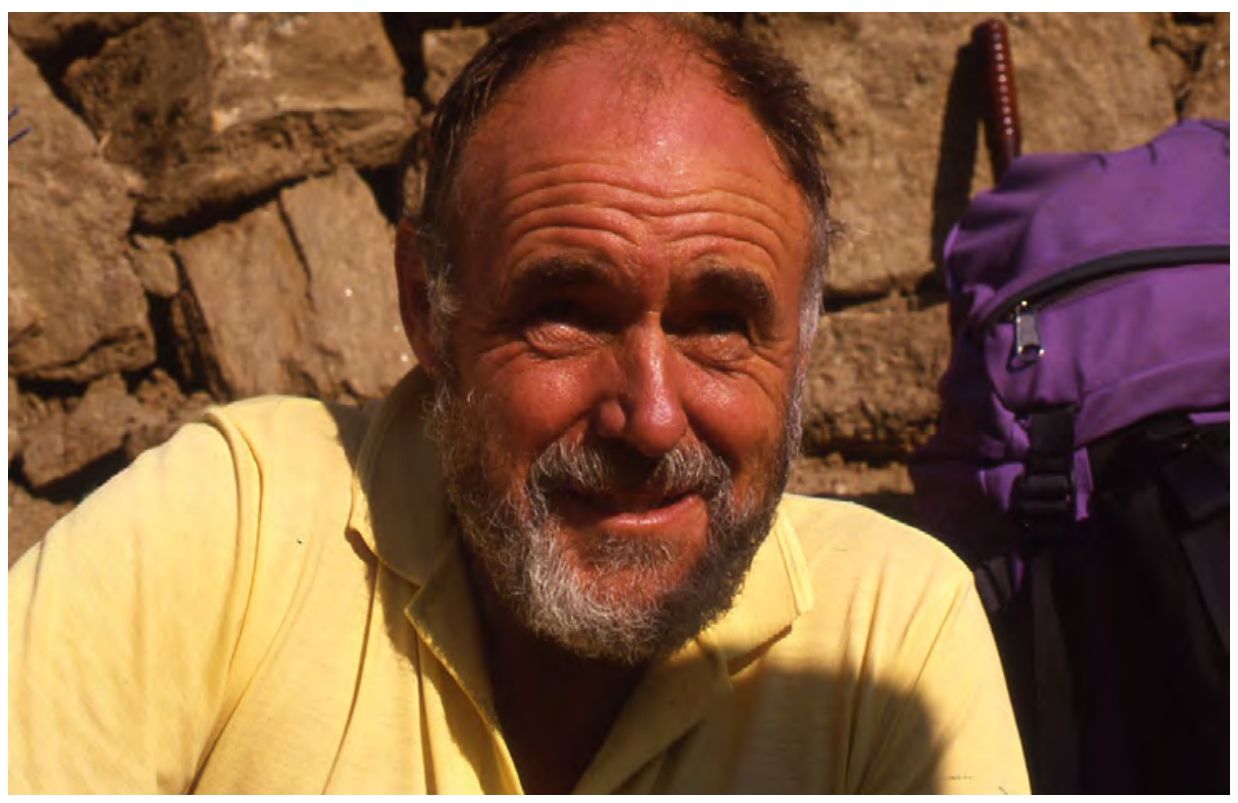

Image 22.2. Portrait of Austin Brookes, the leader of the ABEE.

Photo by Zac Zaharias

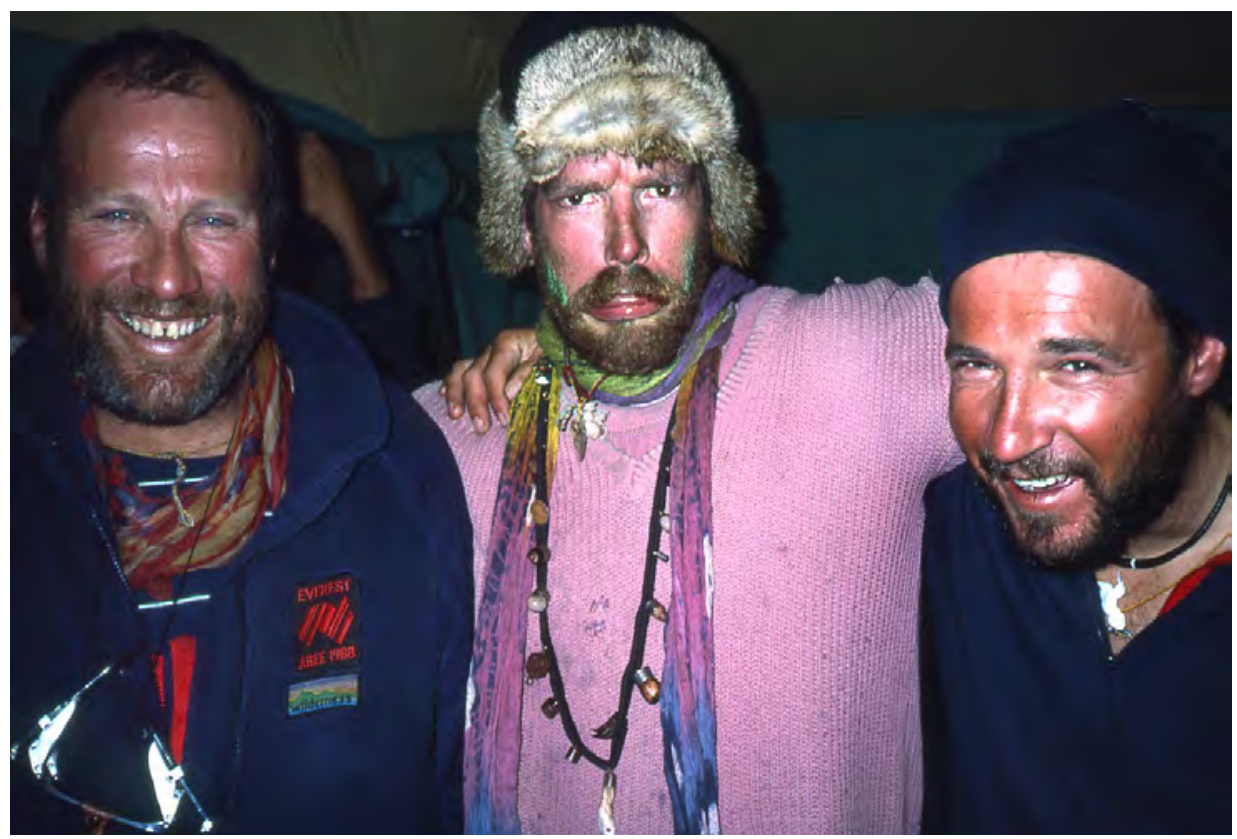

Image 22.3. From left, Bruce Farmer, Jon Muir and Terry Tremble, ABEE expedition, 1988.

Photo by Zac Zaharias 


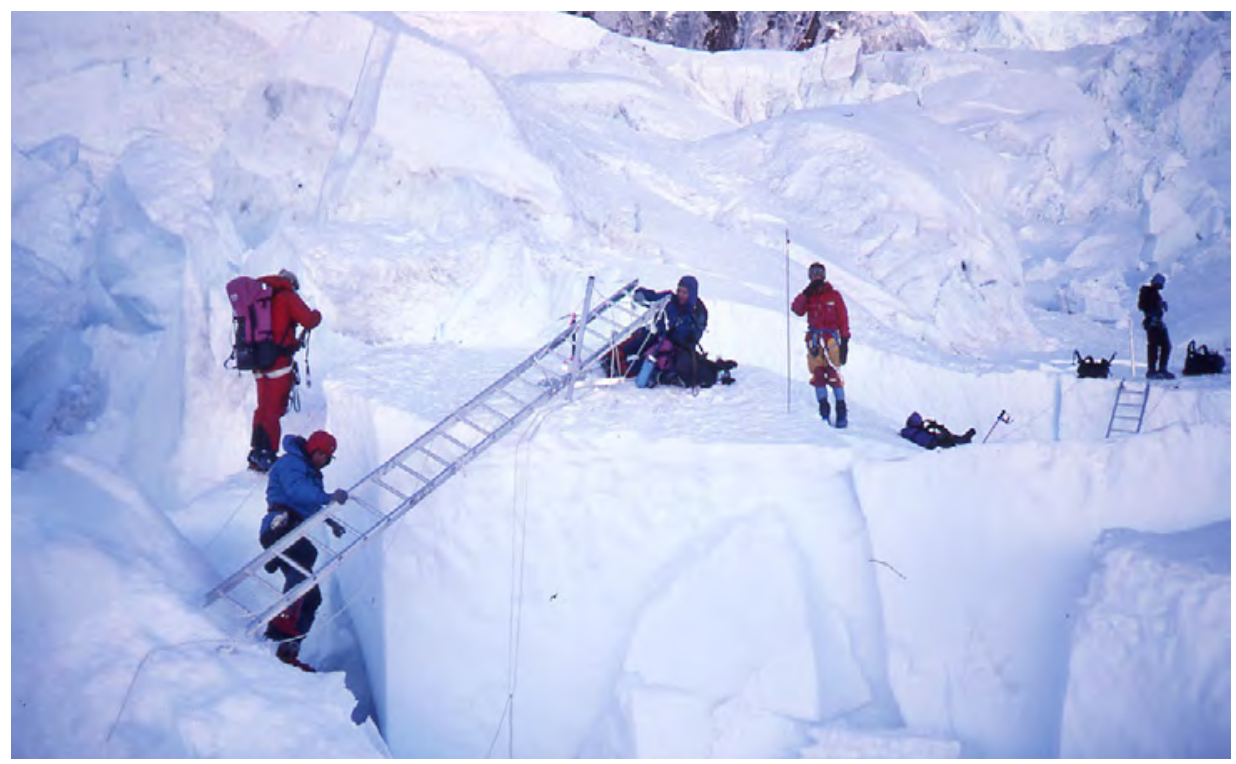

Image 22.4. ABEE climbers repair a section of the Khumbu icefall route after the ladders were damaged during a slump in the ice, Mt Everest, 1988.

Photo by Zac Zaharias

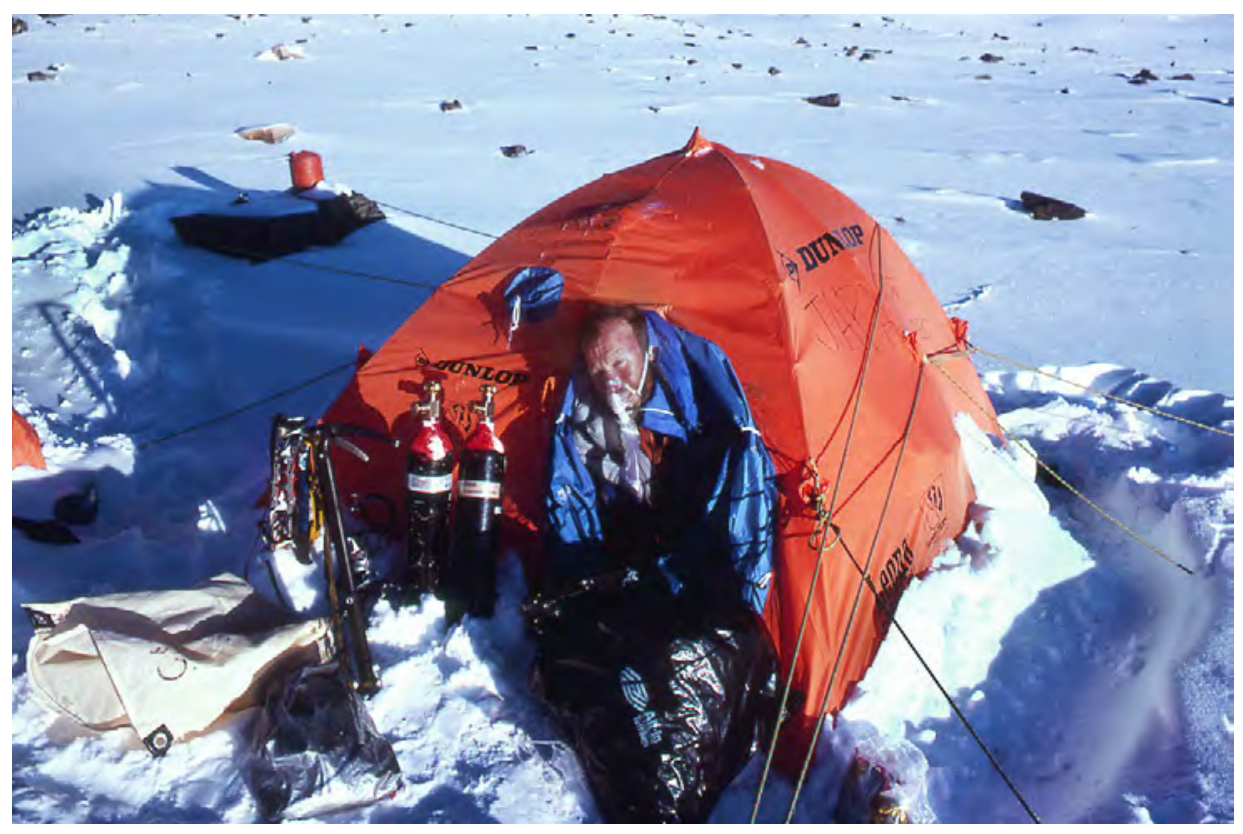

Image 22.5. Bruce Farmer with oxygen at the South Col, Mt Everest, the day before Zac's Yaks' summit attempt that reached $8600 \mathrm{~m}$.

Photo by Zac Zaharias 


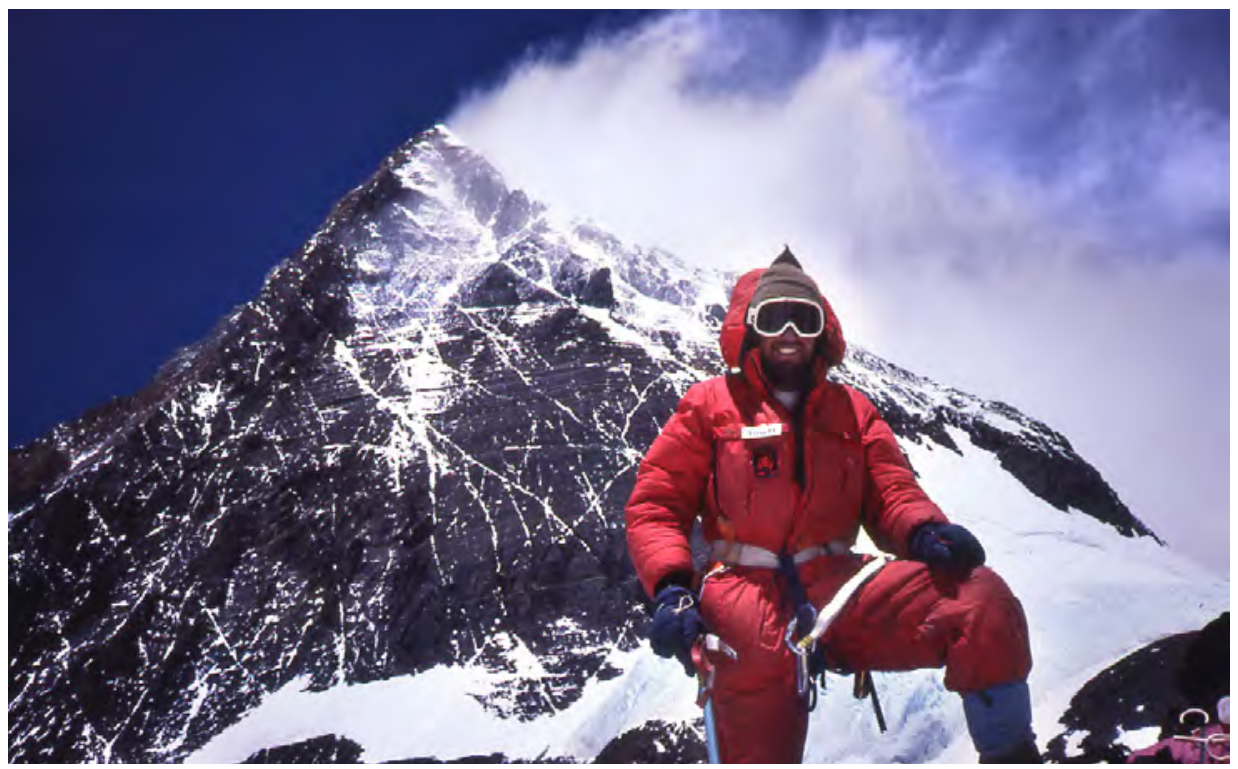

Image 22.6. Pat Cullinan with the summit of Everest in the background.

Photo by Paul Bayne

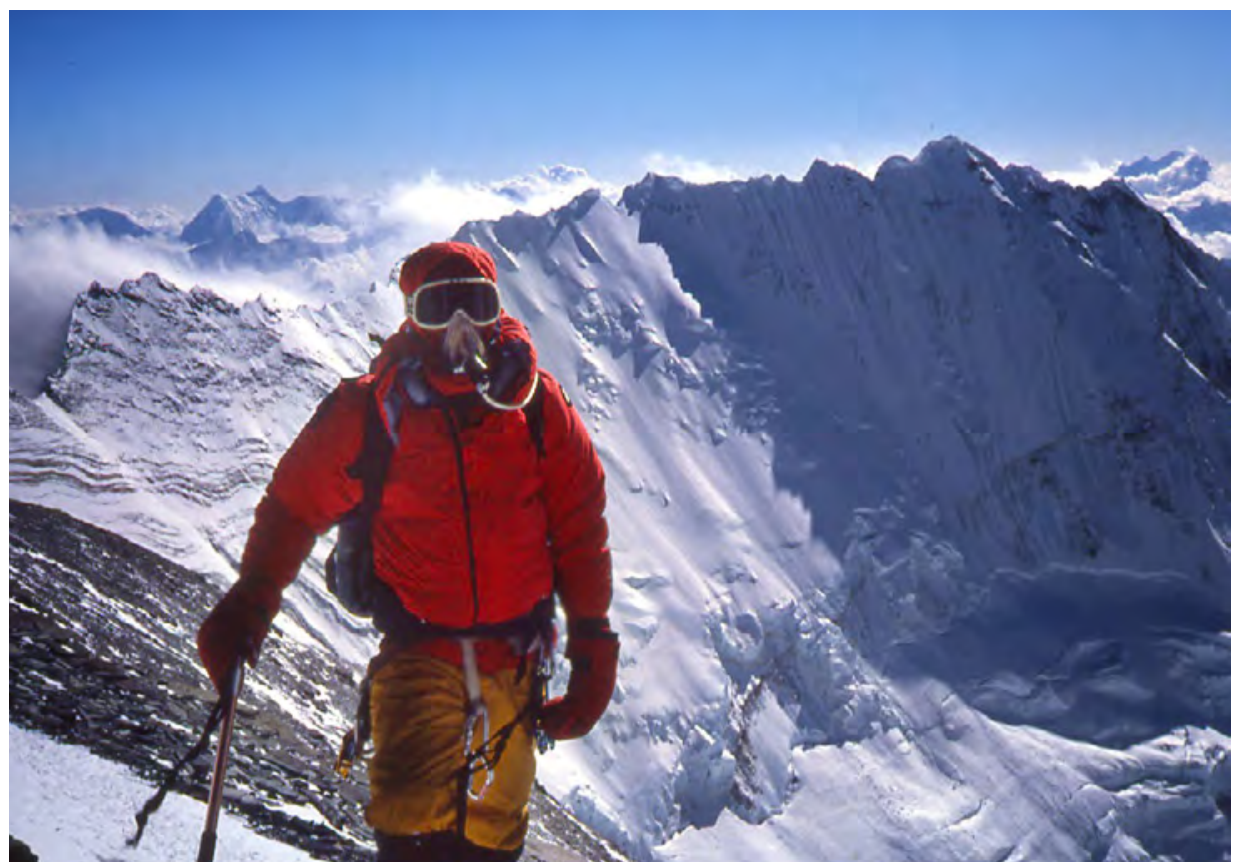

Image 23.1. Norm Crookston with oxygen approaching the South Col, Mt Everest.

Photo provided by Pat Cullinan 


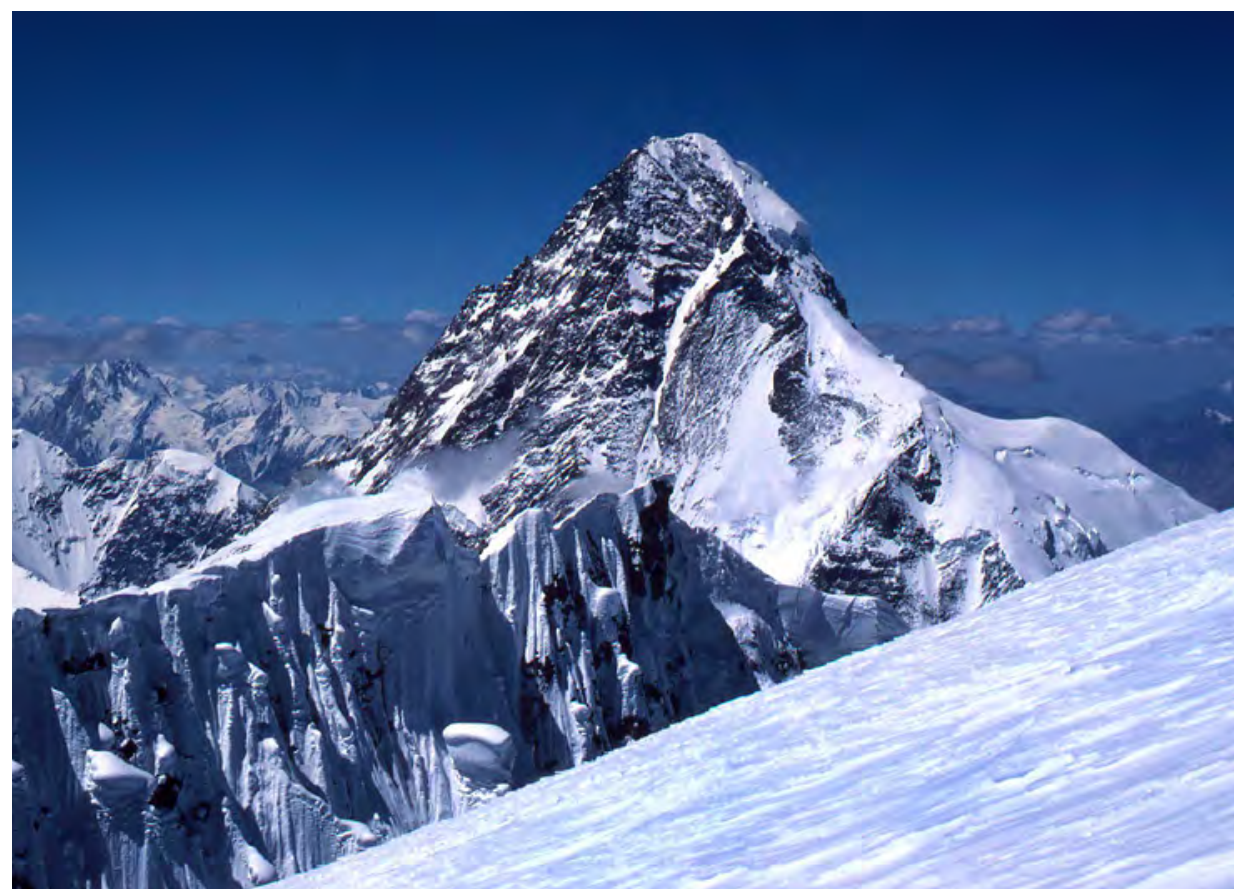

Image 25.1. The soaring summit of K2, as seen from Broad Peak.

Photo by Zac Zaharias

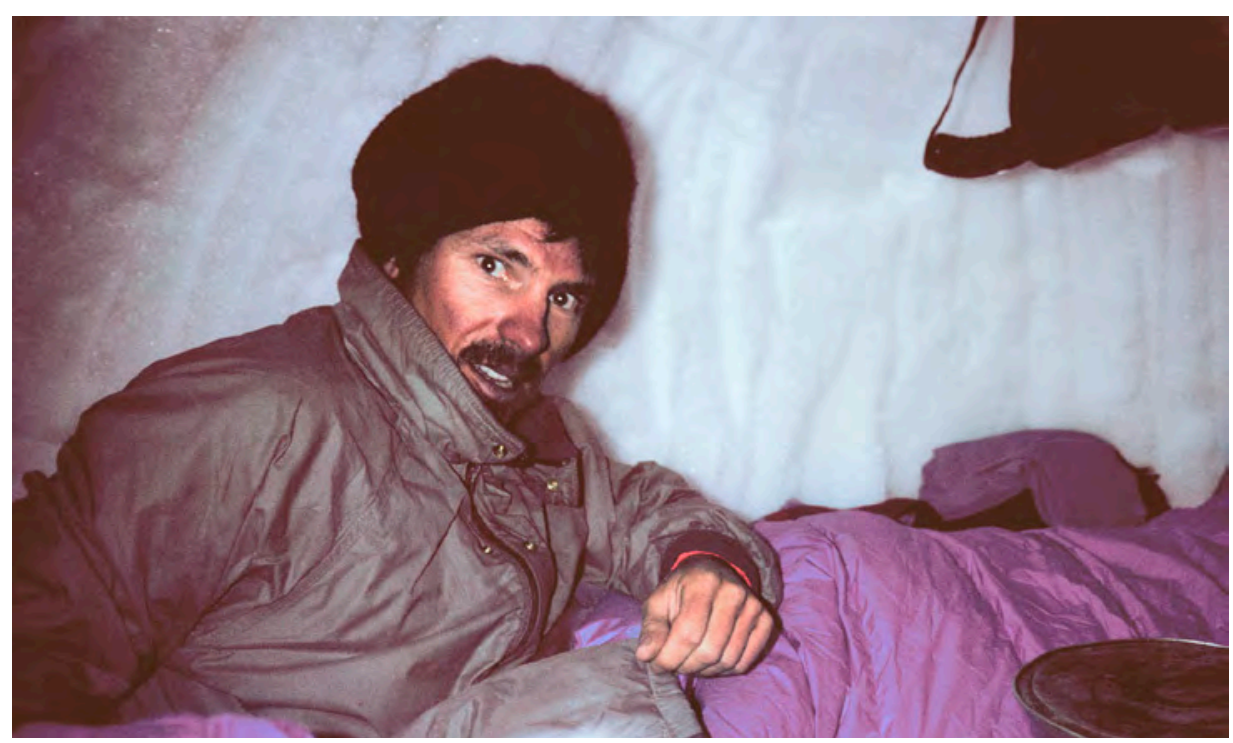

Image 25.2. Greg Child in the snow cave (camp three) on Gasherbrum IV, Pakistan.

Photo by Tim Macartney-Snape 


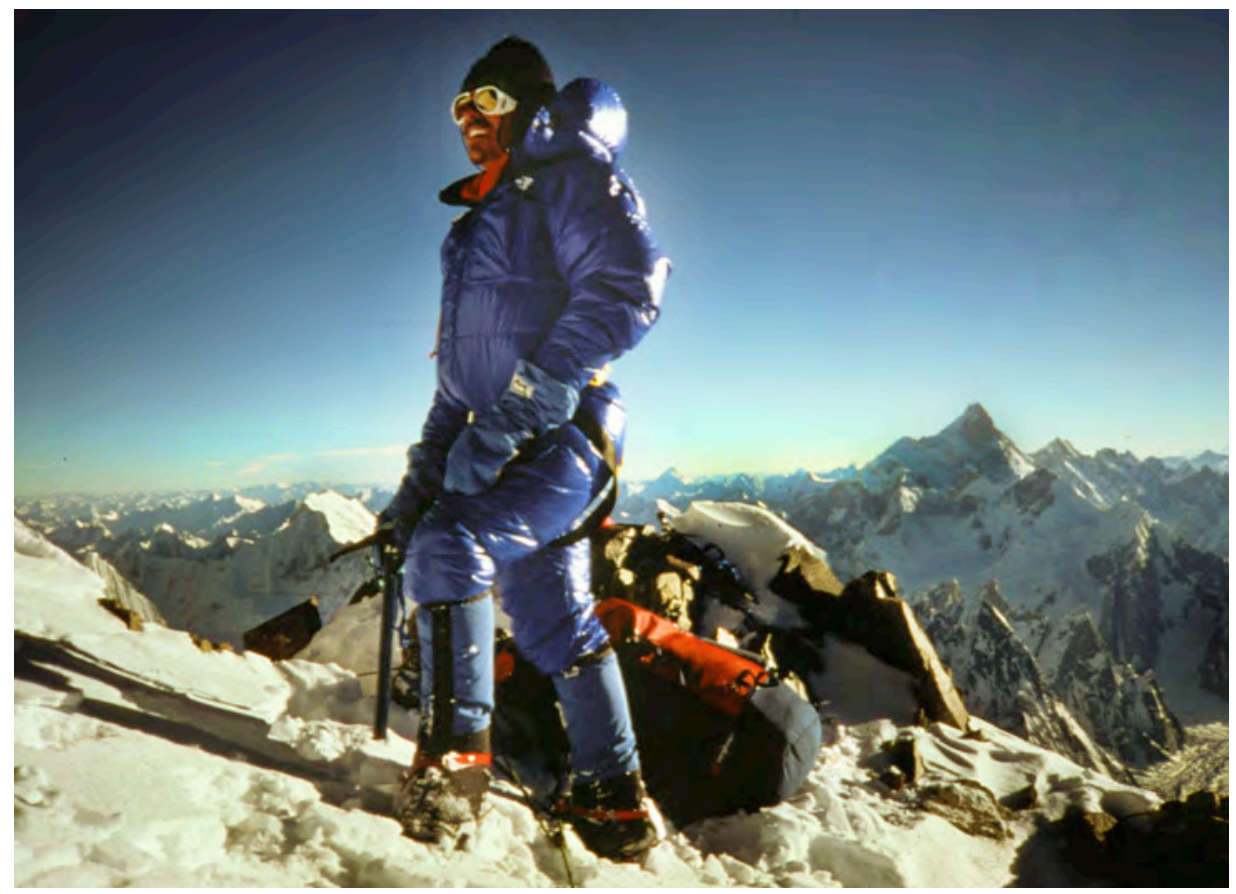

Image 25.3. High on Gasherbrum IV, Greg Child leaving camp four for the summit.

Photo by Tim Macartney-Snape

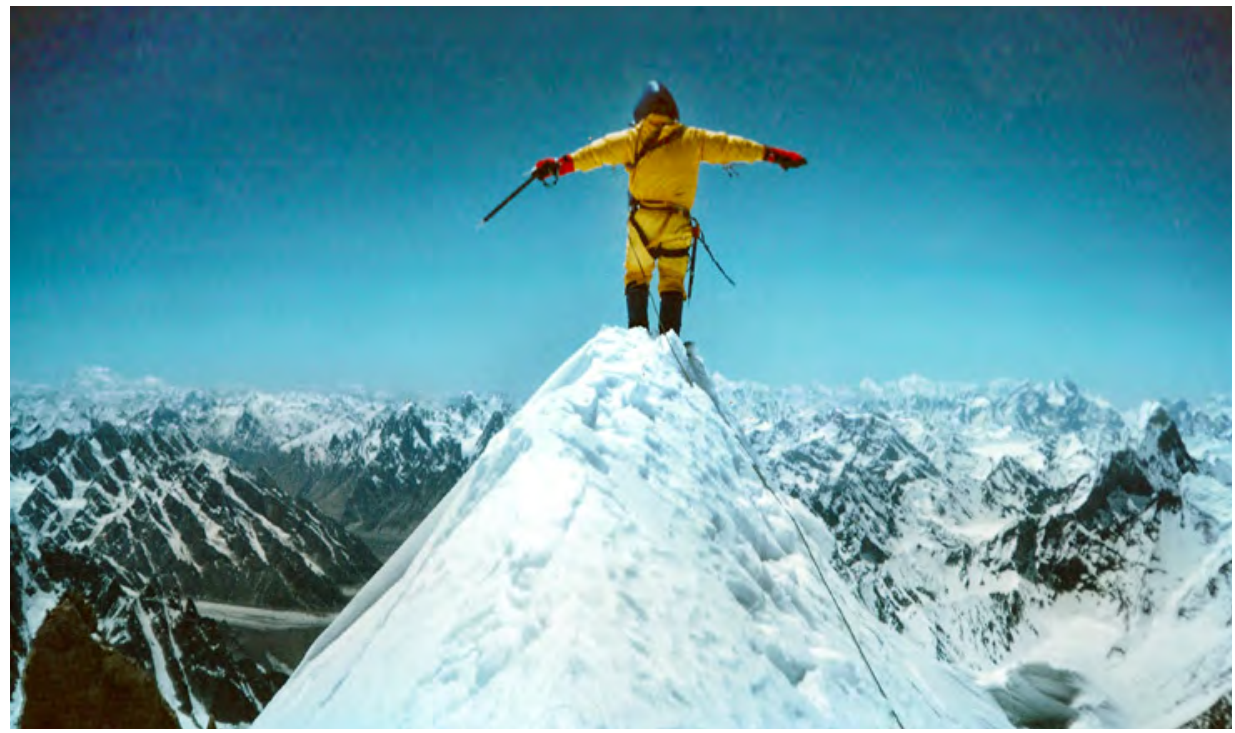

Image 25.4. Greg Child high on a ridge near the north summit of Gasherbrum IV (7925 m), Pakistan.

Photo by Tim Macartney-Snape 


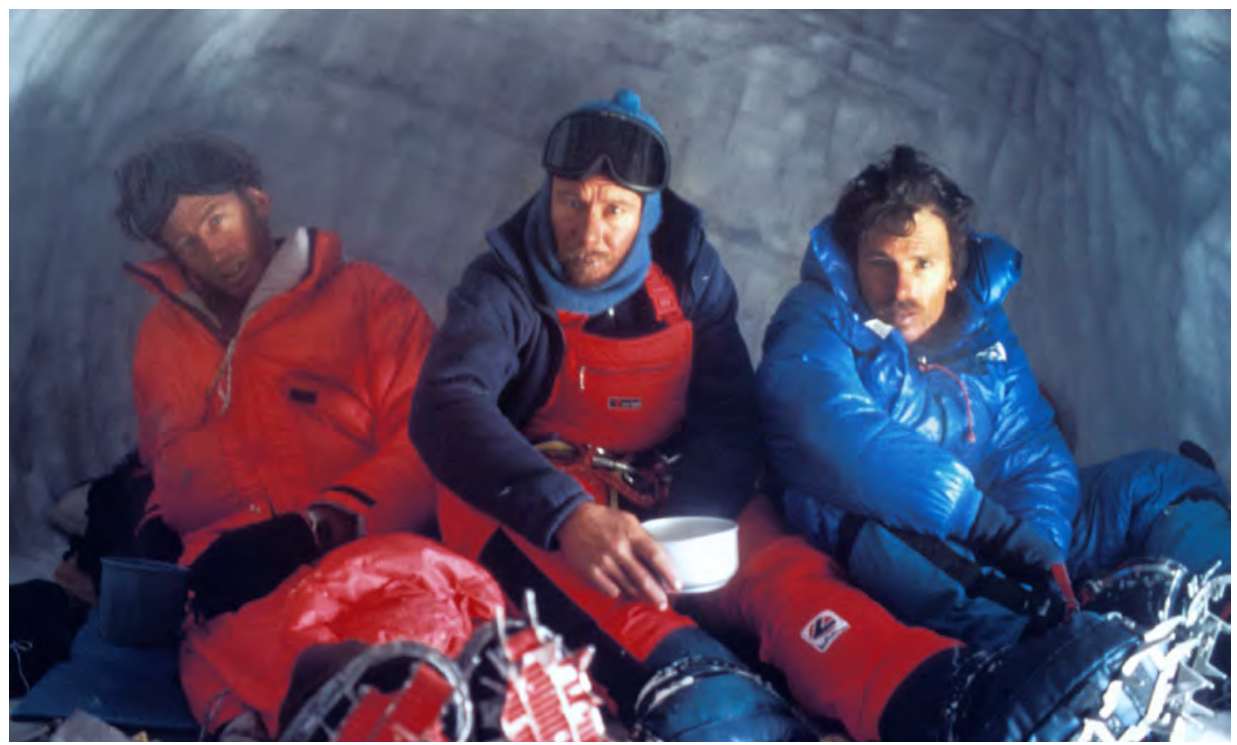

Image 25.5. The three climbers who reached the summit of Gasherbrum IV, after their successful ascent but still high on the mountain. From left: Tim Macartney-Snape, Tom Hargis and Greg Child.

Photo by Randy Leavitt

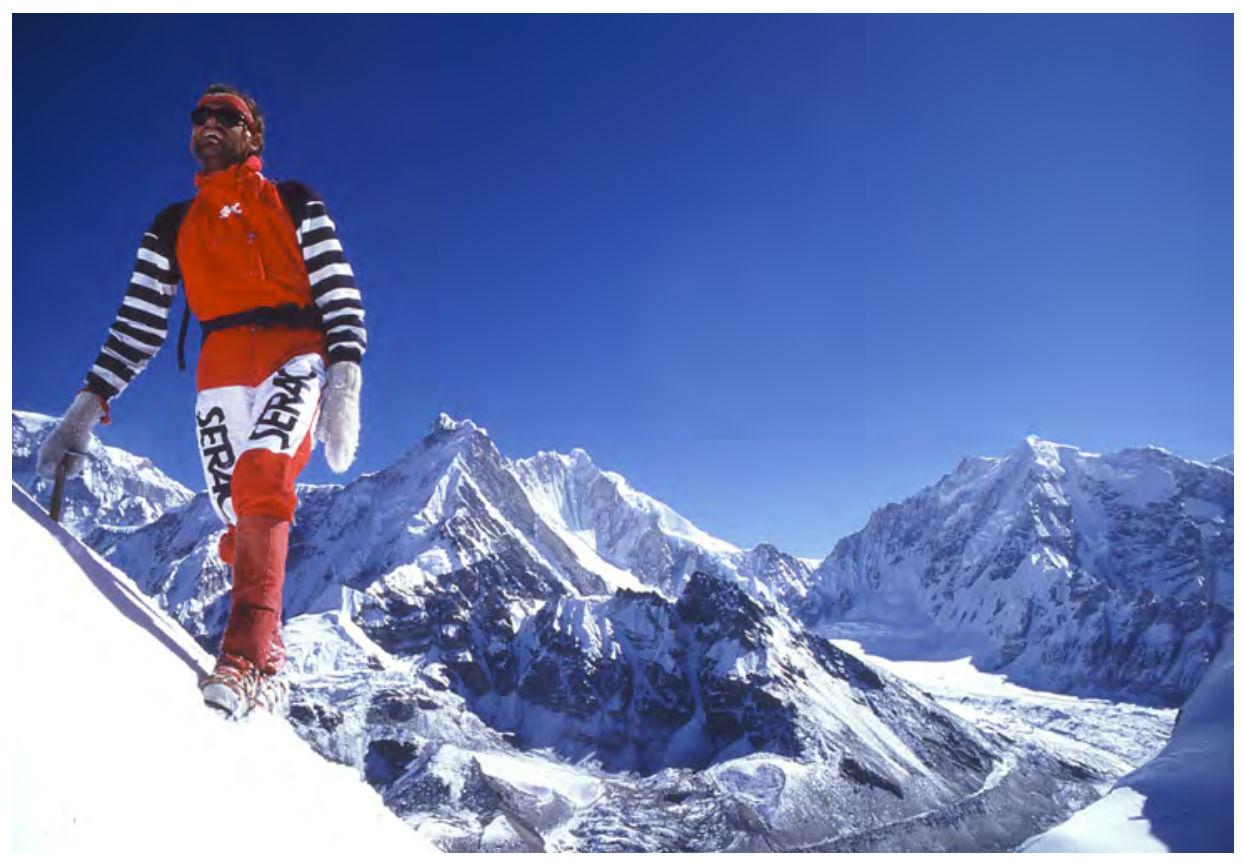

Image 26.1. John Coulton climbing high in the Himalaya, 1987.

Photo by Michael Groom 


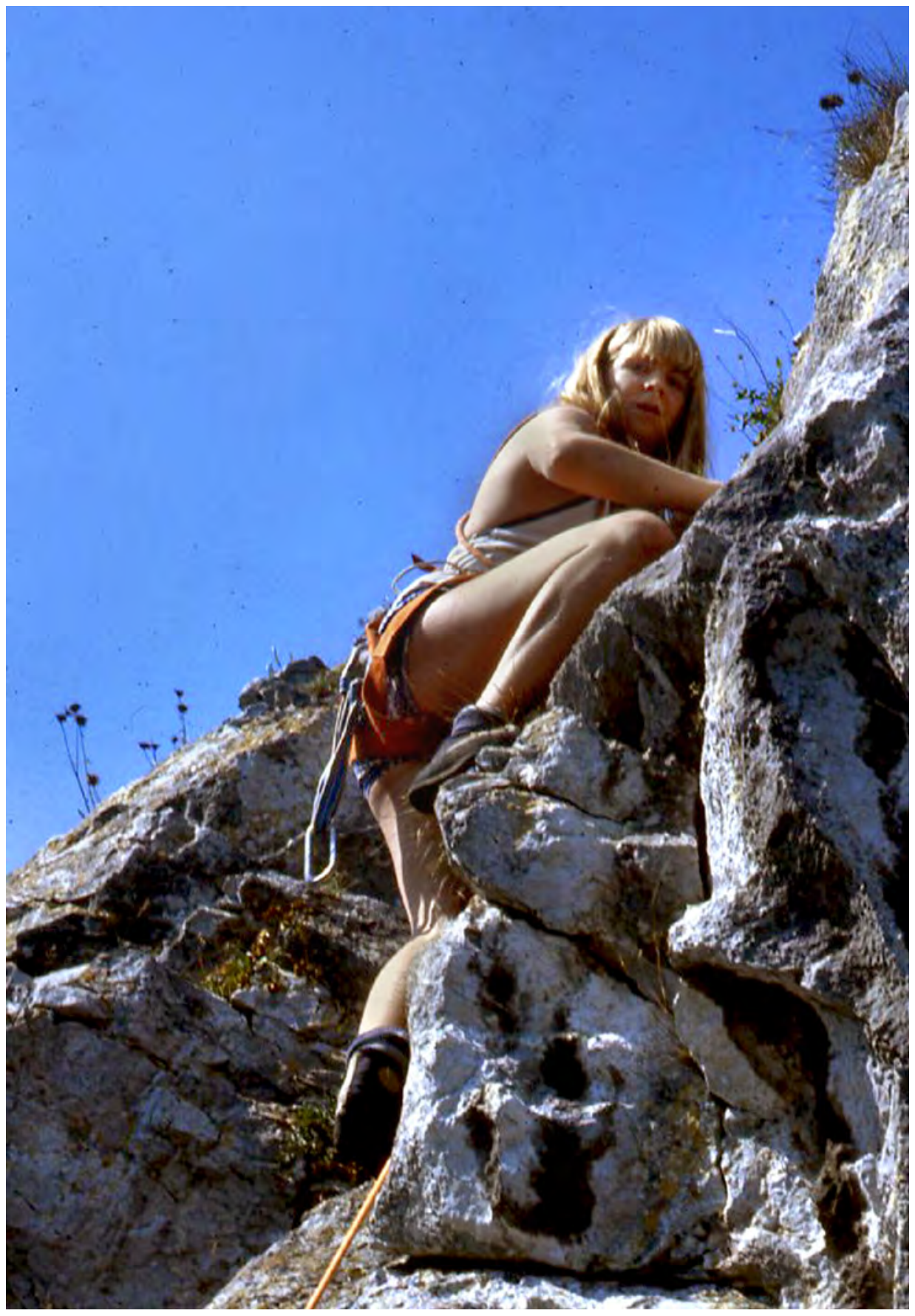

Image 28.1. Brigitte Muir climbing at Mont St Michel, Calanque de Morgiou, southern France, late 1970s.

Photo provided by Brigitte Muir 


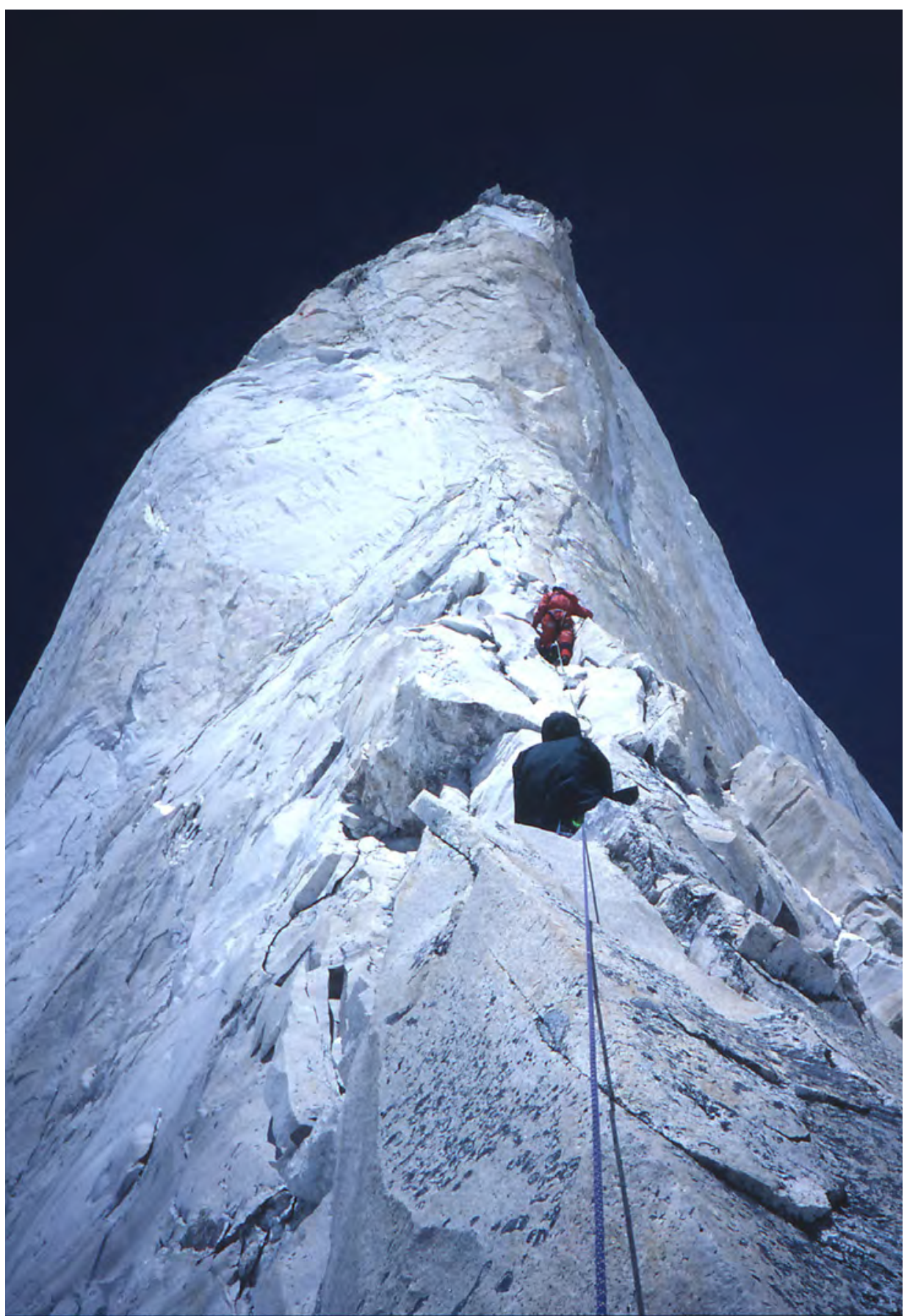

Image 28.2. Brigitte Muir (above, in red) and Graeme Hill climbing below the prow on a new route on the west ridge, Shivling, India, 1986.

Photo by Jon Muir 


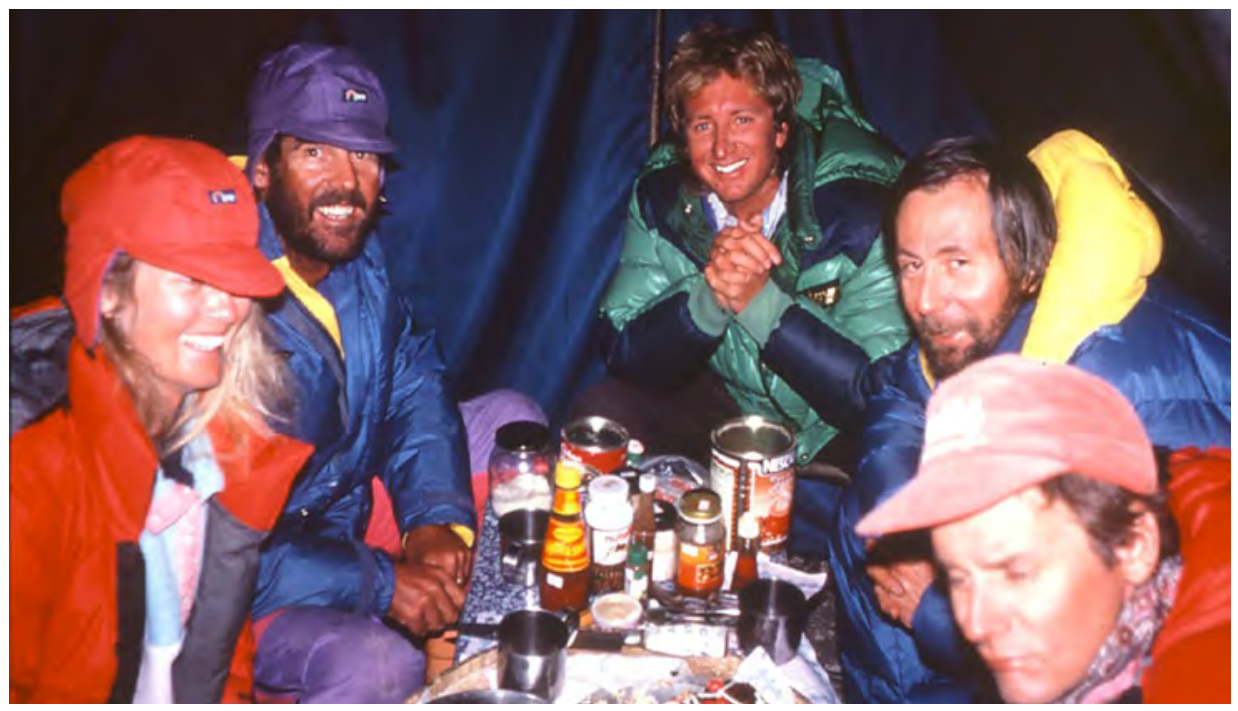

Image 29.1. The 1990 Cho Oyu, Nepal, expedition team at base camp after the successful summit attempt. From left, Jane White, Rick White, Michael Groom, Steve McDowell and Tony Dignan.

Photo from the Michael Groom collection

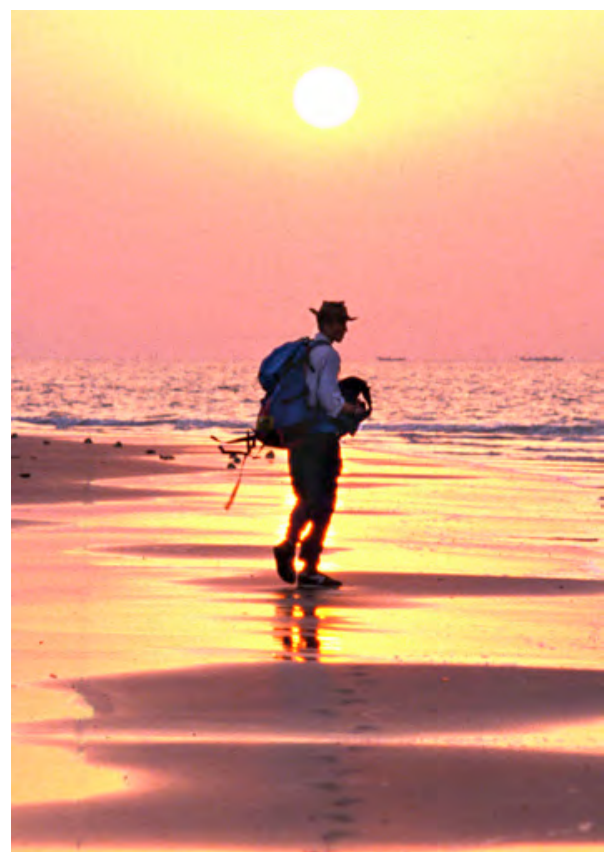

Image 29.2. Tim Macartney-Snape at Ganga Sagar on the Bay of Bengal, India, beginning the long journey to Everest. 


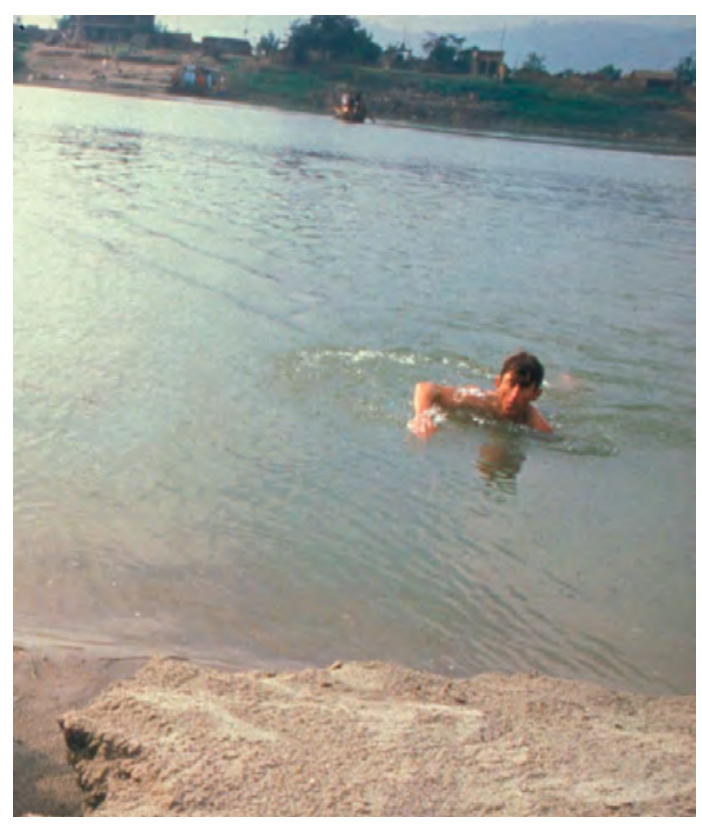

Image 29.3. Tim Macartney-Snape swimming across the Ganges River, India, on the way to the Himalayan mountains.

Photo by Pip Macartney-Snape

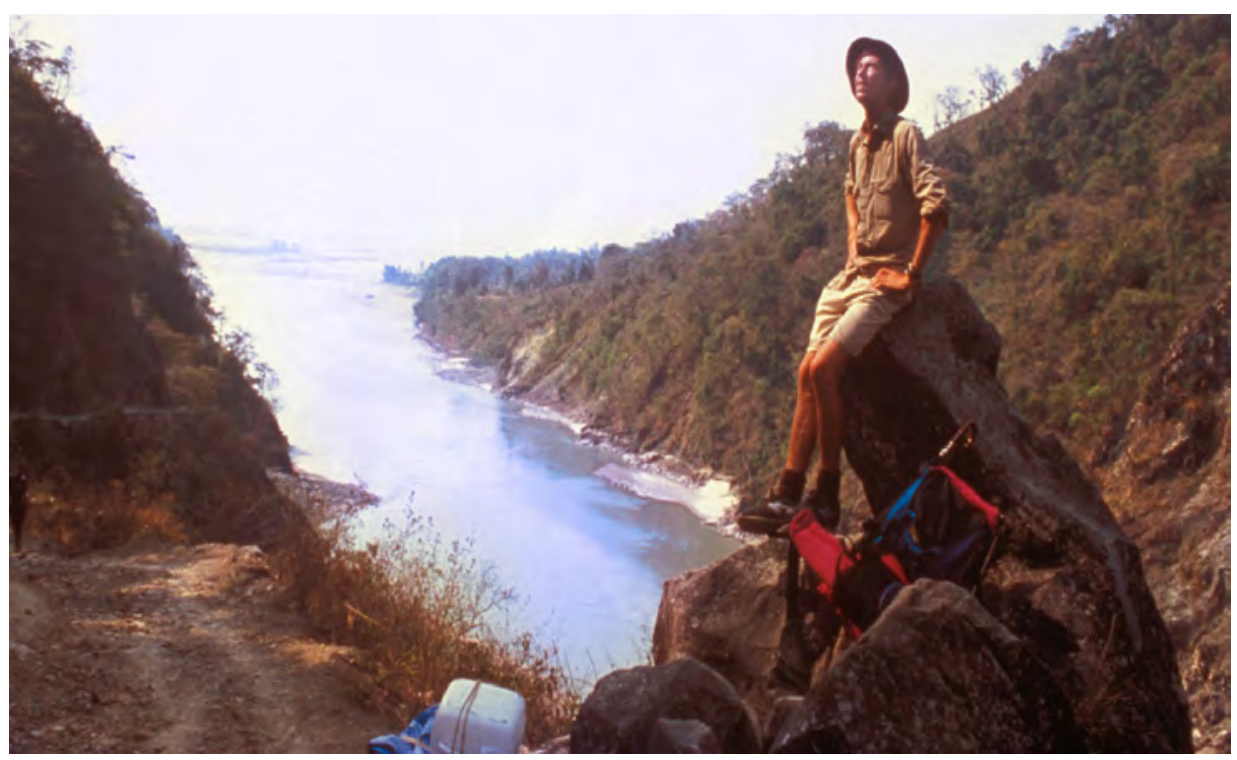

Image 29.4. Tim Macartney-Snape at the start of the Himalayan foothills, Nepal.

Photo by Ann Ward 


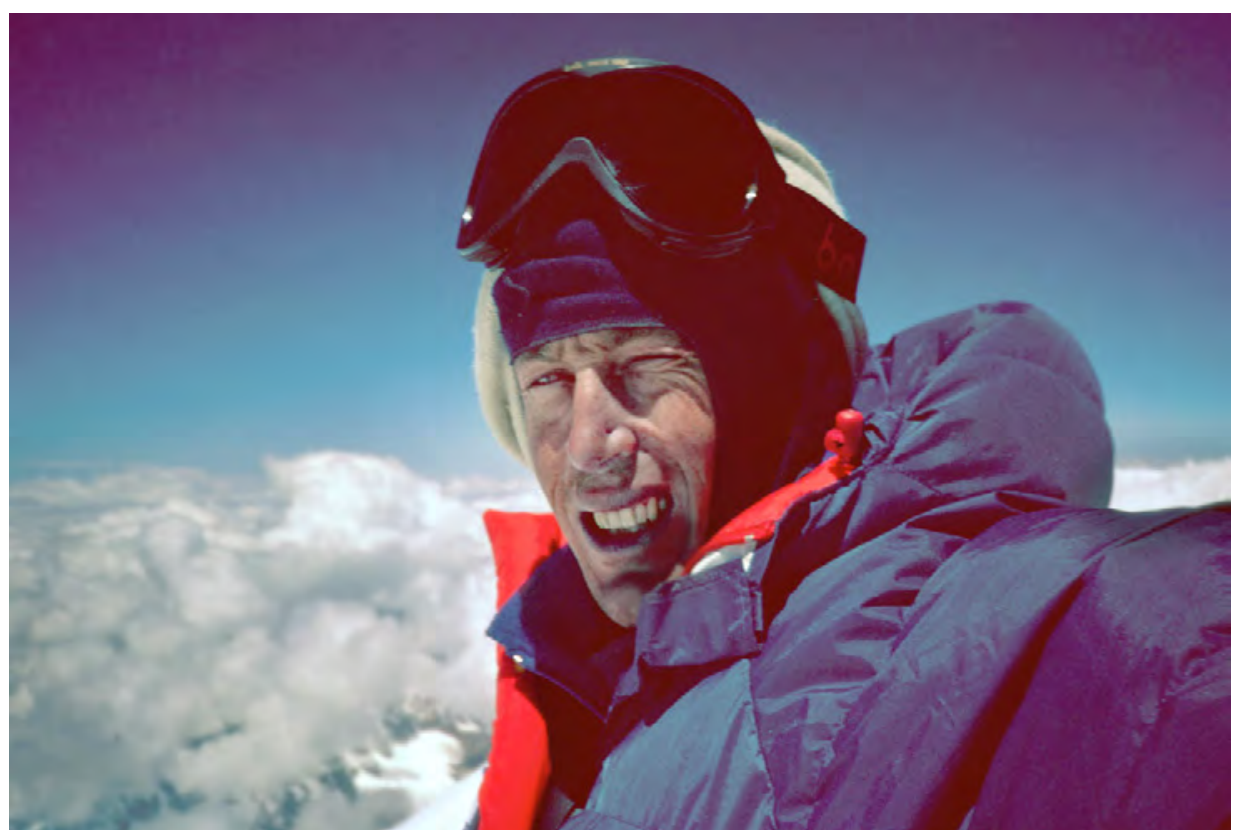

Image 29.5. Tim Macartney-Snape on the summit of Mt Everest, May 1990, having climbed all 8850 metres of the mountain.

Photo by Tim Macartney-Snape 



\section{Part 4: Combat zone- soldiers in the mountains}





\section{A colonel's dream}

As their truck rumbled slowly away from the Rongbuk Valley and back towards the Tibetan settlements of Xegar and Xigatse, Tim Macartney-Snape, Lincoln Hall, Greg Mortimer, Andy Henderson and Geof Bartram no doubt felt a great sense of relief and release - relief, because the ever-present danger of climbing on a high Himalayan peak was over, and release, because the dominating influence of Mt Everest on their lives had finally waned. Although they were the first Australians to climb the mountain, they were not the first to experience the lure of Everest.

Earlier a small group of Australians had trekked up to Everest base camp from the south, from the Nepalese side of the mountain. It was February, the winter season, and as they sat on the little hillock called Kala Pattar, they could see the jet stream blow an enormous plume of cloud off the imposing rock pyramid. The view of Everest from Kala Pattar - the Khumbu Icefall, the South Col and the windblown summit itself - is one of the classics in Himalayan trekking. It is one that invariably leaves trekkers in a state of awe and often triggers dreams of climbing to the highest place on Earth.

For most, the dreams remain just that. For the leader of the Australian trekking group, however, the view from Kala Pattar spawned dreams that would launch and maintain an important strand of Australian mountaineering for more than a decade. The Australian trekkers were 17 members of the Australian Army, predominantly Royal Australian Engineers, and their leader was Colonel Peter Gration. Gration's dream, as he looked up at Everest's summit, was to put an Australian Army team on the top. He realised that it would have to be a longterm goal, as at that time the army had no significant pool of experienced mountaineers.

The year was 1975, the same year that the young members of the ANU Mountaineering Club (ANUMC) were starting to dream about their own Himalayan trip and the year that Warwick Deacock took the first Australian expedition into the Himalaya. Gration, of course, had no knowledge of these events at the time, but he knew enough about Himalayan climbing to suggest that 1988, Australia's bicentennial year, would be an appropriate target date for an Australian Army ascent of Everest. In the intervening 13 years, the army could train enough mountaineers to make the goal feasible.

Gration's dream was the conceptual genesis of the 1988 Australian Bicentennial Everest Expedition (ABEE). The ABEE was by far the largest and most expensive 
Himalayan expedition ever to leave Australian shores and it required a massive organisational and fundraising effort involving many man-years of work. In the end, it brought together representatives of most of Australia's Himalayan climbing groups. Its members included mountaineers of extraordinarily diverse personalities, from the most individualistic, almost anarchic young civilian climbers to the most team-oriented, disciplined military mountaineers of the old school.

The ABEE brought Australia its second success on Mt Everest - a victory snatched at the last moment against all odds. The ascent was finally made by two exhausted climbers dangerously close to overstepping their limits on the agonising final stage up the South-East Ridge. One of the ascensionists had never been to the Himalaya before. In addition, the ABEE's climb was the first on Everest's traditional South Col route without the help of Sherpa support; it was virtually all done, including all of the exhausting load carrying, by the climbers themselves under their own steam.

The ABEE's ascent of Mt Everest was a bittersweet victory in many regards. The expedition was beset by deep-seated conflicts from the start: disagreements over the size and composition of the team, the style of leadership and the dayto-day conduct of the expedition - conflicts that stemmed from fundamental differences in perceptions of the Himalayan climbing experience itself. The disputes, building for years in the lead-up to the expedition, often flared into open conflicts in the pressure-cooker atmosphere of Everest itself. They left deep wounds on some climbers - a poignant counterpoint to the magnificence of the achievement.

The long and contorted saga of the ABEE was yet to unfold as Colonel Gration sat on Kala Pattar and gazed at Everest's summit. That story would be told over the next 13 years. His mind was on more immediate matters. Gration's first task was to begin to build the cadre of army climbers needed to tackle Everest, in essence to start one of the most significant strands that would be woven into the fabric of the ABEE.

When Gration returned to Australia after the 1975 trek, he set about revitalising the Army Alpine Association (AAA) as the vehicle for building an army climbing team. The AAA had existed for five years, but its original purpose was to promote alpine skiing. The club had lapsed significantly since its inception and was ripe for conversion to a mountaineering-oriented organisation.

Gration's interest in reviving the AAA was in more than just putting Australian Army personnel on the summit of Everest for the glory of it. He believed that the 
long process of building up the skills and experience needed to climb Everest would be valuable for the cadets at the Royal Military College, Duntroon, in Canberra, as an activity in its own right. He called it 'adventure training'.

'In a peacetime army, to develop and hone the skills we believe we need in war, you need some sort of activity that will stretch people physically and psychologically. To me, climbing is, by definition, that sort of activity. It also brings out the qualities of teamwork and leadership,' Gration argued. ${ }^{1}$

Tim Macartney-Snape, although coming from a civilian background, reinforces Gration's beliefs:

The risks of injury or death during mountain-climbing are similar to the risks run by people in war zones. It [mountain-climbing] is going to a remote place and being put in the situation where you have to give your utmost... and that's what you're constantly having to do on a climb. The price for doing it wrong is very high, so you're really put in the situation where you have to perform, and it's very rewarding when you pull through. ${ }^{2}$

Gration's push to revitalise the AAA was the boost needed to get the group going from a nucleus that already existed at the Royal Military College (RMC). The RMC cadets, with their long-term commitment to the army and potential leadership skills, were the obvious choice for the source of future army mountaineers. The core of RMC personnel who had mountaineering experience included Major Paul Mench, Major Jake O'Donnell and Dr John Cashman, a lecturer in electrical engineering. All three attended a meeting in 1975 to revive the AAA, as did Warwick Deacock, who led the first Australian expedition to the Himalaya (Chapter 5).

Cashman was particularly keen to get a climbing club going. As a member of the Canberra Bushwalking Club, he had made frequent tramping/climbing trips to New Zealand. Also, in 1968 he had joined Robin Miller of the Canberra Bushwalking Club and Jake O'Donnell for a trek up the Kali Gandaki Gorge in central Nepal; the trio hooked onto a trip organised by Warwick Deacock. With that extensive mountain background, Cashman had tried since the mid-1960s to interest RMC cadets in forming a climbing club but had had little success.

In 1975, Cashman had, in one of his classes, two cadets who were enthusiastic climbers themselves and had been to New Zealand the year before. The pair, Jim Truscott and Lester Cornall, was most receptive to Cashman's suggestion that an RMC mountaineering club be formed. The 'magic bullet', however, according to

1 P. Gration, Interview.

2 Hefner, R. 1987, 'Team set for assault on remote Himalayan peak', The Canberra Times, 18 October 1987, p. 8 . 
Cashman, was Gration's backing of the AAA: 'Suddenly there was an enormous amount of interest amongst the cadets.' ${ }^{3}$ As Truscott put it, 'Colonels were like gods to us at RMC.' ${ }^{4}$ Although the RMC Mountaineering Club and the AAA were independent organisations, their active memberships were virtually identical and they operated essentially as one group.

The increase in enthusiasm and membership of the AAA quickly led to summertime trips to New Zealand, where the cadets took formalised mountaineering courses from companies such as Alpine Guides and then went out and climbed in the Southern Alps in small groups of their own. From very early on, the cadets established a reputation for being the most zealous of organisers. Although it would eventually pay off in the ABEE, their organisational drive was definitely overkill for a New Zealand trip, as Cashman remembered with some amusement:

Army people are incredible organisers. It is not at all to make life easier. It's the goal itself. There's a statement attributed to Bill Tilman-'If you can't organise the expedition on the back of an envelope, you shouldn't be going.' Tilman would have been horrified by the army trip to New Zealand. These guys were writing letters to the NZ Army organising accommodation, kombi vans, and all sorts of things. The vans were used to transport people who otherwise would have gone by bus with far less trouble and far less expense. They thought they were going to get it all scot-free. The NZ Army, in fact, someone who didn't really have the authority, said that there may be some nominal charges that might be levied, but that the bills probably wouldn't be presented. Well, the bills were presented. And how! People ended up paying a lot more money than they had ever imagined. ${ }^{5}$

The New Zealand trips gave the cadets just the sort of experiences they needed to survive and function effectively in big mountains (see images 13.1 and 13.2). There were falls in crevasses, midnight trips in fog up the Tasman Glacier, periods of weather-enforced inactivity in mountain huts, doses of steep and hard climbing and the magic moments - such as Peter Lambert's recollection of climbing up a steep snow slope on a moonlit night with only the sounds of crampons crunching in the firm snow and carabiners gently clinking to break the silence - that kept mountaineers coming back to do it all again.

Some of the many cadets who climbed in New Zealand in the early years were later to play important roles in army mountaineering. These included, in addition to Truscott and Lambert, Zac Zaharias, Dave Simpson, Brian Agnew, Rick Moor, Phil Pitham and Terry McCullagh. In the best style of leadership, 
Peter Gration himself participated in one of the early New Zealand climbing trips and quickly got into the action. Gration accompanied Cashman on a sortie up the Tasman Glacier. The pair was almost immediately holed up in de la Beche Hut by bad weather, whereupon, according to Cashman, 'Gration found out what mountaineering was all about - long periods without having a bath and not being able to see a blue sky' ${ }^{6}$

The cadets' training was not confined to New Zealand. Some were avid rock climbers, as were many of the civilian mountaineers, and climbed on the local Australian crags. In addition, many made annual expeditions to the Snowy Mountains. These 'August epics', as they quickly became known, were valuable in giving the cadets winter experience in mountains (see images 13.3 and 13.4). As Jim Truscott pointed out, "These "Epics" included ski mountaineering, building and living in snow caves, snow and ice climbing... August is notorious for bad weather and many of the August trips have become virtual survival exercises, providing a good psychological and physical introduction to mountaineering. ${ }^{7}$

An important non-army person involved in these Snowy Mountains excursions was Fritz Schaumburg, manager of the Paddy Pallin outdoor shop in Canberra. Of all the people involved with the revitalisation of the AAA during the second half of the 1970s, Schaumburg was probably the most skilled and experienced mountaineer. Originally from Switzerland, he was raised in the Alps. He was skiing by the age of four and when he was thirteen climbed the Jungfrau, a formidable peak in the Bernese Oberland, with a retired guide. Later he lived in a ski resort but could not afford the cost of lift tickets, so he simply walked up the mountains and then skied down - four hours of climbing for a 15-minute run.

Schaumburg migrated to Australia in 1956. Four years later, he signed on as a ski instructor for six weeks in New Zealand, but remained there for four years and became a climbing guide at Mt Cook. During that time, he climbed nearly all of the $10000 \mathrm{ft}(3000 \mathrm{~m})$ peaks in the Southern Alps and made some notable ascents, including the first ascent of the South Face of Mt Sefton and the second ascent of the East Face of Mt Tasman. He was obviously one of Australia's most experienced alpine climbers.

In the mid-1970s, as the AAA was being rejuvenated under Gration's influence, Schaumburg was asked to assist in the introductory mountaineering coursesthe 'August epics' - in the Snowy Mountains. This he gladly did, leading an

6 Ibid.

7 Truscott, J. 1990, Military mountaineering: a decade and a half of experience, Unpublished ms. 
ice-climbing trip to Watsons Crags in 1977, and subsequently became, along with Cashman, Truscott and Cornall, a driving force in the early years of the reconstituted AAA.

So, during the period 1975-80, the AAA was rapidly building up a cadre of alpine climbers, introduced to the sport in the Snowy Mountains and toughened by several seasons in New Zealand. It was precisely during this period that the ANUMC, located just a few kilometres away at the other end of Lake Burley Griffin in Canberra, was itself building up steam for its historic expedition to Dunagiri in 1978. There was, however, little regular contact between the two clubs - with very few exceptions, they did not climb with each other, attend each other's meetings or even exchange newsletters. They operated almost independently of one another.

By 1979, plans for an AAA overseas climbing trip were under way. After earlier proposed trips to Punjak Jayawijaya (5039 m) in Irian Jaya and Mt Vinson $(5139 \mathrm{~m})$ in Antarctica fell through, the army climbers set their sights on the Himalaya. Their objective was Tirich Mir, the highest peak in the Hindu Kush region of Pakistan. At $7706 \mathrm{~m}$, Tirich Mir is an exceedingly high peak for a first expedition to the Himalaya, but one, unlike Dunagiri, that has a straightforward route to the summit. Two events in June 1980, however, put an end to that proposed adventure as well. The first was the tragic death of Lieutenant Colonel Paul Mench, who was the highest-ranking experienced mountaineer in the AAA and had been the first choice as leader of the Tirich Mir expedition (but was not released from duties for that trip) and a potential leader for future expeditions. In a most bizarre accident in Lamington National Park in southern Queensland, Mench fell to his death from a lookout when a rock on which he was standing broke away.

The second was the withdrawal of approval by the army for the expedition on advice from the Department of Foreign Affairs. Soviet troops had just invaded Afghanistan and, as Tirich Mir was located only a few kilometres from the Pakistan-Afghanistan border, it was not thought prudent to have Australian troops so close to the border. This last-minute cancellation, three weeks before the team was set to leave Australia, was a particularly bitter blow as all of the planning and organisation had been done and members had secured time away from their units.

Not wanting to waste all of that effort, the team quickly set about finding an alternative objective. After an exchange of letters with Nepalese authorities, they obtained permission to attempt Ganesh IV in the pre-monsoon season of 1981. They had wanted Ganesh I, the highest peak of the range, but border sensitivities - this time between Nepal and China-again frustrated them. Ganesh IV, however, was a formidable enough objective for a group of very 
young climbers on their first trip to the Himalaya. A part of the range clearly visible from the city of Kathmandu, the mountain is $7102 \mathrm{~m}$ high and offers a number of challenging routes. The route of the Australian attempt was one of the less technically difficult but, in the event, was fatal.

The team that the AAA sent to Ganesh IV was pretty much the one originally set to attempt Tirich Mir. The core of the group were seven young climbers: Brian Agnew, Zac Zaharias, Jim Truscott, David Sloane, David Simpson, Robert Phillpot and Phil Pitham. All had several seasons of New Zealand mountaineering under their belts and had taken part in numerous August epics. The strength of the team was greatly enhanced by the inclusion of John Cashman and Fritz Schaumburg, the two most experienced climbers in the AAA (see images 13.5 and 13.6).

The route the group had chosen on Ganesh IV demanded a large dose of experience and judgment. It was a long route that followed a contorted glacier for a while before gaining the East Ridge and then headed more straightforwardly to the summit. The glacier was formed by tier upon tier of ice cliffs linked by crevasse-riddled slopes, the only feasible lines of ascent being tortuous journeys into and out of crevasses and under rotting seracs.

From camp one at $5000 \mathrm{~m}$ to camp two at $5800 \mathrm{~m}$, the route was particularly convoluted. Cashman's description of a segment of it is illuminating: 'It wormed under a teetering serac gutted by melt seepages, up a gully littered with fresh avalanche debris, out into the centre of the ice fall. ${ }^{8}$ The location of camp two was critical, as it had to be somewhere in the icefall - an area they knew to be prone to frequent small avalanches. The site they eventually found, although a long way from camp one, was the best possible. It was on top of a broad ridge and tucked under ice cliffs; the combination should guide any avalanches to the sides or over the top. The campsite was, all agreed, 'as safe as houses'. ${ }^{9}$

Just as camp two was being stocked with supplies and readied for the push onto the East Ridge and then the summit, bad weather intervened. The snowstorm was unusually heavy and prolonged for mid-April - a full six weeks before the monsoon was due to arrive. The climbers retreated to base camp to wait out the storm and remained there for a few extra days to allow the newly fallen snow to consolidate. On 20 April, they returned to camp one and two days later carried supplies back up to camp two (see image 13.7). Truscott, Sloane, Simpson and Maila Pemba, the expedition's sirdar, remained to begin rebuilding camp two.

The trip from camp one to camp two was rather unnerving, as Cashman reported: 'We didn't like what we saw of the ice fall - there was fresh avalanche debris

8 Cashman, J. 1981, 'An excellent campsite', AAA Newsletter, no. 1/81 (August), pp. 4-7.

9 Ibid 
everywhere, the terrain was unrecognisable as that which we had explored a week earlier, the nasty gully had a new charge of detritus every time we passed through it.' ${ }^{10}$ At least they had sited the camp in a safe spot and had allowed several days for the snow to settle. They had done everything by the book. Ganesh IV, however, had not read the book.

On the morning of 23 April, Cashman was back out on the glacier:

Zac and I went for a wander up the glacier, which came directly down toward Camp I. We had always gone into this crevasse and through these rotten seracs so Zac and I spent the morning trying to find a way directly up the glacier. We were back about lunchtime. The snow was getting soft and it wasn't much fun being out in the 'solar reflector'.

We were still roped up. Then there was this colossal noise. As it is with avalanches, the noise comes some time after the visible phenomena. It might even be that the visible part of it has disappeared by the time you hear about it. This time the sound was coming from an ominous direction so we looked straight up. In fact, this time we heard the noise before we saw it. It occurred a lot further up the mountain. When we heard it, it must have still been above the ice cliffs. Then suddenly it burst across the ice cliffs. It was an awful feeling knowing there were four people up there.

Aside from the human aspect, it was just an awesome physical phenomenon (see image 13.8). It was the closest I've ever been to an avalanche. We just stood there and looked at it.

Then I remembered stories from New Zealand where climbers had been so awe-struck by the wonderful appearance of an avalanche that they just watched and watched, and were eventually wiped out by it. I suddenly had this feeling - it's coming straight towards us. I began fumbling, trying to undo knots. Although the knot was a bowline, and I can do those in my sleep, I couldn't get it undone. So without taking the rope off, I ran behind a rock. It wouldn't have done me much good.

In the event the avalanche really didn't come very near us, but it completely clouded out the sky. Then an age seemed to go by. The avalanche was so big and so engulfing, I didn't really expect anyone to survive. Then, about an hour later, we saw a figure coming down. It was Maila Pemba. ${ }^{11}$

Jim Truscott described what happened at camp two:

10 Ibid.

11 J. Cashman, Interview and expedition diary. 
It had been a very windy night. Maila Pemba was up all night prayingit shook up the rest of us. The next morning, on the way up toward the camp three site, we crossed a lot of avalanche debris. We decided to retreat back to camp two.

I started digging a snow cave into the face of the ice cliff to make the camp more secure. Then I heard a roar like a train coming down the mountain. I stood up. A huge wall of snow was coming down at us. I shouted to the other blokes to get out of the tents. They stuck their heads out and then it hit.

I was engulfed. It was like being tossed around in surf-I tumbled over and over. It seemed like a very long time but it probably was only 10 or 15 seconds. Fortunately, most of it went over the top of us. I swam toward the top, then stood up and got to the top. I looked out and saw two guys further down. Maila was crying; he totally went to pieces. There was no sign of Dave Sloane - he had obviously been swept over a big icefall below us.

I was the only one with boots on; the others had just down booties or slippers. Both tents were swept away. We had no choice but to spend the night in a crevasse. I had to cut steps down into it for the others to get safely down. Maila wanted to go down, even without boots! I gave him my boots and sent him down with half a tent pole as a walking stick. We saw him fall a couple of times in the icefall and thought he was a goner. ${ }^{12}$

From Maila Pemba's garbled account, the climbers at camp one could not determine how many survivors there were and who they were. A rescue was immediately organised and by mid-afternoon Cashman was heading up the glacier again, this time accompanied by another of the Sherpa staff.

The weather had clagged in. Lots of thunder reverberated around, sounding much like avalanches. It was very frightening. We saw debris of the big one; we were ploughing through it up to our waists. It became very dangerous and the Sherpa was losing his nerve, so we turned back. It began to look like we would be throwing more lives after the first one $[s] .^{13}$

Another rescue was organised and at 1.30am, Zac Zaharias and Brian Agnew set out for camp two. It was still risky, as thunderstorms were rolling around and boulders were tumbling down from higher on the mountain. The pair pushed on and arrived at the camp two site just after daybreak.

12 J. Truscott, Interview.

13 J. Cashman, Interview. 
'It was a very emotional time as we came over the top,' Agnew remembered. 'We were greeted by Dave Simpson and Jim Truscott, so we instantly knew that Dave Sloane had been swept to his death.' ${ }^{\prime 4}$

\section{An excellent campsite \\ John Cashman}

15 April 1981.

Two days ago the start of the route from Camp 1 to Camp 2 had been broken by Jim Truscott, Maila Pemba and Dave Sloane. It wormed under a teetering serac gutted by melt seepages, up a gully littered with fresh avalanche debris, out into the centre of the ice fall, from where the going became steep but straight forward. 'It gets less steep as you get higher, and there's no avalanche debris.' The gully is nasty. Some dangers are unavoidable. You get past them as quickly as snow, altitude and concentration permit. Tomorrow they will fix ropes to reduce gully time to a minimum.

Yesterday Maila Pemba, Temba, Dave Simpson and I pushed the route further. The climb was without incident except for extraordinary views of the Anku Khola shimmering in the haze, the village of Hingdung where our porters lived and back to the Kathmandu valley in the distance. Two myths exploded: it doesn't get less steep; and it's all avalanche debris. To unacclimatised red blood corpuscles climbing between 16,000 and $19,000 \mathrm{ft}$ is hard work. Maila and Temba were 100 yards ahead of Dave and me-a distance which precluded discussion of anything. Every time they appeared on top of a rise we hoped they would drop their packs and declare Camp 1. Eventually when we stopped and yelled to them through the thin air they yielded, found a spot below some low ice cliffs and began digging a platform for the tents. By the time Dave and I shambled up they were nearly finished. The site was on a broad ridge, which should shed avalanches, and under some ice cliffs which should fire any falling debris over the top of the camp. The site was excellent, except that it seemed a long way from Camp 1.

After the site is established the ferrying of stores begins to stock the camp for habitationseveral days of unskilled labour. Today's caravan-Jim Truscott, Dave Sloane, Maila and Temba-discharged its task without incident. I thought the distance was overlong. It would become easier when we were acclimatised, was Dave Sloane's opinion. 'It's an excellent camp-site.'

Dave Sloane and Jim Truscott have been working at Camp 1 for some days and now descended to base camp for a well earned rest. Others of us remained, intending to carry loads to Camp 2 tomorrow. This was not to be-a depression brought heavy snow falls; we decided after a couple of days to pack up the camp for its own protection. We retreated to base camp.

\section{April}

We returned to Camp 1 on the 20th and 21 st and on the 22nd we set off at 3 am for Camp 2, some of us ferrying stores and four-Jim Truscott, Maila Pemba, Dave Sloane and Dave Simpson-to rebuild and man Camp 2. Camp 2 was half buried under the recently fallen snow, the tents collapsed with their ridge poles snapped. We the drones, dumped our loads, left the others in the terrible beauty of their eyrie, and slithered down to Camp 1. We didn't like what we saw of the ice fall-there was fresh avalanche debris everywhere, the terrain was unrecognisable as that which we had explored a week earlier, the nasty gully had a new charge of detritus every time we passed through it. We concluded that the ice fall needed a couple more days of sun and nights of frost to congeal the loose snow. The site of Camp 2 however, we were unanimous, on its ridge, under the ice cliffs, was as safe as houses. 
In the afternoon more snow fell, more avalanche fodder. There should be no climbing in the ice fall until it stopped. Tomorrow will be a lay day, and perhaps too the day after. We calculated that Camp 2 could survive for a week, if necessary, without resupply.

That was yesterday. Today Zac Zaharias and I made a sortie into the lowest part of the ice fall and found a way to avoid the gully. Well pleased with ourselves, still roped together, we were bragging of our discovery to the others at Camp 1, when our story was lost in the seismic boom of a large avalanche. You hear lots of avalanche noises and there is sport in locating the snow plume before it falls out of sight. So we were staring at the head of the ice fall, at the ice cliffs which overhung it, above which we knew the tents of Camp 2 were huddled, above which seemed to be the source of this avalanche. Suddenly the line of ice cliffs exploded in powder snow. The face of the avalanche was a mile across. Millions of tons of snow and ice were sweeping across Camp 2. Three thousand feet below we felt the cold wind generated in the commotion above. Then the mountain became quiet. The sun was brilliant again. The sky was infinitely blue. It was 11:40 a.m.

After a while we heard a voice on the walkie-talkie. Someone had survived. Then we saw Maila Pemba at the head of the ice fall coming down. We watched his lonely figure for an hour before he reached us. They had lost all their equipment, he said, they cannot move without boots. Maila was shocked and his English was broken. Who 'they' were was not clear.

We started immediately with boots and sleeping bags but were defeated by a storm when we were only half way to the stranded survivors. The following morning a second party left Camp 1 at 1:30 a.m. and reached them about 6 a.m. They were back at 8 a.m. 'They' were Jim Truscott and Dave Simpson. Dave Sloane was dead.

When the avalanche hit them they were slouching about the camp, some in tents, some outside. Jim Truscott saw it first and shouted to those in the tents to get out. Afterwards when they dug themselves out, they were in different places to where they had been buried. The camp was smashed, gear was everywhere. They probed in the snow with tent poles but Dave Sloane was gone.

They had one pair of boots. They gave them to Maila, who was shocked and bruised the worst, and sent him down with the news. They found a shovel and dug a snow hole in which they spent the night. They made themselves comfortable in odds and ends which they had found-by one of life's ordinary bizarreries, much of it belonged to Dave Sloane-a sleeping bag, a duvet jacket, a pair of inner boots... When they were found next morning they were, physically, not the worse for wear, though later Dave Simpson was to have such painful feet that he had to be carried home on porters' backs.

\section{April}

Base camp had been struck. Just before we left we came together on the square of snow where Dave Sloane's tent had been and looked at the mountain for a few moments: Ganesh, the god with a human body and the head of an elephant, son of Shiva and Parvati.

From $A A A$ Newsletter, no. 1/81 (August 1981), pp. 4-7.

The avalanche had taken not only Sloane but much of the equipment and supplies stashed at camp two. With the loss of that much gear in addition to the tremendous psychological blow of losing a colleague and close friend, there was no option but to abandon the expedition. It was a bitter blow to the AAA. After years of training in Australia and New Zealand and after the disappointment of having to cancel the Tirich Mir trip at the last minute, they had been struck with tragedy on their first Himalayan attempt. 
At the end of 1981, the AAA was still a long way from being in a position to attempt Everest. Six years had passed since Peter Gration stood on Kala Pattar and dreamed of Australian soldiers climbing Everest; only seven years remained until the 1988 target date. Although a cadre of mountaineers had been built up in the AAA, their Himalayan experience was still very thin indeed.

Something positive, however, did come out of the Ganesh IV experience. Four of the climbers would eventually go on to play important roles in the ABEE. For them, the experiences on Ganesh IV were undoubtedly a thorough and harsh introduction to the realities of Himalayan climbing. Two of the climbers - Jim Truscott and Zac Zaharias - were destined to become intense adversaries in the planning and organisation of the ABEE and would become involved in a sometimes bitter dispute that persisted during and after the expedition itself.

Truscott was unique among the cadets who formed the original core of AAA Himalayan climbers. Originally from near Brisbane, he was the only one who had become involved in climbing before the Gration-led push revitalised the AAA. Truscott was rock climbing at the age of fifteen on crags around southern Queensland and climbed with members of the Brisbane Rockclimbing Club. In 1974, a year before Gration's trek, he went to New Zealand and participated in an Alpine Guides' course.

When the RMC Mountaineering Club was formed in 1975 and the AAA reconstituted, Truscott was in on the ground floor. An intense man of few words, he was an organisational driving force in many early AAA adventures and always did much to ensure that expeditions ran smoothly and efficiently. In addition, Truscott was a member of the Special Air Service (SAS) during the Ganesh IV expedition and, on his return to Perth, he promoted AAA activities there (see Chapter 14).

Zaharias, on the other hand, had done very little climbing, and none on rock, when he went with an AAA group to New Zealand at the end of 1976. What inspired him?

I had been in Scouts and done some bushwalking. Then I read Chris Bonington's book on the South-West Face of Everest. That really inspired me, particularly the photographs. They were so appealing. Then I went to a AAA meeting in early 1976 and decided to give it a go. I was off to New Zealand at the end of the year. ${ }^{15}$

The Alpine Guides' basic mountaineering course came as somewhat of a shock to Zaharias: 'I bit off more than I could chew. After the course, I decided to pack up my gear and go home. Then John Cashman invited me to come up the 
Tasman Glacier with him. It was the best thing I could have done-I learned a lot from him. ${ }^{16}$ Just as Lincoln Hall had been equivocal about his first alpine climbing trip and decided to give it a second try, Zaharias had second thoughts about continuing in mountaineering after his first experience. He persevered, however, and eventually became one of the leaders in the AAA climbing team.

The third Ganesh IV climber who would play important roles in future AAA climbs was Brian Agnew. Like Zaharias, Agnew had no background in rock climbing when he joined the 1976 instructional trip to New Zealand. And, like others, he had his 'fair dose of Bonington'17 to get him interested in mountaineering initially.

During that first trip to New Zealand, Agnew teamed with Peter Lambert to climb a small peak in the Mt Cook region. During the ascent, Lambert remarked, 'Just imagine we're struggling with a load up to the South Col.' ${ }^{18}$ Twelve years later, the pair would be in a camp on the icy Lhotse Face preparing to do just that.

Of those four Ganesh IV members who continued as active climbers into the late 1980s, only Phil Pitham came from outside the AAA framework of August epics and New Zealand instructional trips. Like Truscott, originally from Queensland, Pitham was a very active athlete in high school, reaching state level in competitive swimming, athletics and cycling. Meanwhile, he drifted into bushwalking at the age of fourteen or fifteen and soon was 'walking' up terrain so steep that he was advised by others to start using a rope or he would kill himself. He quickly mastered rope techniques and soon was a regular at Frog Buttress, a popular crag south-west of Brisbane.

Pitham was also inspired by some of Bonington's mountaineering books so decided to give alpine climbing a go. He went to New Zealand during the 1976-77 summer - the same time that Zaharias, Lambert and Agnew made their first trip to the Southern Alps. Pitham, however, was independent of the AAA. He teamed with a Brisbane rock climber, a 'local tiger', who, Pitham recalled, 'freaked out on our first climb, so I left him and went to the top alone'. ${ }^{19}$

Turning in his hired gear, Pitham bought his own crampons and ice axe, took a basic mountaineering course and then joined a visiting Scottish climber to knock off a phenomenal 26 summits in an eight-week orgy of climbing. He joined the army in 1979 and quickly found his way to the AAA. 
Although not a member of the Ganesh IV expedition, Peter Lambert was another of the early members of the AAA who was to play a prominent role in the development of the club through the 1980s and in the ABEE. His love for the mountains was sparked at the age of fifteen by a Bonington book, The South Face of Annapurna. Hanging around the Sydney Rockclimbing Club's pub in The Rocks did not quite fulfil the yearning for high mountain adventure that Bonington books inspired, and it was not until Lambert entered the RMC in 1976 and joined the recently revitalised AAA that his thirst for the hills began to be satisfied. He was certainly one of the AAA's most active members. He took part in the August epics and climbed in New Zealand every year from 1976 to 1980.

Lambert also learned firsthand early in his career of the dangers of mountaineering. While participating in a Geoff Wayatt advanced ice-climbing course in December 1981 in the Mt Aspiring region of New Zealand, Lambert watched helplessly as his rope-mate and best friend, Rick Butler, was killed by a falling rock dislodged by another climber. Ironically, Dave Simpson, who witnessed the death of Dave Sloane the year before on Ganesh IV, was also present. Simpson gave up climbing shortly thereafter, likely because of the death of two friends in two years.

\section{Unlikely source}

The focus of early AAA climbing activity was the RMC Mountaineering Club based in Duntroon, Canberra, and it was essentially that club that sent Truscott, Zaharias, Agnew, Pitham and the others to Ganesh IV. There was, however, in the late 1970s and early 1980s, another branch of the AAA. It was located in Perth - only marginally more likely as a source of mountaineers than places such as Darwin or Alice Springs. Its leader was a man who combined an almost superhuman desire to succeed and a love/hate relationship with the mountains - in short, the most enigmatic character ever to appear on the Australian Himalayan climbing scene. 


\section{Ordered to climb}

Most climbers find their way into the sport through a love of mountains, the lure of a personal challenge or the enjoyment of the gymnastic skills needed to master movement on steep terrain. They start with perhaps some family camping trips, bushwalking with school or outdoor groups or scrambling on steep rocks with a few friends. Then, with some inspiration from local climbers or Bonington mountaineering books, they move on to technical rock climbing and alpine climbing.

Pat Cullinan's entry into mountaineering, on the other hand, was the most unusual of any of Australia's Himalayan climbers. He was, almost literally, ordered to climb.

A member of the Special Air Service (SAS), Cullinan was sent to Perth and made 'Climbing Troop Commander'. The members of each SAS unit, in addition to mastering all of the usual military skills, must learn a 'specialist skill', and in the case of Cullinan's troop, climbing was that skill. The year of Cullinan's posting was 1975 - that critical year during which so much of Australian Himalayan climbing had its start.

Although Cullinan had done no climbing before he was assigned to the Perth SAS unit, he was not uninitiated in outdoor pursuits. Before his move to Perth, he had done some bushwalking in the Snowy Mountains region of New South Wales and in 1976 made the classic trek to Everest base camp.

Cullinan's climbing career began in the course of duty, with rock-climbing instruction at Mt Arapiles in western Victoria followed with excursions to the crags of the Stirling Range south-east of Perth. By the late 1970s, Cullinan thought his SAS troops, to fully develop their skills as climbing specialists, needed a more challenging objective further afield.

The next advance for most Australian climbers at this stage of their careers is a trip to New Zealand, where they take an introductory course in alpine climbing and then hone their new skills on some of the more straightforward mountains in the Southern Alps. A few do go directly to the Himalaya without New Zealand experience under their belts, but they invariably confine a first trip to one of the lower, less-demanding of the 'trekking peaks' or an equivalent.

Cullinan, however, had something vastly different in mind for his troops. He not only bypassed New Zealand, he led them in 1980 straight to Nepal - in fact, to a high, unclimbed, difficult Himalayan peak. Their mountain was Gauri Shankar, 
an impressive peak rising precipitously from the remote Rolwaling Valley in eastern Nepal. At $7150 \mathrm{~m}$, it is slightly higher than Dunagiri-the objective of the ANU Mountaineering Club (ANUMC) expedition two years earlier - and is even more difficult technically. In fact, only the northern summit of Gauri Shankar's complex upper structure had been climbed, and that by a strong and experienced American team in 1979. Cullinan's audacious plan was to climb to the main southern summit via the $5 \mathrm{~km}$-long South-East Ridge, replete with ice towers, rock gendarmes and double cornices - in short, a climbing nightmare. In attempting this route to an unclimbed Himalayan summit more than $7000 \mathrm{~m}$ high, the group of raw climbing recruits from hot, flat Western Australia was very much out of their depth.

Cullinan and his colleagues quickly realised that they did not have the experience, skill, time or equipment to climb Gauri Shankar. Their planned approach to the South-East Ridge would, however, take them near a subsidiary summit, Tseringma. At $6333 \mathrm{~m}$, Tseringma offered some interesting climbing and, as it was an unclimbed summit, was a particularly attractive target for a team on their first expedition to the Himalaya.

The early part of the expedition went smoothly as the group set up a series of three camps up snow ramps and a gully to within striking distance of the summit. Then the realities of Himalayan climbing began to slow the drive to the top, as Cullinan reported.

In a short period of time a number of things happened. Firstly, the youngest expedition member, Jim MacDonald [twenty], failed to acclimatise and returned to Australia. Secondly, a fierce, consistent snow storm of 48 hours duration made the gully a death trap. It buried Paul Richards and [staff member] Shambu Tamang for 24 hours at Camp 3. They survived by cutting a hole in the top of the tent and forcing the windshield from the MSR stove through the top as an airway. The storm damaged both high camps and base camp, collapsing the kitchen and forcing everyone off the mountain. Thirdly, the tragic news of three Australians killed in an avalanche on Annapurna III from the same storm reached the expedition on 1 April and cast a cloud of gloom over all.

We were running out of time. The weather had not let up. We had taken a wrong fork in the gully above Camp 3 and had to re-route the fixed lines. We were experiencing difficulty in finding a suitable site for another camp. The gully was in a continual state of avalanche due to continually heavy snow falls, making movement on the mountain very dangerous. There had been a few near misses but then at 1.40 p.m. on 3 April it happened. 
First a yell, and then the two lead climbers saw Barry Young literally disappear into a cloud below. Barry, after detaching himself from the safety rope, had tripped and fallen down the gully, which descends some 5,000 feet over an ice cliff into an icefall below. The two lead climbers, Mick Hardless and Wayne Carroll, immediately headed down to Camp 3 at 18,600 feet, where they saw Sherpa Anu. Mick yelled out to Anu, 'Barry's dead!' Anu replied, 'No he's not. He's in the tent.' It was unbelievable but true. The one-in-a-million chance had happened. Anu was just about to climb into his tent when he saw a pack fly past out of the surrounding mist. He knew it was possible a climber could be falling the same way. Still tied to the safety rope by his waist band, he quickly moved into the gully and, with both arms, grabbed Barry as he came past, and so saved his life. Barry had just fallen over 1,200 feet and lived. His pack went on for another 3,500 feet and over an ice cliff. It was a miracle. ${ }^{1}$

Despite Young's close call, the other climbers pushed on and the next day Mick Hardless and Wayne Carroll established camp four at nearly $6000 \mathrm{~m}$. There still remained some difficult technical climbing just below the summit. Richards overcame a vertical ice pitch and, on 11 April, he, Graham Brammer and Shambu Tamang reached the summit. Two days later, Cullinan, Hardless, Carroll and John Remynse matched their accomplishment.

The climb was the first ascent of Tseringma and left Cullinan happy with his team's performance:

We didn't get to the top of Gauri Shankar as we had initially planned, however we returned to Australia satisfied. We had pioneered a new route at least part way up one of the world's most technically difficult and serious mountains. We were generally happy with our overall performance, especially considering none of us had ever done any Himalayan climbing before. ${ }^{2}$

The 1980 Gauri Shankar expedition was the first official Australian expedition in Nepal. It was carried out under the auspices of the AAA and under the patronage of Peter Gration, by then Major General Gration, OBE. The venture was, however, conceived and conducted entirely by Cullinan and his SAS unit in Perth with no operational links with the main body of AAA climbers based in Canberra. The expedition would have become simply a curious sideshow to the

1 Cullinan, P. and Brammer, G. 1980, Report on the first ascent of Tseringma Peak, Report no. 852/1/1, 23 October 1980, Australian Army Alpine Association, Canberra.

2 Ibid. 
main AAA climbing program building towards Everest had it not been for the involvement of Cullinan, the only member of the 10-man Gauri Shankar team to return to the Himalaya.

The Gauri Shankar attempt was perhaps typical of Cullinan's approach to mountaineering in the Himalaya. It was an extraordinarily ambitious project, one that he and his team had no real chance of completing, yet they acquitted themselves remarkably well and pulled off a significant first ascent in the process. Their feat was saluted by Harish Kapidia, editor of the Himalayan Journal, as one of the best climbs in the Himalaya in $1980 .^{3}$

Cullinan would later take on challenges every bit as daunting as the Gauri Shankar task and pull them off with an unwavering determination that left even his own team-mates amazed and perplexed. He was, without doubt, the most puzzling of the many pieces that made up the complex ABEE mosaic.

His next trip to the Himalaya did not come until 1986, but Cullinan continued to develop his alpine climbing skills in the interim. In 1982, while posted in Africa on a peacekeeping mission, he climbed Mt Kilimanjaro, the continent's highest mountain, and ascended Victoria Emanuel (5030 m) in the little-visited Ruwenzori Range in Uganda. The latter involved $600 \mathrm{~m}$ of ice climbing near the summit. Three years later, he was in New Zealand's Southern Alps on one of Geoff Wayatt's advanced ice-climbing courses, during which he did a number of long traverses in the Mt Aspiring region.

Meanwhile, the main body of AAA climbers in the eastern states was regrouping after the tragedy on Ganesh IV in 1981. Their next objective, Denali (Mt McKinley) in Alaska, was less ambitious than Ganesh IV but perhaps more appropriate for a group of mountaineers still in the early stages of their highaltitude climbing careers.

Although not in the Himalaya, Denali is a mountain of Himalayan proportions. It is $6194 \mathrm{~m}$ high, but since it is only $300 \mathrm{~km}$ south of the Arctic Circle, the somewhat reduced atmospheric pressure means that the mountain is effectively a few hundred metres higher. Furthermore, temperatures of -40 degrees Celsius and wind speeds of up to $160 \mathrm{~km} /$ hour are not uncommon during the summer season - conditions experienced on only the highest of Himalayan summits.

The seven-man expedition, organised by Peter Lambert and led by Zac Zaharias, chose the West Buttress route, a route first climbed in 1951 and considered to be one of the safer and easier routes on the mountain. It turned out to be a wise

3 Kapadia, H. 1980, 'Editorial', Himalayan Journal, vol. 37, p. 1. 
choice as the 1982 summer season in Alaska was not blessed with particularly good weather. Of the 21 days the AAA team spent on Denali, only three were fine.

The climb was done alpine style. Five camps were established above a base camp on the Kahiltna Glacier and on 12 June, Zaharias, Lambert, Phil Pitham and Tony Delaney reached the summit (see images 14.1 and 14.2). Denali lived up to its reputation as one of the harshest places on the planet. On the summit day, a relatively fine one, the temperature was $-35^{\circ} \mathrm{C}$ and $50 \mathrm{~km} / \mathrm{h}$ winds buffeted the top of the mountain.

Getting to the summit of Denali was just as dramatic and exciting as topping out on a much higher Himalayan peak, as Lambert recalled:

As we climbed the summit slopes some of us began to hallucinate-'red snow with yellow edges? Impossible. Breathe deeply and maybe it will go away.' Our progress slowed as we approached the summit ridge and we cached our packs, moving on with axes only. When we reached the ridge we found a narrow and windy ridge leading about $300 \mathrm{~m}$ to the summit. It was magnificent.

On the left the slopes dropped away into the crevassed Harper Glacier to be finally cradled by the black rock buttresses of the North Peak. To the right the South Face dropped 9,000 feet into the East forks of the Kahiltna Glacier. Stunning ice gullies disappeared into the void below, enclosed by ice ridges adorned with twisted and wind-blown cornices. We moved slowly along and up the ridge to the summit. An elongated snow mound twenty thousand three hundred and twenty feet above sea level...we were on top of North America. ${ }^{4}$

During the ascent, Denali continued to provide a stern test of altitude and severe conditions. Two climbers, Dave Smith and Joe Lorincz, were forced to turn back at $5200 \mathrm{~m}$; Smith was suffering from pulmonary oedema and Lorincz from cerebral oedema. On the summit day, Bernie McGee was forced to retreat at $5800 \mathrm{~m}$ as he was hallucinating.

The Denali success was a great morale booster for the AAA. The expedition was carried out most competently, in planning and execution, and it was at least partial compensation for the disappointment of the Ganesh IV experience, particularly for Zaharias and Pitham. Most importantly, it was a big step in the right direction for Everest - success on a formidable $6000 \mathrm{~m}$ mountain under harsh conditions.

4 P. Lambert quoted in Zaharias, Z. 1982, Mt McKinley expedition report, Report no. MCK/66, Australian Army Alpine Association, Canberra. 
Zaharias and Pitham were not the only Ganesh IV members back in the big mountains in 1982. Brian Agnew, the climbing leader of the Ganesh IV expedition, joined a large British Army trip officially named the 'West Nepal Expedition 1982'. The primary objective was Peak 29, also known as Manaslu South or Dakura, a difficult 7837 m peak just east of the Annapurna Himal. Peak 29 had been climbed previously by a Japanese expedition that had, according to Agnew, 'used 30 men in a wedge to plough their way to the summit'.

The reason for Agnew's participation in the Peak 29 expedition was to learn more leadership skills and broaden his Himalayan experience generally. The British Army had by the early 1980s already run a number of successful Himalayan expeditions, so, at least in theory, it would be able to provide valuable instruction to Australian Army climbers, who were relative newcomers to the game.

In practice, however, Agnew had managed to latch on to a very early expedition of the second generation of British Army mountaineers who were even lower on the learning curve than their AAA counterparts. In addition, there were no members on the trip from the older, more experienced generation of British Army climbers; everything would have to be learned from the very start. Agnew described the result as 'an unmitigated failure from day one'. ${ }^{6}$

The debacle began in Kathmandu, where the British climbers landed without their equipment; it was stuck on a ship in Bombay (Mumbai). More disasters followed. They somehow managed to take the wrong approach march and ended up on the wrong side of the mountain. The trek route mistake was compounded by a massive brawl with local villagers on the way. When they finally did get to Peak 29, they were confronted with a forbidding $5 \mathrm{~km}$-long ridge followed by a steep face climb. Faced with these difficulties, one of the British climbers feigned illness and went home, the leader had to be coaxed up to camp one for a fleeting visit and the two best climbers - the 'guns' of the expedition - spent the trip in their tents pumping weights.

Agnew and Merv Middleton, one of the few British climbers not daunted by the mountain, did much of the lead climbing along the ridge. The high point reached was only $6000 \mathrm{~m}$, as they were often forced to wade through shoulderdeep snow. After eight consecutive days of that, they ran out of steam.

The Peak 29 expedition turned out to be quite an experience for Agnew. He certainly learned a lot about expedition leadership from the British Army team, but much in the same way that one learns forensic skills by watching Inspector Clouseau bumble his way through a Pink Panther movie.

5 B. Agnew, Interview.

6 Ibid. 


\section{The British Army West Nepal expedition in 1982: how not to organise an expedition \\ Brian Agnew}

Day One and I meet the guys in Kathmandu. Day Two and they break the news to me that they have no equipment. It's still on the ship in Bombay. Here we are-great British Army organisation; some of these guys had just come from the Falklands War-and they had no gear. Luckily I had brought my own equipment. I was the only one with an ice axe.

They then proceeded to strip the bazaars of Kathmandu. They had unbelievable sums of money as they had sent a message home and the British Army Climbing Association gave them a complete new issue of kit! But they had no idea of just what they needed and how to get it. Organisationally we bumbled our way through Kathmandu.

Even in finding their way to the end of the road at Trisuli Bazaar they were hopeless. They had no idea of where to hire porters or where to go. I didn't want to come to the fore too early in the expedition, but I had been to Trisuli Bazaar 12 months earlier as leader of the Ganesh IV expedition. I could have said, 'We did this, this, and this,' and set them straight. But I didn't want to be the Australian know-it-all, so I kept waiting for their 'experts' to come forward.

We finally did arrange porters, but we had a porter strike on the walk in. This is apparently traditional on the walk in to Manaslu. There is always trouble at a particular village, so the authorities put a police post there. The 'baddies' just moved up to the next village, which we had to go through anyway. We came into that village with the lowland porters we had contracted. The porters were all shuffled into a courtyard in the centre of the village by the locals, who were drugged to the eyeballs on marijuana. They let the members go through, as they didn't really want to stop us, but we soon realised our porters weren't getting through so we doubled back. There were all our porters cowering in the courtyard. They had been rounded up by a group of big Tibetans.

We had a massive argument. In fact, we came to blows with these big Tibetans; blood was drawn on both sides. We had planned to take the lowland porters all the way to Base Camp, but after the fisticuffs we realised that if we didn't hire these Tibetans, we wouldn't be able to take anything out of the village. We quickly learned that in porter strikes, they have the upper hand.

It transpired that the Tibetans were terrific porters. Most carried triple loads (about $75 \mathrm{~kg}$ ) and one even carried five loads, a monstrous load! We eventually became very good friends with them, as they were just below Base Camp in their summer pastures.

The porter problems were bad enough, but they weren't the end. Our next great disaster is that we took the wrong route in. Instead of going in the easy way around to the rear of the mountain and going at it from there, we took the frontal approach. We were faced with this horrendous ridge for five kilometres followed by a steep face climb!

Confronted with this situation, our leader and some of the members just couldn't cope. In an Australian Army expedition, the senior man is boss; it is very hierarchical. But the Brits do things differently. They put an NCO [non-commissioned officer] in charge if he's the most experienced climber; in theory he could be leading officers. In fact, that's just what happened in our expedition. But our leader, an NCO, just didn't have the fortitude to face the Himalaya. $\mathrm{He}$ was at home in the European Alps but was totally daunted by the Himalaya. He never got above Camp I; he was totally in awe of it all. 
Many of the other members weren't much better. One of them went home early, feigning illness. We had two world-class rockclimbers, a couple of climbing instructors, and others who had taken mountaineering courses. All were 'experts' in some phase of climbing, but when it came to the Himalaya, they were daunted. Even the two world-class climbers couldn't cope. They stayed in their tents for the duration of the trip and pumped weights.

So Merv Middleton, a good SAS bloke who was keen to have a go at it, and I were sent out in front to do the climbing. We got Camp I in but not without a few dramas. One of these supposed experts-he'd represented Great Britain in the Olympics in canoeing-was also a mountaineer and a physical education instructor in school, an all-around great athlete. But he'd lost a kidney in one of his trips. We had a bad night with him. He and his partner were in one of the tents at Camp I, and Merv and I were in the other. We quickly realised he was in a very bad way, really knocked up. We put him on oxygen and gave him everything we had. We said, 'See you in the morning', and crawled back into the tent, but we didn't expect to see him alive the next morning.

Somehow he survived the night. We took him back down to Base Camp. It was quite a heroic trip on Merv's part as we had to go through an avalanche-prone basin while it was snowing heavily. We flipped a coin as to who would take him across and Merv lost-no use risking two lives. Just as Merv went across, his footprints created the 'zipper' for the whole slope to go. It cleaned the basin right out. Luckily, Merv rolled the right way-out of the avalancheand dragged the other bloke with him. Merv got up, shook himself off, and continued.

From Camp I to Camp II the route was horrendous. Merv and I spent eight days up there pushing the route out to Camp II with no help from down below. We could do only 200 or so metres a day. Merv would find the route and I'd carry the ropes. We'd often sink into the deep snow up to our shoulders; we were continually pulling ourselves out of the snow.

Suffice it to say we didn't get very far along that ridge. The expedition was a dead loss, one that you just chalk up to a negative experience. Fortunately, I had work commitments so I had a good reason to leave the trip early.

I literally ran back out in three days. I hired an 18-year-old Tibetan and a 12-year-old boy to get my gear out. The lads were just great. We stopped the night in their village on the way out and they gave me dinner at their house. Unfortunately I became violently ill during the meal, walked over to the balcony, and vomited. It was a sign of things to come.

I got back to Kathmandu at 7.00 a.m. on the morning my flight was due to leave, and discovered that I was locked out of my hotel. I had heard that Fritz Schaumburg was in town, went across to his hotel, banged on his door, had a quick shower, and just made the plane.

Back in Australia I discovered that my sudden illness in the Tibetan village was the onset of amoebic dysentery. The reason I had to leave the expedition early was that I was doing a course at Puckapunyal, just outside of Melbourne. Every morning I drove flat out along the road-I had an RX-7 in those days-and then suddenly came to a screaming halt. All the people I had just overtaken would stare at me in amazement as I'd race out into the fields and drop my strides. Another ten kilometres and I'd race out and drop the strides again. This went on for some 18 days, a legacy of that disastrous trip to Peak 29.

So 1982 closed on a much brighter note for the AAA than did the previous year. A 6000 m mountain had been climbed and Brian Agnew had acquitted himself well on the British expedition. At least a good start had been made on the program of preparatory climbs for the Everest attempt in 1988. A big hurdle, however, remained: getting permission from the Nepalese authorities to climb the mountain. 
The problem of booking a confirmed route on Everest became urgent by early 1983. The goal of climbing the world's highest mountain in 1988 was widely advertised within the AAA in 1981 and a carefully planned series of lead-up climbs had been organised, beginning with the Denali trip. Pat Cullinan, who was stationed in Africa for six months beginning in September 1982, returned to Australia via Nepal and was asked by General Gration to secure a booking for Everest.

Cullinan's stopover put the application process in train and by late 1983 the AAA had its official booking for Everest. The approved route, however, was the West Ridge, which was more difficult than the South Col route they had originally wanted. The problem was that the South Col route had already been booked in 1980 by another group and was therefore unavailable. The AAA had been beaten to the punch and ironically it was by another group of Australian climbers.

A group of Australians booking Mt Everest in 1980? Who were they? Where did they come from? And why were they so confident that they booked Everest even before Tim Macartney-Snape and Lincoln Hall began thinking about climbing it? 



\section{By the book}

Every country has its sporting heroes and Australia probably has more than most, given the prominence of sport in our culture and the proliferation of football codes by geographical region. Greg Norman, Shane Warne, Ian Thorpe and Cathy Freeman are all household names, and even many Victorians would know who Stirling Mortlock is. Mention Greg Mortimer, however, and you would be very lucky to find one in 1000 Australians who have the faintest notion of what he has done. Mortimer, it turns out, is the first Australian to have climbed both Mt Everest and K2, the world's two highest mountains.

Himalayan mountaineering, although one of the most physically and mentally demanding activities ever devised by humans, is also one of the least known to the general public. Its heroes are recognised mainly by hardcore devotees who read specialist magazines and its achievements are rarely reported in the electronic media or in the popular press.

If there is one mountaineer who has broken out of this obscurity to become a well-known public personality - at least in the English-speaking world-it would have to be Chris Bonington. A professional climber for more than 30 years, Bonington has been on nearly 20 Himalayan expeditions and the list of those with whom he has climbed is a virtual who's who of British climbing. He has scaled sea-stacks on live television, filmed a historic ascent of the infamous North Wall of the Eiger and, through television documentaries, has brought Himalayan expeditions into the living rooms of homes around the world.

It is primarily his writing, however, that has propelled Bonington into the limelight and has inspired numerous aspiring mountaineers, including several of the Australian Army Alpine Association (AAA) members, to journey to the Himalaya. One of the earliest and most influential of his expedition books is his account of the ascent of Annapurna I's South Face in 1970, a landmark climb that ushered in an era of big-wall climbing in the Himalaya. The story and photos of that expedition proved an irresistible attraction to high-altitude mountaineering for countless British climbers - and for at least one Australian.

In 1972, Michael Rheinberger, an electrical engineer working in Melbourne for the predecessor of Telstra, won a two-year scholarship to study in Britain. There, a friend loaned him a mountaineering book: Chris Bonington's account of the 1970 Annapurna expedition. Rheinberger read it avidly and was, as he later put 
it, 'very captivated by it'; $^{1}$ thus was born the career of one of Australia's most successful Himalayan climbers and a key member of the Australian Bicentennial Everest Expedition (ABEE).

On returning to Australia after his stay in Britain, Rheinberger enrolled in a rock-climbing course run by the Victorian Climbing Club-his first taste of the experience of climbing itself. He was thirty-five years old at the time. During the 1976-77 summer season, he made his first climbing trip to New Zealand's Southern Alps and by the end of the decade, had helped organise and run the first expedition from the Melbourne climbing community to the Himalaya. During the 1980s, he was one of Australia's most prolific Himalayan mountaineers, taking part in nine expeditions to the great ranges of Asia.

Although Rheinberger was closely associated with Melbourne climbing, he was not originally a Victorian. Born in the NSW South Coast town of Bega, he received part of his secondary schooling there before moving to a boarding college in Goulburn, a rural community on the NSW Southern Tablelands, when he was fourteen. After finishing high school there, he went to the University of New South Wales in Sydney and graduated in 1961 with a degree in electrical engineering. Six years later, after two years' professional experience in (then) West Germany, he settled in Melbourne and worked until 1988 for Telecom and its successor, Telstra.

The southern section of the New Zealand Alpine Club (NZAC) was formed just before Rheinberger became actively involved in mountaineering in the late 1970s, but the roots of Melbourne's alpine climbing community went back much further than that - back nearly to the days of World War II. About 1945, a mountaineering club was established at the University of Melbourne by Professor Tom Cherry, an Englishman who set up the club along the lines of the traditional British university mountaineering clubs.

Members of the Melbourne University Mountaineering Club (MUMC) were the pioneers of climbing in the Melbourne area from the 1940s until the 1960s. They gave instructional courses in alpine-climbing techniques at Mt Feathertop, where they built a hut, and provided advice for those going to New Zealand. They organised trips further afield - to the European Alps and to Antarctica, for example. The MUMC, however, unlike its counterpart at The Australian National University in Canberra, never got around to organising an expedition to the Himalaya.

By the late 1960s, the character of the MUMC had changed. Many of those interested in alpine climbing had become involved in the Australian section

1 M. Rheinberger, Interview. 
of the NZAC and for a while the MUMC and NZAC ran parallel instructional courses. Eventually, the NZAC became the dominant focus for overseas climbing among Melbourne's mountaineering community.

In 1969, a group of Melbourne climbers, with assistance from the NZAC and the Mt Everest Foundation, organised a trip to the Andes Mountains of South America; it was the first major overseas expedition from Victoria and a precursor to its first Himalayan expedition 10 years later. The party, led by Ross Wyborn, included John Retchford, active for years in the MUMC and one of the early pillars of Melbourne climbing; Dot Butler, the driving force behind the establishment of the Australian section of the NZAC (see Chapter 4) and a link to the Sydney climbing community; and Jack Higgs, a member of the ill-fated expedition to Annapurna III in 1980.

By the 1970s, the MUMC had competition from another quarter. The Victorian Climbing Club (VCC) was rapidly gaining strength, coincidentally with the rapid rise in popularity of rock climbing. Mt Arapiles in western Victoria had become the centre of Australian rock climbing and the VCC was the preferred organisation for the growing army of hot, young rock climbers.

The NZAC group continued to gain strength during the decade as well. There was enough interest that by the mid-1970s, former New Zealander Rob Mitchell officially guided the southern section of the NZAC into existence. During this period, the MUMC by no means faded away but continued to spawn a large number of lean, fit bushwalkers, rock climbers and mountaineers. Towards the end of the 1970s, therefore, the Melbourne climbing community was thrivingready for the inspiration and organisational drive needed to mount a Himalayan expedition.

It was during this period that Michael Rheinberger, infused with a bit of the Bonington magic, returned to Melbourne from his study leave in Britain. He quickly found his way to the NZAC, then a very active club centred on a core group that included Mitchell, Retchford, Pat Miller, Tony Crapper, Greg Martin, Andrew Rothfield, Anton Halibut, Nick Reeves and Mike Feller.

Rheinberger's arrival on the scene was half the spark needed to ignite a Himalayan trip. The other half was provided by Peter Allen, a soft-spoken town planner who became actively involved in the NZAC about the same time as Rheinberger. That pair, along with Rothfield, got the first Melbourne-based expedition to the Himalaya off the ground-organised for 1979 under the auspices of the southern Australian section of the NZAC. 
The expedition was, as many were, 'dreamed up in the pub one night', ${ }^{2}$ according to Rothfield, but it did get some impetus also from the ANU Mountaineering Club's (ANUMC) well-publicised trip to Dunagiri. If a group of university students from Canberra could mount an expedition to a major Himalayan peak, why couldn't a group of Melbourne alpine climbers do likewise? It was a good example of the effect of the Dunagiri climb in showing the way for other groups of would-be Australian Himalayan climbers.

It was Peter Allen's idea to mount an expedition and since he had the organisational skills needed to plan and run a Himalayan expedition, he was endorsed as the leader. He and Max Berry, another climber in the group, did much of the research and the bureaucratic legwork needed to get the trip off the ground and into the field in the Himalaya. Ed Neve and Gary Wills completed the six-man climbing team (see image 15.1).

As their objective, the group settled on White Sail-now known officially as Dharamsura - a $6445 \mathrm{~m}$ mountain in the Kulu region of India. It was the ideal choice for a first trip to the Himalaya - far more appropriate than the ANUMC's Dunagiri objective the previous year. That peak, although climbed by Tim Macartney-Snape, proved much too high, difficult and dangerous for most of the ANUMC team. White Sail, on the other hand, was of moderate height and offered enough stretches of difficult climbing to make the ascent interesting. Furthermore, it had no continuous stretches of difficulties and danger-like Dunagiri's summit ridge - to make the ascent desperate. Finally, with just a three-day march to the base of the mountain, it was one of the most accessible of all Himalayan peaks.

The White Sail expedition went smoothly from the start. It was only eight months from the time the idea surfaced over a beer in a pub until the team's departure for India. After obtaining the peak permit within a week after arriving in New Delhiquite a short time by the standards of Indian bureaucracy - the climbers were on a bus headed for Manali and the start of the walk in. Even the bus ride was tame compared with the epic journey of the Mulkila expeditioners in the same region of India four years earlier, although Berry noted that 'to find comfort on an Indian bus you have to be no taller than five feet, no wider than one foot and have a cast iron backside'. ${ }^{3}$

The climbing also was generally straightforward - just about right for a first trip to the Himalaya. Much of it was snow climbing on moderately angled slopes, but there were a couple of icefalls, with their crevasse fields and steep pitches of climbing, to negotiate (see image 15.2). Add to that a storm, some avalanche conditions and a forced retreat and you have a rather complete Himalayan experience. Allen described the retreat as 'an eerie journey down through a strange white and grey landscape as we followed the seemingly aimless wanderings of our old tracks in and out among the hidden crevasses and the swirling cloud'. ${ }^{4}$ 


\section{White Sail: the magic of a first Himalayan summit Peter Allen}

We were soon at grips with the steeper ground of the icecliffs. Ed led the first pitch over a bergschrund and upward and leftward below a huge wall of icicles. Gary and I followed, then it was my lead on the traverse left along the base of the icicle wall. It wasn't as hard as it had seemed from below, although the ice was rotten and brittle and I just reached the end of the wall before the rope ran out. I put in a couple of ice screws and the others came across. The stance was rather small and Gary had to dangle on an ice screw while Ed pushed straight on up. That was the end of the steep stuff and Ed's belay was only a ropelength below the south ridge.

What a ropelength! The snow was steep and bottomless and cut by a series of slots that you could only see when you fell into them. The most effective way to make progress was by a cross between breast stroke and dog paddle. By the time we reached the crest of the ridge we had left a trench we could still see as we descended the glacier 1000 metres below, the next day.

We found a sheltered hollow on the broad ridge crest and stopped to get our breath back. Before us was a new panorama which had previously been hidden behind White Sail. Directly opposite was the huge east face of Papsura and the steep sinuous ridges of beautiful Devachen. Behind these were the endless brown ranks of the mysterious peaks of Ladakh.

The summit ridge seemed very long. It rose in gentle steps until the final summit cone which produced two pitches of steeper ice as a last token gesture before a small snow summit. At first we were not quite sure it was the summit but a glance over the other side and the small red pennant left by a previous Japanese expedition confirmed that it was. It was 3:30 in the afternoon.

A strong wind had sprung up as we approached and on the top we had to shout to be heard. We took a few pictures and ritually devoured our three jelly beans each before setting off down. The valleys were rapidly filling with swirling clouds and the wind stung our cheeks. Eight months of preparations and a month of travelling to reach the top and we stood there for less than five minutes!

We raced down the ridge and plunged over the side into the trench which led down to the icecliffs. As soon as we dropped off the crest of the ridge we were enveloped in thick cloud and visibility dropped to about half a ropelength. The return trip through the icecliffs was uneventful and by $6 \mathrm{pm}$ we were trudging back across the football field in the dark. Even after I remembered to take my sunglasses off it was still very gloomy. The batteries in the headtorch were almost flat so we saved it for the more difficult stretches further down.

We eventually came out of the cloud in time to see a long purple line on the horizon fade and disappear. The headtorch came out at last and we traversed back towards the col and down onto the glacier. We stumbled along like drunks behind the feeble flicker of the torch until, quite suddenly, the tents appeared. We had been gone for exactly 12 hours.

As we reached the tents a cold wind swept up the glacier and grew steadily more violent. We crawled wearily into our sleeping bags and Ed and Gary managed to produce a mug of nearly-hot chocolate. Spindrift began to beat on the tent walls and the wind raged all night but we were too tired to care. 
By morning it was calm again. I awoke to find the sides of my tent crushed by windpacked snow. I could not turn over and my sleeping bag was coated with ice. The morning sun eventually thawed things out and after a leisurely breakfast we set off for the glacier camp in perfect conditions. In three hours we charged down what had taken a day and a half to climb. Success was short-lived however, because the others had abandoned the glacier camp. The snow had all disappeared and there was nothing there now but bare ice and running water.

The sun was sinking as we wearily dropped our packs on the grassy shelf where the next camp was pitched. All around the peaks glowed gold and crimson. The six of us were all together again on solid, horizontal earth. Max thrust a mug of steaming hot tea into my hands and there was nowhere else I would rather have been.

From 'White Sail: the ascent', Backpack, no. 2 (1980), p. 23.

Within three weeks of arriving at base camp, the team had put all but one of the members on the summit of White Sail. Rheinberger and Rothfield were the first up, and Allen, Neve and Wills followed them to the top a few days later. The southern Australian section of the NZAC had achieved a solid success in its first Himalayan attempt.

Rheinberger was quick to follow up the White Sail ascent. Just a year later he was back in the Himalaya again, leading a southern section-NZAC expedition to Changabang in the Garhwal region of India. In choosing Changabang, Rheinberger was following the recommended pattern of building up Himalayan experience in a progression of peaks increasing gradually in height and difficulty. At 6864 $\mathrm{m}$, Changabang, an exceptionally beautiful mountain, is about $400 \mathrm{~m}$ higher than White Sail. The East Ridge route-probably the easiest on the mountain and the one attempted by the Sydney group in their 1977 expedition (Chapter 9) - was nevertheless steeper, more sustained, more exposed and more difficult technically than the ascent of White Sail. It was just about the ideal second peak to try; Rheinberger was doing things strictly by the book.

In addition to Rheinberger, the Changabang team included three other White Sail members: Allen, Berry and Rothfield. Melbourne climbers Paul Anderson, John Dunlop, Tim Hughes and Pat Miller also joined the team, which was completed by the addition of Malcolm Noble, a member of the 1977 group that had come so close to getting to the top of the peak. Noble's inclusion meant that the team had that valuable firsthand experience of the access route through the Rishi Gorge, of siting of base camp and higher camps on the mountain and of general snow and ice conditions on the Kalanka Face and the summit ridge.

Knowledge of the route through the treacherous Rishi Gorge did not, however, make it any easier - nor did the retinue of 70 goats, which were taken along as load-bearing animals to avoid the problem of hiring additional porters to carry food for the others. The goats did admirably well, as expected, on the 
rugged tracks clinging to the gorge walls high above the Rishi Ganga, but it was a different matter when the track dropped down to a river crossing. One particular crossing was difficult, as Rheinberger recalled: 'We toiled for about one hour, felling trees, dragging them to the water and man-handling them into position. They were then lashed with spare rope and stepping stones laid across. Once enticed onto the structure, the agile goats danced across and we breathed a collective sigh of relief. ${ }^{5}$ It was then decided, however, since the gorge became even more difficult ahead, that that would be the end of the line for the goats.

Beyond the junction of the outflow of the Rhamani Glacier, where the route to the Dunagiri base camp branches off, the Rishi Gorge, as Rheinberger describes,

narrows and becomes increasingly sinister. Down to the left $500 \mathrm{~m}$ below us somewhere was the Rishi. High above it colossal cliffs reared. We travelled slowly, following a devious path that wound tortuously in and out of gullies and defiles...In places the way seemed impassable but always the track found a gully or a terrace and snaked onwards and upwards toward the Sanctuary. ${ }^{6}$

Just when the team appeared to be safely out of the gorge, disaster nearly struck Tim Hughes. Rheinberger recounted the incident, as the group was crossing the northern branch of the Rishi on the way to the base of Changabang:

The porters refused to cross and continued on up the true left bank of the stream. On a belay I took a climbing rope across and fixed a handline. It was here that we almost lost Tim, who let go one hand during his crossing and was swiftly carried away until slammed and held against a rock mid-stream. Several of us swiftly formed a human chain and fished him out but he required three hours in a sleeping bag to thaw out. ${ }^{7}$

Base camp was established at the foot of the Changabang Glacier, about $6 \mathrm{~km}$ from the base of the mountain and therefore too far away to be of much practical use as a climbing base. Advanced base camp was set up at the foot of the Kalanka Face and the first period of the climb was spent simply carrying up loads to stock the upper camp.

The climb was attempted in pure alpine style in that no trips were made above advanced base camp until the climbers began the push for the summit itself. Loaded with food and fuel for two camps and a possible bivouac, they made rapid progress up the lower reaches of the Kalanka Face and established camp

5 Rheinberger, M. 1981, 'Changabang', Mountaineering '81 (Melbourne University Mountaineering Club journal), pp. 38-46.

6 Ibid.

7 Ibid. 
one on a hacked-out, narrow ledge of ice about halfway up the face. More steady progress the next day brought them to within $100 \mathrm{~m}$ of the col, where they set up their second camp.

Already, however, attrition had begun to take a toll. Berry did not climb above advanced base camp, Hughes was moving very slowly early on and retreated from low on the face and Dunlop and Miller turned back from a point a little higher as Dunlop was not acclimatising well. That left five of the original nine climbers-Allen, Anderson, Noble, Rheinberger and Rothfield-to carry on.

A short climb above camp two gained the col between Kalanka and Changabang and the start of the East Ridge proper. Then the climbing really got interesting, according to Rheinberger:

[T] he ridge ahead curved up steeply, a long, narrow, corniced knifeblade which terminated about $500 \mathrm{~m}$ up on a conspicuous bump. This was the lower summit and beyond it, hidden from view, was the true summit about $100 \mathrm{~m}$ higher. It was a splendid situation. On the Nanda Devi, or southern side, the face seemed to average about 50 degrees, somewhat steeper in places. Numerous runnels and scours indicated that most of the newly fallen snow had slid off and we judged the ridge to be objectively safe. To the north, the face fell away at a fearsome angle, the cornice leaning to that side. ${ }^{8}$

The team made steady progress along the difficult ridge but still found themselves significantly short of the summit late in the afternoon (see image 15.3). The expected bivouac turned into a reality as they hastily dug a rudimentary snow cave. The next morning an exhausted Noble announced that he had had enough and when his rope-mate declined to descend with him, Allen agreed to do so. That left only Anderson, Rheinberger and Rothfield to continue on up the ridge towards the top. Rheinberger takes up the story just below the summit:

The next pitch was very steep, on the crest of the ridge. I struggled with the wind and at one point had to proceed bent over like a chimpanzee. The others had me on a good belay, and I soon reached the top of the difficult section. From there I picked my way along a gentle rise towards the summit. Just short of it, the rope ran out and I bridled my impatience as the others climbed through. Another five minutes and we were all shaking hands on the top.

I was surprised at my feelings. There was nothing like the emotional elation I had experienced on Dharamsura; just a sense of achievement and satisfaction at a task accomplished. Still the position was stunning. 
To the west lay Dunagiri, and as my eye swept round to the north I recognised the Badrinath/Kedarnath peaks, Kamet, then, in the distance, the Tibetan plateau and remote snow caps. Further around was Hardeol, then the steep Kalanka west ridge, followed by the peaks of the Sanctuary. By climbing to the lip (on a good belay!) we were able to look straight on to Nanda Devi and the peaks of the Southern Sanctuary. It was a splendid moment but the wind was chilling. Photographs, the Australian and Indian flags, a bite of chocolate, and it was time to begin the descent. ${ }^{9}$

The Changabang success was another milestone in Australian Himalayan climbing. It was the first Australian ascent of this beautiful mountain and it was the second-highest peak climbed by Australians at that time. Two years earlier, the ANUMC team had succeeded on Dunagiri, just to the west and only about $200 \mathrm{~m}$ higher than Changabang.

More importantly, the climb was another success for the southern Australian section of the NZAC and for the trio of Allen, Rheinberger and Rothfield. They were progressing steadily up the learning curve of Himalayan mountaineering; a few more successes would put them in position to tackle one of the $8000 \mathrm{~m}$ peaks and, eventually, Mt Everest.

Before their celebrations of the Changabang ascent had even finished, however, tragedy struck the team. On the walk out from the mountain, Tim Hughes, who had a narrow escape on the walk in, was not so lucky. He slipped while traversing one of the treacherous sections of the Rishi Gorge, fell from the track and was killed. It was a staggering psychological blow to the group and turned their magnificent achievement on Changabang into a hollow, bittersweet victory.

The tragic death of Hughes meant more than the loss of a good friend and climbing companion to the Melbourne mountaineering community. Just before the Changabang trip, Hughes had written to Peter Allen suggesting that the bicentenary in 1988 would be an appropriate time for an Australian attempt on Mt Everest. Like Peter Gration, Hughes and Australian film producer Mike Dillon had the vision to see that a realistic attempt on the world's highest mountain required years of preparation and that 1980 was therefore not too early to begin planning for an expedition eight years in the future. Furthermore, they were able to follow up immediately on the idea. Before the Changabang expedition, the pair was in Nepal working on a film about the life of Sir Edmund Hillary. At that time, Hughes dropped by the Ministry of Tourism in Kathmandu and 
applied for the South Col route on Everest in 1988 on behalf of the southern Australian section of the NZAC. The permit was granted early in 1981-after Hughes had been killed.

So the two strands of Australian Himalayan climbing - the AAA and the southern Australian section of the NZAC - which would eventually combine to form the ABEE were each initially pushed towards Everest by people destined to take no significant part in the expedition itself. Peter Gration was unable to become heavily involved in the AAA build-up to Everest due to the heavy demands of his career and, of course, Hughes' involvement ended with the accident on the return from Changabang.

Work commitments prevented Mike Rheinberger from undertaking an expedition in 1981, so two years elapsed between the Changabang ascent and his next trip to the Himalaya. By 1982, the active core of the Melbourne climbing group had changed somewhat. A year earlier, Andrew Rothfield had decided to withdraw from active climbing and Peter Allen was unavailable for an overseas trip in 1982. (He had just returned from a year of climbing in the United Kingdom and the United States; one of his achievements during that period was a traverse of Denali from the north.) Rheinberger was able to recruit Ed Neve and Gary Wills - both members of the White Sail expedition - to his team and added three newcomers to Himalayan climbing: Keith Egerton, Hugh Foxcroft and Tom Millar.

Despite the dangerous, difficult and uncomfortable passage up the Rishi Gorge, Rheinberger was enticed back to the Nanda Devi Sanctuary in 1982. This time the objective was Nanda Devi itself - at $7816 \mathrm{~m}$, the queen of the sanctuary and the highest peak in the Indian Himalaya. It was yet another step up in height and difficulty from Changabang and a next logical step in the steady progression towards the Himalayan giants and then Everest. Also, Rheinberger was captivated by the exploration and mountaineering feats of Shipton and Tilman, who first forged a passage up the famous Rishi Gorge.

The bad luck that struck the Changabang group during its retreat from the sanctuary plagued the Nanda Devi expedition from the start. On arriving in New Delhi, Rheinberger discovered that an attempt on Nanda Devi required a second permit from the Ministries of Home Affairs and Defence in addition to the normal permit from the Indian Mountaineering Foundation. Having additional, unexpected hassles with the Indian bureaucracy at the start of an expedition was not a good omen.

Shortly thereafter, the Rishi Gorge nearly claimed a second Australian victim. Hugh Foxcroft was close to disaster crossing the Trisul River, as Rheinberger recalled: 
While attempting a photograph, Hugh slipped and quickly found himself in the raging torrent. Quite remarkably he managed to jam himself between boulders and hung on until he was able to have a rope thrown him. Two hours in his sleeping bag and plenty of hot tea and he was up to moving again, though badly shaken physically and mentally bruised. ${ }^{10}$

The next mishap occurred as the team was beginning their attempt on the mountain itself. Camp one was situated on a flat section of a spur leading up to the South-East Ridge of Nandi Devi. As the campsite was located just under the ridge, it was subject to occasional rock falls from above.

With Egerton, Neve and Wills in residence after carrying loads from base camp, a rock fall came down during the night and struck Neve while he was asleep in one of the tents. The next morning, the other two found him unconscious with a large wound to his head. Somewhat later, Rheinberger, Foxcroft and Millar arrived from base camp. By that time, Neve had regained consciousness but he was nauseated, his memory was very blurred and he was unable to stand. He was forced to remain at camp one for some time until his condition improved enough that he could be moved.

Meanwhile, Rheinberger began a rescue operation. He, Wills and the expedition's liaison officer set out for the base camp of an Indian expedition attempting Nanda Devi from the north in the hope that their doctor could be spared to attend to Neve or that at least they had a radio so that a message could be sent to Joshimath. The trip was a wasted effort, however, as the Indians had no radio and their doctor, occupied at their camp one, was unable to leave his duties there.

The trio then pushed back in haste to their own base camp, from which the liaison officer and one of the staff members were dispatched to march to Lata as quickly as possible and organise a helicopter. That operation, however, would take a minimum of three days.

The day after the messengers were sent back down through the gorge, the rest of the team were up at camp one preparing to assist Neve from the mountain and back to base camp. Rheinberger observed:

Ed was given 30 minutes of oxygen at 8 litres/min and then with one of us tied in on each side with a short sling to his waist harness, Ed literally

10 Rheinberger, M. 1983, ‘Nanda Devi 1982', New Zealand Alpine Journal, vol. 36, pp. 86-92. 
could not fall over. With the fifth man carrying his pack we set off and by tedious progress, numerous rest stops and a further administration of oxygen we reached $\mathrm{BC}$ in $4 \frac{1}{2}$ hours of concentrated effort. ${ }^{11}$

Rheinberger's woes multiplied at base camp when the next morning Millar was struck with an epileptic seizure. It took the remaining healthy climbers to restrain him until he fell into a deep sleep. The fit came more as a surprise to Millar than to anyone else as he had no previous history of epileptic fits. Now Neve would have company during his evacuation from the sanctuary back to civilisation.

Late on the morning of the appointed day, an Indian Air Force helicopter droned up the gorge and into the sanctuary to collect the stricken climbers. The Indian authorities had, however, expected only one casualty and so had brought along an extra officer for the ride. The evacuation of Millar thus required an extra trip back up the gorge, which the Indian authorities gladly undertook.

Despite the setback of losing not one but two climbers of a small team to injury and illness, Rheinberger was nevertheless keen to have a solid attempt at Nanda Devi. Circumstances, however, had now forced him into a lightweight attempt with a small team in a very limited time. Nanda Devi had become an even more formidable mountain.

The number of available climbers was down to four: Egerton, Foxcroft, Rheinberger and Wills. Their first task was to regain camp two, which had been established on the ridge itself before the accident, stock it and push the route up to camp three. Hopefully, that would be the top camp - in striking distance of the summit with a long day's effort.

The attempt ran into trouble almost immediately. The climbing above camp two proved harder than expected, with rocky gendarmes and then a sharp ice ridge slowing progress. At least there was plenty of old fixed rope along the route from previous expeditions - badly needed to supplement the team's meagre supplies - but it required careful testing and refixing to ensure reliability.

Another blow was the further reduction of the team's strength. Hugh Foxcroft had continual problems with acclimatisation during the expedition and, despite a valiant effort in carrying loads to camp two and one above, he was forced to retire from the attempt before camp three was established. Keith Egerton, too, was soon forced off the mountain. Suffering badly in the wind and extreme cold of the exposed ridge above camp two, he appeared to have contracted retinal haemorrhaging and had to descend. That left only Rheinberger and Wills to carry on. 
The odds for success were now very long indeed. With only two active climbers and no back-up, much difficult climbing still lay ahead. It had become apparent that another camp would be needed above camp three and even with that the summit day would be long and arduous.

Still the pair battled on. Above camp three, the difficulty of the climbing eased only slightly, with a band of rotten rock providing the major problem. To ensure that they would be able to retreat rapidly in case of bad weather higher on the mountain, the two climbers took considerable care in rearranging and securing the bits of rope left in the rock band by previous expeditions. Finally, above the rock, they regained the crest of the ridge, only to be met by icy gales. It was late in the day and they were forced to drop back down below the ridge crest and secure a bivouac site on a sloping ledge. The continuing strong wind, which precluded the erection of a tent, and intense cold were definite threats, as Rheinberger recalled:

Gary's cup of tea and soup were splendid and we settled into our sleeping bags out of the wind which was whipping up spindrift and threatening to take away anything not firmly lashed down. I tied into my axe and hammer and with singlet, wool shirt, pile jacket and duvet, in my bag I was quite warm enough but now that activity had ceased I became acutely aware of a most peculiar sensation in my toes, something between a numbness and a slight tingle.

The morning of 28 September was cold and extremely windy. It was difficult to move and pack without spindrift entering pack, sleeping bag and clothing. There was no question of lighting the stove. Our concern was to regain the ridge and drop back to $\mathrm{C} 3$ to sit out the wind until a better day.

At C3 Gary had a brew going and in the shelter of the tent we looked forward to a good night's sleep. Hopefully the wind would blow over and we could go up again.

However, over dinner, Gary revealed suspected frost nip on several fingers. His flesh was extremely cold, the skin blanched and sensation gone from the finger tips. I then noticed that I had also had a similar condition on two or three fingers. ${ }^{12}$

Rheinberger and Wills judged that the risk of more serious damage to their hands was very high if they continued, so they retreated back down the mountain without further delay. The attempt on Nanda Devi was over. 
On the surface of it, the Nanda Devi expedition would have to be considered a failure. Indeed, it seemed to teeter on the brink of disaster throughout. Foxcroft was fortunate not to have drowned in the Rishi on the walk in; Neve could easily have been killed by the rock fall at camp one; and Millar's sudden attack of epilepsy might have ended in a far more severe medical emergency. The group was lucky to escape with everyone alive; multiple deaths could just as easily have been the outcome.

On another level, however, the trip was a considerable success. The group, and particularly the leader, Rheinberger, undoubtedly learned much more from the experience than if they had made a straightforward ascent of the mountain. Rheinberger had to organise two rescues quickly and efficiently to ensure the safety of his stricken colleagues, and as a result had to revise considerably his planned attack on the mountain at several stages. Despite all these problems, which in the end severely reduced the strength of an already small party, Rheinberger and his team made a very credible attempt on the peak.

The Nanda Devi expedition was thus another important step in their careful progression towards Mt Everest. It was a higher and more difficult mountain than either White Sail or Changabang. Rheinberger and Wills climbed to about $7400 \mathrm{~m}$ - higher than either of them had previously climbed. Furthermore, they gained a wealth of experience in coping with the unexpected twists and turns of a Himalayan expedition.

So, who were the Australians who had booked Mt Everest in 1980? They were a core group of Melbourne-based mountaineers from the southern Australian section of the NZAC. They had booked Mt Everest two years ahead of the AAA and their build-up of Himalayan experience was also well advanced compared with that of the AAA. If they continued to progress at their rate of the early 1980s, they would be in a very strong position by 1988 to make the first Australian ascent of Mt Everest by the classic South Col route. 


\section{An arranged marriage}

By the 1980s, large expeditions had become something of an anachronism in the Himalaya. Although Mt Everest was first climbed in 1953 by a very large British expedition, the trend since then has undoubtedly been towards small, lightweight teams. Not only are they much less expensive and logistically simpler, they mean that the mountain is attempted in what climbers call the 'best style' - that is, the emphasis is on the strength, stamina and skill of the individual climbers rather than on organisation and sheer numbers of climbers.

The first Australian ascent of Mt Everest in 1984 was a classic example of an expedition in the modern lightweight style. It became almost ridiculously lightweight, as Andy Henderson quipped, when a significant amount of gear was buried at the bottom of the mountain by an avalanche. In the end, the ascent was a triumph of determination and persistence, as the small group of mountaineers climbed most of the massive North Face in a single push.

It was an attempt in a similar style that Michael Rheinberger and his colleagues in the Melbourne climbing community had in mind when they made plans in the early 1980s for their eventual attempt on the world's highest peak in 1988. At that time, the Army Alpine Association (AAA) was only beginning to formulate its own ideas for Everest in the bicentenary. There was no contact between the two groups and both were blissfully unaware of the labyrinthine organisational manoeuvres that would later lead to the formation of the Australian Bicentennial Everest Expedition (ABEE).

The Melbourne group's plan was to mount a small, lightweight expedition consisting of about eight climbers. Although their route - the South Col routewas closely linked with very big, siege-style expeditions, they were modelling their attempt after a 1977 New Zealand expedition that used modern tactics on the traditional route. The Kiwis eventually ran out of steam at the South Col, but the Australian team hoped to find that extra bit of drive that would get them to the summit.

Planning proceeded smoothly for the southern Australian section of the NZAC until September 1983, when the AAA received official approval from the Nepalese authorities to attempt Mt Everest's West Ridge in the pre-monsoon season of 1988. Why should that affect the Melbourne group's plans? After all, their permit and that of the AAA were for different routes. Furthermore, the 
planned style of the AAA West Ridge attempt - a large expedition with many climbers, heavy Sherpa support and copious amounts of bottled oxygen - was the antithesis of that of the Melbourne group.

Yet, despite the strong desire of Rheinberger and his colleagues to maintain their own small team and their own style of climbing and the equally strong desire of elements of the AAA to attempt the West Ridge in their preferred style, the two groups were inexorably drawn together into one large expedition. In retrospect, the fact that both expeditions would take place in the bicentenary worked strongly against the two groups maintaining their independence.

Finance also played an important role. An expedition to Mt Everest is a very expensive affair, even for a lightweight attempt. The booking fee alone is very high. Both groups were therefore in need of external financial support - the AAA group probably less so as they would most likely get some support from the army. Clearly, it would be counterproductive for two different Australian expeditions - both attempting Mt Everest in the pre-monsoon season of 1988 to compete for support from the same group of potential sponsors.

Even more damaging would be open competition for support from the Australian Bicentennial Authority (ABA), which was undoubtedly the single largest potential source of direct financial assistance. Both groups were in need of cash from the ABA, so when the ABA later declared that it would not countenance two separate Australian Everest expeditions during the bicentenary, there was no choice but to merge, at least organisationally.

The army climbers were aware for some time before they obtained their permit for the West Ridge that the Melbourne group would be climbing the original route at the same time. About the time the AAA team gained approval for the West Ridge route (September 1983), Pat Cullinan, Mike Rheinberger, Peter Allen and Andrew Rothfield met at Rheinberger's house to discuss the situation. The meeting was cordial but unproductive. The Melbourne climbers, naturally enough, wanted to maintain their expedition as a small, closely knit, lightweight one. Merging with the AAA would immeasurably change the character of the trip and the civilian climbers were therefore very cool towards the idea.

Also about that time, the army climbers had put a formal organisation in place for their attempt on Everest. An interim Everest Committee of Management (ECM) was formed in August 1983 at a meeting at Fritz Schaumburg's house in Melbourne. Cullinan was elected chairman, with Brian Agnew vice-chairman and Zac Zaharias, Peter Lambert and Schaumburg members. During the next few months, in his research on legal and financial aspects of the expedition, Cullinan also enlisted the services of John Peryman, a former Army Reservist 
who managed a consulting company, to coordinate the fundraising efforts. Since the AAA effort on the West Ridge would be a big one in the traditional style, considerable support would be needed.

Events began to unfold rapidly from the end of 1983 to mid-1984, and the union between the two groups finally began to form, albeit along a somewhat rocky path. The AAA ECM (renamed the West Ridge Everest Committee, WREC) met again in November 1983, by which time it had become apparent to the army group that, despite their plans for a siege-style assault on the West Ridge, some form of cooperation with the civilian climbers would be useful. They decided to try again to form one 'umbrella' expedition but with the two groups retaining their individual routes.

The civilian group, too, had begun to realise that some sort of formal organisational merger was necessary. Peter Allen had lodged an application with the ABA in mid-1983 for financial assistance for their Everest attempt. When an application also appeared from the AAA for support for an Everest expedition in 1988, the ABA made it clear that they preferred a single Australian expedition to attempt Everest. Support for neither group was thus forthcoming. It appeared obvious that a merger was required to gain ABA support. What very much complicated the issue, however - and very nearly destroyed the fragile partnership that was beginning to emerge between the two groups - was alleged correspondence later in 1983 from the army to the ABA.

Mike Rheinberger said:

What greatly upset us [the civilian group] was the appearance of a letter which was written to the bicentennial authority from defence headquarters. The letter tried to point out that the authority would be much better advised to sling its financial weight behind the army attempt because the army attempt would have a much greater chance of success than the attempt by relatively few civilian climbers. ${ }^{1}$

The alleged letter fuelled the suspicions of the civilian group. They were already very wary of their impending forced marriage to the AAA as that union, despite its preservation of the separate routes, would impinge on their plans for a relatively small, tightly knit attempt on Everest. They no doubt felt a little like the small, cohesive company that was suddenly subject to a takeover bid by a larger corporation. Furthermore, the delicate question of financial support was another bone that stuck in the craw of the civilian climbers. 'Another galling aspect of the whole business,' Rheinberger pointed out, 'was that the army already had a lot of support behind it.'2

1 M. Rheinberger, Interview.

2 Ibid 
The content of the alleged letter, indeed even its existence, remained a controversial issue well after the expedition itself. Several members of the AAA denied its existence, while the core of the Melbourne climbing community that participated in the ABEE claimed to have held a copy of the letter but declined to make it available. An attempt to obtain a copy of the letter from the liquidator of the ABA was not successful; the letter was not among the file of correspondence provided.

Despite the ill-feeling generated by the alleged letter, the two groups met jointly for the first time later in November at Bonegilla, a small town near Wodonga, Victoria. At that meeting, an ABEE committee was officially formed, consisting of Pat Cullinan, Peter Lambert and Zac Zaharias of the AAA and Peter Allen, Mike Rheinberger and Andrew Rothfield of the Melbourne group.

Shortly thereafter, Allen and Lambert drafted a single, joint proposal for support to the ABA. In addition, the AAA had completed its Everest plan and had submitted it to the army for approval. At least now a single Australian expedition would go to Mt Everest in 1988, which would make support much more likely from the ABA.

Cullinan met with General Gration in January 1984 and secured his enthusiastic support for the AAA plan. That was a big step forward in eventually gaining official army approval. More good news came two months later when the ABA expressed support in principle for the joint expedition, although it indicated that a financial grant would be forthcoming only when the ABEE was already on a firm financial footing.

In May 1984, the ABEE committee met again, this time in Watsonia, Victoria, and with the AAA's financial consultant, John Peryman, in attendance. The meeting was a milestone in the development of the ABEE. To assist fundraising, the committee was incorporated as a limited liability company. A formal committee was elected, consisting of Cullinan as president, Zaharias as vice-president, Peryman as secretary/treasurer and Allen, Rheinberger, Lambert and Rothfield as board members. A Sydney-based executive committee of Cullinan, Zaharias and Peryman was formed to handle the day-to-day operation of the ABEE. It was decided at the meeting that a formal joint plan should be developed, including objectives, organisation and method of operation.

In October 1984, Pat Cullinan and John Peryman met in the Army Office in Canberra to present the plan to Major General Neville Smethurst, the Chief of Operations - Army. His support was vital from the AAA's point of viewboth for the availability of climbers (the army climbers needed permission from their individual commanding officers to take part in the expedition) and for the resources the army could potentially provide. 
A big hurdle was cleared when Smethurst approved army support for the plan. Army personnel participating in the expedition would be classified as 'on duty' and would thus continue to be paid for the duration of the expedition. Just as importantly, Smethurst's support meant that significant parts of army operations, such as communications and transport, would be available to assist the expedition.

By the end of 1984, a reasonable working relationship had been established between the two groups. The key to the successful merger was the preservation of the two routes; the two teams could operate pretty much as they had originally planned. Indeed, the plan made a virtue of necessity in that the two teams could attempt a double traverse of Everest - a feat never before accomplished. If things went well, the civilian group would climb the mountain via the South Col route and descend via the West Ridge; the AAA team would climb the West Ridge and descend via the South Col. With a bit of luck in timing, the two teams could celebrate together on the summit.

One could be forgiven for thinking that the ABEE climbers exhausted their energies in 1983 and 1984 in simply getting the expedition organised. Considerable effort was expended in getting the ABEE off the ground. Nevertheless, many of the team did not forget that the ultimate aim of the whole exercise was to get out into the mountains and climb.

The AAA was back again in the Himalaya in the post-monsoon season of 1983. After their tragic attempt on Ganesh IV in 1981, the army had regrouped and mounted a successful trip to Denali in Alaska the next year. The next step was to have a go at another $7000 \mathrm{~m}$ peak in the Himalaya, so they settled on Nilgiri North - a $7061 \mathrm{~m}$ mountain in the Annapurna Range of central Nepal - as an appropriate target.

Nilgiri North was a turning point for the AAA in its preparation for Everest. The Nilgiri North expedition was organised by Terry McCullagh and Zac Zaharias, with Zaharias, who had led the successful climb of Denali in 1982, as the leader. Zaharias realised by early 1983 - even before the two groups that would attempt Everest in 1988 had begun to come together - that cooperation on the mountain would be essential. He took the opportunity, in keeping with AAA policy, to get that cooperation under way by inviting Peter Allen along on the Nilgiri North trip (see image 16.1). The inclusion of Allen had an important effect on creating the necessary partnership between the AAA and the Melbourne group and was a vital antidote to the somewhat poisonous interactions that were occurring simultaneously at the organisational level. 
Zaharias was in a good position to begin building the bridge between the two groups. He regularly climbed with civilians in New Zealand and maintained a close connection with the Sydney-based northern Australian section of the NZAC. In fact, he became chairman of the section in 1983 and 1984.

The Nilgiri North expedition was also critical for the morale of the AAA. It was then eight years since Peter Gration had conceived the idea of Australian soldiers on top of Everest; less than five years remained until the pre-monsoon season of 1988. The AAA was still a long way from having a reasonably sized cadre of strong, experienced Himalayan climbers. Indeed, the army climbers had not yet succeeded on a $7000 \mathrm{~m}$ peak and had only one Himalayan ascent to their collective credit (the ascent of Tseringma by Pat Cullinan's Perth-based SAS unit in 1980). A failure on Nilgiri North would be a blow from which the AAA would have great difficulty recovering.

Nilgiri North - about the same height as Ganesh IV-was more difficult technically but at least the route was considerably less threatened by avalanches. The AAA team was climbing from the south-east side - a route climbed once previously, by a Japanese expedition the previous year. The most difficult section of the climb would be the very narrow South-East Ridge itself.

Even before the climbing began, however, Zaharias had a medical emergency on his hands.

The paradox on the expedition was that of all members of the team it was the doctor who needed to be evacuated as he had developed pneumonia at base camp. His condition deteriorated from the time of arrival and was not assisted by the poor weather. Luckily an Italian doctor was available at Annapurna I base camp only 20 minutes away. He was able to diagnose and care for him. Due to his condition the decision was made on 13 October to send for a helicopter. Any further delay could have resulted in death. ${ }^{3}$

The doctor, Bruce Fox of the Royal Australian Air Force, had duty status for the time at base camp but not for travel to Nepal and the walk-in. He made the classic mistake of rushing up to high altitude much too quickly.

Another classic problem developed soon after the climbing began, when the team was split into a lead and a support group of climbers. The lead climbing team consisted of Dave Evans and Phil Pitham of the AAA, Peter Allen and Mark Whetu, a New Zealand civilian. Zaharias, Peter Lambert and Terry McCullagh, all AAA members, formed the support team.

3 Zaharias, Z. 1984, Report on expedition to Nepalese Himalaya 20 Sep 83 - 16 Nov 83, [AAA Nilgiri report], 28 September 1984, Australian Army Alpine Association, Canberra. 
Zaharias recalled, 'It was the same old situation - the lead climbers thought the support group weren't pulling their weight and the support group thought the leaders were a bunch of prima donnas. ${ }^{4} \mathrm{McCullagh}$ had a slightly different perspective, in that any friction arose because the roles of the two groups did not change during the entire expedition so his group did not get a chance to do any lead climbing. ${ }^{5}$

The strategy was to establish camp one at the base of a couloir that led to the ridge (see image 16.2), put camp two on the ridge at the top of the couloir (5500 $\mathrm{m})$ and then perhaps make an alpine-style push from there. On gaining the ridge, the climbers were in for a surprise, as Lambert remembered: 'The climb was very protected until we got to the ridge, then suddenly became terribly exposed. We got a huge shock to our systems when we went up there for the first time.' ${ }^{6}$

Pitham was also impressed:

The top of the couloir was a knife-edged ridge, with nowhere to pitch a tent or even dump gear without a great deal of digging. We tried a few spots, only to find hard ice just below the surface. Then Mark, wandering off by himself, found a buried schrund... The entrance was on the other side of the ridge and very exposed, so we put in a fixed rope to prevent stepping out of the door and ending up 1000 metres lower. $^{7}$

The climbing above camp two proved difficult and very exposed (see images 16.3 and 16.4), so the lead team spent a week putting in $800 \mathrm{~m}$ of fixed rope. A further camp was established above ice cliffs at the end of the ridge itself. From there, in deteriorating weather, Evans, Whetu and Pitham went for the top; Allen was recovering from being hit by a rock fall and had dropped back down to join the second group.

'We spent a terrible night [at camp three] with the three of us crammed in a two man Omnipotent,' Pitham said:

Rime kept falling all night and by morning everything was sodden. After a half cup of tea each for breakfast, we began the painful process of dressing. Not a very pleasant day for climbing; 25 below zero and we could only see 50 metres because of the cloud being whipped across the mountain.

4 Z. Zaharias, Interview.

5 T. McCullagh, Correspondence.

6 P. Lambert, Interview.

7 Pitham, P. 1984, 'Nilgiri', New Zealand Alpine Journal, vol. 37, pp. 56-8. 
We climbed the last of the ice cliffs and through a series of wind scoops. The weather was deteriorating as we made our way across a small plateau to the final summit pyramid. Mark and I cowered in a sheltered groove trying to warm frozen feet, while Dave pressed on alone, not wanting to get cold himself. Mark and I followed soon after. The summit came as a surprise only 20 minutes later. There was too much cloud to see a lot, and too cold to hang about, so we took a few quick photos and raced down to Camp III. ${ }^{8}$

Two days later, the other four climbers reached the top, but only after some demanding climbing. Allen, Lambert, McCullagh and Zaharias, along with Maila Pemba, made the arduous ascent to camp three in a long day, with Lambert and Zaharias suffering from the cold and altitude on arrival at the camp. The next day, all five continued on to the summit and returned to camp three safely and in good time (see image 16.5).

On the descent of the second team after their summit success, however, a conflict involving the clearing of gear from the mountain soured the expedition's success. Peter Allen and Maila Pemba carried large loads down, but much gear remained on the mountain. At camp three, a lively discussion started when Zaharias proposed that the mountain be cleared of fixed rope; the discussion centred on the ethics of leaving the mountain clean versus the risk of spending extra time on the route. McCullagh was particularly keen to avoid further risk given the objective danger on the exposed, steep route between camps two and three, while others judged the objective danger to be somewhat less and thus opted for removing as much gear as possible. In addition, Zaharias thought that the plan might give the second team a chance to 'lead' by spending a couple of days clearing the mountain.

Eventually a compromise was reached whereby McCullagh and Lambert abseiled first and Zaharias came down last, doubling the rope through the anchors and then retrieving it. The three were then to share the load carrying. This system seemed to work well at first. The three climbers worked as they descended, first clearing the fixed ropes between camp three and the rock band and then, the next day, returning from camp two to the rock band to clear it.

All three had heavy loads and were very tired as they descended to the bottom of the couloir below camp two. From there, McCullagh and Lambert continued on to camp one, where they informed Mark Whetu and Phil Pitham, who were already at the camp, that Zaharias was about 20-30 minutes behind them. This left Zaharias with the relatively easier route from the bottom of the couloir to camp one, but with a very heavy load and near the end of an exhausting day. 
'I was loaded to the gunnels,' Zaharias recalled:

In fact, at one time I was carrying eight ropes as well as a host of other gear...It took me a long time to get down by myself. By the time I was out of the couloir it was dark and I nearly missed Camp I. Had it not been for Mark Whetu and Phil Pitham, who, waiting patiently for me at Camp I, switched on a torch inside their tent just as I stumbled past only 100 metres away, I would have ended up heading into the glacier below. ${ }^{9}$

Peter Lambert admitted that leaving Zaharias was 'the worst decision I've ever made in the mountains' ${ }^{10}$ He later apologised to Zaharias and the rest of the team for leaving him on the mountain on his own, but Zaharias' attempt to patch things up with Terry McCullagh failed. The two had a 'one-way' conversation, as Zaharias put it. ${ }^{11}$ Although the incident seemed a minor one, it was a harbinger of problems that would bedevil the AAA on the lead-up to and during the Everest trip.

Nevertheless, the Nilgiri North success was an enormous morale booster for the AAA. They had climbed their first major Himalayan peak - and indeed only the third $7000 \mathrm{~m}$ peak climbed by Australians at that time (after Dunagiri and Annapurna II). It was a demanding and challenging climb that pushed the climbers to their mental and physical limits and clearly showed that the AAA team had the capability to succeed on big Himalayan peaks. They were back on track for Everest in 1988.

The inclusion of Peter Allen in the expedition paid great dividends. Not only did Allen and the AAA climbers establish a very good working relationship on the mountains, Allen's skills and experience, as Zaharias readily acknowledged, played a key role in the successful ascent: 'It was a very difficult climb. We certainly needed Peter's expertise. ${ }^{\prime 2}$

From Allen's perspective, the Nilgiri success proved that the two groups could work well together: 'It indicated to me (and therefore the 'civilians') that Zac, Peter, and Phil were people we could work with and climb with, and were people who understood our climbing philosophy and have an interest in practising it. ${ }^{13}$

Peter Lambert summarised the importance of the Nilgiri North success to the AAA program:

9 Zaharias, Report on expedition to Nepalese Himalaya 20 Sep $83-16$ Nov 83.

10 P. Lambert, Interview.

11 Z. Zaharias, Interview.

12 Z. Zaharias, Interview.

13 P. Allen, Interview. 
Nilgiri had a tremendous psychological effect on us personally. It showed us what we could do, what our skills really were. And it showed me just what I could and couldn't do, just what my limitations are. That is something you need to know when you try to climb the big mountains. ${ }^{14}$

In addition to climbing higher and harder mountains, the AAA needed to expand its pool of high-altitude mountaineers. To that end, Lambert was back in the Himalaya a year later with a group of six relatively inexperienced climbers. He had chosen a most appropriate introduction for the new recruits: two 'trekking peaks' of modest altitude within the Annapurna sanctuary.

The sanctuary, a high, glaciated valley nestled in the middle of the Annapurna Himal and encircled by a ring of spectacular peaks, was a good place for firsttimers. Access was via a short, straightforward trek from Pokhara and the base of the valley was not exceedingly high for the location of a base camp.

The term 'trekking peak' conjures in many people's minds the picture of a low Himalayan mountain of no great technical difficulty - in effect, a 'walk-up' suitable for trekkers unskilled in the techniques of alpine climbing. The term, however, is used by Nepalese authorities to describe a specific group of peaks, usually of moderate altitude but of greatly varying technical difficulty, that are open to climbing by foreigners without the necessity of liaison officers and the other bureaucratic accoutrements required for 'expedition peaks'.

Trekking peak expeditions are thus cheaper and less cumbersome to organise; the climbing, however, can be just as difficult and hazardous as that on any other Himalayan mountain.

Lambert first led his group to Tharpu Chuli (Tent Peak, 5000 m), just inside the entrance to the sanctuary. Their initial attempt was turned back by white-out conditions, deep snow and lack of acclimatisation. The team then turned their attention to Singu Chuli (Fluted Peak), a $6501 \mathrm{~m}$ mountain that presented a significant mountaineering challenge. Singu Chuli was first climbed in 1957 by Wilfred Noyce and David Cox, members of a strong British expedition that was attempting the nearby Matterhorn look-alike, Machhapuchhare. Since then, Singu Chuli has repulsed most attempts made on its summit.

Approaching the mountain from the north, the AAA team put in two camps, the second a bivouac, in an alpine-style attempt that reached $5950 \mathrm{~m}$ before being defeated by what Lambert described as 'appalling snow conditions'. ${ }^{15}$

14 P. Lambert, Interview.

15 Ibid. 


\section{Rape in the rice paddies Peter Lambert}

On the Annapurna Sanctuary expedition, one of the guys-Lawdie-was really sick most of the time. We didn't know why. We thought he had piles, and he thought he had piles, but no-one was willing to look. This was one of the big lessons I learned from this expedition: if someone is sick, you as leader look yourself.

We were at base camp and we got a French doctor, a woman, to look. But she didn't actually look or examine him; she just consulted him. We thought he'd been properly examined as she gave him all these suppositories. We thought Lawdie was going to be fixed. But it got worse....and worse.... and worse.

We finished the expedition and he was in absolute agony. He could hardly walk. Eventually, one night, whatever the problem was, burst; and filled the tent with an absolutely foul mixture of molten suppositories. The problem turned out to be an ingrown hair that had gotten infected, but we didn't know that at the time.

Then we went to an Italian doctor. He had a look and said, 'I'm not going to touch that; otherwise you're going to sue me.' So we went down to these bare stepped terraces-all the rice had been harvested. We put a mat down. Then he pulled his trousers down and leaned over the terrace looking up the hill toward the village. His legs were down below the terrace.

We were behind him trying to squeeze all the bad stuff out of his wound. Of course, I never touched him. I wasn't going to do it. I turned to his best mate-Wardie-they were Lawdie and Wardie, both Air Force-and I said, 'Wardie, you're his best mate. You can do the work.'

So we all supervised. We stood around respectfully concerned, albeit slightly amused, as Wardie was squeezing his mate's abscess. He was in absolute pain. Maila Pemba, our Sherpa, was there, and Maila was kept right out of it. 'This is a sahib's problem,' we told him. We just didn't want to involve him in something that was so personal. But he kept snooping around and asking what's wrong. We finally told him, and he said, 'Ah, very, very common. Let me have a look.' And he went in there and gave this thing one almighty squeeze. Lawdie screamed, absolutely screamed.

While he was screaming, there were a couple of Australian nurses walking along a ridge up on top. They looked down and asked, 'What's wrong? What's wrong?' They were really concerned. We said, 'We're OK. We're just working on him a bit.'

In the middle of this Lawdie screamed, 'They're raping me!' The nurses were horrified and promptly ran off. They thought we were doing something very animalistic down there on the terraces. We saw them later in Kathmandu and they wouldn't speak to us.

A few days later, he and two of his recruits returned to nearby Tharpu Chuli and succeeded on the rarely climbed East Face in 'interesting and spectacular climbing'.16

In 1985, the AAA further expanded its cadre of experienced Himalayan mountaineers with another trip to a group of Nepalese trekking peaks. Rick Moor was the leader of the seven-man climbing team that again ventured into the Annapurna region of central Nepal. Their objectives were Pisang Peak (6091 $\mathrm{m})$, Chulu West $(6250 \mathrm{~m})$ and Chulu East $(6200 \mathrm{~m})$ - three mountains easily 
accessible from the popular 'Around Annapurna' trekking route as it passed north of the main Annapurna massif. (The AAA originally had a permit for Kangguru, but did not take it up because of its significantly increased cost compared with trekking peaks.)

Pisang Peak was first to fall, as six of the seven team members struggled to the summit in what Moor said could 'only be described as full conditions' ${ }^{17}$ The descent was complicated by a blizzard, which pinned the climbers high on the mountain for a night. Chulu West was climbed in uneventful fashion with five members reaching the top. Lack of time and diminishing food supplies prevented an attempt on Chulu East.

The success of the Pisang/Chulu expedition was another step towards assembling a large, competent AAA Everest team. Four of the team members who had their introduction to Himalayan climbing on the trip-Moor, Mick Pezet, James Strohfeldt and Jim van Gelder (the last two civilians) - would be members of the ABEE. A fifth eventual ABEE climber, Andrew Smith, was a member of the Pisang/Chulu team and Peter Lambert's group that climbed in the Annapurna Sanctuary in 1984.

Himalayan peaks of moderate altitude, whether they were Nepalese trekking peaks or mountains elsewhere in Asia, seemed to be the order of the day for army climbers in the mid-1980s. In 1984, Steve Simpson joined Dave Evans and Phil Pitham of the Nilgiri team for an attempt on $6000 \mathrm{~m}$ Devachen, a beautifully shaped mountain near Dharamsura in the Kulu region of India.

The attempt on the North Ridge ended at $5790 \mathrm{~m}$ in spectacular fashion when Pitham suddenly ran into physical problems:

Something happened to me at $19000 \mathrm{ft}$. It must have been a mild version of cerebral oedema. I blacked out and went face first into the snow. Four hours of my life went missing. I got down to $16000 \mathrm{ft}$ and the lights switched back on again. I became aware again and was wondering why we were going down. That was the end of the trip. ${ }^{18}$

Undaunted by his close call, Pitham returned to the Kulu in 1985 with Sydney rock climber Frank Moon for an attempt on the East Ridge of $6451 \mathrm{~m}$ Papsura. They were joined in the region by Zac Zaharias, who was on leave from United Nations duty as an observer along the India-Pakistan border. The trio had a good look at the predominantly rock route, decided they did not like it and returned to their various duties after climbing another peak in the area.

17 Moor, R. 1985, Report on the army expedition to the Nepalese Himalaya 13 Sep - 15 Nov 85, Report no. R852-5-1(2), 19 December 1985, Australian Army Alpine Association, Canberra.

18 P. Pitham, Interview. 
While the AAA climbers were busy increasing their numbers with Himalayan experience, the Melbourne-based civilian climbers were also actively pursuing their preparation for the 1988 attempt on Everest. As he had been in the early 1980s, Mike Rheinberger was the most active of the group.

After previously confining his Himalayan mountaineering experience to the Kulu and Garhwal regions of India, Rheinberger journeyed to Nepal in late 1984 for three months of trekking and climbing. (A planned expedition to Pumori [7145 m] in 1983 was abandoned when he fractured an ankle early that year.) Rheinberger chose the winter months to experience the harsher conditions of that season. He began the trip in the Khumbu region of eastern Nepal, where he joined Greg Martin for an attempt on Kwangde, a $6187 \mathrm{~m}$ trekking peak near the large Sherpa village of Namche Bazaar.

Just the trip to base camp was somewhat of an epic as the pair crossed the seldom used Moro La directly opposite the airstrip village of Lukla and approached the mountain from the south. Their attempt, at the beginning of the winter season, was abandoned at just above $6000 \mathrm{~m}$ after a very cold bivouac.

The main thrust of Rheinberger's 1984 efforts, however, was aimed at Kangguru, a $7010 \mathrm{~m}$ peak in a remote region near the Tibetan border to the north-east of the Annapurna Range. The climb would be made in the heart of the winter season - the first time an Australian had attempted to climb in the most severe of the three Nepalese climbing seasons. If Rheinberger was after a taste of the extraordinary cold and vicious winds that winter in the high Himalaya had to offer, he could not have been disappointed.

Climbing with Martin, Englishman Mick Chapman and Sherpa Maila Pemba, he got his first blast at $6400 \mathrm{~m}$ :

[A]s we returned to the [VE24] tent we were concerned at the build-up of wind and its variable direction. The VE24 looked far from secure and we debated whether a snow cave might not be more appropriate, but compromised by erecting a substantial wall of snow blocks, three layers thick and about a metre high. Thus fortified, we turned in for what was a harrowing night with little rest. Thankfully, our wall survived more or less intact and protected the tent from what I believe would otherwise have been certain destruction.

Next day the wind scarcely abated and climbing was hardly conceivable. It was difficult to retain footing even on short comfort forays. The valley below was shrouded and plumes flew off the high Annapurnas. ${ }^{19}$ 
The summit attempt the next day by Rheinberger and Maila was stopped at about $6900 \mathrm{~m}$ by what Rheinberger described as 'not really climbing weather', with the wind 'gusting most powerfully'.

Around midday we reached the summit ridge. Ahead lay a long curving spine of hard packed snow, frequently smeared with the dull glaze of ice. To the left a rather alarming drop of several thousand feet took one's eye to the glaciers draining the main frontier range. To the right I looked down a steepish face towards the south east and the Manaslu group. The wind gusted and tore at my pack forcing a halting progress. Despite two sets of underwear, two pile jackets and parka, I was barely warm enough.

Still, conditions were bearable and we continued to progress. A further one and a half hours saw the ridge steepen sharply and extreme care was required in sensing the gusts and striving to maintain balance... At one point I clung to the ridge, axe and hammer well fixed and crampons well placed, only to feel myself being ever so slowly moved by a tremendous gust. It was probably only a matter of time before one of us mistimed a gust and was off. ${ }^{20}$

A few days later, Rheinberger and Martin were back up at the top camp for another summit bid. They found that the wind was just as strong and that the three-layer-thick protective ice wall around the earlier tent site had been destroyed. Conditions for this attempt were no better, as Rheinberger reported: 'If anything, the weather was worse than on the day of our previous attempt. It was dangerous to move unroped yet far too slow if we belayed. ${ }^{21}$ Again they retreated and abandoned the attempt.

After the expedition, Rheinberger was philosophical about the unsuccessful winter attempt on Kangguru: 'We had survived for another day; we had an exciting prospect yet in store; we had felt a touch of winter conditions and I was happier for the experience. ${ }^{22}$

The AAA adventures during 1984-85 and Rheinberger's Khumbu and Kangguru sorties were no doubt full of valuable lessons in Himalayan mountaineering. The winter Kangguru epic was particularly valuable in giving Rheinberger a taste of the very harsh conditions that existed on the upper reaches of Everest during any season. All of those experiences, however, lacked one vital ingredient in 
the preparation for Everest: coming to grips with the effects of the most extreme altitudes. There was only one way to get that experience and that was to climb on one of the Himalaya's 8000 m peaks.

In 1985, Rheinberger and his longstanding Melbourne colleague Peter Allen rectified that deficiency by joining a large expedition to the north side of $\mathrm{Mt}$ Everest: the NZAC Chomolungma expedition 1985 (see image 16.6). What better way to train for the ABEE than to have a preliminary go at the Big E itself?

The New Zealand expedition appeared to have an excellent chance of success. It had 14 climbers, the cream of Southern Alps mountaineering, it was backed by major sponsors at the level of NZ\$170 000 and was officially sanctioned by the NZAC. Brimming with confidence based on their vast collective experience on difficult and dangerous snow and ice, the team hoped to put a majority of members on Everest's summit via the West Ridge, from the northern (Tibetan) side.

What they had not reckoned on, however, was the mountain's extreme treachery in the post-monsoon season of 1985. Even by Everest standards, it was a horrific show of massive avalanches and sudden, vicious storms. Even so, the Australian and New Zealand climbers battled away for more than two months on three separate routes, only to retreat frustrated and exhausted with nerves shattered by conditions so full of risk they made many war zones seem like havens of safety in comparison.

The strong team put their initial efforts into the route up the West Ridge. Even very early in that attempt, it became apparent that the mountain was in a dangerous condition, as New Zealander Mike Perry reported: 'About three o'clock every afternoon cloud would come over from Nepal and then it would snow. Never much, maybe a couple of inches, but day by day this snow built up, pushing already loaded and dangerous slopes ever closer to that ugly moment when avalanche was inevitable. ${ }^{23}$

The first of those ugly moments came at night after several camps had been established on the ridge. Perry recalled:

That night, at 16 minutes past midnight, our strong conviction that we were on a safe route took a mortal blow. About 60 metres above camp 1.8 a complex of windslabs sheared off to a depth of about two metres. The afternoon snows had done their damage. In an instant, camp 1.8 disintegrated. The entire snow cave slid off and the tent, which was firmly tied to the fixed rope, was shredded.

23 Perry, M. 1986, ‘Qomolungma 1985', New Zealand Alpine Journal, vol. 39, pp. 49-56. 
In Camp 2 [a crevasse camp], 250 metres below, Toyota [the teams of four climbers each were named after major sponsors] was awakened by a freight-train roar as the outside two metres of their slope was sheared off and cascaded to the glacier 800 metres below. Graeme Dingle's crampons at the feet of his sleeping bag, attached by rope to a snowstake outside, were whipped out into the night never to be seen again. ${ }^{24}$

A day or two later, Perry's team returned to the mountain to replace the climbers that had narrowly escaped the big avalanche. 'In the now thoroughly unwelcome afternoon snowstorm, we crossed paths with Toyota on the fixed ropes. They looked drawn, the dark rings under their eyes telling their story more eloquently than words. ${ }^{25}$

Two members of Perry's team were the Australians Rheinberger and Allen. Their task was to push the route up to camp three and then beyond. While the two Australians did the lead climbing, Perry and Warwick Anderson set about making camp three as safe as possible by digging a snow cave deep into the slope to eventually replace the tents. Still, it was a dangerous site, and no matter how careful Rheinberger and Allen were in climbing above, there was a good chance they would trigger another slab avalanche (see image 16.7). In fact, as Perry pointed out, another slide was almost predictable:

As it happened the events of the following day were even more grotesque than we had feared. That next morning, 10 September, Peter and Mike climbed the 150 metre slope above the camp. As predicted, a slab a thousand metres wide and up to two metres deep broke off beneath their feet. Also as predicted, they avoided being swept down in the debris, which did run right over the camp. And Warwick and I happened to be in residence.

The sound of the slab break, when it came, was soft, understated, and almost marvellous in the way its terminal message was so gently delivered-a shout from Peter Allen arriving milliseconds later was utterly superfluous. Warwick, and I were well advanced at least mentally in our lunge for survival. He dashed into his incipient snowcave and I followed, honing in on the sound of his voice instants before it all came down over the top.

We were buried. The camp, of course, was devastated. In the filledin cave we were immobile, our heads together in a small air cavity, facing the prospect of impending suffocation with minds of an orderly 
demeanour and lungs that were definitely over-excited, until Warwick managed to straighten up one arm and punch it through the surface. His red-gloved hand enabled the others to find us.

We were soon dug out and shortly afterwards reported wryly to our much relieved leader, Austin Brookes, who had witnessed the avalanche from Camp 1, that not only had we failed to reach a Camp 4 site, but had accidentally demolished Camp 3 as well. In turn we were informed that the main body of the slide had swept right down to the glacier thousands of metres below, had swept across it and then collided with the lower few hundred metres of the slopes of Khumbutse opposite. We had been lucky our cave wasn't sheared off with it. ${ }^{26}$

That avalanche put a definitive end to the attempt on the West Ridge. The team was not, however, ready to call it quits yet. They shifted their attack to the massive North Face - the one the first Australian Mt Everest expedition had climbed 12 months earlier.

In 1985, however, conditions on the North Face were very different. Shaun Norman, another of the very experienced New Zealand climbers, observed that 'day after day big ones [avalanches] peeled down the Great Couloir and blasted the Australians' route' ${ }^{27}$ The incessant avalanches had changed the mood of the trip. Perry said:

Black humour abounded, the landscape glowered, and because avalanches had become a twenty-four-hour-a-day phenomenon, sleep was never quite relaxed. A sharp cry or the roar of an avalanche always produced an involuntary cringe and quickening of breath in me, and judging by the number of heads anxiously popping out of tents at such moments, I was not alone. ${ }^{28}$

The group tried to climb a route up a smooth snow slope between the North Ridge and the Australian Great Couloir route, but if anything, the avalanche risk had worsened. The experience of Mike Rheinberger and Warwick Anderson, climbing at about $7000 \mathrm{~m}$, was illustrative. According to Perry, they 'had windslab cracks open up below, level with, and above them when they were descending from Camp 3 after a snowfall. Fortunately, nothing moved-they would have had no run-out.' ${ }^{29}$ 
A few more close calls and the North Face route was abandoned. Perry expressed the feelings of the team: 'By now the expedition had escaped fatal accidents so many times that it made our heads spin - surely we should accept our luck and walk away alive. ${ }^{30}$ There was, however, still one more session of avalanche cheating before they eventually returned to the Antipodes. Five of the climbers mounted a last-ditch effort to get up the North Ridge but were again turned back at about $7000 \mathrm{~m}$ - this time by a severe early winter storm.

The 1985 New Zealand Everest expedition was a most sobering experience for all involved. It is a classic example of the old adage that mountaineers do not conquer mountains, rather it is the mountain that decides when it will be climbed and by whom. The best of New Zealand's considerably skilled alpine climbers could not get much above $7000 \mathrm{~m}$.

The two Australians, Rheinberger and Allen, acquitted themselves very well. Both climbed strongly and did not flinch in the face of very high risk. Indeed, Rheinberger reached the high point on all three attempts - the only climber on the expedition to do so.

Finally, at least two of the ABEE participants had obtained some high-altitude experience. Although none of the attempts got much above $7000 \mathrm{~m}$, collectively, they represented a considerable amount of experience in climbing in harsh and dangerous conditions. The other ABEE climbers would need more such experience. So, the next year, more returned to the high mountains of Asia, and this time it was the turn of the AAA component of the team to rub noses with one of the giants of the Himalaya. 


\section{Training on the big ones}

It was 1986, six years since Pat Cullinan led his Perth-based Special Air Service (SAS) troops to Nepal for the attempt on Gauri Shankar. During that time, his colleagues in the eastern states had made considerable progress in their preparations for Everest. They had climbed Denali in Alaska in addition to several trekking peaks in Nepal. Nilgiri North was a real achievement - a $7000 \mathrm{~m}$ peak and by a reasonably difficult route. Just as Tim Macartney-Snape, Lincoln Hall and their fellow climbers found in the early 1980s, what they really needed before Everest, however, was a hard climb on an $8000 \mathrm{~m}$ peak-or something very close to it. And Everest was only two years away.

The Army Alpine Association (AAA) high-altitude test was to be Broad Peak, one of the world's 14 giants of more than $8000 \mathrm{~m}$. Located in the spectacular Karakoram Range of Pakistan, Broad Peak is $8047 \mathrm{~m}$ high and is considered one of the more straightforward of the 8000-ers - at least technically. Nevertheless, it would severely test the climbers' stamina and ability to cope with extreme altitudes and, as many mountaineers had earlier found on Broad Peak, the long summit ridge was not exactly a doddle.

Cullinan was the leader of the 14-man Broad Peak expedition, which included most of the AAA Everest aspirants. Cullinan's deputy was Brian Agnew, who was the climbing leader of the 1981 Ganesh IV expedition and had participated in the 1982 farce on Peak 29 organised by the British Army. Other experienced AAA climbers included Zac Zaharias, a veteran of trips to Ganesh IV, Denali, Nilgiri North and Papsura; Peter Lambert, who had led the 1984 Annapurna Sanctuary expedition in addition to climbing Denali and Nilgiri North; and Jim Truscott, a foundation member of the AAA and a survivor of the Ganesh IV avalanche. They were joined by Terry McCullagh, another Nilgiri North veteran, and Rick Moor, Derek Murphy, Mick Pezet and Jim van Gelder - all of whom had been on trips to Nepalese trekking peaks. Tony Delaney was the expedition's doctor and Norm Crookston the base camp manager-coopted at short notice from an AAA trek in the Baltoro region at the same time.

The strength of the team was boosted considerably by the addition of two civilian mountaineers: Mike Rheinberger and Jonathan Chester. The inclusion of civilians in an AAA expedition followed the examples set by the Nilgiri North and Ganesh IV expeditions and was another vital step in building the rapport between civilian and military climbers that was necessary for success on Everest. In addition, van Gelder, an Army Reservist, had established links of 
his own as he was just coming off a civilian expedition to Kangchenjunga, the world's third-highest mountain. That experience had given him a very valuable taste of climbing at high altitude.

Rheinberger, who had been very active throughout the 1980s, was easily the most experienced Himalayan mountaineer of the team (see image 17.1). He had climbed Dharamsura and Changabang, had been very close to the summits of Kwangde and Kangguru and had climbed high on Nanda Devi and Everest.

Chester had been on two previous Himalayan expeditions - ironically, both to Annapurna III in central Nepal. The first was the ill-fated 1980 trip, in which three of his colleagues were killed in an avalanche and a fourth, Faye Kerr, died in India shortly after the expedition. The second, three years later, was rather more successful.

Another of the 1980 team, Steve McDowell, joined Chester in the 1983 attempt. The small group was completed by Adrian Teague, a civil engineer; David Wagland, a geologist; and Steve Bunton, a former teacher - all of whom were on their first mountaineering expedition to the Himalaya. Bunton, however, was no stranger to abseiling and climbing up ropes, as he was one of Australia's most experienced cavers. The caving techniques would undoubtedly prove useful on the fixed ropes, but Annapurna III was about to deal out treatment he could scarcely have imagined in the depths of caves.

With the tragedies of 1980 still somewhat fresh in their minds, Chester and McDowell took their team to the other side of Annapurna III, to the South-West Face. It was a route steeper and more difficult than the north side but one less likely to hold large amounts of snow and thus less likely to send avalanches roaring down the slopes. Access was easier too, as the approach was from Pokhara via the very popular Annapurna Sanctuary trek.

Progress on the lower slopes leading to the South-West Face was initially rapid, but then freakish, heavy post-monsoon snowstorms suddenly made the climbing very treacherous. It appeared that the gods of Annapurna III had singled out Chester and McDowell for another dose of nasty treatment. In a rather frightening repeat of the 1980 experience, avalanches began tumbling down. Chester described one as 'a great wave of snow that came down', ' while another buried their tent, which was supposedly tucked safely under a rock overhang. They managed to dig out of that one and descend to base camp, lucky to be alive.

1 Sheridan, G. 1984, 'The icy hell of Annapurna', The Bulletin, 21 February 1984, pp. 49-54. 
The team persevered, however, and with time running short, mounted one concerted push towards the summit after the series of storms had abated. Bunton described the difficulty of ploughing back up through the deep, newly fallen snow to re-establish the higher camps.

Ever known you were waking up to the worst day of your life? Four men in a dome tent. The chill breeze blowing as we make our 3 am start. After the cramped chaos we moved quickly up to the end of the trodden trench. The onerous task of breaking trail took us $13 \frac{1}{2}$ hours before Camp II was reached. It took a further three hours to excavate and re-erect them. Tomorrow would probably be worse, we thought, as we crashed into our sleeping bags, and we were right. After a whole day's battle we only ascended $400 \mathrm{~m}$ of fixed rope and regained the ridge which led to Camp III. A day later the camp was similarly resurrected from beneath the deep snow. ${ }^{2}$

After regaining camp four, located in a bergschrund at the base of the upper face, Chester, Bunton, McDowell and Teague made another 3am start for the final push to the summit. They climbed the rest of the face, but it took longer than they had anticipated. Bunton decided to retreat to camp four, while Chester, McDowell and Teague pressed on. They were forced to bivouac, however, at the top of the face. It turned out to be a harrowing night as they could not get their stove to work and so were forced to survive, in a severely dehydrated state, for about 24 hours without fluids. To top it off, Chester had spilled some kerosene on his gloves while he was fiddling with the stove and heat loss from the evaporating fluid caused frostbite in his hands. Teague also suffered frostbite, but to his feet.

In the morning, the climbers were forced to descend. Although the summit was only a few hundred metres away up a gently angled ridge, it would have been most foolhardy to continue in their dehydrated, frostbitten state. Their ordeal, on the other hand, was not quite over.

At camp four, their much-needed rest was suddenly interrupted by large thunderheads that rose from the valleys, drifted onto the mountain and began belting the South-West Face with more snow. As the night wore on, small avalanches began to hit the tent. About $11 \mathrm{pm}$, Bunton and his colleagues, who had taken sleeping tablets to ensure a night's rest, were forced to abandon the camp and start climbing down in the dark. Bunton recalled the epic retreat:

No longer was spindrift hitting the tent, it was now being covered in a sound-proof coating of fresh-fallen snow. It was 10:30 pm and we were slowly being buried. At 11:30 we decided to abandon camp. At 12:30

2 Bunton, S. 1984, 'Annapurna III', Action Outdoor, August/September, pp. 40-5. 
we quit the tents as small avalanches began to fill us in. We could only rescue one tent and left the other to be buried. On the tail of the fixed rope we abandoned Camp IV flinging ourselves down the face clipped into a cows-tail and karabiner.

Re-establishing ourselves on our feet we found ourselves soloing down the steep, treacherous slopes to Camp III. We fought to proceed into the teeth of the blizzard, snowflakes stinging our eyes and faces, the cold numbing noses and worsening the frostbite injuries sustained the previous night. The most frightening prospect was the squeaky snow upon which we trod. We were in grave danger of setting off the whole slope in one all-consuming avalanche. We climbed as nimbly as possible but with the others full of sleeping pills, I felt as though I was herding a group of zombies. ${ }^{3}$

The exhausted climbers managed to battle through the combined effects of darkness, blizzard and sleeping tablets to get off the mountain safely. This time they had escaped Annapurna III, and indeed had climbed the South-West Face and had reached $7300 \mathrm{~m}$, only a short distance from the top.

Chester brought more than just the experience of his two Annapurna III trips to the 1986 Broad Peak expedition. Having made several journeys to Antarctica and the sub-Antarctic islands, he was no stranger to the harsh conditions of a Himalayan 8000 m peak. On his trip to Heard Island during the 1982-83 summer, Chester climbed Big Ben, the highest mountain on Australian territory-an adventure that had all the ingredients of a Himalayan climb apart from the altitude.

If the Annapurna III trip was a rugged warm-up to an $8000 \mathrm{~m}$ peak for Chester, the attempt on Kangchenjunga early in 1986 was a real eye-opener for the relatively inexperienced Jim van Gelder, a doctor interested in high-altitude medicine as well as mountaineering.

Unlike nearly all other Australian Himalayan mountaineers, van Gelder made the jump directly from rock climbing to the high Himalaya without the normal period of apprenticeship in the Southern Alps of New Zealand. He was very much a do-it-yourself climber, first learning rock climbing at age fifteen on the crags around Canberra by 'reading about it in a book and then going out and doing it myself'. ${ }^{4}$ Years later, he met the AAA's Rick Moor, who was organising a trip to Nepal, and talked his way on as the expedition doctor. That was the expedition in the post-monsoon season of 1985 that climbed Pisang Peak and Chulu West, two trekking peaks north of the Annapurna Himal.

3 Ibid.

4 J. van Gelder, Interview. 
To go from a trekking peak to the world's third-highest mountain was probably an even bigger jump than going from rock climbing to a trekking peak, but van Gelder was undaunted by the prospect of tackling Kangchenjunga (8598 $\mathrm{m})$ when he received a last-minute invitation from Mike Groom. With attempts on Trisul and Annapurna II under his belt, Groom was the most experienced climber of his small team. The others were Shane Chemello and Chris Frost, both on their first Himalayan expedition, and van Gelder's friend James Strohfeldt, who had also been on the 1985 Pisang/Chulu trip.

So, among the five there were only three Himalayan expeditions to their credit and Groom was the only one to have climbed to $7000 \mathrm{~m}$. That lack of experience, combined with the very short lead time of six months to organise the trip (Groom picked up the permit when Peter Hillary had to cancel his planned expedition), meant that Kangchenjunga was an even bigger challenge than it ordinarily would have been. Not surprisingly, things began to go awry from the start.

The walk-in became somewhat of an epic when early season snows and a dearth of able-bodied porters, due to a lack of money to pay them, forced team members to shuttle loads for two and a half weeks just to get to get to base camp. Despite that delay, good progress was made early on the mountain and two camps were quickly established and stocked with another round of load carrying. The climbers were attempting the South-West Face of Kangchenjunga, which was not a particularly difficult route but was rather long and would force the climbers to spend a long period above $7000 \mathrm{~m}$. Before they could gain the upper reaches of the mountain, however, and make an attempt on the summit, a series of storms, with heavy snowfalls and the consequent avalanche danger, forced them back down to base camp.

Normally a spell at base camp could be a relaxing, recuperative time of rest and good food, but for the Kangchenjunga team it was almost the opposite. Their cook, Trising, was a rather active chap with a morbid curiosity. One day he dug up a grave near the mess tent and the climbers, wandering in for a meal, were confronted with 'the uncovered outline of a body steaming in the hot sun', Groom said. 'Trising seemed quite pleased with his find as he poked it with a stick. I turned away, followed by Trising, who ran after me with his hands clamped firmly over his nose and mouth. ${ }^{5}$

Remains of dead climbers notwithstanding, the mess tent was not a very pleasant place anyway, as van Gelder recalled: 'Due to our financial straits, we had only

5 Groom, M. 1986, ‘Himalayan apprenticeship', Wild, no. 22 (Spring), pp. 55-6. 
lentils and rice, and someone had spilled kerosene in the cooking oil so we had kero-flavoured fried rice for meal after meal. There was a bit of flour left too so on occasion we had some kerosene-flavoured chapattis as well.' ${ }^{6}$

After a lengthy stay at base camp, morale had dropped. Strohfeldt summed it up: 'we were under-financed, under-experienced, under-led and under a hell of a lot of snow.' 7

When the storms cleared, there was still plenty of time to climb the mountain before the monsoon set in; however, money and food had virtually run out so mid-May was set as the date the porters would return and the expedition would leave the mountain. With that sort of constraint, there was time for only one more attempt on the summit.

In conditions not unlike Chester and his team faced in their last-ditch attempt on Annapurna III, Groom, Chemello and van Gelder forced their way through deep snow to re-establish camps one and two and then pushed higher to set up two more camps, the highest at $7000 \mathrm{~m}$. From there, the three launched their bid for the top of Kangchenjunga.

Chemello and van Gelder set personal altitude records, but it was Groom who came closest to the summit:

I made good progress without a pack on my back and soon found myself at the bottom of the Gangway, a gully that leads almost to the summit, and normally containing bare ice. I found the ice covered by 30 centimetres of snow, which slowed my progress on the Gangway. I left my empty water bottle at 8,000 metres and continued, barely managing 10 or 15 steps between rests. When I reached 8,200 metres the summit started to disappear in cloud, but I slowly made my way up to the 8,400 metre level. It was 2:30 pm and I had to leave the Gangway to traverse right across mixed ground to the summit. I was so near to the summit but my will power and strength were almost gone. I made a few more steps, rested, then a few more, before stopping to think what I should do. Clouds raced past and the wind was blowing snow in all directions. I pulled my head in tight to cover my mouth and headed down. I had expected that it would be easier going down but I still had to stop for regular rests.

About an hour down the Gangway I stopped to look back up. The summit was clear and calm. ${ }^{8}$

6 J. van Gelder, Interview.

7 J. Strohfeldt, Interview.

8 Groom, 'Himalayan apprenticeship'. 
Considering the size of the mountain and the relative inexperience of the team, it was a tremendous effort. Groom narrowly missed getting to the top of Kangchenjunga and van Gelder climbed past the magic $8000 \mathrm{~m}$ mark-in fact, to about $8200 \mathrm{~m}$, which was higher than the summit of Broad Peak. He would not have to wait long for the chance to repeat that feat. Just three and a half weeks after returning to Australia from the Kangchenjunga trip, van Gelder was on an airplane heading for Pakistan and the great Karakoram Range with the AAA Broad Peak expedition.

Pakistan and the Karakoram were a new experience for all of the Broad Peak expedition members; their previous Himalayan climbing trips had been to the Nepalese, Indian or Tibetan segments of the range. Containing four of the world's $8000 \mathrm{~m}$ peaks, the Karakoram is arguably the Himalaya's most spectacular group of mountains. It features not only a wild array of massive snow and icecovered peaks - Chogolisa, Skyang Kangri, Baltoro Kangri (Golden Throne) and the Masherbrum and Gasherbrum groups - but a liberal sprinkling of the most steep and apparently impregnable granite spires, walls and battlements to be found outside Patagonia: Lobsang Spire, Mustagh Tower and the great Trango Tower. Presiding over this most marvellous of mountain scenes is K2, the world's second-highest peak and a mountain more difficult to climb and more beautiful to look on than Everest.

Broad Peak stands near the centre of the Karakoram Range, next to K2 and not far from Hidden Peak and Gasherbrum II, the other $8000 \mathrm{~m}$ peaks. Access to Broad Peak and the central Karakoram is via the Braldu Gorge and Baltoro Glacier, an arduous trek but surely one of the most magnificent mountain walks anywhere in the world.

Before the Australian Broad Peak aspirants could begin their journey into the heart of the Karakoram, they had to get through Pakistani bureaucracy, get to Skardu and the trailhead and then organise porters. The first task proved somewhat tricky, as Rheinberger recalled:

In Rawalpindi we were quartered at the famous Flashmans Hotel, a comfortable old establishment growing used to the peculiar demands of a mountaineering expedition. While there we packed the food, carefully organised by Mick Pezet in Australia. With the fierce heat of Pakistan, Mick's pride and joy, viz three legs of pork, did not survive. Needless to say, it required great tact to dispose of those stinking parcels in Muslim Pakistan. ${ }^{9}$

9 M. Rheinberger in Cullinan, P. 1987, Report of the Army Alpine Association Broad Peak (8047 metres) expedition, Pakistan, 28 June to 7 September 1986, Report no. R852-5-2, Australian Army Alpine Association, Canberra. 
Another problem arose at the trail head. With 1986 a record year for the number of expeditions to $\mathrm{K} 2$ and the Karakoram in general, there was a dearth of ablebodied porters to carry gear up the Baltoro. A bit of Australian resourcefulness solved the problem, however, as Cullinan commandeered some time on Radio Pakistan to broadcast his plea and he and Chester scoured about 20 local villages in search of porters. It was a solution typical of the AAA Broad Peak expedition, which turned out to be a particularly well-organised outfit. Little did they realise at the start of the walk-in that their organisational skills and medical supplies would literally be lifesavers. It was to be the most tragic season in Karakoram mountaineering.

Aussie resourcefulness came to the fore again on arrival at Broad Peak base camp. An early courtesy call to K2 base camp was quickly followed by what Cullinan called

deviously planned foraging expeditions...A captured elaborate Spanish tent which could fit up to 20 persons became our luxurious dining area in which we could dine on exotic captured items such as German sausage, smoked oysters, pate, biscuits, herring, Korean tea, chocolate and Spanish olives. It's a wonder we ever got onto the mountain! ${ }^{10}$

The scavenged gear was obtained from the dumps left behind by other expeditions. No doubt the results of the raids were a great relief to van Gelder, who a couple of months earlier had, at Kangchenjunga base camp, been forced to subsist on a diet of kerosene-flavoured fried rice.

The Aussie resourcefulness in obtaining food from K2 base camp dumps was perhaps born of necessity. Several climbers commented later on the paucity of food on the Broad Peak trip. In fact, Peter Lambert said, 'This was the first expedition I had been on where I actually lost weight before I reached base camp! Without the scrounging we would have definitely run out of base camp food and have had to leave well before we could climb the mountain.' ${ }^{11}$

Despite the problems with food, the team did get onto the mountain and made steady progress up the bulky peak. They approached the climb in the more traditional siege style, with four camps placed successively higher up the West Face/Ridge route, a moderately angled route used by most parties on Broad Peak. The climbing was carefully organised and executed, with two teams of mountaineers alternating (see images 17.2 and 17.3), one in the lead and the other stocking the previously established camps. Shortly after camp four was put in at $7500 \mathrm{~m}$ high on the face, one of the teams - consisting of Zaharias,

10 Cullinan, Report of the Army Alpine Association Broad Peak (8047 metres) expedition.

11 P. Lambert, Interview. 
Agnew, McCullagh, van Gelder, Truscott and Lambert - was at the camp in position for a summit attempt. Cullinan, Rheinberger, Chester, Delaney, Murphy and Pezet were in residence at camp three at $7100 \mathrm{~m}$.

Early on the morning of 16 August, a clear but particularly cold morning, the higher team set out for the summit, following German climber Michel Dacher, who was on the same route and had, in fact, spent the night with the Australians. The cold was intense and McCullagh and Truscott, who retreated from their early morning start, were back at camp four when Rheinberger and Chester, moving up from below, arrived. The pair set out again with their colleagues from camp three, but again Truscott was forced to retire from the summit bid when he felt too tired and lethargic to continue.

Rheinberger and Chester, joined also by Cullinan from camp three, continued on through camp four to push on towards the top themselves. They discovered that all of the interesting climbing on Broad Peak was near the summit, as Rheinberger recounted:

The route from Camp 4 towards the Col skirted an evil looking crevasse and then took a straightforward line up an ever steepening snow slope. Beneath the col the last $100 \mathrm{~m}$ was quite steep, perhaps 50 degrees near the top, until Jonathan Chester, Pat Cullinan and I emerged onto the summit ridge, the border of Pakistan and China, and a splendid view over the western Sinkiang plains...

The summit ridge reared dramatically towards the south... By now it was mid-afternoon and the weather was clear and settled - a beautiful day. To the southwest some light cloud was visible but there appeared no real threat for the time being.

The summit ridge was steep and dangerous in places with a dramatic drop of 2,500 m on the Chinese side, sometimes corniced, and a mixture of broken rock and softish, unconsolidated snow. In places, remnants of old fixed rope had to be carefully tested before any reliance was placed on them.

As I moved along this ridge, an appreciation of my situation sank in. Here, above 8,000 $\mathrm{m}$ on a perfect day feeling good-a great thrill.

The day wore on and I began to meet returning climbers - firstly Michel Dacher, then Zac Zaharias, who was the first of our group to the top, Terry McCullagh, who made a very fast trip, Peter Lambert and Brian Agnew.

After about 3 hours, I neared the true summit. Ahead slightly were Jonathan and Jim van Gelder and a German couple. Behind were Pat 
and Karl [another of the German climbers]. The Gasherbrums directly ahead. Chogolisa, Masherbrum and far to the west, the huge bulk of Nanga Parbat.

On the top congratulations and photographs as Pat Cullinan joined us. Then the prospect of a long descent. It was now almost 6:30 pm and Karl was still about $200 \mathrm{~m}$ from the top. ${ }^{12}$

The last statement gives little hint of the epic about to unfold. Karl Fassnacht, the German climber, never made the summit. In fact, he very nearly did not return from Broad Peak. If it had not been for a decision made by Pat Cullinan a few days earlier, Fassnacht would undoubtedly have perished on the summit ridge.

Cullinan and his team-mates were confronted with a dilemma common to mountaineers facing a very long summit day and possible bivouac. If they took enough gear to ensure a safe and relatively comfortable bivouac, the excess weight would likely slow them enough that they would be forced to bivouac. It would become a self-fulfilling prophecy. If, however, they travelled as light as possible to optimise speed and thus avoid a night out, they would be in dire straits if some unforeseen event forced them to bivouac.

All but Cullinan of the Australian Broad Peak climbers opted to travel lightly on the summit day. 'We took virtually nothing the summit day,' Zaharias said, 'and we had a "turn-around time". Either we made it by that time or we came down. But Pat was going to climb Broad Peak. He took an enormous pack: bivvy bag, gas stove, everything under the sun.'13

Cullinan's performance was a harbinger of things to come on Everest. Showing a fierce determination to keep on going no matter what obstacles were thrown in his way, Cullinan plugged away and by the end of the day was on the summit of Broad Peak (see image 17.4). He was the last of the Australians to make the top, but he got there. And, his decision to haul up full bivouac gear - a rather questionable decision according to conventional mountaineering wisdomproved to be a lifesaving one for Fassnacht. Cullinan takes up the story:

I had been climbing continuously from $5.30 \mathrm{am}$ to $6 \mathrm{pm}$, when I reached the summit. I started descending about 6.30pm. About $200 \mathrm{~m}$ from the summit, I met Karl Fassnacht, one of the German climbers. He seemed to be in a bad way, but we couldn't communicate as I spoke no German and he spoke no English.

12 Rheinberger, M. 1987, 'Broad Peak 1986', New Zealand Alpine Journal, vol. 40, pp. 91-2.

13 Z. Zaharias, Interview. 
He turned around and started back with me. The rest of his team had left him. He was a good climber, so the other Germans assumed he would be able to get off the mountain himself.

We were only $400 \mathrm{~m}$ from the top when it started to get dark. At that point the summit ridge is very narrow with big drops on either side. He stopped and began to clear an area. I was trying to get him to keep moving, to get us off the mountain as fast as we could, but he wouldn't budge.

Luckily I found a hole along the ridge. We spent the night there sitting on our packs. Ironically, I learned a week later from the German expedition leader that Karl's pack was filled with warm clothing. He didn't put any of it on during the night! ${ }^{14}$

Meanwhile, the absence of Cullinan and Fassnacht was causing some worry, as Rheinberger reported:

Chester, van Gelder and I waited at the Col until, after two hours, we concluded that the pair had bivouaced or that a disaster had overtaken them. Either way we were best advised to return to Camp IV, which we did late in the evening. Chester and van Gelder, feeling poorly, continued to Camp III while I decided to wait at Camp IV. ${ }^{15}$

Cullinan continued:

The next day, we descended to the col at $7800 \mathrm{~m}$. There I boiled some water and we waited for a few hours. He couldn't eat or drink; he was in a very bad way. I then had no choice but to start lowering him in his bivvy bag down the mountain as a dead weight. ${ }^{16}$

Fortunately, late in the day, the German leader, Sigi Hupfauer, and Rheinberger, who had been waiting at camp four and who had heard Cullinan's shouts, arrived and helped Cullinan get Fassnacht down to camp four. There, Rheinberger administered dexamethazone (a treatment for pulmonary oedema) to Fassnacht, who was suffering badly. The next day, they all reached camp three, where Tony Delaney administered oxygen to Fassnacht and rendered further medical attention. A storm kept the climbers pinned at camp three for two more days before they completed the descent, reaching base camp on 22 August after spending a further night at camp two.

14 P. Cullinan, Interview.

15 M. Rheinberger in Cullinan, Report of the Army Alpine Association Broad Peak (8047 metres) expedition.

16 P. Cullinan, Interview. 
There is little doubt that Pat Cullinan saved Karl Fassnacht's life and in doing so he put his own life at considerable risk. Had a storm arisen while the pair was bivvied on the summit ridge, they would have been in deep trouble. Cullinan was later awarded the Star of Courage medal for his rescue.

The rescue of Fassnacht was not the first time the well-equipped and organised Australians, particularly their very competent doctor, Tony Delaney, came to the aid of stricken climbers. Earlier a pair of Yugoslav climbers, on the same route on Broad Peak, received oxygen and other medical help from Delaney at camp one after they returned from the summit suffering frostbite, dehydration and exhaustion. They were subsequently looked after at the Australian base camp for a fortnight until they could be evacuated by helicopter.

Delaney also came to the aid of Jonathan Chester at base camp. 'Jonathan was suffering from severe colic,' Brian Agnew recalled. 'He was in the tent next to us. He'd take air into his stomach and then belch it back up. He was in a very bad way. Delaney gave him a few jabs and sorted him out. Tony probably saved him. ${ }^{\prime 17}$

Chester also had problems earlier on the descent from camp four to camp three. Suffering from dehydration and altitude sickness, he tripped and slid down the snow slope towards ice cliffs. Fortunately, he was able to self-arrest in time. Peter Lambert then administered an injection of dexamethasone, as Rheinberger had done for Fassnacht.

The biggest problems, however, were not occurring on Broad Peak but on neighbouring K2. During the summer of 1986, one of the most amazing sagas in Himalayan climbing history was unfolding on the world's second-highest mountain. Twenty-seven climbers - a record - scaled K2 during that season, but just as the triumphs were mounting up, so too was a series of mountaineering tragedies of truly horrible dimensions. Thirteen climbers lost their lives on K2 and the circumstances surrounding many of the deaths triggered a barrage of criticism, second-guessing and soul-searching among the Himalayan climbing community.

First, two Americans were killed by an avalanche, followed by the disappearance of a French husband-and-wife team high on the mountain. A Pole fell from the Abruzzi Ridge after reaching the summit via the South Face and one of his countrymen, on the South-South-West Ridge, plunged to his death when he abseiled off the end of a fixed rope. A local high-altitude porter was killed by a rock fall. Perhaps most tragically of all, Italian solo climber Renato Casarotto died minutes from safety when he fell into a crevasse near base camp. 
Worse was to come. As if K2 were exacting one final, horrible price from a climbing community already reeling from disaster, six experienced mountaineers of three nationalities, including well-known Britons Julie Tullis and Alan Rouse, perished high on the Abruzzi Ridge in a bizarre combination of events: makeshift partnerships, haphazard logistical arrangements, muddled communication, misguided ambition and misjudged weather conditions.

Experienced British climber Jim Curran, who chronicled the events in his excellent book K2, Triumph and Tragedy, was at K2 base camp throughout the season. When Austrians Willie Bauer and Kurt Diemberger stumbled off the Abruzzi Ridge as the only survivors of the final tragedy, Curran was almost too overwhelmed by the latest shocks to be of much help.

Providentially, Delaney and Rheinberger were on their way to K2 base camp just at the right time. Curran described their arrival:

At last to my relief, figures, like the cavalry at the end of a western, appeared on the horizon. Thank God. It proved to be members of the Australian Army Broad Peak expedition, whom I had met before. They had come up to K2 Base Camp to find out the latest news. They couldn't have timed it better. They had brought materials for an improvised stretcher. They were calm, capable and confident. ${ }^{18}$

British climber Don Whillans once said of an expedition doctor, during a trip to the Gangotri region of India, 'Expedition doctors are either good doctors and lousy climbers or lousy doctors and good climbers. This bloke is neither.' ${ }^{19}$ Tony Delaney, on the other hand, was very competent at both. If ever there was an expedition doctor who deserved as much credit as the climbers, it was Delaney, who provided some much-needed emergency medical aid in the upper Baltoro in 1986 .

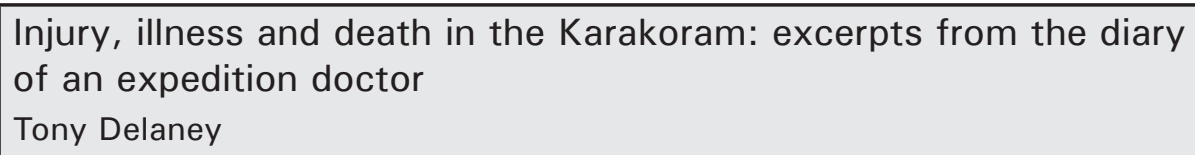

FRI 27 JUN: I had left my sports medicine practice at 1700, Charlotte Pass, in the Snowy Mountains and drove to Sydney, arriving early am.

SAT 28 JUN: Final immunisations administered to various team members at Mascot Airport.

WED 2 JUL: We proceed by 'Magic Bus' to Gilgit and Skardu-22 hours on the Karakoram Highway, a masterpiece of engineering which requires the distribution of a few anti-nauseants. Those team members who ate injudiciously from road-side stalls also required anti-nauseants, plus fluids and metronidazole.

18 Curran, J. 1989, K2, Triumph and Tragedy, Grafton Books, London, p. 157.

19 D. Whillans in Child, G. 1988, Thin Air, Encounters in the Himalayas, Patrick Stephens, Wellingborough, England, p. 23. 
SAT 12 JUL: Contestants in the Himalaya Super Marathon pass through, mostly in good shape and hydration, with some obviously feeling the effects of moderate altitude. I made a $10 \mathrm{~km}$ run with the women's 50 mile world record holder and enjoy the benefit of one extra week's acclimatisation to $8,500 \mathrm{ft}$.

[Delaney was part of a rear party bringing up supplies left behind due to a delay in obtaining porters.]

MON 14 JUL: Rest of porters arrive and we set out to rejoin the team. I commenced a regular evening sick parade, before dinner, which enabled us to treat porters early, and keep tabs on the unfit. This proved of great value to the porters' morale and helped prevent porters' strikes which are the bane of any expedition and usually are timed with the skill of a pre-Christmas brewery strike.

FRI 18 JUL: Proceed to Paiju. The last stand of trees for $80 \mathrm{~km}$. The number of treks and expeditions going into Karakoram, allied with no latrine or garbage dumps, leads to faeces and rubbish being scattered all over an otherwise lovely area.

MON 21 JUL: Move over Baltoro glacier toward Concordia. The incidence of altitude headaches amongst porters climbs to $40 \%$. Aspirin dispensed plentifully.

THU 24 JUL: Large avalanche down the central gully of Broad Peak sent Jonathan Chester and Mike Rheinberger into a spring. They also find the body of a German-Canadian, who died in an avalanche 3 years previously. The glacier disgorged him. He was subsequently reburied by Jim Truscott and Derek Murphy.

SUN 27 JUL: I carry a leaking jerry can of kero to Camp 1 and feel nauseous all the way. I wondered how much was due to altitude and how much due to the kero!

WED 30 JUL: Load carry to Camp 2. Depart Camp 2 at 1150 . Await a Yugoslav climber, Rado, at Camp 1 who is suffering from dehydration and 3 degree frostbite to his fingertips. Rehydrate him with 2-3 litres of fluids, apply oxygen by mask. Descend with him to Base Camp and dress his frostbite.

FRI 1 AUG: Hike up to K2 Base Camp, conversations with Austrians, Koreans, Brits. 3 Koreans, Alan Rouse, Kurt Diemberger, Willie Bauer, Julie Tullis, two Austrians and a Polish woman hope to reach $\mathrm{K} 2$ summit in 2-3 days. Voytek, a Pole, falls off the end of a fixed rope to his death during a night descent.

SUN 3 AUG: 3 Korean climbers attain summit of $\mathrm{K} 2$.

MON 4 AUG: Al Rouse, Julie Tullis, Kurt Diemberger, Willie Bauer and another Austrian summit K2.

TUE 5 AUG: Weather deteriorates, two Yugoslavs missing on Broad Peak.

WED 6 AUG: 2 Polish climbers reach K2 Base Camp after an epic 4 day descent.

THU 7 AUG: Yugoslav rescue party returns with its two missing members. We treat them for mild frostbite and dehydration.

SAT 9 AUG: 7 still missing on $\mathrm{K} 2$.

TUE 12 AUG: Willie Bauer regains K2 Base Camp after a terrible 8 days at over $8000 \mathrm{~m}$.

WED 13 AUG: Mike Rheinberger and myself go to K2 Base Camp. Kurt Diemberger is in very poor condition at Advanced Base Camp. I organise porters, Dr Jong of the Korean expedition, and skis, climbing rope and a sleeping bag. We ascend the Godwin-Austen glacier to meet Diemberger and carry him back to K2 Base Camp, where we dress his frostbitten hands and feet and rehydrate him. 
THU 14 AUG: Bauer and Diemberger much better. Awaiting helicopter evacuation. We have given up hope for remaining group on K2. I climb to Camp 2 [on Broad Peak].

SAT 16 AUG: Zac, Jim van Gelder, Peter Lambert, Brian Agnew, Terry McCullagh, Pat Cullinan, Jonathan Chester, Mike Rheinberger reach summit. Pat Cullinan encounters Karl, a German climber who is suffering high altitude cerebral oedema on the summit ridge of Broad Peak (8000 metres + ). Pat has extreme difficulty in communicating to a non-English speaking German with scrambled thinking (due to HACE) and they bivouac out. Pat leads him down to the saddle.

SUN 17 AUG: Most of the team return to Camp 3. I send Mick Pezet and Terry McCullagh down to Camp 2 as they are showing increasing signs of mountain sickness. Sigi Hupfauer and Mike Rheinberger remain at Camp 4 to help Pat and Karl.

Zac, Jim Truscott and myself remain at Camp 3 to help re-hydrate and treat descending climbers before they continue back to base camp. Pat and Karl [assisted by Hupfauer and Rheinberger] struggle into Camp 4 at 2300, by which time we were alarmed about their chances of survival.

MON 18 AUG: Sigi, Pat, Mike, Karl reach Camp 3. I re-hydrate Karl, give him 100\% oxygen by mask and IM Dexamethasone. Karl was being dragged by the others but was able to stagger onwards with oxygen mask.

[There is no entry for 19 August. Rheinberger notes: 'We were forced to spend an extra day at camp three. I left camp three on the 20th, reaching base camp on the $21 \mathrm{st}$. Tony and Pat may have stayed the night of the 20th at camp three, reaching camp one on the 21st.']

WED 20 AUG: A fierce storm at Camp 3 causes some concern, but Karl continues to improve with more rest, warmth and fluids.

THU 21 AUG: We break out from Camp 3 despite a continuing storm, as we don't wish to share the fate of the K2 dead. After 6 days at 7100 metres I am starting to acclimatise, with much improved sleep patterns and strength. Pat is very tired from his efforts, having undoubtedly saved Karl's life, and placed his own in jeopardy in doing so. We rest at Camp 3 and continue the descent to Camp 2 by night where we both sleep soundly.

FRI 22 AUG: On arrival at Base Camp I'm busy treating frost-bitten extremities on Karl, Brian Agnew, Peter Lambert and attending to other minor medical matters. We attend to vasodilation and re-hydration with a home brew beer-ingredients courtesy of Fullers $\mathrm{K} 2$ expedition joined by Michel Dacher, who has climbed 9 × 8000 m peaks. Sigi Hupfauer and his wife and the Yugoslav have stayed with the Australian base camp whilst awaiting evacuation. Three Scots join us from the British Chogolisa Expedition, one of whom is later to fall to his death from the summit ridge of Broad Peak.

SUN 24 AUG: We commence the long trek back to Dasso. It is gratifying for James van Gelder and myself to have been stopped in the villages and shown healed wounds, or goitres that have shrunk with iodine administration. I act as seeing eye dog for James van Gelder (Retinal Haemorrhages).

THU 4 SEP: Embassy reception, meet press and Pakistani Ministry of Tourism Officials. Again, excellent treatment of team by Australian Ambassador and his staff.

FRI 5 SEP: Commence long flight home, board our Thai Airways Jet, and fly out 2 hours prior to the adjacent Pan Am 747, which is hit by terrorists, resulting in multiple deaths and woundings.

From Report of the Army Alpine Association Broad Peak (8047 metres) expedition, Pakistan, 28 June to 7 September 1986, Report no. R852-5-2, Army Alpine Association, Canberra, pp. H-3-7. 
The Australian climbers should have been pleased with their performance on Broad Peak. Eight of the 14-man team reached the summit. It was only the second $8000 \mathrm{~m}$ mountain climbed by an Australian expedition and it brought to 10 the number of Australian climbers to have stood on an $8000 \mathrm{~m}$ summit. The other two were, of course, Tim Macartney-Snape and Greg Mortimer on Everest in 1984.

Every much a breakthrough as the Nilgiri North expedition in 1983, the AAA Broad Peak success was a great psychological boost in their preparations for Everest. They proved that they could handle the organisation and logistics to mount a big, siege-style attack on Everest's West Ridge and they put six of their members on an $8000 \mathrm{~m}$ summit.

Jim van Gelder, however, sounded a cautionary note. He pointed out that although the trip seemed to be a very big success on the surface, it was very close to having been a failure, even a disaster:

We weren't properly acclimatised on Broad Peak. We didn't take enough time. There was a very short deadline on the trip; we climbed the mountain in the last week. A lot of people were very close to their limits. There were cases of frostbite and retinal haemorrhaging. We were very close to getting nobody up. Had bad weather come at the wrong time, we could have easily had a disaster. ${ }^{20}$

Peter Lambert echoed van Gelder's concerns:

I was very close to my limit on Broad Peak. I became a bit hypothermic as a zip broke on my duvet and I had a cold wind on my neck all the way to the summit. It was quite an effort to get off. Coming back down into camp four, I was significantly exhausted. I had to sit down every couple of steps. I vowed I would never let myself get in that position again. It was a close call. ${ }^{21}$

Such thoughts were an antidote to any over-confidence as a result of the Broad Peak success. Everest, even by the traditional South Col route, would be higher and harder than Broad Peak - a point that Rheinberger often made to board members during the lead-up to the Australian Bicentennial Everest Expedition (ABEE).

Several of the climbers appeared to be close to their limits on Broad Peak; Mike Rheinberger obviously was not. In addition to his very strong performance on the summit day, in which he climbed all the way from camp three at $7100 \mathrm{~m}$ to the top and then descended to camp four, Rheinberger was involved in several of

20 J. van Gelder, Interview.

21 P. Lambert, Interview. 
the rescues. Immediately after that long summit day, Rheinberger was the first of the Australians back up from camp four to help Cullinan lower Fassnacht down the slopes below the col. Not only that, he accompanied Delaney over to the K2 base camp to assist in treating the survivors of that tragedy. Given his strong performance on Broad Peak and his considerable experience, Rheinberger was truly ready for the ABEE in 1988. Still, he was not content to rest on his laurels for the intervening two years. In 1987, he was back among the Himalayan giants again - in fact, having another go at Everest itself.

For Rheinberger, this Everest expedition was quite a contrast with the large New Zealand trip in which he participated in 1985 on the north side of the mountain. The 1987 attempt was by a very small team by any measure; he joined only three other climbers: New Zealanders Peter Hillary and Kim Logan and Jon Muir, a young Australian from western Victoria. It was an exceptionally strong team. Hillary, son of Sir Edmund, was an experienced mountaineer in his own right, Logan was one of New Zealand's most accomplished ice climbers and Muir was a very skilled rock climber who, according to some observers, had become Australia's best alpinist. Rheinberger, of course, added a plentiful dose of experience, steadiness and all-round mountaineering skills and judgment to the team.

This time Rheinberger and his colleagues approached Everest from the south. Their route was a variant of the standard South Col route. They would follow the traditional line of ascent through the Khumbu Icefall and Western Cwm, but instead of climbing the Lhotse Face at the end of the cwm and then traversing across the top of a rock rib called the Geneva Spur onto the South Col, they would climb directly from the end of the cwm onto the South-East Ridge via a steep ice route between the Geneva Spur and a feature called the South Pillar. It was an ambitious project for such a small team, particularly in the colder, windier post-monsoon season.

If Rheinberger thought the mountain would be a little kinder to him than it was two years earlier, he was in for a big disappointment. It was to be another frustrating sojourn on Everest for him. In 1985, severe avalanche risk forced the New Zealand team down from all three routes they attempted; in 1987, it was the premature lowering of the jet stream and the accompanying fierce winds and raging storms that beat back the attempt. In fact, during the post-monsoon season of 1987, more than 150 climbers attempted Everest from all sides and none reached the top.

Of the New Zealand/Australian team, Logan and Rheinberger had the first crack at the top, in late September, when they climbed from the cwm (camp two) to $8100 \mathrm{~m}$ and then bivouacked in preparation for a summit bid the next day. The brief window of fine weather slammed shut quickly, however, and the pair was 
forced to fight for their lives in the heightening storm and then retreat via the South Col at the first opportunity in the morning. It was a harrowing night, as Rheinberger and Logan were forced to wedge their bodies across the tent to keep it from disintegrating. In the morning, they were repeatedly blown off their feet as they crossed the South Col. By the time they reached camp two in the Western Cwm, both were badly dehydrated and Logan was suffering second and third-degree frostbite to his fingers. That was punishment enough for the pair and they retired from the climbing.

Hillary and Muir, however, kept up the vigil at camp two throughout the rest of September and much of October in hopes that the incessant gales would abate long enough to make a dash for the top. Everest, however, had even worse in store.

On 19 October, with a steadily dropping barometer and high clouds blasting over the summit pyramid, Hillary and Muir descended to base camp, fearing the worst. Their judgment was faultless. More than $1 \mathrm{~m}$ of snow, whipped up by high winds, fell at base camp and forced the climbers to dismantle their mess tent to prevent its collapse under the load of snow. Higher on the mountain, two American climbers were in for one of the most frightening experiences of their lives, as Hillary recalled:

Peter Whittaker [one of the American climbers] later told me that he had lost his tent and all his equipment when he crawled from his tent briefly. A sudden gust had ripped the tent from its tie-downs, cartwheeling both the tent and Peter down the glacier. Peter relinquished his hold after the third rotation, the tent flew out of sight down the glacier, and Peter scrambled on all fours to the French box tent, which was still standing.

Elsewhere in the Mt Everest area nine people died in avalanches and from exposure. ${ }^{22}$

The storm was so severe that it forced Hillary and Muir to retreat even further, as they were 'marooned by miles of snow drifts'. ${ }^{23}$ They were forced several kilometres down the Khumbu Glacier below base camp. Not long afterwards, the pair turned their backs on Everest, still being lashed by unrelenting winds and shrouded in horrifyingly cold conditions. As Hillary and Muir descended through the Khumbu Icefall for the last time after having climbed back up to camp two to recover gear after the big storm, the mountain threw one last scare at them, as Hillary recalled:

22 Hillary, P. 1988, 'Everest south pillar', New Zealand Alpine Journal, vol. 41, pp. 34-5.

23 Ibid. 
Jon pulled on a [fixed] rope and, suddenly, all hell broke loose.

With a 'crack' an area $100 \mathrm{~m}$ deep and $200 \mathrm{~m}$ wide moved with a violence that gave neither of us time to do anything. Great crevasses opened around us, and snow tumbled into them. Other chasms dramatically snapped closed. The snow-covered surface of the ice buckled and corrugated like the rise and fall of surf upon a wild coastline. I unclipped from the fixed rope, as it had become taut, and began to run back up the slope. After five seconds all movement ceased, as quickly as it had started. We stood motionless looking at one another and after a minute we both shrugged and continued on into the chaos that had only then been rearranged.

Lugging our heavy packs of equipment, we negotiated the collapsed section of the ice fall, climbing vertical steps where there had been none before and ambling past horizontal ladders where they had previously been vertical. It was dark before we stumbled back into Base Camp, exhausted. ${ }^{24}$

The narrow escape was yet another reminder of Everest's considerable defences. If the threat of massive avalanches, hurricane-force winds and life-threatening cold were not enough, the Russian roulette-like quality of journeys through the Khumbu Icefall would certainly send chills down the spines of the most experienced, competent mountaineers. If any of the ABEE climbers might have harboured thoughts that the South Col route-sometimes dubbed the 'Yak Route' by those unconvinced of Everest's potential for viciousness - would be a pushover, Rheinberger could put them straight.

Despite the failure to reach the summit, it was another consistently strong performance by Rheinberger. For the second time in two years, he climbed to more than $8000 \mathrm{~m}$ and on the Everest attempt he was forced to survive a dreadful night high on the mountain and then descend in the most appalling conditions. With his increasing depth and breadth of Himalayan experience and two recent attempts at Everest to his credit, Rheinberger was clearly ready for a third crack at the world's highest mountain with the ABEE in 1988. Where, however, were the rest of the civilians? 



\section{Part 5: Team building- mail-order mountaineers}





\section{Climbers wanted}

By the mid to late 1980s, the nature of the Melbourne mountaineering community had changed quite considerably from that of 1980, when Tim Hughes had applied for the permit for Everest in 1988 on behalf of the southern Australian section of the New Zealand Alpine Club (NZAC). In 1980, the idea was simple: the small, closely knit core of Melbourne climbers would continue to build their base of Himalayan experience until they were ready to mount a lightweight attempt on the South Col route on Everest.

As described previously, those aspirations became inextricably bound up with the plans of the Army Alpine Association (AAA) for their attempt on Everest in 1988. Even had that not been the case, however, the original idea of the Melbourne-based Everest expedition would have had to change significantly simply because of attrition to the group through the 1980s.

The driving force for the early expeditions to Dharamsura, Changabang and Nanda Devi was undoubtedly the trio of Peter Allen, Mike Rheinberger and Andrew Rothfield. (Rothfield had left the climbing scene in 1981, before Nanda Devi.) Rheinberger, of course, was one of the most prolific of Australian Himalayan climbers throughout the decade. Allen, too, had considerable Himalayan experience, as he had taken part in the 1983 AAA Nilgiri North climb and the 1985 New Zealand Everest expedition in addition to the earlier Dharamsura and Changabang trips. He had also climbed Denali in 1981. Allen, however, although one of the strongest potential Everest participants on the civilian side, opted out of an active climbing role in the Australian Bicentennial Everest Expedition (ABEE) as he had just married, thereby acquiring a young family, and judged that the multiple trips through the Khumbu Icefall would be too risky. Rothfield was also out of contention as an ABEE climber. He gave up active climbing in 1981, just before he was set to go to Denali (Mt McKinley) in Alaska with Rheinberger. So of the three civilians who were on the ABEE board of management - Rheinberger, Allen and Rothfield - only Rheinberger was in a position to set foot on the mountain itself.

The other Melbourne climbers who accompanied the trio on their early Himalayan trips had also dropped out of the mountaineering picture one by one. Of the other three members of the 1979 Dharamsura expedition, Max Berry and Gary Wills each made only one other trip to the Himalaya: Berry to Changabang in 1980 and Wills to Nanda Devi in 1982. Ed Neve returned twice: to Nanda Devi in 1982 and Shivling in 1985. Of the other Changabang climbers-Paul Anderson, John Dunlop, Pat Miller and Mal Noble-none returned to the 
Himalaya, nor did Hugh Foxcroft or Tom Millar of the Nanda Devi team. Apart from Rheinberger, only Keith Egerton of the 1982 Nanda Devi team climbed again in the Himalaya and he met a tragic end on Jannu two years before he had a chance to climb with the ABEE.

The changes that were occurring to the Melbourne mountaineering community during the 1980s were paralleled by changes to the southern Australian section of the NZAC. In fact, the section, as well as its northern counterpart in Sydney, was wound up and all Australian members of the NZAC were put on the 'unattached' list. About the same time, in late 1983, a new organisation was formed - the Australian Alpine Climbing Club (AACC) - to look after the interests of Australia's alpine climbers, especially in their dealings with the mountaineering authorities in Nepal, India and Pakistan.

As an active climbing club, the AACC was short-lived. It enlisted 112 members, only half of whom were active climbers; published one newsletter; provided several endorsements for Australian expeditions going to India and Nepal; and, about a year after it was formed, lapsed into inactivity. During that year, however, the AACC had officially taken over from the southern Australian section of the NZAC as the permit holder for the South Col route on Everest in 1988. In theory, the AACC should therefore have been in an ideal position to supply civilian climbers for the ABEE, but its defunct state prevented it from playing that important role.

So by 1985 it had become clear to the civilian members of the ABEE board that they would have to actively recruit members for the civilian side of the expedition. 'Climbers wanted' advertisements, in the form of a small brochure on the ABEE, were sent to Australian members of the NZAC and posted in climbing shops around the country. The most effective method, however, was probably word of mouth within the Australian alpine climbing community.

The ABEE board received nearly 100 applications from Australian climbers. That large number reflected the state of Australian Himalayan climbing in the mid1980s. What began with the Mulkila, Changabang, Dunagiri and Dharamsura trips in the 1970s as a trickle had become a decade later an increasingly heavy flow of Australian mountaineers to take on the world's highest peaks. Many of these expeditions were related to Australian attempts on Everest, but many others were not. Australians were broadening their horizons and beginning to sample the tremendous variety of challenges the Himalaya have to offer: other $8000 \mathrm{~m}$ peaks besides Everest, rock climbing of the highest standard on great granite towers and mixed ice and rock climbing of considerable technical difficulty on beautiful and sometimes remote Himalayan mountains. 
Although the entire ABEE board selected the climbing team, it was left to the civilian board members - Allen, Rheinberger and Rothfield - to select the civilian climbers, as it was left to the AAA to sort out its part of the team. The process of selection 'worked itself out', as Allen recalled. 'People pretty much chose themselves by their own experience. Also, we tended to prefer people that we knew, people that we'd climbed with or that close friends of ours had climbed with.' ${ }^{1}$ Firsthand knowledge is extremely important in Himalayan mountaineering, as climbers literally put each other's lives in their hands when they climb together as a roped pair.

The number of civilian climbers chosen was not determined a priori but was finally determined late in the lead-up to the expedition. In the end, it represented a delicate compromise between conflicting pressures. As described later in Chapter 21, there was pressure from some quarters in the AAA to include as many of their representatives as possible, including some whose qualifications were questioned by the board. On the other hand, the civilian side had rather more well-experienced climbers to draw on. Parity had to be maintained, however, and the total team size had to be large enough to allow for an anticipated high attrition rate.

Several civilian climbers originally selected dropped out for various reasons. Ed Neve and Jonathan Chester withdrew, Geof Bartram dropped out when he thought the team had become too large, Michael Groom could not participate because of injuries suffered on Kangchenjunga (see Chapter 27) and Keith Egerton was killed on Jannu.

Despite these withdrawals, the civilian component of the team was very strong. It reflected the broad range of backgrounds and experiences of Australian Himalayan climbers in the mid-1980s. The ABEE climbers ranged from one who had never been to the Himalaya before, but had a very strong record of hard climbing in New Zealand, to one of Australia's most experienced and active Himalayan climbers.

One of the earliest choices was Phil Pitham. Although closely associated with the AAA because of his participation in two of the early AAA expeditions and his stint in the army from 1979 to 1986, Pitham was in fact selected as one of the civilian members. He was a member of the 1981 Ganesh IV expedition, summited on Nilgiri North two years later and climbed in the Kulu region in 1984 and 1985.

James Strohfeldt, one of four medical doctors on the ABEE team, was a climber who had built up his experience rapidly since 1985. In that year, he was invited on the AAA expedition that climbed Pisang and Chulu West, two trekking

$1 \quad$ P. Allen, Interview. 
peaks in central Nepal, and in 1986 was a member of Mike Groom's trip to Kangchenjunga. In addition, Strohfeldt climbed Denali (Mt McKinley) in 1987 as a member of an AAA expedition.

One of the more interesting choices was Chris Curry, in that he was a 'secondgeneration' Australian Himalayan climber. His first introduction to mountains, like Tim Macartney-Snape's, came in East Africa. Born in Kenya, Curry grew up within sight of Mounts Kilimanjaro and Kenya, but he never had the chance to climb either before his family moved to Australia.

It was veteran Australian mountain guide Geof Bartram who later gave him his start in alpine climbing. In 1981, Curry joined a trek accompanying the Australian expedition to Anyemaqin in China, and during that trip he met Macartney-Snape, Bartram, Lincoln Hall and Andy Henderson. While trekking with Bartram later in Nepal, he was invited to join an expedition that Bartram was leading in 1984 to Pumori, a beautifully conical $7145 \mathrm{~m}$ peak just west of Everest. (The permit for this expedition was obtained from Rheinberger, who was forced to abandon his plans because of his broken ankle.) The keen Curry did not have to think twice before accepting, but admitted to Bartram, 'Hell! I don't know one end of a crampon from the other!'

That was quickly remedied during the intervening two years. Curry climbed with Bartram for four months in South America and took mountaineering courses at Mount Blanc in France and in Switzerland. When 1984 rolled around, Curry was ready and joined Bartram and the other members of the seven-man team on the summit of Pumori after an ascent of the mountain by a new route on the South-East Face.

Curry, another of the medical doctors on the ABEE team, picked up more highaltitude experience after the Pumori expedition by climbing the highest peaks in North and South America: Denali and Aconcagua. The latter, at just less than $7000 \mathrm{~m}$, is the highest mountain outside the great ranges of Asia. Curry's most impressive feat, on the other hand, was his ascent in 1985 of Pik Kommunizma, 7495 m, and Pik Korzhenevskaya, 7105 m, in the Soviet Union's Pamir Mountains, a range at the north-western end of the Greater Himalaya. It is rare for a climber to succeed on two $7000 \mathrm{~m}$ peaks during the same expedition.

One of the applications that stood out among those received by the ABEE board was that of Terry Tremble. After a start in rock climbing in 1982, Tremble soon gained a reputation as one of Australia's most skilled alpine climbers, one who was not averse to taking on big and dangerous mountains by difficult routes. His exploits in 1986 in the European Alps turned a few heads in Australian climbing circles. In addition to climbing Mt Blanc, the highest peak in the

2 Wilby, S. 1989, Beyond the Icefall, Childs \& Associates, Sydney. 
Alps, he polished off some of the range's most demanding routes: the Bonatti Pillar and the Dru Couloir, two classic routes on the Petit Dru; the Walker Spur of the Grandes Jorasses; and the North Face of the Droites. He topped off the spectacular season with an ascent of the infamous North Wall of the Eiger - the first time an Australian had succeeded on that alpine test piece.

Before his magnificent season in the Alps, Tremble had made a visit to the Himalaya, to a striking mountain called Shivling in the Gangotri region of India. He was joined by Ed Neve, a member of earlier expeditions to Dharamsura and Nanda Devi, and by Brigitte and Jon Muir, more of whom will be described later. Their attempts on two new routes did not meet with much success. During one attempt, Neve took a fall and decided thereafter to return to Australia; the Shivling trip was to be his last to the Himalaya. The other attempt was stopped by the arrival of the monsoonal snowstorms after a height of only $5900 \mathrm{~m}$ had been reached.

Later in the year of his alpine exploits, 1986, Tremble was in the Himalaya again - this time as a member of a three-man team to attempt Jannu, a $7710 \mathrm{~m}$ peak in the Kangchenjunga region of eastern Nepal. It was a most ambitious undertaking, but, given his impressive season in the Alps, one well within his capabilities. The other members of the Jannu team were New Zealander Don French and Victorian Keith Egerton, who was a member of the 1982 Australian expedition to Nanda Devi. Although small even by modern Himalayan standards, the team comprised very experienced mountaineers and thus had a good chance of success.

Tremble, French and Egerton attempted Jannu by the South-West Ridge, the route of the original French ascent but on the opposite side of the mountain from the route attempted by the New Zealand expedition in 1975. With only three climbers, there was little choice as to what style would be employed in the 1986 attempt; a siege-style ascent would have required at least three times that number.

In true alpine style, the trio was laden with heavy packs the first time they set foot on the mountain to climb as high as they could and, with a bit of luck, to the summit. After five days, they had climbed past three bivouac sites to about $6000 \mathrm{~m}$, where they dumped much of their gear and headed back down to base camp to allow further acclimatisation. A second attempt was aborted at about the same point when a snowstorm struck. A third attempt, in mid-October, was thwarted by the loss of much gear and all of the team's high-altitude food rations when an avalanche obliterated a dump. The team overcame this serious situation by intercepting a French expedition retreating from a nearby mountain and appropriating the remains of their high-altitude rations. 
Although the weather had finally cleared, luck was still not with the group. They climbed past their previous high point to a fourth bivvy site at $6700 \mathrm{~m}$, in position for an attempt on the summit. After a windy night in the tent, they were ready for the final $1000 \mathrm{~m}$ of climbing when Egerton became ill. It soon became apparent that he was seriously ill, so Tremble and French shifted their focus from the summit to a rapid descent. It was to no avail. Egerton's condition deteriorated quickly and he died, probably of pulmonary oedema, just $200 \mathrm{~m}$ below the highest bivouac.

Egerton's death is a graphic reminder of just how suddenly oedema can strike and how vulnerable climbers are when high on a Himalayan mountain. The tragic demise of Egerton on Jannu was another blow to the Melbourne Himalayan climbing community, which had lost Tim Hughes in the accident in the Rishi Gorge in 1980 and, as noted later, suffered other tragic losses during the early 1980s.

The shock of the death of a friend on a first Himalayan expedition was a sobering experience for Tremble, but he was back in the Himalaya a year later for another go - in fact in very nearly the same place and again as a member of a three-person team. Their objective was Kangchenjunga itself, the world's third-highest mountain, and the team consisted of Tremble, Jim van Gelder and Carol Brand-Maher. In effect, it was a two-man climbing team as Brand-Maher had not done any climbing previously - in fact, she had never been on snow or camped in a tent! In the event, she climbed to $6000 \mathrm{~m}$ on Kangchenjunga's North Face and stood up well to the isolation of a very remote base camp.

Despite its enormous size, Kangchenjunga seems to attract many very small expeditions. The attempt by Tremble and van Gelder was only one of three two-person teams involving Australians to take on the mountain; of the other two teams, as described later, one pushed itself to the very limit of endurance and the other, tragically, beyond.

The van Gelder/Tremble attempt in 1987 did not quite reach those extremes. Nevertheless, it was a solid effort on the north side of the mountain, on a route steeper and more difficult than the one van Gelder and his colleagues tried the year before. Their attempt was done in a mixture of styles, with four camps established on the route and rope fixed to $7200 \mathrm{~m}$. As it turned out, the fixed rope came in handy when a rapid descent was required.

In their first summit bid, Tremble and van Gelder moved quickly up through the camps, bivvied at the top of the fixed ropes and then climbed another 300 vertical metres when Tremble began to show symptoms of cerebral oedema. With the death of Egerton the previous year undoubtedly on his mind, Tremble immediately backed off and, with the aid of the fixed ropes, descended very 
quickly. The retreat turned out to be strategically timed as a massive snowstorm lashed the mountain soon after they arrived at base camp. When the storm cleared, the pair made a final attempt at the top but was beaten back by high winds and cold weather.

The expedition had its share of light moments; a Japanese team attempting the same route provided one of them. One of its members proudly announced to van Gelder and Tremble that they were adopting the modern approach and making a 'really light-weight attempt' ${ }^{3}$ The Australians later learned that the Japanese team consisted of 16 climbers!

Brand-Maher had an even more bizarre encounter near base camp. One day she saw two figures approaching and, after having spent weeks on her own at a very lonely base camp, she raced up to greet them. She could not understand why they turned and ran when she shouted excitedly to them. Later she learned that they were two Australian trekkers searching for peace and solitude in the most remote corner of the Himalaya. They thought the north side of Kangchenjunga was it. Imagine their horror when they not only saw another human being, but were greeted by a cheery voice with an Australian accent!

Tremble had therefore served a busy apprenticeship to the ABEE with a lot of climbing packed into two years: the impressive season in the Alps followed by expeditions to Jannu and Kangchenjunga. In addition to Tremble, van Gelder was also an obvious choice for the ABEE team. He, like a couple of the other climbers, had a foot in both the civilian and the AAA groups; he had climbed on AAA expeditions and was an officer in the Army Reserve.

If Tremble and van Gelder were obvious choices for the ABEE, Paul Bayne certainly was not. One of the essential criteria for selection to the team was a certain minimum of Himalayan experience and preferably some experience above 7000 m. Not only had Bayne never been to the Himalaya, he had climbed nothing higher than New Zealand's Mt Cook, a modest $3764 \mathrm{~m}$ and considerably lower than virtually any Himalayan base camp, let alone summit. 'We took a bit of a punt on Paul,' Peter Allen admitted. ${ }^{4}$ If Allen gambled on the horses like he did on Bayne, he would be a millionaire many times over by now.

The one thing that did stand out in Bayne's application was the sheer amount of mountaineering experience he had amassed. A Sydneysider, Bayne's experience in the hills was centred primarily on bushwalking in the Blue Mountains until he joined an 'end-of-school' trip to New Zealand. There the students walked the Routeburn Track, one of New Zealand's most well-known tramping routes, and

3 J. van Gelder, Interview.

4 P. Allen, Interview. 
then paid a visit to Mt Cook. One look at the high peaks of the Southern Alps and Bayne was hooked; he instantly fell in love with the area and decided to stay. It was early 1973 and Bayne was sixteen years old.

For the next 10 or 12 years, Bayne, as he put it, 'hung out' in the Mt Cook area. He worked for two or three-month stints at The Hermitage, the tourist resort hotel below Mt Cook, and then climbed for two or three months. He took every Alpine Guides course he could, from basic mountaineering to skimountaineering in the winter season, and by 1976 began to guide himself. Five years later, he had finished the guiding courses and became a fully certified guide - in fact, the first Australian to become a Union Internationale des Associations d'Alpinisme (UIAA) certified guide.

Although from then on Bayne spent nearly every fine day guiding other people up climbs they wanted to do, in 1985, he did manage to sneak in a climb of his own - one that stood out even among the extreme ascents being made by the hard men of the New Zealand ice-climbing scene.

The setting was Mt Tasman, New Zealand's second-highest peak, and the climb Bayne had in mind was the Balfour Face, a very steep, very committing, technically demanding ice climb. It was a route that was often talked about with considerable awe by other climbers during conversations in the huts. Bayne had his first view of the Balfour Face when he was caught in a storm on Mt Silberhorn, a nearby mountain, and peered through a momentary break in the clouds. What he saw confirmed what he had heard in hut conversations. When he found the opportunity to attempt it, he polished off the route in remarkable fashion: in record time and solo-the first time the Balfour Face had been climbed by a single person not roped to a partner. It was a triumph of technical skill, confidence and daring.

The solo ascent of the Balfour Face could easily have made the difference for the success of Bayne's application for the ABEE team. Even with that achievement to his credit, he was, however, originally accepted only as a 'reserve' because of his lack of high-altitude experience. After all, he was not only going to the Himalaya for the first time, he was going to attempt Everest, the highest of them all.

Did that lack of high-altitude experience worry Bayne? 'No, not really. I had a lot of mileage in the mountains - a lot of experience in alpine climbing over 10 or 12 years. Altitude isn't that big a thing, just an exaggeration of the pain and suffering scale that you experience on any big climb. ${ }^{5}$ What Bayne did not realise at the time was that on Everest he was going to go further along the pain and suffering scale than he ever dreamt was possible. 
There were two late inclusions to the team. One was Bruce Farmer, a climber with considerable alpine climbing experience and with two Himalayan expeditions under his belt. He was a New Zealander, previously a president of the NZAC, but on moving to Tasmania, he became an Australian citizen. Until the ABEE, all of his expedition climbing had been done with New Zealand teams. He was deputy leader of the Southland Patagonian expedition to South America in 1977, a position he also held in both of his Himalayan expeditions - to Molamenqing in 1981 and Everest in 1985. On the latter, of course, he climbed with Rheinberger and Allen.

The last climber to join the team, in December 1987, was Jon Muir. Muir's late inclusion had nothing to do with his experience or climbing ability; apart from Mike Rheinberger, he was easily the most experienced Himalayan climber of the ABEE team, having made two previous attempts on Everest and several other trips to mountains in the Indian Himalaya. The problem was that Muir simply could not afford the contribution that each ABEE climber had to make. The situation was resolved when it was eventually arranged that he should be invited to join the expedition as a cameraman for the Australian Broadcasting Corporation (ABC), which was to film the climb. Muir's late addition to the team did more than just add a very strong mountaineer; it gave the ABEE one of the liveliest characters ever to appear 



\section{Turkeys on ice}

Jon Muir is one of those people who can truly be described as unforgettable. Redhaired and freckle-faced, he possesses a zany sense of humour, an inexhaustible amount of energy and an unbounded zest for life that never fail to impress people on meeting him.

Sorrel Wilby, in her book Beyond the Icefall, described Muir as 'by far the most interesting guy on the [Australian Bicentennial Everest Expedition] team; irreverent, crazy, uninhibited, good humoured and so intense his eyes were permanently popping out of their freckled sockets'. ${ }^{1}$ Muir's Australian Bicentennial Everest Expedition (ABEE) colleague Jim Truscott, in recounting a satirical book review of a mythical volume on the expedition, included a chapter entitled 'Am I normal - the Ozymandias story (Readers - judge this catalogue of Jon Muir's weirdness for yourselves)' .2

It is his wild sense of humour, however, that is probably the most prominent trait in Muir's character. Wilby recalls being kept awake one night during the walk in to the ABEE base camp by 'Jon's manic laughter, ringing out from the adjoining room', ${ }^{3}$ and, at another point when he led the response to his own joke, 'even his freckles started shaking with laughter' ${ }^{4}$ She concluded, even before the ABEE team had arrived in Kathmandu, that Muir was 'ready for a strait-jacket — not a climbing harness'. ${ }^{5}$

His climbing exploits kept up with his sense of humour. He seemed equally at home on Australian rock, in the alpine environments of Europe and New Zealand and in the rarefied atmosphere of the Himalaya; and he climbed at the very highest of standards regardless of medium or location. By 1987, his record of achievements was so impressive that the New Zealand Alpine Club Bulletin followed its account of his latest Himalayan trip with a profile entitled 'Who is Jon Muir?'. ${ }^{6}$

Who is Jon Muir indeed?

Born in the NSW coastal city of Wollongong, Muir was a rather typical young lad by the time he was fifteen years old. He was starting to wonder what to do

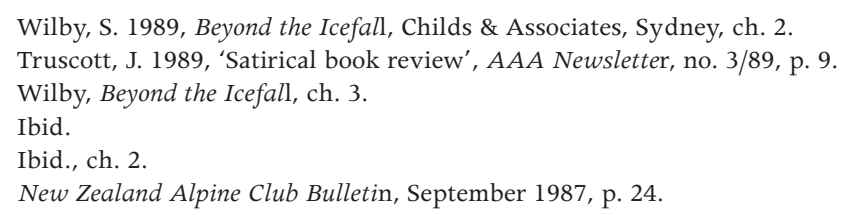


with his life. He had read all of the career books at school but nothing appealed to him. Then, as he recalled with considerable enthusiasm, a single event occurred that was to irrevocably change his life.

One evening I was watching the BBC TV documentary Everest the Hard Way, the account of Chris Bonington's 1975 British expedition to the South-West Face of Everest. Then, during the program, it was like this hand leapt out of the screen and grabbed me by the heart. I jumped up and yelled, 'That's what I want to do! I want to climb Mt Everest!'

So after that I went down to the Wollongong library and read every book on climbing that I could find. Then I went out and started doing some rock climbing myself on the cliffs behind Wollongong. I started off soloing. Eventually I convinced a few of my friends to climb with me. I borrowed my sister's horse rope. We'd wrap it around a tree at the top of the cliff and then belay around another tree at the bottom; there was enough friction for it to work. Even at that time, though, I still really wanted to climb mountains, not just rock faces. ${ }^{7}$

Before long, the young Jon Muir had his chance to climb mountains. He met what he described as 'real climbers, with clanking gear and things like that'. ${ }^{8}$ Two of those climbers were Graeme Hill and Russell Chudleigh and Hill soon became Muir's teacher-for rock climbing and mountaineering. In early 1978, Hill took Muir to New Zealand for his first taste of alpine climbing and the pair returned the next two seasons to climb together in the Southern Alps.

The first year was devoted to ascents of easy and medium-grade climbs, but Muir rapidly graduated from those and by 1980 was climbing some of the hardest routes in the Mt Cook region. Hill, recalling some of their early epics such as getting lost on a descent from the Footstool and battling rockfalls and green ice to the top of Malte Brun, described Muir as 'strong but senseless' with 'far too much push for the first season'. ${ }^{9}$ He also, however, quickly discerned a trait that would later be responsible for keeping Muir alive through some harrowing experiences: 'When we got into tight situations, he always made good decisions. ${ }^{\prime 10}$

The other quality that got Muir out of difficult situations was his climbing prowess; often he could simply climb his way out of a tight spot. Hill remembered their night-time ascent of the Syme Ridge of Mt Tasman:

\footnotetext{
7 J. Muir, Interview.

8 Ibid.

9 G. Hill, Interview.

10 Ibid.
} 
We had only one torch, and Jon led the difficult mixed rock and ice route up the ridge. It was a tricky route, even in daylight. Jon would lead up and then yell down, 'You head for the torch. I'll keep you on a tight rope.' It was hard climbing on horrendously loose rock. I just scrabbled around in the darkness and Jon pulled me up. ${ }^{11}$

Muir's exuberant personality was also apparent in his early trips to New Zealand, as Jim Truscott recalled: 'Rick Moor and I were at Pudding Rock and watched Muir and another climber heading up to Empress with a full stereo system (large!) on top of their packs, booming across the glacier!'12

During his 1980 New Zealand trip, Muir, and his irrepressible sense of humour, launched a group of young Australian climbers he dubbed the 'International Turkey Patrol'. The ITP held great promise to become a leading Australian force in Himalayan climbing, indeed to push the standard of Australian mountaineering in the great ranges of Asia to even higher standards. Before that potential could be fully realised, however, tragic accidents would decimate the ranks of the ITP and leave the survivors under no illusions about the sober reality of the dangers of climbing in the Himalaya.

The ITP was born one typical New Zealand day in 1980 with the weather too foul for climbing, so a group of mountaineers was holed up in Plateau Hut near the base of Mt Cook - as was usual for periods of bad weather. Two of the inhabitants of Plateau Hut were Muir and a young Victorian climber, Roddy Mackenzie, who had been identifying themselves around the Southern Alps as the 'Turkey Patrol'. They appropriated that tag from a rock route of the same name first climbed by John Smoothie, a Blue Mountains rock climber, at Mt Piddington. A Canadian mountaineer also ensconced at Plateau Hut was taken by the name 'Turkey Patrol', so was appointed to the group. The Turkey Patrol had gone international.

The ITP, however, eventually came to be associated with a group of four young Australian climbers. Muir and Mackenzie were founding members and two young Victorian climbers, Mark Moorhead and Craig Nottle, joined them in their most memorable exploits. The four climbers shared several traits: they all became very skilled rock climbers, with Mt Arapiles in western Victoria the focus of their climbing; they all sought out challenging climbs, on rock and ice, and pushed their abilities to ever higher standards; and they all possessed a robust sense of humour and an enthusiasm for life that gained them just as much notoriety as did their hard climbing.

11 Ibid.

12 J. Truscott, Personal communication. 
Mackenzie's start in climbing had much in common with that of several other Australian Himalayan mountaineers. Like Tim Macartney-Snape, Mackenzie attended Timbertop, the outdoor activities centre for Geelong Grammar School, and went bushwalking and kayaking, mostly in the Victorian Alps and Snowy Mountains. At the age of fifteen, he climbed Tasmania's Federation Peak-a serious undertaking for a young bushwalker - with Tim van Gelder, Jim's brother.

Like Jon Muir, Mackenzie was captivated by the television documentary Everest the Hard Way and decided that climbing mountains was something he would like to do. Furthermore, as had many other Australians before him, he initially took a Mountain Recreation course from Geoff Wayatt in New Zealand before going on to harder alpine climbing in the Southern Alps. The turning point of his career came in 1980, when Mackenzie spent six months climbing in New Zealand, much of it with Russell Braddock, a very skilled Kiwi ice climber. It was during that period also that Mackenzie teamed up with Muir for the first time, although it was the next season that the pair combined again to climb many of the classic routes in the Southern Alps.

If there was anything as notable as Mackenzie's climbing skill, it was his rather casual appearance. Peter Hillary was suitably impressed on visiting Mackenzie at the family property in western Victoria before a later Himalayan expedition:

I arrived in mid-afternoon. It was very hot and the only thing that moved were great squadrons of lazy flies that homed in to form a halo round me and the dust-covered four-wheel drive inside which I sat wiping sweat from my brow.

A shot rang out and then another. I looked out in the direction of the shots. Roddy came swaggering round the corner of the old white weatherboard homestead. Consistent with his philosophy that farm apparel should be rugged, dispensable and, principally, old, his shoes, a pair of expedition issue from a previous mountaineering adventure, had self destructed to the point where he was having difficulty containing his toes. The green cotton trousers were now little more than shredded canvas with a facility for stuffing hands into pockets. Indeed, the uniformed observer would have assumed they were a form of grass skirt, a touching memento from one of Roddy Mackenzie's many exploits. But it was his shirt that had delivered the most outstanding value, as he had worn it since the third form at school. Roddy is a big man. Only two buttons were capable of sustaining the pressure put upon them, 
with the result that the garment was also well-ventilated. Six feet above this splendidly personalised outfit was the affable Mackenzie smile, alert eyes, and an extraordinary mop of tightly curled golden fleece. ${ }^{13}$

Mackenzie had come to know the other two members of the ITP, Mark Moorhead and Craig Nottle, in the late 1970s at Mt Arapiles in western Victoria. Both had quickly established reputations by then and had done some of the hardest climbs at Australia's most popular crag. Like Muir and Mackenzie, Moorhead possessed a lively sense of humour, being described by Nottle as 'a campfire comedian' and as having 'a ridiculing Pythonesque humour [that] kept everything well within perspective' ${ }^{14}$ As for his climbing, Moorhead was smaller and not as strong as Muir or Mackenzie, but was just as skilled, being able to climb the hardest routes at Arapiles and take part in the development of many new climbs in the area.

Nottle was rather different from the other three members of the ITP. Although he too possessed a keen wit (it would have been impossible to be a member of the ITP without one), he also had a serious side. He had his start in climbing with the Melbourne University Mountaineering Club (MUMC); he was a medical student at Melbourne University at the time. His sharp analytical mind was applied to climbing as well as to his academic work. He was always careful to ensure that every bit of his equipment was precisely matched to the task and that he took nothing extraneous up the mountain. Always present, however, as a counterpoint to the serious side, was the humour that was such an important part of ITP adventures.

Although the members of the ITP climbed at Mt Arapiles and in the Southern Alps in the late 1970s and early 1980s, it was in 1982 that they put it all together for a two-pronged assault on the mountains - first the European Alps and then the Himalaya.

Their tour de force in the Alps in 1982 was just as impressive as the season Terry Tremble would notch up in the Alps four years later. Only three of the ITP-Muir, Moorhead and Nottle - participated in the 1982 alpine adventures; Mackenzie thought the Alps too crowded and competitive for his tastes, so he headed for the mecca of big-wall climbing: California's Yosemite Valley. There he put in a solid six weeks of hard climbing, which included an ascent in only two days of a famous route called the 'Nose'.

Meanwhile back in the Alps, the other three ITP members were doing some very hard climbing themselves. In just a few weeks based at Chamonix, they knocked off some of the most well-known and difficult routes in the Mt Blanc

13 Hillary, P. 1988, Rimo. Mountain on the Silk Road, Hodder \& Stoughton, London, ch. 1.

14 Nottle, C. 1984, ‘Obituary. Mark Moorhead', New Zealand Alpine Club Bulletin, vol. 37, p. 132. 
area: the North Faces of Les Droites and the Charmoz, the Central Pillar of Freney on Mt Blanc, the Walker Spur on the Grandes Jorasses and the Dru Couloir, among others. Ticking off their list of successes, however, gave little hint of the desperate climbing, uncomfortable bivouacs and terrifying storms they had to endure on these test pieces of alpine climbing. Muir's account of their epic on the Walker Spur is typical of their wild adventures:

We had no knowledge of the descent route and the storm had obliterated any tracks that may have shown the way. It was time to bivouac. As usual, we had no spare clothes, no sleeping bags or mats, no stove or food, so it didn't take long to prepare for the night. We just squeezed into the one-person bivvy sack and started to shiver. It was the longest and coldest night of our lives.

Some time in the middle of it the lightning began. The flashes, crashes and booms were blinding and deafening; inside the sack it was brighter than day. The storm was right over our heads; our fingers and toes tingled and buzzed. We were wet, freezing, starving, thirsty and exhausted and at any moment might have been fried to a crisp, but we were happy.

It wasn't for sunny days in friction boots on warm granite that we had travelled half the world. We had come for the excitement and adventure of a desperate struggle. We sang Always Look on the Bright Side of Life from The Life of Brian and laughed till we cried. Though I wasn't sorry to see it end, it had been a great night.

A fine morning greeting us and we were up and away in no time. We found Craig and his partner camped in a nearby crevasse. They had been severely jolted by lightning three times. Their confused talk and the wild look in their eyes said it all; they were more spaced out than anyone I had ever seen. ${ }^{15}$

One would have thought that after weeks of adventures like that, they might have been ready for a few quiet days in the sun on the beach. The ITP, however, was not finished for 1982. Muir, Moorhead and Nottle called in, on their way back from Europe, on the Indian Himalaya, where they were joined by Mackenzie (see image 19.1). The mountain they had in their sights was Changabang (6864 $\mathrm{m})$ and they were going to climb it by a technically very difficult route.

The suggestion to attempt Changabang came from Jim Duff, another inhabitant of Plateau Hut at the time the ITP was being formed. Duff, as noted earlier, 
was the doctor on the 1984 Australian Everest expedition. He had also been a member of several British expeditions to the Himalaya and thus knew the region quite well.

The four young Australians, even though they had just come from two of the most beautiful mountain settings in the world, could not have been anything but amazed by their first sight of Changabang.

English climber Peter Boardman said:

Changabang is a miraculous peak in that it is quite unlike any of those surrounding it. Longstaff [Tom Longstaff, an English climber of the early 1900s] described it as the most superbly beautiful mountain he had ever seen. Perhaps it would melt away if set amongst the towers of the Karakoram, but in the Garhwal its suspended stone stands alone and distinct - a fascinating challenge. ${ }^{16}$

Another early English climber, Frank Smythe, was also taken by 'the terrible precipices of Changabang, a peak that falls from crest to glacier in a wall that might have been sliced in a single cut of a knife' ${ }^{17}$

By 1982, Changabang had been climbed a few times and, indeed, Australians had been to the summit on the successful 1980 trip led by Mike Rheinberger. That climb - as had the first ascent by a British team in 1974-followed the line of least resistance: a snow climb up the face of neighbouring Kalanka and then a traverse of Changabang's icy South-East Ridge to the top. Even bigger climbing challenges, however, lay on the other side of Changabang, on the sheer rock faces and ridges of its southern and western aspects. It was to a prominent feature on this side of the mountain, the South-West Ridge, that the ITP turned their attention.

Australian mountaineering in the Himalaya was still in its rather early stages at the time of the ITP attempt on Changabang in 1982. At that time, Australians had climbed only one 7000 m peak - nearby Dunagiri in 1978 - and nearly all Australian climbs in the Himalaya had been attempted on the easiest route on the mountain. Although some of these, such as Dunagiri, were quite difficult in their own right, only one (Greg Child and Rick White's ascent of Shivling in 1981; see Chapter 24) was as technically difficult as the routes on Changabang's precipitous rock walls. Muir, Moorhead, Mackenzie and Nottle would face climbing just as difficult technically as many of their routes on the sun-drenched rock of Mt Arapiles, but on Changabang they would have to contend with the

16 Boardman, P. 1977, 'Changabang commentary', Mountain, no. 55 (May-June), pp. 18-27.

17 Mackenzie, R. 1983, ‘Frozen turkey', New Zealand Alpine Club Bulletin, vol. 36, pp. 93-6. 
awkwardness of climbing with heavy packs, the treachery of rock coated with snow or ice, the danger of sudden changes in weather and the debilitating effects of high altitude. It was a formidable challenge for first-timers to the Himalaya.

Before they could come to grips with the challenge of Changabang, however, they had to get to the base of the mountain. Even hardened adventurers such as the ITP could not help but be amazed by the bus ride to Lata. Mackenzie recalled:

The word 'road' scarcely conveys the horror of it, a truly fantastic piece of engineering. In several places you could step off the road and not touch anything till you met the Ganges 600 metres below. Encouraging little signs like 'Your family is awaiting your return, drive safely' and 'Life is short, don't make it shorter' adorned the sharp corners. ${ }^{18}$

Just as impressive were their first views of Changabang itself. 'Quite a sight,' Mackenzie said, 'the sort of thing you can sit and look at for a long time and then decide that (a) the angle you are looking from is deceptive and it can't really be like that or (b) you have had too much to drink, smoke or the altitude has done something funny. ${ }^{19}$ Muir also found the mountain almost surreal: 'It's incredible. I can't believe it's real. ${ }^{20}$

Changabang was indeed real and the foursome soon faced the task of trying to scale the South-West Ridge. Interestingly, that difficult route had previously been climbed, not once but twice, by Japanese and Italian teams that used different starting points to join the main ridge higher on the mountain. Both ascents employed siege tactics. In fact, the Japanese fixed nearly $2500 \mathrm{~m}$ of rope, used 300 pitons and took 33 days of climbing to gain the summit! The ITP would have none of the siege tactics; even had they been able to afford the thousands of metres of fixed rope, it simply was not their style. They would employ alpinestyle tactics, much in the way that Peter Boardman and Joe Tasker climbed the West Face in 1976.

Their first attempt ended in typically swashbuckling ITP style. After five days of climbing on the Japanese route, a storm forced them off the ridge at about $6500 \mathrm{~m}$ and down to the Italian Col, below the point where the ridge bifurcated. They abseiled down the steep rock wall below the col, leaving their four $50 \mathrm{~m}$ climbing ropes in place to use when they would climb back to the col. They did not, however, reckon on a continuous rock band that interrupted the slabs that led down from the wall. With no ropes left, they were forced to tie all of their slings, etriers and hardware together, and even that makeshift chain left them 10 
m short. They had no choice but to descend hand over hand down the chain and then drop off the end and hope for the best. Luckily, they landed in a powder snowdrift and slid harmlessly down a snow slope.

After a five-day rest, they were back on the attack, the attempt now following the Italian route. This time the weather held and with the team at the peak of acclimatisation, they made rapid progress. It was absorbing climbing. Nearly every pitch, according to Muir, was truly mixed climbing, with crampons on and then off to handle the variation in medium from snow to rock. The route was liberally sprinkled with difficult rock pitches that required the full bag of rock climber's tools: laybacks, finger and hand jams, bridging across corners on small holds and a reasonable dose of aid climbing as well.

After nearly $2000 \mathrm{~m}$ of such climbing, the four Australians were on the summit of Changabang. It was only four days after they had left advanced base camp-a remarkable contrast with the 33 days it had taken the Japanese team. After a bivouac just beneath the summit, they descended the original route of ascent to the Changabang Glacier. They had planned to cross the Italian Col back over to the basin of the Rhamani Glacier and to their base camp, but the col was out of condition and they were forced to descend the Changabang Glacier all the way to the Rishi Gorge.

The elation of their tremendous performance on the mountain turned into the dread of a desperate trudge, as they were very short on food. 'We soon found ourselves at the bottom of the Changabang Glacier at an old derelict expedition hut shell,' Mackenzie remembered:

The scene was bizarre, as if we had been transported into Polanski's Macbeth. Scores of ravens wheeled and cawed while lammergeyers and vultures soared above us in spiralling circles as we rummaged through the debris left by the previous expedition looking for food. All the while an old horned animal skull peered down on us from the stone wall. ${ }^{21}$

Fortunately for the wasting ITP members, the Melbourne-based expedition from Nanda Devi was returning down the Rishi Gorge at the same time and they were still reasonably laden with food. The spectacle of Muir, Moorhead, Mackenzie and Nottle ravenously downing mountains of chappattis and jam was one that greatly amused the local staff and porters.

The Changabang success presaged great things for the self-styled ITP. In their first trip to the Himalaya, they had taken on a difficult mountain by a difficult route and blazed up it in only four days. It was a bold undertaking for such a young group and it marked the entry of Australian expeditions into the

21 Mackenzie, 'Frozen turkey'. 
recent trend of small teams tackling very severe mixed ice and rock routes in the rarefied atmosphere of the high Himalaya. There seemed to be no limit to what the boisterous ITP members could achieve in the next decade, either individually or as a group.

Mark Moorhead was the first of the ITP to return to the Himalaya, joining a small team to attempt Makalu, the world's fifth-highest mountain, in the postmonsoon season of 1983. The four-man team was led by New Zealander Peter Hillary and included another New Zealander, Bill Denz. Another of the hard young Kiwi ice climbers, Denz had made a name for himself by soloing several difficult routes in the Southern Alps and by a number of very difficult climbs in the Darran Mountains of Fiordland and in Patagonia. The fourth member of the team was an Australian, Fred From.

If Australians in general are unlikely Himalayan mountaineers, then Queenslanders, such as Fred From, are even more so. From's start in climbing went back to the early 1970s and was firmly rooted in the rock-climbing scene of south-eastern Queensland. Throughout the 1970s, he was in the forefront, doing new routes and repeating others at the very highest standards. He was also generous to beginners and gave his time often as an instructor for the University of Queensland Climbing Club. His connection with the university went beyond climbing. He first gained a Bachelor of Applied Science degree and then in 1984 received a Doctorate in ionospheric physics.

From, however, was most notable for his penchant for climbing barefooted, no matter how rough the rock was. Even in New Zealand, he shunned shoes as much as he could. Geoff Wayatt recalled:

Fred From spending a week in the Matukituki Valley barefoot the whole time below the snowline - a fit climber with tough feet! But then I had to laugh when I saw him later in Wanaka walking the streets in a new pair of cheap white running shoes. The Matuki is a tough valley. ${ }^{22}$

From's trip to Makalu in 1983 was not his first encounter with a Himalayan giant. A year earlier he had been a member of another four-man team-again led by Peter Hillary - to Lhotse, Everest's neighbour and, at $8501 \mathrm{~m}$, the fourthhighest mountain in the world. The Lhotse team was notable on two accounts. The first was its multinational character; in addition to Australian From and New Zealander Hillary, it consisted of Englishman Adrian Burgess and Scot Paul Moores. Hillary added that the members 'were not entirely united by the English language - a spectral assortment of dialects existed' ${ }^{23}$ The team's other

22 G. Wayatt, Personal communication.

23 Hillary, P. 1983, 'Lhotse '82', New Zealand Alpine Club Bulletin, vol. 38, pp. 71-6. 
notable characteristic was its bulk; the climbers weighed $93 \mathrm{~kg}, 92 \mathrm{~kg}, 76 \mathrm{~kg}$ and $75 \mathrm{~kg}$. A French mountaineer in Kathmandu labelled them 'the heaviest expedition he had ever seen'. ${ }^{24}$

Their bulk was matched by strength and determination. After negotiating the dangerous Khumbu Icefall (in which a Canadian climber was killed during a simultaneous expedition to Mt Everest), they spent three weeks in the Western Cwm primarily fixing ropes up the West Face of Lhotse. Their route followed the classic South Col route on Everest as far as the Geneva Spur at $7800 \mathrm{~m}$. There the route on Lhotse continued up the face while Everest climbers would begin the traverse across to the South Col.

Hillary's team had put itself in good position for the summit with the establishment of a high camp at $7800 \mathrm{~m}$ on the flanks of the Geneva Spur. Their bid for the top was, unfortunately, thwarted by the weather. Despite an ominous plume of windblown snow trailing off the top of adjacent Everest, the four climbers pushed on towards Lhotse's summit pyramid and began to pick their way through the rock towers via a system of gullies. With the wind howling and snow beginning to fall, however, the wise choice was to retreat.

It was a particularly rough decision for From, who wanted to continue. He was out in front, going strongly and only 250 vertical metres below the summit. In climbing to $8250 \mathrm{~m}$ on Lhotse, From became only the second Australian at that time to have climbed above the magic $8000 \mathrm{~m}$ level. The first, of course, was George Ingle Finch on the 1922 British Everest expedition. From, therefore, was the first Australian to climb past $8000 \mathrm{~m}$ without the aid of artificial oxygen.

The next year, From and Hillary, this time joined by Denz and Moorhead, were

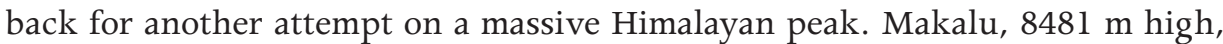
is only marginally lower than Lhotse and their route, the West Ridge, is a much more aesthetic line of ascent than their route on Lhotse. Viewed from the upper Barun Plateau, the West Ridge of Makalu rises in a single graceful arc towards the summit. It is undoubtedly one of the most beautiful lines in the Himalaya and what makes it doubly attractive is that it leads to the top of one of the world's most massive peaks.

The alluring route had been climbed twice before - by the French in 1971 and the Americans in 1980 - but both were large teams that essentially sieged the mountain. Like the ITP had done on Changabang, the small Australian-New Zealand team on Makalu would attempt the route in alpine style - in essence, a first ascent of a classic route in the new, lightweight style. 
Despite the persistence of monsoonal cloud in early September, the quartet pushed the route out from camp one at the edge of permanent snow along a scary, knife-edged ridge to camp two, a roomy crevasse that provided almost palatial trappings at $6800 \mathrm{~m}$. Above that point, the climbing became even more difficult, with sections named the 'Terrible Traverse' and 'Little Eiger face'. ${ }^{25}$

Progress was slowed but remained steady. Camp three was an ice cave, beyond which the ridge steepened even further and ice and snow-covered rock made the climbing even more difficult. After a day of hard work above camp three, in which the route was established to $7300 \mathrm{~m}$, a powder-snow avalanche swept across the descending climbers' path. From was lucky to escape, but Denz was caught in the slide and carried to his death.

It was a terrible blow to the small, closely knit team. The scheduled rest at base camp before pushing higher turned into a sad period of mourning and reflection. The remaining three decided to continue with the expedition and put all their effort into getting to the top of Makalu.

It seemed at first as though their determination would pay off. They moved back up the ridge and climbed past their previous high point and up to more than $7600 \mathrm{~m}$. They had surpassed most of the technical difficulties and had a good run from there to the summit. 'It had seemed to us more a question of how many would reach the top,' Hillary said, 'success was almost taken for granted.' ${ }^{26}$ Virtually nothing, however, can be taken for granted in the Himalaya.

They decided to descend once more to base camp for another rest before finally going for the summit. On the way back down the ridge, Moorhead fell and was killed. Two tragedies in just a fortnight were too much for the stunned From and Hillary to overcome. Not only had the small team been cut in half, the surviving pair had lost two companions. They had little choice but to abandon the climb, even though success seemed imminent, and return to Australia.

The double tragedy on Makalu was another reminder to the Australian climbing community of the dangerous reality of climbing in the Himalaya. Australians had just begun to forget the horrible tragedy three years earlier on Annapurna III, when three Australian mountaineers were killed in a freak avalanche.

For the ITP, the death of Moorhead was a cruel blow to such a young group with so much potential. They had already shown what they were capable of with the tremendous success on Changabang in their first Himalayan trip. They had

25 Hillary, P. 1984, 'Makalu West Pillar', New Zealand Alpine Club Bulletin, vol. 37, p. 51.

26 Ibid. 
many more ideas and plans for daring ascents in the Himalaya. Even before they could recover from the loss of Moorhead, however, and begin to fulfil some of their hopes and dreams, the ITP would be dealt another savage blow. 



\section{Innocence lost}

'TUR...KEY...PA...TROL!!!' The call echoed across the Western Cwm, the floor of the great horseshoe formed by Nuptse, Lhotse and Mt Everest. It must have seemed impossible to the callers - a group of skiers perched on the Lho La - that their cry could have been heard by the inhabitants of the tiny tents pitched at the side of an enormous crevasse under the huge north wall of Nuptse. Yet, a short while later, the return call of 'A...TEAM!!' wafted back up across the Lho La. ${ }^{1}$

The year was 1984 and the skiers atop the Lho La, a pass at the base of Everest's West Ridge, were members of the first Australian expedition to the world's highest peak. As described in Chapter 12, two of that team's climbers, Tim Macartney-Snape and Greg Mortimer, became the first Australians to reach the summit of Mt Everest with their impressive ascent of the Great Couloir.

Macartney-Snape, Mortimer, Lincoln Hall, Andy Henderson and Geof Bartramsometimes dubbed the A-team - were not the only Australian mountaineers attempting Everest in the post-monsoon season of 1984. Based in the Western Cwm on the other side of the mountain were four Australians and two New Zealanders, ready to tackle the formidable West Ridge in an alpine-style push. At the time, it would have been very difficult to predict which team had the better chance of success. In fact, a betting man would probably have put money on the six Antipodeans preparing to do battle with the West Ridge.

Recall the situation in September 1984. The North Face team led by MacartneySnape and Hall certainly had the most experienced Australian climbers in the Himalaya but none of them had previously climbed to $8000 \mathrm{~m}$ (although all but Bartram nearly did so in their ascent of Annapurna II). Furthermore, they were to attempt a new route on Everest and no-one had ever made a first ascent of a route on Everest without using artificial oxygen or with such a small party.

At least the other group knew that their route, the West Ridge, was climbable. An American team had scaled it in 1963. And the Australian/New Zealand 1984 team was not exactly lacking in talent or experience either. One of the Kiwis was Peter Hillary, who had been high on both Makalu and Lhotse in the previous two years. The other was Kim Logan, the strong ice climber who would join Hillary, Mike Rheinberger and Jon Muir on the Everest South Pillar expedition in 1987.

1 Hall, L. 1985, White Limbo, Weldons, Sydney, ch. 9. 
After Moorhead's death on Makalu the previous year, the remaining three ITP members - Muir, Roddy Mackenzie and Craig Nottle - had regrouped to form the core of the Australian contingent. The fourth member was Fred From, who had put in two very strong performances on Himalayan giants, first climbing to well above $8000 \mathrm{~m}$ on Lhotse and then reaching the high point on Makalu. With the ITP's remarkable ascent of Changabang still fresh in the minds of most Australasian mountaineers, the six-man West Ridge group seemed odds-on favourites to send the first Australian(s) to the top of the world.

Muir, in particular, was a good bet to get to the top. He followed his 1982 grand tour of the Alps and then Changabang with another trip to Europe in 1983. During this trip, he attempted an even more severe route: 'Rolling Stone', on the North Face of the Grandes Jorasses. His experience was remarkable, not for his success but for his sixth sense in snuffing out dangers when none seemed apparent and convincing the four British climbers who made up the rest of the team to turn back in the face of perfect conditions. That intuitive decision resulted in a narrow escape from an enormous rock fall.

\section{Rolling Stone}

Jon Muir

As a 15-year-old, I read the book North Face-The Second Conquest of the Alps. The North Face of the Grandes Jorasses has fascinated me ever since. Although I'd climbed it by the classic Walker Spur in 1982, I was still obsessed, and keen to attempt one of the more 'modern' routes.

A year later, this time with four powerful British climbers, I headed up the Leschaux Glacier once more. We planned to make the second ascent of the 1979 route, Rolling Stone. We were a very experienced and determined team, and set off with the feeling that nothing could stop us.

After a huge feast, we bedded down on grassy terraces beside the glacier. In the first light of the new day, we sweated under heavy loads as we approached the start of the route. It was a beautiful morning but something wasn't right. Conditions were too dry, too hot, too... something I couldn't quite fathom. The atmosphere was charged with foreboding. Most of us had the giggles, a sure sign that the subconscious was registering danger even though none was apparent. Around us was a deathly silence.

We came across an ancient rucksack with odds and ends scattered about. A stove, bits of rope, a boot complete with foot - that sort of thing. It didn't do much for my already dampened spirits.

It can be hard to suggest retreat when all appears to be going well, but one must never allow pride to cloud one's instinct in a dangerous environment. I voiced my concern. The team was divided, and those in favour of continuing wanted to discuss things at the bergschrund, the point where the face emerges from the glacier.

We stood at the foot of the wall. Above our heads rose 1,200 metres of vertical. I was afraid. It seemed to take forever to convince everyone of the folly of continuing in such warm dry conditions. 
The return to Chamonix was finally agreed upon. Rob set off. He'd gone only four metres down a steep slope when it happened. Thousands of tonnes of rock, some blocks bigger than trucks, came screaming down from high on the face. The fear of death gripped us all as we struggled to get packs over our heads. Rob tried to regain the vague shelter of a small overhang just above us, but was hit in the side by a rock the size of a brick. He crumpled and began to slide down the slope towards a crevasse. His close friend and climbing partner, Jon Tinker leapt out into the firing line to save him. We watched horrified as rocks of all sizes fell among them. On reaching Rob and arresting his slide, Jon shielded Rob's body from further injury with his own. It was the bravest and maddest human action I'd ever witnessed.

We dragged Rob away from the wall and examined him. There was a huge gaping hole in his side and we sent someone to organise a chopper. Suddenly Rob leapt to his feet and insisted that he could walk down. Blood gushed from his side, completely soaking his pants and staining the snow. He looked at the wound, bewildered, and turned white.

'On second thoughts, get me that chopper!'

From 'At the edge', Rock, no. 12 (January-June 1990), p. 27.

It is innate mountain sense such as that that is so important in keeping one alive in the Himalaya. There was a good chance Muir would have to call on his intuition again as conditions often became treacherous on Everest's West Ridge.

Conditions in 1984 on the West Ridge, however, were kind to the climbers, apart from a week-long spell of marginal weather in September. As a result, they made excellent progress and by early October were in striking distance of the summit. They had negotiated the Khumbu Icefall, climbed the West Shoulder and established a high camp at $7900 \mathrm{~m}$ on the ridge. All six were in residence at the high camp on the night of 8 October. At 2.30am the next day, all except for Mackenzie, who was not feeling well, headed for the top. Muir takes up the story:

We were climbing in the Hornbein Couloir up to $8200 \mathrm{~m}$. The snow conditions were 'fast' for cramponing up. I climbed from 8000 to $8200 \mathrm{~m}$ in just an hour. It was easily a fast enough pace for us to get to the top.

We had two radios, but Fred dropped one and it nearly hit a few of us on the way down. Then we stopped and I pulled out the other one to call base camp. It was incredibly windy - we were in the jet stream - even though we were in a relatively sheltered position.

I couldn't operate the radio properly so I pulled off one of my mitts for just a minute. I still couldn't get base camp; only a couple of words came through. I chucked it back in my pack. 
In just that one minute my hands had gotten really cold. I couldn't get them warm again. I realised they were slightly damaged, slightly frostnipped.

Now it was very windy, I yelled to Craig and Peter, 'I'm going down.' Both nodded their heads. Kim and Fred were ahead, about 50 or $60 \mathrm{ft}$. The others waited until they looked down. We pointed down. They conferred and then pointed up.

There was no question in my mind-I was going down. I was worried about damage to my hands and the wind was incredible. I knew I would get frostbite if I continued. Peter, Craig and I headed down. I was still feeling clear-headed and strong and got ahead of the other two.

We were facing out. The slope was 40 degrees, not terribly steep, but it was icy and the wind was even stronger as we came out of the couloir and began the $150 \mathrm{~m}$ traverse to camp.

Then I sensed that something was wrong. I stopped in my tracks and looked around. I saw a person cartwheeling down. He almost hit Peter, who had stopped. Craig just kept on going down the North Face. It was absolutely horrifying.

He stopped on a shelf about $200 \mathrm{~m}$ below us and I went down to him but there was nothing we could do. We started to climb back up.

We saw the other two [From and Logan] descending. They had seen people very low, below the level of camp four and knew something was wrong.

Peter and I put our heads down and kept slowly slogging back up to the camp. The next time we looked up, another person went flying past us, only 20-30 m away. He went straight over the shelf, didn't even stop.

We got back to camp four. Kim had arrived so we knew it was Fred who had fallen. We radioed base camp, packed up the tents and went down. That was the last day of the expedition. ${ }^{2}$

It was a bitter end to an expedition that had promised so much (see image 20.1). On a day when it appeared that a majority of the team would reach the summit of Everest - the first time the West Ridge would have been climbed without supplementary oxygen - the team instead was rocked by the death of two of their members. Ironically, Fred From appeared to have fallen from very nearly the same spot where Craig Nottle had slipped.

2 J. Muir, Interview. 
The double tragedy on Everest's West Ridge was the death knell for the International Turkey Patrol. It seemed hard to believe that so much had gone wrong in just two years. After their blitz of the European Alps and then Changabang in 1982, it appeared they had the mountaineering world at their feet. They were young, full of energy and enthusiasm and had a wealth of climbing skills among them. They could handle almost any conditions that mountains could throw at them and they seemed to relish a storm-bound night high on a peak even more than a straightforward ascent in fine weather.

Tackling Himalayan mountains, particularly those more than $8000 \mathrm{~m}$, is a risky business, even for the world's most skilled and experienced climbers. In just two Himalayan expeditions, the ITP had been decimated and a big hole had been knocked in the ranks of Australia's young mountaineers. First, Moorhead died in a fall from Makalu, after New Zealander Denz had been swept away by an avalanche earlier in the same trip, then Nottle and From tragically slipped at nearly the same place on Everest's West Ridge.

For Mackenzie and Muir, the loss of Nottle and From was a brutal blow. It took Mackenzie a long time to recover. After he returned to Kathmandu, he tried to drown his grief in Nepalese grog. For the rest of 1984 and much of 1985, he was too depressed to go back into the mountains and spent that period at his home.

For some time after the tragedy, Muir, too, could not find the heart to head back into the mountains and climb hard. He did return to the Himalaya in 1985, but, as he recalled, he 'was still shell-shocked from Everest' ${ }^{3}$ and failed to make much progress on Shivling, a mountain in the Gangotri region of India. Muir and his wife, Brigitte, a Belgian who was a very skilled climber in her own right, were invited on the Shivling expedition by Terry Tremble, who organised the trip. The other member of the team was Ed Neve, who had been on the 1979 Dharamsura and 1982 Nanda Devi expeditions. Their attempt, which reached a high point of only $5900 \mathrm{~m}$, suffered also from the early onset of the monsoon, which dumped much heavy, wet snow on the mountain and made conditions generally miserable.

Shivling had obviously made an impression on the Muirs, as they returned the next year, 1986, with Jon's old climbing partner Graeme Hill and his wife, Veronique, Brigitte's sister and also a very good climber.

One of the holiest mountains in the Indian Himalaya, Shivling is located near the source of the holy Ganges River. It rises as a single massive spike of rock and ice, somewhat in the same vein as Changabang, and is revered by Hindus as the divine phallus of Lord Shiva. It thus represents the life-originating powers of one of the most important gods in the Hindu pantheon. 
For mountaineers, Shivling presents challenges similar to those on Changabang: soaring ridges of chiselled granite and sheer faces of ice and rock. The Australian foursome had exciting plans for the spectacular peak. While the two Hills, Brigitte Muir and the team's liaison officer, Doctor M. O. Vahanvati, would climb the original route up the North-West Ridge to the main summit, Jon Muir would attempt to climb solo a new route up the South-West Pillar to Shivling's western summit, $6505 \mathrm{~m}$.

The plan appeared reasonable on the surface of it, as Vahanvati was reportedly an experienced Himalayan climber so his inclusion in the climbing team would allow two ropes of two climbers rather than the more awkward number of three climbers. Vahanvati, however, who had even done some lead climbing on a previous Himalayan expedition, had difficulty from the very outset of the Shivling attempt in handling Himalayan conditions and, in a bizarre sequence of events, died while trying to ascend a fixed rope low on the mountain.

Graeme Hill's recollection of the fatal incident, and the lead-up to it, shed some light on what was reported very sketchily and somewhat inaccurately in the mountaineering literature at the time. Vahanvati had considerable difficulty, according to Hill, on the first attempt, which ended quickly when the two women were suffering headaches from the altitude and so retreated to advanced base camp. During that brief sortie, the liaison officer was lethargic, had nearly fallen when he dropped a water bottle and slipped while trying to retrieve it, did not have the energy to cook the evening meal (it was his turn) at advanced base camp and declined to either eat or drink at advanced base camp.

Brigitte Muir, who had climbed with Vahanvati on the first attempt, refused to rope up with him again and Veronique Hill decided that she too would not participate in another attempt. That left Graeme Hill, who agreed to another attempt when Vahanvati, despite his refusal to eat or drink again the next morning at advanced base camp, insisted he was still fit to climb. Hill knew that he was going to have to do all the hard work on the route and ascertained, after some apparent misunderstandings, that the liaison officer had experience in jumaring up fixed ropes, a technique that would undoubtedly be required often for Vahanvati to follow Hill.

Things quickly went wrong again, as Hill recalled:

To regain the ridge, I had first climbed up mixed ground, then up a short, steep pitch, possibly slightly overhung, to a large ledge. I expected the LO [liaison officer] to jumar up the steep section after me. I waited a long time for him to appear. It was warm and sunny, so I rested and ate a bit of food. But where was the LO? 
Then I heard some noises. I went to the top of the rope and saw Vahanvati only five metres below, hanging on the rope. 'I'm dying,' he gasped, 'I need food and water.' I told him to throw away his pack and I lowered him down another jumar. It was very likely that his harness was pulling up tightly on his diaphragm, making it very difficult for him to breathe. He was literally suffocating.

I went back to the gear cache and got some food and water. When I got back to him he was unconscious. I knew I had to get to him, but at first I couldn't get down. How do you get down a tight rope when you've got only one jumar and can't get on the rope to abseil? Eventually I rigged up a reverse jumar system and lowered myself down.

I couldn't feel a pulse. I looked in his eyes. He was gone. We were spinning around on the rope. I gave him a few thumps on the chest as best I could; I tried everything I could think of but couldn't revive him. He was dead.

I pulled a rope out of his pack and lowered him down. Ironically, a couple of metres down there was a good stance. Had he known how to reverse jumar, he would have survived. He must have been suffering terribly from dehydration. It was a hot, sunny day and he was wearing a lot of clothing - thermal underwear, pile jacket, duvet. ${ }^{4}$

The Australians then walked out to the nearest village to report the death to the Indian authorities. The subsequent recovery of the body by a group of Indian climbers from a nearby mountaineering school led to some misunderstanding. By the time the party arrived, Shivling had been lashed by a big storm and Vahanvati's body, minus the duvet, which Hill had removed, was frozen into the green ice. The Indian climbers apparently concluded that the liaison officer had died of exposure due to the negligence of the Australian team.

The unfortunate misunderstanding with the Indian authorities, and the shock of Vahanvati's death in most unusual circumstances, cast a pall over the team. The decision was eventually made, however, to continue the attempt on Shivling but with changed tactics. Veronique Hill retired from the climbing, so Graeme Hill joined the two Muirs on the attempt on the South-West Pillar.

The trio adopted an approach to the climb called 'capsule style' - somewhat of a compromise between siege tactics and true alpine style. A capsule-style ascent would start with the adoption of siege-style tactics, use of fixed ropes and multiple carries of gear, from the base of the mountain to the first camp. The last climber up would remove the fixed ropes and carry them up to the camp. The

4 G. Hill, Interview. 
process would then be repeated between the next pair of camps. Capsule style allows a team to remain on a route for a long time but requires much carrying of heavy loads. Unlike siege style, however, there is no connection with the bottom of the mountain and a descent forced by deteriorating conditions can be just as problematical as in an alpine-style attempt.

The three Australians employed the capsule-style tactics to good effect and, in 14 days of continuous climbing and load carrying, surmounted the South-West Pillar of Shivling - the last of the major ridges to be climbed - and stood on the mountain's western summit. The route gave them a taste of virtually every type of climbing the Himalaya had to offer (see image 20.2). 'The first third was snow and ice,' Jon Muir said, 'the second third mixed, and the top third rock. ${ }^{5}$

Hill's account of one of his leads high on the ridge gives an idea of the delicacy and standard of the climbing:

The climbing was getting trickier, and I had changed into my friction boots to aid progress. With a light rack of gear I bridged off up the next pitch, pushing as much as I could rather than pulling on anything that looked loose. The granite was badly shattered in places, and the runners were mostly placed behind suspicious-looking flakes, but I reasoned that if I had enough of them one would hold before I hit my belayer. The bridging got steeper and finally led to a short overhang which was disposed of with a few quick layback moves, a technique more suited to rockclimbing at home on Mt Keira than here at 6,000 metres. ${ }^{6}$

Muir's assessment of the climbing difficulties corroborated Hill's impressions: 'There was a lot of grade 16 to 18 rock climbing, with the odd pitch of 20 or 21 . There was some aid-climbing [where the climber uses hardware placed on the mountain to aid his upward progress] at A2, A3 and A4 standard. ${ }^{7}$ In fact, Muir led the crux pitch, a seven-hour struggle up a long corner system that he rated at $21, \mathrm{~A} 4$.

The ascent of the South-West Pillar of Shivling eclipsed the 1982 ITP ascent of Changabang in technical difficulty. It was just as impressive because of the small size of the team, all three of whom shared the leading and the onerous load carrying during the 14 days of climbing.

For Jon Muir, it was a welcome move back into the ranks of successful Australian Himalayan mountaineers. After the disappointment and tragedy on the West Ridge of Mt Everest in 1984 and the earlier unsuccessful attempt on Shivling, Muir's very strong performance on the South-West Pillar in 1986 put him back

5 J. Muir, Interview.

6 Hill, G. 1986, 'Shivling sojourn', Wild, no. 22 (Spring), pp. 44-8.

7 J. Muir, Interview. 
at the forefront of Australian alpinists. He did not rest on his laurels. For the third year in succession, he was in India's Gangotri region in 1987, for a trip that proved he had phenomenal strength as well as remarkable technical skill to display in the Himalaya.

Again in 1987, Muir climbed with his wife, Brigitte, along with Australians Louise Shepherd, Geoff Little and New Zealander Lydia Bradey, who was later to be involved in a very controversial claimed ascent of Mt Everest. Shepherd, one of Australia's leading rock climbers, was on her first trip to the Himalaya.

The team's objectives lay in the Kedarnath Range, just next to Shivling, and consisted of a traverse of Kedarnath Dome (6830 m) and Kedarnath Peak (6968 $\mathrm{m})$, as well as an attempt on the East Face of neighbouring Meru Peak.

Although not technically difficult, the traverse of the Kedarnath mountains was a very serious undertaking as it involved a long, committing climb at high altitude into positions from which retreat would be difficult. The team's first attempt at the traverse proved just how tricky an apparently straightforward technical climb could be in the high Himalaya, as Muir wrote:

We bivvied at 16,500 ft [5029 m] on Kedarnath Dome but Louise was unable to go further due to the altitude. At Bivvy 2 at 18,500 ft [5639 m] Geoff and Brigitte suffered similarly and only Lydia and I headed off on the 20th [May] to the third bivvy at 20,500 ft [6248 m]. Feeling strong and confident, we traversed Kedarnath Dome [22,500 ft, $6858 \mathrm{~m}$ ] to a fourth bivvy in a 'schrund at 22,000 ft [6706 m] on the col between the Dome and Kedarnath Peak. The next day we were trapped by a storm and with Lydia now suffering from going too high, too fast, our situation was very serious.

On the 23rd, the 6th day of the climb, we had to descend in the storm and it turned into a true epic. With no rope we had to descend difficult serac barriers in appallingly soft snow and were hit by six avalanches. After a long and frightening struggle that went on all day, we waited, in an apparently safe spot with avalanches coming down on both sides of us, for nightfall. We could then continue descending to our sixth bivvy at the foot of the face. All next day was needed to plough our way back to $\mathrm{ABC}$ [advanced base camp], and on the 25th we reached Base Camp, weary and wasted. ${ }^{8}$

Little and Brigitte Muir had battled on also and eventually reached the top of Kedarnath Dome, which at least was some consolation for them. The team's other climbing plans, however, had to be modified. Little, Bradey and Brigitte

8 Muir, J. and Bradey, L. 1987, 'Gangotri', New Zealand Alpine Club Bulletin, September, pp. 22-3. 
Muir retreated to join the large 1987 New Zealand Karakoram expedition, while Shepherd went down the valley for a while to recover from her first bout with high altitude. That left Jon Muir, but he had suffered frost-nip on his fingers and toes during his earlier ordeal and was forced to abandon his solo attempt on Meru. He was not, however, finished with the Kedarnath peaks.

In an amazing display of speed and stamina, he raced across the traverse, this time in the opposite order, in just 41 hours. The ascent of Kedarnath Peak, the higher of the two summits, was completed under moonlight in beautiful conditions, but when storm clouds began to appear as he rested at the col, Muir had visions of a repeat of his earlier epic:

$[\mathrm{H}]$ aunted by our epic three weeks before, I quickly packed and moved on, feeling hunted. Intermittent snow storms swept over me as I traversed over Kedarnath Dome again. Starting down the northeast ridge and then dropping down the northwest face, I lost height rapidly. By making a number of controlled bum slides, I managed to descend the $7,000 \mathrm{ft}[2134 \mathrm{~m}]$ to the glacier in two hours and another four hours to advance base by dark. ${ }^{9}$

Meanwhile, Muir's teammate Geoff Little was pulling off another coup for Australian Himalayan mountaineering in the Karakoram. The New Zealand expedition that he and Brigitte Muir had joined was originally targeting two massive peaks - Gasherbrum I (Hidden Peak), 8068 m, and Baltoro Kangri (Golden Throne), $7300 \mathrm{~m}$ - but the latter was declared out of bounds because of its proximity to the border clashes between Pakistan and India.

The 15-strong team therefore set to work on Gasherbrum I. They quickly discovered that the mountain was also beset by high risks - this time, of a less anthropogenic nature. Their intended line of ascent-via a Japanese route up a couloir and through a series of icefalls on the North-West Ridge/Facewas abandoned due to avalanche danger. Their high point was only $6500 \mathrm{~m}$. A smaller group then teamed with some Basque climbers to attempt a route originally climbed by Reinhold Messner and Peter Habeler, but were turned back at $6800 \mathrm{~m}$ by dangerous conditions. In fact, the whole mountain was in a treacherous state. Four Pakistani climbers were swept to their deaths by an avalanche, an incident that convinced most of the New Zealand team to forgo any further attempts on the peak.

Three of the expedition members, on the other hand, did not want to come away from the Karakoram empty-handed. Just nearby lay Gasherbrum II - at 8035 m, 
one of the world's 14 highest mountains and within easy striking distance from base camp. The only problem was a bureaucratic one; they held no permit for Gasherbrum II.

That obstacle was overcome when the Pakistani liaison officer unofficially approved the attempt in return for a good deed the New Zealanders had done for one of his countrymen. They had saved the life of a Pakistani army officer who had fallen into a deep crevasse on the Gasherbrum Glacier. The liaison officer no doubt thought turning a blind eye to the Gasherbrum II attempt was an appropriate gesture of gratitude for the rescue.

Still, there was little time remaining; in fact, just time enough for a single, alpine-style strike. That, however, was enough for Bradey, Little and New Zealander Carol McDermott to charge up the South-East Ridge, the route of the original French ascent. It took the trio only three days from camp one, low on the Gasherbrum I/II massif, to snatch the last-ditch victory at the very end of the expedition.

The Australian summiteer, Geoff Little, was a relative newcomer to Himalayan climbing, and indeed to alpine climbing. Although Little had been rock climbing since 1975-primarily at Mt Arapiles and the Grampian ranges - he did not get a start in alpine climbing until 1986 with a trip to New Zealand. He did not waste any time tackling the big ones. 'The second day I had crampons on I climbed Mt Cook,' Little said, 'and then later in the same trip I got up Tasman [New Zealand's second-highest peak]. ${ }^{10}$

Later in 1986, Little joined Lydia Bradey for a short trip to the Kulu Valley in the Indian Himalaya, where they climbed a number of smaller peaks in the 5000-5800 m height range. Gasherbrum II, then, was a very big step up in altitude for Little.

Gasherbrum II was also a big step for Australian Himalayan mountaineering. It was only the third $8000 \mathrm{~m}$ peak climbed by an Australian; the first two were Everest in 1984 and the Army Alpine Association (AAA) expedition's ascent of Broad Peak in 1986. Little's climb of Gasherbrum II was important also in that it was not connected with Mt Everest, as either a training climb for or an attempt on the world's highest peak. It represented a maturing and broadening of Australian interest to many diverse areas of the Greater Himalaya - a trend that was gathering momentum in the mid-1980s.

10 G. Little, Interview. 
Only months after his marathon performance on the Kedarnath peaks, Jon Muir was back in the Himalaya again. He was a member of Peter Hillary's four-man team that attempted the South-West Pillar of Mt Everest but was beaten back by the intense cold and unusually vicious winds of the post-monsoon season.

The trips to Shivling, the traverse of the Kedarnath Range and the attempts on Mt Everest seemed like a well-planned build-up for the Australian Bicentennial Everest Expedition (ABEE). Muir, however, obviously did not plan it that way. In fact, even after he returned from the 1987 Everest attempt, he still did not know that he would be going on the ABEE, which was then only a few months away.

I had answered an ad back in 1985 and applied for the ABEE then. But then this letter came, and I was asked to pay money-instalments of $\$ 1000, \$ 2000$, etc., over the next three years. I couldn't afford it. I didn't work; I just climbed.

I got back from the South-West Pillar expedition to Everest on 19 November 1987, and just before Christmas I got a phone call from the ABC [Australian Broadcasting Corporation]. They wanted me to go along on the ABEE and shoot film for them. And they would pay for it! So a couple of months later I was back at Everest again. ${ }^{11}$

It was a good move - for the ABEE and for Muir himself. The ABEE knew it was getting one of Australia's best Himalayan mountaineers and had, in fact, lobbied hard with the Australian Bicentennial Commission for Muir's inclusion as a climber/cameraman. It was, however, a different Jon Muir from the brash young climber who went to Changabang in 1982. He still had enormous energy and enthusiasm and, of course, that zany sense of humour, but gone forever was the innocence of the early days of the ITP. Muir had seen too many of his close friends perish in the Himalaya and he was well aware of the hazards he would face yet again. He was fit, strong and skilled and by 1988, had amassed the depth of experience in the mountains that made him the complete Himalayan mountaineer. 


\section{Part 6: Everest II-the bicentennial ascent}





\section{A strained relationship}

Jon Muir's very late inclusion on the Australian Bicentennial Everest Expedition (ABEE) team was beneficial to him for more reasons than just the financial. As long as he thought the ABEE was too expensive for him and that there was no possibility of participating in the expedition, he could happily climb away on Himalayan mountains of his choosing, oblivious to the developments that were occurring in the organisation of the ABEE. The tortuous task of getting the ABEE from the drawing boards of Australian meeting rooms to the base of the Khumbu Icefall was someone else's problem — and quite a problem it turned out to be.

Planning proceeded throughout 1985 and into 1986 on the basis of the understanding reached between the Army Alpine Association (AAA) and the civilian group two years earlier (see Chapter 16). The groundwork for the execution of the expedition began to be laid. Alternative types of equipment were investigated and tested, the all-important matter of food was considered in earnest and more support, in the form of donations, discounts and cash gifts, was actively sought.

By mid-1986, however, some hard decisions had to be made about personnel and logistics. Although the AAA and the civilian group wanted to retain their own routes in their own chosen styles, it was becoming increasingly clear to the civilians that that degree of freedom just was not feasible with the resources at hand. The AAA had prepared a detailed plan for the West Ridge and it required more resources than the $\mathrm{ABEE}$ looked likely to raise. The route would be attempted in the traditional (siege) style, which would require a lot of fixed rope, food, tents, anchors, carabiners and all the other paraphernalia required for high-altitude mountaineering. More specifically, the plan called for 12 AAA climbers, five camps on the ridge, the use of bottled oxygen above $7700 \mathrm{~m}$ and the installation of a winch on the Lho La to haul loads up the steep headwall below. In addition, it would require a large number of Sherpas as high-altitude porters and, by 1988, Sherpas had become very expensive indeed. When the sums were done, the estimated cost of the AAA West Ridge route was about five times that of the civilian South Col attempt. There was concern among some civilians that the West Ridge route could easily have consumed all of the resources available to the ABEE.

Mike Rheinberger put the problem succinctly: 
It became obvious that the two approaches to climbing the mountain were completely out of kilter. The army plan called for a massive assault on the West Ridge involving as many as 16 climbers, just as many Sherpas, and huge amounts of oxygen...the original estimates were for something like 100 bottles. It was going to be a mega-attempt on the West Ridge, whereas we were still wishing to go lightweight style on the South Col route. ${ }^{1}$

A related problem was the number of qualified climbers. Early on, the AAA had set out criteria for inclusion in the army part of the ABEE team:

1. contribute $\$ 5000$ towards the expedition

2. have had Himalayan experience and climbed to $20000 \mathrm{ft}(6000 \mathrm{~m})$

3. ability to put team interests before individual interests

4. be able to climb Alpine Grade 3

5. be fit, determined and capable of interacting with other members, nationalities and cultures. ${ }^{2}$

The crunch came after the 1986 Broad Peak expedition when the AAA had to put forward its team for the Everest attempt. At that time, at most seven AAA members satisfied the well-known selection criteria. Two additional AAA climbers would have qualified had they made the necessary financial commitment. Had they done so, the AAA would still have been well short of the number of qualified mountaineers it needed to attempt the West Ridge in the traditional style. Furthermore, it could be argued that, given the seriousness of the West Ridge route, qualified climbers should have had several Himalayan expeditions under their belt and should have climbed to well above $20000 \mathrm{ft}$ $(6000 \mathrm{~m})$.

The matter came to a head at the October 1986 ABEE board meeting. After a prolonged and sometimes heated discussion, it was reluctantly decided that the two teams - AAA and civilians - would combine forces and attempt only one route. It was a decision forced on the board by the realities of available resources and the number of qualified climbers. There simply was little choice. The board members - civilian and military - agreed that it was better to have one strong team put at least one Australian on top of Everest during the bicentenary than to have two separate teams each get 90 per cent of the way up their routes.

The decision to form one team precipitated considerable conflict within the ranks of the AAA, a rift that plagued the final build-up to the ABEE and, unfortunately,

1 M. Rheinberger, Interview.

2 Jim Truscott maintained that criterion no. 5 was 'an ABEE add-on and not part of the AAA criteria'. 
soured relationships during the expedition itself. Like most conflicts that occur during the course of Himalayan expeditions, this one was rooted in differences of objectives, styles and philosophies_-legitimate points of difference among climbers - and was overlaid and exacerbated by personality conflicts.

Underlying the conflict was the change of style necessitated by the merger of the two teams. Gone were the two separate styles originally proposed within the 'umbrella' expedition. Now there truly was one expedition and a modification to the traditional-style attempt with large numbers of Sherpas was a significant change. The compromise reached between the AAA and civilian board members called for a team of climbers to attempt the South Col route without the help of high-altitude porters - the philosophy always espoused by the civilians. The climbers themselves would do all the load carrying as well as the lead climbing. The use of supplementary oxygen was left to the discretion of the individual climbers, but enough would be taken for several summit attempts.

The merger also brought about a more subtle but very much more profound change to the original plan: a change to a single climbing philosophy. As long as the two-route concept was retained, the AAA could attempt the West Ridge with a more structured approach to the climb. There would be a more definitive chain of command with a clear division of responsibilities and organisation of personnel and equipment. And that approach would have made considerable sense in a traditional-style attempt with a large number of climbers and Sherpas, long lengths of fixed rope, large and well-stocked camps and a long time on the mountain. There was, however, no way a majority of the civilian climbers would have accepted that style of expedition. The AAA would have to compromise and accept a style of operation that was palatable to the civilians.

The civilians, however, had to make even more compromises. Gone was their original idea of a small, closely knit group to attempt Everest in lightweight style. Now there would be a large team and the attempt would be made with fixed camps and ropes. In essence, the expedition would be carried out in a style very similar to that which the military climbers were comfortable with, but without the use of high-altitude Sherpas. This one concession to their original idea seemed under threat from those AAA climbers (referred to, for convenience, as the 'West Ridge group') who still wanted a traditional-style attempt with the use of Sherpas to carry loads. As Peter Allen recalled, 'When we combined, our [the civilians'] original idea was lost, but we continually fought a rearguard action for years to retain some sort of style, to climb the mountain without Sherpas. ${ }^{3}$ 
After the October 1986 ABEE board meeting, the rift within the AAA deepened. There were several AAA climbers who were concerned to varying degrees about the merger of the teams and the abandonment of the West Ridge route. Jim Truscott was the most vocal, but Rick Moor, Brian Agnew, Terry McCullagh, Jim van Gelder, Andrew Smith and James Strohfeldt and perhaps others had reservations as well (van Gelder and Strohfeldt were, strictly speaking, members from the civilian side but had climbed on AAA expeditions and were closely associated with the AAA). Much of the anger and frustration that built up among some of the West Ridge group was vented towards Zac Zaharias, one of the AAA members of the ABEE board. It was Zaharias who initiated climbing contact with the Melbourne-based Everest aspirants by inviting Allen on the 1983 Nilgiri North expedition, and who, along with Peter Lambert, agreed in 1986 with Rheinberger's assessment that the AAA did not have the resources and manpower to mount a credible attempt on the West Ridge. Pat Cullinan too, however, supported the ABEE board's decision as the best for the AAA. $\mathrm{He}$ also felt that a single team on the South Col route had the best chance of success. Curiously, Cullinan, and to a large degree Lambert, were immune from the criticisms of the West Ridge group. Zaharias copped nearly all of it.

Many of the West Ridge group felt strongly that Zaharias had too quickly and easily abandoned the concept of an autonomous AAA attempt on Mt Everest. From their point of view, the primary objective was for the AAA, as a club, to mount its own expedition with its own members in its own style. It was something they strongly believed in and something they had worked very hard for throughout the 1980s. When the objective was changed significantly, they felt they had been sold out. The change of plans became known as 'Zac's betrayal'.

The change of objectives was particularly difficult for Truscott to accept. Jim Truscott had been a pillar of the AAA from its very start. He was one of two cadets who had taken up climbing even before the Peter Gration-inspired revitalisation of the AAA in the late 1970s. He was a member of the AAA's first expedition to the Himalaya - to Ganesh IV in 1981 - and was nearly killed in the avalanche that blasted camp two. He had been involved in the AAA's plans for a 1988 Everest trip from the very start and laboured hard on behalf of the expedition. He marshalled support from various quarters within the army and investigated and tested gear for the ABEE team. He had worked very long for an army expedition to Mt Everest and the amalgamation with the civilians had irrevocably altered the style and ethos with which he thought an AAA team should attempt the mountain.

In addition, some within the West Ridge group felt honour-bound to push for more involvement by the AAA, and the army in general, in the expedition. Not only was it their style of leadership and organisation they strongly preferred, 
the army had contributed so much in the way of material and logistical support that if there had to be a merger, the single route should be attempted in the traditional AAA style.

There was yet another problem that the merging of the two teams caused for some of the AAA West Ridge group. As long as the AAA was attempting the West Ridge by itself in traditional style, a large climbing team would be required and every fit, reasonably experienced AAA mountaineer would be on the team. With the merger, however, there could be as few as five or six military climbers on the combined team. Suddenly there would be competition for places and some of those who would have gone on a West Ridge team would now be left at home.

Truscott, McCullagh and some of the others (for example, Rick Moor and Andrew Smith) of the West Ridge group did not give up their hopes for a separate West Ridge attempt even after the October 1986 ABEE board meeting. They continued to lobby Zaharias, Lambert and Cullinan - the three AAA members of the board - for a reversal of the decision to amalgamate teams. Their efforts were to no avail, however, as the ABEE board stuck to its decision to merge even when it appeared at one stage that the decision could cause a formal split in the ranks of the AAA climbers.

Zaharias copped much of the pressure. He said:

As late as 1987, we still had a lot of letters coming to us demanding that we split and have our own routes. I went to Jim Truscott and said, 'You want the West Ridge? You take it, and all the climbers you reckon we've got.' I knew we didn't have enough climbers with the experience and judgment to do a demanding route like the West Ridge. ${ }^{4}$

The question of what to do with the West Ridge permit was caught up in some interesting international politics. Long after the Australian permit for the South Col route had been granted, Nepalese authorities sanctioned the huge tri-nation (China, Japan, Nepal) expedition for the same route (see Chapter 22). The trination team, in fact, also held a permit for the North Ridge on the Tibetan side of the mountain and hoped to do a double traverse of Mt Everest. At one stage, it looked like the ABEE could be forced off the South-East Ridge (South $\mathrm{Col}$ ) route, but the friendly relations between Nepal and Australia (enhanced by the Nepalese King's visit to Australia about that time) and the fact that the then Prime Minister, Bob Hawke, was Chief Patron of the ABEE, saved the day. Nevertheless, the ABEE board thought it prudent to retain the West Ridge permit.

4 Z. Zaharias, Interview. 
By early 1987, with only a year to go to the climb itself, it was time for the team members to bury their differences and pull together for the final preparations. Yet, if anything, the problems worsened during the first half of 1987. Certainly communication was a big problem. Truscott and others in the West Ridge group complained that they were not consulted enough about ABEE board decisions and Zaharias and Lambert noted that important AAA decisions were made when they were absent from the meetings.

Unfortunately, at this point, the actions of some within the West Ridge group raised the level of tension even higher. For example, an open letter was written to the board in which the case for a separate AAA attempt on the West Ridge was raised yet again in a forceful, if somewhat rambling and confused, way. The letter went on, however, to attack the motives and personal integrity of ABEE board members. Also, there was an attempt to add another AAA representative to the board, thus tipping the balance of power in favour of the AAA over the civilian group. At one point, Peter Lambert was asked directly to step aside from the ABEE board, presumably to make way for someone with greater leanings towards the views of the West Ridge group.

The selection of the AAA part of the climbing team worsened the split, as Lambert recalled:

Zac and I did a list, based on experience, ability, personality, temperament, etc. We could choose only six or eight. When we published the list and some people saw that we hadn't included them, we had all hell to pay. Most of the anger was directed at Zac, although I had as much to do with the decisions as he did. ${ }^{5}$

Peter Lambert was probably the AAA member most sceptical about their chances of success if they were to stick with their own attempt on the West Ridge: 'I lost my faith in the ability of the AAA to do anything other than a "Scott-ofthe-Antarctic" type expedition. If they had gone for the West Ridge, there's no way they'd have gotten to the top. ${ }^{6}$ Not surprisingly, Pat Cullinan, the leader of the original West Ridge team, disagreed: 'Personally, I believe that with the numbers we had plus Sherpa support, the plan would have worked. ${ }^{7}$

The split between Zaharias/Lambert and Truscott and the others of the West Ridge group could easily have become a formal split within the AAA. 'Zac and I had very real fears that if the AAA went its own way,' Lambert said, 'we'd go with the civilians.' ${ }^{8}$

\footnotetext{
P. Lambert, Interview.

Ibid.

P. Cullinan, Interview.

P. Lambert, Interview.
} 
Ironically, just as the AAA seemed as divided as ever during the final hectic preparations for the trip, relations with the civilians could hardly have been better. To an outsider, the AAA-civilian interface would have been the most likely point of conflict, but the inclusion of civilians on AAA expeditions, such as Nilgiri North and Broad Peak, had led to an excellent working relationship. Although many ABEE members, civilian and military alike, made significant contributions to the planning and execution of the expedition, Zaharias and Lambert were particularly impressed with the knowledge and expertise that Peter Allen and Mike Rheinberger brought to the ABEE.

'Peter Allen's experience was of tremendous value,' Lambert recalled:

The AAA would say, 'Let's take a tonne of carabiners because we might need them', while Allen would say, 'Let's take 35 carabiners because that's how many I know I'll need.' Peter and Mike Rheinberger were very good at this sort of organisational detail. They really knew what they were doing. In fact, the work that Peter and Mike put in was the most significant for the success of the expedition. They had a much more measured, experienced and rational response than the AAA to the requirements of the expedition. ${ }^{9}$

Another person who contributed much to the organisational development of the ABEE was Charlie Hart, managing director of a Brisbane-based company, Proplan, which specialised in critical path planning and programming. Hart's computer services were most useful in keeping track of the more than 1000 different items that the ABEE took to Mt Everest.

Although attention to organisational detail is undeniably important to the success of an expedition as big as the ABEE, leadership is even more critical. When a large number of individualistic, highly motivated mountaineers, each with their own personal ambitions, are brought together in the same expedition, the task of keeping them working together as a team effectively and efficiently can be a monumental one. Choosing a leader to undertake that task was a problem the ABEE board was grappling with in mid-1986.

There was one rather clear choice. Rheinberger had the experience and leadership skills to head the ABEE and there was considerable support within the board for his appointment. In fact, Pat Cullinan formally requested his appointment as leader. The board, however, decided that the leader and team doctor should not climb above camp two in the Western Cwm (a similar restriction applied to the leader and doctor of the 1985 New Zealand Alpine Club Everest expedition). As Rheinberger had a strong personal desire to reach the summit, he declined the 
offer to be leader. The ABEE board was then forced to take the rather unusual step of drawing up a set of selection criteria and searching for a group of suitable candidates.

Five potential leaders - three from the military and two civilians-were eventually identified and evaluated. They were: Brigadier Tony Hammett, a regular soldier and a former Olympian; Major General Sharpe, an Army Reservist and former Commander of the 2nd Division; Lieutenant Colonel Paul Feeney, an Army Reservist with some mountaineering experience; Peter Arriens, a civilian who had served as officer-in-charge of the Antarctic Division's Mawson Base; and Austin Brookes, a New Zealand-based mountaineer who had led two previous Himalayan expeditions.

The board opted for Brookes. He easily had the most experience in leading Himalayan expeditions; in fact, he was the only one of the five candidates to have led a Himalayan climbing trip. Indeed, it was Brookes who led the $1985 \mathrm{New}$ Zealand attempt on the north side of Everest, the one so plagued by avalanches that the team was lucky to escape without loss of life. Mike Rheinberger and Peter Allen had been climbers on that expedition, so were in an excellent position to judge Brookes' leadership qualities. Their strong recommendations no doubt had much to do with Brookes' selection.

On one point, though, Brookes nearly did not qualify. A requirement for selection to the ABEE was Australian citizenship and Brookes, originally from Great Britain and a longstanding New Zealand resident, had just moved to Australia and, providentially, had just begun the process of obtaining Australian citizenship. In every other way, however, he was well qualified to lead the ABEE.

His climbing career started about as far away from the South Island of New Zealand that one could possibly go: arctic Norway and Sweden. There he and a friend from England climbed a few mountains and, in the process, Brookes was bitten by the climbing bug. On returning home, he became involved in rock climbing through the Leeds University climbing community and, like many English climbers, subsequently made several trips to the French Alps and the Dolomites.

Brookes moved to New Zealand in 1962 to take up a teaching position in South Island and quickly became involved in mountaineering in the Southern Alps through the New Zealand Alpine Club (NZAC). He focused on the Darran Mountains of Fiordland, where he made seven first ascents of routes, and the Mt Cook district, where he was on the first ascent of the Sheila Face of Mt Cook itself.

After a brief return to the United Kingdom in 1968-70, when he climbed extensively in Wales and the Lakes District, he was back in the mountains of 
New Zealand and broadened his skills to include ski-mountaineering. In 1973, Brookes began to travel further afield for his adventures; he was employed as a survival instructor for an American group in Antarctica. Three years later, he was leader of a most successful New Zealand expedition to Cerro Stokes and Aconcagua in South America. The team made three first ascents and climbed the Polish Direct route on Aconcagua, the highest mountain outside the Himalaya.

In 1981, Brookes got his chance to not only climb in the Himalaya, but to lead a New Zealand expedition to one of the highest remaining unclimbed mountains in the world: $7703 \mathrm{~m}$ Molamenqing in Tibet. The expedition was successful and the ascent still stands as the highest virgin peak climbed by a New Zealand team. In 1985, of course, Brookes was again in the Himalaya, this time leading the New Zealand expedition to the north side of Everest.

This very impressive background of mountaineering experience was a great boost to Brookes in the ABEE leadership selection process, but so too perhaps was his relaxed attitude. 'I was invited for an evening at Middle Head Barracks in Sydney,' he recalled. 'I didn't realise it was the selection evening so consequently I didn't take it too seriously. I was quite surprised when I found out that I'd got the job. ${ }^{\prime 10}$

Brookes was soon plunged into the thick of the planning action. Joined by Zaharias and Allen to form an executive committee to handle the day-to-day operation of the expedition, he and his colleagues had less than 18 months to get the largest Himalayan expedition ever mounted from Australia to Everest base camp and hopefully then to the top of the mountain.

If Brookes had harboured any concerns about the organisation of the ABEE during the critical final year before departure for Nepal, he need not have. With the full support of the Australian Bicentennial Authority (ABA), the army and a host of sponsors, and with the considerable organisational skill and drive of the AAA coupled with the experience of Peter Allen and Mike Rheinberger, there was nothing to worry about. Task leaders were assigned to look after every aspect of the expedition, from communications and food to equipment and oxygen. No detail was omitted. In December 1987, most of the ABEE equipment and supplies were flown from Richmond Air Force Base in a C-130 Hercules aircraft to Kathmandu. Then, in a testament to the ABEE's organisational skill, and to Peter Lambert's nous as 'movements' task leader, the 6 tonnes of gear cleared Nepalese customs in only four hours - a record (see image 21.1).

The gear was then in Nepal and so too, a few months later, would be the climbers. All that remained was for one or more of the Australians to stand on top of $\mathrm{Mt}$ Everest. That three Australians did eventually climb the mountain is now history

10 A. Brookes, Personal communication, 1 November 1989. 
and, according to the international mountaineering press, not particularly noteworthy history. That was a big injustice. The magnificent achievement of the ABEE deserved much better recognition. It was an outstanding effort, characterised by grim determination and exceedingly hard work, even by Himalayan standards, and by a large measure of drama. Just when it appeared all of the hard work would be in vain, success was snatched at the very last moment in a heart-stopping drive for the summit against all odds. 


\section{ABEE: the climb}

The dramatic finish to the Australian Bicentennial Everest Expedition (ABEE) was a fitting climax to a tremendous team effort, one that had begun years earlier with the first training climbs and planning meetings. The final stage of the 1988 Australian success on Mt Everest, however, began where all of the preparation, planning and training left off: at the foot of the mountain (see images 22.1, 22.2 and 22.3). For those attempting Everest by the South Col route, there is no more daunting start to a climb than the Khumbu Icefall.

'When you arrive at Base Camp,' Pat Cullinan recalled, 'you're face-to-face with Everest. It's right in front of you. But what's really staring you in the face is this massive icefall.' ${ }^{\prime}$

Jim Truscott was no less impressed: 'We'd always look up at this damn thing and wonder how we were going to come to terms with it. I went through the Icefall 21 times on the expedition and I kept thinking, if it's going to happen to you, it's probably going to happen in the Icefall.' ${ }^{2}$

Perhaps the Australians had good reason to be wary of the Khumbu Icefall and its considerable reputation for nasty surprises. During the 1972 British attempt on the South-West Face of Everest, an Australian, Tony Tighe, who was helping at base camp, was tragically killed in the icefall during the final days of the expedition. Chris Bonington, the expedition leader, had allowed Tighe to go up the icefall route:

[T] o reward him [for his work at base camp] I agreed to him accompanying Sherpas on a trip to Camp I to bring down the final loads, so that he should enjoy the wonderful view up the Western Cwm. Moving a little more slowly than the Sherpas, he was caught when an ice tower collapsed. It could have happened to any of us - such is the cruel Russian roulette of the Khumbu Icefall where it is impossible to guarantee a safe route. ${ }^{3}$

The treachery of the icefall was further impressed on the 1988 Australian team when they discovered early in the trip the bodies of two Sherpas killed in the icefall during the Canadian expedition of 1982.

1 P. Cullinan in Ryan, R. (dir) and Humphrey, S. (prod.) 1989, One More Step. The Australian Defence Force on Everest 1988, Video by Australian Army and Film Australia.

2 J. Truscott in ibid.

3 Bonington, C. 1989, Mountaineer, Diadem Books, London, ch. 5. 
The icefall is a serious matter for any climber who ventures into it, but it was far more serious for the ABEE team. Nearly all expeditions that attempt Mt Everest via the South Col route employ Sherpas as high-altitude porters. The Sherpas usually have to put the route through the icefall and then make repeated trips through it to stock the higher camps. The mountaineers themselves then need to make only a very few trips through the icefall and thus minimise their exposure to the danger. By eschewing the use of high-altitude porters, the Australian climbers were not only making a lot more work for themselves, they were exposing themselves to considerably more danger. They would have to do all the dirty work themselves by making repeated backbreaking load hauls through the labyrinth of tottering ice towers and menacing crevasses.

What is the Khumbu Icefall really like and what makes it so treacherous? It is perhaps best described as 100-200 massive blocks of ice the size of three or four-storey buildings and 100-200 massive crevasses thrown together in a chaotic jumble. It is formed by the ice of the Western Cwm flowing over the lip of the cwm for about 600 vertical metres down to the floor of the upper Khumbu Valley. The ice is always moving, albeit slowly, and that motion leads to blocks suddenly tumbling over and crevasses unexpectedly opening where there was smooth snow seconds earlier. 'Terrible teetering towers' is how Mike Rheinberger described the seracs or ice towers. 'Lying in your sleeping-bag at base camp,' he recalled, 'you'd hear rumbles and crunches in the icefall all through the night.' Truscott added, 'We had names for parts of the icefall, like the Marblefield, the Bowl [which later disintegrated] and Hideous Hanging Seracs. $^{5}$

As they would have to spend so much time in the icefall, the ABEE team took much care in choosing and securing the best possible route. The route finding was entrusted to 'Dad's Army', a five-man climbing unit headed by Rheinberger and including Jon Muir, Jim Truscott, Phil Pitham and James Strohfeldt. Austin Brookes, in following the strategy he used in the 1985 New Zealand expedition to Everest, had divided up the team into four units of four or five climbers each. It made much sense to send Dad's Army into the icefall first as Rheinberger and Muir had been through it just months earlier in the 1987 attempt on the South Pillar so had a good idea of how to attack it.

They accomplished the task in good time overall and with a minimum of snags. 'The Icefall was reasonably straightforward because of the experience of Mike Rheinberger and Jon Muir,' Brookes pointed out, 'without them it would have

4 M. Rheinberger, Interview.

5 J. Truscott, Personal communication. 
been a much bigger obstacle. It was always the most dangerous part of the route - and it was dangerous. The numerous journeys every climber had to make to shift the gear to Camp II was a real strain on the nerves.' ${ }^{6}$

The route was secured with fixed ropes and aluminium ladders to bridge crevasses and scale ice walls (see image 22.4). In all, nearly $4000 \mathrm{~m}$ of rope was fixed and 50 ladders of various lengths were put in place. It was slow and painstaking work but it was needed to maximise safety for the numerous carries each climber would have to make through the icefall.

Then the drudgery began: getting more than 1 tonne of gear through the icefall and up into the cwm for the attempt on the mountain itself. Strohfeldt vividly described what those carries through the icefall were like:

I remember also how easy the danger was to come to terms with - at least at one level. The Icefall had to be passed in order to climb the mountain, so we simply had to do it as often as necessary. Make it as safe as possible, pause, then run under a serac; clip onto the fixed rope to jump a crevasse; knock the snow off one's crampons to balance across an aluminium bridge; leave the rest to fate! The Icefall never got boring. It flowed and fluxed, sometimes whole sections buckling and heaving overnight, tearing aluminium ladders to pieces and stretching ropes whip tight. Sometimes it was knee deep in new snow, in others blunt crampons would skid and screech on the hard ice. It was never safe; but it was always one hell of a place to be. ${ }^{7}$

Muir would not argue with Strohfeldt's description as he had another close call, reminiscent of his lucky escape from the icefall in 1987:

I was flying through the air down a massive crevasse. Eight metres down, the fixed line stopped me with a jolt which almost ripped the rope from my hands. The collapsed snow bridge kept going down into bottomless blue depths. The facts of the situation, and the advice for such a predicament, raced through my head-you're alone, the crevasse is very deep, you're tired; do something quick! ${ }^{8}$

Muir took his own advice and extricated himself quickly from the crevasse.

Not all feelings about the icefall were negative. Paul Bayne recalled its austere beauty as one of the highlights of the expedition:

6 A. Brookes, Personal communication, 1 November 1989.

7 J. Strohfeldt in Wilby, S. 1989, Beyond the Icefall, Child \& Associates, Sydney, ch. 5.

8 Muir, J. 1989, 'To the roof of the world', Wild, no. 31 (Summer), pp. 36-9. 
Trips through the icefall were a real high point for me, for the beauty of it. It was an amazingly wild and fantastic place. I remember sometimes descending in afternoon storms, having dumped heavy loads, and coming down through the mist listening to the walkman, looking around at the wild beauty of the place. But it was never a place I wanted to hang around. ${ }^{9}$

Beyond the icefall lay the Western Cwm and although passage through it was not completely safe, as avalanches threatened from Everest's West Shoulder and the Nuptse Wall, it was less dangerous than the icefall. Camp one was established on the lip of the cwm, just above the top of the icefall, and camp two was set up near the head of the cwm, at the head of the giant horseshoe formed by Everest, Lhotse and Nuptse.

The problems of load carrying from camp one to two lay not in technical difficulty or in danger, but in the energy-sapping struggle through soft snow in searing heat up a gently inclined slope. The Western Cwm, with its floor and walls of ice and snow, is probably one of the world's biggest natural solar reflectors. Anyone caught out in it with a heavy load in the middle of the dayas many who made the carry from base camp to camp two in a single push were - would be subject to severe heat exhaustion and dehydration. The ABEE climbers were getting a good lesson in what Sherpas often had to go through on behalf of their Western employers.

The statistics of the load carrying, as recounted by Sorrel Wilby in her book Beyond the Icefall, tell an impressive story of what the Australians had really undertaken by not using high-altitude porters.

From Base Camp to Camp I or II the climbers could feasibly carry loads weighing 12-20 kilograms, but higher on the hill, carries between Camp III and the 8,000-metre South Col would amount to only 7 or 8 kilograms. In real terms, that meant most climbers would have to make two or three trips into the Icefall with ladders and ropes, three trips from Base Camp to Camp I, another five or six load carries right through from Base Camp to Camp II, and at least three trips up to Camp III from the Western Cwm. If they still had any energy left, they would have to do at least one carry to the South Col, before returning for a final summit attempt. As an indicator of just how daunting a task that really was, Pat Cullinan figured it would take one person a six-day round trip to get just one oxygen cylinder up to the South Col. ${ }^{10}$

9 P. Bayne, Interview.

10 Wilby, Beyond the Icefall, ch. 7. 
At the head of the cwm, the route steepened as it began the ascent of the Lhotse Face and the surface changed from soft snow to hard, glassy ice. The lack of snow the previous winter coupled with high winds meant that the ice on the face was unusually polished. The angle of the slope, too, made climbing difficult. It was not quite steep enough to make front-pointing convenient but was just a little too steep to allow a more ordinary walking style to be comfortable.

Camp three was established partway up the Lhotse Face, above $7400 \mathrm{~m}$. As that camp began to be stocked, however, serious problems were becoming apparent. The expedition appeared to be losing momentum as the movement of supplies upward was slowing to a trickle and several attempts at pushing the route further fell well short of the South Col. It appeared as though the attempt had reached an impasse.

The problem was one familiar to those few other expeditions that had attempted Everest's South Col route without the aid of high-altitude porters. Attrition was beginning to take a toll as more and more climbers, exhausted by numerous carries through the icefall and up the Western Cwm, began to succumb to fatigue and various related ailments. It had been nearly two months since the ABEE team had arrived at base camp and most members had done 16-20 carries. It was a critical point in the expedition as further failures to reach the col could prove fatal to morale and the ABEE would prove yet again that Everest's South Col route could not be climbed without Sherpa support.

Sensing that something had to be done quickly to break the impasse, Peter Lambert set out from camp three for the col with an oxygen bottle on his back. The original plan had called for supplemental oxygen to be used only above the South Col, but Lambert knew he had to try something. The oxygen gave him the extra spurt of energy he needed and he struggled over the top of the Geneva Spur and onto the South Col. His account of the day's climb gives some indication of the intense physical effort needed to climb high on Everest, even with the help of supplemental oxygen.

I climbed across the snow slope to the yellow band. A short but steepish pitch at the start - a high rate of oxygen flow for that, then, once over the top, I moved up a short scrabbly bit of snow on rock. The rock under the snow made the short pitch extremely uncomfortable. I traversed through the yellow band, then on a further rope length to the cache of Zac's Yaks [another of the sub-teams]. I was beginning to wonder whether the oxygen cylinder I was breathing from was worth carrying.

The snow on the next slope was about ankle deep, and I moved slowly across and up to the base of the Geneva Spur. I glanced up towards the summit of Lhotse every now and then, wondering how stable the slope 
was above me. Step slide, step slide, step slide - the movement of my feet and the Petzl jumar built up a rhythm. I counted my steps, aiming at taking forty steps before leaning over and resting on my ice-axe. At one of the anchors, I stopped for a while longer. The view down the Lhotse Face and right along the Western Cwm was spectacular. Above me the clouds were stringing out-blown off Everest and Lhotse by high winds. I had a drink; it didn't do me any good - I threw up on the spot...

It seemed to go on forever; the top seemed a long way away for the whole climb. I started to worry about time now: would I get to the Col with enough time to descend safely to Camp III? I decided, come what may, I would have to turn around at 3.30 p.m. I pulled myself up over the edge of the Geneva Spur. From there, I could see I would make it without any problems.

About a kilometre away, I could see the South Col. A couple of Sherpas [from the tri-nation expedition] were coming down the ropes and they said I had just one hour to go. It was an easy traverse around the spur and onto the Col. As I moved up, more and more of the Col came into view. It was a huge place, and as far as I could see, there were signs of past visits; tattered tents and oxygen cylinders everywhere. ${ }^{11}$

The way was now open to camp four at about $8000 \mathrm{~m}$-in striking distance of the summit. The next task was to set up and stock the South Col camp in preparation for one or more summit bids. Lambert's breakthrough seemed to breathe new life into the expedition and morale improved even further when the next day Chris Curry and Jim Truscott, climbing without supplemental oxygen, carried substantial loads to the col. In the end, 15 of the 18 climbers, most of them climbing without supplemental oxygen, carried loads to the South Col.

By the time the Australians were pushing their route up the Lhotse Face, the situation on the south side of Everest was complicated by the arrival of another expedition to attempt the South Col route. In the 1980s, this was a most unusual situation as the Nepalese authorities did not normally allow more than one expedition to attempt a particular route at the same time. ${ }^{12}$ This other group, however, was no ordinary expedition.

The ABEE climbers were sharing their route with the massive tri-nation expedition - one of the largest expeditions ever to set foot on Everest.

11 P. Lambert in ibid., ch. 8.

12 This was the policy of the Nepalese Government in 1988. It has since changed and more than one expedition is now allowed on a particular route at the same time. 
Bankrolled by Japanese support to the tune of A $\$ 24$ million, it consisted of 45 climbers in a total of 250 members from Nepal, China and Japan. It aimed to climb the mountain simultaneously from north and south, then telecast the victory celebrations live as climbers from all three nations met on the summit. With an extravaganza like that heavily supported by the Nepalese Government, the much smaller Australian expedition could easily have been booted off the mountain despite their prior booking of the route, as some rumours indicated might happen. Then Prime Minister, Bob Hawke, was, however, Patron-in-Chief of the ABEE and the Nepalese Government's support of the Australian attempt had been publicly acknowledged as part of Nepal's contribution to Australia's bicentenary celebrations. It would have thus been rather undiplomatic to pull the plug on the Australian expedition at the last minute. Even if it had, the ABEE still held the West Ridge permit (see Chapter 21).

In the event, relations between the two expeditions were most amicable, but each operated pretty much independently of the other. The tri-nation team arrived several weeks after the Australians, so found the icefall route already in place. In return for using the Australian icefall route, the tri-nation team agreed to maintain it for the duration of the expedition, although the ABEE climbers were never very happy with the standard of the maintenance and ended up doing much of the repair work themselves, especially Phil Pitham. In addition, the tri-nation climbers frequently failed to observe the ABEE's precaution that only one person at a time should be on the ladders, thus bringing the longerterm integrity of the ladders into question.

With their massive support and large number of high-altitude porters, the trination team steamed up the mountain and overtook the struggling Australians partway up the Lhotse Face. Thus, when Lambert made the breakthrough to the South Col, he was following the route put in earlier by the tri-nation's lead climbers.

Right on schedule, on 5 May, the tri-nation team reached the summit of Mt Everest with three Chinese, two Nepalese and one Japanese climber celebrating on top in front of a television camera beaming the scene back to Japan. (Ironically, only a few seconds were shown as it clashed with a national baseball game in Japan.) Then, just as quickly as they had arrived, the tri-nation expedition descended the mountain and left the Australians to their own personal struggle of putting someone on the summit without the aid of high-altitude porters.

With a reasonable amount of supplies stocked on the South Col after some exhausting hauls to $8000 \mathrm{~m}$, the stage was set for one of the most desperate struggles ever undertaken on Everest's South Ridge. After a first summit team, led by Mike Rheinberger, was stopped at camp three by high winds and then 
forced to retreat, a second team pushed its way to the South Col in preparation for its summit attempt. The group, Zac's Yaks, consisted of Zac Zaharias, Peter Lambert, Jim van Gelder and Bruce Farmer (see image 22.5).

The team's original purpose in pushing to the col was to 'render assistance' to three climbers - Steve Venables, Robert Anderson and Ed Webster-who had reportedly made the first ascent of Everest's Kangshung Face and were attempting to continue on, without the aid of supplemental oxygen, from the South Col to the summit. As it turned out, Venables did make the summit and the three were able to retreat without help. The Australian group, then, was in an ideal position to make a summit attempt of its own.

Arriving at the col on a windy afternoon in mid-May, they spent the next day settling in at camp four and scavenging as many full and partially full oxygen cylinders as they could find. The next night, at 1.30am on 16 May, the four climbers set out on what they hoped would be the culmination of years of training, planning and preparation: the successful ascent of Mt Everest by ABEE team members. On the surface, it appeared that the foursome had an excellent chance of success. Lambert had proved his toughness with his initial push to the South Col and the other three had suffered less from fatigue and burn-out than many others on the expedition.

Even with eight full bottles of oxygen among the four of them and after a reasonably comfortable day's rest at camp four, they proved unable, however, to overcome the very difficult conditions high on the mountain. From the very start of the climb above the South Col, up snow gullies and slopes to the South Ridge itself, they found the going excruciatingly slow.

'I could tell we were going to have problems,' Peter Lambert recalled. 'The snow was much too heavy and our climbing rate too slow. It took us six hours to reach the tri-nation camp four, which was only 300 vertical metres above the col.' ${ }^{13}$ They had run into a problem that plagues many parties climbing high on Himalayan peaks: deep, heavy snow that makes each step an energy-sapping exercise and quickly drains a climber's strength before the summit is in sight.

The four Australians struggled on, each one taking turns at the onerous task of plugging steps in the snow and, after more than 12 hours of brutal effort, they had just managed to reach the ridge at nearly $8600 \mathrm{~m}$. It was a rough experience, as van Gelder recalled: 'My oxygen apparatus was barely working as the regulator was iced over. I ended up carrying a virtually full bottle of oxygen both up and down. To top it off, my toes were frostbitten as one of my socks had come off the foot.'14

13 P. Lambert, Interview.

14 J. van Gelder, Interview. 
By the time they reached the ridge, it had become painfully obvious to all four that they could not get to the summit and back down again that same day. If they continued, they would surely have to spend a night out high on Everestand that was a risk that none of them wanted to take. They had to admit defeat and slowly return to the col while they had the time and energy to do so.

'We set off convinced we were going to climb the mountain,' van Gelder said. 'We soon found that, although we could have climbed the mountain, we didn't want to go to that extreme. I realised that if I continued to the summit, I could possibly have been "ga ga" for the rest of my life. ${ }^{\prime 15}$ This first attempt was not without controversy, as discussed in the next chapter.

With the failure of this first attempt, morale began to drop. With each day gone, the monsoon was closer, and the increasingly fickle weather was a clear indication that it was not far away. Still, with a bit of luck, there would be time for one last shot at the top, even though it held little chance of success. The team next in turn up the mountain consisted of Paul Bayne and Pat Cullinan, who reached camp four on 19 May, which was their second time to the col (see image 22.6). A day later, another team, consisting of Mike Rheinberger, Chris Curry, Terry McCullagh and James Strohfeldt, arrived on the col. This team, Dad's Army, had changed considerably in composition. Jon Muir was recovering from an attack of worms, Curry had replaced Truscott and Pitham was injured. In addition, McCullagh was unwell and intended to do only a supporting carry to the South Col. This team was the one that was supposed to have been in position for the next (and almost certainly last) summit attempt. Bayne and Cullinan had missed a critical base camp conference after Zac's Yaks summit attempt and did not know they were to have given way to Rheinberger's group.

As it turned out, it did not matter who was meant to be making the summit attempt as the weather deteriorated and no-one was able to climb. It was typical late-May weather on the South Col. The place was blasted with gale-force winds and it was bitterly cold. There was nothing to do but sit it out in the tents and hope for a break in the weather long enough to allow one last push for the top.

Every day confined to the tents, however, meant further deterioration in the physical condition of the climbers. They had already done an enormous amount of load carrying at very high altitudes - much more than the usual Everest climber would have done. Furthermore, even the use of small amounts of oxygen while resting or sleeping could not arrest the rapid deterioration that occurred at or above $8000 \mathrm{~m}$. Every day spent waiting would make it that much harder to climb the mountain or to descend in bad weather if that option was forced on them. 
Cullinan described what it was like to hang on in a tent at $8000 \mathrm{~m}$ waiting for the weather to clear:

Your whole body is slowing down. You're in a 'stunned mullet' state. Your faculties just aren't working as well as they should. You want to put a boot on, and you hold it at the bottom of your foot. Time passesmaybe 10 minutes. Then your mate asks you whether you're taking the boot off or putting it on, and you don't know. ${ }^{16}$

As the days of bad weather wore on, the situation began to look very grim indeed. In the backs of the climbers' minds was the horrific Indian tragedy on the South Col in 1985. In that incident, four of India's best mountaineers perished from exhaustion under very similar circumstances to those the Australians were experiencing. The Indians had been trapped on the col by a storm for four days, exhausted their oxygen and other supplies and succumbed just before the weather cleared and a rescue party could reach the col. The Indians made repeated attempts to get to the start of the fixed ropes at the top of the Lhotse Face but could not find it in the storm. Cullinan wanted to make sure the Australians did not meet a similar fate so he took a compass bearing from the tents to the top of the ropes.

As the tent-bound days dragged on, the climbers began to reassess their situation. First, Strohfeldt and Curry decided not to push their luck and went down and, when the weather still showed no signs of abating, Rheinberger descended as well, after four days on the col. His retreat was not made without considerable personal agony.

Bayne, too, had thoughts of retreat but he and Cullinan decided to stick it out longer on the col. Cullinan said:

The sensible thing to do was to move down to Camp II, yet this would be our only chance to get a summit attempt. But we were exhausted just getting to the Col. Our deterioration rate was phenomenal. We would almost feel ourselves deteriorating by the hour. It was cold, windy, noisy and uncomfortable; we got very little sleep.

We virtually ran out of food by Day Three and had to search the South Col during a break in the weather for some. We finally found some Chinese noodles.

During our time on the Col, we spent much time in finalizing our plans. During that time I kept a daily account of exactly how many drinks Paul

16 P. Cullinan, Interview. 
and I had had. If I had had 10 and he eight, it was time to get another two into him. Dehydration being the problem it is at high altitude, it was essential we got liquids down.

\section{South Col: a reluctant retreat}

\section{Michael Rheinberger}

With Terry [McCullagh] on his way down, James Strohfeldt and I soberly considered the team's and our own chances of gaining the summit. Outside the wind howled, temperatures hovered around -25 to $-35^{\circ} \mathrm{C}$ and the weather forecasts were pessimistic. I was determined that I should not leave the mountain until I had given my best. James, too, wanted a go at the summit but for him, participation and doing his best for the team seemed to be sufficient. I was in a personal dilemma. I knew that in good health, Chris, Paul and even James had been faster through the camps than I. However, I had been a consistent performer, without sickness, and much faster than Pat. I believed the best chance of a team success would be gained by establishing a camp five at around $8350-8400 \mathrm{~m}$, or by using a Japanese camp five, if its tent was serviceable. Although the tent was visible from the col, no-one really knew if it had collapsed. Clearly, team success was more likely if two climbers were selected as the lead pair and the others moved in support, helping to break trail and carrying support oxygen.

In the solitude of our tent, James and I stewed over the situation until James won the upper hand and I agreed that we would support Chris and Paul in an initial summit bid the following day, provided the weather improved beyond the horrendous 50-60-knot winds which blasted the col. We called Chris to the tent and conveyed the plan, although he indicated that he would stay for only one further day, being well aware of overall deterioration at that altitude.

We called Pat to the tent and outlined the plan. Pat was aghast and argued vehemently that payment of $\$ 5000$ should guarantee a shot at the summit. There followed a bitter scene between him and me, as I had been placed in control of all personnel on the col. Invective flew on invective, fuelled by anger and frustration. Finally in disgust, I told Pat to exercise his own judgment and the meeting broke up in a bitter mood.

Outside, the wind howled and the evening radio schedule predicted continuing poor conditions. Later Pat returned to our tent, apologising for his outburst and promising to help in the carries. As it happened, the wind never abated and in the morning Chris and James decided to descend. Pat and Paul, who had already been on the col for a day longer than the others, decided to stay, now joined by me only. Pat had been keeping a record of everything he and Paul were drinking and eating, in order to stay on top of the dehydration problem and felt confident they could hang on a few days longer.

The 23rd [May] came and went. Chris and James descended. Personal differences temporarily buried, the remaining three prepared ourselves to begin a summit push on that evening if only the weather would relent. However, by $10 \mathrm{pm}$, the wind still roared and to have set out would have been utterly foolhardy.

In my tent I dozed the night away. I had resolved to descend on the 24th unless the weather improved, rest up at base camp and return again to the fray. The 24th dawned as gusty and violent as before and I descended, fighting a bitter internal war. Had I capitulated or had I exercised sound judgment?

Pat and Paul stayed. The winds had not eased since they arrived on the col, but their faith remained as unshakeable as the mighty Mother Goddess herself. 
We were both pretty weak. I had been coughing up a lot of dried blood and puss. I coughed it up into a plastic bag under the strange idea that I'd show it to a doctor at Base Camp, and he'd prescribe the right medicine for me. I showed it to Paul. He was disgusted! ${ }^{17}$

Even though they knew they were deteriorating rapidly, Bayne and Cullinan, despite the fact that they had arrived a day earlier than the others, were determined to hang on for as long as they could. The mood at base camp was becoming extremely tense as the pair was into their sixth day on the South Col. They were still alive, but no non-Sherpa had survived that long on the col before. Would they have enough strength to escape and get off the mountain when the weather cleared?

As leader, Brookes was extraordinarily concerned for the pair and had stationed a support team at camp two in addition to organising other climbers to head up from base camp if they were needed to effect a rescue. Rheinberger and McCullagh stopped at camp two on their descent from the South Col and were joined by Brian Agnew, who had ascended from base camp, to form the support team should Cullinan and Bayne need help returning from the col. Near the end of the sixth day, the weather showed signs of improving and radio contact was made with the climbers on the col.

The relief at base camp when they learned that Bayne and Cullinan were able to move under their own steam quickly turned into surprise and then even greater anxiety when the pair announced that they were not coming down but going up! To have stayed on the col for six days was risky enough, but, in the view of many at base camp, to then go for the summit of Everest was foolhardy and dangerous in the extreme. It was certainly inviting a disaster to happen.

'It was a very emotional time for everyone,' Brian Agnew recalled. 'We thought they'd expire up there. We were all exhausted, physically drained. All of the promises of success were fading, and then to have fatalities...Those of us remaining were in the depths of despair.' ${ }^{18}$

Back up on the col, Bayne and Cullinan slowly readied themselves to climb and left their tent at 10pm on 24 May 1988 to go to the top of Mt Everest. It is usual for many climbers to return from an Everest ascent in a totally exhausted state, but very few set out for the top in a state near to total exhaustion. Bayne's account of the summit day - a drama of amazing determination, of utter relief at reaching the top and of wild hallucinations and virtual sleepwalking on the descent - is testament to the strength he was able to summon to keep going.

17 P. Cullinan, Personal communication.

18 B. Agnew, Interview. 


\section{Summit day on Mt Everest Paul Bayne}

Pat and I left the tents on the South Col about 10pm. As we set out across the flats toward the bottom of the face, Pat remarked on how slowly I was walking and how bad I looked. I felt at the limit of exhaustion just walking on flat terrain.

We climbed slowly together up the ice gullies toward the South Ridge. No matter how exhausted I felt, I was always able to dredge up some more energy from somewhere.

We reached the South Ridge and left the shelter of the gullies below. A light breeze was blowing and I felt chilled.

Soon we were forced onto the Kangshung side of the ridge into horror snow conditions. It was bottomless, and I sank in up to my chest. I had to punch my arms in up to my shoulders to make sure I didn't slip away. Under those conditions it was every man for himself. We were concentrating so hard on the climbing that we just drifted apart.

Above the Hillary Step the angle eased off considerably and the summit was very near. Yet I still wasn't sure that I would make it. I felt very much at my limit.

I had stopped carrying my ice axe above the Step, and had slung it over my pack. I needed my hands to support my knees as I felt that I would collapse at any time. Even 20 feet from the top I still didn't know I would make it. It would have been no surprise had my legs buckled beneath me.

I'm not sure when I actually reached the top. My memories of the summit day are a combination of moments of exceptional clarity and vague blurs. But it was some time in the early afternoon, and I instantly collapsed onto the snow. I didn't even open my eyes for 15 or 20 minutes.

When I did open them, I slowly turned around on my stomach about 5 or 10 degrees at a time, until I had seen the 360-degree panorama.

The weather had been improving as we climbed. At first the big peaks like Everest and Makalu were in and out of hogsbacks, but the clouds gradually dissipated as the day wore on. When I reached the summit, there was no high cloud at all. Lower cloud had built up in Nepal to 24 $000 \mathrm{ft}[7300 \mathrm{~m}]$. All of the big peaks were glistening above in the brilliant sun.

When I looked down the South Ridge, I could see Pat, coming up slowly, just below the Hillary Step. It is the only place on the ridge where you can actually see the summit.

Pat was climbing near the edge of a great, overhanging cornice, and I was very concerned for his safety. Pat later told me that he could see me standing rather toward the edge of Everest's summit cornice, and he was worried about me!

I must have been on the summit for about 45 minutes or an hour before I started down. I passed Pat just above the Hillary Step. That was undoubtedly one of the biggest thrills of the entire expedition. I knew then that he was going to make it. It gave me a very good, warm feeling.

We had a very short, stunted conversation and then continued on. Even though Pat was only 50 metres or so from the summit, he was two hours behind me.

The descent was an amazing experience. I knew that it would be a very interesting game to see if I could get down.

I knew that I had to concentrate on my crampon placements but it was impossible. My mind kept drifting and I began to hallucinate wildly. 
Little metallic figures were racing around me on the ridge, and strange clouds were swirling around chaotically above my head. Suddenly I would realise that I had been looking up at the clouds while I was walking along a very narrow ridge with steep drop-offs on both sides. Then my concentration would snap back to my crampons for a few moments before more little metallic figures began dancing along the ridge.

I got back to the South Col at dusk and grabbed the radio to let the others know that we had succeeded. Before I made the call, I looked up to check Pat's position and was horrified to see that he was still at the South Summit.

I decided not to make a radio call then, as Pat's position would undoubtedly have caused great concern. In fact, I wasn't certain then that Pat would survive the descent.

He arrived at the Col sometime during the night, after I had crashed. It was the next morning, then, that I radioed the others to tell them we had made it and were now safe.

Cullinan's performance was, if anything, even more dogged and determined:

When I was on the South Col that night getting ready to go for it I knew that the next 24 hours would be the most traumatic of my life. It's a bit like being in the Olympic Games and going for a Gold Medal-you can't do a rerun. You have to make everything of the one chance you've got. Even though we felt exhausted just moving across the flat ground on the col, we knew we had to just keep going. It was mind over body. There was no other way. We had come to climb Everest and we would. It was as simple as that.

We later learned what dangerous physical condition we were in. Five days after the climb my blood was measured to be over six times thicker than normal! The doctors estimated that during the ascent our blood must have been about eight times thicker! We were certainly prime material for strokes and heart attacks.

The climbing was very exciting along the South-East Ridge, very narrow in parts with big drops on either side $-9000 \mathrm{ft}$ [2700 m] into Nepal and $12000 \mathrm{ft}[3700 \mathrm{~m}]$ into Tibet. At times I was forced by big cornices onto rock on the Nepalese side. It was very tricky climbing in parts. I could feel my crampons scratching around on the rock for a grip. And I had to climb along this ridge in a very bad state; I felt worse than a drunk driving home at night. ${ }^{19}$

Cullinan reached the summit of Mt Everest at $2.15 \mathrm{pm}$ on 25 May, about two hours after Bayne had made the top. The two met briefly about $50 \mathrm{~m}$ from the summit, with Bayne on the way down and Cullinan still struggling to get to the top of the world.

19 P. Cullinan, Interview. 


\section{Cullinan said:}

When I got to the summit, I took off the oxygen bottle and put it down. It was probably the worst feeling I had on the whole expedition. After a few minutes a tremendous claustrophobic feeling swept over me. I thought I'd die. I put the bottle on again. I put a sticker with the Australian flag and the words 'Have a Go Australia' on the summit, along with a Comalco sticker [for Bruce Farmer]. I was too worn out to pull out the bigger Australian and 1 Commando Regiment flags. I was in a bad way. Finally, I took a few photos and headed down quickly.

I ran out of oxygen just after the Hillary Step, and then started hallucinating. Fortunately, I picked up a partially full bottle at the trination camp five and used it down to the South Col, where it ran out. I didn't get more oxygen until the next day. Paul had set up a bottle in my tent but I was in such a bad way that I couldn't get it going. ${ }^{20}$

It was nearly midnight when Cullinan finally arrived back at the col; he had been climbing for more than 24 hours. Until Cullinan's safe return, Bayne decided not to radio down to base camp to avoid raising fears about Cullinan's position. The fact that there had been no radio contact for more than 24 hours after the pair had set out caused worry enough at base camp. It took little imagination to guess the most likely reason for the lack of radio contact, particularly since the climbers had set out on their summit attempt after having spent a recordbreaking six days pinned down on the South Col.

On the morning of 26 May, Chris Curry, Jon Muir, James Strohfeldt and Zac Zaharias were dispatched to steam up the mountain as fast as they could to see if Cullinan and Bayne were still alive and to render assistance if needed. Their first task was to relieve Brian Agnew, Terry McCullagh and Mike Rheinberger, who were still in camp two in support, and then await a radio call from camp four before proceeding further. When they learned that Cullinan and Bayne were not only safe but had both reached the summit of Everest, they would have jumped for joy had they the strength to do so at that altitude. Their services would, however, still very likely be required as the radio reports indicated that Cullinan was in a bad way and would probably need help to descend from the South Col.

Feeling strong and fit, Curry and Muir powered up all the way from camp two to the South Col the next day while Strohfeldt and Zaharias returned to base camp. Much to their relief and delight, Cullinan was somehow able to pluck a bit more energy out of his extraordinary store and move down the mountain on his own. With the two fresh climbers installed in camp four, the fine weather holding out and some oxygen still left, the rescue was instantly turned into another summit bid. 
Himalayan Dreaming

Muir described his experience:

A wild night greeted us as we stumbled out of the tents just after midnight. Strong winds gusted across the Col and bands of dark cloud raced by. It looked terrible, but we set off nevertheless. Deep in my heart, the little person who guides me through the most difficult times, who I suspect can glimpse the future, whispered that this was my day...

Thigh-deep snow led to the South Summit, 200 metres above. Energy from outside my body surged through my entire being, and steadily I ploughed on up. We had left Base Camp 48 hours earlier and yet I felt stronger than ever.

The wind, my great foe, plucked at me as I literally crawled out of the last of the deep snow and on to the South Summit. The wind blew a massive plume off the final ridge, gusting hard every few minutes, trying to entice me on a brief tour of Tibet.

I shot some film and checked the oxygen; heaps left. I turned it up full blast and charged off. Now on perfect snow and carrying just one cylinder, I could really move. Despite the wind, it was pure joy to be up there alone...

Lhotse was now well below and Nuptse, which had towered over me for so many months, looked tiny. A grin spread from ear to ear as I slowly realized that now nothing would stop me.

Feeling more like a spaceman on a distant world than a mountaineer, I moved rapidly up the final slopes. The world fell away in all directions. A thousand thoughts and emotions crashed over me. For an hour I stood alone with an overwhelming sensation of isolation and insignificance. ${ }^{21}$

Muir's feat was nearly duplicated by Curry, who narrowly missed reaching the summit when the regulator on his non-Australian oxygen cylinder malfunctioned. After climbing to $8700 \mathrm{~m}$ and seeming certain to become the fourth $\mathrm{ABEE}$ member to stand on the summit of Everest, he was forced to descend. Curry's performance was, however, particularly impressive since he had been on the South Col when Bayne and Cullinan began their long vigil. To have descended all the way to base camp and then to climb quickly back up, nearly to the top, showed remarkable strength and determination. In fact, Curry climbed to the South Col three times - the only member of the expedition to do so.

21 Muir, 'To the roof of the world'. 
The expedition faced one last hurdle in getting everyone safely off the mountain. Agnew had accompanied Cullinan and Bayne through the icefall and down to base camp, leaving McCullagh and Rheinberger at camp two in support. The pair had spent 10 days at camp two and was much in need of relief. Brookes, however, could not convince any of the remaining climbers to take over the support role at camp two. Indeed, several climbers had already departed base camp for Kathmandu. Worse yet, the icefall route was not being maintained.

When Muir and Curry reached camp two and joined McCullagh and Rheinberger for the last trip down the mountain, there had been no maintenance on the icefall route for 14 days. The route had deteriorated considerably and become exceedingly dangerous, as McCullagh recalled:

The descent was horrendous. With the approaching warmer summer weather, ladders had collapsed, fixed ropes had been destroyed, and seracs had obliterated tracks. It was a painstaking and dangerous descent off the mountain for the final four climbers, who were already very tired. It was some of the most difficult climbing that I have ever experienced..$^{22}$

Somehow the four descended the treacherous icefall safely, bringing the ABEE to a successful conclusion. The three ascents had been a remarkable finale to an expedition that at one point seemed on the verge of collapse. Indeed, the line between exhilarating success and tragic failure for the ABEE was extremely thin. Just as finely balanced, however, were many other aspects of the ABEEthe most complex and fascinating Australian expedition ever to venture into the Himalaya. 



\section{ABEE: an analysis}

There is no doubt that the Australian Bicentennial Everest Expedition (ABEE) was a remarkable achievement. Yet, in the aftermath of the climb, it received very little attention, even in the Australian press. In the international mountaineering literature, it was virtually ignored. Much of the reason for the lack of recognition, at least in Australia, was that it was not the first Australian ascent of the world's highest mountain. That honour belonged to Tim Macartney-Snape and Greg Mortimer. Unfortunately, in our society, we put much emphasis on being first; being the second or third to do something receives little reward, even though the achievement might be just as outstanding in other ways.

The ABEE was the largest and most complex expedition to the Himalaya from the Antipodes and, partly as a result, it was undoubtedly the most conflict ridden. No analysis of the ABEE can ignore the role of conflict in the conduct of the expedition. It is a theme that is treated at great length in Sorrel Wilby's account of the ABEE, Beyond the Icefall. Indeed, her exhaustive expose of the conflict aspect of the trip seems to overshadow any analysis of the enormity of the team's achievement. As veteran New Zealand climber Colin Monteath noted in his review of Beyond the Icefall, it was 'a big expedition with a lot of fragile egos-amazing it didn't fly apart'. ${ }^{1}$

So why didn't it fly apart? What was the nature of the conflict? How serious was it? How did it affect the expedition?

Wilby's account makes absorbing reading. It provides insight into the inner workings of a large Everest expedition and, according to many of the ABEE members, is a very faithful record of what the trip was really like. Written from the perspective of a non-climber, it exudes fascination for the number and intensity of the outbursts, arguments, wrangles, confrontations and acrimonious meetings that seemed to be a continual part of the trip. To understand the nature of the divisiveness that plagued the ABEE, however, it is necessary to examine its origins and dynamics and then put it in perspective with the overall achievements of the expedition.

It is often said that, particularly for large expeditions, there is not one expedition but many, depending on the perceptions of the individual climbers. This was undoubtedly true for the ABEE, especially when examining the role of conflict in the expedition. Many climbers were virtually oblivious to the problems and

1 Monteath, C. 1990, “'Beyond the Icefall." Himalaya. Alpine book roundup', New Zealand Alpine Club Bulletin, June/July, p. 58. 
claimed that accounts of conflict and divisiveness within the ABEE were vastly overstated. Others, however, were deeply affected by the acrimony, carrying scars for months or years later. The first part of this chapter examines in some detail the perceptions of those climbers most embroiled in the conflict and attempts to present each of their individual points of view. Such an account can never be complete, but hopefully it will shed at least some light on the nature of the problems that, years later, still arouse intense feelings in some ABEE members.

The conflict can be analysed at three levels. The first - often categorised as 'personality conflict' - is common to all large Himalayan expeditions (and some smaller ones). Its origins are easy to understand. Climbers in the high Himalaya are under considerable stress. They are highly motivated to achieve a very single-minded objective - getting to the top of the mountain - yet at the same time are operating in conditions of hardship: cold and uncomfortable living arrangements, monotonous and increasingly unpalatable food (it is only a slight exaggeration to say that a climber's performance in the Himalaya is strongly correlated with his ability to ingest expedition food) and the ever-present tension that results from working and living in a very dangerous arena. In conditions such as these, very small personality traits that would go unnoticed in everyday life at sea level can assume major importance on a Himalayan expedition. As Bill Packard, the very experienced New Zealand mountaineer who was the advisor to the ANU Mountaineering Club's 1978 expedition to Dunagiri, once noted: 'Up in the Himalaya very little things can trigger intense conflict-like the colour of a man's socks, not to mention the smell. ${ }^{2}$ On the ABEE, there was plenty of scope for that type of conflict.

The second level of conflict is one that invariably appears on large Everest expeditions, although it often occurs on other very large Himalayan mountains. It is related to the fact that climbers have a very intense desire to succeed. On large expeditions to big mountains, only a few people reach the summit, often as the result of very hard work put in by the rest of the team. That can create frustrated people who believe they are not getting a fair go for their own personal summit aspirations. This level of conflict is often manifested in charges that the leader has already picked a summit team or that some people are not doing enough in the early stages of the expedition so they can save themselves for a summit attempt. This is a classic problem on large Everest expeditions and is certainly one that contributed to the ABEE's problems.

Brian Agnew summed it up very well: 'The ambitions of individual climbers on Everest are unbelievable. That's what drove most people. The niceties of other

2 B. Packard, Interview. 
expeditions are put aside. Ruthless ambition came to the fore. ${ }^{3}$ The results of that ambition led to some classic behaviour on the ABEE, particularly among the civilian climbers. Jim van Gelder noted that there were 'some Machiavellian characters amongst the civilians, [there were] a few very destructive forces there'. ${ }^{4}$ Peter Lambert added that 'some of the civilians were quite selfish in trying to achieve their aims'. ${ }^{5}$ At least one ABEE member - a civilian - was accused of hiding an oxygen cylinder on the South Col after a load carry to improve his chances later. Others noted that some military climbers could be accused of similar sins, although in general the military climbers were strongly grounded in the ethos of teamwork and trust.

Paul Bayne, one of the three to reach the summit, expressed the common feeling that one was not being given a chance for the summit:

One of the low points of the expedition for me was the jockeying for positions for a summit attempt. When everyone is spread out on the mountain, it is easy to feel you're not getting a fair go. You can easily feel that you've been put on a 'load-carrying team', and that you wouldn't get a fair chance for the summit. If you think you're getting a raw deal, it's hard not to be frustrated. ${ }^{6}$

These first two levels of conflict represent totally normal behaviour for highly motivated mountaineers on a big, dangerous peak such as Everest. The third level of conflict, however, was based on the deep-seated, philosophical differences that had led to the serious split in the Army Alpine Association (AAA) team in the lead-up to the expedition (see Chapter 21). The three levels of conflict, of course, did not operate independently but were intertwined, often in the same argument or confrontation, to create some nasty incidents. It is really the third level of conflict, however, fuelled by liberal doses of the first two, that has the potential to blow a big expedition such as the ABEE apart and cause its failure.

As described in the development of the 1978 Dunagiri expedition, the confused roles of Peter Cocker, the official leader of the expedition, and Ken Baldwin, the prime organiser and de facto leader in the final months before the climb itself, created a situation that could have led to this deep level of conflict on the expedition. Their roles, however, were clarified just before the expedition left Australia and it was conducted in a generally harmonious way. Unfortunately for the ABEE, the philosophical split that rent the AAA was carried over to the expedition itself and seriously harmed its conduct.

\footnotetext{
3 B. Agnew, Interview.

J. van Gelder, Interview.

P. Lambert, Interview.

P. Bayne, Interview.
} 
Again on the mountain, severe problems flared between those, such as Jim Truscott and Terry McCullagh, who believed that a well-organised militarystyle approach based on teamwork and trust offered the best chance of success and those, such as Zac Zaharias and Peter Lambert, who thought that a more civilian-style approach was appropriate. The former argued for a more militarystyle expedition, with a hierarchical structure and a clearly defined but flexible plan of action that required careful coordination and communication. They firmly believed that this was the best way to tackle the South Col route on Everest with such a large team and would give the best chance of success. The difference of opinion was often couched in terms of an individualistic or egalitarian approach (civilian) versus a more team-oriented approach (military).

Truscott, however, maintained that the divisiveness was across the board and had little to do with the split in the AAA or with a military versus civilian grouping. He traced the root of the conflict to the fact that many people would support a plan that would benefit them personally and that would give them the best chance to get to the top. Others wanted an approach that would get someone, not necessarily them individually, to the top. Others floated between the two groups. Thus, in Truscott's view, the causes of the intense conflicts were also related to that classic Everest problem of climbers believing they were not getting a fair go at the summit. In an atmosphere of apparent egalitarianism, some climbers' ambitions would be sacrificed to get others to the top without a clear and mutually agreed plan to do so.

Truscott said:

The first week of the expedition at Base Camp was the philosophical crux of the climb. It was at this stage that the leader announced how the mountain was to be climbed and it was a significant departure from the conventional approach to climbing Himalayan mountains. Instead of getting sufficient supplies to the highest camp to support an initial summit party of the two to four most likely climbers to succeed, it was announced that additional supplies would be carried up to allow each of the four groups as equal a chance as possible in getting to the top. It was a very egalitarian plan but as always, would be subject to the vagaries of luck, weather and attrition in the team. The plan was hardly questioned at the time as everyone was more concerned with the prospect of establishing a route through the Icefall without the use of Sherpas. Those who did think it through knew that no matter what plan was implemented, conventional or egalitarian, performance at altitude is 
the unknown variable. In hindsight the egalitarian plan prevented team cohesion right from the start. It fostered separation of four groups and prevented the coalescence of individual, group and team goals. ${ }^{7}$

Interestingly, Paul Bayne also criticised the splitting of the team into four distinct groups, but from a practical point of view:

The idea of having sub-teams was a bit crazy. The days I felt good were rest days and the days we worked I felt awful. You just couldn't jump in when you felt strong. Teams couldn't be mixed and matched depending on how people felt- the system was not flexible enough. ${ }^{8}$

Brian Agnew suggested that three teams of six might have been better, allowing individuals to rest at their own rates within a team.

Austin Brookes, from his perspective as leader, maintained that the creation of smaller groups was the most sensible approach and that problems arose because it worked too well:

[I]t was patently obvious that (i) there was an abundance of talented people each with their own leadership skills. They had to be given more responsibility than just satisfying their own personal climbing ambition, and (ii) communication and leadership would best be exercised by coordinating the efforts of several small groups rather than attempting to orchestrate the efforts of a large group of talented and experienced climbers.

I was convinced that the splitting of the expedition into several smaller teams was the sensible way to handle the initial build-up. Each leader of these smaller teams acted very responsibly in choosing his own team. They based their choice on their knowledge and experience of the climbers, a desire to be fair and to consider the best interests of the expedition. They saved me from having to make some very tough decisions that I had anticipated would be necessary. There was no attempt to select either their own personal friends or the strongest climbers.

I was also convinced that later attrition would force us to change teams and work on the basis of a summit team (or two) and support climbers. At various stages in the later part of the expedition I put this point of

7 Truscott, J. 1989, 'A lesson in high altitude expedition leadership', AAA Newsletter, no. 4/89.

8 P. Bayne, Interview. 
view as an alternative. Basically the original strategy had worked too well. The teams had established an identity and spirit which made them loath to change. ${ }^{9}$

Those who supported a civilian-style approach to the expedition had a much different perspective on the nature of the deep-seated differences between the two AAA groups that incited such frequent and acrimonious incidents. They argued that it had much less to do with an individual versus teambased approach, or the break-up of the large team into subunits, than with the opposition of part of the AAA contingent to a more consensus or collaborative style of operation.

Lambert said:

I had the feeling throughout the expedition that some people in the army expected to be told everything. They wanted to know where to put the next foot. Without that, they felt somewhat threatened. That's perhaps an indictment against the way we train our people. They are told everything; there are orders. Austin's style is very different: 'I think this would be a good idea. What do you think?' Some of the officers expected orders like they would give to their soldiers. So when they weren't told exactly what they were to do, they felt a bit uncomfortable. ${ }^{10}$

Mike Rheinberger expressed that point of view more forcefully:

Certain AAA members still believed the whole thing was a military expedition, and they looked for a style of leadership that's more relevant to certain military situations. They looked for orders. It became absurd. Early on, some AAA members wanted to know the precise day we were going to leave the mountain. It showed a real lack of appreciation of what we were trying to do.

We had a very dynamic situation. It called for judgment and flexibility. Some people on the trip showed remarkable inflexibility. It was allied with quite outrageous behaviour directed against certain perceived inadequacies in the food, and in the Sherpas' preparation of the food. ${ }^{11}$

Terry McCullagh, on the other hand, strongly disagreed with Rheinberger's assessment of the military climbers: A military style [of climbing] does not

9 A. Brookes, Personal communication.

10 P. Lambert, Interview.

11 M. Rheinberger, Interview. 
mean orders which must be blindly followed. Nothing could be further from the truth. I do not think this point was well understood by the civilian members of the team. ${ }^{12}$

He also noted the significant weaknesses that could arise from a more laissezfaire style of leadership:

The magnitude of the task demanded complex planning, sound coordination, excellent communications, positive leadership and a good dose of determination. We needed to ensure that the right people and supplies were in the right location at the right time...People's independence and personal desires should have been subordinate to the requirements of the overall plan. ${ }^{13}$

An example of the weaknesses of a laissez-faire style of leadership was the lack of discipline near the end of the expedition, when Rheinberger, McCullagh, Muir and Curry were forced to descend a very dangerous Khumbu Icefall route that had not been maintained for a fortnight.

Rick Moor, not one of the principals embroiled in the conflict, offered another perspective: 'Most members of the expedition, both military and civilian, were bemused by rather than involved in the infighting within the AAA between those supporting a more individual approach and those [who] supported the team-based option.' ${ }^{14}$

Nevertheless, Moor had clear ideas on the origins of the infighting:

Some of the military members were antagonistic towards Zaharias and Lambert because they felt that they had been betrayed by them when the team was initially selected - that is, when several fully paid and qualified military members were initially excluded from the team. It was believed that Zaharias and Lambert had been disloyal to the AAA [see Chapter 21]. It was felt that they were placing individual ambition before group loyalty. [Individual ambition being to ensure that they were members of the team and group loyalty being their assumed obligations to AAA members.] It is quite possible that they were not disloyal to the AAA members in question; however, at no stage did they explain their actions. Therefore, the perception remained. ${ }^{15}$

Lack of communication between the AAA West Ridge group (essentially those who accused Zaharias and Lambert of disloyalty) and Zaharias and Lambert

12 T. McCullagh, Correspondence.

13 Ibid.

14 R. Moor, Personal communication.

15 Ibid. 
certainly accentuated the original problem. To accuse Zaharias and Lambert of not explaining their actions appears, however, to be unfair. On several occasions, Lambert wrote to Truscott asking that they get together informally and discuss developments in the ABEE. These were genuine attempts by Lambert to clear the air and improve relationships among the AAA climbers. Lambert received replies to none of the letters.

In general, however, two-way communication problems between the ABEE board and the AAA were undoubtedly a significant contributing factor to the conflict. There was deep-seated concern among several AAA members that they were not consulted on critical issues that affected them and that they were informed of board decisions without any attempt to seek their views on those decisions.

On the other hand, some critical AAA committee meetings were held when the three AAA members on the ABEE board-Zaharias, Lambert and Cullinanwere not present. The minutes from these meetings sometimes contained directives on the conduct of the ABEE for the three to implement. When, as Zaharias noted, the directives were 'often totally impractical or expensive'16 and were thus not implemented by the ABEE board, he and his AAA colleagues on the board copped the bitter complaints that came from some of the AAA climbers.

Another problem that often beset Himalayan expeditions probably exacerbated the conflict. Food, or rather the lack of quality or quantity thereof, is often a problem. Rheinberger's comments indicated that it also became a bone of contention within the ABEE. As to the nature of the 'perceived inadequacies', as Rheinberger put it, Moor suggested that 'it wasn't so much that the food was bland or inadequate, it was that there was no reason for it to be so' ${ }^{17}$ Unfortunately, Zaharias was the expedition's rations officer and copped some heavy criticism from those dissatisfied with the food.

Judgment of the quality of expedition food is a very relative thing. Four members of the 1988 Australian Baruntse expedition visited the ABEE base camp near the end of the expedition. They sampled the base camp food and the high-altitude rations and declared them 'superb' compared with the fare they had suffered through on Baruntse!

Given these various perspectives, how serious was this third level of conflict? The first two levels of conflict almost always disappear after an expedition is over and have no lasting effects, but not so for the third. Although some ABEE

16 Z. Zaharias, Correspondence.

17 R. Moor, Personal communication. 
team members were able to pretty much isolate themselves from the disputes or simply let the conflict wash over them without much effect, it was clear that others were deeply troubled by what happened on the mountain.

'I can't really say at the end of the expedition that I enjoyed it,' Lambert said. 'There was much more physical and psychological stress then enjoyment. The psychological stress saps you as much or more than the physical stress. ${ }^{18}$

During the expedition, Zaharias suffered far more criticism from some of the military climbers than did Lambert or Cullinan - the other two AAA members of the ABEE board. Some of the hostility was intensely personal, Zaharias recalled: 'Many of the criticisms were levelled in a most hurtful and insensitive manner to whomever was the target, and they were mostly towards me. ${ }^{19}$

Rheinberger was particularly upset by the whole experience:

I feel very sorry that there still seems to linger some ill will between some members of the expedition...I wish a lot of it could just be forgotten. It's not doing people's reputations or friendships much good at all.

A lot of us came away extremely depressed and disappointed by events on the mountain. I personally had a very rotten time for at least three months afterwards. I literally went bush when I came home. After having put in all that effort for so many years, to see certain things happen. ${ }^{20}$

Finally, in a succinct and penetrating fashion, Phil Pitham summed up the conflict aspect of the trip: 'We all got back safely, but we didn't leave the mountain as mates. ${ }^{21}$

To put the entire conflict issue into perspective, however, it is very important to remember that, in the final analysis, the ABEE was a magnificent success. Despite the severity of the conflicts, when the going really got tough, even by Himalayan standards, the ABEE was able to snatch a most remarkable victory from a situation that looked almost beyond recovery. The expedition did not blow apart due to internal pressures, as many other large Himalayan expeditions had.

Much to their credit, the antagonists within the AAA ultimately put the ABEE's overall goal above their differences and put everything they had into the success of the expedition. The genuine joy that all of the ABEE team experienced with the last-minute success was a real highlight of the trip for Bayne: 'When we came

18 P. Lambert, Interview.

19 Z. Zaharias, Correspondence.

20 M. Rheinberger, Interview.

21 P. Pitham, Interview. 
down, the main antagonists were genuinely pleased that we had succeeded. They were very enthusiastic and happy for us. It wiped out a lot of the bad feelings earlier on in the expedition.' ${ }^{22}$

Austin Brookes, who as leader copped many of the criticisms and attacks that resulted from the conflicts within the AAA, was nevertheless very impressed with the ability of the AAA climbers to perform as a team:

Despite the differences within the military group, they continued to work together and overall the military climber lasted the pace better than some of the civilians. The civilians had the more accomplished and experienced climbers but the attitude of the military climber was exemplified by Pat Cullinan. I developed a healthy respect for the determination of Pat in particular, and of the military climber in general. ${ }^{23}$

If the perceived lack of flexibility among some AAA members revealed a deficiency in the way the army trained its people, perhaps the ability of the military climbers to overcome intense personal differences for the good of the team and their ability to see out a task to its conclusion no matter how arduous and frustrating pointed to strengths in army training methods.

Before evaluating the significance of the ABEE's achievement, one very important individual contribution - not as glamorous or as publicly visible as the efforts of those who reached the summit or of those who worked so tirelessly on the mountain in support - should be recognised. Peter Allen never set foot on Everest in 1988, yet he played an essential part in the success of the ABEE. He brought a considerable amount of expertise and experience to the planning of the ABEE from the very start and he matched his knowledge with tireless effort to ensure that the ABEE was in the best possible organisational state when it reached the mountain. It is no secret that good organisation is an indispensable ingredient in the success of a Himalayan expedition. Some members thought it a considerable injustice when Allen was overlooked in the awarding of Orders of Australia to some members following the success of the ABEE.

Allen was one of the most skilled and experienced of the civilian climbers, but he opted for personal reasons not to risk climbing through the icefall. It was sometimes a frustrating experience for him at base camp to see events unfold on the mountain: 'Sometimes it was very, very hard to take not being involved in the climbing. Because you're not climbing, you have to bite your tongue. You can see things happening but since you're not going through the icefall,

22 P. Bayne, Interview.

23 A. Brookes, Personal communication, 1 November 1989. 
you can't really voice your opinions.' ${ }^{24}$ The selfless contributions of Allen and numerous other support personnel, as well as the entire climbing team, led to the ABEE's achievement.

The contribution of another non-climbing member of the ABEE should be acknowledged. Andrew Rothfield was a thoroughly competent treasurer and, as Mike Rheinberger put it, 'ran the finances with an iron hand' ${ }^{25}$

Turning to an analysis of the climbing itself, some controversy was raised by the summit attempt of Zac Zaharias, Peter Lambert, Jim van Gelder and Bruce Farmer, which reached $8600 \mathrm{~m}$. Although that attempt came close to success, it was viewed in several different ways according to one's perspective - from a major psychological breakthrough to a useless squandering of eight precious bottles of oxygen.

The controversy surrounding the attempt was centred on two issues: the first being the necessity, or otherwise, for a fifth camp, at about $8350 \mathrm{~m}$ on the South-East Ridge - that is, above the South Col. There was much discussion on this point, with Zaharias one of those who believed an ABEE team could climb Everest in a single push from the col. He maintained that his group's attempt, in less than ideal snow conditions, proved that the mountain could be climbed from camp four in better conditions, so that a camp five was not needed. In the event, Bayne, Cullinan and Muir all climbed to the summit from the South Col without an intervening camp.

Mike Rheinberger, however, was of a different opinion. He argued that the failure of Zaharias' team proved the opposite - that a fifth camp would greatly increase the chances of success. 'In fact, it [the failed attempt] was good evidence that Everest couldn't be climbed from the col unless conditions were optimum, which did not often occur,' Rheinberger said. ${ }^{26}$

The second issue was whether, in a four-man team, all four should go for the top or whether two should support the other two by breaking trail and carrying loads. In fact, Brookes had recommended, during a lengthy radio call, that two climbers should be chosen from the four for the summit attempt, with the other two in support. This would maximise the chances of success. In the event, this strategy was not used and eight cylinders of oxygen were consumed. This led to some resentment within the team. In defence of Zaharias and his team, however, it is an extremely difficult thing to somewhat arbitrarily assign two fit climbers

24 P. Allen, Interview.

25 M. Rheinberger, Personal communication.

26 Ibid. 
to a 'support' role when the summit of Everest is so close. Recall (Chapter 22) the personal agony that Rheinberger went through when he decided to work in support of Curry and Bayne and thus forgo his own summit ambitions.

Another critical factor should not be overlooked. The snow condition was not only 'less than ideal', it was exceedingly deep and soft-in a word, horrific. It took Zac's Yaks more than 12 hours to reach the South-East Ridge propersomething that normally took four to six hours. There was simply no way they could have continued in those conditions to the summit and then have expected to all return safely. Had the snow conditions been better, perhaps four ABEE members would have stood on the summit of Everest on their first attempt from the South Col.

All of these issues became academic when Paul Bayne and Pat Cullinan later went to the summit. By then gales had scoured the ridge of loose, soft snow and had greatly improved conditions for climbing. That is not to take anything away from the achievement of Bayne and Cullinan. They climbed without another pair in support and they climbed all the way from the South Col in a single push. Despite their incredible personal efforts, it was still very much a team effort. Just to have become so well established on the South Col that more than one summit attempt could be made was a major victory for the ABEE.

How important was the ABEE ascent, given that the South Col route on Everest had been climbed many times before and that the ABEE success was given scant acknowledgment in the mountaineering press? The simple answer is that it is far more important than most people, including some experienced mountaineers, have given it credit for. It was a most notable accomplishment-like the 1978 ascent of Everest by Reinhold Messner and Peter Habeler without the aid of supplementary oxygen and the 1984 first ascent of the Great Couloir by Tim Macartney-Snape and Greg Mortimer without supplementary oxygen-because it broke down a significant psychological barrier. It climbed Everest by the South Col route, usually considered to be one of the longest and most physically demanding routes on the mountain, for the first time without the assistance of high-altitude porters - that is, without Sherpa support above base camp.

It should be noted at the outset that the ABEE climbers did benefit from the presence of the huge tri-nation expedition on the same route. The tri-nation team used massive Sherpa support to climb the mountain. The route from camp three to the South Col was initially established by the tri-nation team, which overtook the Australian team at that point. The ABEE climbers subsequently followed this route. Also, the tri-nation climbers left some tents and oxygen cylinders at the South Col for the Australians to use. The tri-nation oxygen was used while the Australian climbers were in residence at camp four, but all three ABEE summiters climbed only with Australian oxygen bottles carried all the 
way up the mountain by Australian climbers. So, compared with the massive amount of effort expended by Australian climbers in establishing the route to camp three and particularly in doing all of the load carrying, the help from the tri-nation team was very small indeed. It can be fairly claimed that the ABEE was the first expedition to climb the South Col route without Sherpa support.

As Zaharias noted, it took the entire ABEE team (18 climbers) 11 days to carry and fix the $4000 \mathrm{~m}$ of rope and 50 ladders in the icefall. As most expeditions contract out this work [to Sherpas], they have no idea how demanding and dangerous this work is, taking it completely for granted.' ${ }^{27}$

The ABEE achievement is thus no mere gimmick. John Roskelley, arguably America's best Himalayan climber at the time and certainly one of the world's best, had put forward the proposition that Western climbers should do just what the Australians did in 1988: refuse to use Sherpas as paid high-altitude porters on Everest expeditions. Ironically, Roskelley put forward this proposal in 1985- a year after he had returned from the north side of Everest, where he witnessed the record-breaking Australian ascent of the Great Couloir. No doubt his respect for Australian Himalayan mountaineers went even higher when he learned of the ABEE's success in 1988.

Roskelley's arguments are based on ethics: it is unethical, or at least very bad style, to pay Sherpas to do all of the dirty work in the Khumbu Icefall - that is, to shoulder most of the risk associated with climbing Everest via the South Col route. According to Roskelley, there are only two ethical courses of action: either include Sherpas as fully fledged members of the expedition or do all of the load carrying through the icefall yourself. So, from the ethical point of view, the ABEE ascent was without Sherpa support. Not a single Sherpa was paid by the ABEE to work on its behalf above base camp.

A second aspect is related to the physical load taken off Western climbers by high-altitude porters. On the usual ascent of the South Col route, climbers make only a few trips through the icefall — perhaps two or three to aid acclimatisation early in the expedition and then the final trip through on the summit attempt. Meanwhile, while the climbers rest at base camp and marshal their strength to push to the top, the Sherpas do all the hard physical work of establishing the route and camps, putting in the ladders and fixing ropes in the icefall and carrying all of the gear and supplies, particularly the bottled oxygen, up the mountain. In many cases, the Sherpas are also in residence in the higher camps to prepare the meals and melt snow for drinking water as the Western climbers move through on their summit attempt.

27 Z. Zaharias, Correspondence. 
Jon Muir was under no illusions about the magnitude of the task the ABEE had undertaken:

You wouldn't believe the difference climbing without Sherpas! I've seen a lot of these other expeditions, like recent American and Dutch expeditions. The Sherpas do everything - fix the icefall, carry loads, set up camps, cook meals. All of those things take tremendous effort at high altitude. Then the climbers just come along with day packs, following the Sherpas. ${ }^{28}$

It is hard to imagine the physical and psychological stress the ABEE team endured. Just to get camp three established partway up the Lhotse Face and most of the gear up to the top of the Western Cwm required on average 1520 carries by each climber. A 'carry' is a major effort: a very hard day's work hauling 15-20 kg loads at $6000 \mathrm{~m}$ or higher. Then, when fatigue, exhaustion and the physical deterioration associated with operating at high altitudes for a long period had truly set in, the climbers had to make a carry to the South $\mathrm{Col}$ - that is, in effect climb an $8000 \mathrm{~m}$ mountain carrying a load! Soon after that, those still able to function at extreme altitudes had to go back up and try to climb Mt Everest, the highest peak in the world! All the while the repeated trips through the treacherous Khumbu Icefall would be eating away at the climbers' psychological stamina. When viewed in those terms, it is little wonder that the few previous attempts to climb the South Col route without Sherpa support ended with exhausted climbers at or below the South Col. It is a remarkable testament to the overall strength of the team that 15 ABEE members climbed to the South Col at least once (see image 23.1).

Pat Cullinan summed up the achievement:

No team has ever climbed Everest harder than the ABEE... We did it on completely insufficient food, with blood being extracted from us every three or four days [for medical tests], and often when sick. Many climbers lost 10 to $15 \mathrm{kgs}$, which is a lot for a fit climber to lose... The team took on a real challenge and succeeded against all odds. ${ }^{29}$

One of the most remarkable aspects of the ABEE's historic ascent was the way in which the summit itself was attained. By rights, Bayne and Cullinan were lucky to have simply survived their long stay at the South Col. After all, they had survived there longer than any other non-Sherpas had previously survived, and they did so after an extremely long and arduous period of work at very high

28 J. Muir, Interview.

29 P. Cullinan, Personal communication. 
altitudes. By any reckoning, they should have been in no condition to go for the summit. What drove them to go for the top under such conditions and how risky was their decision?

With his background as a medical doctor, Jim van Gelder was in a good position to comment on the pair's decision to go for the top after such a long stay at the South Col: 'By all standards of mountaineering sense, their decision to go for the summit was crazy. The chances of death were high and the chances of brain damage almost certain. But for some weeks before both had been adamant that they were going to climb the mountain. ${ }^{30}$

Van Gelder's last comment points to the extremely delicate balance in mountaineering between the determination needed to push one's body to its ultimate limits and the foolhardiness in pushing it past them. Or as Brian Agnew puts it, 'There's a very thin line between courage and madness.' ${ }^{31}$

It is the judgment of how close one is to that line that often spells the difference between success and tragedy in the Himalaya. The decision by Bayne and Cullinan to go for the top evoked strong reactions from other ABEE climbers. Most agreed with van Gelder that it was madness and that the risk of tragedy was unacceptably high.

Pat Cullinan's determined struggle to the top evoked the most comment. He was well known to the rest of the AAA climbers, while Bayne, on his very first Himalayan expedition, was very much an unknown quantity. Furthermore, even by his own admission, Cullinan was not as skilled or as physically strong as many of the other climbers on the ABEE team.

Peter Lambert's reaction to Cullinan's ascent was perhaps typical. On Broad Peak, Lambert came perilously close to his own personal limit and vowed never to come that close again. He believed that on Everest, Cullinan pushed himself far too close to his personal limit. Nevertheless, Lambert had enormous respect for Cullinan's determination.

'He was mad and he was dangerous,' Lambert remarked. 'Maybe that's what it takes to get to the top of a mountain like Everest, but it wasn't for me. Pat was a physical wreck - he had a bad chest infection — but he still pushed himself to the top. The mental side of climbing is so important. ${ }^{32}$ 
Zac Zaharias shared Lambert's opinion: 'Pat has had the goal of climbing Everest for a long, long time. He's not a very good climber technically and not very strong physically, but he has incredible determination. ${ }^{33}$

'Pat was always one of the slowest climbers on the mountain,' van Gelder recalled. 'During the load-carrying phase, you'd be on your way down from a camp and there would be Pat still struggling on. But he obviously has the ability to just keep going about the same speed no matter what altitude he's working at.' $^{34}$

How did Cullinan himself view his decision to start out for the top in such an exhausted state? For him, it was a problem of literally taking one step at a time:

You can always go one more step. I certainly looked at it that way on Everest. You get to the point where you think you can't go on any more. Then I'd say to myself mentally, 'I can go on. I can go one more step.' And the fact of the matter is you can. ${ }^{35}$

I was very fortunate in being with Paul, with his incredible determination. He's a far better mountaineer than I. But I never give up-I've never pulled out of anything. I wasn't going to let Everest be the first time I pulled out of anything. ${ }^{36}$

What is even more impressive about their successful ascent is that the top part of the climb - from camp four to the summit - is the most technically difficult part of the South Col route. Even a Himalayan climber as experienced as Jon Muir was impressed by that segment of the route: 'I was amazed by the difficulty - it wasn't easy at all. I found there was another steep step before the Hillary Step, and lower down there were steep bowls of light snow covering rubble that made for very treacherous climbing. It was steeper and harder than I thought. ${ }^{37}$

Another factor that increased the difficulty of their ascent, particularly given their slowed mental function at that extreme altitude, was a psychological one. 'There is a big mental jump when you set out on your own above the col,' James Strohfeldt pointed out. 'You are suddenly beyond the fixed ropes, beyond the "umbilical cord" by which you can always descend in safety. Above the fixed ropes you're doing it on your own and you have to take responsibility for your own safety.' ${ }^{38}$

\footnotetext{
3 Z. Zaharias, Interview.

J. van Gelder, Interview.

P. Cullinan in Ryan and Humphrey, One More Step.

P. Cullinan, Interview.

J. Muir, Interview.

J. Strohfeldt, Interview.
} 
A further interesting question is why, given their very slow rate of climbing and their obvious weakened condition, did they not stop at the South Summit or earlier and return to the col? After all, most climbers, particularly at those extreme altitudes, monitor their own condition closely and if they have not reached the summit by a certain time or if they are simply feeling too bad, they turn around and descend. For example, the earlier ABEE summit attempt ended near the South Summit when the climbers realised they were moving too slowly and they returned to the col.

Bayne's response was direct:

If you've left any escape valve in your head, you'll use it. You'll turn around and go down. You need that hard push to succeed. You'll always feel very, very bad, so that in itself is not a good enough reason to turn back. You need something to happen, some event, to make that decision for you. ${ }^{39}$

To a large extent, Cullinan relied on Bayne to make any decision to turn back:

On the climb from the South Col I felt really, really crook. I just followed Paul. And I said to him, 'If you turn back, I'll turn back.' After sitting with Paul in a tent for six days at the South Col, I knew if he turned back, then the situation would be serious and he would need help. But he didn't turn back. ${ }^{40}$

All in all, the ascent of Everest by Bayne and Cullinan was a feat of almost superhuman stamina-physical and mental-and of an unwavering determination. 'This isn't the sort of achievement that comes from just running around the block a few times or pumping iron in a gym,' ABEE doctor Tony Delaney pointed out. 'It demands extreme mental fortitude, and a clear idea you're going to come back alive. ${ }^{41}$

So, how close were Bayne and Cullinan to stepping over that line between courage and madness? By every conceivable indication, they were very, very close. It would undoubtedly have taken a very minor perturbation - such as a small storm or even just a strong, unexpected gust of wind-and they would have been in serious trouble. In the end, however, they were able to find within themselves whatever it took to keep going, to take that one more step.

The ascent by Jon Muir and the near-ascent by Chris Curry also deserve comment. Muir had nearly missed his last chance for the summit when even his legendary strength began to be sapped. Earlier, while in residence with Dad's

39 P. Bayne, Interview.

40 P. Cullinan, Interview and personal communication.

41 T. Delaney in Ryan and Humphrey, One More Step. 
Army at camp three, he suddenly became ill. 'From feeling great to vomiting vigorously took about half a minute,' Muir recalled. 'Litres of precious liquids gushed forth and amongst it all, a 20 centimetre roundworm. ${ }^{42}$ Dehydrated and weakened, Muir had no choice but to return to base camp to rest and rid himself of the worms. It appeared that the incident marked the end of his chances to reach the summit.

When anxiety was reaching very high levels at base camp as Bayne and Cullinan made their do-or-die push for the top, a rested and very much stronger Muir was an obvious choice to move back up the mountain for the anticipated rescue operation. Muir certainly made the most of his unexpected opportunity. Learning that Bayne and Cullinan had reached the summit and had descended safely to the South Col, he and Chris Curry moved up to camp two at the head of the Western Cwm to help the exhausted climbers down from the col if necessary.

Moving as quickly as they could, Muir and Curry climbed the whole of the Lhotse Face in a single day and, after learning to their great relief that Bayne and Cullinan could descend unassisted, decided to keep going up. After a short rest at camp four, Muir and Curry set out about midnight for the top of Everest. The next day, just after 1 lam, Muir was on top. He had climbed from camp two in the Western Cwm to the summit in just more than 30 hours - at that time a record for the quickest ascent of Everest. The previous fastest time was about 40 hours, from the foot of the North Face. The head of the Western Cwm and the base of the North Face are at about the same altitude.

It was a vintage performance by Muir. James Strohfeldt was particularly impressed by the ascent: Muir "was so much stronger than anyone else on the trip. He was never "not strong", always a powerhouse. Some people have good and bad days, but not Jon. He was always strong. ${ }^{43}$

Muir, however, certainly had competition as the expedition's fittest and toughest climber. When he and Curry climbed back up to be in a position to help Bayne and Cullinan, Curry had just returned from high on the mountain. In fact, he climbed to the South Col three times in all and still had the strength on the last trip up to keep going towards the top. Unfortunately, a leaky regulator on a tri-nation oxygen cylinder forced Curry to turn back at $8700 \mathrm{~m}$ - less than 200 vertical metres from the top. He very nearly became the fourth Australian to stand on top of the world in 1988.

It was a real injustice that a technical failure cost Curry his chance for the summit as he had put in so much work on the mountain. He, like Muir, was

42 Muir, J. 1989, 'To the roof of the world', Wild, no. 31 (Summer), pp. 36-9.

43 J. Strohfeldt, Interview. 
strong throughout the expedition and was always willing to carry extra loads and do extra tasks. He had come a long, long way since 1984 when Geof Bartram guided him to the summit of nearby Pumori.

Muir's quick dash to the top at the very end of the expedition therefore put an emphatic final stamp on the Australian effort. Despite the sometimes bitter and acrimonious conflict during the trip and despite the considerable consternation at base camp caused by Bayne and Cullinan's death-defying performance above the South Col, the ABEE was a resounding success. Three Australians had climbed Mt Everest in the bicentenary, all team members had come back alive and without serious injury and, to top it off, the ascent had been made in good style.

ABEE leader, Austin Brookes, summed up the significance of the feat:

What in fact stood out was the real commitment to a team effort by all of the climbers. To climb Everest by the South Col route is not particularly difficult, but to accomplish this in a particular year was the main problem, particularly as we had decided to dispense with high altitude porters... The three who made it to the top obviously made outstanding efforts but to get enough gear to the South Col for eight to attempt the summit was the result of a fine team effort.

The only regret I have is that Chris Curry and Mike Rheinberger didn't get a 'fair go' at the summit, for their contributions were truly outstanding. However, there were others who simply buggered themselves getting the gear to the Col-they knew they were reducing their chances of personal success in making their efforts but they made them nonetheless. That, I think, was the main thing that remains in my memory. Twentyfive Australians wanted an Australian to climb Everest in 1988 and put their heart and soul into achieving that. ${ }^{44}$

Peter Gration, who had by 1988 become General P. C. Gration, AC, OBE, Chief of Defence Force, was delighted by the magnificent achievements of the ABEE team - and particularly of the AAA climbers: 'The contribution that these fellows made, and the example this will set for young men and women in the army for many years, is absolutely outstanding. ${ }^{45}$ Gration's adventure-training program, set up after his trek to Everest base camp in 1975, had indeed paid handsome dividends.

44 A. Brookes, Personal communication, 1 November 1989.

45 P. Gration, Interview. 
Gration, who was in a very good position to recognise outstanding leadership, was most impressed by the effort of Brookes in leading the ABEE to its success: 'I thought we were well served by Austin, particularly bearing in mind the very diverse nature of the climbers. We were lucky to have him.' ${ }^{46}$

It had been a long haul for the AAA since their first trips to New Zealand in the late 1970s. After initial success on Tseringma in 1980, their next venture into the Himalaya had ended in tragedy on Ganesh IV in 1981 when Dave Sloane was killed in an avalanche. They persevered, however, following that with a solid base of climbing on trekking peaks and Denali, a successful ascent of a difficult route on Nilgiri North and the climb of Broad Peak-one of the 14 peaks of more than $8000 \mathrm{~m}$. Now Cullinan's magnificent effort capped more than a decade of military mountaineering with success on the world's highest mountain arguably the most coveted prize in Himalayan mountaineering.

The ABEE ascent of Everest also marked the end of the mountaineering career of Pat Cullinan, the most enigmatic of all Australian Himalayan climbers. Before his exhausting, nerve-wracking, desperate push to the top of Everest, Cullinan had already decided to hang up his boots. Before the expedition left Australia, he had promised his wife, Sharon, that, whether he reached the top or not, he would retire from climbing. In addition, he realised how close he had come to overstepping even his considerable limits. 'I'm lucky to still be alive,' he said after the Everest ascent. 'When I get on a mountain, I'm pretty determined to get to the top. ${ }^{\prime 7}$

Cullinan's career had begun in unusual fashion - he had taken up climbing as part of his duties as commander of a Special Air Service (SAS) unit - and had ended in an equally unconventional way: with his controversial and very risky decision to tackle the most difficult and dangerous part of the Everest climb in a seriously weakened and rapidly deteriorating condition. It was not the first time Cullinan had courted disaster by staying high on a big mountain. His ascent and subsequent rescue of Karl Fassnacht on Broad Peak had also raised doubts about his mountaineering judgment. In the most important decision of all, however - when to call it quits - Cullinan had shown he had the selfknowledge and ability to clearly think out the consequences of his actions, and thus ultimately to survive. The Himalaya are littered with the bodies of those who did not know when to stop.

So, with the ABEE success on Mt Everest in 1988, ended the unusual career of Pat Cullinan - above all else, a testament to drive and determination of the most extraordinary kind.

46 Ibid.

47 P. Cullinan, Interview. 


\section{Part 7: Peak performance-tough climbs on big mountains}





\section{Master of all trades}

One could be forgiven for thinking that Australian climbers have a fixation on Mt Everest. Over the years until 1990, Australians had been members of nine Everest expeditions, while the other 13 of the world's $8000 \mathrm{~m}$ peaks had been attempted by only 15 expeditions with at least one Australian member. There are occasional references in the mountaineering literature to Australians' fixation on Everest and from time to time climbers have been heard to mutter something to the effect that 'when Australians finally get over their obsession with Everest, then you'll really see something in the Himalaya'.

Indeed, even the structure of this book has emphasised the role of Everest ascents and attempts in the history of Australian mountaineering in the Himalaya. Although it is convenient organisationally to consider the earlier climbs of the major players in Australian Everest expeditions as lead-ups to Everest, it should be reiterated that many of these trips were not designed specifically as training climbs for Everest but were undertaken as worthy objectives in their own right. In many cases, the climbers involved had, at the time, no more than a vague notion that one day they would like to have a go at Everest and certainly had no definite Everest commitments. For example, Jon Muir's expedition to Changabang in 1982 with the International Turkey Patrol (Chapter 19) and his trips to Gangotri in the mid-1980s (Chapter 20) were not simply training climbs for subsequent Everest attempts, and the expeditions to Dunagiri (Chapters 6 and 7) and Ama Dablam (Chapter 9) of which Tim Macartney-Snape and Lincoln Hall were members were undertaken before they had even obtained a booking for their 1984 attempt on Everest.

Nevertheless, nearly all of the major Australian Himalayan mountaineers Tim Macartney-Snape, Lincoln Hall, Greg Mortimer, Zac Zaharias, Jon Muir, Michael Rheinberger - have sooner or later been lured into attempting the world's highest peak. It seems to have an overpowering attraction that few mountaineers can resist. There is, however, one Australian climber of truly international standard with a long string of Himalayan achievements who in the pre-1990 period had never been involved with an Everest attempt, or even climbed with any of these other Australian mountaineers on any of their preEverest expeditions. That climber is Greg Child and he is arguably the best all-round mountaineer Australia has ever produced. He has put up some of the most technically difficult rock routes in Australia, matched the best of the American hard men on the big walls of Yosemite and climbed with the cream of 
the international mountaineering community on some of the biggest and most spectacular Himalayan peaks. In the climbing business, Greg Child is a master of all trades.

Child's rise to prominence as Australia's most versatile climber began more than 15 years ago, as Chris Baxter, then editor of Wild magazine and one of the most insightful observers of the Australian climbing scene, recalled:

I first met Greg Child in the mid-1970s. He was still a schoolboy-barely emerged from the educational chrysalis and ready for flight, as it were. It was already apparent, however, that what this young Sydney climber lacked in stature he more than made up for in courage, determination and resourcefulness, and that he would go far in climbing. How far, no one could have foreseen. ${ }^{1}$

Baxter seemed to foresee Child's greatness nearly 10 years earlier. In an article in the Melbourne University Mountaineering Club's journal, Mountaineering '81, on Australia's foremost climbers of the 1970s, Baxter wrote, 'There are those, and this writer is among them, who believe that Greg Child is the best and most promising all-around Australian climber...Child is seen as a "natural" climber, who apparently does very little training, is immensely strong, and almost totally unflappable.'2

As so many Sydney climbers have done, Child had his start in climbing in the neighbouring Blue Mountains. 'I started climbing mainly through Scouting (I joined the Boy Scouts out of a fascination for traipsing around the bush to look at reptiles) with Chris Peisker,' Child said:

It amazes me that we survived a self-taught climbing beginning. We had an old book called Outdoor Senior Scouting, which Peisker foisted on us. From this we learned knots and techniques. We even used hemp ropes. We had about a dozen pitons and half a dozen nuts (some of them machine nuts on rope) and a dozen karabiners between us and we went out and did climbs in the Blue Mountains. The first was the Three Sisters, in the early 1970s, when I was 13. Things progressed fairly well until I had a monstrous fall at Mt Piddington. Inexperience was the cause of that, or thinking that we were more experienced than we were. ${ }^{3}$

1 Baxter, C. 1990, 'Child's play', Wild, no. 37 (Winter), pp. 58-63.

2 Baxter, C. 1981, 'Australia's leading climbers', Mountaineering '81, (Melbourne University Mountaineering Club journal), vol. 1989, pp. 23-4.

3 G. Child in Baxter, 'Child's play'. 
The fall Child referred to was a $25 \mathrm{~m}$ ground fall, one that in most circumstances would have been fatal. He was only sixteen at the time. Child's reaction to the fall demonstrated, however, a fierce tenacity that would later carry him through many tight situations on big mountains:

I can just remember lying on my back after the accident - smashed to pieces, facing about nine months of surgery, not being able to walk, and certainly being out of climbing for a long time- just looking up at the climb, thinking 'Damn, I've got to come back and do this', and being worried about how long I'd be out of climbing. ${ }^{4}$

By the late 1970s, Child had more than overcome his near-fatal fall; he had become one of Australia's most skilled rock climbers. He already had an array of impressive new free climbs and first free ascents to his credit - such as Manic Depressive (grade 25), Los Endos (22) and Die Loaded (24). He did not, however, stop there. When thoughts of climbing further afield entered his head, he did not follow the scores of Aussies to New Zealand, as the notion of climbing in the cold and snowy Southern Alps did not enthuse him. Rather, he headed for North America, for the vast granite walls of the Yosemite Valley.

At Yosemite, he found warm rock like that he excelled on back home, but on a scale not found anywhere in Australia. The Yosemite Valley is the mecca of big-wall climbing - a very different climbing game from rock climbing on one's local crag. Big-wall climbing is far more committing and requires stamina and endurance in addition to technical skills of the highest standard. The Yosemite walls are vertical, sometimes even overhanging, and average about $1000 \mathrm{~m} \mathrm{high}$. Climbing them usually requires many days, so the climbers must carry water, stoves, food and survival gear in addition to their climbing equipment and must often sleep in precarious positions from hanging belays. A significant amount of the climbing itself is 'aid climbing' - that is, the climber advances by stepping up into slings, or etriers, attached to pitons or other pieces of protection that the climber has placed above his head, sometimes behind flakes of dubious strength or in thin, shallow cracks. Aid climbing demands considerable strength and endurance, as well as unfailing technical ability to ensure reliable placement of protection. Perhaps more importantly, it requires mental stamina to keep pushing upward, toting heavy haul bags, day after day, sometimes making less than $100 \mathrm{~m}$ progress a day over difficult sections.

Child quickly took to the big walls of Yosemite and within a few years in the late 1970s, he had earned the respect of America's most experienced big-wall climbers. Perhaps his greatest achievement during that period was the second ascent of El Capitan's Pacific Ocean Wall - a test piece for the hardest of the 
Californian hard men. It had the reputation as the most difficult big-wall climb in North America and one of its pitches was the hardest bit of aid climbing anywhere on El Capitan. On that unremittingly steep and demanding face, Child teamed with well-known Australian rock climber Kim Carrigan and Canadians Darryl Hatten and Eric Weinstein to hammer, tap, jumar, swing, pendulum and occasionally free climb their way to the top in a seven-day push during the summer of 1977. It was an ascent that established Child as one of the world's best climbers on rock walls of any scale.

With an extensive background in crag and big-wall climbing, Child first turned his attention to snow and ice in 1979 on a trip to the British Isles. He got his start on some moderately difficult routes in the classic ice gullies in Scotland, climbs on which many of Britain's most well-known high-altitude mountaineers first cut their alpine teeth. It was in Scotland that Child chanced to meet Doug Scott, one of the pillars of the substantial British Himalayan climbing community and the person who would eventually give Child his start in the Himalaya.

Scott was obviously impressed with Child from the start, as he later wrote:

Greg was a good lad. He was, for his age, remarkably self-contained and sure of himself, abrasive at times but with a twinkle in his eye and a huge disarming grin. I soon took to this warm-hearted Australian and thus our paths met and have continued to do so sporadically since on trips to the mountains. ${ }^{5}$

Several years later, in 1980, Scott remembered the warm-hearted Australian when he was organising a Himalayan expedition and invited Child to join him on the 1981 British expedition to the Gangotri region of India. At that time, Child's only experience on snow and ice was in the Scottish gullies in winterchallenging enough technically but hardly the complete alpine climbing experience that a season in the European Alps or New Zealand afforded. Like Pat Cullinan and his troops from Perth on their expedition to Gauri Shankar, Child would be attempting a difficult Himalayan mountain on his first alpine climbing trip. The difference, of course, was that, whereas none of Cullinan's team had any significant alpine climbing experience before attempting Gauri Shankar, Child would be climbing with some of Britain's most-accomplished Himalayan mountaineers.

Child's association with Scott-beginning with the meeting in Scotland and strengthened with the 1981 and subsequent Himalayan expeditions - was one of two important factors that led to the development of Child's Himalayan career,

5 Scott, D. 1988, 'Forward', in G. Child, Thin Air: Encounters in the Himalayas, Patrick Stephens, Wellingborough, England. 
independent of the major strands of Australia's Himalayan mountaineering community. The other was his move to the west coast of the United States - not so much to climb there as to maintain a relationship with an American woman.

Child explained:

I'd met my wife, Salley Oberlin, on a trip to Yosemite. After a while we couldn't keep the trans-Pacific relationship going — she'd visit Australia and I'd visit the USA - so to continue the relationship we had to get married. I got married not in order to live in the US and climb, despite what a few people probably thought, but so that Salley and I could continue to be with each other. ${ }^{6}$

By living in the United States, Child developed links with American climbers that would also lead to the Himalaya. Furthermore, in the early to mid 1980s, it was simply easier to get to the Himalaya by joining an American or British expedition than to try to mount an expedition from Australia, where Himalayan mountaineering was still an obscure activity and sponsorship was difficult to find.

In 1981, Child joined Scott, Don Whillans and Georges Bettembourg-three very experienced Himalayan mountaineers - on the trails towards the sacred mountains near the source of the Ganges River in the Indian Himalaya. The other four members of the team were Englishman Colin Downer, American Steve Sustad, New Zealander Merv English and another Australian rock climber, Rick White.

Even by 1981, White had become somewhat of a legend in Australian climbing circles. Although originally from Mt Gambier in South Australia, he was indelibly linked with the development of rock climbing in Queensland. He not only discovered and named Frog Buttress on Mt French in south-eastern Queensland - that state's most popular crag-he was a leading force in its development, putting up climbs at a standard as high as anywhere else in the country.

Like Child, White's first overseas climbing trip was to the Yosemite Valley, where in 1973 he became the first Australian to climb El Capitan. Later, with Child, on an earlier attempt on the Pacific Ocean wall, White led the notorious A5 crux sixth pitch before the pair was forced to retreat. He led the first Australian expedition to the Patagonian Andes in 1975 and five years later made one of the early ascents of Balls Pyramid (near Lord Howe Island), the world's largest sea-stack.

6 G. Child in Baxter, 'Child's play'. 
White was just as well known for his forceful personality as for his climbing prowess. His reputation as a tough and forthright character extended to business, where he established and operated the very successful outdoor equipment business Mountain Designs. As Chris Baxter put it, 'White has left a trail of bruised egos, stomped corns and paranoid and jealous rivals.' ${ }^{7}$ It should be added that White has done much for Australian Himalayan mountaineering through the years by sponsoring expeditions and climbers with equipment from his Mountain Designs line.

When it came to climbing in the Himalaya in the early 1980s, however, White, like Child, was very much a newcomer. And what Scott had settled on as an objective for the 1981 expedition was anything but a newcomer's mountain. He had his eye on Shivling, the strikingly beautiful sacred peak rising above the Gangotri Glacier near the headwaters of the holy Ganges River. It was the mountain whose South-West Pillar was attempted in 1985 and then climbed in 1986 by Australian expeditions involving Brigitte and Jon Muir (see Chapter 20).

In 1981, the attention of Scott's international group was focused on the East Pillar, described by Child as incorporating

every type of alpine climbing, with rock walls, narrow ridge crests, and ice smears plastering the final headwall. It was a magnificent sight, hard to stop staring at and hard to imagine in terms of difficulty. The scale was as if Yosemite Valley's El Capitan had been stacked upon itself twice, dumped on top of Northwest USA's Mt Rainier, then crowned with an icy cone. ${ }^{8}$

They attempted the pillar in alpine style, in a single push with no previously established camps on the mountain. It was thus a technically demanding and, at the same time, very committing attempt, the type of extreme Himalayan climbing for which Scott had a well-earned reputation.

The group split into two teams, with Scott leading the East Pillar group and the veteran Whillans joining a group attempting the less severe original route of ascent on the other side of the mountain. The East Pillar team was a fascinating group. In addition to Scott, it comprised the effervescent Bettembourg and the two Australians, Child and White, both of whom were highly skilled rock climbers and very competent on big walls, but very much neophytes in the rarefied atmosphere of the Himalaya.

7 Baxter, C. 1985, 'White knight?', Wild, no. 18 (Spring), pp. 22-7.

8 Child, G. 1988, Thin Air: Encounters in the Himalayas, Patrick Stephens, Wellingborough, England, ch. 2. 
On the first day of the attempt, the Australians received a stark reminder that they could not expect in the Himalaya the generally reliable weather of the sundrenched walls of Yosemite. Child recalled:

A sudden ripping sound a thousand feet above makes us look up. Out of nowhere appear a pair of whirlwinds. Caused by the straining of wind through the turrets of the pillar, they tear at the ice and rock, scouring and feeding on the mountain like a living organism. They reach a frenetic pitch, then subside as suddenly as they appeared, dropping lumps of ice tinkling down the walls. I'd seen a tornado in Wyoming once, but a twister on a Himalayan peak is something entirely unexpected. Rick looks at me with eyes that seem to say 'What the hell have we got ourselves into?' Contemplating what would happen if we were caught in one, I remember the Whillans euphemism for catastrophic events: 'End of story,' he'd say. ${ }^{9}$

The four continued on, despite the problematical weather and battled on along an almost-horizontal ridge that led to the steeper section of the pillar. On the second night out, Child and White experienced another of the vagaries of Himalayan climbing: dealing with recalcitrant stoves at high altitude after a tiring day of climbing.

As Rick and I flop about exhausted in our tent we hear the patter of snowflakes on the roof. I scoop up a pot-full of snow to melt to water, light the Bluet gas stove, and settle back in my sleeping bag.

'Damn. The stove has gone out,' I say to Rick. I light it again, but it fizzles after a spurt of flame.

'The cartridge must be empty,' says Rick, unscrewing the old cartridge and replacing it with another. A brief hiss of gas escapes. We open the tent door to vent the gas out, then I light the stove.

'Wumph!'

'A fireball fills the tent, hanging above our heads like a sun. Rick buries his face against the floor. I toss the blazing stove out the door, feel the lick of fire against my face, scream, then dive out of the tent onto the ridge. The stove sizzles in the snow and a smell of burned nylon and hair rises from the tent. Our eyebrows are cauterized from our faces. Snowflakes dropping in the quiet night sky are caught by the beams of Doug's and Georges' headlamps, as they peer toward us.

'What the hell is going on?' calls Doug.

9 Ibid., ch. 3 
Himalayan Dreaming

'The tent! The tent!' I yell back.

'What about the tent?'

'Is it insured?'

The tent is a disaster. Its interior looks like the burned out cockpit of a crashed plane. The entire upper section of the inner tent is vaporized, leaving only the stitched seams suspended from the poles, and the reflective aluminium-coated fly-sheet, which deflected the fireball. Our mistake is a bad one, but remarkably, the tent is salvageable. As Doug and Georges survey the damage they look at each other, dumbfounded, yet not entirely unamused. ${ }^{10}$

Tornadoes and scorched tents notwithstanding, Scott, Bettembourg, Child and White pressed on. The fourth day found them on the East Pillar itself. The climbing was hard, perhaps even harder than they had expected. Much of it was severe rock climbing, sometimes aid climbing, at which the Australians excelled, with the occasional pitch of steep snow smeared over the rock or smooth ice packed into fissures or gullies. Slowly, they overcame each difficulty, often with a desperate struggle by the leader, but their progress was much slower than they had planned for.

Day nine and they were still far short of the summit ice cap. They were also short of food and consumed the last of their solid food that evening. A storm the next day delayed them further and on the eleventh day, they consumed the last of their food of any kind - a bit of sugarless tea - two days, as it would turn out, before they reached the summit.

It was yet another sobering experience for Child and White. They had heard about the 'commitment' needed for a big Himalayan climb, but they had not reckoned on starving. There they were, however, high on Shivling's East Pillar, with no realistic descent route possible, so committed to continuing the climb to the top as the only feasible way of getting themselves off the mountain. When Child, realising the seriousness of their predicament, muttered something about starvation, the laconic Scott replied, 'Well, you'll never find enlightenment on a full stomach.' ${ }^{\prime 1}$

On the twelfth day, they summoned their remaining strength and surmounted the headwall at the top of the pillar and much of the summit ice cap. On the morning of their thirteenth day since leaving base camp, and the fourth since

10 Ibid.

11 D. Scott, in ibid., ch. 5. 
they had eaten solid food, the four climbers plugged the final few steps to the top of Shivling and, shortly thereafter, began what they hoped would be a quick descent down the West Face.

Weakened by the lack of food, however, Child and White courted disaster again on the descent, as Child recalled vividly:

Rick starts down, $150 \mathrm{ft}$ above me. I stop to wait for him.

On the flat bowl $800 \mathrm{ft}$ below, Doug mentions to Georges what a good effort Rick and I have put in for our first Himalayan climb. He is cut short by Georges' scream of 'Merde!' as he sees the horrible happen.

Rick, now $100 \mathrm{ft}$ above me, places his foot in a step and something goes wrong. Perhaps it is the step crumbling beneath him, or perhaps his weak ankle gives out, but suddenly he is sliding, raking feverishly at the sugary snow with his alpine hammer. The pick fails to arrest him. He gains speed. I see this as a split second blur out of the corner of my eye.

'Here I come!' Rick yells. It is the understatement of our lives.

Fired by a surge of adrenalin, a flood of possibilities enter my mind. Plunge the shaft of my alpine hammer into the snow to hold Rick's fallno chance it'll stop him; catch him as he slides past-he's out of reach; cut the rope to save myself-no time; untie - less time; climb down the slope-impossible; jump off-suicide...

The coil of rope beside me whips out as he slides past, looking like a harpooned whale plunging into the deep to drag the ship down with it. The chances for survival diminish as I watch the rope flick into the air. My mind casts out an apology to my wife Salley as I realize the folly of this final act, then in futility I plunge the shaft of my alpine hammer into the slope. The rope stretches against my waist, then propels me into the air. I suffer a final thought: 'This is it.'

We bounce down the slope, tumbling for $700 \mathrm{ft}$, legs and arms flailing like rag dolls. I land on my back, feel the wind knocked out of me, bounce again, then feel razor sharp crystals of snow grind against my cheek as I slide face-first down the slope. We hurtle over a gaping bergschrund, then slowly come to a stop in the bowl.

It's windless in the bowl, noiseless. The hiss of disturbed snow sliding down behind me sets my mind back into gear. I return from black silence 
as blood trickles out of my nose and onto my lips. I twitch my limbsnothing broken - then get to my feet. Rick is lying ten feet away, feeling his ribs. He thinks a few are cracked, but otherwise we're unscathed. ${ }^{12}$

Lucky to be alive, the pair picked themselves up, dusted themselves off and continued on down the West Face. Nearing the end of their thirteenth day on the mountain, and their fourth day without any food, Child and White thought that their dreams had come true when, on the final slopes of the West Face, they saw a figure waiting for them - presumably someone from the other party with some lifesaving food.

Child recalled:

As we grew closer, the figure takes on a familiar form-Whillans!

Whillans the phrase-maker, the clairvoyant, the sage - the bringer of food! Thoughts of what he might have brought-chocolate, biscuits, sardines - squeeze a last burst of energy from our legs. I hallucinate the sweet aroma of tea wafting through the air. By the time I reach him Doug has told him the tale of our thirteen-day climb, including an account of the exploding tent and our tumble down the mountain. Whillans sits calmly, like the all-knowing Buddha, and transfixes me with the same piercing glare he'd cast over the Indian boy at Delhi airport a month before. The meerest hint of a smile cracks his parched lips.

'Well done, lads. You made it back,' he says. Then, satisfied that all is well, he trots off down the Meru Glacier, beginning the four-mile hike back to Tapovan.'

'Did he bring anything to eat?' I ask.

'Yeah. But he got hungry while he was waiting and ate it,' Rick replies. But it's the thought that counts. ${ }^{13}$

Child was no doubt happy and considerably relieved to return to the more predictable world of Yosemite after his adventures on Shivling. His ascent, however, was a remarkable achievement, particularly considering the state of Australian Himalayan mountaineering in 1981. At that time, Australians had climbed only one 7000 m peak: Dunagiri. The Army Alpine Association (AAA) was taking its first tentative steps into the Himalaya with its ill-fated expedition to Ganesh IV. Michael Rheinberger was only beginning his long career in the Himalaya and Jon Muir and Greg Mortimer had yet to set foot in the world's greatest ranges. Tim Macartney-Snape and Lincoln Hall were absorbed with 
Ama Dablam and Anyemaqin; Everest was still three years away for them. So Child and White's ascent of the East Pillar of Shivling was easily the most difficult Himalayan route that Australians had climbed, or even attempted, at that time. The International Turkey Patrol's ascent of Changabang, on a route of perhaps comparable difficulty, was a year away.

Back in Yosemite, Child picked up where he left off: doing week-long journeys up the vast walls of granite on routes of the highest standard. The lure of the Himalaya, however, was soon to prove too strong to resist. In 1983, Child was on his way to Pakistan to climb in the spectacular Karakoram Range. Again, Doug Scott was the architect of the expedition and it was a trip of typical Scott design with multiple objectives leading to an attempt on one of the world's great peaks. The team would start with the unclimbed Lobsang Spire, one of the many great rock monoliths looming among the ice giants of the Karakoram. It would be a climb of great technical difficulty but of only moderate altitude $(5715 \mathrm{~m})$. They would then tackle Broad Peak by the West Face, a route of only moderate difficulty but on a peak more than $8000 \mathrm{~m}$ high. Finally, with training on technically difficult and high mountains, they would go after K2- the world's second-highest peak - by a new route up a spur on the South Face.

In addition to Scott and Child, the climbing team included the veteran Whillans and English climbers Peter Thexton, Roger Baxter-Jones, Andy Parkin and Alan Rouse.

Frenchman Jean Afanasieff and American Stephen Sustad completed the group. It was a far more high-powered, and competitive, team than on Shivling. Rouse had moved rapidly, with ascents of Jannu and Nuptse, to the forefront of British mountaineering and Afanasieff was the first French climber to reach the summit of Everest.

Despite the serious objectives of the expedition and the very competitive make-up of the team, the trip to base camp did have its lighter moments. Most Himalayan trips begin with wild bus rides - as the members of the very first Australian expedition to the Himalaya, to Mulkila in 1975, discovered-but there is something bordering on the insane about rattling along the Karakoram Highway in one of the garishly festooned trucks sometimes dubbed the 'magic bus'. The 1983 trip to Skardu, as Child recounted with some amazement, was perhaps not too unusual:

As the sun sets into a purple horizon the spine-jarring journey begins. Hours pass. The junga [bus] gears down and zigzags up endless switchbacks. My ears pop, signalling that we are crawling into the foothills of the Karakoram. Sleep is impossible as the junga bounces and creaks from pothole to pothole. 
'What the hell is that coming up behind us?' says Steve, pointing to a bright light bearing down on us from behind.

The multi-coloured light, accompanied by loud, inexplicable music, flashes like a Christmas tree. As it closes the gap we see that the vehicle is not a travelling discotheque, but merely the night bus to Skardu. Inside, red, green, and orange lights pulsate stroboscopically, illuminating the tangled limbs and bloodshot eyes of passengers jammed six abreast. The light show is synchronized to the deafening beat of taped Pakistani pop music. Shrill vocals, twanging strings, and thumping drums overtake us and wail on down the road. 'The Bedlam Express', Whillans christens it. $^{14}$

From Skardu, the route to base camp followed the deep Braldu Gorge to the source of the river at the snout of the Baltoro Glacier and then along the Baltoro to a place called Concordia, where several glaciers tumbling off $\mathrm{K} 2$ and its neighbours joined to form the Baltoro. It is the only feasible access route to most of the major peaks in the Karakoram and therefore is very heavily travelled-by expeditions and by trekking groups wanting to see the 'pick of the Karakoram'.

The heavy traffic year after year had created environmental problems similar to those occurring further east in Nepal. Some of the most beautiful campsites in the Himalaya were slowly becoming rubbish dumps. Doug Scott was annoyed enough about the situation at Paiju, one of potentially the most beautiful spots on the walk-in, that he decided to do something about it.

With the expedition's liaison officer acting as an interpreter, Scott gathered the local Balti porters together and explained to them the concept of picking up the rubbish - something that did not come naturally to them. It is not that Baltis are ignorant people, or people with a throw-away mentality, it is simply that they are so poor materially that they do not generate any trash in their normal, everyday lives so they do not know what to do when confronted with it.

The Baltis quickly took Scott's exhortations to heart and began collecting old tins, boxes and other disused expedition gear and piling the rubbish at Scott's feet. They did not, however, stop there. Soon they began to collect natural bits of the landscape - rocks, clumps of grass, twigs and other pieces of wood-and added them to the growing mountain at Scott's feet. The game became even more fun when they set out after living things, such as lizards and birds, and began churning up the river for anything unusual they could add to the expedition leader's collection. 
Scott was powerless to stop the Balti attack. Fortunately, the porters, who had carried heavy loads the previous day, soon tired and the environment of the Paiju hillsides was left to recover from its unexpected pillaging.

Soon after Paiju, the group reached the site of the Lobsang Spire base camp at Urdukas. As the team readied for attempts on its first objective, Child quickly discovered just how competitive and potentially divisive the team was. It was far different from the small, happy four-man team that surmounted the East Pillar of Shivling two years earlier.

First, tension was already developing about Scott's idea of attempting two other mountains before K2. About half of the team was itching to have a go at the big one, perhaps with a warm-up on Broad Peak, and thought the climb of Lobsang Spire to be unnecessary.

Then, during an acclimatisation attempt with Rouse, Parkin and Thexton on a subsidiary peak they christened Biale One, Child had an abrupt introduction to Rouse's competitiveness. The quartet was on Biale One's summit ridge - only 10 vertical metres below the true summit but about $150 \mathrm{~m}$ away horizontally along a difficult, knife-edge ridge - with darkness only an hour or so away and a storm brewing. Child and Thexton suggested a descent, as no-one had any bivouac gear. Rouse finally consented but was somewhat miffed. He was apparently quite prepared to spend a very uncomfortable and potentially dangerous night out to reach the summit of a small, warm-up peak.

The experience raised serious doubts in Child's mind about what he had got himself into. 'Were we a team?' Child wondered. 'A collection of firey [sic], strong-willed individuals, yes, but not a cohesive group striving for a common goal. We probably couldn't climb "as one", or "for the good of the group", if we tried. Alpine-style climbing is a sport of individualists rather than team players. $^{\prime 15}$

The brief disagreement between Child and Rouse was not the only outcome of the Biale One excursion. A rapport between the young Australian and Thexton, a medical doctor and a very strong climber, had begun to grow. So that pair joined with Scott to form a three-man team to attempt Lobsang Spire, independent of the attempt that Rouse and Parkin would make on a different route on the same peak.

Despite the fact that Thexton had little experience in aid climbing, the ChildScott-Thexton team was exceptionally well equipped to tackle Lobsang Spire. Child, with his seasons of experience at Yosemite, was in his element on the steep, expansive walls of Lobsang. In addition, earlier in his climbing career, Scott 
had concentrated on scaling big rock walls around the world; that experience, coupled with his legendary strength, cunning and uncanny ability to survive anything mountains could throw in his path, meant that he and Child were an extremely potent pair to tackle a big rock climb anywhere.

The route they chose on Lobsang Spire followed a series of cracks that split the South Face. There were other less steep alternatives (indeed, Rouse and Parkin later failed on the slabby West Face, a route of a much less intimidating angle), but at least the crack system looked continuous.

Soon the three-man team fell into an efficient rhythm. One would lead up the crack, sometimes free climbing but often banging in pitons, attaching etriers and then stepping up to repeat the process. Despite his lack of experience in this style of climbing, Thexton soon became a powerful lead climber, taking his turn at the sharp end of the rope as the other two jumared up the rope behind him with the loads.

The steepness of the route soon became apparent. On one rather typical pitch led by Thexton, consisting of a series of bulges tucked into a corner, the rope hung free of the wall by $4 \mathrm{~m}$ or so when Thexton had reached a belay point. As Child succinctly put it, 'The going is slow, the climbing difficult. Waiting is frustrating. ${ }^{16}$ It was a typical big-wall climb.

Day by day, as the trio whacked their way up Lobsang Spire's South Face, it was obvious that this was no ordinary big-wall climb. The setting was spectacular. The Biale Glacier slowly dropped away straight below while K2 and the stunningly symmetrical Gasherbrum IV began to loom in the distance. All around were the granite towers and snow-covered giants that made the Karakoram perhaps the most magnificent of all the sub-ranges of the Himalaya.

Lobsang Spire, however, had one last surprise. The mountain's top is capped by a 30 m monolithic block; it is steep on every side, blank and crack-free. After a brilliant five-day performance, would Child, Scott and Thexton be denied the true summit?

During his years of extreme climbing in Yosemite, Child had acquired a diverse bag of rock-climbing tricks, one of which was to overcome blank walls by a clever application of rivets, bolts, skyhooks and a hand-twist drill. Child just happened to have the appropriate supply to, as he put it, 'murder the impossible $^{\prime 17}$ on Lobsang Spire. At first, Scott was not sure, for ethical reasons, that Child should drill his way to the top of the small summit block. There was, however, no alternative. Scott eventually relented, commenting that 'my old

16 Ibid., ch. 10.

17 Ibid. 
mate Dougal Haston used to say that ethics are like erections: No matter how well intentioned they might be they are prone to sudden deflation.' ${ }^{18}$ Scott's deflated ethics notwithstanding, Child led the way up the last $30 \mathrm{~m}$ and onto the summit.

With his well-earned success on Lobsang Spire - a first ascent of the peakChild began to view the expedition in a far more positive light. In addition to gaining a very worthwhile summit in its own right, he had continued to build a solid climbing partnership with Thexton. They had obviously achieved a healthy mutual respect for each other's climbing ability on Lobsang's walls, but more importantly for climbing in the Himalaya, they had the similarity of mountaineering outlook and philosophy, and the complementarity of personality, that typified potent partnerships, such as that of Tim MacartneySnape and Lincoln Hall.

The next part of Scott's Karakoram trilogy - after the Lobsang Spire ascentwas Broad Peak. It was a logical next step towards K2. Whereas Lobsang Spire offered technical difficulty but not extreme altitude, Broad Peak was one of the 14 peaks in the world above $8000 \mathrm{~m}$, but by its standard route was not particularly difficult. $\mathrm{K} 2$, of course, requires technically demanding climbing at the most extreme of altitudes and thus an aspiring $\mathrm{K} 2$ climber benefits from Lobsang's difficulty and Broad Peak's altitude. The latter was particularly important for Child, who had not yet climbed to $7000 \mathrm{~m}$, let alone $8000 \mathrm{~m}$.

With visions of climbing $\mathrm{K} 2$ together in the back of their minds, Child and Thexton, after a well-earned rest at the expedition's K2/Broad Peak base camp at Concordia, set out early one evening in late June across the glacier towards the base of Broad Peak's West Face. They had decided-for safety and ease of climbing - to begin the ascent by moonlight and tackle the couloirs at the bottom of the face when the snow was firm.

They made rapid progress in the good snow conditions and, as dawn came, decided to keep on climbing into the day and ascend as many of the straightforward lower reaches of the mountain as they could on the first day. It was a strong performance as they finally stopped at $6700 \mathrm{~m}$ near midday.

The next morning, they were pushing upward again-first along a low-angled spur of snow and ice and diagonally up a moderately angled snow slope leading towards a small icefall and a steep chute that led onto Broad Peak's long summit ridge. After another long day of climbing, Child and Thexton decided to pitch the tent near the seracs of the icefall at nearly $7500 \mathrm{~m}$ - much higher than Child had ever been before on a mountain. Also, after only two days and one night of climbing, they were in a position to launch a bid for Broad Peak's summit. 
The rapid ascent was, however, beginning to take its toll. Both men had a miserable night. With stomachs queasy, eating and drinking were difficult. During the night, as Child graphically put it, 'altitude creeps into our heads. By morning it is bashing away inside our skulls. Waking is a long and difficult process, cloudy and drug-like.' ${ }^{19}$

Worse, much worse, was, however, yet to come. Despite their considerable physical discomfort, the pair decided to go for the top. They plugged slowly up past the small icefall, then up the chute and onto the summit ridge. Then they began to pick their way along the tricky ridge, discovering, as would the members of the 1986 AAA expedition to Broad Peak, that the mountain was no walkover near the top. They passed the $8000 \mathrm{~m}$ mark as they met Scott and Sustad returning from their successful summit attempt.

Soon after they passed through the $8000 \mathrm{~m}$ barrier, however, into what climbers called the 'death zone', Child's physical and mental control mechanisms began to disintegrate rapidly and he was plunged into a desperate struggle to hang onto his life.

Moving at 8,000 metres is like wading through treacle. I gradually become aware of a peculiar sense of disassociation with myself, as if a part of me is external to my body, yet is looking on. I feel this most when setting up boot-axe belays or making difficult moves, a strong feeling as if someone is peering over my shoulder keeping an eye on me, or even as if I have a second invisible head on my shoulders.

We traverse for another half-hour to the False Summit, an icy, corniced dome at 8,043 metres. There we sit, looking toward the tantalizingly close Main Summit. By now those sensations of disassociation are punctuated by feelings of total absence: momentary blackouts, when neither I nor the guy over my shoulder seem to be around. I would emerge from those absences a few paces from where they'd struck me, leading to a concern over stepping off the narrow ridge...

I look ahead: The corniced ridge dips down and curves left in a final long, easy slope to the summit, only six metres higher than our position. We are nearly there, thirty minutes away. But my fears about what is happening to me double. A vicious headache rings in my ears and pounds at my temples, and a tingling in my arms grows so intense that my fingers curl into a tight fist, making it hard to grip my ice axe. My last shred of rational consciousness raises a cry of concern over the possibility of a stroke, or cerebral edema... 
The idea of turning away from success when it is so close was maddening to me... and Pete's ever present determination nearly got me going. I tried to ascertain whether the sensations I felt were imaginary, or were really the beginning of some short circuiting of my body chemistry. There is a state of mind that sometimes infests climbers in which the end result achieves a significance beyond anything that the future may hold. For a few minutes or hours one casts aside all that had been previously held as worth living for, and focuses on one risky move or stretch of ground that becomes the only thing that has ever mattered. This state of mind is what is both fantastic and reckless about the game. Since everything is at stake in these moments, one had better be sure to recognize them and have no illusions about what lies on the other side of luck. It was one of those times. I had to weigh up what was important and what was most important...

The decision to descend comes without a word. We just get up and begin the long path down, seeing that those red hills in China are now covered in cotton wool clouds, encircling K2 and lapping at Broad Peak's East Face.

A few hundred feet from our high point I feel a sensation like a light blank out in my brain. I have just enough time to kneel down before I slump backwards onto a patch of snow, then black out into a half-world of semi-consciousness and inaction...

'So this is it', I think with a strangely detached curiosity as the day turns pitch; 'this is where the plunge into senselessness and apathy begins, where the shades of death descend.' Yet at the same time I am conscious of my swaying head and my incoherent mumbling. I think of Salley, whom I have no right to inflict such folly upon. 'Get up you idiot, get up,' I keep telling myself, until vision gradually returns. How long had I been out? I cannot tell.

Next to me sits Pete, observing my state as a good doctor should. He wears a white lab coat with a stethoscope draped around his neck; I double-check; nonsense. He is wearing his red high-altitude suit. I am beginning to imagine things. A minute later I regain control of myself, as suddenly as I'd lost it. Pete puts a brew of hot grape drink in my hands. As soon as I drink the liquid I throw it up...

The purple stain in the snow forms intricate arabesque designs that grow onto the snow crystals glinting in the afternoon light. I could have watched these hallucinations all day, but Pete urges us onto our feet. 
Rapidly I begin to improve. My strength and mental faculties return. I'd made it back through the 8,000 metre door before it slammed shut and locked me in. But I'd cut it close. ${ }^{20}$

Suddenly, just as suddenly as Child pulled out of his close encounter with death, it was Thexton who was in desperate trouble. As the pair reached the col leading off the summit ridge and down the chute towards the top camp, Thexton could hardly move. His lips were blue and he was having trouble breathing. They were classic symptoms of pulmonary oedema; the only course of action was to get Thexton down the mountain as quickly as possible.

Somehow Child managed to summon up the strength to take charge of the situation. Below the narrow chute, wind and driving snow were raking the snowfield and it was rapidly growing dark. Child had to cajole every step out of Thexton, as he slumped into the snow with increasing regularity. Then his vision failed and Child had to talk him down the snow slope towards the small icefall and the top camp.

It was a Herculean effort by Child, who had only hours earlier been so incapacitated by the altitude that he had himself nearly perished on Broad Peak's summit ridge. Somehow he managed to guide, drag and lower Thexton through the dark down past the seracs to their tent, occupied by Don Whillans and Gohar, a Balti high-altitude porter, who were preparing for their own summit attempt.

The veteran Whillans then took over. He brewed up liquids for the two exhausted climbers and looked after Thexton while Child pitched another tent and crawled into his sleeping-bag for some well-earned rest.

There was not much of the night left and at dawn, only two hours later, Child was awakened by the calls of Whillans and Gohar. Thexton was dead, they said. In fact, he had just died as Gohar lifted a cup of warm tea to his lips.

It was a calm, clear dawn; the storm had suddenly abated. 'Notice that the wind has suddenly dropped,' remarked Whillans. 'Not a breath. It's always the same when death is about, always a lot of noise and wind, but as soon as it gets what it's after it quietens down. I've seen it before and it's always the same. ${ }^{21}$

20 Ibid.

21 D. Whillans in ibid. 


\section{Death of a friend Greg Child}

We carried on along the summit ridge to about 7,990 metres, where we met Doug and Steve returning. They said the top was two hours away, but wasted no time to talk as Steve's feet were frozen in the blasting wind. Clouds were welling up beneath us, blanketing the red peaks of China, pointing to a change in the weather. But it wasn't only weather that disturbed me.

An hour from the top the alien physical sensations that I had begun to note grew too bizarre to be ignored. Massive headache, tingling in the arms and hands, lengthy black-outs and an eerie sense of being outside of my body and looking on led to concern of cerebral oedema. When I started vomiting and hallucinating it was agreed that, as close as we were to the summit, it was too dangerous to go on. In two-and-a-half days we had gone from 4,880 metres to 7,920 metres and the strain was showing.

We retraced our steps in the afternoon light, which saturated the panorama with colour, and reached the col, at just under 7,900 metres. I began to regain control over myself, but Pete suddenly developed problems of his own. In the high mountains, avalanche, cold and storm are not the only dangers. Other unseen dangers lie within us, like time-bombs waiting to be triggered by the altitude. These deadly short-circuitings of body chemistry take two principal forms. Cerebral oedema, the accumulation of fluid on the brain, had shown me its first signs near the summit. The other, pulmonary oedema, is the build-up of fluid in the lungs, literally drowning the victim. When Pete suddenly grew weak and told me through blue, oxygenstarved lips that he could barely breathe, a shiver went through me as the urgency of our conditions sunk in.

After an abseil to the steep snowfield I began wading a trail through soft snow. All our tracks had been blown over by a howling wind. After 100 metres I turned to check on Pete and found him not behind me but slumped in the snow, far away. By the time I crawled back up to him it was dark and his condition was extreme; not only could he not breathe, but he was blind, cerebral oedema hitting him as well.

So there we were, in the dark, at nearly 8,000 metres, no tent or sleeping bags, a howling maelstrom blowing spindrift everywhere and Pete immobile. It was like some heavy scene you read of in a magazine, but no, it was real and we were in it up to our necks.

Conversation was superfluous, if not impossible. I roped Pete down as far as he could move, cajoling every step out of him, then began carrying and dragging him. From somewhere a reservoir of energy came to me, and that strange feeling of being outside of myself returned, as if a third person was there, helping. At midnight we reached the ice cliffs, traversing the lip to find the pass and our tent. The spindrift blasted our faces as if it would take them off, and the cold was bitter. Pete mustered himself to follow my short leads across the top of the cliffs, but at the end passed out, sliding to the edge, almost dragging the ice axe that held us out of the snow and taking us into the abyss.

We located the pass and I lowered him to the tent, where Don and Gohar were resting. It was 2 am and we had been on the go for 22 hours. Pete perked up with a cup of tea, asked me how I was; done in, I assured him. We would descend at dawn I added, before falling asleep. Those were our last words.

Whillans woke me in the morning. He had impossible, terrible news. Pete was dead. I tried to bring him to life with mouth to mouth, cardiac massage, and finally hysterical pleas. But my friend, the quietly-spoken Englishman, whose subtle humour and personal warmth had reached out to remind me what friendship was, would only lie there, with an expression of sublime peace on his face. 
The dawn was beautiful, windless, as we sat stunned, looking from Pete to the horizon, as if the contrast had some meaning. It was as if the mountains were saying yes, this endless splash of glowing horizon is the reward for your efforts, and Pete was the price. A muddled thought, but I remember it well.

The wind then returned, like a cracking whip, tearing at the tent. We covered Pete as best we could, then began the long descent back into the world of men, our heads full of sad thoughts.

From 'Mixed emotions', Wild, no. 12 (Autumn 1984), pp. 33-4.

For Child, that sudden, extremely painful blow - the loss of a climbing partnermeant the end of an expedition that had had its ups and downs. While some of the other expedition members stayed on to attempt K2, Child joined Whillans for the sombre walk out of the Karakoram and back to civilisation.

Like the Australians on Annapurna III in 1980 had experienced, and like the 1984 Australian Everest West Ridge team would experience the next year, Child had learned firsthand about the down side of Himalayan mountaineering: the alltoo-frequent loss of a friend, companion, climbing partner. It is an experience that most mountaineers who make repeated trips to the Himalaya sooner or later have to endure.

By the end of 1983, even with just two Himalayan expeditions under his belt, Greg Child had already served an impressive apprenticeship. Doug Scott led both expeditions and they involved almost the full range of experiences encountered in high-altitude mountaineering as well as featuring climbing itself at the very highest standard technically. Coupled with Child's strength and innate climbing ability, those experiences put him in a firm position to move out from under Scott's wing and launch a Himalayan career under his own direction.

During the early 1980s, when Child was serving his apprenticeship with Scott, some major strands of the Australian Himalayan mountaineering tapestry were growing stronger and beginning to interconnect. The AAA climbers were taking their first tentative steps into the Himalaya, while the southern Australian section of the New Zealand Alpine Club (NZAC) was progressing steadily towards its eventual marriage with the AAA to mount the bicentennial Everest expedition. The International Turkey Patrol burst onto the scene in 1982 with their amazing ascent of Changabang and the first major strand-spawned by Dunagiri in 1978 - was nearing Australia's first success on Mt Everest.

During the second half of the decade, the time was right for Child, who had learned his high-altitude skills by climbing with some of Britain's best mountaineers, to join forces with this burgeoning community of Australian Himalayan climbers. He decided to set his sights high and link up with Tim 
Macartney-Snape and Greg Mortimer, Australia's first two Everest ascensionists. When he did, some remarkable things were bound to happen.During our time on the Col, we spent much time in finalizing our plans. During that time I kept a daily account of exactly how many drinks Paul and I had had. If I had had 10 and he eight, it was time to get another two into him. Dehydration being the problem it is at high altitude, it was essential we got liquids down. 



\section{An even score}

Greg Child's 1983 trip to the Karakoram left him with a chaotic collage of experiences - from the exhilaration of a first ascent of Lobsang Spire to the feeling of hopelessness and depression from losing a friend and climbing partner. It also left his mind filled with strong memories - of people, of events and of mountains.

Of the images of mountains that remained sharply focused in Child's mind, the most enduring perhaps was not that of $\mathrm{K} 2$ or its satellite $8000 \mathrm{~m}$ peaks. It was of Gasherbrum IV, a strikingly symmetrical trapezoid of rock and ice that presided over Concordia at the head of the Baltoro Glacier (see image 25.1). Though far less familiar than Ama Dablam, Machhapuchhare or the Matterhorn, it is undeniably one of the world's most beautiful mountains.

Child said:

After Broad Peak I'd promised myself I would never return to the Himalayas. It was a personal, emphatic, and categoric promise. It was also a promise I could not keep. Again and again the symmetrical silhouette of a truncated, pyramidal mountain kept appearing in my thoughts: Gasherbrum IV. My recollection of it from the summit ridge of Broad Peak, and Pete's suggestion to some day climb its Northwest Ridge, remained etched in my memory. ${ }^{1}$

Gasherbrum IV offered a considerable climbing challenge in addition to its beauty. Remarkably, the peak had been climbed only once-in 1958, by its North-East Ridge by Italians Carlo Mauri and Walter Bonatti. There are at least two reasons for its amazing lack of attention. The first is its height. At $7925 \mathrm{~m}$ (or $7980 \mathrm{~m}$, according to some surveys), it was just short of the magical $8000 \mathrm{~m}$ mark. Anyone attempting it would have to endure virtually all the dangers and hardships of climbing one of the world's highest peaks but without the glory of attaining an $8000 \mathrm{~m}$ summit. The second reason is difficulty. Gasherbrum IV is unrelentingly steep from any angle; there are no straightforward, technically easy routes of ascent or descent.

Going after something like Gasherbrum IV, however, even though he had not yet summited an 8000 m peak, was in keeping with Child's philosophy of climbing big mountains: 'I'm not so interested in climbing mountains because they're the

1 Child, G. 1988, Thin Air: Encounters in the Himalayas, Patrick Stephens, Wellingborough, England, ch. 15. 
highest or because they're 8,000 metre peaks. The important thing is the route, the line on the mountain. It could be a 6,000 metre mountain, it could be an 8,000 metre mountain.' ${ }^{2}$

The line Child chose for Gasherbrum IV - the North-West Ridge - was classic in its simplicity, directness and steepness, but, not surprisingly, it had not gone unnoticed by other climbers visiting the Karakoram. In fact, in 1984, a year after Child was in the region, an American team made an attempt on the NorthWest Ridge. They fell short - reaching $7300 \mathrm{~m}$ - but they got far enough up the route to determine that it was consistently serious and technically difficult.

One of the American climbers on that 1984 expedition, Geoff Radford, had met Child and was keen to have another go at Gasherbrum IV when Child suggested a trip for 1986. The pair formed the nucleus of the primarily American team, assembled through their contacts within the climbing community of the United States' West Coast.

Joining Child and Radford were Tom Hargis, a mountain guide from Seattle; Steve Risse, the expedition doctor; Andy Tuthill, who had climbed with Radford on Denali and Aconcagua; and Randy Leavitt, a rock-climbing mate of Child's who was a relative newcomer to alpine climbing and who had not done any high-altitude mountaineering.

Gasherbrum IV, with only one ascent, had proved in the past to be an exceedingly difficult and elusive objective, so Child knew that the team, to have any chance of success, would have to be an exceptionally strong one. To complete the team, Child needed what he called a 'secret weapon' - a climber or climbers of unquestionable strength and endurance - and for that he turned to his native Australia and to the potent climbing partnership of Tim Macartney-Snape and Lincoln Hall.

The Macartney-Snape/Hall team was an obvious choice. They had just capped their illustrious Himalayan careers with the first Australian ascent of Mt Everest, in 1984. Not only was the Everest ascent a milestone in the newly emerging history of Australian Himalayan climbing, it was a remarkable ascent by any standards of Himalayan mountaineering.

Unfortunately, Hall decided not to join the expedition. In his place, MacartneySnape invited fellow Everest summiter Greg Mortimer, who was, MacartneySnape said, 'the only other person available I would have considered climbing with' ${ }^{3}$ Just a few months before the expedition was to begin, however, Mortimer was forced to withdraw after he had earlier agreed to join the attempt. The

2 G. Child in Baxter, C. 1990, 'Child's play', Wild, no. 37 (Winter), pp. 58-63.

3 Macartney-Snape, T. 1986, 'Gasherbrum IV', Wild, no. 22 (Spring), pp. 48-54. 
combination of Child and Mortimer thus would not be formed for another four years, but when it was, some spectacular things happened in the Karakoram. For 1986, however, it was only Macartney-Snape from Australia who was able to join his compatriot and the American members for the trip to Gasherbrum IV.

Although Child and Macartney-Snape were both at the forefront of Australian high-altitude climbing, they had never met. It was testament to their mutual respect that Child issued the invitation to join the Gasherbrum IV expedition, and Macartney-Snape accepted, before the pair had a chance to meet.

The Karakoram was not the easiest region of the Himalaya for a climber to lead his first big expedition in and the Gasherbrum IV trip turned out to be a baptism of fire for Greg Child. Problems arose almost immediately when a particularly aggressive Balti forced his way onto the expedition as sirdar, or leader of the porters and local staff.

He was one of those people who looked vaguely familiar and Child had the distinct impression that he had seen the tall Balti before. Furthermore, he had a distinct feeling of distrust and unease about the man, but since he could not link those suspicions with anything substantial, he reluctantly agreed to hire him.

It proved almost instantly to be a mistake. The sirdar rapidly turned the newly hired porters against their employers and excessive demands were being made even before the first load was shouldered. Child and his colleagues had the rare experience of being hit by a porter strike even before the march to base camp had begun!

It was only when a Basque climber, also at the trailhead at Skardu, warned Geoff Radford about the Balti that the penny dropped for Child. The man's name was Sher Khan and he had been the sirdar for a Basque expedition to K2 in 1983-at the same time Child had been in the area with Scott's expedition to Lobsang Spire, Broad Peak and K2. Child had seen Sher Khan when he met the Basques and was amazed at their stories about their wild-eyed sirdar.

Sher Khan, it seemed, was a religious fanatic. He apparently forced his porters to whip themselves to atone for their sins - as though carrying loads up the rugged Baltoro for Western climbers was not punishment enough - and flogged their backs with ropes and branches. He turned on his employers as well and when the Basques refused to cave in to his extravagant demands for extra equipment, he stirred up the porters to threaten the climbers with staves and rocks. At one point, the enraged Baltis, whipped into a frenzy by Sher Khan's religious fervour, had the Basques backed against the wall of the Braldu Gorge. Lastminute intervention by the expedition's liaison officer rescued the situation. 
When Child realised who the tall Balti with the crazed look in his eyes really was, he devised a clever plan to get rid of Sher Khan. Faced with a contract requiring stringent behaviour, which was to be lodged with the Pakistan Ministry of Tourism in Skardu, Sher Khan was happy to take a day's wages and disappear. Child was rapidly acquiring the skills needed to be a successful expedition leader.

Like most mountaineers in the Karakoram, Child, Macartney-Snape and their colleagues heaved a collective sigh of relief when they finally arrived at base camp, on the West Gasherbrum Glacier, and watched the porters disappear back down the Baltoro Glacier. Now they could concentrate on climbing and they would get plenty of that on the imposing Gasherbrum IV.

Their approach to climbing Gasherbrum IV, like that of many modern Himalayan expeditions, was a hybrid one. Camps and fixed ropes were established lower on the mountain and a high camp was used to launch an alpine-style attack on the summit. Their route led first up the glacier to its head and then up a moderately steep couloir to a gap at the lower end of the North-West Ridge, the site of camp two. Camp three and the end of the fixed ropes were located at nearly $7000 \mathrm{~m}$ on the ridge itself (see image 25.2). It was at that point that the real difficulties on the ridge began - and continued virtually without respite to the summit.

The climbing and establishment of the first three camps were done in bursts, interrupted by long bouts of bad weather. Even when the weather was reasonably agreeable, the conditions were harsh. The temperature on a sunny day on the West Gasherbrum Glacier, where the climbers were toiling with loads to camp one, was the highest that Macartney-Snape, a veteran of seven previous expeditions, had ever experienced in the Himalaya. Higher on the mountain, he endured some of the most vicious storms and the coldest conditions he had ever been subjected to.

During one of those storms on their first trip to camp three, Child discovered just how difficult and awkward even the most basic bodily functions could be at high altitude.

On the third storm-bound day in the snowcave I develop an unpleasant accompaniment to cold feet: swelling bowels. Try as I may to put it off, after some seventy hours I have no choice but to relieve myself. I look up and burrow headfirst out of the snow-clogged exit to emerge in a maelstrom of blasting snow and wind, with a wad of toilet paper streaming in one gloved hand. Unzipping zippers, I shed layers of pile and Gortex. The wind, thick with spindrift, makes it impossible to 
breathe. Snow quickly fills my pants, my goggles ice over. To execute even this simple, urgent business proves out of the question. In no small distress I burrow back into the cave.

'Can't do it! Too windy out there,' I report to Tim.

'Oh dear,' he replies.

'But I still have to go. Look, sorry about this but I'm going to have to settle this in here.'

'Oh no!'

'I grab the shovel, fill it with snow, drop my pants, squat astride the shovel, and commence the awful deed. The stench is spectacular. Tim retreats into his sleeping bag and emits strangled gasps of protest. Finished, I zip myself back into my windsuit, crawl back out [of] the cave with the shovel at arm's reach, and then pitch the shovel-load over the West Face. The gale atomizes the turd and broadcasts it in equal amounts over China and Pakistan.

Back inside the cave I pant breathlessly. It is the most exercise I'd had for several days. Tim slowly pokes his head out of his sleeping bag, as if emerging from a bomb shelter after a nuclear explosion. ${ }^{4}$

After a spell at base camp forced by bad weather, Child and Macartney-Snape again found themselves in the snow cave at camp three. Radford, Hargis and Tuthill joined them. It was now mid-June; time was getting on and the climbers knew that the next spell of good weather, which appeared to be upon them now, would be their best chance to climb the mountain. Any further delays and their supplies would begin to run low, their bodies would start to deteriorate more rapidly and the expedition would start the exponential slide to an unsuccessful conclusion.

Their plan was straightforward. Using camp three as a staging post, they would climb as high on the ridge as possible in a day, set up their three tents and the next day go as lightly as possible in a push for the summit.

Gasherbrum IV, however, like most difficult Himalayan peaks, was not amenable to such precise planning. It would prove to be an exhausting and very risky objective, one that Macartney-Snape would later dub 'harder than Everest'.

Child, Thin Air: Encounters in the Himalayas, ch. 17.

5 Macartney-Snape, T. 1987, Harder Than Everest, Film, Australian Broadcasting Corporation, Sydney. 
It would severely test Child's judgment, on the first Himalayan expedition after the tragedy at nearly $8000 \mathrm{~m}$ on Broad Peak, and it would challenge even Macartney-Snape's legendary strength and endurance at high altitude.

Even with the aid of some fixed ropes left by the 1984 American expedition, the going above camp three was slower than they had hoped. Much of the problem was caused by the first of the rock bands that guarded the upper reaches of Gasherbrum IV's North-West Ridge. The obstacle was overcome late in the day when Macartney-Snape circumvented the last bit of steep rock by leading up a steep ice gully threatened by $30 \mathrm{~m}$ ice pinnacles. Camp four, just above the rock band, was only $7300 \mathrm{~m}$ or so. That left a long way to go on the summit day, with much of it over very difficult terrain.

The next morning, the five climbers faced difficulties almost immediately on leaving the tents (see image 25.3). They were climbing extremely lightly, with two stoves, some packets of noodle soup, some teabags, a few cakes of chocolate and a couple of sleeping-bags and foam pads for the intended bivouac on the descent. They had a close scrape with an avalanche-prone slope that cracked but did not slide, some heart-stopping solo climbing on steep, exposed ice slopes and technical rock climbing up steep, smooth bands of marble-climbing that would have been challenging at sea level on a sunny day.

Macartney-Snape described the physical effort it took to cope with such climbing at $7500 \mathrm{~m}$ :

It's like running a 100-metre dash perpetually. You are always operating with a severe oxygen debt.

You feel very lethargic. When you sit down, you want to go to sleep. You have to force yourself to do anything. In conditions like these, the good weather and beautiful views high on a mountain are something to be feared. They draw you up. You find yourself on the summit at the end of the day facing a dangerous descent in the dark. ${ }^{6}$

The Australians and Americans found themselves in just such a situation high on Gasherbrum IV. By 4pm, they had just surmounted the last of the technical difficulties but they were still below the northern, lower summit. There was no way they could climb to that summit, traverse the $400 \mathrm{~m}$ to the main summit and return again before dark.

They had left even the meagre bivouac gear they had been carrying below the last rock band in an effort to make a last-ditch dash to the top. Radford, plagued by a broken crampon, had already turned back. The other four climbers were 
faced with a nasty choice: retreat to the safety of the tents below and virtually concede defeat or risk a night out at nearly $8000 \mathrm{~m}$ with no bivouac gear. A wrong decision in a situation like this is what often costs climbers their toes and fingers, and sometimes their lives.

For two people, the decision was clear. Andy Tuthill thought the risk too great and had no trouble deciding to retreat. Macartney-Snape, on the other had, was determined to climb Gasherbrum IV and knew, from his previous experiences high on Himalayan mountains, that he would survive the night.

Macartney-Snape said:

I decided quickly to bivvy out. For me psychologically, to descend would have meant defeat. I was reasonably sure things would be OK. We had to find a place out of the wind and maintain a positive attitude.

It's always exciting to bivvy out on a mountain. But to do it at 26,000 feet [nearly $8000 \mathrm{~m}$ ] with no gear is really exciting! In a perverse way, I was really looking forward to it. I tend to be optimistic. I guess I don't have the imagination to realise what could happen to me. Andy did. ${ }^{7}$

The decision was more difficult for Child:

We have nothing but the clothes on our backs. No water, food, or stove. I'd read long ago about Hermann Buhl sitting out a night just below the summit of Nanga Parbat. It seemed to me then something only a superman could endure or a madman conceive. I'd also heard the separate tales of Nazir Sabir and Jim Wickwire, both of whom had sat out nights near the summit of K2. Nazir had suffered memory loss for months. Jim's bivouac had cost him a piece of lung when fluid had frozen in his chest. And there was Bonatti and Mahdi on K2. Even with an oxygen cylinder, Mahdi had lost his feet. A bivouac here would be harsh, but at the same time I felt that our chances were good; the weather was clear, and we still had some strength left. Instinct condoned the idea, the ambition put words in my mouth. ${ }^{8}$

Child decided to bivouac. As he put it, 'Our own private epic began to take shape. ${ }^{9}$ Joining Child and Macartney-Snape on the impending epic was Hargis, who, despite a lung infection and the resulting violent bouts of coughing, was determined to get to the top.

7 Ibid.

8 Child, Thin Air: Encounters in the Himalayas, ch. 18.

9 Ibid. 
The three climbers found just enough snow below the north summit to dig a rudimentary snow cave. It was essential that they shelter themselves from the life-threatening icy gales that gusted across the top of Gasherbrum IV. As Child helped dig out the shallow cave, the reasons for his decision to risk the night out became more clear:

Framed in the entrance to the cave is Broad Peak, where Pete [Thexton] had died and where he still lay. It is almost three years to the day since our struggle to get down the mountain. As oxygen starved as my thoughts are, the essence of my reason for returning to the Karakoram falls clearly into place, as never before. It seemed that finishing that idea I had shared with Pete, to climb Gasherbrum IV, would close a circle, would somehow set a cruel score a little more even. ${ }^{10}$

Like nearly all high-mountain bivouacs, the night in the tiny, cramped snow cave passed excruciatingly slowly. 'I was the only one with a watch,' MacartneySnape recalled. 'After what seemed an eternity, we all had a guess at the time. We thought it was somewhere between midnight and 2.00 a.m. It was 8.30 p.m.!'11

It was a long, long night, as Child recalled:

My shivering gradually becomes a low wail that sounds very much like someone in constant pain. I begin to think about the pain we are feeling now, the pain of cold. What is it like, how to quantify it? Like having a tooth pulled without an anaesthetic, all day...Tom coughs again. Something like a pale green, blood-spattered tadpole flies out of his gullet, hits the wall, and freezes solid. He retreats into himself and takes on the countenance of a zombie...As we sit shivering, a state, neither sleep nor wake but more like a sedative overdose, full of strange, restless dreams, carries us into our own worlds.

As 22 June dawns, sunlight creeps into the snowcave and onto our stiff, hurting bodies. A miniscule veil of frozen moisture momentarily clasps my eyelids together, then releases. We look at each other. Faces are puffed and bloated with mild edema. Capillaries bulge red and angry on our brows. Lips and noses look like peeling sausages. Icicles hang from beards and noses. I recognize none of this ugly crew. ${ }^{12}$

Fortunately, the fine weather held and the three climbers miraculously survived the night with no frostbite. They slowly readied themselves for the day's climbing, crawled into the sharp, cold breeze and began the traverse across the summit ridge. By 10am, they were on the summit of Gasherbrum IV. Their

10 Ibid.

11 Macartney-Snape, Harder Than Everest.

12 Child, Thin Air: Encounters in the Himalayas, ch. 19. 
risky decision to endure a bivouac high on the peak had paid handsome dividends. They had become only the second team ever to stand on the summit of Gasherbrum IV (see image 25.4).

The drama was not quite over, however. As Child and Macartney-Snape were reversing the traverse back across the summit ridge, they nearly met with disaster when the latter tried to remove a piece of protection they placed in the rock on a difficult section of the ridge.

'[T]he momentarily incomprehensible sight of Tim's ice axe and the piton flying through the air, then jangling down the rocks, wrenches me to attention,' Child vividly remembered:

I look across to see a red blur-Tim - cartwheeling backwards over the West Face. He seems to fall in slow motion. I haul in a yard of rope. Still he's falling, 40, $50 \mathrm{ft}$, dropping down, swinging like a pendulum towards me. The boot-axe belay seems a token gesture, a text book theory incapable of holding a fall. I await a grand tour of the 10,000 ft $[3000 \mathrm{~m}]$ West Face. ${ }^{13}$

The grand tour never came. With the help of the rope fortuitously hooking over a tiny knob of rock, Child's shaky belay held. There were, however, moments of extreme anxiety as Macartney-Snape's full weight came onto the rope and Child realised he could not hold it for long.

A final option comes to mind as I feel the outline of a pen-knife in my pocket. I'll have to make a choice about this soon, I tell myself. The idea is horrible to contemplate, but as more and more rope slips through my hands, I find myself thinking with the cold practicality of Clint Eastwood. But the rope moves. I cast the knife out of my thoughts and pull the rope in, and in, and in. Tim appears. Feathers fly out of his ripped down suit. He looks as if he's been blasted with buckshot. ${ }^{14}$

The rest of the descent was thankfully uneventful ( see image 25.5).

The Gasherbrum IV ascent was a real gem, another landmark for Australian Himalayan mountaineering. Out from under Scott's tutelage, Child put in a masterful performance - from the early planning phases through to the bold drive up the taxing North-West Ridge to the summit. For Macartney-Snape, it was another stunning success to add to his growing list of Himalayan achievements. 


\section{A quick descent...nearly Tim Macartney-Snape}

[W] hen I reached the piton which was the only device attaching both Greg and I to Gasherbrum IV I began taking it out with a zeal fired by impatience. Greg was belaying me with the rope running round the shaft of his ice axe which he had firmly embedded in the wind-packed snow. 'I've never put too much faith in these things,' he commented on the belay, in the slow deliberate speech of high altitude, 'but I suppose it's better than nothing...'

The soft steel piton stuck in its crack with the stubbornness of chewing gum when it sticks to your foot on a hot summer's day. The ice axe was not designed as a hammer, and even though mine did a good job of hammering loose the piton I had a hard time. With both hands I finally placed the pick of the ice axe in the eye of the piton and pulled vigorously sideways on the shaft. The levering action worked, and the piton flew out with a jerk that upset the delicate footing of my crampons. First the points of my right crampon skidded over the sloping ledge they had been perched on and the momentum swung my body around so that now my right foot began to pivot and then slither. I began to fall. It has always seemed unfair that whilst oxygen diminishes with altitude, the force of gravity seems to remain the same; and so with the full force of the Earth's gravitational pull I began accelerating down the West Face, bouncing off rough protrusions of rock. The greatest adjustment one makes to the limitations of altitude is to slow down the pace of everything to such an extent that even one's concept of time slows down. Now the speed at which everything was happening to me came as a numbing shock. Looking back on it all, I can understand why there have been so many incidents at high altitude were simple falls that could have been arrested have ended in tragedy. Not that I could have done anything to stop myself. My only hope was in Greg, and my mind was occupied solely with the question of if and when he was going to stop me. My axe temporarily snagged on a rock and was torn from my hands.

I fell faster. The thin green rope finally pulled taut and I came to a halt. I was breathless, tufts of down drifted out from tears in my down suit, and my ice axe was gone. 'Thanks Greg', I bleated hoarsely between breaths. But he did not hear, an anxious call came down from him. He had visions of having to cope with a seriously injured companion. What could he do? Nothing much. Serious injury in that place would almost certainly have meant death, as it was hard enough getting one's own able body back down. Although we climbed as a team, each person took ultimate responsibility for himself. This thought struck home hard as we both pondered the situation. However, my strength flooded back and I was able to put Greg's mind at rest by climbing back up to him. I had only fallen about 20 metres. 'I don't believe it, these belays actually work. I even had time to pull in some slack. Are you okay?' Greg seemed as nervous as I; but then he was tied to the other end of the rope.

From 'Gasherbrum IV', Wild, no. 22 (Spring 1986), pp. 49, 53.

He has proved that he is without peer among Australian mountaineers in determination, strength and the ability to function at extreme altitudes; and, indeed, that there are very few mountaineers anywhere in the world who can match his incredible drive and willpower in the most desperate of situations. Combining those qualities with Child's consummate skill in all phases of climbing and his own remarkable determination formed a team that the world's most difficult 'nearly 8000-er' could not repulse. Their success was made even sweeter by the dogged push to the summit by the ailing American Tom Hargis, an effort reminiscent of the outstanding mental and physical stamina that would carry Pat Cullinan to the summit of Everest two years later. 
Child, however, was not quite through with the Karakoram for 1986. In true Doug Scott fashion, he had planned multiple objectives for the trip. He, Hargis and rock ace Randy Leavitt wanted to climb Nameless Tower after they had finished off Gasherbrum IV. Although it suffers from having been named by a person with either a total lack of imagination or an extremely subtle sense of humour, Nameless Tower is the most stunning-and probably the most daunting to climb - of any of the majestic Trango group of granite towers.

It would be a climb in big-wall fashion - bigger than the ascent of Lobsang Spire three years earlier. Whereas Lobsang Spire had been tackled at the beginning of the 1983 expedition, when the climbers were fresh, Child and Hargis were considerably drained from their desperate ascent of Gasherbrum IV. Leavitt too had worked hard on the mountain, climbing to $7300 \mathrm{~m}$ in support of the others. Nevertheless, the trio made a valiant effort on Nameless Tower, climbing to within $300 \mathrm{~m}$ of the $6237 \mathrm{~m}$ summit before being turned back.

Still, the 1986 expedition was a big psychological turning point for Greg Child. He had evened the score with the Karakoram.

Just a year later, Child was back in the Karakoram, trying to go one-up on the massive range. His objective was K2 - the world's second-highest peak-and he was part of a very talented team that included Tim Macartney-Snape, the veteran Doug Scott, Scott's twenty-four-year-old son, Mike, and experienced American climbers Steve Swenson and Phil Erschler. The last was the only climber of the 1984 American Everest North Ridge expedition to reach the summit, a few days after Macartney-Snape and Mortimer completed the first ascent of the spectacular Great Couloir route.

This formidable team aimed to make the first ascent of K2's East Face - and to do it in alpine style. They were destined, however, to make hardly any impression at all on the mountain and to prove once again the old adage that climbers do not conquer mountains; it is the mountain that decides when and by whom it will be climbed. In 1987, weather and dangerous snow conditions proved to be K2's impregnable defences.

Macartney-Snape recalled:

We sat in Base Camp, prisoners of our ambition and the weather. The frustrating thing was that below 7,000 metres the weather was never really that bad. The lashing blizzards of the previous year never came. Instead, we had an interminable succession of blandly bad days, occasionally broken by one and, rarely, two fine days which kept our hopes alive- something like commercial television. ${ }^{15}$

15 Macartney-Snape, T. 1988, 'K2', Wild, no. 28 (Autumn), pp. 36-7. 
The bad weather above $7000 \mathrm{~m}$ was putting the upper ramparts of $\mathrm{K} 2$ dangerously out of condition. The situation became clear as some members of the team spent a bit of their pent-up energies on a nearby $7000 \mathrm{~m}$ ice peak.

Macartney-Snape was not impressed with what he saw of K2's East Face from high on the training peak:

[A]s I examined the vast sloping snow plateau below the summit pyramid through my binoculars, I came to the horrified conclusion that the 500 metre line I was looking at was not a shallow ice cliff but the crown of a giant slab avalanche which must have been ten metres deep at the fracture! The avalanche would have swept straight down our proposed route and across the glacier...I was no longer very interested in the East Face. ${ }^{16}$

After a month of such frustrations, Macartney-Snape felt that his 'commitment to life in that other world beyond the expedition' ${ }^{17}$ was weakening his resolve and he left for Australia. After his departure, some of the other members, including Child, made three attempts on $\mathrm{K} 2$ itself, but in each case dangerous snow conditions and the unreliable weather stopped the climbers. Two of the attempts did break the 7000 m mark, but the summit was still well out of reach. The Karakoram had gone one-up on Child again this time.

At this stage, Greg Child's Himalayan career had spanned seven years and included four expeditions, with successful ascents of Shivling, Lobsang Spire and Gasherbrum IV. His record contained great variety - in sizes of peaks and nature and difficulty of routes. What it did not yet include was a trip to Nepal, the small kingdom that contained the highest concentration of big Himalayan peaks of any of Asia's mountain nations or provinces. That omission, however, was about to be rectified.

A year after his $1987 \mathrm{~K} 2$ attempt, Child again teamed with Scott - this time for an expedition into Nepal. For a first trip into the land of Everest and Annapurna, Child did it right. Not only was he heading for an attempt on Makalu, the world's fifth-highest peak and undoubtedly one of the most graceful and beautiful of the 8000 m mountains, he approached Makalu with surely the most spectacular trek of eastern Nepal and one of the loveliest anywhere in the Himalaya.

Makalu, however, had not been kind to Antipodean climbers. In 1983, Mark Moorhead and Bill Denz - half of a four-man team-were killed in separate accidents on Makalu's West Ridge (see Chapter 19). It was the western side of 
Makalu that had attracted Scott and his international band of mountaineers, which included an Irishman, two Indians and six more Britons, in addition to Child.

Early on in the expedition, it was obvious that the West Face of Makalu was out of condition, so Scott and his team eventually settled for an attempt on the original French route via the Makalu Col, a notch in the ridge to the north of the summit. Even before Child had had a reasonable chance on that route, however, a near-tragedy, due to dangerous wind-slab conditions, proved to be a serious blow to the expedition.

Doug Scott recounted:

Alan [Hinkes] and Rick [Allen] continued up to 8,100 m. Al was dubious about continuing. Rick pushed on until he avalanched past Alan, who had let go of the rope as he had a poor belay. Rick went down $500 \mathrm{~m}$ over snow and rock. His head was badly lacerated. Al managed to get him down to the Makalu La.

Greg and myself reach Rick there [at $7000 \mathrm{~m}$ ], after coming up directly from Advanced Base Camp [in a single day, after having descended from $7000 \mathrm{~m}$ the previous day!]...We thought it prudent to evacuate him by helicopter. He flew away to Kathmandu with wife Alison [they were on honeymoon]... Rick luckily made a complete recovery from his head injuries but spent a week in hospital with malaria! ${ }^{18}$

'After the drama of rescuing Rick and getting him out by helicopter,' Child added, 'the raging winds of October set in and our progress on the mountain ground to a halt. By mid-October we'd quit Makalu. ${ }^{19}$ Again, conditions and incidents beyond his control had cost Child a reasonable go at the summit of one of the Himalaya's great peaks.

Greg Child is not one to leave an aesthetic, challenging line on a mountain alone after just one attempt. In 1989, he was back in the Karakoram to settle a score again - not with K2 this time but with Nameless Tower. The North-East Face still beckoned after his 1986 attempt with Hargis and Leavitt. This time, he convinced another of America's many gifted rock climbers, Mark Wilford, to join him in the attempt. Their route, on the same face attempted in 1986, was up $1500 \mathrm{~m}$ of steep, difficult rock.

'We almost climbed it,' Child said:

18 Scott, D. 1988, 'British Makalu expedition, 1988', Himalayan Journal, vol. 46, pp. 139-40.

19 G. Child in Baxter, 'Child's play'. 
but we were on the wall for 13 days, completely alpine style, living in Porta-ledges. It was difficult climbing - some A5 aid climbing, and grade 21 free climbing. The weather was horrendous. We didn't get up because of the weather.

I think I was more physically and mentally extended then than on almost anything else I've ever done. We nearly 'bought the farm' on that one; we became hypothermic, and couldn't Jumar the ropes to get to each other. Both of us were coated in ice and were wet all day. We set up a Porta-ledge in a spindrift storm. The ledge collapsed twice and our fingers were badly nipped by the cold. ${ }^{20}$

Did a frightening experience like that put Child off another attempt? If anything, it increased his resolve to return and master the challenging route. 'So close did we get, and so inspired are we by the ground we covered,' he wrote, 'that we intend to return in 1990 to complete the route.'21

Other events intervened in 1990, however. Greg Child had another Karakoram score to settle: with the king of Karakoram peaks, K2. In 1990, he finally had a chance to climb in the Himalaya with Greg Mortimer, the other member of Australia's first Everest expedition to have reached the summit. When that pair got together, great things happened on K2, just as the combination of Child and Macartney-Snape had been the driving force for the magnificent ascent of Gasherbrum IV.

Throughout the 1980s, another Australian climber was building up an impressive career in the Himalaya, almost unnoticed in both the Australian and international mountaineering communities. His career would also lead to a major ascent in 1990 - one of several remarkable Australian achievements that year on the very highest of Himalayan peaks. 


\section{A quiet achiever}

A few days' trek south of Pumori lies the graceful Ama Dablam (6854 m), the most beautiful mountain in the Khumbu and, according to some observers, the most beautiful mountain in the world. Beauty notwithstanding, Ama Dablam is a severe mountaineering challenge by any line of attack. It took the formidable trio of Tim Macartney-Snape, Lincoln Hall and Andy Henderson to make the only Australian ascent of the peak (in 1981; see Chapter 9), despite two subsequent attempts by strong parties.

The first of these was a 1985 winter-season attempt by a New Zealand expedition that included Queenslander Robert Staszewski. It was not a happy trip for Staszewski, who had a nasty brush with cerebral oedema that put an abrupt end to his summit attempt.

Staszewski said:

In the chill of pre-dawn greyness my stumbling effort to rise on the 8th [December] clearly indicated poor acclimatisation. Severe acute mountain sickness [cerebral oedema] had caused fluid retention in my brain leading to concussion. The internal bruising was already causing loss of coordination, blurred vision, slurred speech and eventuallypossible death. The magnetic poles immediately reversed. I forgot the summit, and fixed my gaze on base camp and lower. What followed was a deteriorating nightmare of subconscious stumbling, constant weariness, dehydration, swimming horizons, and assistance from friends. ${ }^{1}$

Further illness and deteriorating weather forced the abandonment of the expedition a short while after Staszewski's epic retreat.

The second attempt on Ama Dablam - this time in 1989 on the South-West Ridge - was led by Michael Groom and was nearly successful. Groom and John Coulton were forced to back off only $60 \mathrm{~m}$ from the top by unstable snow conditions and a lack of time. It was an exciting and enjoyable route, according to Groom, who described it as 'good rock climbing followed by good ice climbing' ${ }^{2}$

Of far more significance than the near-success was that the 1989 Ama Dablam expedition marked the return to the Himalaya of Mike Groom. His career leads back to the giants, the 8000 m peaks: first back to an amazing ascent of the world's

1 Staszewski, R. 1987, 'Ama Dablam in winter', Damart Newsletter, p. 5.

2 M. Groom, Interview. 
third-highest mountain, a story of extraordinary courage and determination; and then forward, in the final chapter, to a climb that contributed to Australia's most successful year ever in the Himalaya.

Michael Groom could well be called Australian mountaineering's quiet achiever. He is exceedingly modest about his considerable achievements, preferring to keep a very low profile within the climbing community. His only article for many years - on the 1986 Kangchenjunga attempt - was written for Wild magazine in a moment of dire need. 'Unfortunately, I was desperate for money before I left,' he admitted, 'and was given $\$ 200$ in advance for the article. ${ }^{3}$

The early part of Groom's Himalayan career was described earlier: his climbing on the Trisul and Annapurna II expeditions (Chapter 10) and on Kangchenjunga (Chapter 17). These earlier trips hinted at Groom's future string of Himalayan achievements, particularly the 1986 Kangchenjunga expedition, on which he nearly reached the summit.

Groom is unique among Australian Himalayan mountaineers in that his start in the activity of climbing was truly a family affair, with a connection with exploration and adventure going back three generations. His grandfather was a keen explorer and was one of two men who established the Binna Burra Lodge adjacent to Lamington National Park in south-eastern Queensland.

His father, Donn Groom, was a pioneer of rock climbing in Queensland, having explored the Glasshouse Mountains and done some of the early climbing on $\mathrm{Mt}$ Barney. The elder Groom also had considerable New Zealand experience, with ascents of Mounts Tasman and Malte Brun and participation in a difficult rescue on Mt Cook.

'My father had me scrambling around Mt Barney before I was in school,' Michael Groom remembered. 'After he later went to Alaska to live, I went up there for a year and he took me up a few "hills".'4

With a background like that, it was no surprise that Groom soon found his way to New Zealand, enrolling in a Mountain Recreation course in the early 1980s. The trip to Trisul, in 1982, followed soon thereafter. From Groom's point of view, it was an interesting experience - an encounter with a severe storm on his first trip to the Himalaya.

We were in camp three - three North Face tents - when a storm built up quickly during the night. One tent, the one I was in, blew away. Then I got blown over twice just crawling to the next tent. I piled in with three

3 M. Groom, Personal communication, 7 November 1989.

4 M. Groom, Interview. 
Americans in the VE24. The wind picked us up, tent and all. We had to dive for the end to keep the tent on the ledge. Then that tent blew apart. At morning there was a slight break, and we headed straight down. ${ }^{5}$

The Trisul trip, however, did have two tangible benefits, as well as the accumulation of experience, which any excursion in the mountains, no matter how disastrous, could be said to have. The other Australian client on the trip, in addition to the three Americans, was Melbourne climber John Coulton (see image 26.1), and he and Groom would later form a powerful partnership on Kangchenjunga.

Of more immediate benefit was the link with Tim Macartney-Snape and Lincoln Hall, who were two of the guides on the Trisul trip. A year later, Groom joined that duo, Greg Mortimer and Andy Henderson on the Annapurna II expedition. That ascent, by a new, impressive route up the South Face, was a key climb in the lead-up to the 1984 Everest success (see Chapter 10). Through Groom's eyes, though, on his second trip to the Himalaya, the expedition looked a little different.

I went on the trip with the intention of learning. I had somewhat of a tough time lower down, about $6000 \mathrm{~m}$, but when I made it up to camp three at $7300 \mathrm{~m}$ and felt all right, I asked Tim if I could go to the top. He said no, as it would break up two ropes of two climbers each. I was very disappointed at the time, but I realised that these guys were world-class climbers, and that I was still learning. ${ }^{6}$

It was not long before Groom was putting in some world-class performances himself in the Himalaya. In 1986, he nearly pushed to the top of Kangchenjunga as leader of a five-man team (see Chapter 17). He turned back at $8400 \mathrm{~m}$, only $200 \mathrm{~m}$ from the top after a very strong performance on the summit day.

Groom recalled:

At 8.30 am on the 12th of May I left Camp IV [7750 m] for the summit, a late departure after discussing with Shane [Chemello] and Jim [van Gelder] as to what they would do. When I left the tent, I still wasn't sure. A couple of hours climbing and I was in the Gangway, from which I could see Shane and Jim climbing above Camp IV. Shane would reach 7,900 $\mathrm{m}$ and Jim would go on to reach around 8,000 $\mathrm{m}$ before turning around.

I continued to make good progress until at $1.30 \mathrm{pm}$ at $8,400 \mathrm{~m}$ I stopped to consider the remainder of the climb. I felt as well as one could feel at 
Himalayan Dreaming

this height and calculated that it would take another three hours or more to reach the summit. This was fine by me but what I had to consider was that my two climbing partners were already exhausted and we were a long way from the safety of Base Camp.

By climbing to the summit and back to Camp IV I too would undoubtedly have been exhausted, and three exhausted climbers high on Kangchenjunga allowed no room for error or problems with the weather. Safety was more important to me than the summit, especially on the first expedition I was leading to the Himalaya. After all, I could always return to Kangchenjunga another time.

I was not fooled by a passing cloud into thinking the weather was deteriorating, but it helped make my decision a little easier. So I started to descend. Along the way I would stop occasionally to look up at the summit and think to myself 'maybe I should have'. ${ }^{7}$

Fired by the determination to turn that 'maybe' into something more definite, Groom went straight to the Ministry of Tourism in Kathmandu at the conclusion of the expedition and reapplied for Kangchenjunga. His application was successful for the same route a year later, in the post-monsoon season of 1987.

Groom's second Kangchenjunga attempt was an astounding performance, the equal of any other Australian exploit in the Himalaya. It is, however, without doubt the least well known of any major Australian achievement in the great ranges of Asia and has received hardly a mention in the international mountaineering literature.

Confident of his own ability to climb the mountain, the world's third highest, Groom opted for a team of only two and asked John Coulton, whom he remembered from the Trisul expedition as a 'very strong and competent climber', ${ }^{8}$ to join him.

From their arrival in Kathmandu on 3 August, the pair was faced with adversityof a sometimes extraordinary nature - that plagued them for the duration of the trip. The first blow was struck even before the walk to base camp began, as floods and massive landslides - the worst disaster in Nepal for years - forced them to walk for three days along washed-out roads just to get to the start of the trek. Twenty-three soggy days later, they finally arrived at base camp.

Their long route on Kangchenjunga's South-West Face forced them into some difficult tactical decisions. A totally alpine-style ascent would be very risky, particularly since some icefalls along the way would no doubt slow their rate,

7 Groom, M. 1986, 'Himalayan apprenticeship', Wild, no. 22 (Spring), pp. 55-6.

8 M. Groom, Interview. 
force extra days on the mountain and thus require them to carry more supplies. Establishing well-stocked camps, however, would sap their strength, possibly before they had a chance at a viable summit bid.

They opted for a mixed style, setting up three camps lower on the mountain while they acclimatised and stocking the top camp with 10 days' worth of food and fuel to use as a launching pad for the summit. After a month of work, and then a break at base camp, they were ready to go for the top.

Groom said:

On October 7 we started up and moved the tent from camp one to two. We didn't have enough tents to leave them permanently at each site. Two days later we set out from our top camp with heavy loads and moved up to $7900 \mathrm{~m}$, where we established camp four.

On October 10 we went for the top. We got started at 7.30am, later than we wanted, but the extreme cold and high altitude slowed us down. We moved unroped, taking turns breaking trail up a 50-55-degree gully. About 1pm, it was John's turn to take over, but he took a long while to catch up.

We were at $8400 \mathrm{~m}$ and John said that he'd had enough. I almost said, 'Yeh, I've had enough too', but then I realised that we were at precisely the same spot at which I had turned around last year. I didn't say anything. I just put my pack down and went up. I climbed up onto the West Ridge and kept going.

The climbing steepened up after our stop, with some 3-5 m rock walls, necessitating some scrambling, interspersed with big ledges. Finally, at $6.15 \mathrm{pm}$, I was on top, or at least about $8 \mathrm{~m}$ from the top, where I stopped in deference to local religious beliefs. ${ }^{9}$

Coulton reached the summit a little later in the evening. Shortly thereafter began a most frightening and desperate descent for the two exhausted climbers. Their vision failing due to retinal haemorrhaging, they fought their way down Kangchenjunga on instinct and determination. At one point, in an incident somewhat reminiscent of Joe Simpson's miraculous escape from death on an Andean mountain, described poignantly in Touching the Void, Groom walked into a gaping crevasse, landed on a snow bridge, then had enough presence of mind and climbing instinct to extricate himself. The descent eventually ended with a helicopter evacuation to Kathmandu. 


\section{Kangchenjunga 1987 \\ Michael Groom}

It was $6.15 \mathrm{pm}$ on 10 th October 1987 . There was another $8 \mathrm{~m}$ to go to the summit of Kangchenjunga, but out of respect for local beliefs that the summit was sacred I went no further. There was no sense of achievement standing on the third-highest point in the world but there was a fantastic view off to the west. The sun had set behind the curve of the Earth and I could make out the dark silhouette of Everest on the western horizon. What made this position even more spectacular was that I was standing in the only patch of sunlight anywhere. It was night-time in the valleys below and the fine line between night and day was fast approaching where I was standing. It was time to go after one quick photo.

I expected to meet John following my tracks up the ridge as I descended from the summit. After 15 minutes, the difficult and time-consuming sections of the West Ridge began to look very unattractive in what little light was left. A shortcut across the South-West Face that I had mapped out while climbing up earlier that day was the way I chose to go, even though I knew it was not a wise thing to do on such a high mountain so late in the day. Nevertheless, I lost height quickly and it seemed I had made the right decision until I came to a $12 \mathrm{~m}$ cliff just short of entering the gully which led down to C4 [camp four]. It was almost dark but I could see that a fall from here would only stop somewhere below C4. I managed to climb down the first $6 \mathrm{~m}$ with difficulty but in complete darkness I could find no more holds so I was forced to climb back up. Faced with the long climb back up to the West Ridge, which I knew would be impossible in my exhausted state, I composed myself and once again faced the $12 \mathrm{~m}$ cliff.

I hung onto handholds and footholds which I couldn't feel inside of double boots and three pairs of gloves. It was more good luck than good climbing that I found myself walking away from the base of the cliff.

I stumbled across my pack, which I had left well below the West Ridge. Sitting down, I began to wait for John, impatiently and in the bitterly cold night. While waiting I felt this strange sensation, and when I looked up to see John's headlamp on the ridge, I knew there was something wrong with my eyes. I could not tell how far away he was from me. I didn't know it at the time but it was retinal haemorrhage.

It seemed to take forever for John to reach me. I asked him to lead, not wanting to concern him with my problems, and I followed as best as I could. But it was the blind leading the blind as John had the same problem. Soon the full moon would be up, but it made no difference to what little we could see as we descended by feel and sense of direction.

After two or three hours we were down at the approximate altitude of C4, $7900 \mathrm{~m}$. Feeling confident that our tent was around here somewhere, I took over the lead from John. As we traversed across steep snow slopes to our right, John started to lag behind. A dark line, which I took to be a crevasse, appeared in front of me. Kneeling down and looking as best I could, I was excited by the idea that this was the crevasse that we had so easily stepped across this morning just above $\mathrm{C} 4$.

I stepped out confidently. But it was a step into the unknown as I felt the sickening sensation of falling. Bouncing off the walls of the crevasse two or three times, I came to a sudden stop on the bottom, so I thought. Stunned by the impact, I could so easily have drifted into unconsciousness, but the warm blood running from my nose, and the freezing snow stuck to my face, helped bring me back to my senses. My first thoughts, apart from that I had obviously stepped over the wrong crevasse, was that my left leg, hanging awkwardly underneath me, was broken. It didn't take me long to figure out that I had, in fact, landed on a false floor of the crevasse and my left leg had broken through and was dangling over the chasm below. 
Although I didn't want to move for fear of falling further, I managed to crawl on my elbows in complete darkness to the wall of the crevasse. Luckily my ice axe was still strapped to my right hand. I was able to strike the ice above me, but it took several strikes before the axe would stick. Using both hands to pull myself up, and with my heart racing, I put all my weight on both feet, without breaking through. Fortunately the downhill wall of the crevasse was not as steep as the one I had just fallen over. Although I could not see where I was going, I was able to climb the short steep wall by using my ice axe to chop handholds. I was able to crawl out of a potentially fatal mistake with no more than a broken nose and a couple of cracked ribs.

Suddenly the light from John's head-torch appeared above me, and it was then that I realised how far I had fallen. I warned him of the crevasse and he was able to find his way around to join me below. Too tired to give details as John sat beside me in the snow, I set off in search of the tent.

Despite the light of the full moon, my eyes had failed me. I was still stunned by the fall; I was climbing on luck. Knowing I wouldn't be so lucky if I fell into another crevasse, I returned to John's position. The only safe solution was to stay where we were until daylight, and as we dug out a seat in the ice, John complained of his failing eyesight.

It had been $-20^{\circ} \mathrm{C}$ in the tent the night before but that temperature was taken after three hours of body heat and three hours of cooking on the stove had warmed the tent. We had nothing to eat or drink and no extra clothing to protect us from what would be the longest night of our lives. The night dragged by while I refused to look at my watch. Occasionally I would stand up to look for the tent.

The most wonderful sight I have seen in a long time was the sun coming up over the eastern slopes of Kangchenjunga on the 11 th October. With more light came better vision and a sight that I really didn't want to see: our tent less than $100 \mathrm{~m}$ from where we were sitting!

Leaving John to put on his crampons, I climbed down to the tent, fell inside, and crawled into my sleeping-bag. Several hours passed before I woke to find that John had not arrived. Outside I found a set of tracks going down to C3 [camp three], but as I was not able to see well I couldn't see if John was below or not. Quickly packing everything at C4, I started down at around 10.30 am, but trying to carry what John and I had carried up was more than I could manage.

With a worsening cough, which I thought was the start of pulmonary oedema, I had to stop every 10 or $30 \mathrm{~m}$. I was tempted to sit and never get up. By late afternoon I reached C3, but there was still no sign of John. I could go no further, so I put up the tent and crawled into my sleeping-bag. My coughing by this stage had become constant and the wind blew with such force that the tent, which I hadn't tied down securely, started to slide off the ledge. I couldn't have cared less. As I could not gain my breath, I lay down and shortly after became unaware of my surroundings except for the strange sensation that there was someone in the tent with me. They had a very strong left hand because they placed it in the centre of my back and lifted me into an upright position. I could see myself sitting up with my head between my knees, and breathing became easier in this position. On the morning of the 12th October I was still sitting in this position and there was no-one in the tent but me.

I knew I had to get to base camp today if I was to survive this climb. Abandoning all of our equipment at C3 except my camera and film, I descended to $\mathrm{C} 2$ [camp two] and there I found John. It was here that John told me of his hallucinations which started on the morning of the 11th October at $\mathrm{C} 4$. He had seen several tents there, and his mixed up mind told him this camp belonged to someone else so he continued the descent in search of C4. As he descended, he turned to see me following approximately $20 \mathrm{~m}$ behind and on a number of occasions he asked me how I was going. These hallucinations continued until he reached the lower altitude of $\mathrm{C} 2$, where he came to his senses and realised I was still high on the mountain. 
We had our first hot drink since leaving for the summit on the 10th October. We left for base camp, leaving most of our equipment at $\mathrm{C} 2$, and by mid-afternoon reached the safety of base camp. A Belgian doctor who was climbing in the area examined our frostbite and said that we might loose the tips of some fingers and toes.

While resting at base camp for a couple of days, we sent our mail runner out to the nearest village which had radio contact with Kathmandu. Tapeljung was six days away but Rinzi made it in three days.

A helicopter was arranged to pick John and me up, a day's walk down [the] valley from base camp. With a dozen porters who had arrived to help us carry our gear out, we left base camp on the 16th October for the hard day's walk to Ramchi, where the helicopter would meet us on the 20th. John was able to walk but I was carried in a cane basket. Because of this, our progress over the moraine of the Yalung Glacier was painfully slow. Although we walked all day, we camped only three hours from base camp. That night it began to snow. Next morning the light snowfall turned into a storm and soon my friends were wading through two feet of snow at the same time someone was trying to carry me with as much care as they could. By mid-morning the storm had turned into what people would later call 'the October storm of 1987'. We were all now lost on the glacier and in danger of dying from exposure in the blizzard conditions.

In an effort to improve the pace at which we were travelling so that we could either find shelter on the glacier or push our luck and try and make it to the lone hut at Ramchi, I hopped out of the basket in which I was being carried and started walking with only a pair of heavyduty slippers (or base camp booties) on my feet. I knew all too well that what I was doing would only damage my frostbitten toes even more and may even cost me all of them, but I felt at peace now that I was helping to survive this storm rather than be a dead weight on someone's shoulders.

We no longer fought the storm and around mid-afternoon the tents were put up as the weather worsened. It wasn't until next morning that we emerged with the storm having passed during the night.

Under clear blue skies our porters and base camp staff broke trail through deep snow and I followed as best as I could. Our food and fuel supplies had run out the day before and we were now into the fourth day of our one-day walk to Ramchi. This day was the 20th October, the day the helicopter was to pick us up at Ramchi. By nightfall, however, we were still four or five hours short. Once again we set up camp on the glacier, but this time the night was calm.

On 21 st October 1987 at 11.30 am the co-pilot of the helicopter that had just landed in front of us motioned for us to come quickly. As John and I crawled into the back of the helicopter, I realised that we would finally escape the clutches of Kangchenjunga.

Groom and Coulton had climbed Kangchenjunga, 8598 m, on their own without supplementary oxygen, but they paid a terrible price. Both suffered badly from frostbite - Coulton mainly in the hands and Groom in the feet, and both lost much of their damaged tissue. In fact, Groom not only lost all of his toes, but 2 $\mathrm{cm}$ off both feet.

Although the severe frostbite injury to Groom, which occurred in late 1987, put paid to his chances to join the Australian Bicentennial Everest Expedition (ABEE) a few months later, it certainly did not end his Himalayan career. Showing the same level of determination that got him to the top of Kangchenjunga (and to 
the bottom!), he was back in the Himalaya only 15 months later, on the 1989 expedition to Ama Dablam. Although unsuccessful, that attempt put Groom back on track for another impressive achievement in 1990, the year Australian Himalayan mountaineering really came of age.

The decade of the 1980s laid the foundation for a grand slam of impressive Australian ascents in the Himalaya in 1990. In addition, the 1980s was the decade in which Australian Himalayan climbing blossomed more generally, with a growing number of Australian climbers attempting some of the lesser (in height but not necessarily in difficulty or danger!) summits in the great ranges of Asia. Behind the well-known names and their successes stands a large body of Australians, attempting and succeeding on a wide variety of challenging mountaineering projects throughout the Himalaya. 



\section{Part 8: New summits- beyond the trade routes}





\section{Small is beautiful}

In most places in the world, a $6000 \mathrm{~m}$ mountain would be a massive peak, dominating a range and towering over the surrounding landscape. The Himalaya, however, are filled with mountains in the 6000-7000 $\mathrm{m}$ range-hundreds of them. Although they are often overshadowed by their larger neighbours - and for that reason are sometimes overlooked by mountaineers intent on climbing as high as they can - the $6000 \mathrm{~m}$ Himalayan peaks often make up for in climbing quality what they lack in relative altitude.

Lower Himalayan mountains can be very attractive climbing objectives in their own right. Access is often easier than for some of the larger Himalayan peaks and because of their lower absolute altitude, they can be climbed in a shorter timean important consideration for those busy climbers with a limited amount of holiday time. In addition, the risk of altitude sickness, exposure or exhaustion is often less. Routes on these lower peaks range from straightforward glacier walks or snow plods up gentle ridges to a couple of thousand metres of desperate ice or mixed rock and ice climbing on steep faces, so there is something for everyone.

The virtues of these lesser Himalayan peaks have not gone unnoticed in the Australian mountaineering community. While much of the media attention has focused on well-known climbers and their attempts on Everest and other Himalayan giants, many Australian climbers have been pegging away quietly at these lower targets, building up a solid base of skills and experience that underpins the Australian effort on larger mountains.

For many of these climbers, a smaller peak offers a logical first step into the world of high-altitude mountaineering, an objective high enough to experience the difficulties of altitude but well below the 'death zone' of $8000 \mathrm{~m}$ and above. Indeed, most experienced Himalayan mountaineers strongly recommend that novices begin on something about 6000-6500 m high.

Another attraction is a practical one. The major Himalayan nations-Nepal, India and Pakistan - have cut the expense and red tape for those wanting to climb lower peaks. The peak fees themselves are much less, there are no liaison officers and there is a lesser requirement for local staff. In short, expeditions to these lower peaks are cheaper, much easier to organise and less complicated to run.

Taken together, these advantages have made the lower Himalayan peaks one of the mountaineering world's best kept secrets. For the many climbers who eschew the 8000-ers and return time and again to their lower neighbours, the 
rewards are some of the Himalaya's most classic and technically demanding lines on beautiful mountains far removed from the tension and crowds of Everest, K2 and other popular giants.

The Kulu and Lahoul areas of the Indian Himalaya have long been favourites for those climbers aiming for 6000-6500 m peaks. In fact, Australia's first Himalayan expedition, to Mulkila IV in 1975, and the expedition that launched the southern Australian section of the New Zealand Alpine Club (NZAC) into the Himalaya, to Dharamsura in 1979, both went into these areas. In each case, the objectives were considered ideal for a first mountaineering attempt for Himalayan newcomers.

Australian interest in the Kulu region intensified in the 1980s. Much of the activity was inspired by Australian climber Terry Ryan, who found the Kulu so to his liking that he established a company, Kulu-Indian Himalayan Journeys, based in Manali, to organise trekking, climbing and skiing holidays for clients.

Ryan himself remained an active climber through that period and, with various partners, made first Australian ascents of a number of Kulu summits: Kulu Makalu (5882 m), Corner Peak (6140 m), Tiger Tooth (5980 m), The Dome (5880 $\mathrm{m})$ and Shigri Parbat $(6640 \mathrm{~m})$, to name a few. That these climbs, although of modest altitude, can offer the danger and deprivation associated with the true Himalayan experience is evidenced by a few cryptic comments by Ryan:

...attempt abandoned due to extreme cold.

...Terry Ryan badly injured after falling 100 feet into crevasse unroped - a difficult eight-day retreat followed.

... attempt abandoned due to technical difficulties.

...stopped due to lack of time and bad weather.

...John Burrow badly injured after 800-foot fall, much of it 'through the air'. Another difficult eight-day retreat followed. Nick Groves frostbitten on his toes. ${ }^{1}$

If the Kulu has earned a reputation for enjoyable and less serious (despite some of Ryan's [mis]adventures) Himalayan climbing at moderate altitudes, the Karakoram is firmly associated with extremes - either of altitude, with K2 and its massive satellite peaks, or of technical difficulty, with the sheer granite walls of the Trango Towers and Lobsang Spire.

1 T. Ryan, Personal communication, 4 September 1990. 
Away from the Baltoro Glacier, however, on which so much of the climbing and trekking in the region is centred, there is a very different side to the Karakoram. There are seldom-visited areas of long glaciers, high snow basins and scores of attractive peaks. Australians were again active in these areas decades ago. Geoff Bratt and Grahame Budd were members of one of Eric Shipton's exploratory expeditions in the Siachen Glacier region and Jon Stephenson became the first Australian to climb to $7000 \mathrm{~m}$ without the aid of supplementary oxygen during an attempt on $\mathrm{K} 12$.

Even into the 1990s, the off-the-beaten-path Karakoram offered some of the most enjoyable and exciting Himalayan adventures imaginable, not to mention challenging climbing. A classic example is a 24-day traverse of the $240 \mathrm{~km}$ long Biafo-Hispar Glacier system by a pair of South Australian climbers, Wade Stevens and Damian Barrett, during the northern hemisphere summer of 1989.

The trip demonstrated the possibilities for exciting adventure right from the very start when the pair's camp along the Biafo Glacier was raided by a bear, as Stevens recounted:

We awoke early the next morning to a rustling sound outside the tent, and the knowing glances we exchanged confirmed our worst fears. Peeking out through the narrowest possible slit in the door zip, I saw a six foot bear dragging my $\$ 300$ Lowe pack off for breakfast.

Neither of us wished to actually contest this gigantic beast, so we resorted to trying to scare the omnivore away with a mixture of plate banging and high decibel 'ra ra ras'. Of course this was followed rapidly by some serious cowering within the tenuous stronghold of our double skin nylon Trilogy bear fortress, as soon as our guest looked up. For a while, it seemed happy enough tugging at the double cordura, like lolly paper to its huge claws, and just as we were wondering if we were for dessert, it ran off. ${ }^{2}$

After the bear attack, their adventure assumed more traditional Himalayan dimensions as, carrying heavy packs, they battled thigh-deep soft snow up the head of the glacier towards the col between the Biafo and Hispar Glaciers. The reward for their hard work was a beautiful view from the col of a spectacular and remote part of the Himalaya: the vast 'Snow Lake', with the shapely Snow Lake Peak presiding over it, the Latok group of peaks, the Ogre and the Solu Towers.

2 Stevens, W. 1991, 'Both ends burning', Long Reach, (journal of the Adelaide University Mountaineering Club), Summer, pp. 18-24. 
Rising about $700 \mathrm{~m}$ directly above the col was a small mountain, Peak 5886, which would afford even better views of the surrounding mountains, glaciers and valleys. Taking advantage of the Pakistani regulation that no permit was needed to climb any peak less than $6000 \mathrm{~m}$ high, Stevens and Barrett decided to have a go at the peak as a day climb from the col.

Eschewing the standard route up the mountain's South-West Ridge, the two climbers headed instead for the imposing South Face. Suddenly the climb took on an entirely different character. Instead of a straightforward slog to the summit, it became a real Himalayan challenge of steep ice gullies and treacherous snow slopes. The reality of the long day's climbing lived up to its promise.

'I recall a montage of racing the sun, long runouts on spaced or marginal protection, exhilarating position, those marvellous views as we peeked over the summit ridge, and exhaustion on top,' Stevens recalled. ${ }^{3}$

The descent completed the genuine Himalayan mountaineering experience. Plagued by severe dehydration as well as exhaustion, the climbers alternately faced soft snow and green ice on the descent route, then had the frustrating experience of breaking through the thin crust of the glacier surface every few steps on the plod back to the tent.

The Stevens/Barrett trip was perhaps a forerunner of more Australian trips to the lesser known peaks of the Karakoram. Further to the south-east, in Nepal, Australians have been much more active in the past 15 years. There the possibilities for climbing peaks of moderate altitude are better known, with the procedures and regulations well established and publicised.

In addition to its larger peaks, Nepal makes available about 20 so-called 'trekking peaks' to climbers looking for a simpler, less expensive alternative to a fullscale expedition to a major Himalayan peak. The cost of peak fees is only a few hundred dollars, the mountains can be booked on the spot in Kathmandu and there is no requirement for a liaison officer to accompany the climbing group.

The term 'trekking peak' is, however, a bit misleading. That title, coupled with the ease of booking and low peak fees, conjures up images of small peaks that are simply 'walk-ups' for inexperienced groups of trekkers. They are thus often viewed as peaks a little higher than the traditional trekking hills of Kala Pattar or Gokyo Ri, perhaps with a bit of snow on top, but certainly posing no challenges to experienced mountaineers.

That impression is decidedly wrong. Nepal's trekking peaks range in height from $5500 \mathrm{~m}$ Tharpu Chuli (Tent Peak) in the Annapurna Sanctuary to $6584 \mathrm{~m}$ 
Chulu East north of the Annapurna Range. In difficulty, their variation is even more striking. Peaks such as Pisang (6091 m), Paldor (5928 m) and Mera (6476 $\mathrm{m}$ ) are indeed straightforward mountaineering propositions (by the standard routes), but knowledge of safe glacier travel and basic snow and ice-climbing techniques, and the ability to judge mountain weather patterns, is essential.

At the other end of the scale, mountains such as Singu Chuli (Fluted Peak, $6501 \mathrm{~m}$ ) and Hiunchuli $(6331 \mathrm{~m}$ ) are serious challenges for even experienced Himalayan climbers. The most difficult of all the trekking peaks, Kusum Kanguru (6369 $\mathrm{m})$, is harder technically than the majority of expedition peaks and is therefore rarely climbed. Even Imja Tse (Island Peak, $6189 \mathrm{~m}$ ), the most popular of the trekking peaks, can be difficult under some snow conditions.

Australians took an early interest in Nepal's trekking peaks, with the first successful expedition in 1977, only two years after the first Australian expedition anywhere in the Himalaya. That 1977 trip - by Tasmanian climbers Geoff Batten, Mike Douglas, Fergus Fitzgerald, Greg Hodge, Phil Robinson and Mendelt Tillema - made the first Australian ascents of Imja Tse and Parchamo, a $6187 \mathrm{~m}$ peak above Tesi Lapcha Pass, which separated the Khumbu and Rolwaling Valleys.

It was five more years before the next trekking peak fell to an Australian climber, then Kwangde Shar (6093 m), Mera and Pisang Peak were all climbed by Australians. Mick Chapman and Colin Pont ascended Kwangde's eastern summit - conveniently accessible from the Sherpa capital of Namche Bazaar. Eight climbers - Stephen Bunton, Tim Carroll, Jeff Crass, Ivan Desailly, Steve McDowell, Ron Miller, Mike Myers and Peter Webber-were successful on Mera and on neighbouring Nau Lekh (6363 m) as well. A group led by Fritz Schaumburg, who was a key figure in the early development of the Army Alpine Association (AAA) mountaineering program (see Chapter 13), made the first Australian ascent of Pisang.

An example of what Australian climbers had in store for them when tackling one of Nepal's trekking peaks was the experience of a group of Canberra-based climbers on a 1983 attempt on Kwangde. The party consisted of two husbandand-wife teams, Guy and Emma de Lacy and Richard Howes and Catherine McGammon, and Ray Vran.

The group was certainly not short of mountaineering experience. The de Lacys were originally from New Zealand and had extensive experience in their home ranges. Howes and McGammon also had plenty of snow and ice-climbing experience, and Vran had made numerous trips to New Zealand as well. In addition, just before the Nepal trip, he had spent six months in Alaska, where 
he made three ascents of Denali, by two different routes. The last trip to the top was particularly impressive, as he climbed from a camp at just above $4000 \mathrm{~m}$ to the summit, $6194 \mathrm{~m}$, in a single 16-hour push.

Kwangde seemed the ideal first Himalayan mountain to attempt. At $6187 \mathrm{~m}$, it was virtually the same height as Denali, and for a Himalayan peak it was easily accessible, just a few days' walk from the mountain airstrip at Lukla. Furthermore, it was inexpensive. Vran noted that the total cost for seven weeks in Nepal was only $\$ 700-$ a very cheap 'holiday' by any standards. ${ }^{4}$

As for the climbing, Kwangde proved, like many of the other Nepalese trekking peaks, to pack more of a punch than its modest altitude or ease of access might have indicated. The team opted for a route from the south, up a striking ice ridge that led directly towards Kwangde Lho, one of the mountain's multiple summits. They planned to place only one camp above base camp and then climb to the top in a single push from there.

Once on the route itself, however, they discovered that Kwangde was certainly going to be no walk-up. 'The ice on the ridge was atrocious,' Vran recalled. 'We couldn't place ice screws at all. Every time we tried, the ice shattered and broke away. We couldn't get any protection in. We eventually got around the problem by soloing the ridge. ${ }^{5}$

If the poor ice conditions and consequent soloing did not make the climbing serious enough, the weather added another element of risk. The usual afternoon snow showers of the pre-monsoon season slowed progress and, just as Howes and Vran had seemingly overcome all the obstacles and were only about 100 $\mathrm{m}$ below the summit, an unusually severe and prolonged storm, in the words of Vran, 'cleaned us up'. ${ }^{6}$ Kwangde had provided very close to the complete Himalayan experience.

Trekking peaks often serve as an introduction to Himalayan climbing for mountaineers who later go on to tackle higher objectives. Kwangde served that role for Vran and Howes. In fact, while climbing high on the South Ridge of Kwangde Lho, Vran looked across the valley and was taken by a larger peak that dominated the range of mountains to the south. Eighteen months later, he was back in the same valley to attempt the mountain.

The peak was Khartang, a 6853 m-high 'expedition' peak. Only one other mountaineer, Canberran John Lamb, accompanied Vran on the climb and they were attempting the steep North-East Face during Nepal's winter climbing season.

\footnotetext{
4 R. Vran, Interview.

5 Ibid.

6 Ibid.
} 
Vran and Lamb were two of the first four Australians to attempt a Himalayan ascent in the newly instituted winter climbing season in Nepal. The other two were Mike Rheinberger and Greg Martin, who attempted Kangguru in the winter season of 1984 (Chapter 16).

Like Rheinberger and Martin, Vran and Lamb quickly discovered why climbing in the Himalaya in the winter season was so difficult and dangerous: the deadly combination of cold and high winds. In fact, the pair got a good taste of what winter winds could do in the Himalaya well before they even reached the base of the mountain.

'The wind was so strong that we regularly got knocked over just walking along the moraine to base camp,' Vran said. 'At one point a porter was physically picked up by the wind and carried along the moraine! ${ }^{7}$

A massive rock fall added to the dangers of the approach to base camp. With the party pinned between the edge of a lake and a steep slope, a one-minute deluge of rocks the size of television sets cascaded down the slope and into the lake. Since Lamb, Vran and the local staff were all carrying heavy loads, they could not dodge the falling rocks. Miraculously, no-one suffered a direct hit and all escaped without serious injury.

The fierce wind conditions they experienced on the short trek to base camp were only a mild forerunner of what they would find on the face itself. After their tents were flattened at base camp, they realised that their thoughts of a quick, lightweight ascent were only wishful thinking. They would have to fix ropes on the face to ensure their safety. That would be a daunting task for a twoman team as there would be no second or third teams to come in and take turns.

At first the pair thought that the wind would make the mountain unclimbable, but as they took their first tentative steps up the face from a camp at $5300 \mathrm{~m}$ at the peak's base, they realised that with care, and a lot of fortitude, they could make some progress.

'The wind roared straight down the face,' Vran recalled. 'You could hear the intense gusts coming. You just dug in your tools and held on until it passed.'

Even without the wind, the conditions on the face were desperate. Since it faced the north-east, the face received no sun at all during the day; the highest temperature the climbers recorded on the face was $-25^{\circ} \mathrm{C}$. To make matters worse, their gas stoves frequently malfunctioned and they had to spend an inordinate amount of time trying to cook and melt snow. As a result, they rarely started climbing before 10am. 
The pair battled on for 10 continuous days on the face under those conditions. They reached a high point of $6100 \mathrm{~m}$ - still $700 \mathrm{~m}$ short of the summit-before they decided to retreat. As Vran put it, 'We were just burnt out.'

The severe conditions had taken their toll, even in that short time. Vran suffered a mild case of frostbite and his sleeping-bag, which had a small slit in it, had pieces of ice the size of a hand inside it.

There was no question of going back up, even though they had plenty of time for a second attempt. 'This was December,' Vran said, 'and when we thought of Australia, we thought of warm sand between our toes. ${ }^{\prime 10}$ It was time to go home.

The experiences of Vran and his colleagues on Kwangde and Khartang are a graphic illustration of what climbers can face on Nepal's trekking peaks and other mountains of modest altitude. Not all smaller Himalayan peaks, however, treat their aspiring ascensionists so harshly. Some afford the type of experience such mountains are supposed to offer: delightful climbing in pleasant surrounds free from the expense and bureaucratic hassles of the bigger mountains.

A classic example of such an experience is the 1986 climb of Langshisa Ri by Australians John Goulstone and Steve Upton and New Zealanders Simon Cox and Marty Hunter. Langshisa Ri is a striking mountain, a small spike of fluted ice set in the Langtang Himal directly north of Kathmandu. Although technically an expedition mountain, it has much in common with the more difficult of the trekking peaks. It is $6437 \mathrm{~m}$ high and its classic ridgelines and steep faces would have even the most experienced Himalayan mountaineers drooling at the possibilities for technically demanding routes of the highest standard.

The four Antipodeans picked a plum - a line directly up a couloir on the mountain's south side and then straight up the steepening South Face. The logistics were simple, almost like a climb in the Southern Alps. Above base camp, the climbers placed a single camp on a snow plateau at the base of the peak and from there went for the summit in a single push-no load carrying to stock camps and no fixing of ropes, just climbing.

Once out of the couloir, the climbing was hard but very rewarding, as Cox reported:

Out on the face we were much more exposed, and the view around us steadily grew more impressive as we climbed...

About 20 metres out onto the slope, the sun snuck around the face and hit me. Instantly I started sweating, my head started spinning and my 
mouth felt like a packet of muesli. I managed to place my ice tools deeply and hang on them while I gingerly removed some clothing and waited for my heart to stop racing.

From then on, it was desperately hard work as the slope got progressively steeper. Place a hammer, then an axe, kick, kick, puff puff puff puff, uurrgggh, place a hammer, then an axe...At $12.30 \mathrm{pm}$, after seven pitches, Marty and I stepped out onto the summit. We were followed a bit later by John and Steve. The view was amazing. The clouds, which typically rolled in at about this time, held back and left Langshisa Ri and us in a clearing. ${ }^{11}$

The four climbers abseiled down the face to the top of the couloir, climbed down that and traversed back across the snow plateau to their camp. They had therefore completed a beautiful climb on a moderate Himalayan peak in a single day - not unlike a hard day's climbing in New Zealand but in the highest mountain range in the world. It is experiences like this that are attracting increasing numbers of mountaineers to the 5500-6500 m Himalayan peaks as worthy objectives in their own right.

No account of Australian Himalayan climbing in the 1980s would be complete, however, without considering peaks in the 6800-7800 m range, many of them in the more remote parts of the Himalaya. These mountains, particularly at the higher end of the range, are more serious objectives because of their higher altitude than the peaks whose ascents have been described earlier in this chapter. Accounts of Australian expeditions to these higher peaks include some fascinating adventures: climbs of some of the world's most aesthetic mountains, danger in the far corners of the Indian Himalaya, a wild trek across the entire width of Nepal and an astonishing ascent of one of the Himalayan giants. The account will eventually lead back to the 8000-ers, and to 1990, when Australians recorded a most impressive string of successes, including ascents of the world's two highest mountains.

Remoteness can be a strong lure for climbers. The desire to visit an out-of-the way place and climb far from the throngs of trekkers and climbers that frequent the well-worn paths in Nepal and the Karakoram can be as strong an attraction as the absolute altitude of a mountain or the aesthetics of the proposed line of ascent. Despite the dramatic rise in popularity of Himalayan mountaineering in the past two decades or so, there are still many exceedingly remote ranges and valleys for mountaineers to explore and climb. Australian expeditions have found their way in the past 15 years into some of these areas, with mixed success but never without interesting incidents, and some nasty surprises in one case.

11 Cox, S. 1986, 'Bumblies abroad', New Zealand Alpine Journal, vol. 39, pp. 60-3. 
Until recently, the Pamir Range was arguably the least known of the great ranges of Asia - at least for climbers from Western countries. Stretching in an arc between the Karakoram and the Tien Shan Mountains to the north, the Pamirs straddle the border between China and Tajikistan, a former Soviet republic. Most of the high peaks, including the highest mountain in the range, Pik Kommunizma, lie on the Tajik side of the border.

Australians have made occasional forays into the Pamirs with Chris Curry's ascents of Kommunizma (7495 m) and Pik Korzhenevskaya (7105 m) the most notable achievement (Chapter 18). The first Australian-led expedition to the Pamirs, under the guidance of Steve McDowell, attempted Kommunizma in 1986. It was McDowell's fifth Himalayan expedition, having taken part in both Australian attempts on Annapurna III, been a member of the first Australian team to climb Mera Peak (6476 m) in 1982 and attempted Mustagh Ata in 1985.

Of a much wilder nature than the Pamir journeys, however, was a 1986 expedition to the far north-eastern corner of the Karakoram, a trip that started with the promise of a once-in-a-lifetime adventure and ended in extreme danger, far from the mountain itself. The mountain was Rimo, a $7395 \mathrm{~m}$ unclimbed peak not far off the old Silk Road that snaked through the Karakoram between India and China.

The expedition to Rimo was the brainchild of Terry Ryan and his brother, Brett. As noted earlier, Ryan had a long association with mountaineering in the Indian Himalaya. It was through these long-time connections with the Indian mountaineering bureaucracy that Ryan was able to get permission to mount an expedition to Rimo. The mountain is located in a very sensitive position, near the disputed border between India and Pakistan and not far from the Chinese border as well. One of the conditions of the trip was that it be a joint expedition with Indian military climbers, with an Indian officer as leader.

The trip promised much in the way of adventure. The trek in along the old Silk Road would be fascinating. In fact, the last Westerner to travel the route was the legendary mountain explorer Eric Shipton, on his way to a diplomatic posting in Kashgar in the late 1940s. Then there was the mountain itself-one of the few unclimbed $7000 \mathrm{~m}$ peaks left in the Himalaya. To top if off, the team planned to return by rafting down the Shyok River, which would be the highest river ever rafted.

Joining the Ryan brothers on the trip were Roddy Mackenzie and Peter Hillary. MacKenzie, one of the original members of the International Turkey Patrol (Chapters 19 and 20), was making his return to the Himalaya after the tragic Everest West Ridge expedition in 1984. Hillary, now settled in Melbourne, was 
climbing more and more with Australians in the Himalaya. Dave Read, originally from the United Kingdom, and American Skip Horner completed the climbing team.

At first, the adventure went without major problems. Despite a two-week delay in Leh at the start when last-minute snags in the Indian bureaucracy had to be overcome, the trek to the base of Rimo proved to be every bit as rewarding as it promised.

Once at the base of the mountain, however, a few problems began to arise. The Western contingent favoured an alpine-style approach to the climb, while the Indians would not contemplate any route that did not allow for a copious amount of fixed rope. A joint expedition is fine in theory, but friction often develops in practice, as Hillary recalls:

This conflict of climbing styles was complicated by the politics of international expeditioning and the limited time we had available, particularly for a conventional, fixed-rope/large-logistics approach to climbing the mountain. Compromise was to be the name of the game and, as is so often the case with compromise, it is seldom as satisfactory as a clear-cut decision. ${ }^{12}$

Nevertheless, the team worked amicably together to make a sustained attempt on the difficult peak. In the end, Hillary, Mackenzie and Horner were forced to retreat from high on the South-East Ridge by a combination of exceedingly dangerous snow conditions and deteriorating weather. The ridge suffered from the very unusual condition of being very narrow, double corniced and deeply crevassed all at the same time.

The ridge might have been frightening, but it turned out to be nothing compared with what lay ahead on the return to civilisation. The climbing team descended to discover that base camp had been abandoned with virtually no food remaining. The Indian leader and all of his climbers had left, leaving the Westerners to fend for themselves in the extremely sensitive border area. Furthermore, the climbers learned from a note left behind by one of their colleagues that the leader of the rafting party had been arrested as a suspected Central Intelligence Agency (CIA) agent by the Indian Army and was being marched at gunpoint back to Leh.

Against this very disturbing backdrop of developments, the Ryan brothers, Mackenzie, Hillary and Horner shouldered their $45 \mathrm{~kg}$ loads - virtually none of which was food or fuel - and started back out towards Leh, in hopes the main party would wait for them a few days' march from base camp.

12 Hillary, P. 1988, Rimo. Mountain on the Silk Road, Hodder \& Stoughton, London, ch. 7. 
Winter was descending on the Karakoram and the cold conditions made the trek out even more difficult for the weakening climbers. Hillary recounted the pain and danger of fording the icy Shyok River:

It had been an exceptionally cold night and the evidence of this lay on the banks of the river. Ice reached two yards out into the swiftly flowing water and, to our astonishment, we could see that a sludge of large ice crystals was already beginning to coat the round stones in the bottom of the river. Another few days of these low temperatures and the Shyok would certainly freeze completely, but not soon enough for us. We sat down on the river flat and removed our shoes and socks and marched towards the rushing clear ribbon of water.

The pain was excruciating. It was about twenty below as I followed Skip across the shelf of ice that bordered the river, my skinny white feet radiating much of my body heat to the frigid air and the slick ice underfoot. Stepping off the ice into the knee-deep water, my right foot found the slushy ice of the river-bed which moved around it like thick mud. As I moved cautiously forward the streaming water leeched all the remaining warmth from my feet, and I could no longer sense where my feet stopped and the ice began.

Using a ski pole to aid my balance I stumbled across the ice-shelf on the far side, threw down my pack and sat heavily upon it. The bitterly cold air attacked the wooden stumps that were my feet as I rubbed them with some gloves and pulled on my socks. ${ }^{13}$

Encounters with the Indian military were just as chilling. Not long after they had left base camp, the unaccompanied Westerners were detained by a military patrol, the leader of which had them and their packs thoroughly searched and all of their film confiscated. Later, just when it appeared they might escape back to Leh before their expedition permits expired, Hillary had a narrow scrape with death or at least serious injury.

The expedition caravan, which they had managed to join shortly after their first encounter with the Indian military, had abandoned ponies for trucks, which were winding their way towards the top of the last high pass before Leh. It had been snowing heavily and avalanches blocked the last section of road before the pass. The expedition members were forced to shoulder loads yet again and haul the gear up to the pass itself to be transferred to another truck on the other side.

On one such load haul to the pass, Hillary suggested to the expedition's liaison officer that he pitch in and lend a hand. The liaison officer took extreme exception 
to Hillary's suggestion and screamed that no-one could talk to an officer of the army in the way that Hillary allegedly had. The liaison officer then stormed off in a rage, threatening Hillary with a quick and violent end if he dared suggest anything like that again.

A short while later, Hillary went into the construction shed at the top of the pass, to which the liaison officer had retreated, to discuss their confrontation. But the liaison officer, who was still incensed, grabbed a loaded rifle and held Hillary at gunpoint and threatened to bury him outside the door. Some minutes later, which no doubt seemed an eternity to Hillary, the liaison officer finally removed the weapon from point-blank range and the ordeal was over.

Remote Himalayan adventures do not have to be as hair-raising as the Rimo expedition. The 1988 Australian Baruntse expedition is a good case in point. Set in the well-travelled eastern part of Nepal with a mountain in the Everest region as the objective, the Baruntse trip proved that even in that geographical setting a surprisingly little-travelled trekking route could be found into a marvellously remote high valley a stone's throw from Everest, Lhotse and Makalu.

The trip was a throwback to the early days of Himalayan expeditioning, when road access was virtually nonexistent and marches began from the Kathmandu Valley or from the plains of India. The Baruntse team started its wild trek from the little southern Nepalese village of Chatra, where the very first of the Himalayan foothills rose from the Gangetic Plain. The subsequent 25-day journey took the climbers through steamy river valleys, along a gloriously open ridge with stunning views of the high Himalaya, through some of the last stands of undisturbed rhododendron forest in eastern Nepal, across a high, stormlashed pass into the wild Hinku Valley and finally into the upper Hongu Basin, surrounded by a magnificent array of icy peaks and guarded by high, difficult passes and impassable gorges.

The Baruntse trip had other links with Himalayan history. Its leader was John Finnigan, one of the members of the landmark 1978 ANU Mountaineering Club (ANUMC) expedition to Dunagiri, the most significant of the early Australian expeditions to the Himalaya (Chapters 6 and 7). Indeed, the Baruntse trip was somewhat of a Dunagiri reunion. In addition to Finnigan, Ken Baldwin, the organisational driving force of the Dunagiri trip, John Armstrong, Ken Bell and Theo Hooy were all old Dunagiri hands who joined the Baruntse team. And Charlie Barton, who had to drop out of the Dunagiri expedition at the last minute, finally made it to the Himalaya. Indeed, even Tim Macartney-Snape was involved, as he suggested the trekking route and his company, Wilderness Expeditions, provided logistical support for the expedition. 
The expedition's links with the past go back much further even than 1978. One of the Baruntse team members was then fifty-nine-year-old Tom Barcham, a New Zealander who had nearly been a member of one of Sir Edmund Hillary's early expeditions to Nepal. Until internal politics in the NZAC bumped him off the trip at the last minute, Barcham was a member of Hillary's 1954 New Zealand expedition to the Barun Valley. Ironically, that team made the first ascent of Baruntse (7168 m).

Barcham's dream of climbing Baruntse 34 years after his first potential encounter with the mountain did not quite come true. He pushed hard to carry loads to camp two on the West Col, at just above $6000 \mathrm{~m}$, but problems with altitude prevented him from going higher. It was, however, the highest Barcham had ever climbed. Indeed, all 10 members of the expedition set personal altitude records; ironically though, none reached the summit.

Despite a valiant effort by Finnigan, Hooy and American Peter Hodge, unstable snow conditions high on Baruntse's narrow summit ridge blocked further progress only 100 vertical metres below the top. A second summit attempt, by Baldwin and expedition doctor Peter Lane, was stopped at the same point.

Baldwin, Barton, Hodge and Hooy then completed their journey across nearly the entire width of Nepal by crossing the Amphu Lapcha and trekking on to Everest base camp, where they visited the Australian Bicentennial Everest Expedition (ABEE) climbers just days before the dramatic conclusion to their expedition. The Baruntse trip was perhaps a modest forerunner of a much more remarkable journey - from the Bay of Bengal all the way to the summit of $\mathrm{Mt}$ Everest itself (see Chapter 29).

One of the most exotic of the remote corners of the Himalaya visited by Australians lies in far western China, near the old city of Kashgar. This was the city where the legendary Eric Shipton was posted for two periods, immediately before and after World War II. Near Kashgar rise two most impressive, isolated mountain massifs: Kongur (7719 m) and Mustagh Ata (7546 m).

Mustagh Ata, in particular, is a rather unusual mountain. Rising like a giant, white-backed, beached whale, it looms over the parched seasonal grazing country of south-western China, a land of camels and nomads. Its western ramparts - formally the West Face - form a long, very gently angled arc of snow that leads eventually to the summit. It is one of the technically easiest routes of any mountain of comparable size in the Himalaya.

Mustagh Ata could, however, be surprisingly difficult to climb, as Eric Shipton and Bill Tilman discovered on their attempted ascent during a break in one of Shipton's sojourns at Kashgar. The easily angled West Face route means that climbers must spend much time and cover a lot of distance plodding through 
often deep snow at high altitude. It was just this deadly Himalayan combination of altitude, exhaustion and dehydration, rather than technical difficulty, which forced such experienced climbers as Shipton and Tilman to retreat before they reached the summit.

In recent times, skis have made the ascent of Mustagh Ata much less arduous, as they allow the climber to move more quickly and to remain on top of deep snow. The descent, of course, is decidedly quicker, and a good deal more exciting, on skis.

An Australian climber added a new twist to the style of Mustagh Ata ascents in 1989. Mike Rheinberger, the most active Australian Himalayan mountaineer of the 1980s, joined New Zealander Shaun Norman to guide a group of four clients up the standard West Face route. The two guides and two of their clients, both British climbers, reached the summit. Norman and the two clients used skis, as had become the normal mode of ascent in recent times, but Rheinberger opted for snow shoes. It was a wise choice, as Rheinberger, in a tortoise-and-hare-like story, beat the three skiers on the descent. It turned out that the broad slope was sufficiently crevassed to allow the steady plod of the snow-shoer to outpace the stop-and-start skiers, who could not gather speed or maintain a rhythm on the cut-up slope.

The 1989 Mustagh Ata expedition illustrates a growing trend towards guided climbing in the Himalaya. Once the standard mode of climbing in the Alps, guided climbing has had something of a renaissance in the Himalaya. By the early 1980s, many adventure-travel companies, particularly those operating from Britain and the United States, were offering 'mail-order mountaineering' trips to the Nepalese trekking peaks - particularly Imja Tse (Island Peak) and the peaks in the Annapurna Sanctuary. The number of widely advertised guided climbs increased rapidly in the late 1980s, with the objectives becoming larger, and sometimes more difficult, 'expedition' peaks. The Nun Kun massif in Kashmir and Mustagh Ata were particularly popular targets. By the end of the decade, Everest itself was being advertised in climbing magazines; with enough money, any fit climber with a modicum of experience could have a go at the world's highest mountain.

Experienced Australian climbers have occasionally mounted a guided climb in the Himalaya (see, for example, the attempt on Trisul in Chapter 10), but it was not until the late 1980s that Australians, as guides and clients, became involved more frequently in guided climbing.

Guiding relatively inexperienced clients in the Himalaya is serious business, as Geof Bartram can affirm. Bartram, who had much experience guiding in South 
America, was through the 1980s Australia's most experienced high-altitude guide, and the only one to have guided three Himalayan trips. The outcomes of those trips touched the extremes of the Himalayan climbing experience.

The Trisul attempt was a near disaster when a vicious storm demolished two of the expedition's tents at a high camp and left one of the novice climbers wandering around on the side of the mountain. It was all Bartram and colleagues Lincoln Hall and Tim Macartney-Snape could do to get all their clients down safely. On the other hand, Bartram's ascent of Pumori in 1984 was a resounding success. Not only did all seven climbers reach the summit, they climbed a new route on the steep South-East Face. It was the ideal guided climb.

Bartram's third guided expedition - an attempt on Nun (7135 m) in 1988again demonstrated that any Himalayan expedition was a serious undertaking. Guiding six American climbers, Bartram had his team established at a camp at $6000 \mathrm{~m}$ when a three-day snowstorm lashed the mountain with more than $2 \mathrm{~m}$ of fresh snow. Bartram was able to get his charges off the peak in dangerous conditions, but the epic turned into a tragedy when the expedition's liaison officer was lost during the descent and died of exposure.

Despite risks such as these, the trend in guided climbing in recent years has been towards more difficult routes on higher mountains. In the Australian context, the best example is the 1989 ascent of Himalchuli West (7540 m) by a small team led by Paul Bayne of ABEE fame and New Zealand guide Russell Brice.

The Himalchuli West climb would have been a notable achievement even by an expedition of very experienced mountaineers. The peak had been climbed only once previously, and the new route climbed by the Bayne/Brice team was technically difficult and physically demanding. It is a testament to the guiding skill and stamina of Bayne and Brice, and to the tenacity and determination of the clients who summited-Australian Campbell Mercer and Norwegian Jan Gangdal - that they achieved success on such a daunting objective. Indeed, it could be argued that the South-West Ridge of Himalchuli West was no place for a guided climb.

To be fair to expedition organiser, Steve Bell, Himalchuli West was not the first choice. The original target, Everest's northern outlier Changtse, was of nearly the same height but far more tractable technically. Political unrest in Tibet, however, put Changtse out of bounds and Bell was forced to go to Nepalese authorities for a last-minute replacement. Himalchuli West was the most viable alternative. 
In addition to being a stopgap alternative, Himalchuli was very much an unknown as far as climbing difficulty, and even the route itself, was concernedjust the sort of uncertainty that added spice to a trip of veterans but could give guides ulcers and clients nightmares.

'All we had was a postcard taken from the Indian plains,' Bayne said. 'We got information on the trekking route into the mountain from local villagers as we walked in. We didn't even know which valley to go up.' ${ }^{14}$

The full implications of what they had taken on did not become clear until the party began climbing on Himalchuli, as Bell recounted:

From base camp we could see very little of the line we had selected, but after climbing $900 \mathrm{~m}$ to a point on the southwest ridge we were confronted with a spectacle that left us in no doubt of the enormity of what we had taken on. Between us and the mountain lay a three kilometre ridge, bristling with no less than eleven major pinnacles, all of which would have to be climbed or bypassed. The far end of the ridge butted into the main bulk of Himalchuli, at an altitude of 5,790 m, a mere $900 \mathrm{~m}$ higher than the start of the ridge. Above this lay $1700 \mathrm{~m}$ of snow slopes and ice cliffs. ${ }^{15}$

As it turned out, every one of the pinnacles - which the climbers christened with names such as 'The Castle', 'Graham's Knob', 'The Fortress', 'Jon's Icecream' and 'Brice's Buttress'16 - turned out to be a major climbing challenge. Only after some extreme climbing by the guides, plenty of solid support work by the clients and more than $3 \mathrm{~km}$ of fixed rope was the ridge finally climbed. In fact, at one point the expedition's cook was sent back to Kathmandu to buy more rope!

After Brice surmounted a $100 \mathrm{~m}$ ice cliff higher on the mountain, the way was clear to the summit. Bayne and Gangdal then pushed on to the top, followed by Brice and Mercer a day later. The Himalchuli ascent was an astounding success against heavy odds, particularly for a 'mail-order' team. It proved that Bayne's heroics on Everest the previous year were no fluke and that he was a wellrounded Himalayan mountaineer with skill and stamina of a very high standard.

Some of the most visually spectacular mountains in the world — such as Shivling, Ama Dablam and Pumori - are not as remote, yet all of these peaks have played a part in the story of Australian mountaineering in the Himalaya. All have been

14 P. Bayne, Interview.

15 Bell, S. 1989, 'The international Himalchuli West expedition, 1989', Himalayan Journal, vol. 46, pp. 35-8.

16 Ibid. 
climbed by Everest aspirants at one time or another before their attempt on Everest itself. These magnificent mountains have, however, also attracted other groups of Australian climbers, with a few more notable successes.

Shivling — climbed earlier by Jon Muir (Chapter 20) and Greg Child (Chapter 24) - was attempted again in 1988 by a large group led by Nic Deka and Jim Duff of Hobart. Duff was the doctor for the first Australian ascent of Mt Everest in 1984. Their goal was a climb of Shivling's South Pillar and although heavy snowfalls put that route out of condition, 11 Australian members climbed nearby Kedarnath Dome $(6831 \mathrm{~m})$. The expedition also marked the return to the Himalaya of Andy Henderson, who came so close to climbing Everest in 1984.

There was another Australian ascent in 1989 of Everest itself that deserves mention. American Karen Flerhoff organised the 15-member Snowbird International Everest Expedition for climbers who had failed previously on the mountain - a repechage, as it were, for Everest climbers. One of the 15 members was Roddy Mackenzie, who was on the ill-fated 1984 West Ridge attempt.

This time luck was with Mackenzie. Climbing on the South Col route with Colorado-based Briton Adrian Burgess, he became the sixth Australian to reach the highest point on Earth. Mackenzie was modest about his achievement, preferring to comment on the view rather than the climb:

Getting to the summit means more to people who don't climb than to people who do. The most glorious thing about reaching the top is the view...You can see for about 300 miles. The sky is very blue. There are a lot of clouds below and around you...It looks like a Landsat photo-you almost feel that you're out in space. ${ }^{17}$

Unfortunately, Peter Hillary was not as lucky as Mackenzie. Deteriorating weather just one day after his colleague's success forced him to abandon his summit attempt at a point well above the South Col.

While Australians were battling their way up and down Everest by various routes in the 1980s, many of their colleagues were having a bash at three stunning Everest acolytes: Changtse, Pumori and Ama Dablam. The first of these provided a small group of Australians with some very tense moments during a 1987 trip, before political turmoil closed off the mountain for a while.

The Australian Changtse traverse expedition, as it was called, provided the springboard for a pair of adventurous New South Welshmen, Glen Nash and Rod Turner, to launch a successful assault on the North Face of Changtse (7560 m). The climb, done in a four-day, alpine-style push, was not for the faint-hearted. 
The moderately angled face was, in the parlance of mountaineers, 'loaded' and the two climbers were lucky not to have been taken by a slab avalanche, particularly on the descent.

Turner recalled:

It's bad, worse than the ascent, with fresh slab debris everywhere, but there's no choice. We plunge down, absolutely exhausted but very much on edge. Finally we stop with 200 metres to go. The slope is obviously loaded and we're the trigger. There's no real choice but we decide on going leftwards. I take five steps and the whole slope goes, slowly dissolving into slabs that disappear down in an ominously slow and quiet motion. The fracture line runs clearly a metre behind me. The only piece that didn't go is the piece I'm standing in. ${ }^{18}$

The experiences of Turner and Nash on the North Face of Changtse are another reminder that moderately angled snow slopes are often something to be feared. So, if there is relative safety in steepness then Pumori (7145 m), another of Everest's satellite peaks, is a much better bet. Rising as a beautifully symmetrical spike of ice to the west of Everest, Pumori is a mountain much admired by trekkers and climbers heading for the base camp of its more famous neighbour. Trying to climb Pumori seems to have become a biennial event for Australian mountaineers.

In 1986, two years after Geof Bartram and his clients had climbed the mountain, Australian Steve MacDonald was attempting Pumori with a group of New Zealand climbers. A string of illnesses, however, including dysentery, cerebral oedema and an abscessed wisdom tooth, forced a retreat from about $6500 \mathrm{~m}$ on the South Ridge.

Two years later, again in the post-monsoon season, an Australian expedition had another go at the South Ridge, which rose in spectacular fashion directly above the popular trekking hillock Kala Pattar — and this time they made quick work of the peak. Only four weeks after their arrival at Tribhuvan Airport in Kathmandu, they had organised their gear, marched to the bottom of the mountain, established base camp and climbed to the summit.

The organiser and leader of this most efficient group was Jeff Williams and his climbing team included American guide Scott Woolums and Australians Ray Vran and Richard Howes, who had climbed together on Kwangde several years earlier. Armando Corvini, Ken Lock and Matt Godbold, also Australians, were the other members.

18 Turner, R. 1988, 'Australian Himalayan climbs. Changtse', Wild, no. 28 (Autumn), pp. 33-6. 
For forty-eight-year-old Corvini, who along with Woolums, Vran and Howes reached the summit, the climb fulfilled his dream of reaching the top of a 7000 $\mathrm{m}$ peak before his fiftieth birthday. The achievement was not without its costs, however. Corvini and Howes were forced to bivouac on the way up and, as a result of the cold night out on the mountain, Corvini suffered frostbite and eventually lost parts of several toes on his return to Australia.

The base of Australian Himalayan climbing had indeed broadened to include a large number of climbers. Virtually all of them, however, were men. Where were Australia's female mountaineers? 


\section{Where are the women?}

The statistics on female Australian climbers in the Himalaya up to 1990 were not impressive. None had climbed an 8000 m mountain or indeed a 7000 m peak. In fact, there had been fewer than 20 attempts in total on major Himalayan peaks by Australian women. Curiously enough, the distribution of this very small sample was strongly bimodal, with seven attempts on $6000 \mathrm{~m}$ peaks and eight on 8000 $\mathrm{m}$ peaks, but only two on $7000 \mathrm{~m}$ mountains. Of these attempts, only a handful was successful. By 1990, apart from a very few who climbed trekking peaks, only two Australian women had stood on the summits of Himalayan mountains $6000 \mathrm{~m}$ or higher. And no Australian woman had climbed past $8000 \mathrm{~m}$.

This Himalayan record is even more surprising given the strong role that Australian women played in the development of Australian alpine climbing earlier in the past century. Indeed, in the early history of Australian mountaineering in New Zealand's Southern Alps, it was the women who took a decided lead over their male counterparts.

As noted in Chapter 4, Dot Butler was the main driving force in establishing training courses for Australians in the Southern Alps in the 1960s. She was one of Australia's leading alpinists in her own right and was a qualified guide at Mt Cook. Even before Butler, however, there were two other Australian women who excelled in alpine climbing; in fact, they were arguably Australia's best alpine climbers of their era and certainly more well known than any Australian male climbers.

The first in this impressive lineage of female Australian mountaineers was the incomparable Freda du Faur. Her climbing career, although it ended before the advent of Himalayan expeditioning, included one of the most spectacular first ascents in New Zealand's Southern Alps - a climb that merits a closer look.

Just after the turn of the twentieth century, du Faur travelled to New Zealand for several consecutive climbing seasons and quickly amassed an astounding record. In an era in which women were supposed to be at home doing the washing and minding the children, the young Australian woman must have put some mighty dents in many male egos.

The first of her major achievements was the first ascent of Mt Cook by a woman, which was accomplished in the summer of 1910 with guides Peter and Alec Graham. That in itself would have earned her a place in history, but three years 
later she again teamed with Peter Graham, and with another guide, Darby Thomson, to grab the most prized mountaineering plum of the day in New Zealand: the Grand Traverse of Mt Cook.

New Zealand's highest mountain is a complicated massif with three major summits - the Low (3593 m), Middle (3722 m) and High (3764 m) Peaks connected by a ridge about $2 \mathrm{~km}$ long. The traverse of this ridge-physically demanding and technically challenging - is a major mountaineering undertaking. The ridge between the Middle and High Peaks - a sinewy knife blade, often treacherously icy, with cornices on one side and a steep drop to the Hooker Glacier on the other-is a particularly daunting part of the climb. The Grand Traverse or ' $\mathrm{GT}^{\prime}$ ', as it is commonly known among climbers, is still, in the twenty-first century, one of the most thrilling routes anywhere in the Southern Alps.

In du Faur's time, an attempt on the GT was at least an order of magnitude more difficult than it is today. First, the era before World War I was well before the time of crampons and modern protective devices for ice and snow. Every steep section had to be climbed by arduous step-cutting and careful, balanced climbing protected by dubious belays, which probably had only 'psychological' value. Second, there was the fear of the unknown. The summit ridge of Mt Cook had never been climbed in its entirety. As many climbers have noted, difficulties are magnified by the knowledge that no human has ever tread on the terrain one is attempting and the consequent fears of unknown dangers and difficulties possibly beyond one's capabilities.

Although du Faur was climbing with two professional guides, her contribution to the ascent should not be underestimated. She did none of the step-cutting (in fact, Graham did nearly all of it himself), but in every other respect she had to have the same skills as the others: the technical ability to climb anything that Mt Cook threw in their way, the physical stamina to move quickly throughout the very long climb and, most importantly, the mental toughness to conquer the fear of the unknown.

In January 1913, the three climbers captured Mt Cook's most sought-after prize in a brilliant display of competence and strength. Du Faur's own account of the final climb along the summit ridge captures the drama and excitement of the first GT:

Ever since we had decided to attempt the traverse, the steep knife-edged ridge between the middle and high peak had been to me a haunting horror. From wherever you look upon it it appears impossible. Now,

1 The height of Mt Cook's High Peak has recently been reduced by several metres due to a massive rock fall on the East Face. Mt Cook is still the highest mountain in New Zealand. 
the moment I had dreaded had arrived, and the reality was all that imagination had pictured it. Steep, narrow, and horribly corniced, the ridge dropped sharply for a hundred feet. More than once as we descended it an icy shiver ran down my spine, as the ice-axe sank deeply into the overhanging cornice, and on withdrawal disclosed through the tiny hole the awful gap between us and the glacier thousands of feet beneath. Later, when we compared notes, we all confessed to wondering what would happen if a cornice broke away. Would the shock startle us into eternity? The mere noise and vibration of the falling mass would be enough to shake the strongest nerves, and we only stood about two feet from the junction of solid ice and cornice. At last we accomplished the many windings of the arete, and started up the highest peak. The relief of ascending with a wall in front to look at was tremendous, after the nerve-wracking, downward ridge of the last hour. Fate was again kind, and we only had an hour's step-cutting on the final slope.

At half past one we stood on the highest summit of Mount Cook, conquerors indeed. We were filled with mingled pride and thankfulness, as our eyes roved backwards over the great ridge we had spent the last six and a half hours in vanquishing. Very heartily we wrung one another's hands, and marvelled at our phenomenal luck in obtaining weather conditions which had enabled us to accomplish the greatest climb in New Zealand at the first attempt. Very happily we lay at ease on the summit, and putting all thoughts of the descent out of our minds, concerned ourselves only with the joy and triumph of the present. ${ }^{2}$

Images of Freda du Faur in the Southern Alps, clad in a long skirt and a trim white blouse, holding an ice axe and staring at the surrounding peaks with a fixed gaze of steely determination will long stand as a testament to the skill and toughness of one of Australia's two early world-class alpine climbers. (The other was George Ingle Finch; Chapter 2.)

The next in the line of Australian women who excelled in alpine climbing, after du Faur, was Marie Byles. Born in England in 1900, Byles moved to Australia in 1911 with her family. It did not take long for her to make an impact on Australian society. By the age of twenty-four, she had become Australia's first woman lawyer, as well as a writer, feminist and world-class adventurer.

Her first major climbing trip was a most ambitious undertaking for that time. In 1927, she set off around the world by cargo boat, stopping by any ports that had mountains nearby. Her long list of ascents on that trip included peaks in England, Scotland, Norway, North America and New Zealand.

2 F. du Faur in Keenlyside, F. 1975, Peaks and Pioneers, Elk, London, ch. 6. 
Byles spent even more climbing seasons in New Zealand than du Faur and recorded some notable ascents. She climbed Mt Cook in 1935 and later made first ascents of several peaks rising above the remote Mahitahi Valley in Westland. Perhaps her most important mountaineering achievement, however, was to organise and lead an expedition to Mt Sansato, a $6000 \mathrm{~m}$ peak in the high mountains of western China. Although it could not be classed as a Himalayan expedition (Mt Sansato is north of the greater Himalayan ranges), the trip to the 'White Dragon' was certainly the first Australian climbing trip to a big Asian mountain. Although Byles and her colleagues were thwarted by bad weather in their attempt on Mt Sansato, they did make first ascents of several lesser peaks in the region.

Marie Byles' mountaineering career was cut short in 1941 by a bushwalking accident, but not before she had passed the mantle of Australian women's climbing on to Dot Butler.

Butler met Byles through the Sydney Bush Walkers. Although Butler was quite a bit younger than Byles, the two became quick friends. '[D]ifference in age means nothing to bushwalkers,' Butler noted. 'Marie lent me mountaineering books which fired my imagination - the reconnaissance of Everest by Shipton and Tilman, polar exploration, both Arctic and Antarctic, adventuring in Greenland and Iceland. It excited me enormously.' ${ }^{3}$

Closer to home, Byles was instrumental in involving the young Butler in Australia's most challenging climbing venture of the time. In the 1930s, word came back to Sydney from the western slopes of New South Wales of a small range of spectacular rock spires, pinnacles and walls - some of them $1500 \mathrm{ft}$ (450 $\mathrm{m})$ high. The peaks in this range, the Warrumbungle Mountains, soon attracted the best of Australia's climbers of the time.

Under the leadership of Dr Eric Dark of the Blue Mountains Climbing Club, an expedition was mounted to the Warrumbungles in 1936. The young Dot Butler, known for her 'tiger walking' and her ability to scramble on rock, was invited along. At that time, she had not yet done any roped climbing, but her natural talent became apparent so quickly that it was she with whom Dark paired for the major objective of the trip. Butler, climbing barefoot as usual, and Dark succeeded in knocking off Crater Bluff, the most highly prized peak in the range. It was an impressive accomplishment. On making a subsequent ascent of the route using fixed ropes left in place, the veteran Byles noted that it was a difficult climb by either New Zealand or Canadian standards, even with the ropes in place.

3 Butler, D. 1991, The Barefoot Bushwalker, Australian Broadcasting Corporation, Sydney, ch. 4. 
In their joy at attaining the summit of Crater Bluff, Dark and Butler lit a fire on top as a signal to the rest of their group and to the people of Tooraweenah, a nearby township. The fire, however, quickly got out of control, so Butler and Dark not only made the first ascent of Crater Bluff, but razed its summit as well!

It was in alpine climbing, on the other hand, that Butler had her most significant influence on Australian mountaineering. Chapter 4 described the pivotal role she played in establishing training courses in New Zealand for novice Australian alpinists. She was a member of the 1969 Australian expedition to the Andes, which was the first major Australian overseas expedition of the 'modern' era (Chapter 15).

Although she was not the leader of the team, Butler's contribution to the Andes expedition was significant. She was the organisational driving force from the beginning, helped to select the team and was one of the three-person advance party that smoothed the way for the main group in Peru. In the mountains, she was the most experienced of the team, providing a wealth of good advice, sound judgment and encouragement. In addition, she led many of the climbs herself.

The trip was an unqualified success. The party climbed 27 mountains in Peru's Cordillera Vilcabamba - mostly above $18000 \mathrm{ft}(5500 \mathrm{~m})$ - and several members reached the summit of Lasunayoc $(20000 \mathrm{ft}, 6000 \mathrm{~m})$, the highest objective of the trip.

With this extraordinarily strong background in alpine climbing, and with some high-altitude mountaineering experience under her belt, Butler would have been an obvious person to play a direct role in Australia's entry into Himalayan mountaineering in the 1970s. She made only one trip herself to the Himalaya, however - a primarily trekking holiday in Nepal in early 1970. Her party attempted a couple of small peaks in the Kali Gandaki Valley, climbing to 12 $000 \mathrm{ft}(3700 \mathrm{~m})$ on White Peak (17 $000 \mathrm{ft}$ [5200 m], an outlier of Dhaulagiri) and reaching the summit of a small peak (13 $500 \mathrm{ft}, 4100 \mathrm{~m})$ further up the valley.

It was a pity that Butler made no serious mountaineering trips to the Himalaya. With her legendary strength and stamina, her remarkable career as an adventurer and her skill as a rock, snow and ice climber, there is little doubt she would have been a Himalayan powerhouse. She would have been the ideal climber to lead the first groups of Australians to the great ranges of Asia in the 1960s and 1970s, but that was not to be.

The period from 1975 to 1980 was pivotal for the development of Australian Himalayan mountaineering. For Australian women, there were some promising starts during that period, but tragedy and changed directions knocked out the potential female mountaineers of the time and effectively cut the long and 
impressive line of Australian women alpinists begun by Freda du Faur early in the century. The 1980s, a golden era in general for Australian climbing in the Himalaya, was a very quiet time for Australian women.

The first of the promising starters in the 1970s was Josephine Flood, a member of the initial Australian expedition to the Himalaya: the 1975 expedition to Mulkila in the Kulu region of India. She and the leader, Warwick Deacock, were easily the most experienced climbers on the team. Indeed, based on her past achievements, she clearly was a world-class mountaineer.

Like Deacock and several of the other early Australian climbers in the Himalaya, Flood was originally from England, with a very strong background in climbing there before she moved to Australia. Then Josephine Scarr (she married after coming to Australia in 1963), she excelled in the competitive and high-standard British rock-climbing scene. She was the first woman to lead Cenotaph Cornerone of the test pieces of British rock climbing at the time (well-known mountain photographer John Cleare followed her up the climb on the end of the rope)and she became a climbing instructor at the prestigious Plas-y-Brenin National Recreational Centre in Wales.

In 1961, she and Barbara Spark set out on 'The Women's Kulu Expedition, $1961^{\prime}$, an ambitious project for a pair of young female climbers, as it involved an overland trip through the Middle East in addition to attempts on several unclimbed $6000 \mathrm{~m}$ mountains in the Indian Himalaya. Their journey by Land Rover from England to India was an amazing adventure in its own right, with an ascent of Mt Olympus in Greece, a frightening off-road drive lost in the shifting sands of southern Iran and long delays in Pakistan due to flooded roads.

Once in the mountains of northern India, Scarr and Spark proved more than equal to the challenge. They organised local porters and equipment, marched into an unknown part of the range, carried out some useful survey work and, most importantly, had a feast of excellent climbing on an array of virgin peaks. It was a tour de force for the two young mountaineers.

Their climbs included first ascents of two major peaks rising above the Bara Shigri Basin: the Lion (20 $100 \mathrm{ft}, 6147 \mathrm{~m}$ ) and Central Peak (20 $620 \mathrm{ft}, 6306 \mathrm{~m}$ ). Scarr's feelings on the summit of Central Peak after climbing a narrow rock buttress that led directly up the South Face gave a hint of the delightful climbing the pair experienced in the remote mountains of the Kulu:

Like a good book, I did not want it to end, and was almost sorry when we came to the top. It was a cartoonist's summit, a sharp point capped by a small block... The air was crisp and clear as though it were early morning and the sky quite cloudless, so that we could see for fifty or sixty miles in every direction. Range after range of mountains stretched 
as far as the eye could see; the snow and ice peaks of Kulu to the west and south, barren Spiti to the east, and northwards, beyond the low rock peaks of Lahul, the red-brown mountain waste of Tibet.

I felt wonderfully happy, and so light that it seemed to be only my heavy boots that were preventing me drifting off like gossamer. I remember contemplating taking them off to see what happened. ${ }^{4}$

After those first ascents, the pair, along with one of their Sherpas, finished the expedition by pulling off a near-ascent of an unclimbed $20495 \mathrm{ft}$ (6268 m) mountain in the region. Climbing directly up a steep, technically challenging face in a bold style 20 years ahead of its time, they were forced back by darkness and deteriorating weather only $15 \mathrm{~m}$ below the true summit.

With climbs of two major and several lesser summits, the expedition would be a hard act to follow. As Scarr noted, 'it would be difficult to have a happier or better expedition than this had been'. ${ }^{5}$ Just a few months later, however, Scarr and Spark were back in the Himalaya on a trip that proved to be just as rewarding.

Before they had left England for their Kulu expedition, the pair agreed to join an English women's expedition to western Nepal the next pre-monsoon season. Led by Countess Dorothea Gravina, the six-person team would attempt the unclimbed highest peak in the remote Kanjiroba Himal. In 1962, that region had barely been touched by Western exploration. Only one botanical, one historical and two mountaineering expeditions had passed by, with none penetrating the heart of the range. It was truly uncharted territory.

After some initial difficult reconnaissance work, the party established itself in a valley below the Himal's major peak, Lha Shamma (21 $035 \mathrm{ft}, 6433 \mathrm{~m})$. It was a mountaineer's paradise. 'If we ourselves had designed the ideal climbing area it could not have been better,' Scarr recalled, 'a pleasant green valley with water and firewood, and a host of mountains of all sizes and degrees of difficulty. ${ }^{6}$

After climbing some smaller peaks around the valley, the team set to work establishing three camps along one of the many long, winding ridges that emanated from the summit of Lha Shamma. Racing failing weather on their second attempt at the summit from camp three, Scarr and Spark, followed by two of the Sherpa staff, led the way along the narrow ridge and finally gained the top amid strong winds and swirling clouds.

\footnotetext{
Scarr, J. 1966, Four Miles High, Victor Gollancz, London, ch. 9.

Ibid., ch. 11.

Ibid., ch. 18.
} 
It was their second remarkable success in the Himalaya in less than a year. In fact, Scarr and Spark were the first two women ever to stand on the summit of a $21000 \mathrm{ft}$ mountain.

The next year, Jo Scarr decided to travel even further afield to climb-her target: the Southern Alps of New Zealand. On the way, however, she stopped in Australia. It meant a profound change of direction in her life.

Although she did get to New Zealand and climbed Mt Cook during the Christmas season in 1963, mountains soon began to recede in importance in her life. She exchanged mountaineering expeditions for archaeological ones and her earlier interest in classical Greek archaeology for Aboriginal prehistory. She completed a Master of Arts degree in 1964 at The Australian National University in Canberra and, while raising three small children, worked on a doctorate in Aboriginal prehistory. She received her PhD in 1973.

Jo Flood is probably now most well known in Australia for her work in discovering, documenting and conserving sites of Aboriginal significance. Much of that work was carried out with the Australian Heritage Commission, where her major task was to compile the Aboriginal part of the Register of the National Estate.

Going on archaeological expeditions can give much the same satisfaction as going on mountaineering trips, according to Flood: 'There is the same sense of discovery and of being outdoors. There is certainly at least the same intellectual challenge, if not more. And archaeological expeditions are not without their dangers. On a trip to the Northern Territory in 1989, I found a taipan in one of the excavation pits! ${ }^{7}$

Flood did return to the Himalaya in 1975 as a member of the Mulkila expedition. Given her experience in the Himalaya, where she had made first ascents of previously unclimbed peaks, the Mulkila trip proved to be not particularly challenging or satisfying.

'We went to the foot of the glacier by bus; it was all so easy and civilised. Also, Mulkila itself had been climbed previously. I found it rather unsatisfactory; I wasn't particularly motivated to risk my neck climbing anything. ${ }^{\prime 8}$

Nevertheless, her interest in Himalayan mountaineering was rekindled in the mid-1970s. She had also applied to be a member of Chris Bonington's 1975 expedition to Mt Everest, but was not selected. It is interesting to speculate what Jo Flood might have contributed to Australian Himalayan mountaineering had she been selected for Bonington's team.

7 J. Flood, Interview.

8 Ibid. 
Like Dot Butler, Flood had an extraordinarily strong mountaineering background, including an impressive Himalayan component. It should be emphasised that Flood led, or co-led, every climb she did in the Himalaya. Unlike many other women, who tended to climb with husbands, boyfriends or other men, Flood never climbed with men in the Himalaya (apart from some Sherpa staff, with whom she had some interesting wrangles over leadership, as she recounted in her excellent book Four Miles High). She therefore had all the responsibilities and mental stress of being, as climbers put it, 'on the sharp end of the rope'. And to top it off, every peak she climbed in the Himalaya was a first ascent. Jo Flood was certainly in a position to lead the early Australian mountaineering effort in the Himalaya, but that was not to be.

Flood, it should be added, was one of two women on the Mulkila expedition. The other was Dorothy Brown, who, by her own description, was primarily a bushwalker and not so interested in getting to the tops of mountains. She was happy just to walk through the valleys and look at the big peaks. Interestingly, Brown, a retired Canberra schoolteacher, remembers Ken Baldwin, of Dunagiri and Baruntse fame, as a conscientious first-grade pupil at Campbell Primary School.

Two other women made brief appearances in the early days of Australian Himalayan climbing, but both met with tragic ends in 1980.

The first was Faye Kerr, a member of the Annapurna III expedition. Although one of the older members of the team, Kerr had recorded an impressive number of major climbs in New Zealand earlier in her career. The editor of the 1954 edition of the New Zealand Alpine Journal remarked about 'two young Australians, who have not been in New Zealand long but who, in the last nine months alone have ascended over forty peaks from Egmont to Earnslaw, including many good climbs in the Mt Cook region'.$^{9}$ The pair was 'Kerr and Cutcliffe' and their climbs included Elie de Beaumont, Minarets, Malte Brun, Hardinger, Lendenfield, Tasman, Cook (GT), Hicks, La Perouse, Sefton and the second ascent of the Coxcomb Ridge of Mt Aspiring. Ironically, Faye Kerr survived the treacherous avalanches low on Annapurna III but died of a stomach ulcer in India after the expedition.

The second unfortunate Australian female climber was Lyn Griffith, who was a member of an American women's expedition that attempted Dhaulagiri (8167 $\mathrm{m}$ ) in the post-monsoon season of 1980. Griffith, who had a strong bushwalking and general outdoors background, was leader of the support party that carried loads to camps lower on the mountain. The lower reaches of Himalayan peaks can, however, be just as dangerous as the higher slopes.

9 'Faye Kerr-obituary', New Zealand Alpine Journal, vol. 33 (1980), p. 126. 
While Griffith and four other climbers were resident in camp two at $5900 \mathrm{~m}$, a small slab avalanche came through the camp and pushed a tent, with the five women inside, down the slope and into a crevasse. The tent landed on a snow bridge about $10 \mathrm{~m}$ below the surface. The other four climbers survived, either in the tent or on the snow bridge, but Griffith was apparently swept out of the tent and down into the depths of the crevasse. Despite a two-and-a-half day search, her body was never recovered.

With tragedies and changes of direction decimating the already thin ranks of Australia's female mountaineers, there was virtually no-one to carry on through the 1980s. Only two women figure at all in that decade of Australian Himalayan history - one of those an Australian-born woman who lives in and climbs out of the United States and the other a European woman who immigrated to Australia in 1983, married one of Australia's top Himalayan climbers and has established an impressive mountaineering record of her own.

Cherie Bremer-Kamp has had a most unusual Himalayan mountaineering career. Her story, told poignantly in her book Living on the Edge, is one of romance and tragedy set against the backdrop of the very highest of Himalayan mountains in the very harshest of conditions.

Born in Queensland, Bremer-Kamp's early introduction to climbing was on the sandstone rock faces of the Blue Mountains in New South Wales and the snow peaks of New Zealand. She emigrated to the United States, where she established a career as a nurse and midwife and married an American climber, Terry Bech. She continued her own climbing career as well, joining her husband on an expedition to Dhaulagiri in 1971.

Seven years later, she was back in the Himalaya, opting to join a large American expedition to K2 instead of joining the all-women's American Annapurna expedition, to which she had been invited. Although she was never considered as a potential summiter in the $\mathrm{K} 2$ team, she nevertheless put in an impressive performance, carrying loads to as high as $7700 \mathrm{~m}$ on the mountain. She also received a good dose of the tension and intense personal conflict that seemed to typify the large American Himalayan expeditions of the 1970s.

More significantly, it was on the K2 expedition that she met and fell in love with Chris Chandler, one of the other climbers. Chandler was a skilled climber and skier, having made the first ski descent of Denali (Mt McKinley) in Alaska and having climbed Mt Everest in 1976. On K2, he and Bremer-Kamp formed a liaison that would lead them back to the very highest peaks of the world but away from the large, conflict-ridden expeditions that both had experienced in the 1970s. 
In 1981, the pair ventured again to the Himalaya, to the other end of the range this time, to tackle Kangchenjunga. More specifically, they were going to attempt the complex mountain's western summit, Yalung Kang (8505 m), from the northern side. It would be the first attempt on Yalung Kang from the north and only the fourth from the north on any of Kangchenjunga's summits, and it would be made by a two-person team-certainly not short odds for success.

Bremer-Kamp and Chandler, however, made a valiant effort. They established and stocked three camps on the North Face of Kangchenjunga and then pushed on to nearly $8000 \mathrm{~m}$, climbing on the last day of their attempt from a bivouac at $7800 \mathrm{~m}$. In the end, they were turned back by a lack of supplies combined with difficult climbing high on the mountain. The unsuccessful 1981 attempt was, it turned out, only the prelude to an even more daring attempt a few years later.

In December 1984, the two climbers returned - again to climb as a two-person team only. This time, they would attempt the main summit of Kangchenjunga from the north in winter - the most dangerous and difficult of the three Nepalese climbing seasons. It was an extraordinarily ambitious undertaking, given that they again would be climbing from the remote northern side of the mountain and that they would have no back-up should things go wrong. The odds for success had certainly lengthened.

The expedition quickly took on all the characteristics of a typical Himalayan winter attempt: vicious storms, the lowering of the jet stream onto the mountains, unrelenting cold and long bouts of being tent-bound between bursts of climbing. There was, however, one important difference. Even though their high-altitude porter, Mongol Singh Tamang, helped with the climbing and load carrying, there were still only three of them to do all the work. There were no alternating teams of climbers to jump in and take over from tired comrades.

In an almost superhuman display of determination, the three battled on through almost 40 days of storm, wind and bone-chilling cold to establish four camps on the mountain - the first three of them in the same locations as the equivalent camps on their Yalung Kang attempt a few years earlier. Then with a long-awaited break in the weather in mid-January, they set out for the summit from a snow cave bivouac above camp four. Ironically, they reached almost exactly the same height as they had in their 1981 attempt on Yalung Kang before things suddenly went terribly wrong, leaving Bremer-Kamp in a desperate psychological and physical struggle for survival.

First, Mongol seemed to lose his grip, falling repeatedly during the last day of climbing and being unable to carry out simple camp chores, such as boiling 
a billy of water on the stove. The next morning, after a miserably cold night, Bremer-Kamp had far more to worry about. Chandler had contracted cerebral oedema and was rapidly becoming incapacitated.

Their situation could not have been more serious: high on a massive mountain in winter with no fixed ropes near to aid a quick descent and no other climbers in camps below to help. It was all up to Bremer-Kamp to try to descend with one dying man and another barely functioning. In addition, her fingers and toes were inexorably succumbing to frostbite.

Summoning an unbelievable amount of inner psychological stamina as well as physical strength, Bremer-Kamp took charge of the situation. She got Chandler's crampons and harness on him, organised him and Mongol on the climbing rope and then began painstakingly belaying them down the mountain. Somehow she managed to avoid a fatal tumble in spite of having to hold repeated falls by the much heavier Chandler.

For Chandler, her efforts were to no avail. Cerebral oedema claimed him by the end of the day. He died in a bivvy sac not far below the previous night's bivouac site. There was simply nothing Bremer-Kamp could do. She and Mongol, too stunned to move, bivvied for the night. In the morning, Bremer-Kamp propped up Chandler's body in a sitting position overlooking the vast Tibetan Plateau and then began the painful descent.

Somehow keeping her profound grief in check enough to function, Bremer-Kamp slowly worked her way down the mountain. It was a frightful experience. The allpervading cold was threatening to sap the last bit of life from her, her fingers and toes were by then severely frostbitten and virtually useless and she often had to cajole a sometimes hysterical Mongol into action. Miraculously, she and Mongol persevered, sometimes down-climbing, sometimes abseiling and sometimes literally falling down the mountain. Barely alive after several days of the tortuous descent, they finally stumbled into base camp and into the care of their staff there.

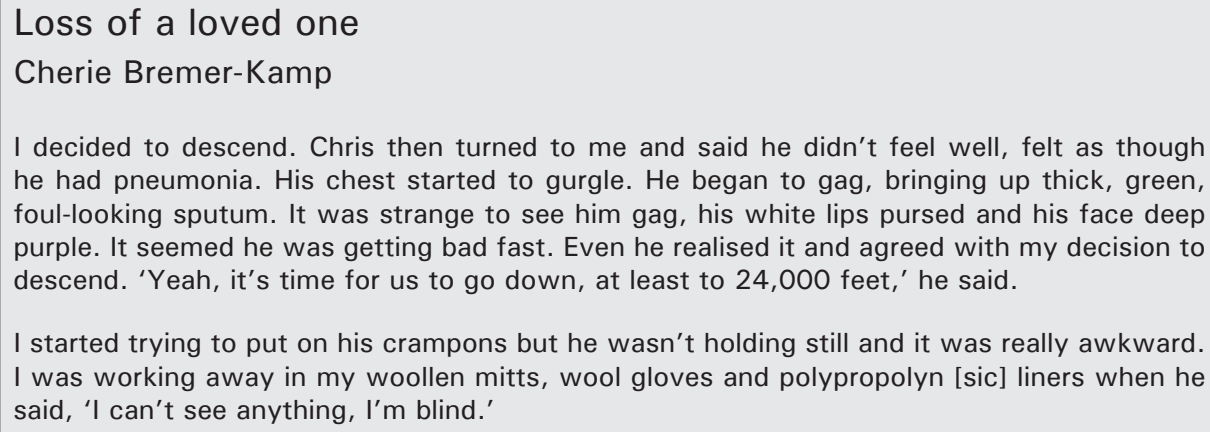
he had pneumonia. His chest started to gurgle. He began to gag, bringing up thick, green, foul-looking sputum. It was strange to see him gag, his white lips pursed and his face deep purple. It seemed he was getting bad fast. Even he realised it and agreed with my decision to descend. 'Yeah, it's time for us to go down, at least to 24,000 feet,' he said.

I started trying to put on his crampons but he wasn't holding still and it was really awkward. I was working away in my woollen mitts, wool gloves and polypropolyn [sic] liners when he said, 'I can't see anything, I'm blind.' 
My heart froze and at the same time my fingers turned stiff and claw-like. My body must have got a sudden rush of adrenalin and clamped down the blood vessels to the extremities, the result of surging fear. It was only now I realised that Chris had probably developed cerebral oedema, and I had been blaming the fumes from the stove [for] his deteriorating condition.

Time became even more critical and I tore off the gloves to look at my hands. The fingers had become white and marble-like. I knocked them together. It sounded as though I was banging two pieces of wood against one another. 'Look at my hands,' I showed them to Chris. He giggled, 'They are pretty bad, aren't they?' I left the gloves off, for in order to do any manipulation at all, the claws needed to be exposed. Periodically I would pull the sleeves of my jacket over them to try and warm them up a bit, and then continue working. Both hands had lost all feeling at this stage and I began imagining them being cut off at the wrist. 'Can't worry about that now. Got to concentrate on saving the whole body. That's what's important now. Got to save the body.'

Finally Chris's crampons were on. I had to get his harness on next, but he couldn't stand up without toppling over. I was beginning to lose my vision, too. It was like peering through a foggy car window on a rainy night. I became even more anxious, fearing that soon I would also succumb. I screamed out to Mongol to help. 'What the hell have you been doing all this time anyway?' He acted surprised that we were going down.

Supported between the two of us, we finally got the harness in place and Chris was tied into the rope. As he couldn't walk without falling over, I put Mongol and Chris together on the rope, moving down on a fixed belay. Chris leant on Mongol so heavily at times that they would both fall down, but were held tight by the rope. Slowly we made progress downwards. We were now traversing under the top of the rock band.

Chris started to topple over and Mongol couldn't support him. I fell onto the ice axe but was yanked off and followed them falling down the slope. We must have dropped about 90-120 $\mathrm{m}(300-400 \mathrm{ft}$ ) before the rope snagged on a frozen snowdrift. I was surprised we'd fallen so far, and that we'd stopped about $9 \mathrm{~m}$ (30 ft) before a cliff. If the rope hadn't snagged we would have travelled over the edge. Well, that's one way of getting down the mountain, I thought to myself.

Packs and various pieces of equipment were scattered over the slope. Mongol unroped and collected it all. Chris was shaken up, but it woke him up a bit more and he started moving better by himself. I looked at the large hole in my glove liner caused by the passage of the rope. I hadn't been able to grasp hold of the rope and it had just passed through my hand.

The fall caused us to lose a little too much altitude and so we had to climb back up about 30 $\mathrm{m}(100 \mathrm{ft})$ before descending by the correct route. Now I placed Chris in the middle of the rope, trying to take advantage of both Mongol's and my belay should he fall again. He moved tenuously between us, stumbling and falling but being held in check by the tight rope.

We had just finished coming through the couloir of the top rock band and were standing resting. It was getting dark already, I couldn't believe it had taken so long to cover such a short distance. Where had the time gone? Still, at least we had made it so far, safe and sound. I turned around and saw Chris untie himself. 'What are you doing? Please don't!' 'I was just trying to help,' he replied. I tied him back in again while he stood meekly, looking like a scolded child.

I turned to discuss with Mongol what our plans should be. Chris had untied himself again. He was playing a game with us! I recognised a cheeky grin on his face. Oh! God please help us. Mongol saw my hands as I was tying Chris back into the rope. 'You stupid, stupid girl. Put gloves on!' I had tried to but at this stage they were so swollen and stiff, even the mitts wouldn't fit. I continued to pull my sleeves down to cover the hands, which helped a little. 
Mongol led off as I moved along with Chris. I couldn't take my eyes off him for a minute. We staggered along like a couple of drunks coming home from a New Year's Eve party, and shared a joke about what bad shape we were in. I had wanted to make it down another 90 $\mathrm{m}(300 \mathrm{ft}$ ) to a bergschrund which I remembered on the way up. It looked as though it would provide a good bivvy site, but in the dark and feeling completely exhausted, with Chris likely to fall at any moment, it seemed wiser to stop where we were, just below the rocks, on a gentle snow slope. Mongol dug out a platform and we got ready to put Chris in his bivvy sac.

I asked Mongol to give Chris his sleeping bag, as he was a dying man and badly needed it. I thought it might just make the difference and tip the scales in favour of life. Mongol refused to part with it. A feeling of rage overwhelmed me. But how could I demand that Mongol give it up? It was, after all, our choice to leave the bags behind. The rage dissipated into a feeling of despair. I lay beside Chris to try to warm him up. He showed me that one of his hands was swollen and blue-looking. He must have lost a glove when we fell. 'Put it under your arm sweetheart, try and warm it up.' Mongol was digging another platform and I asked him to melt snow instead, as Chris desperately needed a hot drink. After being initially restless, Chris had settled down. He was still saying a few words to me.

I needed to empty my bladder and stood up to do so but I couldn't get the harness undone, or undo the zipper. I was becoming distraught. Chris looked up at me and said, 'Just pee down your leg. It doesn't matter.' I did. His voice was kind and reassured me that really everything was going to be OK after all. I let the muscles go, and felt the warmth flow down my leg and fill my boots. I was horrified to see surface the raw and basic instinct for survival. Where lay the separation between us and animals, after all? I shuddered, retracting from the thought.

We had tied Chris off to an ice axe to prevent him sliding down the slope, but I wanted to use another ice axe as a back-up to the first. Chris was lying on part of the rope and my bivvy sac. I needed to get at both. I gently started easing the bag from under him. Trying to help me he suddenly lurched over to one side. In the process he slid off the ledge. I pulled him back into place but he was now restless again, tossing himself around on the narrow platform. I couldn't control him, I needed help. I called to Mongol.

Chris slid off the platform again. Mongol began complaining that I'd already told him to melt snow, now I was telling him to help Chris, and why didn't I make my mind up etc. etc. I was putting all my weight on the ice axe for fear it would be pulled out as Chris was now standing up in the bivvy sac, fearing he was in danger. He panicked and tried to run, but of course got caught up in the bag. His last words were, 'Will somebody help me?' and then he fell down on the snow. He must have exerted an enormous amount of energy in those final moments.

Mongol had been standing motionless, watching the whole scene. He now came over and helped me lower Chris to the partially built platform where he had been standing before. My rage at Mongol overwhelmed me again. Then I saw Chris's limp hand fall out of the bivvy sac. It was mottled and deep blue. We turned him over to look at his face.

His finely sculptured features, gaunt from weeks of gruelling work, had relaxed into an expression of bliss. All the tension and cares of mortal beings had dissolved, there was only peace and beauty shining forth. His skin was warm and glowed with colour. I bent down to kiss his lips. They were strangely lifeless. I couldn't feel his breath upon my cheeks, only perfect stillness.

As death and love met, my whole being filled with terror, I felt him letting go of the past and all that we had shared, yet the future had not arrived. I couldn't let him go so easily, 'I need you Chris, don't leave me!' I screamed in silence.

From Living on the Edge, Macmillan Australia, South Melbourne (1987), pp. 177-80. 
Bremer-Kamp later lost many of her fingers and toes to the frostbite she suffered on Kangchenjunga. The trauma of that and of the tragedy on Kangchenjunga itself did not prevent her from returning to the area again. She trekked back to the village of Ghunsa, the last village before Kangchenjunga base camp, to thank the villagers for the help and support they gave her during those difficult times in 1985. She assisted them in a more concrete way as well by spearheading an effort to raise funds for a school and health clinic for the village.

Cherie Bremer-Kamp's Himalayan climbing career ended with the tragic trip to Kangchenjunga in 1984-85. Despite the fact that she stood on no major summits, she climbed to nearly $8000 \mathrm{~m}$ several times and acquitted herself well under the most extreme conditions climbers could endure. Her account, in Living on the Edge, of Chandler's death, her response and her courageous fight for survival on the descent is one of the most moving adventure and love stories ever told.

Far from the snows of Kangchenjunga, in the dry warm air of western Victoria, romance would again play a role in the history of Australian Himalayan mountaineering. In 1980, a young Belgian woman stopped by Mt Arapiles on a rock-climbing/tourist trip around Australia. She was at that time already an accomplished climber and soon met many of the hot, young local climbers of the Arapiles scene: Mark Moorhead, Roddy Mackenzie, Jon Muir, Chris Shepherd and others.

Although it would be three more years before she married Jon Muir and returned to Australia permanently, Brigitte Muir's first trip was followed by several others to Australia in the early 1980s and by a journey to Nepal in 1982 to join the International Turkey Patrol's expedition to Changabang.

Brigitte Muir was certainly not a neophyte in the climbing game when she first travelled to Australia in 1980. Although her native land, Belgium, is just as flat as Australia, it is located much nearer to some challenging mountainous regions.

Ironically, it was under those mountains rather than on top of them that Muir first got experience in moving in the vertical dimension - she went on caving expeditions in the mid-1970s in Belgium, France, Italy and Spain. Some of her caving friends were rock climbers as well, so she soon traded claustrophobia for vertigo (see image 28.1). By the late 1970s, she had made two major alpine climbing trips: one to the Italian Alps and one to the Logan Mountains of Canada, where she made an ascent of Lotus Flower Mountain. Her best climbing, however, was still to come, after she joined forces with the brash young Aussie climbers of the International Turkey Patrol.

Her first Himalayan experience came on the Changabang expedition. Although the four ITP climbers justifiably received all the kudos for their brilliant ascent 
of the South-West Pillar, Brigitte and Elke Rudoph, Craig Nottle's girlfriend, were not content to sit quietly at base camp. During the course of the expedition, they made ascents of Hanuman and Divan, two $6000 \mathrm{~m}$ peaks in the region.

In 1984, Brigitte Muir again accompanied Jon on a Himalayan expedition, to the West Ridge of Mt Everest. This time she climbed with her sister, Veronique, who had moved to Australia and married Graeme Hill, Jon Muir's friend and climbing partner of long standing. The pair summited on the popular trekking peak Imja Tse (Island Peak).

In between those two trips, Brigitte and Jon were married and went to the European Alps for their honeymoon. While most newlyweds would be happy to spend their days together in Zermatt just looking up at the Matterhorn, the Muirs, of course, climbed the mountain.

Brigitte Muir's big breakthrough in Himalayan climbing came in 1986 on the spectacular mountain Shivling. After an abortive attempt on the peak a year earlier, she, Jon and Graeme Hill made the first ascent of the daunting SouthWest Pillar in impressive style (Chapter 20). It still stands out as one of the most difficult Himalayan climbs ever undertaken by an Australian team-and arguably the most difficult climb successfully completed.

Some of the pitches on the predominantly rock route of Shivling were grade 21, A4. Climbs of that difficulty are challenging enough on sun-drenched Australian rock at modest altitudes, but are significantly harder in the cold, rarefied air of a Himalayan mountain. Furthermore, Brigitte Muir was one of only three climbers and partook fully in the difficulties, dangers and discomforts of such a testing ascent. She took her turns at leading on the steep rock, did her share of arduous load carrying up the fixed ropes that the team employed in their 'capsule'style ascent and had to endure 14 days of cramped camps, even more cramped bivouacs and meagre rations to reach Shivling's West Summit (see image 28.2).

A year later, she returned to the Gangotri region, using a climb partway up Kedarnath Dome as a warm-up before she, Geoff Little and New Zealander Lydia Bradey joined a large New Zealand expedition in the Karakoram. Their objective was one of the $8000 \mathrm{~m}$ peaks, Hidden Peak $(8068 \mathrm{~m})$, but bad weather and heavy snowfalls forced a retreat from $6800 \mathrm{~m}$.

In 1988, she turned her back on the Himalaya, for the time being, but not on mountains. In that year, she embarked on one of the most exciting adventuretravel undertakings in high-altitude mountaineering: the Seven Summits challenge. The Seven Summits refer to the highest mountains on each of the Earth's seven continents. Although some climbers might have contemplated such a project earlier, the Seven Summits idea did not really take off until the early 1980s when wealthy American businessmen Dick Bass and Frank Wells decided 
to become the first to scale the highest peak on each of the continents. Bass eventually succeeded, although on the more difficult mountains professional mountaineers whom he had hired guided him to the summit.

Brigitte Muir's quest to become the first woman to complete the Seven Summits began in 1988. On 28 May, she summited on Denali - at just more than $6000 \mathrm{~m}$, the highest peak in North America. The next year, two more fell: in February, she climbed Africa's Mt Kilimanjaro in a week-long trip, and on Christmas Day 1989, she completed a solo ascent of Aconcagua, South America's highest mountain and the highest peak outside of the Himalaya.

Australia's own Mt Kosciuszko was climbed in 1990, as was Europe's highest mountain, Mt Elbrus in the Caucasus Mountains of Russia. Five down, two to go. The five that Muir had already climbed were, however, the easiest of the seven highest peaks - both technically and logistically. Getting the last two is the trick.

One of the final pair is Mt Vinson, the highest peak in Antarctica. Mt Vinson is not particularly high (just less than $5000 \mathrm{~m}$ ) and it is not difficult technically, especially during the summer when darkness is not a problem. Climbers can set out for the summit any time of the day or night, whenever a spell of fine weather appears.

Logistically, however, Vinson is the most difficult of the seven summits. It is located in Antarctica's Ellsworth Mountains, a long way from any of the scientific research stations or permanent landing strips. Getting there generally requires a special charter flight from Chile or Argentina and an equally expensive flight to be picked up after the climb.

Mt Everest, of course, is the highest of the seven summits and the most difficult technically, even by the standard South Col route. The narrow ridge from the South Summit to the top is a testing piece of climbing, made even more serious by the extreme altitude. In addition, access to Everest has ironically become more difficult recently with the rapidly increasing number of 'mail-order mountaineering' trips on the mountain. The fees for joining one of these trips (sometimes up to US\$30 000 per climber in the late 1980s-considerably more expensive now) have raised the average cost of an Everest attempt in general through market forces by leading to increased peak fees and local staff costs. 
Himalayan Dreaming

\section{Staying safe}

Brigitte Muir and Cherie Bremer-Kamp notwithstanding, the first era of Australian mountaineering in the Himalayan has been an exceedingly quiet one for female climbers. The obvious question is why, particularly since women played such a prominent role in early Australian alpine climbing?

One possible reason is the rapidly rising popularity of 'sport' and 'competition' climbing, in which Australian women perform very well and participate in large numbers. Although that activity bears the general name 'climbing', and indeed is virtually identical physically to rock climbing, it is a fundamentally different activity from Himalayan mountaineering, from alpine climbing in general and from traditional rock climbing. The difference is mental. Modern sport climbing is essentially a safe activity; in traditional climbing, possible serious injury and even death - particularly in Himalayan mountaineering - are essential elements of the activity.

Of course, the desire to avoid the dangers of traditional climbing is attracting males and females to sport climbing. The attraction, however-or the desire to avoid the high risk of hard Himalayan climbing - could be particularly strong for women with children. As Jo Flood put it succinctly: 'Having children changes your attitude. You don't want to leave your children as orphans.'10

Cherie Bremer-Kamp's anguished thoughts just after Chris Chandler died high on Kangchenjunga echoed the same feeling:

I wanted to go with Chris, to seek out where he had gone. A subtle presence became more strongly felt. I recognised it as my two children standing there beside me, looking solemnly at the scene without pleading, grief or tears. I sensed their need for guidance and counsel, especially over the next few years. Although they never asked for help I turned towards them, and Chris went on alone. ${ }^{11}$

Although Bremer-Kamp's bond with her children did not prevent her from undertaking a very risky climb on Kangchenjunga, it undoubtedly gave her the inner strength it took to get herself and Mongol off the mountain alive.

There could be other reasons for the lack of Australian women in the Himalaya. Doug Scott has argued that women, because of their smaller average size and lower strength, cannot compete with men in the modern alpine style of

10 J. Flood, Interview.

11 Bremer-Kamp, Living on the Edge, ch. 9. 
Himalayan mountaineering. That style requires extended periods of difficult climbing while carrying heavy loads. (Ironically, alpine-style climbing is anything but 'lightweight' as far as the individual climbers are concerned!)

Dot Butler has a somewhat different view on the same issue. She agrees that carrying heavy loads could be a problem, but argues that it is not that women cannot carry such loads, but that they do not want to these days. Certainly, as Butler herself proved, a few decades ago in New Zealand, Australian women were the equal of their male counterparts in hauling enormous loads over the Southern Alps and making impressive ascents along the way.

The dearth of Australian female mountaineers could simply be due to practical reasons. Mike Rheinberger notes that, within the Melbourne climbing community, many of the potential women mountaineers are married to climbers and are starting families just at the optimum time for pursuing their own climbing careers.

Jo Flood suggested that lack of opportunity for girls, coupled with the lack of our own major mountain range, could be important factors:

In Britain there were girls' Outward Bound courses. Many became involved in climbing that way. They had female instructors, and a lot of girls took such courses. The system isn't as developed in Australia. Here many girls wouldn't get introduced to climbing. Abseiling is popular, but not climbing.

Also, there are many other sports here that are attractive to girls. In addition, Australia doesn't have its own spectacular peaks - at least not snow and ice mountains - to attract potential climbers. ${ }^{12}$

It is difficult to ascribe the relative lack of female Australian Himalayan mountaineers to any of these factors, or combinations of factors, as the Australian mountaineering community itself is so small. Statistics are virtually meaningless with such a small sample and the absence of Australian female climbers in the great ranges of Asia could simply be a statistical quirk. Indeed, if two or three Australian women had climbed several major Himalayan peaks in the 1980s, including an 8000-er or two and Mt Everest, the question would not even arise.

Perhaps it is best to let Brigitte Muir have the last word: 'Women can climb mountains just as easily as men. We all need the same qualities: stamina, patience, and a strong head. The important thing is the mind driving the body.'13

12 J. Flood, Interview.

13 B. Muir in Freeman-Greene, S. 1991, 'Muir. The Australian way', Australian Airlines In-flight Magazine, April, p. 11. 



\section{A Himalayan grand slam}

By 1990, Australian mountaineering in the Himalaya had come to something of a crossroads. It had been 15 years since Warwick Deacock led the first expedition from Australia to the Himalaya and much had been accomplished in that time. Many of the strands that had been initiated in the mid-1970s had already come to fruition. The Tim Macartney-Snape/Lincoln Hall partnership, launched with the ANU Mountaineering Club's (ANUMC) expedition to Dunagiri in 1978, spearheaded the first Australian ascent of Mt Everest in 1984. Peter Gration's dream of putting Australian soldiers on top of the world's highest summit revitalised the Army Alpine Association (AAA) and guided its development through the 1980s. It led to the merger with the Melbourne-based Himalayan climbing community, which also originated in the late 1970s, to form the Australian Bicentennial Everest Expedition (ABEE). This culminated in success through the remarkable efforts of Pat Cullinan, Paul Bayne and Jon Muir, and the large team of climbers who contributed to the ABEE ascent.

This Australian emphasis on Mt Everest was more than just an artefact of the organisation of this book (Chapter 24). Statistically, Australians had paid far more attention to Everest than to the other $8000 \mathrm{~m}$ peaks. So, with the major strands of Australian Himalayan mountaineering reaching their logical conclusion with success on Everest, the focal point of so much Australian mountaineering in the Himalaya was gone. Although individual climbers would certainly strive to achieve their personal goal of climbing the world's highest mountain, the glitter of Everest in the minds of the Australian public, and to a certain extent in the mountaineering community itself, began to fade in the late 1980s after two major successes.

What, then, would happen to the overall Australian effort in the Himalaya? Would it too begin to fade as interest in Everest waned? Or would Australian climbers continue to broaden their horizons, as Greg Child had done, and tackle some of the other Himalayan giants or challenging and aesthetic routes on some of the lower peaks?

Those questions were answered in 1990. To any who might have questioned Australian climbers' ability to maintain the momentum after the Everest glory days, they answered most emphatically with their best single year ever in the Himalaya - a grand slam of successes on $8000 \mathrm{~m}$ peaks. It was an impressive performance, a most fitting finale to the first 15 years in the Himalaya and a most promising start to the next phase of Australian adventures in the great ranges of Asia. 
The 1990 triumphs included three $8000 \mathrm{~m}$ peaks not previously climbed by Australians, the first Australian ascent of the world's second-highest mountain, $\mathrm{K} 2$, and, perhaps most appropriately, another ascent of Everest, but in an exceedingly bold style with a very unusual lead-up.

Shisha Pangma, the only 8000 m mountain wholly within Tibet, had not, by the late 1980s, even been attempted by an Australian mountaineer. Physically, it was an attractive target. At $8046 \mathrm{~m}$, it was just above the magic 8000 m mark and its North Ridge, originally climbed by a Chinese team, was straightforward technically. The expense and red tape of organising an expedition through the Chinese Mountaineering Association, on the other hand, might have lessened its appeal somewhat.

In May 1990, Shisha Panga became one of three $8000 \mathrm{~m}$ peaks to be climbed by Australians that month, and, along with the other 1990 successes, brought the Australian total of $8000 \mathrm{~m}$ ascents to seven - half the total number of such peaks. The successful climber was Melbourne-based Mark Lemaire, on only his second trip to the Himalaya. In 1988, Lemaire climbed to $7400 \mathrm{~m}$ on the NorthEast Ridge of Changtse during a commercial expedition led by New Zealanders Shaun Norman and Mike Perry.

The 1990 Shisha Pangma trip was led by another well-known New Zealand mountain guide, Russell Brice, and included another New Zealander, one English climber and two Norwegians in addition to Lemaire. The team scored a solid success on the original Chinese route with Brice, Lemaire and three others reaching the mountain's West Summit, which was only a few metres lower than the main summit, in late May.

Lemaire's achievement on Shisha Pangma, which received scant attention in the Australian mountaineering press, was mirrored by the ascent, earlier in May, of Cho Oyu by Mike Groom, the quiet achiever of Australian mountaineering (Chapter 26). It was another very impressive climb by the publicity-shy Groomperhaps not as dramatic as his Kangchenjunga adventure but one that solidified his standing as one of Australia's premier Himalayan climbers.

Lying just to the south-east of Shisha Pangma on the Nepal-Tibet border, Cho Oyu is another of the technically less difficult (by the standard route) of the 8000 -ers. At $8201 \mathrm{~m}$, it is, however, the world's seventh-highest mountain. Groom, who had just missed the summit of Ama Dablam the previous year, was a member of a Queensland-based team led by Rick White (Chapter 24) and including White's wife, Jane, and veteran Himalayan climber Steve McDowell (see image 29.1).

The team initially attempted an impressive unclimbed rock buttress on the northern side of the mountain, but was forced back at $6800 \mathrm{~m}$ and onto the 
normal North Ridge/West Face route. Groom was the only climber to reach the top, but his ascent was nearly duplicated by Tony Dignan, who had to retreat from $8050 \mathrm{~m}$ due to altitude sickness. The others backed off from lower positions because of problems with the altitude.

Those two climbs - the second of which saw Groom become only the second Australian mountaineer to have climbed two $8000 \mathrm{~m}$ peaks (Pat Cullinan was the first, having climbed Broad Peak in 1986 and Everest in 1988) - would, by themselves, have given Australian climbing a most successful Himalayan year in 1990. They turned out to be only the prelude, however, to two stunning achievements that emphasised just how far Australian Himalayan climbing had come in only 15 years.

The first of these was the Australian/American ascent of K2, the monarch of the spectacular Karakoram Range. Often called the 'savage mountain', K2 suffers nothing compared with Everest as a mountaineering objective. The approach trek is longer and more arduous; the mountain itself is steeper, more imposing and more beautiful than Everest; it is considerably more difficult technically to climb even by the 'standard' route (the Abruzzi Ridge); and it is only $239 \mathrm{~m}$ lower than Everest.

Two additional facts indicate the serious nature of any attempt to climb K2. One is that the first British ascent of the mountain was not made until 1986, despite numerous attempts by the cream of the British mountaineering community. Britain is one of the strongest Himalayan climbing nations, its expeditions having made first ascents of many of the highest and most difficult peaks. It was, however, not until Alan Rouse and Julie Tullis summited in 1986 that a British climber had finally conquered K2. Tragically, both perished on the descent.

The second fact is that by $1990 \mathrm{~K} 2$ had not been climbed by anyone by any route since that horrific season of 1986, when a record 27 climbers reached the top but 13 were killed. For the next three years, the mountain repulsed all attempts, even by the most experienced and skilled Himalayan climbers from around the world climbing with the most modern equipment and, in some cases, with the most daring and bold of approaches. There could be little argument that, among the handful of the highest Himalayan mountains, K2 was the ultimate challenge.

Australian mountaineers had attempted K2 only once before-in 1987, when dangerous snow conditions forced Greg Child and Tim Macartney-Snape off the mountain from relatively low altitudes. The pair was part of a seven-person international expedition led by Doug Scott (Chapter 25).

Given those circumstances, one would hardly have put heavy odds on a small group of Australian and American climbers to break the drought on K2 in 1990, particularly since they were not attempting the Abruzzi Ridge but rather a more 
difficult route on the northern side of the mountain. The team did, however, include two of the very best of Australian Himalayan mountaineers: Child and Greg Mortimer. As described in Chapters 24 and 25, Child had, from the outset of his Himalayan career, climbed at the highest standards on difficult peaks and had by 1990 accumulated an enviable record of ascents and strong attempts. Mortimer was also an extremely skilled climber technically, but had made only two previous trips to the Himalaya. Both, however, were remarkable: successes on Annapurna II in 1983 and on Everest the next year.

The two American climbers on the team were also Himalayan veterans. Phil Erschler, ironically, was a member of the 1984 American expedition on the north side of Everest that witnessed the spectacular ascent of the Great Couloir by the small Australian team. In fact, Erschler was the only member of the American expedition to follow Mortimer and Macartney-Snape to the summit. He and the other American member of the K2 team, Steve Swenson, were also members of Scott's 1987 K2 expedition. Australians Lyle Closs, Peter Keustler and Margaret Werner completed the $1990 \mathrm{~K} 2$ team.

The 1990 K2 expedition was Greg Child's second Himalayan trip of the year. Earlier he teamed with American John Roskelley, one of the strongest and most experienced Himalayan mountaineers in the world, to attempt Menlungtse. Roskelley (Chapter 12) was another member of the 1984 American Everest North Ridge expedition that shared the northern side of the mountain with the Australian team.

Menlungtse was one of the plums left in the more heavily frequented parts of the Himalaya. Rising majestically to $7181 \mathrm{~m}$, its summit looks tantalisingly close to trekkers and climbers marching through the picturesque Rolwaling Valley in eastern Nepal. The mountain itself, however, lies wholly within Tibet and thus must be approached from the north. The attendant access problems, combined with its technical difficulty, left Menlungtse, at that time, as the only unclimbed $7000 \mathrm{~m}$ mountain anywhere in the Everest region.

If the peak were to be climbed by a two-man team, it would be hard to pick a stronger, more competent pair than Child and Roskelley. Menlungtse's defences, however - in the form of treacherous double cornicing on a knife-edged ridgeproved more than equal to the challenge and turned the two climbers back at about $6500 \mathrm{~m}$.

The Menlungtse retreat was Child's fifth unsuccessful attempt on a Himalayan peak since the 1986 ascent of Gasherbrum IV. That record, of course, is no reflection at all on Child's ability, but rather a testament to the remarkable difficulty of climbing high Himalayan mountains with very small teams in alpine style. The satisfaction of climbing peaks in such style is immense, but the odds 
of succeeding are lengthened considerably. Now Child would be attempting the difficult and dangerous $\mathrm{K} 2$ with a small team and via one of the most difficult routes on the mountain.

While Child had been very active in the Himalaya during the mid and late 1980s, Mortimer had not climbed or attempted a major Himalayan peak since his ascent of Everest in 1984. Nonetheless, he had remained a very active climber. He had started a guiding venture, called Risky Business, for Australians wanting to learn rock climbing or to climb further afield, including trekking peaks in Nepal and remote mountains in Antarctica. Indeed, Mortimer had considerable experience in the southern continent - as a geologist and as a climber. In the summer of 1987-88, he joined Lincoln Hall, Jonathan Chester, Lyle Closs, Chris Hilton and Glenn Singleman to make the first ascent of Mt Minto (4163 m), the highest peak in the Admiralty Range of North Victoria Land. A year later, he teamed with well-known New Zealand mountaineer Colin Monteath and Mike McDowell to climb Mt Vinson (5139 m), Antarctica's highest peak.

A cloud, however, still hung over Mortimer's ability to handle the extreme altitudes of the highest Himalayan summits. On his ascent of Everest in 1984, he suffered badly from the altitude. He needed assistance to descend the mountain and nearly died in a fall near the bottom of the Great Couloir (Chapter 12). For weeks after his return to Australia, he continued to suffer, being described by some as a 'walking zombie', and there were legitimate fears that he had suffered permanent brain damage. He eventually recovered well from the Everest ordeal, but how would he fare in the equally rarefied air of K2-again without supplementary oxygen?

Before Mortimer and his mates could face the challenge of K2, they had to get to the base of the mountain. That was not a trivial task, particularly when they found the Karakoram Highway closed due to political problems and, along with their four Balti high-altitude porters, they had to approach the range via the circuitous and costly route through Beijing to Kashgar by air and then overland across the arid steppes beneath Mustagh Ata.

The northern part of the Karakoram was Eric Shipton country. In the 1930s, the legendary British mountain explorer charted many of the previously unknown ranges and valleys and made many first ascents of the region's peaks. His descriptions of narrow defiles, arid valleys and broad, fast-flowing rivers fed by the massive glaciers above evoke images of one of the harshest mountain areas on the planet.

Little had changed since the 1930s. Timing was still critical on the northern approach to the Karakoram, as meshing the best time to climb on the region's highest mountains with the time when the rivers were fordable left little room 
for error. The Australian/American team, and their 30-camel caravan, was nearly caught by the treacherous Shaksgam River, its braided channels rising rapidly from snowmelt in its upper catchment. After some debate about the feasibility of attempting a crossing, the climbers and camels plunged into the icy water and struggled across without loss of life, although there was one very close call.

'The second camel on the train carrying our expedition cook stumbled on the far side, and was washed down the river. Somehow both he and the camel managed to find their way to the bank,' Mortimer reported. ${ }^{1}$ An Italian team was not so lucky a week later. While attempting to cross the Shaksgam, one climber and three camels were swept to their deaths.

The camel train ended on a moraine wall some distance from the snout of the North K2 Glacier and the site of base camp. Worse still, base camp-much like the base camp on the northern side of Mt Everest - was a long way from the bottom of the mountain. So even before they could contemplate the task of climbing K2, Child, Mortimer and their colleagues had nearly two weeks of tiresome load carrying to get an advanced base camp established at the head of the glacier.

The North Ridge of $\mathrm{K} 2$ had received some attention in the past, having been climbed by Japanese and Italian teams. It is one of those classic lines in the Himalaya: clean, direct and steep. In addition, it is free from avalanche danger. And to top it off, it has the very rare quality in a major Himalayan mountain of offering interesting climbing of a consistently high standard all the way up the ridge.

The Australian/American team was not disappointed with the quality of the climbing they found on the ridge.

Mortimer recalled:

Above Camp 2, the climbing is continuously steep through a series of rocky buttresses and snow gullies. It is joyfully exposed and elegant climbing - some of the best anywhere in the world. On the left of the ridge is a very steep face which drops 3,000 metres to the glacier below, while the right is the huge sickle-like sweep of the North Face. ${ }^{2}$

The team's strategy was to establish four camps on the North Ridge, stock them with sufficient food and fuel for a few attempts by a small team and then go for the summit from the top camp. Fixed rope left by previous expeditions proved useful in securing the route.

1 Mortimer, G. 1990, 'K2 - savage mountain success', Hostel Travel, (YHA magazine), pp. 8-10.

2 Ibid. 
Progress on the mountain was aided by unusually good weather, with four and five-day spells of fine conditions common. One of the infrequent storms, however, combined with a lack of acclimatisation, snuffed out the first summit attempt in early August. A week after that first aborted attempt, Child, Mortimer and the two Americans were ensconced in the top camp, at nearly $8000 \mathrm{~m}$, for another shot at K2. They knew that climbing the remaining 650 vertical metres or so to the summit would tax their stamina to the very limit, but they had not counted on a couple of other nasty tricks that K2 still had in store for them.

The first was a small, innocuous-looking basin of snow just above camp four. It proved to be dangerously avalanche prone, with the telltale feeling of reverberations under their feet sending shock waves of fear through the climbers. Mortimer described it as 'walking across a big bass drum which was ready to perforate'. ${ }^{3}$

Once above that slope, they were confronted with another jolt. What looked from below like a broad wedge of easily angled snow tucked in under the summit proved to be $400 \mathrm{~m}$ of 45-50-degree snow and ice. The climbers, tackling the top part of the mountain without a rope, had to face this surprisingly steep and exhausting slope alone. A slip would be fatal.

One by one, they slowly kicked steps up the slope and moved out over the top onto the more gently angled, but long and arduous, final ridge to the summit itself. They had passed the 8500 m mark and were well within the 'death zone'. They had very limited time before severe deterioration quickly set in. The final gentle but long approach to the top of $\mathrm{K} 2$ is therefore very much a deathtrap. Once a climber has completed the exhausting push to the top, he is faced with an equally long and tiring plod, with gravity of little help because of the very shallow angle, through sometimes deep snow back across the summit cap. It is no wonder that the death rate on $\mathrm{K} 2$ is so high, with many of the deaths occurring on the descent.

Steve Swenson was the first of the climbers to surmount the steep slope and begin the long trudge to the very top. He was moving strongly and had plenty of time to complete the climb and descend before dark. His countryman, Phil Ershler, was, however, having problems. Ershler, at the back of the string of four climbers, was suffering from a severe headache and was having trouble keeping pace with the others. About $200 \mathrm{~m}$ below the summit, he stopped, considered his situation at length and then began the descent to camp four. K2 can easily exact the ultimate price for a bad decision. 
Ershler's decision to retreat was perhaps made easier by the deteriorating weather. The atmosphere around K2 was showing unmistakable signs of instability early in the day and by the time the climbers were approaching the summit, a cloud had descended on the top of the mountain.

After Swenson, Child was the next to undertake the energy-sapping push across the gentle ridge to the top. He had experienced the mental trauma of climbing at $8000 \mathrm{~m}$ without supplementary oxygen on Broad Peak in 1986, and here he was $600 \mathrm{~m}$ higher. His feelings and thoughts as he finally reached the summit are a riveting account of what it is like to be at extreme altitude in the Himalaya:

I wander around in circles around the summit, stunned to arrive at a place I'd dreamed of for half a lifetime, a place I never really thought I'd reach. Finally, I sit on the snow, lean on my ice axe, and wait for Mortimer.

It's windless, soundless, and surprisingly warm under the blanket of cloud. As I stare down the ridge the line between mountain and heavens begins to merge. 'If it turns to whiteout up here we'll never get down', I think. I check my watch. Somehow, 15 minutes have lapsed since my arrival. It seems like 15 seconds. I wipe my nose and knock an icicle of condensation dangling from it; a drift of snow has formed around my backside. I've been staring statue-like into the void, spacing out the whole time. I recall reading a theory of Messner's about climbers falling into trances on the high summits, and never coming down...

I keep looking at my watch, nervously doing reality checks. Where are you, Mortimer...

Until Mortimer's arrival I'd been so outside myself I'd begun to doubt I was really on the summit. I'd even begun to doubt my own existence. These would seem ludicrous thoughts at sea level, but up here in la-la land, where brain cells are shorting out by the bucket load, anything is possible. ${ }^{4}$

Mortimer reached the summit about 25 minutes after Child. With only a few hours of daylight left and the cloud thickening, they spent a surprisingly long 30 minutes on the summit before starting the descent. They managed to negotiate the steep snow slope in the fading light, but had a nerve-wracking traverse in the dark from the bottom of the slope to the tent at camp four.

The ascent of K2 was another brilliant chapter in Child's prolific Himalayan career. Now he had surmounted virtually every kind of difficulty Himalayan 
climbing had to offer: highly technical rock climbing on the granite towers of the Karakoram, the demanding mixed rock and ice climbing on peaks such as Shivling and Gasherbrum IV and now the extreme altitude of K2. The last was particularly satisfying, as he climbed it without supplementary oxygen on a beautiful and challenging route. For breadth of skill and experience, there are few climbers anywhere in the world who can match Greg Child.

For Greg Mortimer, the climb was just as rewarding: 'Climbing K2 is more satisfying than Everest from a climber's point of view. It is a mountaineer's mountain. With such a fearful reputation it has more kudos, just to do it successfully where so many have failed. ${ }^{\prime 5}$

With the ascent of K2, Mortimer became one of the very few mountaineers in the world who had climbed both Everest and K2 - the world's two highest mountains - without the help of supplementary oxygen. He was in 1990, of course, the only Australian to have climbed both peaks. Adding his $1983 \mathrm{climb}$ of Annapurna II to his Everest and K2 successes gives Mortimer a short but absolutely astonishing list of Himalayan ascents - the world's two highest summits and a 'near 8000-er' - all without supplementary oxygen, all with small teams and all bold ascents in good style on difficult routes.

How did Mortimer's physiology fare at extreme altitude on K2? 'I was in a lot better shape after the climb this time,' he said. 'I was more conscious of getting up and down quickly, I was more relaxed, and I had more rest in between bouts of climbing. ${ }^{6}$

The success of Child and Mortimer on K2 was the first Australian ascent of the mountain. It also marked the completion of Australian climbs on the trilogy of the world's highest mountains: Everest, K2 and Kangchenjunga. It would no doubt be a most appropriate way to conclude the saga of Australia's first 15 years of expeditioning in the Himalaya. Perhaps the only more fitting way to conclude this story of Australian mountaineering in the great ranges of Asia is to return to Everest and to the most well-known of Australian Himalayan mountaineers of the first era: Tim Macartney-Snape.

From the beginning of Australian expeditioning to the Himalaya, MacartneySnape was at the forefront. He was a member of the 1978 Dunagiri expeditionthe most significant of the early Australian trips. His ascent of Dunagiri was the first Australian ascent of a 7000 m peak and his climb of Annapurna II in 1983 was only the second Australian success at $7000 \mathrm{~m}$ or above. In 1984, of course, he and Mortimer were the first Australians to stand on top of the world after their phenomenal ascent of Everest's Great Couloir. With his climb of the

5 Mortimer, 'K2 - savage mountain success'.

6 G. Mortimer, Interview. 
difficult Gasherbrum IV two years later, he had established a Himalayan record unrivalled in Australian mountaineering circles: seven major peaks attempted, six successes, four new routes, one $8000 \mathrm{~m}$ peak and two 'nearly $8000 \mathrm{~m}$ ' peaks.

So what could Macartney-Snape do in 1990 on Everest that was new, significant and challenging, by either his own standards or those of the international mountaineering community? The answer was deceptively simple: he could climb all $8850 \mathrm{~m}$ of the world's highest mountain and he could climb it by himself (above base camp) and without supplementary oxygen - undoubtedly one of the most physically and mentally daunting challenges anywhere on the planet.

Although Everest had been climbed in many different ways, no-one had ever climbed it from sea level. Before the days of the road to Jiri and the airstrip at Lukla, most expeditions started from Kathmandu, which was more than $1000 \mathrm{~m}$ above sea level.

The idea for Macartney-Snape's 'sea-to-summit' expedition came originally from adventure film producer Michael Dillon. As noted in Chapter 15, Dillon was also responsible for the original idea that led to the ABEE. The seed for the sea-to-summit challenge, however, was sown even earlier.

Dillon was the producer of the film of Sir Edmund Hillary's 1977 'ocean-to-sky' expedition. That trip took Hillary up the Ganges River by jet boat to its source in the Indian Himalaya. He and his colleagues then climbed a peak at the head of the glacier from which the Ganges emanated. Many people, on seeing the film, mistook the mountain for Everest. That prompted Dillon to ask himself the question: why not do the real thing? Why not climb Everest all the way from sea level?

He mentioned the idea to a climber or two during the early 1980s but received no response. Then in 1985, while filming a trek with Tim Macartney-Snape and Dick Smith, adventurer and publisher of Australian Geographic, Smith's wife, Pip, and their family, he brought up the idea again. At that time, however, it was only a year since Macartney-Snape had climbed Everest and, with the hardship of that ascent still relatively fresh in his mind, he was not keen to have another crack at Everest so soon.

Still, the idea took hold and a couple of years later, a definite plan was being formulated. In fact, with the encouragement and support of the Australian Broadcasting Corporation ( $\mathrm{ABC}$ ), the sea-to-summit attempt was to be attached to the ABEE to form a sort of Australian super-assault on Everest during the bicentenary. Those plans were, however, eventually dropped before the ABEE team set out for Nepal in 1988. 
The idea was too good to drop altogether and it was quickly resuscitated the next year. Macartney-Snape received official approval for the expedition from Nepalese authorities and Smith promised to support the venture.

In a lead-up reminiscent of Peter Taylor's preparation for his Langtang trip in 1963 (Chapter 3), Macartney-Snape got ready for the biggest climb on Earth by training in one of the planet's flattest areas: the Australian outback. He was based at Meekatharra, Western Australia, where his wife, Ann Ward, was stationed as a doctor with the Royal Flying Doctor Service. Ward was quite an adventurer in her own right, having led several treks into the remote corners of the Himalaya.

Macartney-Snape's training routine was not quite as monotonous as that of Taylor, who lugged rucksacks full of sand up and down the dunes of Cooper Creek, but rather was a bit more in tune with the technical as well as the physical challenges that lay ahead. Macartney-Snape interspersed his demanding runs across the red desert in the mid 40-degree heat with short, solo climbs on the boulders that dotted the Meekatharra landscape.

The notion of climbing Everest all the way from sea level has a philosophical and romantic attractiveness. As a mountaineering enterprise, 'climbing' the 500 vertical metres from the Bay of Bengal to the Himalayan foothills has a few physical challenges as well. The $700 \mathrm{~km}$ walk from the sea through India to the Nepalese border has one of the gentlest gradients anywhere, but the sheer necessity of walking long horizontal distances day after day and the everpresent danger of serious illness make it a challenge, and a risk, that could affect performance on the mountain itself. The trek through India is thus no mere gimmick or holiday, even from a mountaineering perspective.

Although Macartney-Snape would tackle the steep slopes of Everest itself on his own, he was joined on this long trek through India and Nepal by Ann Ward, his sister, Pip, Mike Dillon and Charles Norwood, who drove the Land Rover that carried the group's gear. On the last two weeks of the trek to base camp, the party was joined by Dick and Pip Smith.

Macartney-Snape walked out of the Bay of Bengal at Ganga Sagar on 5 February 1990 to start his epic journey to the top of the world (see image 29.2). Almost immediately, he was confronted with risks. 'The roads in West Bengal are very busy,' he reported in an early dispatch from the trip, 'and I'm constantly on the lookout to avoid being hit by traffic. ${ }^{7}$

7 T. Macartney-Snape in 'Sea-to-summit report', Outside, (Mountain Designs newsletter), vol. 3, no. 1 (March 1990). 
Macartney-Snape's party was responsible for at least one of the frequent traffic jams that slowed progress. At one point, Dillon detoured slightly to inform the participants in a local cricket match that Macartney-Snape was Allan Border's brother. That little joke precipitated a massive traffic jam for at least $5 \mathrm{~km}$ as avid cricket fans tried to get close to the Australian party.

Just as potentially dangerous as the traffic were the insect pests: 'Already my legs are red from mosquito bites,' Macartney-Snape continued. 'We are taking anti-malarial pills but they do not guarantee complete protection from catching a resistant form of the dreaded protozoan that is endemic throughout the area of the first part of my climb.' ${ }^{8}$

Even stiffer challenges lay ahead. After swimming $3 \mathrm{~km}$ across the heavily polluted Ganges River, Macartney-Snape headed for the India-Nepal border and the beginning of the hills (see images 29.3 and 29.4). He was in for a nasty surprise when he reached the checkpoint at Jogbani. Due to tensions between India and Nepal, the border was closed to foreigners.

This was a potentially serious blow. Macartney-Snape was on a fairly tight schedule. He had to allow enough time after he reached Everest base camp to acclimatise properly and for reconnaissance climbs on the mountain. If too much time was lost on the trek to base camp, he would have insufficient time to acclimatise or his attempt would be cut short by the onset of the monsoon. Furthermore, any delays on the trek would have to be made up on foot, as to use vehicles or bicycles would negate the concept of climbing Everest from sea level.

The only feasible solution to the impasse was to detour $180 \mathrm{~km}$ east to Kharkavitta, where the border was apparently open to foreigners. While Dillon and Pip Macartney-Snape joined Norwood in taking the support vehicle to Raxaul, a border crossing far to the west of Jogbani, Ward bought a bicycle to accompany her husband on the eastern detour.

The alternative route through Kharkavitta added a total of $280 \mathrm{~km}$ to the overall journey, which forced Macartney-Snape to up his average rate from 30 to 60 $\mathrm{km}$ a day. A rate of $30 \mathrm{~km}$ a day, even on flat terrain, is a formidable one for a walker, but to double it would require Macartney-Snape to run for much of the day. In his usual modest way, he understated the task: 'It wasn't that far. Only a marathon and a bit every day. ${ }^{\prime}$

8 Ibid.

9 T. Macartney-Snape, Public lecture. 
In fact, he had to cover a marathon and a half each day for three consecutive days to keep on schedule! For most people, this would be an impossible task and, even if they could manage, it would leave them exhausted and in need of a long rest.

For Macartney-Snape, it was only the beginning of the physical hardships. He immediately followed his Herculean effort along the India-Nepal border with a demanding trek through the hills of eastern Nepal. At times, he and his party were wading through chest-deep snow on the high ridge between Bhojpur and the Salpa La.

In early April, Macartney-Snape and his small party ended their epic walk from the Bay of Bengal and arrived at Everest base camp along the Khumbu Glacier at $5300 \mathrm{~m}$. Now the real climbing would begin.

The area was abuzz with activity as three large expeditions were attempting the South Col route in the pre-monsoon season of 1990. Macartney-Snape's sea-tosummit route brought him into the southern side of the mountain - the opposite side to the one he climbed in 1984 .

No doubt he would have preferred a long rest at base camp, but there was much to do in a short time if Macartney-Snape was to achieve his ambitious plans. First was the difficult task of fixing rope for $600 \mathrm{~m}$ up to the Lho La and the beginning of the West Ridge. Macartney-Snape planned to climb Everest via the West Ridge and descend the standard South Col route.

'The West Ridge appealed to me because it is spectacular, had never been climbed solo and would enable me to avoid the three large expeditions...that were attempting to climb the South Col route.' ${ }^{10}$

The magnitude of this undertaking should not be underestimated. Ascents of the West Ridge of Everest are rare and traverses of the mountain are even less common. To contemplate such a route-solo and without supplementary oxygen - was bold by any measure. Only one other climber had ever soloed Everest without supplementary oxygen. That was the legendary Reinhold Messner, who in 1980 ascended the mountain via the North Ridge routearguably the easiest route technically. Even at that, he admitted to being at his absolute limit as he crawled up the last few metres to the summit.

Australians had experienced the difficulty and danger of the West Ridge before. Craig Nottle and Fred From had fallen to their deaths from the ridge on the 1984 post-monsoon attempt (Chapter 20). A year later, Mike Rheinberger and Peter Allen were forced off the ridge by extreme avalanche danger during a New

10 Macartney-Snape, T. 1991, 'From the sea to the top of the world', Australian Geographic, no. 23 (JulySeptember), pp. 30-49. 
Zealand expedition (Chapter 16) and the AAA abandoned its original idea of an ascent of the West Ridge because of the route's difficulty (but not without heated debate; see Chapter 21).

Macartney-Snape received firsthand experience of the problems of the West Ridge route on his preliminary trip up the lower sections of the ridge. First, fixing rope up to the Lho La proved to be a demanding exercise, even though he shared the task with a small Swiss team that was going to climb on the West Ridge as well. The granite headwall steepened sharply below the pass and gave rock climbing of grade 18 or 19 difficulty - made even harder by having to climb in stiff mountaineering boots and bulky clothing.

After fixing rope to the Lho La, Macartney-Snape moved slowly on up the ridge in the first of two planned acclimatisation sorties. He reached nearly 7500 $\mathrm{m}$, but, although the snow on the moderately angled slopes was excellent for cramponing, he realised that any fresh snowfalls over the hard-packed base would make the slopes dangerously avalanche prone.

After that first preliminary trip up the West Ridge, Macartney-Snape was pinned in base camp by two weeks of bad weather, which dumped heavy snow on the mountain. His fears about the route were realised; to pursue that route would have been unjustifiably risky.

The alternative was the South Col route. Although it is the way by which Everest is most often climbed, it is not the 'yak' route it is sometimes dismissed as. The route is long and physically demanding and the last section from the South Summit to the top is very exposed and offers some tricky climbing.

The fact that Macartney-Snape was attempting it solo added another dimension to the challenge. 'It's far more dangerous by yourself,' Lincoln Hall, MacartneySnape's long-time climbing companion, noted:

You've got no one to say 'look out' or 'snap out of it' if you're drifting off.

But I've seen how much he [Macartney-Snape] relishes the situations in the mountains. He just buckles right down and deals with everything that is thrown at him. I've been with some people in some really desperate situations and they're just trying to keep their head above water, whereas Tim's swimming and looking around and seeing which way the current's going. ${ }^{11}$

11 L. Hall in Brennan, W. 1990, 'Mountain man', The Australian Magazine, 15-16 September 1990, pp. 56-66. 
As it unfolded, it would take all of Macartney-Snape's legendary strength and stamina, and his well-honed climbing instincts, to keep his head above water on Everest.

After two preparatory trips through the Khumbu Icefall to the Western Cwm, he set out for the summit on 7 May. Just reaching the South Col, however, at nearly $8000 \mathrm{~m}$, proved exhausting.

Macartney-Snape said:

Reaching the South Col was incredibly hard. I was carrying a pack with a tent, food, fuel and a movie camera. I was just finding it very difficult, I thought I wouldn't even make the South Col. My legs were giving way on me. I felt very weak and light headed.

Climbing up the Lhotse Face was one of the most difficult things I've ever done. I hadn't psyched myself up for what I found. ${ }^{12}$

From that point, it was sheer determination that lifted Macartney-Snape from the South Col to the summit, just as it had Paul Bayne and Pat Cullinan two years earlier. After his exhausting climb to the col, Macartney-Snape felt light-headed and was plagued by bouts of diarrhoea. He was forced to rest a day before he set out for the summit, at $9.30 \mathrm{pm}$, on the brilliantly moonlit night of 10 May. The top came only after an uncharacteristically desperate and uncomfortable final climb for Macartney-Snape up the South-East Ridge.

Beneath the mountain's South Summit, between 8,230 m and 8,536 $\mathrm{m}$, I inched my way upwards in the terrible $-30 \mathrm{C}$ cold. It was now 3 a.m. on 11 May. I was intermittently shaken by bouts of uncontrollable shivering and longed for the sun, which was just beginning to lighten the horizon. I felt terribly tired from the effects of high altitude and was weak from lack of food, having been plagued by nausea and diarrhoea and having eaten little during the previous three days. My legs felt shaky, having just recovered from a severe cramp that had nearly caused me to fall off the mountain at about midnight when I'd stopped to find a better way of carrying my movie camera. The momentum from the year of planning, the effort involved in getting this far and the thought of all those who had helped and encouraged me were all that kept me going...

From an inner pocket of my down suit I took out my water bottle and forced myself to drink a few mouthfuls. Shortly afterwards I vomited.

12 T. Macartney-Snape, Public lecture. 
It is difficult to vomit when you are gasping for breath, but I was more upset at losing all the food I had tried so hard to eat at the South Col. What was going to keep me going now?

I was amused to see the contents of my supper freeze into a stalagmite before me. Mercifully the Sun had now risen and, as I slipped my goggles over my eyes to prevent snow blindness, I felt instant warmth. It gave me the surge of strength I desperately needed to tackle the most dangerous part of the climb. ${ }^{13}$

The stretch of Everest's South-East Ridge from the South Summit to the true summit is narrow and corniced, with precipitous drops into the void on both sides. Even the veteran Macartney-Snape was impressed by its seriousness: 'When you climb up here without a rope, it's quite intimidating. ${ }^{14}$

Slowly, he neared the summit of Everest for the second time:

In the dazzlingly clear air, the panorama below bristled with the most spectacular mountains in the world. The scene made all the risk, pain and hard work worthwhile. As the climbing became increasingly exacting and the view even better, I found myself more engrossed in my position and less concerned with the discomfort of being there. It was truly great to be alive...

At about 9.45 a.m. I took 20 steps without stopping and found there was nothing above me but dark blue space. I was on the summit. ${ }^{15}$

It was another remarkable Macartney-Snape performance. He became the first human to climb, entirely under his own steam, from sea level to the highest point on the planet (see image 29.5). His climb was only the second time Everest had been soloed without supplementary oxygen and the first time it had been climbed in such fashion from the south.

This time, however, unlike his first ascent of Everest in 1984, Macartney-Snape at least showed signs of being something other than superhuman. Like other mortals in the high Himalaya, he had to overcome nausea and shakiness, vomiting and breathlessness to reach the top. Even his seemingly unbounded optimism and drive were severely tested. Under the harshest of psychological conditions, however — climbing alone-he persevered and eventually triumphed.

13 Macartney-Snape, 'From the sea to the top of the world'.

14 Ibid.

15 Ibid. 


\section{The end of an era}

After climbing from the Bay of Bengal to the summit of Mt Everest, Tim Macartney-Snape returned to the red desert sands of Meekatharra. For him, high-altitude climbing was over. He vowed to his wife, Ann, that after the seato-summit adventure he would not climb again at the extreme altitudes of the high Himalaya.

Macartney-Snape's retirement marked the end of the career-or at least the extreme altitude facet of it - of Australia's most successful Himalayan mountaineer. His record is astounding. To the impressive list of ascents noted earlier, he added the solo climb of all $8850 \mathrm{~m}$ of Mt Everest. His tally stood at nine major Himalayan mountains attempted, seven successes, two bold, imaginative ascents of Mt Everest, without supplementary oxygen, climbs of difficult new routes on Annapurna II and Gasherbrum IV and no deaths or serious accidents on any of his expeditions.

At the beginning of the 1990s, no other Australian mountaineer could match that record. Indeed, there would be extremely few climbers from any country that could come close to that success rate in the Himalaya, particularly on the quality of peaks that Macartney-Snape had tackled.

Macartney-Snape's solo ascent of Mt Everest, the climb of K2 by Mortimer and Child and the other two climbs of $8000 \mathrm{~m}$ peaks in 1990 also mark the end of an era for Australian mountaineering in general. Climbers from the world's flattest, hottest continent are no longer such a novelty in the great ranges of Asia. An Australian ascent of Mt Everest is now not such an unusual event. In the 1990s, more Australian climbers viewed a Himalayan expedition not as a difficult, unusual, once-in-a-lifetime goal, but as a natural progression in their alpine climbing careers.

After 1990 Australian Himalayan mountaineering passed into a new era in another way as well. Although there would no doubt be more significant successes by Greg Child, Greg Mortimer, Zac Zaharias, Jon Muir and others from the first generation of Australians in the Himalaya, the next generation of Australian climbers will lead the way in the twenty-first century. Mike Groom, who served an apprenticeship under Macartney-Snape and Hall on Trisul and Annapurna II before going on to lead successful expeditions of his own on two $8000 \mathrm{~m}$ mountains, best exemplifies the new group. Groom, some of his colleagues from the mid and late 1980s and others who learned the ropes under the guidance of Australia's best mountaineers on commercial expeditions will form the nucleus of a continuing strong Australian effort in the Himalaya in the next decade and beyond. 
Finally, the end of Australian mountaineering's first era in the Himalaya marks the beginning of its first legends. Other countries, with much longer mountaineering histories, already have a rich store of heroes and tales. Britain has the incomparable mystery of Mallory and Irvine on Everest in 1924, Shipton and Tilman's explorations of untouched ranges and first ascents of virgin peaks and the more recent heroes: Bonington, Scott, Tasker and Boardman. France has the ascent of Annapurna I - the first $8000 \mathrm{~m}$ peak to be climbed-led by Maurice Herzog and the brilliant alpine careers of Lionel Terray, Gaston Rebuffat and Louis Lachenal. Italy has a rich heritage as well, with climbers such as Walter Bonatti, Riccardo Cassin and Reinhold Messner, and Austria has Hermann Buhl and Peter Habeler.

In the first few decades of this century, Australian mountaineers will almost surely look back on the 1975-90 period as a golden age in Australian Himalayan climbing. They will remember Hall and Macartney-Snape's desperate push along Dunagiri's summit ridge to claim Australia's first $7000 \mathrm{~m}$ summit, and the subsequent successes of that powerful partnership. They will remember the sudden emergence of the brash International Turkey Patrol and its tragic fate, and the steady, consistent, impressive string of successful expeditions of the AAA. Greg Child's bold climbing on the daunting granite pillars of the Karakoram will be held in awe, as will his ascent of K2 with Greg Mortimer. Most of all, however, they will remember the first Australian climbs of Mt Everest: the impeccable style and brilliant execution of the 1984 ascent and the dramatic, nerve-wracking, last-minute triumph of the Australian Bicentennial Everest Expedition. 


\section{Epilogue}

The period 1975-90 was indeed a formative and unique period in Australian Himalayan climbing. Chapter 29 looked forward from 1990 and foreshadowed some significant shifts in the nature of mountaineering in the great ranges of Asia that would mark 1990 as a turning point. Now, 20 years later, many of those projections of change have developed into well-established trends.

Perhaps the most dominant of all the trends has been the move to commercial expeditions. In the 1970s and 1980s, most Himalayan expeditions were largely do-it-yourself affairs - from initial planning, obtaining a permit and organising the equipment to planning the logistics and arranging the transport from Australia. And all of this time-consuming work was expended before the team even reached Asia and began the walk into the hills to eventually tackle the mountain.

From the last decade of the twentieth century there has been a pronounced shift to commercial expeditions. For example, in a survey of Australian Himalayan mountaineering for the period 2001-03, nearly half of the expeditions covered (16 of 33) were commercial. ${ }^{1}$ The trend is probably due to the rising wealth in general of Australians coupled with the increasing time constraints as contemporary society becomes faster paced, allowing less time for planning and organisation. In addition, the Himalayan region has become more accessible and the number of commercial operators in the big mountains has grown sharply.

Two contrasting styles of commercial expedition are important to distinguish. At one extreme lies the fully guided expedition, in which the client is completely taken care of - from armchair to summit. The service provided by the expedition company stretches from all of the preparation, logistics and support to professional mountain guiding to the top of the peak. This allows fit people with little or no mountaineering experience to ascend some of the highest summits in the Himalaya. For busy people, this type of expedition is very attractive, as they can jump over the long apprenticeship in New Zealand and other alpine areas, which 20-30 years ago was a prerequisite for climbing in the Himalaya.

\footnotetext{
1 Unless otherwise noted, all specific information on mountaineers and their climbs included in the epilogue was obtained from the two surveys of Australian Himalayan mountaineering by Zac Zaharias, covering the period 1994-2003: Zaharias, Z. 2001, 'High achievers: Australian Himalayan mountaineering since 1994', Wild, no. 80 (Autumn), pp. 30-5; Zaharias, Z. 2004, 'Top of the world: Australian Himalayan climbing 20012003', Wild, no. 80 (Autumn), pp. 40-7.
} 
Even fully guided expeditions, however, are not without risk. The extreme altitude and fickle weather in the Himalaya remain serious risks despite the best preparations and most advanced support that commercial expeditions can provide. The 1996 debacle on Everest showed that even the world's most experienced mountaineers could not guarantee a safe passage to the summits of the Himalayan giants. The highly publicised tragedy took eight lives, including those of the two expedition leaders, Rob Hall and Scott Fischer.

The second style of commercial expedition is much closer to the earlier do-ityourself approach. In this style, the company organises the peak permit and provides logistical support, but climbers are fully responsible for all aspects of ascending the mountain above base camp. They must take full responsibility for equipment and logistics, do all of the lead climbing and, critically, make all the decisions and judgments along the way that could mean the difference between success and failure, life and death.

Another trend begun about 1990 was the broadening of climbing objectives from Everest and other well-known mountains to some of the lesser-known peaks in the great ranges of Asia. By 1990, Australians had climbed only half of the world's $8000 \mathrm{~m}$ mountains, but that would change rapidly in the last decade of the twentieth century. By the end of 1999, Australian climbers had ascended five of the remaining seven 8000 m summits: Makalu (8481 m), Lhotse (8511 m), Dhaulagiri (8167 m), Gasherbrum I (8068 m) and Nanga Parbat (8125 m). ${ }^{2}$

One projection, though, has not materialised. The focus on Everest has not waned with the first Australian ascent in 1984 and the success of the 1988 bicentennial Everest expedition. On the contrary, Everest has become a stronger magnet than ever. For example, there were 10 Australian attempts on Mt Everest during the period 1994-2000 ( of a total of 57 trips, 30 of which were to 8000 $\mathrm{m}$ peaks), ${ }^{3}$ but that ratio increased dramatically in the next three years. Of the 33 expeditions involving Australians in the period 2001-03, 24 were to $8000 \mathrm{~m}$ peaks and, of these, 11 were to Everest. In the pre-monsoon period of 2001, four separate expeditions involving Australian climbers were simultaneously on the mountain. ${ }^{4}$

Several of the strands of Australian Himalayan mountaineering covered in the book were continued or reached their conclusion after 1990-many of them connected with Mt Everest. In May 1993, Brigitte Muir (Chapter 28) became the first Australian woman to reach the summit of Everest and, with Jon Muir having climbed the mountain in 1998 (Chapter 22), they became the first Australian husband-and-wife team to reach the top of the world. Brigitte Muir

\footnotetext{
Zaharias, 'High achievers: Australian Himalayan mountaineering since 1994'.

4 Zaharias, 'Top of the world: Australian Himalayan climbing 2001-2003'.
} 
was also on Everest in May 1996 at the time of the tragedy involving the Hall and Fischer commercial expeditions; she helped Hall's client Beck Weathers, who barely survived the ordeal, on his descent from the South Col.

A year earlier, Greg Child, one of Australia's most skilled all-round climbers (Chapters 24 and 25), made a successful ascent of Mt Everest via the North Ridge, adding Everest to his very impressive list of accomplishments on mountains around the world. Mike Rheinberger (Chapters 15, 17 and 22) finally realised his dream of standing on top of Everest with an ascent in 1994, but then deteriorated rapidly on the descent and tragically perished from cerebral oedema high on the North Ridge. Greg Mortimer, who along with Tim Macartney-Snape made the first Australian ascent of Everest (Chapter 12), returned to the high Himalaya in 2002 and led a successful expedition to Manaslu (8156 m), reaching the summit himself.

Mike Groom (Chapter 26) continued his remarkable achievements on the very highest of summits into the 1990s with ascents of Mt Everest (8850 m) in 1993, K2 (8611 m) in 1994, Lhotse (8515 m) in 1995 and Makalu (8481 m) in 1999. When he succeeded on K2 in 1994, he became the first Australian to climb the world's three highest mountains (Everest, K2 and Kangchenjunga) and only the eighth climber in the world to do so. With his ascent of Makalu in 1999, Groom became the first Australian to climb the world's six highest peaks.

As one of the major driving forces for Australian Himalayan climbing in the period 1975-90, the Army Alpine Association (AAA) (Chapter 13) has continued a high level of activity into the new millennium. The AAA organised 12 expeditions from 1990 to 2001, with a very high success rate; 10 of the expeditions have placed at least one climber on the summit. ${ }^{5}$ The objectives have spanned a wide range-from the technically challenging trekking peak of Kusum Kanguru to six attempts on 8000 m giants such as Shisha Pangma, Dhaulagiri I and Cho Oyu.

The most well known of the AAA trips was the 2001 Centenary of Federation expedition to the North Ridge of Mt Everest that gained national media attention. The expedition placed three members on the summit on 25 May but the expedition was marred by the tragic deaths in a massive avalanche of the expedition's cameraman and his family while on an acclimatisation trek in Nepal. The expedition was further embroiled in tragedy when Mark Auricht, a team member of the South Australian Everest Expedition, died in Zac Zaharias and Tim Robathan's tent from cerebral oedema. On return to Australia, a 12-month board of inquiry was held by the army to investigate the deaths. Although the inquiry made recommendations supporting the continuation of mountaineering,

5 Z. Zaharias, Personal communication. 
the AAA has not subsequently been permitted to mount overseas expeditions. Thus came an abrupt end to a proud and distinguished quarter-century of arguably Australia's most successful mountaineering club.

The period since 1990 has also seen the development of a large number of outstanding new Australian high-altitude climbers. Although much of the action has occurred on the 8000-ers with the major focus remaining on Everest, a few climbers have bucked the dominant trends and ventured out to tackle other mountains and more varied climbing challenges.

Perhaps the most notable of these is Andrew Lindblade, who, with his New Zealand climbing partner, Athol Whimp, has taken on some technically demanding routes on very remote mountains. In 1996, they attempted the unclimbed North Face of Thalay Sagar (6904 m) in the Indian Himalaya, and returned the next year to complete the route successfully - the first ascent after 10 unsuccessful attempts by a variety of expeditions. The pair followed this success with an ascent in 2000 of the North Face of Jannu (7710 m), the imposing 'Wall of Shadows' (Chapter 3). Even more audacious was their alpinestyle attempt on the sweeping West Face of Gasherbrum IV (7925 m; see Chapter 25); they reached the halfway point on the face before being forced to retreat. Lindblade and Whimp have done all of their Himalayan climbing in do-ityourself style, avoiding the stampede towards commercial expeditions.

Somewhat in the style of Lindblade and Whimp, Duncan Chessell has tackled a range of Himalayan peaks, from popular summits such as Ama Dablam (6854 m) to very challenging trekking peaks such as Kusum Kanguru (6369 m) and the lesser-known Labchi Kang (7367 m). Along the way, he has also ascended two of the world's 8000 m peaks: Everest twice (2001 and 2006) and Cho Oyu.

Brian Laursen has moved up through the AAA system to become one of Australia's leading Himalayan climbers in his own right. With his ascent in 2002 of Manaslu (8156 m), he had climbed four of the world's $8000 \mathrm{~m}$ peaks. Other successful ascents were of Shisha Pangma Central (8024 m), Cho Oyu (8201 m) and Everest (8850 m) during the period 1997-2001.

As noted in Chapter 28, Australian women were somewhat of a novelty in Himalayan mountaineering in the period before 1990. This, too, began to change. Australian women became more numerous in the great ranges of Asia and attacked the full range of Himalayan mountaineering objectives-from precipitous rock spires to the $8000 \mathrm{~m}$ giants. As an example of the former, Vera Wong has made several expeditions to the rock towers of the western Himalaya, making the first ascent of Tenan Tower (5300 m) in Pakistan in 1995, followed three years later with ascents of the rarely climbed Changi Tower (5820 m) and Marpo Brakk (5400 m), also in Pakistan. 
Sue Fear emerged in the first decade of the twenty-first century as Australia's most accomplished female Himalayan climber ever. Beginning with an ascent in 1997 of Makalu II $(7680 \mathrm{~m})$ in the Khumbu region of Nepal, she went on to climb five $8000 \mathrm{~m}$ peaks in the next nine years: Cho Oyu (8201 m), Shisha Pangma Central (8024 m), Everest (8850 m) and Gasherbrum II (8035 m). With her ascent of Everest in 2003, Fear became the second Australian woman, after Brigitte Muir, to climb the world's highest mountain. Tragically, Fear died in 2006 in a crevasse fall during the descent from Manaslu $(8156 \mathrm{~m})$ after having reached the summit.

Of all Australian Himalayan climbers in the period since 1990, undoubtedly the most successful is Andrew Lock. By 2008, he had climbed 13 of the world's 148000 m summits, including Mt Everest; in October 2009, Lock summited on Shishapangma $(8027 \mathrm{~m}$ ) and joined the elite club of mountaineers who had summited all of the world's highest mountains. He is the first Australian to achieve this remarkable feat. ${ }^{6}$

Lock began his assault in 1993 with an ascent of K2 - arguably the hardest of the 8000-ers considering its altitude and technical difficulty. In 1997, he climbed Dhaulagiri (8167 m) and Broad Peak (8047 m), becoming the first Australian to climb two $8000 \mathrm{~m}$ mountains in the same year. He repeated the feat in $2002 \mathrm{with}$ ascents of Manaslu (8156 m) and Lhotse $(8511 \mathrm{~m})$, and in 1999, he reached the summits of Gasherbrum I (8068 m) and II (8035 m) on the same trip. Three of his ascents - Nanga Parbat (8125 m), Annapurna (8091 m) and Gasherbrum I-were first Australian ascents.

Even more impressive is the style of Lock's climbs. He has adopted a bold approach, climbing either alone or in small groups, which emphasises skill, stamina and judgment more than logistical backup. His ascent of Broad Peak in 1997 was typical of his bold approach, with a completely solo climb from base camp to the top and a very high bivvy just under the summit. Lock also has the judgment, however, to pull back when conditions are not right, having retreated from just below the summit of Kangchenjunga, the world's thirdhighest mountain.

Building on the increasing experience of Australians in the great ranges of Asia, more and more Australians are becoming guides on commercial expeditions. Mike Groom was one of the first and his strength and composure on the illfated 1996 commercial expeditions to Everest prevented an even worse disaster. Groom was the only surviving guide from the Rob Hall-led expedition; his tireless efforts along the descent route and at the South Col provided some

6 Groom, M. 1997, Sheer Will, Random House Australia, Milsons Point. 
much needed organisation to a rapidly deteriorating, chaotic situation. ${ }^{7}$ Other Australian mountaineers who have guided on commercial expeditions include Andrew Lock and Duncan Chessell.

\section{The last word}

This book has focused on the years from 1975 to 1990 as the formative period in Australian Himalayan climbing, highlighting two major strands that led to the first Australian ascents of Mt Everest. One of these was centred on the ANU Mountaineering Club (ANUMC), which mounted the first major Australian expedition to the Himalaya in 1978 (Chapters 6 and 7). The ascent of Dunagiri by Tim Macartney-Snape and Lincoln Hall of the ANUMC team was the first 7000 $\mathrm{m}$ success by an Australian expedition and propelled the Macartney-SnapeHall team towards eventual success on Mt Everest in 1984 - the first Australian ascent (by Macartney-Snape and Greg Mortimer; see Chapters 11 and 12).

The second strand centred on the AAA, which had its origins in Canberra about the same time (Chapter 13). From the late 1970s, the AAA steadily amassed a wealth of climbing experience in the great ranges of Asia and built a large cadre of skilled Himalayan climbers. The AAA was a significant driving force behind the 1988 Australian Bicentennial Everest Expedition (ABEE), which achieved the second Australian ascent of the world's highest peak. The final push to the top was a remarkable, nerve-racking fight against high-altitude deterioration and exhaustion by Pat Cullinan and Paul Bayne (Chapter 22).

The lineage of these original two strands of Australian Himalayan mountaineering continues well into the new millennium. In 2006, Lincoln Hall got his second chance at Mt Everest, 22 years after he played an integral part in the first successful ascent. In 1984, poised to go for the summit from the high camp at the top of the Great Couloir on the North Face of Everest, Hall pulled back on the summit day as Macartney-Snape, Mortimer and Andy Henderson continued towards the top. Showing a considerable amount of judgment, Hall had hot tea waiting for the exhausted trio at top camp when they returned and assisted Mortimer on the descent. His own chance to summit Everest had seemingly passed.

In 2006, Lincoln Hall was again on the north side of Everest, ascending towards the top via the North Ridge. This time he was moving well on the upper reaches of the mountain and reached the summit, closing the circle that had begun with the ANUMC's first aspirations for Everest after the Dunagiri success. As is

7 Ibid. 
always the case on big mountains, however, reaching the summit is only half of the climb - often the easier half. Hall's descent of Everest turned into an epic of monumental proportions, achieving headlines in newspapers around the world.

Not far below the summit, Hall began to succumb to altitude sickness, probably cerebral oedema. He deteriorated rapidly and moving soon became difficult. Despite heroic efforts by expedition staff to assist him down, he was eventually left to die high on Everest. Without a sleeping-bag out in the open on the mountain, he was passed in the pre-dawn hours by ascending climbers who assumed he was dead. Reports of his death were dispatched from the expedition base camp and travelled around the world, quickly reaching his family and friends in Australia.

As dawn arrived, Hall almost literally returned to life from an apparent state of death. Surprised to see him alive and able to move and talk, a passing climbing team rendered assistance and, accompanied by members of his expedition's staff, Hall eventually descended and began the long recovery from his ordeal. The account by Hall in his book Dead Lucky of his night on the mountain suspended between life and death has become an instant classic in the mountaineering literature.

If Hall has achieved worldwide fame for defying death high on Everest, Zac Zaharias, whose career originates from the beginnings of the AAA - the other original strand of Australian Himalayan mountaineering - has established the longest climbing career in the Himalaya of any Australian mountaineer.

Starting with the AAA's expedition to Ganesh IV in 1981, Zaharias has remained active in the great ranges of Asia to the present day - a period of 29 years. Through this time, he has participated in 15 Himalayan expeditions, has been leader, co-leader or team leader on 10 of them and has climbed five $8000 \mathrm{~m}$ peaks. On 25th May 2010 Zaharias reached the summit of Everest from the northern side, adding the world's highest peak and his sixth $8000 \mathrm{~m}$ peak to his impressive record. It is fitting that the last word goes to Zaharias:

Many professionals, particularly urban professionals, are now choosing to have their first Himalayan experience, and often their first mountaineering experience, with a commercial operator. The national, club or 'mates' expedition is becoming less prevalent but these 'homegrown', self-help affairs arguably immerse the participants more fully into the total Himalayan experience where one needs to deal with all facets of planning, organisation, negotiation and climbing.

Since the start of the new millennium there have been greater levels of Australian climbing in the Himalayas, with a distinct focus on the 8000 metre peaks. This focus on trade or 'sports' routes is perhaps a reflection 
of the times with greater wealth, easier access to the Himalayas and the need to escape a mundane urban existence driving more Australians into the solitude, tranquillity and sheer challenge of the mountains. Beyond the 8000 metre peaks is a vast, diverse and largely unknown landscape that continues to inspire intrepid climbers who are prepared to go off the beaten track in search of unique and unbridled challenges. ${ }^{8}$ 


\section{Bibliography}

AAA Newsletter 1981, 'Ganesh IV expedition, March to May 1981', AAA Newsletter, no. 1/81 (August), p. 3.

Agnew, B. 1982, Ganesh IV expedition report, AAA Report no. NG 1/82, Australian Army Alpine Association, Canberra.

Allan, R. 1978, 'High adventure on Dunagiri', The Canberra Times, 9 June 1978, p. 8.

Allen, P. 1980, 'White Sail: the ascent', Backpack, no. 2, pp. 20-3.

Allen, P. 1984, 'Nilgiri North. Wild information', Wild, no. 12 (Autumn), pp. 13-17.

Allen, P. 1988, The Australian Bicentennial Everest Expedition 1988, Expedition report, Unpublished ms.

Andrews, R. 1977, 'ANU team plans Himalayan assault', The Canberra Times, 11 July 1977.

Andrews, R. 1978, 'Science of seeds in soiled socks', The Canberra Times, 1 April 1978.

ANU Reporter 1975, 'Mountaineering club plans 1978 Himalayas trip', ANU Reporter, 14 November 1975.

ANU Reporter 1978, ‘ANU mountaineers poised for Aust.'s first Himalayan assault', ANU Reporter, 31 March 1978.

ANU Reporter 1978, 'Dunagiri done!', ANU Reporter, 9 June 1978, p. 1.

ANU Reporter 1990, 'ANU graduate on top of the world', ANU Reporter, vol. 21, no. 7 (25 May 1990), p. 1.

Atkinson, B. 1989, 'Kasum Kangru 1988', New Zealand Alpine Journal, vol. 42, pp. $52-3$.

Australian Army Alpine Association 1986, Report of the Army Alpine Association Broad Peak (8047 metres) expedition, Pakistan, 28 June to 7 September 1986, Report no. R852-5-2, Army Alpine Association, Canberra.

Australian Army Alpine Association 1988, ABEE team profiles, Annex A to CDF Brief, 14 February 1988, Australian Army Alpine Association, Canberra. 
Himalayan Dreaming

Australian Bicentennial Everest Expedition 1988, The Australian bicentennial Everest expedition 1988, Expedition report.

Australian Everest Expedition 1984, Australians on Everest, Brochure accompanying lecture tour, The First Australian Everest Expedition, 1984.

Australian Geographic 1990, 'Corroboree- out there', Australian Geographic, no. 17 (January-March), p. 29.

Australian Geographic 1990, 'Out there', Australian Geographic, no. 18 (AprilJune), p. 27.

Australian Geographic 1991, 'AG Society news', Australian Geographic, no. 23 (July-September), p. 7.

Australian Geographic 1991, 'Out there-corroboree', Australian Geographic, no. 23 (July-September), p. 26.

Australian Geographic Society Members' Newsletter 1991, 'AG Centre visitors', Australian Geographic Society Members' Newsletter, April, pp. 1-2.

Australian Information Service 1978, Australian Expedition to the Himalayas, April 1978, Australian High Commission, New Delhi.

Australian National University Mountaineering Club Himalayan Expedition Incorporated 1977, Himalayan Expedition 1978, Expedition prospectus, Canberra.

Balderstone, S. 1984, 'Everest climbers again set to go', The Canberra Times, 2 October 1984, p. 10.

Balderstone, S. 1984, 'Today's the day for Australians' assault on Everest', The Canberra Times, 2 October 1984, p. 1.

Balderstone, S. 1984, 'Australians conquer Everest', The Age, 5 October 1984, p. 1.

Baldwin, K. 1978, 'Scientific projects for Himalayan climbers', The Canberra Times, 25 March 1978.

Baldwin, K. 1989, 'Not in the brochure', New Zealand Alpine Journal, vol. 42, pp. $47-8$.

Bamford, D. and Rowlands, R. 1985, 'Overseas news', New Zealand Alpine Journal, vol. 38, 58-9.

Bass, R. and Wells, F. with Ridgeway, R. 1986, Seven Summits, Pan Books, London. 
Baxter, C. 1981, 'Australia's leading climbers', Mountaineering '81, (Melbourne University Mountaineering Club journal), pp. 23-4.

Baxter, C. 1985, 'Everest: the other side', Editorial, Wild, no. 15 (Summer), p. 3.

Baxter, C. 1985, 'The West Ridge', Wild, no. 15 (Summer), p. 33.

Baxter, C. 1985, 'Chris Bonington in Australia. Interview', Wild, no. 16 (Autumn), pp. 26-9.

Baxter, C. 1985, 'White knight?', Wild, no. 18 (Spring), pp. 22-7.

Baxter, C. 1989, “Thin Air: Encounters in the Himalayas", by Greg Child. Review', Wild, no. 33 (Winter), p. 77.

Baxter, C. 1990, 'Child's play', Wild, no. 37 (Winter), pp. 58-63.

Bell, S. 1989, 'The international Himalchuli West expedition, 1989', Himalayan Journal, vol. 46, pp. 35-8.

Berry, M. 1980, 'White Sail: the approach', Backpack, no. 2, pp. 15-19.

Boardman, P. 1977, 'Changabang commentary', Mountain, no. 55 (May-June), pp. 18-27.

Boardman, P. 1982, Sacred Summits, Arrow Books, London.

Bonington, C. 1982, Kongur. China's elusive summit, Hodder \& Stoughton, London.

Bonington, C. 1989, Mountaineer. Thirty years of climbing on the world's great peaks, Diadem Books, London.

Bonington, C. and Clarke, C. 1983, Everest: The unclimbed ridge, Hodder \& Stoughton, London.

Borrell, A. 1986, 'To climb a mountain', Saturday Magazine, Townsville Bulletin, 10 January 1986, p. 12.

Bremer-Kamp, C. 1987, Living on the Edge, Macmillan Australia, South Melbourne.

Bremer-Kamp, C. and Chandler, C. 1982, 'Yalung Kang: a two person attempt', Mountain, no. 88 (November/December), pp. 32-4.

Brennan, W. 1990, 'Mountain man', The Australian Magazine, 15-16 September 1990, pp. 56-66. 
Himalayan Dreaming

Buchanan, M. 1985, 'Obituary. Craig Nottle. 1961-1981', New Zealand Alpine Journal, vol. 38, p. 139.

Bunton, S. 1984, 'Annapurna III', Action Outdoor, August/September, pp. 40-5.

Burke, L. 1985, 'Roskelley's sporting proposition', Outside, February, p. 5.

Butler, D. 1980, 'Marie Byles_obituary', New Zealand Alpine Journal, vol. 33, pp. 118-19.

Butler, D. 1990, Private communications, 27 January 1990 and 1 March 1990.

Butler, D. 1991, The Barefoot Bushwalker, Australian Broadcasting Corporation, Sydney.

Carr, S. 1984, 'Overseas info', New Zealand Alpine Journal, vol. 37, p. 62.

Cashman, J. 1981, 'An excellent campsite', AAA Newsletter, no. 1/81 (August), pp. $4-7$.

Cheney, M. J. 1980, Nepal Himalayan expedition report premonsoon 1980, Unpublished ms.

Cheney, M. J. and Hawley, E. 1984, 'Makalu, West Buttress attempt and tragedy', American Alpine Journal, pp. 230-1.

Chester, J. 1981, 'Annapurna tragedy', Australian Rock, vols 3-4, no. 19.

Chester, J. 1987, 'Broadside!', Wild, no. 24 (Autumn), pp. 44-8.

Chester, Q. 1986, 'Doug Scott, the mountaineer's mountaineer. Interview', Wild, no. 20 (Autumn), pp. 38-41.

Child, G. 1977, 'Yosemite: a crash course for the ravers', Thrutch, vol. 73 (197778).

Child, G. 1978, 'Pacific cruise', Mountain, no. 61 (May/June), pp. 37-9.

Child, G. 1981, 'The empire strikes back!', Mountain, no. 78 (March/April), pp. 36-43.

Child, G. 1982, 'Himalayan hopefuls', Wild, no. 3 (Summer), pp. 30-4.

Child, G. 1984, 'Mixed emotions. Australians in the Himalayas', Wild, no. 12 (Autumn), pp. 30-4.

Child, G. 1987, 'Meanwhile, on Gasherbrum IV...' , Outside, (Mountain Designs newsletter), vol. 12, no. 3 (March), pp. 38-77. 
Child, G. 1988, Thin Air: Encounters in the Himalayas, Patrick Stephens, Wellingborough, England.

Child, G. 1989, 'You come back!', in J. Chester, The Himalayan Experience, Simon \& Schuster, Sydney.

Child, G. 1990, 'Australians on K2', Outside, (Mountain Designs newsletter), vol. 3, no. 1 (March).

Child, G. 1991, 'A margin of luck', Climbing, February/March.

Child, G. 1991, 'Makalu pilgrimage', Wild, no. 39 (Summer), pp. 42-7.

Child, G. 1992, 'Triumph on K2', Australian Geographic, no. 25 (JanuaryMarch), pp. 68-89.

Child, G. and Krakauer, J. 1987, 'The dangerous summer', Outside, (Mountain Designs newsletter), vol. 12, no. 3 (March).

Clarke, P., Blair, J. and Beagle, M. 1984, 'Up Everest-by the toughest trail', The Sun, 26 November 1984, p. 12.

Cleare, J. 1975, Mountains, Macmillan, London.

Clio 1990, 'Dr Dark: portrait of a pioneer', Rock, no. 12 (January-June), pp. $18-21$.

Colley, A. 1990, 'Ageless adventurer', Wild, no. 36 (Autumn), pp. 52-5.

Coote, G. 1988, 'The rocks are her friends', Australian Geographic, no. 10 (AprilJune), pp. 112-13.

Coote, G. 1989, 'The rocks are her friends-Dot Butler', Australian Geographic, no. 16 (October-December), pp. 112-13.

Cowper, R. 1991, 'Lydia Bradey', New Zealand Alpine Journal, vol. 78, no. 1 (March/April), pp. 38-41.

Cox, S. 1986, 'Bumblies abroad', New Zealand Alpine Journal, vol. 39, pp. 60-3.

Cullinan, P. 1979, Proposal for Australian Army Alpine Association adventure training Australia-Nepal Mt Gauri Shankar expedition 1980, Report no. 852/2KQ/15, 10 December 1979, Australian Army Alpine Association, Canberra.

Cullinan, P. 1980, 'Australian Gauri Shankar (Tseringma) expedition', Himalayan Journal, vol. 37, pp. 19-22. 
Himalayan Dreaming

Cullinan, P. 1987, Report of the Army Alpine Association Broad Peak (8047 metres) expedition, Pakistan, 28 June to 7 September 1986, Report no. R852-52, Australian Army Alpine Association, Canberra.

Cullinan, P. and Brammer, G. 1980, Report on the first ascent of Tseringma Peak, Report no. 852/1/1, 23 October 1980, Australian Army Alpine Association, Canberra.

Curran, J. 1989, K2, Triumph and Tragedy, Grafton Books, London.

Davis, S. 1990, 'Mustagh Ata', New Zealand Alpine Club Bulletin, November/ December, p. 45.

Deacock, W. 1974-75, 'Mulkila expedition', Seldom Newsletters.

Deacock, W. 1975, 'The Silver God mountain (Mulkila) 1975', Himalayan Journal, vol. 34, pp. 156-7.

Deacock, W. 1975, The fifth silver god, Report on Mulkila expedition, Unpublished ms.

Deacock, W. 1989, 'I remember the days of complete euphoria', in J. Chester, The Himalayan Experience, Simon \& Schuster, Sydney.

Deacock, W. 1989, Private communication, 17 September 1989.

Deka, N. 1989, International Gangotri expedition 1988, Expedition report, Unpublished ms.

Dingle, G. and Perry, M. 1986, 'Chomolungma: New Zealanders on the North Face of Everest (sketch maps)', New Zealand Alpine Club Bulletin, October, pp. 10-11.

du Faur, F. 1915 [1975], 'The conquest of Mt Cook', in F. Keenlyside, Peaks and Pioneers, Paul Elke, London.

Duff, J. 1989, 'On a high', Sunday Herald, 12 November 1989, pp. 30-7.

Farquharson, J. 1977, 'ANU climbers in ambitious mountaineering venture', The Canberra Times, 10 December 1977.

Finch, G. I. 1924, The Making of a Mountaineer, J. W. Arrowsmith, Bristol, [Second edn, 1988].

Freeman-Greene, S. 1991, 'Muir. The Australian way', Australian Airlines Inflight Magazine, April, p. 11. 
French, D. 1987, 'Bataille pour la Jannu', New Zealand Alpine Journal, vol. 40, pp. 88-90.

French, D. 1987, 'Jannu 1986', New Zealand Alpine Club Bulletin, March, pp. 8-9.

From, F. 1984, 'No fun on Makalu', Wild, no. 12 (Autumn), pp. 36-7.

Gabites, G. 1986, 'Ama Dablam. Overseas climbing news', New Zealand Alpine Club Bulletin, April, p. 7.

Glasgow, M. J. P. 1955, 'The gradual approach', New Zealand Alpine Journal, vol. 16, pp. 1-4.

Gordon, J. 1990, 'Macartney-Snape wanted more than "icing on the top"', The National Graduate, (ANU Convocation magazine), vol. 1, no. 1 (Spring), p. 7.

Gration, P. C. 1975, The RAE Himalayan expedition 1975, Expedition report, Unpublished ms.

Groom, M. 1986, 'Himalayan apprenticeship', Wild, no. 22 (Spring), pp. 55-6.

Groom, M. 1997, Sheer Will, Random House Australia, Milsons Point.

Habeler, P. 1978, Everest: Impossible victory, Wilhelm Goldmann, Munich, [English translation by David Heald, 1979, Arlington Books, London].

Haley, V. 1989, 'Dr Flood: climbing life's unconquered peaks', The Canberra Times, 29 October 1989, p. 32.

Hall, L. 1979, 'Dunagiri', New Zealand Alpine Journal, vol. 32, pp. 57-9.

Hall, L. 1982, 'More on China. Wild information', Wild, no. 3 (Summer), p. 10.

Hall, L. 1985, White Limbo, Weldons, Sydney. Re-published in May 2007 by Random House Australia, North Sydney.

Hall, L. 1990, “"Thin Air: Encounters in the Himalaya”, by Greg Child. Review', Australian Geographic, no. 17 (January-March), p. 117.

Hall, L. 1992, 'Greg Mortimer-a profile', Wild, no. 44 (Autumn), pp. 50-4.

Hall, L. 2007, Dead Lucky: Life after death on Mt Everest, Random House Australia, North Sydney.

Hall, L. and Henderson, A. 1985, Public lecture on First Australian Everest Expedition, Coombs Lecture Theatre, The Australian National University, Canberra. 
Himalayan Dreaming

Hefner, R. 1987, 'Team set for assault on remote Himalayan peak', The Canberra Times, 18 October 1987, p. 8.

Henderson, A. 1985, 'Sweet and sour', Mountain, no. 104, pp. 28-33.

Hill, G. 1986, 'Shivling sojourn', Wild, no. 22 (Spring), pp. 44-8.

Hillary, P. 1983, 'Lhotse '82', New Zealand Alpine Journal, vol. 38, pp. 71-6.

Hillary, P. 1984, 'Makalu West Pillar', New Zealand Alpine Journal, vol. 37, p. 51.

Hillary, P. 1988, 'Everest south pillar', New Zealand Alpine Journal, vol. 41, pp. 34-5.

Hillary, P. 1988, Rimo. Mountain on the Silk Road, Hodder \& Stoughton, London.

Himalayan Club Newsletter 1990, 'Himalchuli West (7540 m)', Himalayan Club Newsletter, no. 43, p. 18.

Himalayan Club Newsletter 1990, 'Kashmir 1989', Himalayan Club Newsletter, no. 43 , p. 28.

Himalayan Club Newsletter 1991, 'Everest. Nepal (pre-monsoon) 1990', Himalayan Club Newsletter, no. 44, p. 15.

Himalayan Journal 1977, 'Expeditions, 1977', Himalayan Journal, vol. 35.

Himalayan Journal 1978, 'Expeditions, 1978', Himalayan Journal, vol. 36, p. 232.

Himalayan Journal 1979, 'Expeditions, 1979', Himalayan Journal, vol. 36, p. 218.

Himalayan Journal 1979, 'Expeditions, 1979-Kashmir, Ladakh, Kishtwar',Himalayan Journal, vol. 36, p. 232.

Hindustani Times 1978, 'CIA nuclear device causes concern', Hindustani Times, 14 April 1978, p. 1.

Hunter, M. 1986, 'Overseas climbing news. Langshisa Ri', New Zealand Alpine Club Bulletin, August, p. 7.

Jones, K. 1976, 'Review of “Wall of Shadows" by Graeme Dingle', New Zealand Alpine Journal, vol. 29, pp. 19-20.

Kapadia, H. 1980, 'Editorial', Himalayan Journal, vol. 37, p. 1.

Keenlyside, F. 1975, Peaks and Pioneers, Paul Elke, London. 
Keneally, T. 1989, 'Foreword', The Loneliest Mountain, Simon \& Schuster, Sydney.

Komarkova, V. 1981, 'American women's expedition to Dhaulagiri I, Pear Route attempt', American Alpine Journal, pp. 267-71.

Krakauer, J. 1985, 'Return to the North Face', Outside, (Mountain Designs newsletter), February, pp. 29-32, 68.

Lambert, P. 1984, Report on the army expedition to the Nepalese Himalaya 26 Sep - 1 Nov 84, Report no. R852/1/1, 8 November 1984, Australian Army Alpine Association, Canberra.

Logan, H. 1990, Great Peaks of New Zealand, John McIndoe, Dunedin, New Zealand.

Macartney-Snape, T. 1979, The Ascent of Dunagiri. The Corian, August, Geelong Grammar School, pp. 203-7.

Macartney-Snape, T. 1984, 'Success on Annapurna II', Wild, no. 12 (Autumn), pp. 38-41.

Macartney-Snape, T. 1985, 'Mt Everest, the Australian ascent', Wild, no. 15 (Summer), pp. 26-32.

Macartney-Snape, T. 1986, 'Gasherbrum IV', Wild, no. 22 (Spring), pp. 48-54.

Macartney-Snape, T. 1987, Harder Than Everest, Film, Australian Broadcasting Corporation, Sydney.

Macartney-Snape, T. 1988, 'K2', Wild, no. 28 (Autumn), pp. 36-7.

Macartney-Snape, T. 1989, 'Getting out', Outside, (Mountain Designs newsletter), vol. 2, no. 2 (June), p. 1.

Macartney-Snape, T. 1989, 'Desert climbing', Outside, (Mountain Designs newsletter), vol. 2, no. 3 (December), p. 3.

Macartney-Snape, T. 1990, 'Taking personal responsibility', Australian Geographic, no. 17 (January-March), p. 31.

Macartney-Snape, T. 1991, 'From the sea to the top of the world', Australian Geographic, no. 23 (July-September), pp. 30-49.

Mackenzie, R. 1983, 'Frozen turkey', New Zealand Alpine Journal, vol. 36, pp. 93-6. 
Himalayan Dreaming

McKinnon, M. 1988, 'Australian-Soviet climbing expedition to Central Asian Russia', Australian Rockclimber, pp. 16-17.

McMahon, K. 1981, 'Captain Cruch. The Australian Ama Dablam expedition, 1981', New Zealand Alpine Journal, vol. 34, pp. 63-7.

Mercer, C. 1990, 'On top of the world', Mobilia-Mobil Corporation Newsletter, pp. 6-7.

Miller, K. J. 1958, 'The Imperial College Karakoram expedition, 1957', Himalayan Journal, vol. 21, pp. 71-9.

Miller, K. J. 1989, Private communication, 7 November 1989.

Monteath, C. 1978, 'Overseas news', New Zealand Alpine Journal, vol. 31, p. 52.

Monteath, C. 1980, 'Overseas news', New Zealand Alpine Journal, vol. 33, p. 74-5.

Monteath, C. 1983, 'Overseas mountaineering', New Zealand Alpine Journal, vol. 36, pp. 60-5.

Monteath, C. 1986, 'Interview with Geoff Wayatt', Wild, no. 21 (Winter), pp. 38-41.

Monteath, C. 1986, 'The man who brought English air to Everest', Geo, vol. 8, no. 4 , pp. $40-51$.

Monteath, C. 1988, 'Overseas climbing news 1986-1988', New Zealand Alpine Journal, vol. 41, pp. 54-6.

Monteath, C. 1989, 'New Zealand alpinists climb tower in Pakistan', New Zealand Alpine Club Bulletin, September/October, pp. 30-2.

Monteath, C. 1990, "Beyond the Icefall." Himalaya. Alpine book roundup', New Zealand Alpine Club Bulletin, June/July, p. 58.

Moor, R. 1985, Report on the army expedition to the Nepalese Himalaya 13 Sep - 15 Nov 85, Report no. R852-5-1(2), 19 December 1985, Australian Army Alpine Association, Canberra.

Mortimer, G. 1979, 'Overseas news', New Zealand Alpine Journal, vol. 32, pp. 44-5.

Mortimer, G. 1990, 'K2-savage mountain success', Hostel Travel, (YHA magazine), pp. 8-10.

Mountain 1980, 'Expedition report-Annapurna III', Mountain, no. 74, p. 11. 
Mountain 1981, 'Dhaulagiri I (26,794 ft). Info-Greater Himalaya', Mountain, no. 77 (January/February), p. 11.

Mountain 1981, 'Info-Greater Himalaya', Mountain, no. 80 (July/August), p. 13.

Mountain 1981, 'Shivling (6543 m), Gangotri. Info-Greater Himalaya', Mountain, no. 80 (July/August), p. 13.

Mountain 1984, 'Info-Greater Himalaya', Mountain, no. 96 (March/April).

Mountain 1984, 'Info-Greater Himalaya', Mountain, no. 99 (September/ October), p. 9.

Mountain 1985, 'Antipodean triumph and tragedy. Info-Greater Himalaya', Mountain, no. 102 (March/April), p. 12.

Mountain 1985, 'Kangchenjunga (8586 m). Info-Greater Himalaya', Mountain, no. 102 (March/April), p. 16.

Mountain 1985, 'Stop press. Indian Everest tragedy. Info - Greater Himalaya', Mountain, no. 106 (November/December), p. 13.

Mountain 1986, 'Info-Greater Himalaya', Mountain, no. 110 (July/August), p. 11.

Mountain 1986, 'Gasherbrum IV (7925m). Info- Greater Himalaya', Mountain, no. 111 (September/October), p. 10.

Mountain 1986, 'Nameless Tower (6215m). Info-Greater Himalaya', Mountain, no. 111 (September/October), p. 10.

Mountain 1986, 'Success and disaster on K2. Two major new lines climbed. Casarotto, Pietrowski, Rouse, among those killed. Info-Greater Himalaya', Mountain, no. 111 (September/October), pp. 8-10.

Mountain 1990, 'Cho Oyu (8201m). Info-Greater Himalaya', Mountain, no. 134 (July/August), p. 9.

Mountain 1990, 'Shishapangma (8046m). Info-Greater Himalaya', Mountain, no. 134 (July/August), p. 9.

Mountain 1990, 'American-Australian and Japanese expeditions climb K2 first since 1986. Info-Greater Himalaya', Mountain, no. 136 (November/ December), p. 11.

Mountain 1990, 'Menlungtse (7181m). Info-Greater Himalaya', Mountain, no. 136 (November/December), p. 12. 
Himalayan Dreaming

Muir, B. 1991, 'High-altitude cook', Rock, no. 14 (January-June), pp. 26-8.

Muir, J. 1989, 'To the roof of the world', Wild, no. 31 (Summer), pp. 36-9.

Muir, J. 1990, 'At the edge', Rock, no. 12 (January-June), pp. 26-9.

Muir, J. and Bradey, L. 1987, 'Gangotri', New Zealand Alpine Club Bulletin, September, pp. 22-3.

Nanavita, J. C. 1991, 'Successes on K2', Himalayan Club Newsletter, no. 44, p. 27.

New Zealand Alpine Club Bulletin 1985, 'Overseas news-Everest', New Zealand Alpine Club Bulletin, October, p. 7.

New Zealand Alpine Club Bulletin 1985, 'Ama Dablam winter', New Zealand Alpine Club Bulletin, December, p. 12.

New Zealand Alpine Club Bulletin 1986, 'Don French to attempt Jannu', New Zealand Alpine Club Bulletin, August, pp. 9-10.

New Zealand Alpine Club Bulletin 1986, 'New Zealand Pumori expedition', New Zealand Alpine Club Bulletin, August, p. 9.

New Zealand Alpine Club Bulletin 1986, 'Broad Peak (8056 m)', New Zealand Alpine Club Bulletin, October, p. 8.

New Zealand Alpine Club Bulletin 1986, 'Gasherbrum IV (7925m)', New Zealand Alpine Club Bulletin, October, p. 7.

New Zealand Alpine Club Bulletin 1986, 'Pumori', New Zealand Alpine Club Bulletin, October, p. 5.

New Zealand Alpine Club Bulletin 1986, 'Shivling Southwest (6505 m)', New Zealand Alpine Club Bulletin, October, p. 7.

New Zealand Alpine Club Bulletin 1987, 'Hillary attempts Everest again', New Zealand Alpine Club Bulletin, September, p. 24.

New Zealand Alpine Club Bulletin 1987, 'New Zealand Karakoram expedition 1987', New Zealand Alpine Club Bulletin, September, pp. 15-17.

New Zealand Alpine Club Bulletin 1987, 'Who is Jon Muir?', New Zealand Alpine Club Bulletin, September, p. 24.

New Zealand Alpine Club Bulletin 1987, 'Frostbite nips Everest bid', New Zealand Alpine Club Bulletin, December, p. 21. 
New Zealand Alpine Club Bulletin 1988, 'Live show from Everest', New Zealand Alpine Club Bulletin, February/March, p. 63.

New Zealand Alpine Club Bulletin 1988, Australian bicentennial expedition going well', New Zealand Alpine Club Bulletin, April/May, p. 42.

New Zealand Alpine Club Bulletin 1988, 'Changtse expedition unsuccessful', New Zealand Alpine Club Bulletin, June/July, p. 40.

New Zealand Alpine Club Bulletin 1988, 'Live telecast from Everest', New Zealand Alpine Club Bulletin, June/July, p. 41.

New Zealand Alpine Journal 1960, 'Instruction course for Australians, December, 1959', New Zealand Alpine Journal, vol. 18, pp. 358-60.

New Zealand Alpine Journal 1980, 'Faye Kerr-obituary', New Zealand Alpine Journal, vol. 33, p. 126.

New Zealand Alpine Journal 1981, 'Overseas news', New Zealand Alpine Journal, vol. 34 , p. 51 .

New Zealand Alpine Journal 1982, 'Overseas news', New Zealand Alpine Journal, vol. 35 .

New Zealand Alpine Journal 1983, 'Overseas news', New Zealand Alpine Journal, vol. 36 .

New Zealand Alpine Journal 1985, ‘Obituary. William Robert (Fred) From', New Zealand Alpine Journal, vol. 38, p. 137.

Nicholson, A. M. 1988, 'To the top of the world', Bicentenary Newsletter, p. 24.

Noble, M. 1978, 'Changabang', New Zealand Alpine Journal, vol. 31, pp. 54-8.

Noel, J. B. L. 1927, Through Tibet to Everest, Hodder \& Stoughton, London.

Norman, S. 1985, 'Qomolungma retrospective, or “I'm looking backward to Tibet"', New Zealand Alpine Club Bulletin, December, pp. 9-10.

Nottle, C. 1983, 'Tour de farce', New Zealand Alpine Journal, vol. 36, p. 77.

Nottle, C. 1983, 'Wasted youth', Wild, no. 8 (Autumn), pp. 56-61.

Nottle, C. 1984, 'Obituary. Mark Moorhead', New Zealand Alpine Journal, vol. 37, p. 132.

Nyka, J. 1988, 'Australian bicentennial Everest expedition', New Zealand Alpine Club Bulletin, June/July, p. 39. 
Himalayan Dreaming

O'Connor, W. 1989, The Trekking Peaks of Nepal, The Crowood Press, Ramsbury, England.

O'Dowd, S. 1987, 'Bataille pur la Jannu', New Zealand Alpine Journal, vol. 40, p. 73.

O'Dowd, S. 1987, 'Overseas', New Zealand Alpine Journal, vol. 40, p. 73.

Outside 1989, 'Tim's latest Everest expedition', Outside, (Mountain Designs newsletter), vol. 2, no. 3 (December).

Outside 1990, 'Sea-to-summit report', Outside, (Mountain Designs newsletter), vol. 3, no. 1 (March).

Outside 1990, 'Aussie woman in unique attempt on Cho Oyu', Outside, (Mountain Designs newsletter), vol. 3, no. 2 (June), p. 1.

Outside 1990, 'Tim triumphs in solo climb', Outside, (Mountain Designs newsletter), vol. 3, no. 2 (June).

Outside 1990, 'Aussies scale savage mountain', Outside, (Mountain Designs newsletter), vol. 3, no. 3 (November), p. 1.

Outside 1992, 'Michael Groom - one day in the life', Outside, (Mountain Designs newsletter), Winter, pp. 2-3.

Perry, M. 1986, 'Qomolungma 1985', New Zealand Alpine Journal, vol. 39, pp. 49-56.

Pitham, P. 1984, 'Nilgiri', New Zealand Alpine Journal, vol. 37, pp. 56-8.

Putt, C. 1989, Private communications, 16 September 1989 and 15 January 1991.

Reeves, N. 1980, 'We prayed to the god of Annapurna', The Australian Women's Weekly, 14 May 1980, pp. 2-5.

Rheinberger, M. 1981, 'Changabang', Mountaineering '81, (Melbourne University Mountaineering Club journal), pp. 38-46.

Rheinberger, M. 1983, 'Nanda Devi 1982', New Zealand Alpine Journal, vol. 36, pp. 86-92.

Rheinberger, M. 1985, 'A touch of winter', New Zealand Alpine Journal, vol. 38, pp. $72-5$.

Rheinberger, M. 1987, 'Broad Peak 1986', New Zealand Alpine Journal, vol. 40, pp. 91-2. 
Roberts, D. 1986, 'The direct style of John Roskelley', Moments of Doubt, The Mountaineers, Seattle, Wash., pp. 145-60, [originally published in Outside, July/August 1983].

Roberts, J. 1987, 'Pumori', New Zealand Alpine Journal, vol. 40, pp. 95-6.

Russell, S. 1988, George Finch-The mountaineer. A memoir, J. W. Arrowsmith, Bristol, England.

Ryan, R. (dir) and Humphrey, S. (prod.) 1989, One More Step. The Australian Defence Force on Everest 1988, Video, Australian Army and Film Australia.

Sandilands, B. 1977, 'Australians to try new climb in Himalayas', Sydney Morning Herald, 13 July 1977.

Sandilands, B. 1978, 'Assault on Dunagiri', The Canberra Times, 11 April 1978.

Sandilands, B. 1978, 'Expedition Dunagiri, Himalayas', Sydney Morning Herald, 11 April 1978.

Sandilands, B. 1978, 'ANU team to pass near "CIA nuclear plants"”, The Canberra Times, 15 April 1978, p. 1.

Sandilands, B. 1978, "Spy devices" near our path to peak', Sydney Morning Herald, 15 April 1978, p. 1.

Sandilands, B. 1978, 'Gorge perils for climbers', Sydney Morning Herald, 25 April 1978, p. 1.

Sandilands, B. 1978, 'ANU mountaineers in blizzard on glacier', The Canberra Times, 17 May 1978, p. 3.

Sandilands, B. 1978, 'Snowstorms in the Himalaya lay traps for the unwary', Sydney Morning Herald, 17 May 1978, p. 1.

Sandilands, B. 1978, 'ANU team turns its eyes to Dunagiri's south-west ridge', The Canberra Times, 19 May 1978, p. 3.

Sandilands, B. 1978, 'Aust mountaineers switch their attack on Dunagiri', Sydney Morning Herald, 19 May 1978, p. 1.

Sandilands, B. 1978, 'Monsoon early: grim race for summit', The Canberra Times, 26 May 1978, p. 1.

Sandilands, B. 1978, 'Climbers race early monsoon', Sydney Morning Herald, 29 May 1978, p. 1. 
Sandilands, B. 1978, 'ANU climbing team conquers Dunagiri', The Canberra Times, 6 June 1978, p. 1.

Sandilands, B. 1978, 'Australian climber, 22, conquers Dunagiri', Sydney Morning Herald, 6 June 1978, p. 1.

Sandilands, B. 1978, 'Dunagiri conquered: dangerous descent', Sydney Morning Herald, 10 June 1978, p. 1.

Sandilands, B. 1978, 'Perilous return for climbers', The Canberra Times, 10 June 1978, p. 1.

Sandilands, B. 1978, 'Reflecting on Dunagiri: the final descent', Sydney Morning Herald, 12 June 1978.

Sandilands, B. 1979, 'Himalayan rescue', People, 4 September 1979, pp. 8-9.

Scarr, J. 1966, Four Miles High, Victor Gollancz, London.

Scott, D. 1988, 'British Makalu expedition, 1988', Himalayan Journal, vol. 46, pp. 139-40.

Scott, D. 1988, 'Forward', in G. Child, Thin Air: Encounters in the Himalayas, Patrick Stephens, Wellingborough, England.

Sedeen, M. (ed.) 1988, Mountain Worlds, National Geographic Society, Washington, DC.

Sheppard, T. 1984, 'Lincoln Hall, Everest mountaineer', Australian Adventurers, Angus \& Robertson, Sydney, pp. 3-14.

Sheridan, G. 1984, 'The icy hell of Annapurna', The Bulletin, 21 February 1984, pp. 49-54.

Shipton, E. 1963, Land of Tempest, Hodder \& Stoughton, London.

Shipton, E. 1985, The Six Mountain Travel Books, Diadem Books, London.

Simpson, J. 1988, Touching the Void, Jonathan Cape, London.

Sinclair, J. 1990, Private communication from the Private Secretary to the Prime Minister, 30 May 1990.

Spencer, M. 1982, British Army West Nepal expedition 1982, Report, Unpublished ms, pp. 6-13.

Staszewski, R. 1987, 'Ama Dablam in winter', Damart Newsletter, p. 5. 
Steffen, W. 1989, 'High style in the Himalayas', Silver Kris, (Singapore Airlines in-flight magazine), vol. 14, no. 10 (October), pp. 85-92.

Stephenson, P. J. 1961, 'The Saltoro expedition', The Himalayan Journal, vol. 23, pp. 71-9.

Stephenson, P. J. 1989, Private communication, 19 September 1989.

Stevens, W. 1991, 'Both ends burning', Long Reach, (journal of the Adelaide University Mountaineering Club), Summer, pp. 18-24.

Stone, M. 1979, 'On the shortcomings of Kodachrome', New Zealand Alpine Journal, vol. 32, pp. 60-1.

Strang, J. 1976, 'Jannu retrospect (2)', New Zealand Alpine Journal, vol. 29, pp. 13-16.

Sun Herald 1978, 'Aussie climber's summit ordeal', Sun Herald, 11 June 1978.

Sydney Morning Herald 1977, ‘Australian expedition to tackle Himalayan peaks', Sydney Morning Herald, 14 December 1977.

Sydney Morning Herald 1984, 'Australians on Everest', Sydney Morning Herald, November 1984, p. 8.

Tasker, J. 1982, Savage Arena, Methuen, London.

Taylor, P. 1964, Coopers Creek to Langtang II, Rigby, Adelaide.

Taylor, P. 1964, 'Langtang Himalaya', Himalayan Journal, vol. 25, pp. 69-76.

Taylor, P. 1966, 'Langtang Lirung, 1964', Himalayan Journal, vol. 27, pp. 141-3.

Temple, P. 1969, The World at Their Feet, Whitcombe \& Tombs, Christchurch, New Zealand.

The Canberra Times 1978, 'Three years of planning concludes', The Canberra Times, 30 March 1978.

The Canberra Times 1978, 'Foothill road big danger: climber', The Canberra Times, 9 June 1978, p. 1.

The Canberra Times 1978, 'Rough plaque makes Dunagiri success', The Canberra Times, 12 June 1978.

The Canberra Times 1978, 'Frostbitten ANU man says "I'm lucky", The Canberra Times, 13 June 1978. 
Himalayan Dreaming

The Canberra Times 1978, 'Hillary meets Dunagiri team', The Canberra Times, 14 June 1978.

The Canberra Times 1978, 'Dunagiri - a step towards Mt Everest', The Canberra Times, 15 June 1978.

The Canberra Times 1989, 'Australian man conquers Everest', The Canberra Times, 27 May 1989, p. 3.

The Canberra Times 1989, 'Success on Everest attributed to luck', The Canberra Times, 5 June 1989, p. 3.

The Canberra Times 1990, 'Long assault on Everest', The Canberra Times, 6 February 1990, p. 4.

The Canberra Times 1990, 'High adventure', The Canberra Times, 8 April 1990, p. 3.

The Canberra Times 1990, 'Fears subside for safety of Australian climber on Everest', The Canberra Times, 12 May 1990, p. 1.

The Canberra Times 1990, 'Australian climber of Everest on way down', The Canberra Times, 13 May 1990, p. 3.

The Canberra Times 1990, 'Training for climbers: get into a freezer', The Canberra Times, 3 December 1990, p. 4.

The Statesman 1978, 'MP's concern over Himalayan "spying"', The Statesman, 15 April 1978, p. 1.

The Statesman 1978, '49 harrowing hours to Dunagiri', The Statesman, 10 June 1978, p. 3.

Thompson, K. 1976, 'Jannu retrospect (1)', New Zealand Alpine Journal, vol. 29, pp. 9-13.

Thornton, M. 1990, 'From zero to heaven', The Canberra Times, 25 February 1990, p. 19.

Thornton, M. 1990, 'Faith stilled her fear as she waited', The Canberra Times, 15 September 1990, p. B3.

Thorton, M. and Chester, J. 1983, 'Fire and ice', Wild, no. 9 (Winter), pp. 30-5.

Tremble, T. 1987, 'Eiger!', Wild, no. 25 (Winter), pp. 62-5.

Trihey, L. 1988, 'An interview with Andy Henderson', Australian Rockclimber, pp. 12-13. 
Truscott, J. 1989, 'Satirical book review', AAA Newsletter, no. 3/89, p. 9.

Truscott, J. 1989, 'A lesson in high altitude expedition leadership', $A A A$ Newsletter, no. $4 / 89$.

Truscott, J. 1990, Military Mountaineering: A decade and a half of experience, Unpublished ms.

Turner, R. 1988, 'Australian Himalayan climbs. Changtse', Wild, no. 28 (Autumn), pp. 33-6.

Unsworth, W. 1981, Everest, Penguin Books, Middlesex, England.

Wayatt, G. 1976, 'Then the mountain took control...', New Zealand Alpine Journal, vol. 29, pp. 16-18.

Wayatt, G. 1980, 'Expeditions', New Zealand Alpine Journal, vol. 33, pp. 60-1.

Wells, W. 1980, 'Australian team sets out to climb Annapurna', The Australian Women's Weekly, 26 March 1980, pp. 2-3.

White, R. 1981, 'New Himalayan climb. Wild information', Wild, no. 2 (Spring), p. 6.

Whitehouse, I. 1981, 'Overseas overview', New Zealand Alpine Journal, vol. 34, p. 51.

Wilby, S. 1989, Beyond the Icefall, Child \& Associates, Sydney.

Wild 1981, 'Australians in the Himalayas. Wild information', Wild, no. 1 (Winter), p. 8.

Wild 1981, 'Himalayan tragedy. Wild information', Wild, no. 1 (Winter), p. 8.

Wild 1981, 'More Australian Himalayan climbs. Wild information', Wild, no. 2 (Spring), p. 6.

Wild 1982, 'Contributors - Greg Child', Wild, no. 3 (Summer), p. 13.

Wild 1982, 'Expeditions. Wild information', Wild, no. 5 (Winter), p. 11.

Wild 1982, 'Alpine successes. Wild information', Wild, no. 6 (Spring), p. 16.

Wild 1982, 'Contributors-Stephen Bunton', Wild, no. 6 (Spring), p. 25.

Wild 1982, 'Himalayan news. Wild information', Wild, no. 6 (Spring), p. 16.

Wild 1983, 'Australians on top of America. Wild information', Wild, no. 7 (Summer), p. 18. 
Himalayan Dreaming

Wild 1983, 'Mixed fortunes in the Himalaya. Wild information', Wild, no. 7 (Summer).

Wild 1983, 'Annapurna III revisited. Wild information', Wild, no. 8 (Autumn), p. 21.

Wild 1983, 'Contributors-Craig Nottle', Wild, no. 8 (Autumn), p. 83.

Wild 1983, 'Australian Himalayan news. Wild information', Wild, no. 9 (Winter), p. 17.

Wild 1983, 'Contributors-Jonathan Chester', Wild, no. 9 (Winter), p. 88.

Wild 1983, 'Australian Himalayan news. Wild information', Wild, no. 10 (Spring), p. 14.

Wild 1984, 'Contributors_-Jeff Williams', Wild, no. 11 (Summer), p. 89.

Wild 1984, 'Himalayan news. Wild information', Wild, no. 11 (Summer), p. 14.

Wild 1984, 'Annapurna III. Wild information', Wild, no. 12 (Autumn), p. 13.

Wild 1984, 'Contributors-Fred From', Wild, no. 12 (Autumn), p. 19.

Wild 1984, 'Tim Macartney-Snape. Contributors' profiles', Wild, no. 12 (Autumn), p. 21.

Wild 1984, 'Himalayan news. Wild information', Wild, no. 13 (Winter), p. 1719.

Wild 1984, 'Contributors - Glen Nash', Wild, no. 14 (Spring), p. 27.

Wild 1985, 'Success and tragedy on Mt Everest. Wild information', Wild, no. 15 (Summer), p. 5.

Wild 1985, 'Mountaineering. Wild information', Wild, no. 16 (Autumn), p. 17.

Wild 1985, 'New Zealand alpinism. Wild information', Wild, no. 16 (Autumn), p. 15.

Wild 1985, 'Expeditions. Wild information', Wild, no. 17 (Winter), p. 13.

Wild 1985, 'Ridge of sorrow', Wild, no. 17 (Winter), pp. 40-3.

Wild 1985, 'Wild information', Wild, no. 17 (Winter), p. 15.

Wild 1986, 'Contributors - Geoff Wayatt', Wild, no. 19 (Summer), p. 89.

Wild 1986, 'Overseas climbing news. Wild information', Wild, no. 19 (Summer), p. 16. 
Wild 1986, 'Himalayan news. Wild information', Wild, no. 20 (Autumn), p. 23. Wild 1986, 'Himalayan news. Wild information', Wild, no. 21 (Winter), p. 23. Wild 1986, 'Australian Himalayan successes. Wild information', Wild, no. 22 (Spring), p. 15.

Wild 1986, 'Contributors-Michael Groom', Wild, no. 22 (Spring), p. 85. Wild 1986, 'Himalayas! Wild information', Wild, no. 22 (Spring), p. 15. Wild 1986, 'Stop press. Wild information', Wild, no. 22 (Spring), p. 27. Wild 1987, 'Broad Peak. Wild information', Wild, no. 23 (Summer), p. 23. Wild 1987, 'Keith Egerton. Wild information', Wild, no. 24 (Autumn), p. 17. Wild 1987, 'Alpine style? Wild information', Wild, no. 25 (Winter), p. 27. Wild 1987, 'Arise, Sir Tim. Wild information', Wild, no. 25 (Winter), p. 25. Wild 1987, 'Terry Tremble. Contributors', Wild, no. 25 (Winter), p. 7. Wild 1987, 'Antarctica. Wild information', Wild, no. 26 (Spring), p. 23. Wild 1987, 'Corrections. Wild information', Wild, no. 26 (Spring), p. 23. Wild 1987, 'Himalayan news. Wild information', Wild, no. 26 (Spring), p. 23. Wild 1987, 'Peak season. Wild information', Wild, no. 26 (Spring), p. 15. Wild 1987, 'Wild information', Wild, no. 26 (Spring), p. 21.

Wild 1988, 'Himalayan news. Wild information', Wild, no. 27 (Summer), p. 25. Wild 1988, 'Australians in the Himalayas. Wild information', Wild, no. 28 (Autumn), p. 23.

Wild 1988, 'Contributors-Rod Turner', Wild, no. 28 (Autumn), p. 85.

Wild 1988, 'Success in the south. Wild information', Wild, no. 29 (Winter), pp. 23-4.

Wild 1988, 'Australians climb Mt Everest. Wild information', Wild, no. 30 (Spring), p. 15.

Wild 1989, 'Himalayan news. Wild information', Wild, no. 31 (Summer), p. 25. Wild 1989, 'Antarctica. Wild information', Wild, no. 32 (Autumn), p. 19. 
Himalayan Dreaming

Wild 1989, 'Himalayan news. Wild information', Wild, no. 32 (Autumn), pp. 19-21.

Wild 1989, 'High times. Wild information', Wild, no. 33 (Winter), p. 27.

Wild 1989, 'Australian climbs Mt Everest. Wild information', Wild, no. 34 (Spring), p. 13.

Wild 1990, 'Himalayan new route. Wild information', Wild, no. 35 (Summer), p. 19.

Wild 1990, 'Karakoram new route. Wild information', Wild, no. 35 (Summer), p. 19.

Wild 1990, 'Mustagh Ata. Wild information', Wild, no. 35 (Summer), p. 19.

Wild 1990, 'Final extra. Wild information', Wild, no. 36 (Autumn), p. 15.

Wild 1990, 'Himalayas. Australians fire on the big ones. Wild information', Wild, no. 38 (Spring), p. 15.

Wild 1991, 'Success on the savage mountain. Wild information', Wild, no. 39 (Summer), p. 13.

Williams, J. 1989, 'Affair with a beautiful daughter', Wild, no. 33 (Winter), pp. $42-5$.

Wynne, B. 1978, 'Seeking the mountains' secrets', The Canberra Times, 17 September 1978, p. 9.

Zaharias, Z. 1982, Mt McKinley expedition report, Report no. MCK/66, Australian Army Alpine Association, Canberra.

Zaharias, Z. 1983, 'Australian expeditions to the Himalaya, 1977-1982', New Zealand Alpine Journal, vol. 36, pp. 83-5.

Zaharias, Z. 1984, Report on expedition to Nepalese Himalaya 20 Sep 83 - 16 Nov 83, [AAA Nilgiri report], 28 September 1984, Australian Army Alpine Association, Canberra.

Zaharias, Z. 1989, 'Notes on the lead-up towards Everest-army aspects', $A A A$ Newsletter, no. 3/89, pp. 1-7.

Zaharias, Z. 1990, 'Leadership at work on Everest - the final rejoinder', $A A A$ Newsletter, no. 1/90, pp. 11-24.

Zaharias, Z. 2001, 'High achievers: Australian Himalayan mountaineering since 1994', Wild, no. 80 (Autumn), pp. 30-5. 
Zaharias, Z. 2004, 'Top of the world: Australian Himalayan climbing 2001-2003', Wild, no. 80 (Autumn), pp. 40-7. 



\title{
Appendix: Record of Australian mountaineering in the Himalaya
}

\author{
Zac Zaharias
}

Table 1 Australian Himalayan climbs, 1922-2009 (based on surveys in Wild magazine)

\begin{tabular}{|c|c|c|c|c|}
\hline Year & Peak, route & Party members & Outcome & Comments \\
\hline 1922 & $\begin{array}{l}\text { Mt Everest } \\
\text { (8850 m) } \\
\text { N Ridge/Face, } \\
\text { Tibet }\end{array}$ & $\begin{array}{l}\text { George Finch, } \\
\text { member of } 11 \text {-man } \\
\text { British expedition }\end{array}$ & $\begin{array}{l}\text { Unsuccessful. Finch } \\
\text { and Geoffrey Bruce } \\
\text { reached } 8350 \text { m using } \\
\text { supplementary oxygen. }\end{array}$ & $\begin{array}{l}\text { First serious } \\
\text { attempt on } \\
\text { Mt Everest. } \\
\text { Australian } \\
\text { Finch climbed } \\
\text { higher than any } \\
\text { other human } \\
\text { had previously } \\
\text { climbed. Finch } \\
\text { proved that } \\
\text { supplementary } \\
\text { oxygen could } \\
\text { definitely benefit } \\
\text { climbers. }\end{array}$ \\
\hline 1957 & $\begin{array}{l}\text { Exploratory } \\
\text { expedition, } \\
\text { Karakoram, } \\
\text { Pakistan }\end{array}$ & $\begin{array}{l}\text { Geoffrey Bratt and } \\
\text { Grahame Budd, } \\
\text { members of } \\
\text { eight-man } \\
\text { British expedition } \\
\text { led by Eric Shipton }\end{array}$ & $\begin{array}{l}\text { Explored in Siachen } \\
\text { Glacier area. } \\
\text { Climbed Towitz } \\
\text { Peak (6400 m) and } \\
\text { Island Peak }(6860 \mathrm{~m}) .\end{array}$ & $\begin{array}{l}\text { Exploratory trip } \\
\text { mounted by } \\
\text { Imperial College } \\
\text { Mountaineering } \\
\text { Club. }\end{array}$ \\
\hline 1960 & $\begin{array}{l}\text { K12 (7470 m) } \\
\text { NW Ridge, } \\
\text { Karakoram, } \\
\text { Pakistan }\end{array}$ & $\begin{array}{l}\text { Jon Stephenson, } \\
\text { member of } \\
\text { four-man } \\
\text { British expedition }\end{array}$ & $\begin{array}{l}\text { Unsuccessful. } \\
\text { Stephenson climbed } \\
\text { with porter to } 6640 \\
\mathrm{~m} \text { and solo to } \\
7000 \mathrm{~m} .\end{array}$ & $\begin{array}{l}\text { Stephenson first } \\
\text { Australian to } \\
\text { climb to } 7000 \\
\text { m without } \\
\text { supplementary } \\
\text { oxygen. }\end{array}$ \\
\hline
\end{tabular}




\begin{tabular}{|c|c|c|c|c|}
\hline 1963 & \begin{tabular}{|l} 
Langtang II \\
$(6583 \mathrm{~m})$ \\
E Face, \\
Central Nepal
\end{tabular} & Peter Taylor & $\begin{array}{l}\text { Successful. Climbed } \\
\text { with four Sherpas. } \\
\text { Probably shortest-ever } \\
\text { Himalayan expedition. } \\
\text { Four days from road to } \\
\text { base camp; five days } \\
\text { to climb mountain. }\end{array}$ & $\begin{array}{l}\text { Sometimes cited } \\
\text { as first Australian } \\
\text { expedition } \\
\text { to Himalaya; } \\
\text { however, Taylor } \\
\text { was an itinerant } \\
\text { British geologist } \\
\text { stationed in } \\
\text { Australia for a } \\
\text { few years. }\end{array}$ \\
\hline \multirow[t]{2}{*}{1975} & $\begin{array}{l}\text { Jannu }(7710 \mathrm{~m}) \\
\text { N Face, } \\
\text { Eastern Nepal }\end{array}$ & $\begin{array}{l}\text { Geoff Wayatt, } \\
\text { member of } 12 \text {-man } \\
\text { New Zealand } \\
\text { expedition } \\
\text { led by Peter Farrell }\end{array}$ & $\begin{array}{l}\text { Unsuccessful. High } \\
\text { point reached: } \\
7360 \mathrm{~m} \text {. }\end{array}$ & $\begin{array}{l}\text { Wayatt first } \\
\text { Australian } \\
\text { on 'modern' } \\
\text { expedition. He } \\
\text { and Jim Strang } \\
\text { overcame major } \\
\text { obstacle of route } \\
\text { with bold, alpine- } \\
\text { style assault. }\end{array}$ \\
\hline & $\begin{array}{l}\text { Mulkila IV } \\
\text { (6517 m) } \\
\text { W Ridge, } \\
\text { Lahoul, India }\end{array}$ & $\begin{array}{l}\text { Michel Altermann } \\
\text { (France), Garry } \\
\text { Ash, Adrian Blake, } \\
\text { Dorothy Brown, } \\
\text { Warwick Deacock, } \\
\text { Jim Dorrington, } \\
\text { Harry Eldridge, } \\
\text { Josephine Flood, } \\
\text { Terri Jack (UK), } \\
\text { Derek Lucas, } \\
\text { Peter Morris, } \\
\text { Michael Richards, } \\
\text { John Ryder, } \\
\text { Keith Seddon, } \\
\text { John Wanless }\end{array}$ & $\begin{array}{l}\text { Unsuccessful. Reached } \\
6000 \mathrm{~m} \text {. Six members } \\
\text { subsequently climbed } \\
\text { Mulkila V }(5930 \mathrm{~m}) .\end{array}$ & $\begin{array}{l}\text { First truly } \\
\text { Australian } \\
\text { expedition to } \\
\text { the Himalaya. } \\
\text { Organised and } \\
\text { led by Warwick } \\
\text { Deacock. }\end{array}$ \\
\hline 1976 & $\begin{array}{l}\text { Bethartoli South } \\
\text { (6318 m) } \\
\text { Gangotri, India }\end{array}$ & $\begin{array}{l}\text { John Attkinson, } \\
\text { Peter Marsh, } \\
\text { Bob Ryan, Kevin } \\
\text { Westren } \\
\end{array}$ & Successful. & \\
\hline 1977 & $\begin{array}{l}\text { Changabang } \\
\text { (6864 m) } \\
\text { E Ridge, } \\
\text { Garhwal, India }\end{array}$ & $\begin{array}{l}\text { Charlie } \\
\text { Cuthbertson, } \\
\text { Andy Henderson, } \\
\text { Martin Hendy, } \\
\text { Garry Matthew, } \\
\text { Malcolm Noble }\end{array}$ & $\begin{array}{l}\text { Unsuccessful. } \\
\text { Henderson, Hendy } \\
\text { and Noble climbed to } \\
\text { within } 50 \text { vertical } m \\
\text { of summit. Stopped } \\
\text { by bad weather. }\end{array}$ & $\begin{array}{l}\text { First of many } \\
\text { Australian } \\
\text { attempts on } \\
\text { this striking } \\
\text { and difficult } \\
\text { mountain. }\end{array}$ \\
\hline
\end{tabular}




\begin{tabular}{|c|c|c|c|c|}
\hline & $\begin{array}{l}\text { Khumbu } \\
\text { trekking peaks } \\
\text { Eastern Nepal }\end{array}$ & $\begin{array}{l}\text { Geoff Batten, } \\
\text { Mike Douglas, } \\
\text { Fergus Fitzgerald, } \\
\text { Greg Hodge, } \\
\text { Phil Robinson, } \\
\text { Mendelt Tillema }\end{array}$ & Successful. & $\begin{array}{l}\text { First Australian } \\
\text { ascent of popular } \\
\text { trekking peak } \\
\text { Imja Tse (Island } \\
\text { Peak; } 6189 \mathrm{~m}) \\
\text { and of Parchamo } \\
(6187 \mathrm{~m}) .\end{array}$ \\
\hline 1978 & $\begin{array}{l}\text { Dunagiri } \\
\text { (7066 m) } \\
\text { SW Ridge, } \\
\text { Garhwal, India }\end{array}$ & $\begin{array}{l}\text { John Armstrong, } \\
\text { Ken Baldwin, Ken } \\
\text { Bell, Andy Blakers, } \\
\text { Andrew Bond, } \\
\text { Keith Burns, } \\
\text { Peter Cocker } \\
\text { John Finnigan, } \\
\text { Lincoln Hall, } \\
\text { Theo Hooy, Tim } \\
\text { Macartney-Snape, } \\
\text { Charlie Massy, } \\
\text { Mark Podkolinski, } \\
\text { Ben Sandilands, } \\
\text { Martin Stone }\end{array}$ & $\begin{array}{l}\text { Successful. } \\
\text { Macartney-Snape } \\
\text { reached summit; Hall } \\
\text { stopped } 200 \text { m short. } \\
\text { Epic descent through } \\
\text { electrical storm. Hall } \\
\text { suffered frostbite. }\end{array}$ & $\begin{array}{l}\text { Most significant } \\
\text { of early } \\
\text { Australian } \\
\text { expeditions. First } \\
\text { Australian ascent } \\
\text { of } 7000 \mathrm{~m} \\
\text { peak. Launched } \\
\text { careers of Tim } \\
\text { Macartney-Snape } \\
\text { and Lincoln Hall. }\end{array}$ \\
\hline \multirow[t]{3}{*}{1979} & $\begin{array}{l}\text { Dharamsura } \\
\text { (White Sail, } \\
6445 \mathrm{~m} \text { ) } \\
\text { SW Ridge, } \\
\text { Kulu, India }\end{array}$ & $\begin{array}{l}\text { Peter Allen, Max } \\
\text { Berry, Ed Neve, } \\
\text { Mike Rheinberger, } \\
\text { Andrew Rothfield, } \\
\text { Gary Wills }\end{array}$ & $\begin{array}{l}\text { Successful. All but } \\
\text { Berry reached summit. }\end{array}$ & $\begin{array}{l}\text { First Australian } \\
\text { ascent. Alpine } \\
\text { style. }\end{array}$ \\
\hline & $\begin{array}{l}\text { Angdu Ri } \\
\text { (5954 m) } \\
\text { NE Ridge, } \\
\text { Kulu, India }\end{array}$ & $\begin{array}{l}\text { Mike Rheinberger, } \\
\text { Andrew Rothfield }\end{array}$ & $\begin{array}{l}\text { Successful. Both } \\
\text { reached summit. }\end{array}$ & \\
\hline & $\begin{array}{l}\text { Ali Ratna Tibba } \\
\text { (5750 m) } \\
\text { SW Ridge, } \\
\text { Kulu, India }\end{array}$ & $\begin{array}{l}\text { Phil Cullen, } \\
\text { Lincoln Hall, Tim } \\
\text { Macartney-Snape }\end{array}$ & $\begin{array}{l}\text { Successful. Hall and } \\
\text { Macartney-Snape } \\
\text { reached summit. } \\
\text { They also climbed } \\
\text { Geru }(5100 \mathrm{~m}) \text {. }\end{array}$ & $\begin{array}{l}\text { First Australian } \\
\text { ascent. Alpine } \\
\text { style. }\end{array}$ \\
\hline \multirow[t]{2}{*}{1980} & $\begin{array}{l}\text { Dhaulagiri I } \\
\text { (8167 m) } \\
\text { NW Ridge, } \\
\text { Central Nepal }\end{array}$ & $\begin{array}{l}\text { Lynne Griffith, } \\
\text { member of } \\
\text { US women's } \\
\text { expedition led by } \\
\text { Vera Komarkova }\end{array}$ & $\begin{array}{l}\text { Unsuccessful. High } \\
\text { point reached: } \\
6500 \text { m. Expedition } \\
\text { abandoned when } \\
\text { Griffith killed in } \\
\text { avalanche. }\end{array}$ & $\begin{array}{l}\text { On first trip to } \\
\text { Himalayas, Lynne } \\
\text { Griffith killed } \\
\text { when avalanche } \\
\text { swept Camp II. }\end{array}$ \\
\hline & $\begin{array}{l}\text { Annapurna III } \\
\text { (7555 m) } \\
\text { N Face, } \\
\text { Central Nepal }\end{array}$ & $\begin{array}{l}\text { Geof Bartram, } \\
\text { Adrian Blake, Ken } \\
\text { Bowes, Jonathan } \\
\text { Chester, Steve } \\
\text { Colman, Warwick } \\
\text { Deacock, Brian } \\
\text { Fearnley (NZ), } \\
\text { Jack Higgs, } \\
\text { Ray Johnston, } \\
\text { Faye Kerr, Steve } \\
\text { McDowell, Colin } \\
\text { Monteath (NZ), } \\
\text { Stafford Morse, } \\
\text { Nick Reeves, } \\
\text { Richard Schmidt }\end{array}$ & $\begin{array}{l}\text { Unsuccessful. High } \\
\text { point reached: } \\
5000 \text { m. Expedition } \\
\text { abandoned when } \\
\text { Morse, Reeves } \\
\text { and Schmidt killed } \\
\text { in avalanche. }\end{array}$ & $\begin{array}{l}\text { Worst Australian } \\
\text { tragedy ever } \\
\text { in Himalaya; } \\
\text { compounded } \\
\text { when Faye Kerr } \\
\text { died of stomach } \\
\text { problems in India } \\
\text { after expedition. }\end{array}$ \\
\hline
\end{tabular}




\begin{tabular}{|c|c|c|c|c|}
\hline & $\begin{array}{l}\text { Gauri Shankar } \\
\text { (7146 m) } \\
\text { SE Ridge, } \\
\text { Eastern Nepal }\end{array}$ & $\begin{array}{l}\text { Chris Bennett, } \\
\text { Graham Brammer, } \\
\text { Wayne Carroll, } \\
\text { Pat Cullinan, } \\
\text { Mick Hardless, } \\
\text { Val Lishman, } \\
\text { Jim MacDonald, } \\
\text { John Remynse, } \\
\text { Paul Richards, } \\
\text { Barry Young }\end{array}$ & $\begin{array}{l}\text { Unsuccessful. High } \\
\text { point reached: } \\
\text { subsidiary summit } \\
\text { Tseringma }(6333 \mathrm{~m}) .\end{array}$ & $\begin{array}{l}\text { First Himalayan } \\
\text { expedition of } \\
\text { Army Alpine } \\
\text { Association } \\
\text { (AAA). First } \\
\text { ascent of } \\
\text { Tseringma. }\end{array}$ \\
\hline & $\begin{array}{l}\text { Changabang } \\
\text { (6864 m) } \\
\text { E Ridge, } \\
\text { Garhwal, India }\end{array}$ & $\begin{array}{l}\text { Peter Allen, } \\
\text { Paul Anderson, } \\
\text { Max Berry, John } \\
\text { Dunlop, Tim } \\
\text { Hughes, Pat Miller, } \\
\text { Malcolm Noble, } \\
\text { Mike Rheinberger, } \\
\text { Andrew Rothfield }\end{array}$ & $\begin{array}{l}\text { Successful. Anderson, } \\
\text { Rheinberger and } \\
\text { Rothfield reached } \\
\text { summit. }\end{array}$ & $\begin{array}{l}\text { First Australian } \\
\text { ascent. } \\
\text { Achievement } \\
\text { marred by death } \\
\text { of Tim Hughes in } \\
\text { fall in Rishi Gorge } \\
\text { on walk out. }\end{array}$ \\
\hline \multirow[t]{5}{*}{1981} & $\begin{array}{l}\text { Shivling } \\
\text { (6543 m) } \\
\text { E Pillar, } \\
\text { Gangotri, India }\end{array}$ & $\begin{array}{l}\text { Greg Child and } \\
\text { Rick White, } \\
\text { members of } \\
\text { international } \\
\text { expedition led } \\
\text { by Doug Scott }\end{array}$ & $\begin{array}{l}\text { Successful. Georges } \\
\text { Bettembourg, Child, } \\
\text { Scott and White } \\
\text { reached summit } \\
\text { after 13-day alpine- } \\
\text { style push. }\end{array}$ & $\begin{array}{l}\text { First ascent of E } \\
\text { Pillar of Shivling. } \\
\text { First Himalayan } \\
\text { success for } \\
\text { Greg Child. }\end{array}$ \\
\hline & $\begin{array}{l}\text { Ganesh IV } \\
\text { (7102 m) } \\
\text { S Face/E Ridge, } \\
\text { Central Nepal }\end{array}$ & $\begin{array}{l}\text { Brian Agnew, } \\
\text { John Cashman, } \\
\text { Roy McDonald, } \\
\text { Rob Phillpot, } \\
\text { Phil Pitham, Fritz } \\
\text { Schaumburg, } \\
\text { Dave Simpson, } \\
\text { Dave Sloane, } \\
\text { Jim Truscott, } \\
\text { Zac Zaharias }\end{array}$ & $\begin{array}{l}\text { Unsuccessful. High } \\
\text { point reached: } \\
5800 \text { m. Expedition } \\
\text { abandoned when } \\
\text { Sloane was killed } \\
\text { by avalanche that } \\
\text { swept Camp II. }\end{array}$ & $\begin{array}{l}\text { Second AAA } \\
\text { expedition to } \\
\text { Himalaya. }\end{array}$ \\
\hline & $\begin{array}{l}\text { Ama Dablam } \\
\text { ( } 6854 \mathrm{~m}) \\
\text { N Ridge, } \\
\text { Eastern Nepal }\end{array}$ & $\begin{array}{l}\text { Hooman Aprin } \\
\text { (USA), Lincoln Hall, } \\
\text { Andy Henderson, } \\
\text { Damien Jones, Tim } \\
\text { Macartney-Snape, } \\
\text { Ken McMahon, } \\
\text { Dave Pluth (USA) }\end{array}$ & $\begin{array}{l}\text { Successful. Hall, } \\
\text { Henderson and } \\
\text { Macartney-Snape } \\
\text { reached summit. }\end{array}$ & $\begin{array}{l}\text { First Australian } \\
\text { ascent. }\end{array}$ \\
\hline & $\begin{array}{l}\text { Anyemaqen } \\
\text { (6282 m) } \\
\text { E Face, Kunlun, } \\
\text { Central China }\end{array}$ & $\begin{array}{l}\text { Geof Bartram, } \\
\text { Lincoln Hall, Andy } \\
\text { Henderson, Tim } \\
\text { Macartney-Snape, } \\
\text { Charlie Massy }\end{array}$ & $\begin{array}{l}\text { Successful. Bartram, } \\
\text { Hall, Henderson } \\
\text { and Macartney- } \\
\text { Snape climbed E } \\
\text { Peak (6152 m); Hall } \\
\text { and Macartney- } \\
\text { Snape traversed } \\
\text { to main summit. }\end{array}$ & $\begin{array}{l}\text { First Australian } \\
\text { ascent. }\end{array}$ \\
\hline & $\begin{array}{l}\text { Yalung Kang } \\
(8505 \mathrm{~m}) \\
\text { N Face, } \\
\text { Eastern Nepal }\end{array}$ & $\begin{array}{l}\text { Cherie Bremer- } \\
\text { Kamp, Chris } \\
\text { Chandler (USA) }\end{array}$ & $\begin{array}{l}\text { Unsuccessful. High } \\
\text { point reached: } \\
7800 \mathrm{~m} .\end{array}$ & $\begin{array}{l}\text { Bremer-Kamp had } \\
\text { been on earlier } \\
\text { US expeditions } \\
\text { to Dhaulagiri } \\
\text { and K2. }\end{array}$ \\
\hline
\end{tabular}




\begin{tabular}{|c|c|c|c|c|}
\hline 1982 & $\begin{array}{l}\text { Changabang } \\
\text { (6864 m) } \\
\text { SW Pillar, } \\
\text { Garhwal, India }\end{array}$ & $\begin{array}{l}\text { Roddy Mackenzie, } \\
\text { Mark Moorhead, } \\
\text { Jon Muir, } \\
\text { Craig Nottle }\end{array}$ & $\begin{array}{l}\text { Successful. All } \\
\text { four climbers } \\
\text { reached summit. }\end{array}$ & $\begin{array}{l}\text { Second ascent } \\
\text { of route; first in } \\
\text { alpine style. Very } \\
\text { difficult climb } \\
\text { technically; all } \\
\text { four climbers } \\
\text { on their first } \\
\text { Himalayan trip. }\end{array}$ \\
\hline & $\begin{array}{l}\text { Lhotse }(8516 \mathrm{~m}) \\
\text { N Ridge, } \\
\text { Eastern Nepal }\end{array}$ & $\begin{array}{l}\text { Adrian Burgess } \\
\text { (UK), Fred From, } \\
\text { Peter Hillary (NZ), } \\
\text { Paul Moores (UK) }\end{array}$ & $\begin{array}{l}\text { Unsuccessful. High } \\
\text { point reached: } \\
8250 \mathrm{~m} \text {. }\end{array}$ & $\begin{array}{l}\text { From first } \\
\text { Australian to } \\
\text { climb more than } \\
8000 \text { m without } \\
\text { supplementary } \\
\text { oxygen. }\end{array}$ \\
\hline & $\begin{array}{l}\text { Trisul (7120 m) } \\
\text { Garhwal, India }\end{array}$ & $\begin{array}{l}\text { Geof Bartram, } \\
\text { John Coulton, } \\
\text { Mike Groom, } \\
\text { Lincoln Hall, } \\
\text { Tim Macartney- } \\
\text { Snape and four } \\
\text { US climbers }\end{array}$ & $\begin{array}{l}\text { Unsuccessful. High } \\
\text { point reached: } \\
6800 \mathrm{~m} \text {. Stopped } \\
\text { by sustained, } \\
\text { violent storm. }\end{array}$ & $\begin{array}{l}\text { First guided } \\
\text { Australian climb } \\
\text { in Himalaya. } \\
\text { Bartram, Hall and } \\
\text { Macartney-Snape } \\
\text { were guides. }\end{array}$ \\
\hline & $\begin{array}{l}\text { Nanda Devi } \\
\text { (7816 m) } \\
\text { SE Ridge, } \\
\text { Garhwal, India }\end{array}$ & $\begin{array}{l}\text { Keith Egerton, } \\
\text { Hugh Foxcroft, } \\
\text { Tom Millar, } \\
\text { Ed Neve, Mike } \\
\text { Rheinberger, } \\
\text { Gary Wills }\end{array}$ & $\begin{array}{l}\text { Unsuccessful. High } \\
\text { point reached: } 7400 \\
\text { m, by Rheinberger } \\
\text { and Wills. Stopped } \\
\text { by storm. }\end{array}$ & $\begin{array}{l}\text { Expedition } \\
\text { plagued by illness } \\
\text { and accidents. } \\
\text { Neve and Millar } \\
\text { evacuated by } \\
\text { helicopter. }\end{array}$ \\
\hline & $\begin{array}{l}\text { East Kulu } \\
\text { expedition } \\
\text { Kulu, India }\end{array}$ & $\begin{array}{l}\text { John Burrow, Nick } \\
\text { Groves (UK), John } \\
\text { Marshall, Brett } \\
\text { Ryan, Terry Ryan }\end{array}$ & $\begin{array}{l}\text { Successful. Climbed } \\
\text { a number of peaks: } \\
\text { Corner Peak (6140 } \\
\text { m); Kulu Makalu } \\
(5882 \mathrm{~m}) \text {; Tiger Tooth } \\
(5980 \mathrm{~m}) \text {; The Dome } \\
(5880 \mathrm{~m}) \text {; Shigri } \\
\text { Parbat }(6640 \mathrm{~m}) .\end{array}$ & $\begin{array}{l}\text { First Australian } \\
\text { ascents. }\end{array}$ \\
\hline & $\begin{array}{l}\text { Peak } 29 \\
\text { (Dakura, } \\
7837 \mathrm{~m} \text { ) } \\
\text { S Ridge, } \\
\text { Central Nepal }\end{array}$ & $\begin{array}{l}\text { Brian Agnew, } \\
\text { member of large } \\
\text { British Army } \\
\text { expedition }\end{array}$ & $\begin{array}{l}\text { Unsuccessful. High } \\
\text { point reached: } \\
6000 \mathrm{~m} \text {. }\end{array}$ & $\begin{array}{l}\text { Expedition } \\
\text { plagued by } \\
\text { problems } \\
\text { including: gear } \\
\text { lost in transit, } \\
\text { wrong approach } \\
\text { to mountain, } \\
\text { dispute with } \\
\text { local villagers } \\
\text { on trek in and } \\
\text { horrific snow } \\
\text { conditions on } 8 \\
\text { km-long ridge. }\end{array}$ \\
\hline & $\begin{array}{l}\text { Kwangde Shar } \\
(6093 \mathrm{~m}) \\
\text { Eastern Nepal }\end{array}$ & $\begin{array}{l}\text { Mick Chapman, } \\
\text { Colin Pont }\end{array}$ & Successful. & $\begin{array}{l}\text { First Australian } \\
\text { ascent. }\end{array}$ \\
\hline
\end{tabular}




\begin{tabular}{|c|c|c|c|c|}
\hline & \begin{tabular}{|l} 
Mera Peak \\
(6476 m) \\
N Face (Glacier), \\
Eastern Nepal
\end{tabular} & $\begin{array}{l}\text { Stephen Bunton, } \\
\text { Tim Carroll, } \\
\text { Jeff Crass, Ivan } \\
\text { Dessailly, Mike } \\
\text { Myers, Peter } \\
\text { Webber and one } \\
\text { other climber }\end{array}$ & $\begin{array}{l}\text { Successful. Also } \\
\text { climbed Nau Lekh } \\
\text { (6363 m). }\end{array}$ & $\begin{array}{l}\text { First Australian } \\
\text { ascents. }\end{array}$ \\
\hline & $\begin{array}{l}\text { Pisang Peak } \\
\text { (6091 m) } \\
\text { SW Face/Ridge, } \\
\text { Central Nepal }\end{array}$ & $\begin{array}{l}\text { Bruce Fox, lan } \\
\text { Ravenscroft, } \\
\text { Fritz Schaumburg } \\
\text { (guide), Enn } \\
\text { Troopold and three } \\
\text { other clients }\end{array}$ & Successful. & $\begin{array}{l}\text { First Australian } \\
\text { ascent of this } \\
\text { trekking peak } \\
\text { north of the } \\
\text { Annapurna } \\
\text { Himal. } \\
\end{array}$ \\
\hline \multirow[t]{5}{*}{1983} & $\begin{array}{l}\text { Annapurna II } \\
\text { (7937 m) } \\
\text { S Face, Central } \\
\text { Nepal }\end{array}$ & $\begin{array}{l}\text { Mike Groom, } \\
\text { Lincoln Hall, Andy } \\
\text { Henderson, Tim } \\
\text { Macartney-Snape, } \\
\text { Greg Mortimer }\end{array}$ & $\begin{array}{l}\text { Successful. Hall, } \\
\text { Henderson, Macartney- } \\
\text { Snape and Mortimer } \\
\text { reached summit } \\
\text { after two bivouacs } \\
\text { at } 7800 \mathrm{~m} \text {. }\end{array}$ & $\begin{array}{l}\text { First ascent of } \\
\text { difficult route } \\
\text { on S Face. } \\
\text { Second } 7000 \\
\text { m peak climbed } \\
\text { by Australians. } \\
\end{array}$ \\
\hline & $\begin{array}{l}\text { Annapurna III } \\
\text { (7555 m) } \\
\text { SW Face, } \\
\text { Central Nepal }\end{array}$ & $\begin{array}{l}\text { Stephen Bunton, } \\
\text { Jonathon Chester, } \\
\text { Steve McDowell, } \\
\text { Adrian Teague, } \\
\text { Dave Wagland }\end{array}$ & $\begin{array}{l}\text { Unsuccessful. High } \\
\text { point reached: } 7300 \\
\text { m, by Chester, } \\
\text { McDowell and } \\
\text { Teague. Turned back } \\
\text { on summit ridge } \\
\text { by high winds. } \\
\end{array}$ & \\
\hline & $\begin{array}{l}\text { Makalu } \\
\text { (8463 m) } \\
\text { SW Pillar, } \\
\text { Eastern Nepal }\end{array}$ & $\begin{array}{l}\text { Bill Denz (NZ), } \\
\text { Fred From, Peter } \\
\text { Hillary (NZ), } \\
\text { Mark Moorhead }\end{array}$ & $\begin{array}{l}\text { Unsuccessful. High } \\
\text { point reached: } \\
7600 \text { m, by From } \\
\text { and Moorhead. }\end{array}$ & $\begin{array}{l}\text { Double tragedy } \\
\text { as Denz killed in } \\
\text { avalanche and } \\
\text { Moorhead in fall. }\end{array}$ \\
\hline & $\begin{array}{l}\text { Lobsang Spire } \\
\text { (5715 m) } \\
\text { SE Face } \\
\text { Broad Peak } \\
\text { (8047 m) } \\
\text { W Face } \\
\text { SW Pillar } \\
\text { Karakoram, } \\
\text { Pakistan }\end{array}$ & $\begin{array}{l}\text { Greg Child, } \\
\text { member of } \\
\text { nine-man } \\
\text { international } \\
\text { expedition led by } \\
\text { Doug Scott (UK) }\end{array}$ & $\begin{array}{l}\text { Successful. Child, } \\
\text { Scott and Pete } \\
\text { Thexton (UK) } \\
\text { reached summit of } \\
\text { Lobsang Spire. }\end{array}$ & $\begin{array}{l}\text { First ascent } \\
\text { of Lobsang } \\
\text { Spire. Child } \\
\text { later reached } \\
8000 \text { m on } \\
\text { Broad Peak but } \\
\text { turned back with } \\
\text { ailing partner, } \\
\text { Pete Thexton, } \\
\text { who died of } \\
\text { pulmonary } \\
\text { oedema on } \\
\text { the descent. } \\
\end{array}$ \\
\hline & $\begin{array}{l}\text { Nilgiri North } \\
\text { (7061 m) } \\
\text { SE Face, } \\
\text { Central Nepal }\end{array}$ & $\begin{array}{l}\text { Peter Allen, Dave } \\
\text { Evans, Bruce Fox, } \\
\text { Peter Lambert, } \\
\text { Terry McCullagh, } \\
\text { Phil Pitham, Mark } \\
\text { Whetu (NZ), } \\
\text { Zac Zaharias }\end{array}$ & $\begin{array}{l}\text { Successful. All except } \\
\text { Fox reached summit. }\end{array}$ & $\begin{array}{l}\text { Third } 7000 \mathrm{~m} \\
\text { peak climbed by } \\
\text { Australians. First } \\
\text { major Himalayan } \\
\text { peak climbed } \\
\text { by AAA. Fourth } \\
\text { ascent of Nilgiri } \\
\text { North and second } \\
\text { of SE face. }\end{array}$ \\
\hline
\end{tabular}




\begin{tabular}{|c|c|c|c|c|}
\hline 1984 & $\begin{array}{l}\text { Pumori } \\
(7,161 \mathrm{~m}) \\
\text { SE Face, } \\
\text { Eastern Nepal }\end{array}$ & $\begin{array}{l}\text { Geof Bartram } \\
\text { and Chris Curry, } \\
\text { members of seven- } \\
\text { man international } \\
\text { expedition }\end{array}$ & $\begin{array}{l}\text { Successful. All seven } \\
\text { reached summit. }\end{array}$ & $\begin{array}{l}\text { New route on } \\
\text { SE Face. First } \\
\text { Australian } \\
\text { ascent. }\end{array}$ \\
\hline & $\begin{array}{l}\text { Mt Everest } \\
(8850 \mathrm{~m}) \\
\text { N Face, Tibet }\end{array}$ & $\begin{array}{l}\text { Geof Bartram, } \\
\text { Lincoln Hall, Andy } \\
\text { Henderson, Tim } \\
\text { Macartney-Snape, } \\
\text { Greg Mortimer }\end{array}$ & $\begin{array}{l}\text { Successful. Macartney- } \\
\text { Snape and Mortimer } \\
\text { reached summit. } \\
\text { Henderson stopped } \\
50 \text { vertical m below } \\
\text { summit, suffered } \\
\text { severe frostbite } \\
\text { to both hands. }\end{array}$ & $\begin{array}{l}\text { Remarkable climb } \\
\text { of Mt Everest. } \\
\text { First Australian } \\
\text { ascent. First } \\
\text { ascent of Great } \\
\text { Couloir. First } \\
\text { ascent of new } \\
\text { route without } \\
\text { supplementary } \\
\text { oxygen. Smallest } \\
\text { party ever to } \\
\text { climb new route. }\end{array}$ \\
\hline & $\begin{array}{l}\text { Mt Everest } \\
\text { (8850 m) } \\
\text { W Ridge, } \\
\text { Eastern Nepal }\end{array}$ & $\begin{array}{l}\text { Fred From, Peter } \\
\text { Hillary (NZ), Kim } \\
\text { Logan (NZ), Roddy } \\
\text { Mackenzie, Jon } \\
\text { Muir, Craig Nottle } \\
\end{array}$ & $\begin{array}{l}\text { Unsuccessful. High } \\
\text { point reached: } 8200 \\
\text { m, by From and Logan. }\end{array}$ & $\begin{array}{l}\text { Double tragedy } \\
\text { as From and } \\
\text { Nottle killed in } \\
\text { falls from high } \\
\text { on W Ridge. }\end{array}$ \\
\hline & $\begin{array}{l}\text { Kangguru } \\
\text { (7010 m) } \\
\text { SE Ridge, } \\
\text { Central Nepal }\end{array}$ & $\begin{array}{l}\text { Michael Chapman } \\
\text { (UK), Greg Martin, } \\
\text { Mike Rheinberger }\end{array}$ & $\begin{array}{l}\text { Unsuccessful. High } \\
\text { point reached: } 6930 \\
\text { m, by Rheinberger. }\end{array}$ & $\begin{array}{l}\text { Attempt in } \\
\text { winter. }\end{array}$ \\
\hline & $\begin{array}{l}\text { Kangchenjunga } \\
\text { (8586 m) } \\
\text { N Face, } \\
\text { Eastern Nepal }\end{array}$ & $\begin{array}{l}\text { Cherie Bremer- } \\
\text { Kamp, Chris } \\
\text { Chandler (USA) }\end{array}$ & $\begin{array}{l}\text { Unsuccessful. High } \\
\text { point reached: } 7880 \\
\mathrm{~m} \text {. Chandler died } \\
\text { of cerebral oedema } \\
\text { at high point. }\end{array}$ & $\begin{array}{l}\text { Highest altitude } \\
\text { reached by } \\
\text { Australian } \\
\text { woman. }\end{array}$ \\
\hline & $\begin{array}{l}\text { Khartang } \\
\text { (6853 m) } \\
\text { NE Face, } \\
\text { Eastern Nepal }\end{array}$ & $\begin{array}{l}\text { John Lamb, } \\
\text { Ray Vran }\end{array}$ & $\begin{array}{l}\text { Unsuccessful. High } \\
\text { point reached: } 6100 \\
\text { m. Stopped by cold } \\
\text { and high winds. }\end{array}$ & $\begin{array}{l}\text { Attempt in } \\
\text { winter. }\end{array}$ \\
\hline & $\begin{array}{l}\text { Tharpu Chuli } \\
\text { (Tent Peak, } \\
5500 \mathrm{~m} \text { ) } \\
\text { E Face } \\
\text { Singu Chuli } \\
\text { (Fluted Peak, } \\
6501 \mathrm{~m} \text { ) } \\
\text { Central Nepal }\end{array}$ & $\begin{array}{l}\text { Peter Lambert, } \\
\text { 'Lawdy' Law, } \\
\text { David Munro, } \\
\text { Andrew Smith, } \\
\text { Peter Talbot, } \\
\text { Peter Ward }\end{array}$ & $\begin{array}{l}\text { Successful. Attempt } \\
\text { on nearby Singu } \\
\text { Chuli stopped at } \\
5940 \text { m by deep and } \\
\text { dangerous snow. }\end{array}$ & $\begin{array}{l}\text { AAA expedition. } \\
\text { First Australian } \\
\text { ascent of } \\
\text { Tharpu Chuli. }\end{array}$ \\
\hline 1985 & $\begin{array}{l}\text { Shivling } \\
\text { (6543 m) } \\
\text { SW Pillar, } \\
\text { Gangotri, India }\end{array}$ & $\begin{array}{l}\text { Brigitte Muir, Jon } \\
\text { Muir, Ed Neve, } \\
\text { Terry Tremble }\end{array}$ & $\begin{array}{l}\text { Unsuccessful. High } \\
\text { point reached: } \\
5900 \text { m. Stopped } \\
\text { by bad weather. }\end{array}$ & \\
\hline
\end{tabular}




\begin{tabular}{|c|c|c|c|c|}
\hline & $\begin{array}{l}\text { Mt Everest } \\
(8850 \mathrm{~m}) \\
\text { W Ridge/N } \\
\text { Face/N Ridge, } \\
\text { Tibet }\end{array}$ & $\begin{array}{l}\text { Peter Allen, Bruce } \\
\text { Farmer and Mike } \\
\text { Rheinberger, } \\
\text { members of 14- } \\
\text { man New Zealand } \\
\text { expedition led by } \\
\text { Austin Brookes }\end{array}$ & $\begin{array}{l}\text { Unsuccessful on all } \\
\text { three routes. Severe } \\
\text { avalanche problems. } \\
\text { High points reached: } \\
7165 \text { m on W Ridge; } \\
7165 \text { m on N Face; } \\
7320 \text { m on N Ridge. }\end{array}$ & $\begin{array}{l}\text { Australian } \\
\text { Rheinberger } \\
\text { reached high } \\
\text { point on all } \\
\text { three routes } \\
\text { attempted. } \\
\text { Farmer had been } \\
\text { member of } 1981 \\
\text { New Zealand } \\
\text { expedition to } \\
\text { Molamenqing. }\end{array}$ \\
\hline & $\begin{array}{l}\text { Ama Dablam } \\
(6854 \mathrm{~m}) \\
\text { S Ridge, } \\
\text { Eastern Nepal }\end{array}$ & $\begin{array}{l}\text { Robert Staszewski, } \\
\text { member of five- } \\
\text { man New Zealand } \\
\text { expedition }\end{array}$ & $\begin{array}{l}\text { Unsuccessful. Stopped } \\
\text { by bad weather and } \\
\text { illness of members. }\end{array}$ & $\begin{array}{l}\text { Attempt in } \\
\text { winter. }\end{array}$ \\
\hline & $\begin{array}{l}\text { Mustagh Ata } \\
(7546 \mathrm{~m}) \\
\text { W Face, Pamir, } \\
\text { Western China } \\
\end{array}$ & $\begin{array}{l}\text { Steve McDowell, } \\
\text { Jane White, } \\
\text { Rick White and } \\
\text { other climbers } \\
\end{array}$ & $\begin{array}{l}\text { Unsuccessful. Stopped } \\
\text { by early arrival of } \\
\text { winter weather. }\end{array}$ & \\
\hline & $\begin{array}{l}\text { Lhamu Ghang } \\
\text { (5009 m) } \\
\text { W Face, } \\
\text { Eastern Nepal }\end{array}$ & $\begin{array}{l}\text { Greg Bales } \\
\text { (Canada), Andrew } \\
\text { Borrell and } \\
\text { British climber }\end{array}$ & Successful. & \\
\hline & $\begin{array}{l}\text { Dharamsura } \\
\text { (White Sail, } \\
6445 \mathrm{~m} \text { ) } \\
\text { SW Ridge, } \\
\text { Kulu, India }\end{array}$ & $\begin{array}{l}\text { Frank Moon, } \\
\text { Phil Pitham, } \\
\text { Zac Zaharias }\end{array}$ & $\begin{array}{l}\text { Successful. All } \\
\text { reached } 5800 \mathrm{~m} \text { on } \\
\text { first attempt. Pitham } \\
\text { reached summit } \\
\text { on second attempt } \\
\text { climbing alone. }\end{array}$ & \\
\hline & $\begin{array}{l}\text { North } \\
\text { Annapurna } \\
\text { region } \\
\text { Trekking peaks, } \\
\text { Central Nepal }\end{array}$ & $\begin{array}{l}\text { Rick Moor, } \\
\text { Derek Murphy, } \\
\text { Mick Pezet, } \\
\text { Andrew Smith, } \\
\text { Jim Strohfeldt, } \\
\text { Jim van Gelder, } \\
\text { Jeff Williams }\end{array}$ & $\begin{array}{l}\text { Successful. All but } \\
\text { Murphy climbed Pisang } \\
\text { Peak }(6091 \mathrm{~m}) \text {; all } \\
\text { except Murphy and } \\
\text { Smith climbed Chulu } \\
\text { West }(6220 \mathrm{~m}) \text {. }\end{array}$ & $\begin{array}{l}\text { AAA expedition. } \\
\text { First Australian } \\
\text { ascent of } \\
\text { Chulu West. }\end{array}$ \\
\hline \multirow[t]{2}{*}{1986} & $\begin{array}{l}\text { Jannu }(7710 \mathrm{~m}) \\
\text { SW Ridge, } \\
\text { Eastern Nepal }\end{array}$ & $\begin{array}{l}\text { Keith Egerton, } \\
\text { Don French (NZ), } \\
\text { Terry Tremble }\end{array}$ & $\begin{array}{l}\text { Unsuccessful. High } \\
\text { Point reached: } 7000 \\
\text { m, by French. }\end{array}$ & $\begin{array}{l}\text { Keith Egerton } \\
\text { died at } 6500 \\
\mathrm{~m} \text { of oedema. }\end{array}$ \\
\hline & $\begin{array}{l}\text { Gasherbrum } \\
\text { IV (7925 m) } \\
\text { NW Ridge, } \\
\text { Karakoram, } \\
\text { Pakistan }\end{array}$ & $\begin{array}{l}\text { Phil Balsdom, } \\
\text { Greg Child, Tim } \\
\text { Macartney-Snape, } \\
\text { members of eight- } \\
\text { man Australian/ } \\
\text { US expedition }\end{array}$ & $\begin{array}{l}\text { Successful. Child, } \\
\text { Tom Hall-Hargis (USA) } \\
\text { and Macartney-Snape } \\
\text { reached summit after } \\
\text { bivouac at } 7860 \mathrm{~m} \text {. }\end{array}$ & $\begin{array}{l}\text { First ascent } \\
\text { of NW Ridge. } \\
\text { Second ascent of } \\
\text { mountain. Child, } \\
\text { Hall-Hargis and } \\
\text { Randy Leavitt } \\
\text { (USA) later } \\
\text { unsuccessful } \\
\text { in attempt on E } \\
\text { Face of Nameless } \\
\text { Tower (6237 m), } \\
\text { Trango Group. }\end{array}$ \\
\hline
\end{tabular}




\begin{tabular}{|c|c|c|c|}
\hline $\begin{array}{l}\text { Shivling } \\
\text { (6543 m) } \\
\text { SW Pillar, } \\
\text { Gangotri, India }\end{array}$ & $\begin{array}{l}\text { Graeme Hill, } \\
\text { Veronique Hill, } \\
\text { Brigitte Muir, } \\
\text { Jon Muir }\end{array}$ & $\begin{array}{l}\text { Successful. Graeme } \\
\text { Hill, Brigitte Muir } \\
\text { and Jon Muir } \\
\text { reached summit of } \\
\text { W Peak }(6505 \mathrm{~m}) \text {. }\end{array}$ & $\begin{array}{l}\text { Ascent took } \\
14 \text { days of } \\
\text { continuous } \\
\text { climbing in } \\
\text { 'capsule' style. } \\
\text { Rock pitches } \\
\text { up to grade } \\
21, \text { A4. Liaison } \\
\text { officer died in } \\
\text { freak accident } \\
\text { on fixed ropes in } \\
\text { earlier attempt. }\end{array}$ \\
\hline $\begin{array}{l}\text { Broad Peak } \\
\text { (8047 m) } \\
\text { W Face, } \\
\text { Karakoram, } \\
\text { Pakistan }\end{array}$ & $\begin{array}{l}\text { Brian Agnew, } \\
\text { Jonathan Chester, } \\
\text { Norm Crookston, } \\
\text { Pat Cullinan, } \\
\text { Tony Delaney, } \\
\text { Peter Lambert, } \\
\text { Terry McCullagh, } \\
\text { Rick Moor, Derek } \\
\text { Murphy, Mick } \\
\text { Pezet, Mike } \\
\text { Rheinberger, } \\
\text { Jim Truscott, } \\
\text { Jim van Gelder, } \\
\text { Zac Zaharias }\end{array}$ & $\begin{array}{l}\text { Successful. Agnew, } \\
\text { Chester, Cullinan, } \\
\text { Lambert, McCullagh, } \\
\text { Rheinberger, van } \\
\text { Gelder and Zaharias } \\
\text { reached summit. }\end{array}$ & $\begin{array}{l}\text { First Australian } \\
\text { ascent of Broad } \\
\text { Peak. Second } \\
8000 \text { m peak } \\
\text { climbed by } \\
\text { Australians. } \\
\text { Cullinan rescued } \\
\text { ill German } \\
\text { climber on } \\
\text { descent. }\end{array}$ \\
\hline $\begin{array}{l}\text { Kangchenjunga } \\
\text { (8586 m) } \\
\text { SW Face, } \\
\text { Eastern Nepal }\end{array}$ & $\begin{array}{l}\text { Shane Chemello, } \\
\text { Chris Frost, } \\
\text { Mike Groom, } \\
\text { Jim Strohfeldt, } \\
\text { Jim van Gelder }\end{array}$ & $\begin{array}{l}\text { Unsuccessful. High } \\
\text { point reached: } 8400 \\
\text { m, by Groom. }\end{array}$ & \\
\hline $\begin{array}{l}\text { Rimo I (7385 m) } \\
\text { S Face/SE } \\
\text { Ridge, Eastern } \\
\text { Karakoram, } \\
\text { India }\end{array}$ & $\begin{array}{l}\text { Roddy Mackenzie, } \\
\text { Brett Ryan, Terry } \\
\text { Ryan, members } \\
\text { of 14-person } \\
\text { international } \\
\text { expedition led by } \\
\text { Peter Hillary (NZ) }\end{array}$ & $\begin{array}{l}\text { Unsuccessful. High } \\
\text { point reached: } \\
6800 \mathrm{~m} \text {, by Hillary, } \\
\text { Skip Horner (USA) } \\
\text { and Mackenzie. }\end{array}$ & $\begin{array}{l}\text { One of the } \\
\text { highest } \\
\text { unclimbed peaks } \\
\text { in the world. } \\
\text { Expedition had } \\
\text { problems with } \\
\text { Indian military: } \\
\text { film confiscated, } \\
\text { Hillary held at } \\
\text { gunpoint. }\end{array}$ \\
\hline $\begin{array}{l}\text { Langisha Ri } \\
\text { (6437 m) } \\
\text { S Face, Central } \\
\text { Nepal }\end{array}$ & $\begin{array}{l}\text { Simon Cox (NZ), } \\
\text { John Goulstone, } \\
\text { Marty Hunter (NZ), } \\
\text { Steve Upton }\end{array}$ & Successful. & $\begin{array}{l}\text { First Australian } \\
\text { ascent. }\end{array}$ \\
\hline $\begin{array}{l}\text { Pumori } \\
\text { (7145 m) } \\
\text { S Ridge, } \\
\text { Eastern Nepal }\end{array}$ & $\begin{array}{l}\text { Steve McDonald, } \\
\text { member of six- } \\
\text { man New Zealand } \\
\text { expedition }\end{array}$ & $\begin{array}{l}\text { Unsuccessful. High } \\
\text { point reached: } \\
6545 \mathrm{~m} .\end{array}$ & \\
\hline
\end{tabular}




\begin{tabular}{|c|c|c|c|c|}
\hline 1987 & $\begin{array}{l}\text { Kedarnath Peak } \\
(6940 \mathrm{~m}, 6830 \\
\mathrm{m}, 6500 \mathrm{~m}) \\
\text { Gangotri, India }\end{array}$ & $\begin{array}{l}\text { Lydia Bradey } \\
\text { (NZ), Geoff } \\
\text { Little, Brigitte } \\
\text { Muir, Jon Muir, } \\
\text { Louise Shepherd }\end{array}$ & $\begin{array}{l}\text { Successful. Bradey } \\
\text { and Jon Muir } \\
\text { reached summit of } \\
\text { Kedarnath Dome. } \\
\text { Little and Brigitte Muir } \\
\text { reached } 6250 \mathrm{~m} \text {. }\end{array}$ & $\begin{array}{l}\text { Jon Muir soloed } \\
\text { a traverse of } \\
\text { all three peaks } \\
\text { in } 41 \text { hours. } \\
\text { New route, } \\
\text { alpine style. }\end{array}$ \\
\hline & $\begin{array}{l}\text { Gasherbrum } \\
\text { I (8068 m) } \\
\text { Gasherbrum } \\
\text { II (8035 m) } \\
\text { Karakoram, } \\
\text { Pakistan }\end{array}$ & $\begin{array}{l}\text { Geoff Little and } \\
\text { Brigitte Muir, } \\
\text { members of } \\
\text { 16-person New } \\
\text { Zealand expedition }\end{array}$ & $\begin{array}{l}\text { Successful. Bradey, } \\
\text { Little and Carol } \\
\text { McDermott (NZ) } \\
\text { climbed Gasherbrum } \\
\text { II by SE Ridge. } \\
\text { Unsuccessful on } \\
\text { Gasherbrum I, NW } \\
\text { Ridge/Face. High point } \\
\text { reached: } 6800 \mathrm{~m} \text {. }\end{array}$ & $\begin{array}{l}\text { First Australian } \\
\text { ascent. Third } \\
8000 \text { m peak } \\
\text { climbed by } \\
\text { an Australian. } \\
\text { Peak climbed } \\
\text { in three-day, } \\
\text { alpine-style push } \\
\text { from low camp. }\end{array}$ \\
\hline & $\begin{array}{l}\text { K2 }(8611 \mathrm{~m}) \\
\text { E Face, } \\
\text { Karakoram, } \\
\text { Pakistan }\end{array}$ & $\begin{array}{l}\text { Greg Child and Tim } \\
\text { Macartney-Snape, } \\
\text { members of seven- } \\
\text { man international } \\
\text { expedition led } \\
\text { by Doug Scott }\end{array}$ & $\begin{array}{l}\text { Unsuccessful. High } \\
\text { point reached: } 7100 \\
\text { m. Stopped by bad } \\
\text { weather and poor } \\
\text { snow conditions. }\end{array}$ & $\begin{array}{l}\text { First Australian } \\
\text { attempt on } \\
\text { world's second- } \\
\text { highest peak. }\end{array}$ \\
\hline & $\begin{array}{l}\text { Changtse } \\
(7553 \mathrm{~m}) \\
\text { N Face, Tibet }\end{array}$ & $\begin{array}{l}\text { Colin Gordon, } \\
\text { David Hunter, } \\
\text { Glen Nash, John } \\
\text { Smart, Rod Turner, } \\
\text { Louis Whitton }\end{array}$ & $\begin{array}{l}\text { Successful. Nash } \\
\text { and Turner reached } \\
\text { summit in four-day, } \\
\text { alpine-style push }\end{array}$ & $\begin{array}{l}\text { First Australian } \\
\text { ascent. Third } \\
\text { ascent of } \\
\text { mountain. }\end{array}$ \\
\hline & $\begin{array}{l}\text { Kangchenjunga } \\
\text { (8586 m) } \\
\text { SW Face, } \\
\text { Eastern Nepal }\end{array}$ & $\begin{array}{l}\text { John Coulton, } \\
\text { Mike Groom }\end{array}$ & $\begin{array}{l}\text { Successful. Both } \\
\text { reached summit. }\end{array}$ & $\begin{array}{l}\text { First Australian } \\
\text { ascent. Fourth } \\
8000 \text { m peak } \\
\text { climbed by } \\
\text { Australians. } \\
\text { Forced bivouac } \\
\text { in open at } 7900 \\
\text { m on descent. } \\
\text { Both suffered } \\
\text { severe frostbite. }\end{array}$ \\
\hline & $\begin{array}{l}\text { Kangchenjunga } \\
\text { (8586 m) } \\
\text { W Face, } \\
\text { Eastern Nepal }\end{array}$ & $\begin{array}{l}\text { Carol Brand-Maher, } \\
\text { Terry Tremble, } \\
\text { Jim van Gelder }\end{array}$ & $\begin{array}{l}\text { Unsuccessful. High } \\
\text { point reached: } \\
7500 \mathrm{~m} \text {. }\end{array}$ & \\
\hline & $\begin{array}{l}\text { Mt Everest } \\
\text { (8850 m) } \\
\text { S Pillar, Eastern } \\
\text { Nepal }\end{array}$ & $\begin{array}{l}\text { Peter Hillary (NZ), } \\
\text { Kim Logan (NZ), } \\
\text { Jon Muir, Mike } \\
\text { Rheinberger }\end{array}$ & $\begin{array}{l}\text { Unsuccessful. High } \\
\text { point reached: } \\
8020 \text { m, by Logan } \\
\text { and Rheinberger. }\end{array}$ & $\begin{array}{l}\text { Logan and } \\
\text { Rheinberger } \\
\text { climbed S Pillar } \\
\text { in alpine style } \\
\text { from Camp I at } \\
6860 \mathrm{~m} \text { to high } \\
\text { point at } 8020 \mathrm{~m} \text {. }\end{array}$ \\
\hline 1988 & $\begin{array}{l}\text { Shivling } \\
(6543 \mathrm{~m}) \\
\text { Kedarnath Dome } \\
\text { (6830 m) } \\
\text { Gangotri, India }\end{array}$ & $\begin{array}{l}\text { Nic Deka and Jim } \\
\text { Duff, members } \\
\text { of } 17 \text {-man } \\
\text { international } \\
\text { expedition }\end{array}$ & $\begin{array}{l}\text { Successful on } \\
\text { Kedarnath Dome. } \\
\text { Unsuccessful on S } \\
\text { Pillar of Shivling. }\end{array}$ & \\
\hline
\end{tabular}




\begin{tabular}{|c|c|c|c|c|}
\hline & $\begin{array}{l}\text { Kedarnath Dome } \\
\text { (6830 m) } \\
\text { Gangotri, India }\end{array}$ & $\begin{array}{l}\text { Ydeet Winter- } \\
\text { Irving, member } \\
\text { of international } \\
\text { ski expedition }\end{array}$ & $\begin{array}{l}\text { Successful. Ski } \\
\text { descent from summit. }\end{array}$ & $\begin{array}{l}\text { First Australian } \\
\text { ski descent of } \\
\text { major Himalayan } \\
\text { peak. }\end{array}$ \\
\hline & $\begin{array}{l}\text { Mt Everest } \\
\text { (8850 m) } \\
\text { SE Ridge, } \\
\text { Eastern Nepal }\end{array}$ & $\begin{array}{l}\text { Brian Agnew, } \\
\text { Paul Bayne, } \\
\text { Austin Brookes, } \\
\text { Pat Cullinan, } \\
\text { Chris Curry, Tony } \\
\text { Delaney, Bruce } \\
\text { Farmer, Peter } \\
\text { Lambert, Terry } \\
\text { McCullagh, Rick } \\
\text { Moor, Jon Muir, } \\
\text { Mick Pezet, Phil } \\
\text { Pitham, Mike } \\
\text { Rheinberger, } \\
\text { Andrew Smith, } \\
\text { Jim Strohfeldt, } \\
\text { Terry Tremble, } \\
\text { Jim Truscott, } \\
\text { Jim van Gelder, } \\
\text { Zac Zaharias }\end{array}$ & $\begin{array}{l}\text { Successful. Bayne, } \\
\text { Cullinan and Muir } \\
\text { reached summit. All } \\
\text { used supplementary } \\
\text { oxygen. }\end{array}$ & $\begin{array}{l}\text { Australian } \\
\text { Bicentennial } \\
\text { Everest } \\
\text { Expedition. } \\
\text { Second } \\
\text { Australian ascent } \\
\text { of Mt Everest. } \\
\text { First ascent of } \\
\text { Mt Everest by } \\
\text { South Col route } \\
\text { without using } \\
\text { Sherpa support } \\
\text { on mountain. } \\
\text { Eleven climbers } \\
\text { reached } 8600 \\
\text { m or higher. }\end{array}$ \\
\hline & $\begin{array}{l}\text { Baruntse } \\
\text { (7168 m) } \\
\text { SE Ridge, } \\
\text { Eastern Nepal }\end{array}$ & $\begin{array}{l}\text { John Armstrong, } \\
\text { Ken Baldwin, } \\
\text { Tom Barcham, } \\
\text { Charlie Barton, } \\
\text { Ken Bell, John } \\
\text { Finnigan, Peter } \\
\text { Hodge (USA), } \\
\text { Theo Hooy, Peter } \\
\text { Lane, Will Steffen }\end{array}$ & $\begin{array}{l}\text { Unsuccessful. High } \\
\text { point reached: } 7020 \\
\text { m, by Baldwin, } \\
\text { Finnigan, Hodge, } \\
\text { Hooy, Lane and } \\
\text { Steffen. Stopped } \\
\text { by dangerous } \\
\text { snow conditions } \\
\text { on summit ridge. }\end{array}$ & $\begin{array}{l}\text { Armstrong, } \\
\text { Baldwin, Bell, } \\
\text { Finnigan and } \\
\text { Hooy members } \\
\text { of } 1978 \text { Dunagiri } \\
\text { expedition. }\end{array}$ \\
\hline & $\begin{array}{l}\text { Pumori } \\
\text { (7161 m) } \\
\text { SE Ridge, } \\
\text { Eastern Nepal }\end{array}$ & $\begin{array}{l}\text { Armando Corvini, } \\
\text { Matt Godbold, } \\
\text { Richard Howes, } \\
\text { Andrew Lock, } \\
\text { Ray Vran, Jeff } \\
\text { Williams, Scott } \\
\text { Woolums (USA) }\end{array}$ & $\begin{array}{l}\text { Successful. } \\
\text { Corvini, Howes, } \\
\text { Vran and Woolums } \\
\text { reached summit. }\end{array}$ & $\begin{array}{l}\text { Corvini suffered } \\
\text { frostbite during } \\
\text { bivouac on } \\
\text { ascent. }\end{array}$ \\
\hline & $\begin{array}{l}\text { Makalu } \\
\text { (8463 m) } \\
\text { W Face, } \\
\text { Eastern Nepal }\end{array}$ & $\begin{array}{l}\text { Greg Child, } \\
\text { member of } 11- \\
\text { man international } \\
\text { expedition led } \\
\text { by Doug Scott }\end{array}$ & $\begin{array}{l}\text { Unsuccessful. High } \\
\text { point reached: } 8100 \\
\text { m. Stopped by } \\
\text { evacuation of Rick } \\
\text { Allen (UK), injured } \\
\text { in avalanche. }\end{array}$ & \\
\hline 1989 & $\begin{array}{l}\text { Mt Everest } \\
\text { (8850 m) } \\
\text { SE Ridge, } \\
\text { Eastern Nepal }\end{array}$ & $\begin{array}{l}\text { Roddy Mackenzie, } \\
\text { member of } 15- \\
\text { man international } \\
\text { expedition }\end{array}$ & $\begin{array}{l}\text { Successful. Mackenzie } \\
\text { and Adrian Burgess } \\
\text { (UK) reached } \\
\text { summit. Both used } \\
\text { supplementary oxygen. }\end{array}$ & $\begin{array}{l}\text { Mackenzie } \\
\text { sixth Australian } \\
\text { to stand on } \\
\text { the summit of } \\
\text { Mt Everest. }\end{array}$ \\
\hline
\end{tabular}




\begin{tabular}{|c|c|c|c|c|}
\hline & $\begin{array}{l}\text { Mustagh Ata } \\
\text { (7546 m) } \\
\text { W Face, Pamir, } \\
\text { Western China }\end{array}$ & $\begin{array}{l}\text { Ken McConnell and } \\
\text { Mike Rheinberger } \\
\text { (guide), members } \\
\text { of six-man } \\
\text { international } \\
\text { expedition }\end{array}$ & $\begin{array}{l}\text { Successful. } \\
\text { Rheinberger, Shaun } \\
\text { Norman (NZ) and } \\
\text { two British clients } \\
\text { reached summit. }\end{array}$ & $\begin{array}{l}\text { First Australian } \\
\text { ascent. } \\
\text { Rheinberger } \\
\text { climbed mountain } \\
\text { on snowshoes. }\end{array}$ \\
\hline & $\begin{array}{l}\text { Himalchuli West } \\
\text { (7540 m) } \\
\text { Central Nepal, } \\
\text { SW Ridge }\end{array}$ & $\begin{array}{l}\text { Paul Bayne (guide) } \\
\text { and Campbell } \\
\text { Mercer, members } \\
\text { of } 12 \text {-man } \\
\text { international } \\
\text { expedition }\end{array}$ & $\begin{array}{l}\text { Successful. Bayne, } \\
\text { Russell Brice } \\
\text { (NZ), Jan Gangdal } \\
\text { (Norway) and Mercer } \\
\text { reached summit. }\end{array}$ & $\begin{array}{l}\text { First Australian } \\
\text { ascent. Second } \\
\text { ascent of } \\
\text { mountain. New, } \\
\text { technically hard } \\
\text { route involving } \\
\text { traverse of } 3 \\
\text { km-long ridge } \\
\text { with } 11 \text { major } \\
\text { pinnacles. }\end{array}$ \\
\hline & \begin{tabular}{|l} 
Nameless Tower \\
(6237 m) \\
NE Face, \\
Trango Group, \\
Karakoram, \\
Pakistan \\
\end{tabular} & $\begin{array}{l}\text { Greg Child, Mark } \\
\text { Wilford (USA) }\end{array}$ & $\begin{array}{l}\text { Unsuccessful. High } \\
\text { point reached: } \\
5800 \mathrm{~m} \text {. }\end{array}$ & $\begin{array}{l}\text { Alpine-style } \\
\text { attempt for } 13 \\
\text { consecutive } \\
\text { days on } 1500 \mathrm{~m} \\
\text { vertical wall. Six } \\
\text { days of storm. }\end{array}$ \\
\hline & $\begin{array}{l}\text { Ama Dablam } \\
\text { (6854 m) } \\
\text { SW Ridge, } \\
\text { Eastern Nepal }\end{array}$ & $\begin{array}{l}\text { Shane Chemello, } \\
\text { John Coulton, Paul } \\
\text { Gray, Mike Groom, } \\
\text { Chris Hawthorne, } \\
\text { Stan Pickering }\end{array}$ & $\begin{array}{l}\text { Unsuccessful. High } \\
\text { point reached: } \\
6750 \mathrm{~m} \text {, by Coulton } \\
\text { and Groom. }\end{array}$ & \\
\hline & $\begin{array}{l}\text { Peak } 5886 \\
(5886 \mathrm{~m}) \\
\text { S Face, } \\
\text { Karakoram, } \\
\text { Pakistan }\end{array}$ & $\begin{array}{l}\text { Damien Barrett, } \\
\text { Wade Stevens }\end{array}$ & $\begin{array}{l}\text { Successful. Climbed } \\
\text { during ski traverse } \\
\text { of Biafo-Hispar } \\
\text { Glacier system. }\end{array}$ & \\
\hline \multirow[t]{2}{*}{1990} & $\begin{array}{l}\text { Mt Everest } \\
\text { (8850 m) } \\
\text { SE Ridge, } \\
\text { Eastern Nepal }\end{array}$ & $\begin{array}{l}\text { Tim Macartney- } \\
\text { Snape }\end{array}$ & $\begin{array}{l}\text { Successful. Climbed } \\
\text { SE Ridge after } \\
\text { climbing to } 7500 \\
m \text { on W Ridge. }\end{array}$ & $\begin{array}{l}\text { First ascent of } \\
\text { entire } 8850 \mathrm{~m} \\
\text { of Mt Everest } \\
\text { from sea level } \\
\text { to summit. } \\
\text { Second ascent } \\
\text { of Mt Everest } \\
\text { by Macartney- } \\
\text { Snape, both } \\
\text { without } \\
\text { supplementary } \\
\text { oxygen. }\end{array}$ \\
\hline & $\begin{array}{l}\text { Cho Oyu } \\
\text { (8201 m) } \\
\text { NW Face, Tibet }\end{array}$ & $\begin{array}{l}\text { Tim Ball, Tony } \\
\text { Dignan, Mike } \\
\text { Groom, Steve } \\
\text { McDowell, Jane } \\
\text { White, Rick White }\end{array}$ & $\begin{array}{l}\text { Successful. Groom } \\
\text { reached summit. } \\
\text { Dignan climbed } \\
\text { to } 8050 \mathrm{~m} \text {. }\end{array}$ & $\begin{array}{l}\text { First Australian } \\
\text { ascent. Second } \\
8000 \mathrm{~m} \text { peak } \\
\text { climbed by } \\
\text { Groom. }\end{array}$ \\
\hline
\end{tabular}




\begin{tabular}{|c|c|c|c|c|}
\hline & $\begin{array}{l}\text { Shisha } \\
\text { Pangma(Central } \\
\text { Summit) } \\
\text { (8026 m) } \\
\text { N Ridge, Tibet }\end{array}$ & $\begin{array}{l}\text { Mark Lemaire, } \\
\text { member of six- } \\
\text { man international } \\
\text { expedition }\end{array}$ & $\begin{array}{l}\text { Successful. Russell } \\
\text { Brice (NZ), Lemaire, } \\
\text { Eirik Tryti (Norway), } \\
\text { Olav Ulvund (Norway) } \\
\text { and Mark Vallance } \\
\text { (UK) reached summit. }\end{array}$ & $\begin{array}{l}\text { First Australian } \\
\text { ascent of the } \\
\text { central peak. } \\
\text { Lemaire had } \\
\text { climbed to } 7400 \\
\text { m on Changtse in } \\
1988 \text { as member } \\
\text { of New Zealand } \\
\text { expedition. }\end{array}$ \\
\hline & $\begin{array}{l}\text { Menlungtse } \\
\text { (7181 m) } \\
\text { SE Ridge, Tibet }\end{array}$ & $\begin{array}{l}\text { Greg Child, John } \\
\text { Roskelly (USA) }\end{array}$ & $\begin{array}{l}\text { Unsuccessful. High } \\
\text { point reached: } 6450 \\
\text { m. Stopped by } \\
\text { dangerous cornices. }\end{array}$ & $\begin{array}{l}\text { Alpine-style } \\
\text { attempt on } \\
\text { one of highest } \\
\text { unclimbed peaks } \\
\text { in Himalaya. }\end{array}$ \\
\hline & $\begin{array}{l}\text { Mt Everest } \\
(8850 \mathrm{~m}) \\
\text { N Ridge/NE } \\
\text { Ridge, Tibet }\end{array}$ & $\begin{array}{l}\text { Chris Curry and } \\
\text { Mike Rheinberger, } \\
\text { members of nine- } \\
\text { man New Zealand } \\
\text { expedition }\end{array}$ & $\begin{array}{l}\text { Unsuccessful. High } \\
\text { point reached: } 8650 \\
\mathrm{~m}, \text { by Hugh van } \\
\text { Noorden (NZ). Curry } \\
\text { and Rheinberger } \\
\text { reached } 8565 \mathrm{~m} \text {. } \\
\text { Stopped by storms } \\
\text { and dangerous } \\
\text { snow conditions. }\end{array}$ & $\begin{array}{l}\text { Curry's } \\
\text { second and } \\
\text { Rheinberger's } \\
\text { fourth attempt } \\
\text { on Mt Everest. }\end{array}$ \\
\hline & $\begin{array}{l}\text { K2 }(8611 \mathrm{~m}) \\
\text { N Ridge, } \\
\text { Karakoram, } \\
\text { Pakistan }\end{array}$ & $\begin{array}{l}\text { Greg Child, Lyle } \\
\text { Closs, Phil Erschler } \\
\text { (USA), Peter } \\
\text { Keustler, Greg } \\
\text { Mortimer, Steve } \\
\text { Swenson (USA), } \\
\text { Margaret Werner }\end{array}$ & $\begin{array}{l}\text { Successful. Child, } \\
\text { Mortimer and Swenson } \\
\text { reached summit. } \\
\text { Erschler stopped } \\
200 \text { m short. }\end{array}$ & $\begin{array}{l}\text { First Australian } \\
\text { ascent of world's } \\
\text { second-highest } \\
\text { mountain. } \\
\text { Mortimer only } \\
\text { Australian to } \\
\text { climb world's } \\
\text { two highest } \\
\text { peaks. }\end{array}$ \\
\hline & $\begin{array}{l}\text { Mustagh Ata } \\
\text { (7546 m) } \\
\text { W Face, Pamir, } \\
\text { Western China }\end{array}$ & $\begin{array}{l}\text { Paul Bayne, Simon } \\
\text { Davis (NZ), Rik } \\
\text { Deaton, Philip } \\
\text { Milichamp (NZ) }\end{array}$ & $\begin{array}{l}\text { Successful. Bayne and } \\
\text { Davis reached summit. }\end{array}$ & $\begin{array}{l}\text { Alpine touring } \\
\text { skis used } \\
\text { above } 6100 \mathrm{~m} \\
\text { on ascent. }\end{array}$ \\
\hline \multirow[t]{3}{*}{1991} & $\begin{array}{l}\text { Kedarnath Peak } \\
\text { ( } 6940 \text { m) } \\
\text { N Face, } \\
\text { Gangotri, India }\end{array}$ & $\begin{array}{l}\text { Nevin Agnew, } \\
\text { Lance Einam, } \\
\text { Mike Kilcullen, } \\
\text { Bob Killip, Brian } \\
\text { Morrissey, Zac } \\
\text { Zaharias and } \\
10 \text { Indian Army } \\
\text { members }\end{array}$ & $\begin{array}{l}\text { Successful. Zaharias, } \\
\text { Kilcullen and Indian } \\
\text { members G. Singh, } \\
\text { N. D. Sherpa } \\
\text { and M. R. Yadev } \\
\text { reached summit. }\end{array}$ & $\begin{array}{l}\text { Yadev descended } \\
\text { alone in the dark } \\
\text { and was never } \\
\text { seen again. First } \\
\text { ascent of the } \\
\text { North Face. }\end{array}$ \\
\hline & $\begin{array}{l}\text { Mt Everest } \\
\text { (8850 m) } \\
\text { N Face, Tibet }\end{array}$ & $\begin{array}{l}\text { Mike Rheinberger, } \\
\text { member of US } \\
\text { expedition }\end{array}$ & $\begin{array}{l}\text { Unsuccessful. } \\
\text { Rheinberger turned } \\
\text { back at } 8500 \mathrm{~m} \\
\text { by high winds. }\end{array}$ & $\begin{array}{l}\text { Rheinberger's } \\
\text { fifth Everest } \\
\text { attempt. }\end{array}$ \\
\hline & $\begin{array}{l}\text { Ama Dablam } \\
\text { (6854 m) } \\
\text { SW Ridge, } \\
\text { Nepal }\end{array}$ & $\begin{array}{l}\text { Warwick Baird, } \\
\text { Frank Moon }\end{array}$ & $\begin{array}{l}\text { Successful. Baird } \\
\text { reached summit, } \\
\text { climbing with } \\
\text { Sherpa from Korean } \\
\text { Expedition. }\end{array}$ & $\begin{array}{l}\text { First Australian } \\
\text { winter ascent. }\end{array}$ \\
\hline
\end{tabular}




\begin{tabular}{|c|c|c|c|c|}
\hline & $\begin{array}{l}\text { Mt Everest } \\
\text { (8850 m) } \\
\text { SE Ridge, Nepal }\end{array}$ & $\begin{array}{l}\text { Ian Collins, Michael } \\
\text { Groom, Andrew } \\
\text { Lock, Mark Squires }\end{array}$ & $\begin{array}{l}\text { Unsuccessful. High } \\
\text { point of } 8200 \mathrm{~m} \\
\text { reached. Stopped } \\
\text { by soft snow and } \\
\text { high winds. }\end{array}$ & $\begin{array}{l}\text { Groom survived } \\
900 \mathrm{~m} \text { fall in } \\
\text { avalanche. }\end{array}$ \\
\hline \multirow[t]{6}{*}{1992} & \begin{tabular}{|l} 
Makalu \\
$(8463 \mathrm{~m})$ \\
W Face/NW \\
Ridge, Nepal
\end{tabular} & $\begin{array}{l}\text { Mike Rheinberger, } \\
\text { member of UK } \\
\text { expedition }\end{array}$ & $\begin{array}{l}\text { Unsuccessful. High } \\
\text { point of } 8250 \mathrm{~m} \\
\text { reached on NW Ridge. } \\
\text { Stopped by deep snow } \\
\text { and exhaustion. }\end{array}$ & $\begin{array}{l}\text { Third Australian } \\
\text { attempt on } \\
\text { Makalu. None } \\
\text { successful. }\end{array}$ \\
\hline & $\begin{array}{l}\text { Nameless Tower } \\
(6239 \mathrm{~m}) \\
\text { S Face, } \\
\text { Karakoram, } \\
\text { Pakistan }\end{array}$ & $\begin{array}{l}\text { Greg Child, Mark } \\
\text { Wilford (USA) }\end{array}$ & $\begin{array}{l}\text { Successful. Both } \\
\text { reached summit. New } \\
\text { route up S Face. }\end{array}$ & $\begin{array}{l}\text { First Australian } \\
\text { ascent. Massive } \\
\text { rock fall } \\
\text { obliterated part } \\
\text { of route climbed } \\
\text { days earlier. }\end{array}$ \\
\hline & \begin{tabular}{|l|} 
Great Trango \\
Tower \\
(5753 m) \\
Karakoram, \\
Pakistan
\end{tabular} & $\begin{array}{l}\text { Nic Feteris, Geoff } \\
\text { Gabites (NZ), Vlad } \\
\text { Moroz (Russia), } \\
\text { Glenn Singleman }\end{array}$ & $\begin{array}{l}\text { Successful. All four } \\
\text { climbed to NE summit. } \\
\text { Feteris and Singleman } \\
\text { descended by } 1500 \\
\text { m BASE jump. }\end{array}$ & $\begin{array}{l}\text { First Australian } \\
\text { ascent. Longest } \\
\text { BASE jump from } \\
\text { a mountain. }\end{array}$ \\
\hline & $\begin{array}{l}\text { Ama Dablam } \\
\text { (6854 m) } \\
\text { SE Ridge/SW } \\
\text { Face, Nepal }\end{array}$ & $\begin{array}{l}\text { Kobus Barnard } \\
\text { (Canada), Matt } \\
\text { Godbold, Richard } \\
\text { Howes, Ray Vran }\end{array}$ & $\begin{array}{l}\text { Successful. All four } \\
\text { reached summit. }\end{array}$ & $\begin{array}{l}\text { Second ascent } \\
\text { of route. }\end{array}$ \\
\hline & \begin{tabular}{|l} 
Cholatse \\
(6440 m) \\
W Face, Nepal
\end{tabular} & $\begin{array}{l}\text { Derek Chinn (NZ), } \\
\text { Adam Darragh, } \\
\text { Cam Falkner (NZ), } \\
\text { Marty Hunter (NZ) }\end{array}$ & $\begin{array}{l}\text { Successful. Darragh } \\
\text { soloed the climb in } \\
\text { four days after other } \\
\text { three had completed } \\
\text { alpine-style ascent. }\end{array}$ & $\begin{array}{l}\text { First Australian } \\
\text { ascent. First } \\
\text { solo ascent. }\end{array}$ \\
\hline & $\begin{array}{l}\text { Ramdung Go } \\
\text { (5930 m) } \\
\text { N Face, Nepal }\end{array}$ & $\begin{array}{l}\text { Tony Brennan, } \\
\text { Derek Cannon, } \\
\text { Peter Cullen, } \\
\text { Rhonda Freeman, } \\
\text { Joe Kaplun, } \\
\text { Frank Kenny, } \\
\text { Bob Kenyon, } \\
\text { Joanne Kenyon, } \\
\text { Brian Laursen, } \\
\text { Chris Mayfield, } \\
\text { Paul Morton, Bill } \\
\text { Proctor, Gordon } \\
\text { Stevens, Luke } \\
\text { van Beek }\end{array}$ & $\begin{array}{l}\text { Successful. Cannon, } \\
\text { Cullen, Freeman, } \\
\text { Kaplun, Kenny, } \\
\text { Laursen, Mayfield, } \\
\text { Proctor, Stevens } \\
\text { and van Beek } \\
\text { reached summit. }\end{array}$ & $\begin{array}{l}\text { First Australian } \\
\text { ascent. AAA } \\
\text { expedition. }\end{array}$ \\
\hline 1993 & $\begin{array}{l}\text { Makalu } \\
\text { (8481 m) } \\
\text { W Ridge, Nepal }\end{array}$ & $\begin{array}{l}\text { Warwick Baird, lan } \\
\text { Collins, Michael } \\
\text { Groom, Wil King, } \\
\text { Jonathan Leicester, } \\
\text { Warwick Paten, } \\
\text { Mark Squires, } \\
\text { Duncan Thomas }\end{array}$ & $\begin{array}{l}\text { Unsuccessful. High } \\
\text { point of } 7200 \mathrm{~m} \\
\text { reached. Stopped } \\
\text { by severe monsoon } \\
\text { conditions. }\end{array}$ & $\begin{array}{l}\text { Attempted two } \\
\text { technically } \\
\text { difficult routes. }\end{array}$ \\
\hline
\end{tabular}




\begin{tabular}{|c|c|c|c|}
\hline $\begin{array}{l}\text { Dhaulagiri } \\
\text { (8167 m) } \\
\text { NE Spur, Nepal }\end{array}$ & $\begin{array}{l}\text { Adam Darragh, } \\
\text { Matt Godbold, } \\
\text { Dave Macleod } \\
\text { (NZ), Mick } \\
\text { McCourt, Phil } \\
\text { Pitham, Stephen } \\
\text { Simpson, James } \\
\text { Strohfeldt, Pat } \\
\text { Waddingham, } \\
\text { Mark Watson (UK), } \\
\text { Mark Whetu (NZ) } \\
\text { and Zac Zaharias, } \\
\text { leader of Army } \\
\text { Alpine Association } \\
\text { expedition }\end{array}$ & $\begin{array}{l}\text { Unsuccessful. High } \\
\text { point of } 7400 \mathrm{~m} \\
\text { reached. Stopped } \\
\text { by illness and high } \\
\text { winds. One Camp } \\
\text { IV tent blown off } \\
\text { the mountain. }\end{array}$ & $\begin{array}{l}\text { Second } \\
\text { Australian } \\
\text { attempt on } \\
\text { Dhaulagiri. } \\
\text { Neither } \\
\text { successful. }\end{array}$ \\
\hline $\begin{array}{l}\text { K2 }(8611 \mathrm{~m}) \\
\text { Abruzzi Ridge, } \\
\text { Karakoram, } \\
\text { Pakistan }\end{array}$ & $\begin{array}{l}\text { Michael } \\
\text { Whitehead, } \\
\text { member of } \\
\text { international } \\
\text { expedition }\end{array}$ & $\begin{array}{l}\text { Unsuccessful. High } \\
\text { point of } 7400 \mathrm{~m} \\
\text { reached. Stopped } \\
\text { by poor weather. }\end{array}$ & \\
\hline $\begin{array}{l}\text { Mt Everest } \\
(8850 \mathrm{~m}) \\
\text { SE Ridge, Nepal }\end{array}$ & $\begin{array}{l}\text { Trajce Aleksow, } \\
\text { Lobsang Tshering } \\
\text { Bhutia (Nepal), } \\
\text { Michael Groom, } \\
\text { David Hume, } \\
\text { Andrew Lock, } \\
\text { Tashi Tenzing, } \\
\text { Dimitar Todorovski }\end{array}$ & $\begin{array}{l}\text { Successful. Groom } \\
\text { and Bhutia reached } \\
\text { summit. Bhutia died } \\
\text { in fall from } 8500 \mathrm{~m} \\
\text { during descent. }\end{array}$ & $\begin{array}{l}\text { Climb on 40th } \\
\text { anniversary of } \\
\text { first Everest } \\
\text { ascent. Tashi } \\
\text { Tenzing, } \\
\text { grandson of } \\
\text { Tenzing Norgay, } \\
\text { who made first } \\
\text { ascent of Mt } \\
\text { Everest with } \\
\text { Edmund Hillary. }\end{array}$ \\
\hline $\begin{array}{l}\text { Mt Everest } \\
(8850 \mathrm{~m}) \\
\text { N Ridge, Tibet }\end{array}$ & $\begin{array}{l}\text { Brigitte Muir, Jon } \\
\text { Muir, members } \\
\text { of international } \\
\text { expedition }\end{array}$ & $\begin{array}{l}\text { Muirs reached } 7600 \\
\mathrm{~m} \text {. Stopped by cold } \\
\text { and high winds. Four } \\
\text { members had earlier } \\
\text { reached summit. }\end{array}$ & \\
\hline $\begin{array}{l}\text { North } \\
\text { Annapurna } \\
\text { region, } \\
\text { Trekking } \\
\text { peaks, Nepal }\end{array}$ & $\begin{array}{l}\text { Members of } \\
\text { Sutherland } \\
\text { Bushwalking } \\
\text { Club, Sydney }\end{array}$ & $\begin{array}{l}\text { Successful. Ascents } \\
\text { of Pisang Peak (6091 } \\
\text { m), Chulu East } \\
(6200 \mathrm{~m}), \text { Chulu Far } \\
\text { East }(6059 \mathrm{~m}) \text { and } \\
\text { Thorungtse }(6484 \mathrm{~m}) \text {. }\end{array}$ & $\begin{array}{l}\text { First Australian } \\
\text { ascents of Chulu } \\
\text { East, Chulu } \\
\text { Far East and } \\
\text { Thorungtse. }\end{array}$ \\
\hline $\begin{array}{l}\text { Shivling } \\
\text { (6543 m) } \\
\text { Garhwal, India }\end{array}$ & $\begin{array}{l}\text { John Dunlop, } \\
\text { James Keily }\end{array}$ & $\begin{array}{l}\text { Unsuccessful. Stopped } \\
\text { by early winter storm. }\end{array}$ & \\
\hline $\begin{array}{l}\text { Cholatse } \\
(6440 \mathrm{~m}) \\
\text { NW Ridge, } \\
\text { Nepal }\end{array}$ & $\begin{array}{l}\text { Armando Corvini, } \\
\text { John Lamb, } \\
\text { David Smith }\end{array}$ & $\begin{array}{l}\text { Unsuccessful. Stopped } \\
\text { at } 6000 \mathrm{~m} \text { by lack } \\
\text { of fuel and food. }\end{array}$ & $\begin{array}{l}\text { Earlier attempt on } \\
\text { W Face stopped } \\
\text { by dangerous } \\
\text { conditions. }\end{array}$ \\
\hline $\begin{array}{l}\text { Hushe region, } \\
\text { Karakoram, } \\
\text { Pakistan }\end{array}$ & $\begin{array}{l}\text { Erik Oostra, } \\
\text { Rolf Oostra, } \\
\text { Jeff Sandifort }\end{array}$ & $\begin{array}{l}\text { Successful. Sandifort } \\
\text { and Rolf Oostra } \\
\text { climbed an unnamed } \\
6300 \mathrm{~m} \text { peak adjacent } \\
\text { to Gondogoro Peak. }\end{array}$ & $\begin{array}{l}\text { Attempt on } \\
\text { Gondogoro Peak } \\
\text { defeated by poor } \\
\text { snow conditions. }\end{array}$ \\
\hline
\end{tabular}




\begin{tabular}{|c|c|c|c|c|}
\hline & $\begin{array}{l}\text { K2 }(8611 \mathrm{~m}) \\
\text { Abruzzi Ridge, } \\
\text { Karakoram, } \\
\text { Pakistan }\end{array}$ & $\begin{array}{l}\text { Andrew Lock, } \\
\text { member of German } \\
\text { expedition }\end{array}$ & $\begin{array}{l}\text { Successful. Lock and } \\
\text { three German climbers } \\
\text { reached summit. }\end{array}$ & $\begin{array}{l}\text { Second } \\
\text { Australian ascent } \\
\text { of K2; first of } \\
\text { Abruzzi Ridge. }\end{array}$ \\
\hline \multirow[t]{7}{*}{1994} & \begin{tabular}{|l} 
Mt Everest \\
$(8850 \mathrm{~m})$ \\
N Ridge, Tibet
\end{tabular} & $\begin{array}{l}\text { Mike Rheinberger, } \\
\text { member of US } \\
\text { expedition }\end{array}$ & $\begin{array}{l}\text { Successful. } \\
\text { Rheinberger reached } \\
\text { summit. First } \\
\text { Australian ascent } \\
\text { of N Ridge. }\end{array}$ & $\begin{array}{l}\text { Rheinberger } \\
\text { died of cerebral } \\
\text { oedema on } \\
\text { descent after } \\
\text { forced bivouac } \\
200 \text { m below } \\
\text { summit. New } \\
\text { Zealander Mark } \\
\text { Whetu made } \\
\text { superhuman } \\
\text { effort to save } \\
\text { Rheinberger; } \\
\text { suffered severe } \\
\text { frostbite. }\end{array}$ \\
\hline & $\begin{array}{l}\text { Shisha } \\
\text { Pangma(Central } \\
\text { Summit) } \\
\text { (8026 m) } \\
\text { N Ridge, Tibet }\end{array}$ & $\begin{array}{l}\text { Paul O'Byrne, } \\
\text { member of } \\
\text { Canadian } \\
\text { expedition }\end{array}$ & $\begin{array}{l}\text { Successful. O'Byrne } \\
\text { reached summit. }\end{array}$ & \\
\hline & \begin{tabular}{|l} 
Shisha \\
Pangma(Central \\
Summit) \\
(8026 m) \\
N Ridge, Tibet
\end{tabular} & $\begin{array}{l}\text { Paul Carr, Greg } \\
\text { Lindsell, Brigitte } \\
\text { Muir, members } \\
\text { of commercial } \\
\text { expedition }\end{array}$ & $\begin{array}{l}\text { Successful. Carr, } \\
\text { Lindsell and Muir } \\
\text { reached summit. }\end{array}$ & \\
\hline & $\begin{array}{l}\text { Cho Oyu } \\
\text { (8201 m) } \\
\text { NW Face, Tibet }\end{array}$ & $\begin{array}{l}\text { Mike Brennan, } \\
\text { Brigitte Muir, Bill } \\
\text { Pierson, Babu Chire } \\
\text { Sherpa (Nepal), } \\
\text { Jon Tinker (UK) }\end{array}$ & $\begin{array}{l}\text { Unsuccessful. Turned } \\
\text { back at } 6800 \mathrm{~m} \text { by } \\
\text { early monsoon. }\end{array}$ & $\begin{array}{l}\text { Alpine-style } \\
\text { attempt. }\end{array}$ \\
\hline & $\begin{array}{l}\text { K2 }(8611 \mathrm{~m}) \\
\text { Abruzzi Ridge, } \\
\text { Karakoram, } \\
\text { Pakistan }\end{array}$ & $\begin{array}{l}\text { Michael Groom, } \\
\text { member of US } \\
\text { expedition }\end{array}$ & $\begin{array}{l}\text { Successful. Groom } \\
\text { reached summit by } \\
\text { Abruzzi Ridge with } \\
\text { Finnish partner. }\end{array}$ & $\begin{array}{l}\text { Previous attempt } \\
\text { by S Face failed } \\
30 \mathrm{~m} \text { from } \\
\text { summit. First } \\
\text { Australian to } \\
\text { climb world's } \\
\text { three highest } \\
\text { mountains. }\end{array}$ \\
\hline & \begin{tabular}{|l} 
Broad Peak \\
(8047 m) \\
W Face, \\
Karakoram, \\
Pakistan
\end{tabular} & $\begin{array}{l}\text { Andrew Lock, } \\
\text { member of } \\
\text { Swedish expedition }\end{array}$ & $\begin{array}{l}\text { Lock reached } 8030 \\
\mathrm{~m} \text { (halfway between } \\
\text { the fore-summit and } \\
\text { true summit) but } \\
\text { retreated in the face } \\
\text { of a severe storm. }\end{array}$ & $\begin{array}{l}\text { Lock reached } \\
6500 \mathrm{~m} \text { on an } \\
\text { earlier attempt } \\
\text { on a new route } \\
\text { on S Ridge. }\end{array}$ \\
\hline & \begin{tabular}{|l} 
Carne Peak \\
$(4500 \mathrm{~m})$ \\
Karakoram, \\
Pakistan \\
\end{tabular} & $\begin{array}{l}\text { Tim Harley, } \\
\text { Nigel Murphy }\end{array}$ & Successful. & $\begin{array}{l}\text { New, technical } \\
\text { rock route. }\end{array}$ \\
\hline
\end{tabular}




\begin{tabular}{|c|c|c|c|c|}
\hline & $\begin{array}{l}\text { Chongtar } \\
\text { (7370 m) } \\
\text { W Ridge, } \\
\text { Kashgar, China }\end{array}$ & $\begin{array}{l}\text { Colin Monteath, } \\
\text { Greg Mortimer, } \\
\text { Lucas Trihey, } \\
\text { Sue Werner }\end{array}$ & $\begin{array}{l}\text { Successful. Monteath, } \\
\text { Mortimer and Trihey } \\
\text { reached summit. }\end{array}$ & $\begin{array}{l}\text { First ascent of } \\
\text { major unclimbed } \\
\text { peak by an } \\
\text { Australian team. }\end{array}$ \\
\hline & $\begin{array}{l}\text { Indradhanush } \\
\text { Parbat } \\
(6739 \mathrm{~m}) \text {, } \\
\text { W Face/W } \\
\text { Ridge, Garhwal, } \\
\text { India }\end{array}$ & $\begin{array}{l}\text { Sarah Boyal, Gavin } \\
\text { Dunmall, Grant } \\
\text { Else, Andrew } \\
\text { McNeill, Darren } \\
\text { Miller, Jamie Serle, } \\
\text { Glenn Tempest, } \\
\text { Peter Williams }\end{array}$ & $\begin{array}{l}\text { Successful. Serle and } \\
\text { Tempest summited by } \\
\text { W Face direct; Dunmall } \\
\text { and Miller by W Face } \\
\text { LHS. Else's ascent } \\
\text { was by W Ridge (solo). }\end{array}$ & $\begin{array}{l}\text { First, second and } \\
\text { third ascents } \\
\text { of mountain } \\
\text { previously known } \\
\text { only as Chandra } \\
\text { Parbat South. }\end{array}$ \\
\hline & $\begin{array}{l}\text { Kulu/Zanskar } \\
\text { region, } \\
\text { Trekking } \\
\text { peaks, India }\end{array}$ & $\begin{array}{l}\text { David Burnett, } \\
\text { Steve Carter, Nick } \\
\text { Gust, David Kjar, } \\
\text { Rohan Schaap, } \\
\text { David Wilson }\end{array}$ & $\begin{array}{l}\text { Successful. Carter, } \\
\text { Schaap and Wilson } \\
\text { ascended Shingo La } \\
\text { Peak }(6025 \mathrm{~m}) \text {. }\end{array}$ & $\begin{array}{l}\text { Possible first } \\
\text { ascent of Shingo } \\
\text { La Peak. Attempt } \\
\text { on Hunumann } \\
\text { Tibba ( } 6040 \\
\text { m) defeated by } \\
\text { poor weather. }\end{array}$ \\
\hline & $\begin{array}{l}\text { Bhagirathi III } \\
\text { (6454 m) } \\
\text { SW Pillar, } \\
\text { Garhwal, India }\end{array}$ & $\begin{array}{l}\text { Jonathan } \\
\text { Chapman, } \\
\text { Vera Wong }\end{array}$ & $\begin{array}{l}\text { Successful. Both } \\
\text { climbers reached } \\
\text { summit by } \\
\text { Scottish Route. }\end{array}$ & $\begin{array}{l}\text { Two nights spent } \\
\text { on face; bivvy } \\
\text { on summit. }\end{array}$ \\
\hline & $\begin{array}{l}\text { Kwangde Ri } \\
\text { (6187 m) } \\
\text { S Ridge, Nepal }\end{array}$ & $\begin{array}{l}\text { Gareth Brown, } \\
\text { David Chauval, } \\
\text { Matt Godbold, } \\
\text { Paul Morton, Matt } \\
\text { Rogerson and } \\
\text { Matt Walton }\end{array}$ & $\begin{array}{l}\text { Summit reached by } \\
\text { Chauval, Godbold } \\
\text { and Rogerson. }\end{array}$ & $\begin{array}{l}\text { AAA expedition. } \\
\text { First Australian } \\
\text { ascent. }\end{array}$ \\
\hline & $\begin{array}{l}\text { Pumori } \\
\text { (7161 m) } \\
\text { S Ridge, Nepal }\end{array}$ & $\begin{array}{l}\text { John Barnes (NZ), } \\
\text { Grant Dixon, } \\
\text { Rolan Eberhard, } \\
\text { Stuart Findlay } \\
\text { (UK), Hamish } \\
\text { Morton (UK) and } \\
\text { Wade Stevens }\end{array}$ & $\begin{array}{l}\text { Barnes and Findlay } \\
\text { reached summit on } \\
22 \text { October. Dixon, } \\
\text { Eberhard and Stevens } \\
\text { reached } 6700 \mathrm{~m} \text {. }\end{array}$ & \\
\hline & $\begin{array}{l}\text { Ama Dablam } \\
\text { (6854 m) } \\
\text { S Ridge and SW } \\
\text { Ridge, Nepal }\end{array}$ & $\begin{array}{l}\text { Andrew Burns, } \\
\text { Armando Corvini } \\
\text { (leader), Andrew } \\
\text { McAuley, David } \\
\text { Smith (UK), Rod } \\
\text { Willard (USA) } \\
\text { and Vera Wong }\end{array}$ & $\begin{array}{l}\text { Successful. McAuley, } \\
\text { Willard and Wong } \\
\text { reached summit on } \\
8 \text { November. Burns, } \\
\text { Corvini and Smith } \\
\text { reached summit } \\
\text { two days later. }\end{array}$ & $\begin{array}{l}\text { First Australian } \\
\text { ascent of this } \\
\text { route. Corvini } \\
\text { lost all fingers } \\
\text { and some toes } \\
\text { to frostbite. } \\
\text { Three others } \\
\text { with frostbite. }\end{array}$ \\
\hline & $\begin{array}{l}\text { Kusum Kanguru } \\
\text { (6369 m) } \\
\text { SE Face, Nepal }\end{array}$ & $\begin{array}{l}\text { Alan Adams and } \\
\text { David Gardner }\end{array}$ & $\begin{array}{l}\text { Climbed a direct line } \\
\text { from the Lungsamba } \\
\text { Glacier. Reached } \\
\text { summit ridge just } \\
\text { east of summit. }\end{array}$ & \\
\hline 1995 & $\begin{array}{l}\text { Makalu } \\
\text { (8463 m) } \\
\text { NW Ridge } \\
\text { (French), Nepal }\end{array}$ & $\begin{array}{l}\text { Mark Auricht, } \\
\text { Duncan Chessell, } \\
\text { David Hume, } \\
\text { Paul Rickards, } \\
\text { Matt Rolfe and } \\
\text { David Tingay }\end{array}$ & $\begin{array}{l}\text { Auricht and Hume } \\
\text { reached summit on } 8 \\
\text { May. Hume died during } \\
\text { the descent from a fall } \\
250 \text { m below summit. }\end{array}$ & $\begin{array}{l}\text { First Australian } \\
\text { ascent. Auricht } \\
\text { descended alone } \\
\text { in the dark. }\end{array}$ \\
\hline
\end{tabular}




\begin{tabular}{|c|c|c|c|}
\hline $\begin{array}{l}\text { Mt Everest } \\
\text { (8850 m) } \\
\text { N Ridge, Tibet }\end{array}$ & $\begin{array}{l}\text { George Mallory } \\
\text { II, member of } \\
\text { US expedition }\end{array}$ & $\begin{array}{l}\text { Reached summit } \\
\text { on } 14 \text { May. }\end{array}$ & $\begin{array}{l}\text { Second } \\
\text { Australian ascent } \\
\text { of N Ridge. } \\
\text { Grandson of } \\
\text { George Mallory } \\
\text { participated. }\end{array}$ \\
\hline $\begin{array}{l}\text { Mt Everest } \\
\text { (8850 m) } \\
\text { N Ridge, Tibet }\end{array}$ & $\begin{array}{l}\text { Greg Child on } \\
\text { Russell Brice } \\
\text { (NZ) Himalayan } \\
\text { Experience } \\
\text { expedition }\end{array}$ & Child reached summit. & $\begin{array}{l}\text { Tom Whittaker } \\
\text { (USA) attempted } \\
\text { to make first } \\
\text { disabled ascent } \\
\text { of Everest. He } \\
\text { reached } 8300 \mathrm{~m} \text {. }\end{array}$ \\
\hline $\begin{array}{l}\text { Mt Everest } \\
(8850 \mathrm{~m}) \\
\text { N Ridge, Tibet }\end{array}$ & $\begin{array}{l}\text { James Allen, Kelly } \\
\text { Armitage, Mick } \\
\text { Chapman (UK), } \\
\text { Brigitte Muir, } \\
\text { Jon Muir and } \\
\text { other members of } \\
\text { OTT commercial } \\
\text { expedition led by } \\
\text { Jon Tinker (UK) }\end{array}$ & $\begin{array}{l}\text { Allen reached summit } \\
\text { on } 27 \text { May. Brigitte } \\
\text { Muir reached } 8500 \mathrm{~m} \\
\text { but head-torch failure } \\
\text { forced an all-night } \\
\text { open bivvy at } 8450 \mathrm{~m} \text {. }\end{array}$ & $\begin{array}{l}\text { Guided ascent } \\
\text { by Allen (22), } \\
\text { who became } \\
\text { the youngest } \\
\text { Australian to } \\
\text { climb Everest. } \\
\text { Jon Muir's fifth } \\
\text { expedition to } \\
\text { Mt Everest. } \\
\text { Muirs' attempt } \\
\text { unguided. }\end{array}$ \\
\hline $\begin{array}{l}\text { Cho Oyu } \\
(8201 \mathrm{~m}) \\
\text { NW Face, Tibet }\end{array}$ & Paul Walters & $\begin{array}{l}\text { Reached summit } \\
\text { on } 29 \text { May. }\end{array}$ & \\
\hline $\begin{array}{l}\text { Lhotse }(8516 \mathrm{~m}) \\
\text { W Face, Nepal }\end{array}$ & $\begin{array}{l}\text { Mike Groom and } \\
\text { Veikka Gustafsson } \\
\text { (Finland) }\end{array}$ & $\begin{array}{l}\text { Groom and Gustafsson } \\
\text { reached summit. }\end{array}$ & $\begin{array}{l}\text { First Australian } \\
\text { ascent. }\end{array}$ \\
\hline $\begin{array}{l}\text { Shisha Pangma } \\
\text { (Central } \\
\text { Summit) } \\
\text { (8026 m) } \\
\text { N Ridge, Tibet }\end{array}$ & Mike Groom & $\begin{array}{l}\text { Turned back at } \\
7600 \text { m due to } \\
\text { slab avalanches. }\end{array}$ & \\
\hline $\begin{array}{l}\text { Tirich Mir } \\
\text { (7707 m) } \\
\text { N Face, Hindu } \\
\text { Kush, Pakistan }\end{array}$ & $\begin{array}{l}\text { Semi-commercial } \\
\text { expedition led by } \\
\text { David Hamilton } \\
\text { (UK) and consisting } \\
\text { of Grant Dixon, } \\
\text { Rob Levy, four } \\
\text { Britons and one } \\
\text { Canadian }\end{array}$ & $\begin{array}{l}\text { Dixon and Hamilton } \\
\text { reached summit } \\
\text { on } 17 \text { July. }\end{array}$ & $\begin{array}{l}\text { First Australian } \\
\text { ascent. }\end{array}$ \\
\hline $\begin{array}{l}\text { Nanda Devi } \\
\text { East }(7437 \mathrm{~m}) \\
\text { India }\end{array}$ & $\begin{array}{l}\text { David Chauval, } \\
\text { Jim Truscott, } \\
\text { Chris White and } \\
80 \text { members } \\
\text { of international } \\
\text { expedition } \\
\text { consisting of } \\
\text { Indian, Nepalese, } \\
\text { Australian, } \\
\text { British and US } \\
\text { Army climbers }\end{array}$ & $\begin{array}{l}\text { Truscott and White } \\
\text { reached summit. US } \\
\text { climber fell to his } \\
\text { death during descent. }\end{array}$ & $\begin{array}{l}\text { First Australian } \\
\text { ascent of Nanda } \\
\text { Devi East and } \\
\text { eighth overall } \\
\text { ascent. }\end{array}$ \\
\hline
\end{tabular}




\begin{tabular}{|c|c|c|c|c|}
\hline & $\begin{array}{l}\text { Bublimotin } \\
\text { (6000 m) } \\
\text { Pakistan }\end{array}$ & $\begin{array}{l}\text { Damien Gildea } \\
\text { and Mark Nayar }\end{array}$ & Reached $4700 \mathrm{~m}$. & \\
\hline & $\begin{array}{l}\text { Kusum Kanguru } \\
\text { (6369 m) } \\
\text { N Buttress, } \\
\text { Nepal }\end{array}$ & $\begin{array}{l}\text { Chris Matthews } \\
\text { and Matt Rogerson }\end{array}$ & $\begin{array}{l}\text { High point of } 5600 \\
\mathrm{~m} \text { reached. Climb } \\
\text { abandoned due to poor } \\
\text { snow conditions. }\end{array}$ & $\begin{array}{l}\text { Alpine-style } \\
\text { attempt. AAA } \\
\text { expedition. }\end{array}$ \\
\hline & $\begin{array}{l}\text { Nanga Parbat } \\
\text { (8126 m) } \\
\text { Mazeno Ridge, } \\
\text { Pakistan }\end{array}$ & $\begin{array}{l}\text { Sandy Allan (UK), } \\
\text { Rick Allen (UK), } \\
\text { Voytek Kurtyka } \\
\text { (Poland), Andrew } \\
\text { Lock and Doug } \\
\text { Scott (UK) }\end{array}$ & $\begin{array}{l}\text { Allen, Kurtyka and } \\
\text { Lock made it about } \\
\text { halfway along the } \\
\text { ridge before turning } \\
\text { around due to lack } \\
\text { of food and time. }\end{array}$ & $\begin{array}{l}\text { The furthest } \\
\text { along the long } \\
\text { ridge any attempt } \\
\text { has reached. }\end{array}$ \\
\hline & $\begin{array}{l}\text { Khurdopin } \\
\text { (6465 m) } \\
\text { Pakistan }\end{array}$ & $\begin{array}{l}\text { Members of the } \\
\text { Edith Cowan } \\
\text { Mountaineering } \\
\text { Club }\end{array}$ & $\begin{array}{l}\text { Three members } \\
\text { reached } 5650 \mathrm{~m} .\end{array}$ & $\begin{array}{l}\text { Dangerous } \\
\text { conditions } \\
\text { and severely } \\
\text { corniced ridge } \\
\text { forced retreat. }\end{array}$ \\
\hline & $\begin{array}{l}\text { Tenan Tower } \\
(5300 \mathrm{~m}) \\
\text { Hushoh Puk } \\
(5400 \mathrm{~m}) \\
\text { Nangmar } \\
\text { Couloir, Pakistan }\end{array}$ & $\begin{array}{l}\text { Kynan Bazley (NZ) } \\
\text { and Vera Wong }\end{array}$ & $\begin{array}{l}\text { Summit of Tenan } \\
\text { Tower reached by way } \\
\text { of } 550 \text { m, 11-pitch } \\
\text { rock route. New route } \\
\text { of Hushoh Puk by } \\
\text { way of couloir but } \\
\text { summit not reached. }\end{array}$ & $\begin{array}{l}\text { First ascent of } \\
\text { Tenan Tower. }\end{array}$ \\
\hline & $\begin{array}{l}\text { Cho Oyu } \\
\text { (8201 m) } \\
\text { NW Face, Tibet }\end{array}$ & $\begin{array}{l}\text { Leonard Harvey } \\
\text { and Roman } \\
\text { Rosenbaum }\end{array}$ & $\begin{array}{l}\text { Reached summit on } \\
26 \text { September. }\end{array}$ & $\begin{array}{l}\text { Second } \\
\text { Australian } \\
\text { ascent. }\end{array}$ \\
\hline \multirow[t]{3}{*}{1996} & $\begin{array}{l}\text { Pyramid Peak } \\
\text { (Pathibhara) } \\
\text { (7125 m) } \\
\text { W (S) Ridge, } \\
\text { Nepal }\end{array}$ & $\begin{array}{l}\text { Jon Chapman, } \\
\text { Gavin Dunmall, } \\
\text { Tim Evans, Morvan } \\
\text { Grant, Darren } \\
\text { Miller (leader), } \\
\text { James Serle, } \\
\text { Nicola Sunderland } \\
\text { and Scott Welch }\end{array}$ & $\begin{array}{l}\text { Chapman and Dunmall } \\
\text { reached } 6350 \mathrm{~m} \text {. } \\
\text { Climb abandoned } \\
\text { due to strong winds } \\
\text { and poor weather. }\end{array}$ & $\begin{array}{l}\text { Only one } \\
\text { previous ascent } \\
\text { of mountain, } \\
\text { from Sikkim } \\
\text { side. In 2007, a } \\
\text { Slovenian team } \\
\text { ascended the } \\
\text { Nepalese side. }\end{array}$ \\
\hline & $\begin{array}{l}\text { Mt Everest } \\
\text { (8850 m) } \\
\text { S Col, Nepal }\end{array}$ & $\begin{array}{l}\text { Mike Groom, } \\
\text { John Taske } \\
\text { and members } \\
\text { of Adventure } \\
\text { Consultants } \\
\text { commercial } \\
\text { expedition led by } \\
\text { Rob Hall (NZ) }\end{array}$ & $\begin{array}{l}\text { Groom reached } \\
\text { summit. His second } \\
\text { ascent of } \mathrm{Mt} \text { Everest. }\end{array}$ & $\begin{array}{l}\text { The } 1996 \\
\text { tragedy is } \\
\text { documented in } \\
\text { Jon Krakauer's } \\
\text { book Into Thin } \\
\text { Air. Groom } \\
\text { was the only } \\
\text { guide to survive } \\
\text { the tragedy. }\end{array}$ \\
\hline & $\begin{array}{l}\text { Mt Everest } \\
\text { (8850 m) } \\
\text { S Col, Nepal }\end{array}$ & $\begin{array}{l}\text { Brigitte Muir } \\
\text { on Henry Todd } \\
\text { (UK) Himalayan } \\
\text { Guides commercial } \\
\text { expedition (non- } \\
\text { guided attempt) }\end{array}$ & $\begin{array}{l}\text { Muir reached S Col. } \\
\text { Spent two nights } \\
\text { during storm that } \\
\text { caught out Rob Hall's } \\
\text { expedition. Attempt } \\
\text { abandoned due to } \\
\text { unstable weather. }\end{array}$ & $\begin{array}{l}\text { Muir assisted } \\
\text { Beck Weathers } \\
\text { off S Col. }\end{array}$ \\
\hline
\end{tabular}




\begin{tabular}{|c|c|c|c|c|}
\hline & $\begin{array}{l}\text { Nanga Parbat } \\
\text { (8126 m) } \\
\text { Diamir Face, } \\
\text { Pakistan }\end{array}$ & $\begin{array}{l}\text { Joan Garcia } \\
\text { (Portugal) and } \\
\text { Andrew Lock } \\
\text { on international } \\
\text { expedition } \\
\text { including six Poles } \\
\text { and one Austrian }\end{array}$ & $\begin{array}{l}\text { Garcia and Lock } \\
\text { reached } 7500 \mathrm{~m} . \\
\text { Stopped by bad } \\
\text { conditions. }\end{array}$ & $\begin{array}{l}\text { Poles abandoned } \\
\text { mountain and } \\
\text { took most of } \\
\text { the gear while } \\
\text { Lock was still on } \\
\text { the mountain. }\end{array}$ \\
\hline & $\begin{array}{l}\text { Thalay Sagar } \\
\text { (6904 m) } \\
\text { N Face, India }\end{array}$ & $\begin{array}{l}\text { Andrew Lindblade } \\
\text { and Athol } \\
\text { Whimp (NZ) }\end{array}$ & $\begin{array}{l}\text { Lindblade and Whimp } \\
\text { reached } 6350 \mathrm{~m} . \\
\text { Climb abandoned } \\
\text { due to cold, snow } \\
\text { and avalanche. }\end{array}$ & $\begin{array}{l}\text { Attempt of direct } \\
\text { route on } 2000 \\
\text { m N Face. }\end{array}$ \\
\hline & $\begin{array}{l}\text { Karyolung } \\
\text { (6511 m) } \\
\text { NNW Ridge, } \\
\text { Nepal }\end{array}$ & $\begin{array}{l}\text { Tony Parr (leader), } \\
\text { Katherine Brandis, } \\
\text { Darren Gardner, } \\
\text { Glenn Horrocks, } \\
\text { Myfawny } \\
\text { Lawrence, Guido } \\
\text { Simionato }\end{array}$ & $\begin{array}{l}\text { Attempt abandoned } \\
\text { at } 5700 \mathrm{~m} \text { due to } \\
\text { bad weather. }\end{array}$ & \\
\hline \multirow[t]{4}{*}{1997} & \begin{tabular}{|l|} 
Mt Everest \\
(8850 m) \\
S Col, Nepal
\end{tabular} & $\begin{array}{l}\text { Tashi Tenzing } \\
\text { on commercial } \\
\text { expedition }\end{array}$ & $\begin{array}{l}\text { Reached summit } \\
\text { on } 23 \text { May. }\end{array}$ & $\begin{array}{l}\text { First grandson of } \\
\text { any summiteers. } \\
\text { Guided ascent. }\end{array}$ \\
\hline & $\begin{array}{l}\text { Mt Everest } \\
\text { (8850 m) } \\
\text { S Col, Nepal }\end{array}$ & $\begin{array}{l}\text { Brigitte Muir on } \\
\text { Mal Duff (UK) non- } \\
\text { guided commercial } \\
\text { expedition }\end{array}$ & $\begin{array}{l}\text { Muir reached summit } \\
\text { on } 27 \text { May with Dorje } \\
\text { Sherpa and Kipa- } \\
\text { Sherpa during perfect } \\
\text { weather using oxygen. }\end{array}$ & $\begin{array}{l}\text { First Australian } \\
\text { female (unguided) } \\
\text { ascent. First } \\
\text { Australian } \\
\text { husband-and- } \\
\text { wife summiteers } \\
\text { (Jon Muir, 28 } \\
\text { May 1988). }\end{array}$ \\
\hline & \begin{tabular}{|l} 
Dhaulagiri \\
(8167 m) \\
NE Spur, Nepal
\end{tabular} & $\begin{array}{l}\text { Nevin Agnew, } \\
\text { Allen Caldwell, } \\
\text { Bob Killip, Brian } \\
\text { Laursen, Andrew } \\
\text { Lock, Andrew } \\
\text { Molyneaux, Matt } \\
\text { Rogerson, Jon } \\
\text { Sparks, Alex } \\
\text { van Roy, Matt } \\
\text { Walton and Zac } \\
\text { Zaharias (leader) }\end{array}$ & $\begin{array}{l}\text { Successful. Lock, } \\
\text { Rogerson and Zaharias } \\
\text { reached summit in } \\
\text { the dark at } 9.30 \\
\text { pm on } 25 \text { May. }\end{array}$ & $\begin{array}{l}\text { First Australian } \\
\text { ascent of } \\
\text { Dhaulagiri. Dual } \\
\text { AAA expedition } \\
\text { to Dhaulagiri } \\
\text { and Tukuche. }\end{array}$ \\
\hline & $\begin{array}{l}\text { Tukuche }(6940 \\
\text { m) and } \\
\text { Tukuche South } \\
(6690 \mathrm{~m}) \\
\text { S Ridge, Nepal }\end{array}$ & $\begin{array}{l}\text { Lindsay Adams, } \\
\text { Martin Banfield, } \\
\text { Robb Clifton, } \\
\text { Mike Cook, David } \\
\text { Donaldson, Jamie } \\
\text { Hackett, Andrea } \\
\text { Jopp-McKay, David } \\
\text { McKay, David } \\
\text { Smith and Alex } \\
\text { van Roy (leader) }\end{array}$ & $\begin{array}{l}\text { South summit } \\
\text { reached on } 3 \text { May } \\
\text { by Hackett and van } \\
\text { Roy and on } 4 \text { May by } \\
\text { Adams, Clifton, Cook, } \\
\text { Donaldson, Jopp- } \\
\text { McKay and McKay. } \\
\text { Unable to continue to } \\
\text { main summit due to } \\
\text { difficult conditions. }\end{array}$ & $\begin{array}{l}\text { AAA expedition. } \\
\text { First Australian } \\
\text { expedition to } \\
\text { Tukuche and } \\
\text { first Australian } \\
\text { ascent of S Peak. }\end{array}$ \\
\hline
\end{tabular}




\begin{tabular}{|c|c|c|c|c|}
\hline & $\begin{array}{l}\text { Cho Oyu } \\
\text { (8201 m) } \\
\text { NW Face, Tibet }\end{array}$ & $\begin{array}{l}\text { Geoff Robb on } \\
\text { OTT expedition }\end{array}$ & $\begin{array}{l}\text { Unsuccessful. Robb } \\
\text { reached } 7000 \mathrm{~m} \text { but } \\
\text { abandoned climb } \\
\text { due to chest cold. }\end{array}$ & $\begin{array}{l}\text { Billy Pearson } \\
\text { (USA) and } \\
\text { George Kurtov } \\
\text { (Russia) from } \\
\text { team climbed } \\
\text { new route on } \\
\text { N Ridge. }\end{array}$ \\
\hline & $\begin{array}{l}\text { Broad Peak } \\
\text { (8047 m) } \\
\text { S Ridge and W } \\
\text { Face, Pakistan }\end{array}$ & $\begin{array}{l}\text { Rick Allen (UK) } \\
\text { and Andrew Lock }\end{array}$ & $\begin{array}{l}\text { Allen and Lock reached } \\
7100 \text { m attempting } \\
\text { new route on S } \\
\text { Ridge, climbing higher } \\
\text { than any previous } \\
\text { attempts. Lock later } \\
\text { soloed W Face. }\end{array}$ & $\begin{array}{l}\text { Second } \\
\text { Australian } \\
\text { ascent of Broad } \\
\text { Peak. Lock was } \\
\text { first Australian } \\
\text { to climb two } \\
8000 \text { m peaks } \\
\text { in one year. }\end{array}$ \\
\hline & $\begin{array}{l}\text { Thalay Sagar } \\
\text { (6904 m) } \\
\text { N Face, India }\end{array}$ & $\begin{array}{l}\text { Andrew Lindblade } \\
\text { and Athol } \\
\text { Whimp (NZ) }\end{array}$ & $\begin{array}{l}\text { Lindblade and Whimp } \\
\text { reached summit. }\end{array}$ & $\begin{array}{l}\text { First ascent of } \mathrm{N} \\
\text { Face direct and } \\
\text { first Australian } \\
\text { ascent of this } \\
\text { peak. This } \\
\text { route previously } \\
\text { defeated } \\
10 \text { other } \\
\text { expeditions. }\end{array}$ \\
\hline & $\begin{array}{l}\text { Shivling } \\
\text { (6543 m) } \\
\text { W Ridge, } \\
\text { Gangotri, India }\end{array}$ & $\begin{array}{l}\text { John Barnes } \\
\text { (NZ), Stuart } \\
\text { Findlay (UK), } \\
\text { Chris Grasswick } \\
\text { (Canada) and } \\
\text { Wade Stevens }\end{array}$ & $\begin{array}{l}\text { Route out of condition, } \\
\text { climb abandoned. }\end{array}$ & \\
\hline & $\begin{array}{l}\text { Cho Oyu } \\
\text { (8201 m) } \\
\text { Tibet }\end{array}$ & $\begin{array}{l}\text { Alan Silva, member } \\
\text { of international } \\
\text { commercial } \\
\text { expedition }\end{array}$ & Reached summit. & \\
\hline & $\begin{array}{l}\text { Makalu II } \\
\text { (7680 m) } \\
\text { NW Ridge, } \\
\text { Nepal }\end{array}$ & $\begin{array}{l}\text { Sue Fear, Matt } \\
\text { Gregory and } \\
\text { John Maraz }\end{array}$ & $\begin{array}{l}\text { Fear, Gregory and } \\
\text { Maraz reached summit. }\end{array}$ & $\begin{array}{l}\text { First Australian } \\
\text { ascent. }\end{array}$ \\
\hline \multirow[t]{2}{*}{1998} & $\begin{array}{l}\text { Shisha Pangma } \\
\text { (Central } \\
\text { Summit) } \\
\text { (8026 m) } \\
\text { N Ridge, Tibet }\end{array}$ & $\begin{array}{l}\text { Brian Agnew, } \\
\text { Simon Blackmore } \\
\text { (UK), Ansja de } \\
\text { Boer (NZ), Peter } \\
\text { Hunt, Ralph Pliner, } \\
\text { Geoff Robb and } \\
\text { Zac Zaharias on } \\
\text { Mountain Works } \\
\text { commercial } \\
\text { expedition led } \\
\text { by Mark Whetu }\end{array}$ & $\begin{array}{l}\text { Successful. De Boer, } \\
\text { Pliner, Robb and } \\
\text { Whetu reached Central } \\
\text { Summit on } 20 \text { May. }\end{array}$ & $\begin{array}{l}\text { Pliner and Robb } \\
\text { guided ascent. } \\
\text { Pliner suffered } \\
\text { frostbite to } \\
\text { his fingers. }\end{array}$ \\
\hline & $\begin{array}{l}\text { Mt Everest } \\
\text { (8850 m) } \\
\text { S Col, Nepal }\end{array}$ & $\begin{array}{l}\text { Alan Silva, member } \\
\text { of international } \\
\text { commercial } \\
\text { expedition }\end{array}$ & $\begin{array}{l}\text { Reached summit on } \\
26 \text { May after climbing } \\
\text { alone from } \mathrm{S} \text { Col. }\end{array}$ & \\
\hline
\end{tabular}




\begin{tabular}{|c|c|c|c|c|}
\hline & $\begin{array}{l}\text { Gasherbrum } \\
\text { II (8035 m) } \\
\text { SE Ridge, } \\
\text { Pakistan }\end{array}$ & $\begin{array}{l}\text { Paul Walters and } \\
\text { Ray Brown (UK) }\end{array}$ & $\begin{array}{l}\text { Reached summit } \\
\text { on } 9 \text { July. }\end{array}$ & $\begin{array}{l}\text { Second } \\
\text { Australian ascent } \\
\text { of Gasherbrum II. }\end{array}$ \\
\hline & $\begin{array}{l}\text { Cho Oyu } \\
\text { (8201 m) } \\
\text { NW Face, Tibet }\end{array}$ & $\begin{array}{l}\text { Sue Fear and } \\
\text { Nima Dorje } \\
\text { Tamang (Nepal) }\end{array}$ & $\begin{array}{l}\text { Fear and Nima Dorje } \\
\text { reached summit on } \\
24 \text { September. }\end{array}$ & $\begin{array}{l}\text { First Australian } \\
\text { female ascent } \\
\text { of Cho Oyu and } \\
\text { second Australiar } \\
\text { woman to } \\
\text { summit an } \\
8000 \text { m peak. }\end{array}$ \\
\hline & $\begin{array}{l}\text { Pumori } \\
\text { (7161 m) } \\
\text { SW Ridge, } \\
\text { Nepal }\end{array}$ & $\begin{array}{l}\text { Kynan Bazley } \\
\text { (NZ), Scott Ferris, } \\
\text { Chris Grasswick } \\
\text { (Canada), } \\
\text { Matthew Jones, } \\
\text { John Kelsall, } \\
\text { Theo Kossart } \\
\text { (leader) and Philip } \\
\text { Suisted (NZ) }\end{array}$ & $\begin{array}{l}\text { Successful. Bazley, } \\
\text { Ferris and Suisted } \\
\text { reached summit on } 7 \\
\text { October; Grasswick } \\
\text { and Kossart reached } \\
\text { summit on } 9 \text { October. }\end{array}$ & $\begin{array}{l}\text { Kelsall and } \\
\text { Jones both got } \\
\text { very sick. }\end{array}$ \\
\hline & $\begin{array}{l}\text { Nanga Parbat } \\
(8126 \mathrm{~m}) \\
\text { Kinshofer Route, } \\
\text { Pakistan }\end{array}$ & $\begin{array}{l}\text { Alan Hinks (UK) } \\
\text { and Andrew Lock }\end{array}$ & $\begin{array}{l}\text { Lock successful. } \\
\text { Bivvied on the } \\
\text { descent, about } \\
7500 \mathrm{~m} \text {, while his } \\
\text { companions left him. }\end{array}$ & $\begin{array}{l}\text { First Australian } \\
\text { ascent. }\end{array}$ \\
\hline & $\begin{array}{l}\text { Changi Tower } \\
(5820 \text { m) and } \\
\text { Marpo Brakk } \\
(5400 \text { m) } \\
\text { Hushe Valley, } \\
\text { Pakistan }\end{array}$ & $\begin{array}{l}\text { Ned Norton } \\
\text { (NZ), Abby } \\
\text { Watkins, Paul } \\
\text { Weber (NZ), Vera } \\
\text { Wong and Nicola } \\
\text { Woolford (NZ) }\end{array}$ & $\begin{array}{l}\text { Watkins, Wong and } \\
\text { Woolford reached } \\
\text { summit of Marpo } \\
\text { Brakk by way of } 300 \\
\text { m aid line (grade-20 } \\
\text { crux) and Changi } \\
\text { Tower Main Peak. } \\
\text { N Summit of Changi } \\
\text { Tower climbed by } \\
\text { Norton and Weber. }\end{array}$ & $\begin{array}{l}\text { First ascent of } \\
\text { E Summit of } \\
\text { Marpo Brakk. } \\
\text { First ascent of } \\
\text { Changi Tower } \\
\text { Main Peak. }\end{array}$ \\
\hline & $\begin{array}{l}\text { Ama Dablam } \\
\text { (6854 m) } \\
\text { SW Ridge, } \\
\text { Nepal }\end{array}$ & $\begin{array}{l}\text { Mark Auricht, } \\
\text { Duncan Chessell, } \\
\text { Lorne McClurg, } \\
\text { Adele Pennington } \\
\text { (UK) and David } \\
\text { Wilshire }\end{array}$ & $\begin{array}{l}\text { Auricht and Chessell } \\
\text { reached summit on } \\
5 \text { December with } \\
\text { Pennington and } \\
\text { Wilshire on summit } \\
\text { the next day. } \\
\end{array}$ & $\begin{array}{l}\text { Second } \\
\text { Australian } \\
\text { winter ascent. }\end{array}$ \\
\hline 1999 & $\begin{array}{l}\text { Makalu } \\
\text { (8463 m) } \\
\text { French Spur, } \\
\text { Nepal }\end{array}$ & $\begin{array}{l}\text { Australian-US } \\
\text { expedition with } \\
\text { David Bridges } \\
\text { (USA), Mike Groom } \\
\text { and Lincoln Hall }\end{array}$ & $\begin{array}{l}\text { Bridges and Groom } \\
\text { reached summit } \\
\text { on } 16 \text { May. }\end{array}$ & $\begin{array}{l}\text { Second } \\
\text { Australian ascent } \\
\text { of Makalu. } \\
\text { Groom climbs } \\
\text { his sixth } 8000- \\
\text { er and has } \\
\text { now reached } \\
\text { the summit of } \\
\text { the six highest } \\
\text { mountains in } \\
\text { the world. }\end{array}$ \\
\hline
\end{tabular}




\begin{tabular}{|c|c|c|c|}
\hline $\begin{array}{l}\text { Makalu } \\
\text { (8463 m) } \\
\text { French Spur, } \\
\text { Nepal }\end{array}$ & $\begin{array}{l}\text { International } \\
\text { Makalu expedition } \\
\text { members included } \\
\text { Ginette Harrison } \\
\text { (UK), Brigitte Muir, } \\
\text { Gary Pfisterer } \\
\text { (USA; leader), Billy } \\
\text { Pierson (USA), } \\
\text { Hamish Robertson } \\
\text { and seven other } \\
\text { climbers }\end{array}$ & $\begin{array}{l}\text { Harrison and } \\
\text { Robertson reached } \\
\text { summit at } 6 \mathrm{pm} \text { on } \\
23 \text { May. Muir reached } \\
7600 \text { m; attempt } \\
\text { abandoned after death } \\
\text { of a close friend, } \\
\text { Michael Joergensen } \\
\text { (Denmark), from } \\
\text { another expedition. }\end{array}$ & $\begin{array}{l}\text { Third Australian } \\
\text { ascent of } \\
\text { Makalu. }\end{array}$ \\
\hline $\begin{array}{l}\text { Shisha Pangma } \\
\text { (Central } \\
\text { Summit) } \\
\text { (8026 m) } \\
\text { N Ridge, Tibet }\end{array}$ & $\begin{array}{l}\text { Brian Agnew } \\
\text { (leader), Tanya } \\
\text { Bylart, Allen } \\
\text { Caldwell, Mike } \\
\text { Cook, David } \\
\text { Donaldson, Steve } \\
\text { Graham, Jamie } \\
\text { Hackett, Carl } \\
\text { Johnson, Bob } \\
\text { Killip, Shane Lacey, } \\
\text { Peter Lambert, } \\
\text { Brian Laursen, } \\
\text { Adrian McCallum, } \\
\text { Dean McMaster, } \\
\text { Andrew Peacock, } \\
\text { Brad Reeve, Tim } \\
\text { Robathan, Steve } \\
\text { Simpson, Stuart } \\
\text { Sugden and } \\
\text { Zac Zaharias }\end{array}$ & $\begin{array}{l}\text { Successful. Agnew, } \\
\text { Bylart, Caldwell, Cook, } \\
\text { Donaldson, Graham, } \\
\text { Hackett, Johnson, } \\
\text { Killip, Lambert, } \\
\text { Laursen, McMaster, } \\
\text { Peacock, Reeve, } \\
\text { Robathan, Simpson } \\
\text { and Zaharias reached } \\
\text { summit over four days } \\
\text { from } 25 \text { to } 28 \text { May. }\end{array}$ & $\begin{array}{l}\text { World record of } \\
17 \text { climbers from } \\
\text { one expedition } \\
\text { on an } 8000 \mathrm{~m} \\
\text { summit. A US } \\
\text { and an Italian } \\
\text { climber rescued } \\
\text { by the team in } \\
\text { two separate } \\
\text { incidents. } \\
\text { Bylart was } \\
\text { third Australian } \\
\text { woman to } \\
\text { summit an } \\
8000 \text { m peak. } \\
\text { Robathan (21) } \\
\text { was youngest } \\
\text { Australian to } \\
\text { summit an } \\
8000 \text { m peak. }\end{array}$ \\
\hline $\begin{array}{l}\text { Mt Everest } \\
\text { (8850 m) } \\
\text { N Ridge, Nepal }\end{array}$ & $\begin{array}{l}\text { Geoff Robb } \\
\text { on Himalayan } \\
\text { Experience } \\
\text { commercial } \\
\text { expedition led by } \\
\text { Russell Brice (NZ) } \\
\text { with five clients } \\
\text { and five Sherpas }\end{array}$ & $\begin{array}{l}\text { Successful. Reached } \\
\text { summit on } 27 \text { May. }\end{array}$ & \\
\hline $\begin{array}{l}\text { Gasherbrum } \\
\text { I (8068 m) } \\
\text { Japanese } \\
\text { Couloir and } \\
\text { Gasherbrum } \\
\text { II ( } 8035 \mathrm{~m} \text { ) } \\
\text { SE Ridge, } \\
\text { Pakistan }\end{array}$ & $\begin{array}{l}\text { Abele Blanc (Italy), } \\
\text { Pepe Garces } \\
\text { (Spain), Christian } \\
\text { Kunter (Italy), } \\
\text { Andrew Lock } \\
\text { and Waldemar } \\
\text { Niklevic (Brazil) }\end{array}$ & $\begin{array}{l}\text { Alpine-style ascent } \\
\text { by Lock on G2 with } \\
\text { Garces, a return } \\
\text { trip of three days } \\
\text { after acclimatising } \\
\text { and working on } \mathrm{G} 1 \text {. } \\
\text { Lock then reached } \\
\text { summit of G1. }\end{array}$ & $\begin{array}{l}\text { First Australian } \\
\text { ascent of } \\
\text { Gasherbrum } \\
\text { I. Lock was } \\
\text { first Australian } \\
\text { to climb two } \\
8000 \text { m peaks } \\
\text { in one season. }\end{array}$ \\
\hline $\begin{array}{l}\text { Dhaulagiri } \\
\text { (8167 m) } \\
\text { NE Spur, Nepal }\end{array}$ & Paul Walters & Reached summit. & $\begin{array}{l}\text { Second } \\
\text { Australian } \\
\text { ascent. }\end{array}$ \\
\hline $\begin{array}{l}\text { Kedarnath Peak } \\
\text { (6940 m) } \\
\text { Gangotri, India }\end{array}$ & $\begin{array}{l}\text { Glen Sharrock } \\
\text { (leader) }\end{array}$ & $\begin{array}{l}\text { Reached } 6800 \mathrm{~m} \text {. } \\
\text { Attempt abandoned } \\
\text { due to weather. }\end{array}$ & \\
\hline
\end{tabular}




\begin{tabular}{|c|c|c|c|c|}
\hline & $\begin{array}{l}\text { Kusum Kanguru } \\
\text { (6369 m) } \\
\text { N Face, Nepal }\end{array}$ & $\begin{array}{l}\text { Brede Arkless } \\
\text { (NZ), Duncan } \\
\text { Chessell and David } \\
\text { Ritchie (UK) }\end{array}$ & $\begin{array}{l}\text { Chessell and Ritchie } \\
\text { completed route to } \\
\text { summit ridge between } \\
\text { W and high summits. }\end{array}$ & $\begin{array}{l}\text { Bivvied on } \\
\text { summit ridge. } \\
\text { Complete } \\
\text { alpine-style } \\
\text { ascent of face. }\end{array}$ \\
\hline & $\begin{array}{l}\text { Island Peak } \\
\text { (6189 m) } \\
\text { (Imja Tse) S } \\
\text { Ridge, Nepal }\end{array}$ & Duncan Chessell & $\begin{array}{l}\text { Chessell reached } \\
\text { summit on a possible } \\
\text { new route. }\end{array}$ & Solo ascent. \\
\hline & $\begin{array}{l}\text { Ama Dablam } \\
\text { (6854 m) } \\
\text { SW Ridge, } \\
\text { Nepal }\end{array}$ & $\begin{array}{l}\text { Duncan Chessell } \\
\text { guiding on US } \\
\text { commercial } \\
\text { expedition }\end{array}$ & $\begin{array}{l}\text { Chessell and four } \\
\text { out of five clients } \\
\text { reached summit. }\end{array}$ & $\begin{array}{l}\text { Chessell's } \\
\text { second ascent of } \\
\text { Ama Dablam and } \\
\text { third Australian } \\
\text { winter ascent. }\end{array}$ \\
\hline & $\begin{array}{l}\text { Kedarnath Peak } \\
\text { (6940 m) } \\
\text { Gangotri, India }\end{array}$ & $\begin{array}{l}\text { Lester Joyce, Chris } \\
\text { McElvey, Chris } \\
\text { McGrath, Glen } \\
\text { Sharrock (leader), } \\
\text { Chris Thompson, } \\
\text { Steve Turner }\end{array}$ & $\begin{array}{l}\text { Attempts on } 16 \\
\text { and } 17 \text { September } \\
\text { abandoned due to } \\
\text { weather and deep } \\
\text { snow. McElvey and } \\
\text { McGrath reached } \\
\text { summit on } 18 \\
\text { September. }\end{array}$ & $\begin{array}{l}\text { Proposed climb } \\
\text { on Shivling } \\
\text { abandoned at } \\
\text { advanced base } \\
\text { camp on } 23 \\
\text { September due to } \\
\text { unstable snow. }\end{array}$ \\
\hline \multirow[t]{4}{*}{2000} & $\begin{array}{l}\text { Cho Oyu } \\
\text { (8201 m) } \\
\text { NW Face, Tibet }\end{array}$ & $\begin{array}{l}\text { Allen Caldwell, } \\
\text { Matt Godbold, } \\
\text { Roger Grose } \\
\text { (leader), Bob Killip, } \\
\text { Brian Laursen, } \\
\text { Mick McCourt, } \\
\text { Adam Scott, } \\
\text { Matt Shepley, } \\
\text { Stuart Sugden } \\
\text { and Matt Walton }\end{array}$ & $\begin{array}{l}\text { Successful. Grose } \\
\text { and Laursen reached } \\
\text { summit on } 16 \text { May, } \\
\text { Shepley on } 17 \text { May. } \\
\text { All other members } \\
\text { reached } 7500 \mathrm{~m} \text {. }\end{array}$ & AAA expedition. \\
\hline & $\begin{array}{l}\text { Cho Oyu } \\
\text { (8201 m) } \\
\text { NW Face, Tibet }\end{array}$ & $\begin{array}{l}\text { Duncan Chessell } \\
\text { guiding on US } \\
\text { commercial } \\
\text { expedition with } \\
\text { Malte Hagge } \\
\text { and others }\end{array}$ & $\begin{array}{l}\text { Chessell and Hagge } \\
\text { reached summit } \\
\text { with two Sherpas. }\end{array}$ & $\begin{array}{l}\text { Hagge guided } \\
\text { ascent. }\end{array}$ \\
\hline & \begin{tabular}{|l} 
Mt Everest \\
(8850 m) \\
S Ridge, Nepal
\end{tabular} & $\begin{array}{l}\text { Andrew Lock, } \\
\text { leader of Jagged } \\
\text { Globe commercial } \\
\text { expedition }\end{array}$ & $\begin{array}{l}\text { Lock reached south } \\
\text { summit on } 16 \text { May } \\
\text { and reached summit } \\
\text { on } 24 \text { May with two } \\
\text { other members. }\end{array}$ & $\begin{array}{l}\text { First successful } \\
\text { Australian leader } \\
\text { of a commercial } \\
\text { expedition to } \\
\text { Everest. His } \\
\text { seventh } 8000 \\
\text { m peak. }\end{array}$ \\
\hline & \begin{tabular}{|l} 
Mt Everest \\
(8850 m) \\
N Ridge, Tibet
\end{tabular} & $\begin{array}{l}\text { Roman Rosenbaum } \\
\text { on 26-member } \\
\text { Hosei University } \\
\text { 120th anniversary } \\
\text { expedition led by } \\
\text { Toshio Nakamura } \\
\text { (Japan) }\end{array}$ & $\begin{array}{l}\text { Reached summit on } \\
17 \text { May using oxygen. }\end{array}$ & $\begin{array}{l}\text { Austrian-born } \\
\text { Rosenbaum was } \\
\text { on a five-year } \\
\text { exchange at } \\
\text { Hosei University } \\
\text { (Japan). }\end{array}$ \\
\hline
\end{tabular}




\begin{tabular}{|c|c|c|c|c|}
\hline & $\begin{array}{l}\text { Jannu }(7710 \mathrm{~m}) \\
\text { N Face, Nepal }\end{array}$ & $\begin{array}{l}\text { Andrew Lindblade } \\
\text { and Athol } \\
\text { Whimp (NZ) }\end{array}$ & $\begin{array}{l}\text { Lindblade and Whimp } \\
\text { reached summit. }\end{array}$ & $\begin{array}{l}\text { Lightweight } \\
\text { ascent of } \mathrm{N} \\
\text { Face-Wall of } \\
\text { Shadows. }\end{array}$ \\
\hline & $\begin{array}{l}\text { Shisha Pangma } \\
\text { (Central } \\
\text { Summit) } \\
\text { (8026 m) } \\
\text { N Ridge, Tibet }\end{array}$ & $\begin{array}{l}\text { Colin Chaplin, Sue } \\
\text { Fear, lan Hibbert } \\
\text { and Nawang } \\
\text { Jimba Sherpa }\end{array}$ & $\begin{array}{l}\text { Chaplin and Fear } \\
\text { abandoned climb } \\
\text { at } 7400 \mathrm{~m} \text { after } \\
\text { Nawang suffered } \\
\text { pulmonary oedema. }\end{array}$ & $\begin{array}{l}\text { Fear dragged } \\
\text { Nawang down } \\
\text { from Camp III to } \\
\text { Camp I, where } \\
\text { he recovered. }\end{array}$ \\
\hline & $\begin{array}{l}\text { Cornice (5882 } \\
\text { m) and } \\
\text { Workmans Peak } \\
\text { (5886 m) } \\
\text { Snow Lake, } \\
\text { Pakistan }\end{array}$ & $\begin{array}{l}\text { David Duke on } \\
12 \text {-person New } \\
\text { Zealand Alpine } \\
\text { Club expedition led } \\
\text { by Judy Reid (NZ) }\end{array}$ & $\begin{array}{l}\text { Duke and Toby } \\
\text { Johnson (NZ) reached } \\
\text { summit of both peaks } \\
\text { in early August. }\end{array}$ & $\begin{array}{l}\text { First Australian } \\
\text { ascents. Single- } \\
\text { day ascents with } \\
\text { up to } 1200 \text { m of } \\
\text { steep, technical } \\
\text { climbing. }\end{array}$ \\
\hline & $\begin{array}{l}\text { Ama Dablam } \\
\text { ( } 6854 \mathrm{~m}) \\
\text { SW Ridge, } \\
\text { Nepal }\end{array}$ & $\begin{array}{l}\text { Keith Sloane } \\
\text { on commercial } \\
\text { expedition } \\
\text { led by Dave } \\
\text { Hiddleston (NZ) }\end{array}$ & Successful. & $\begin{array}{l}\text { Sloane did } \\
\text { not summit. } \\
\text { Guided climb. }\end{array}$ \\
\hline \multirow[t]{3}{*}{2001} & $\begin{array}{l}\text { Mt Everest } \\
\text { (8850 m) } \\
\mathrm{N} \text { Ridge and } \\
\text { Lhakpa Ri } \\
\text { (7045 m) } \\
\text { East Rongbuk } \\
\text { Glacier, } \\
\text { Tibet }\end{array}$ & $\begin{array}{l}\text { Mark Auricht, } \\
\text { Tshering Pande } \\
\text { Bhote Sherpa, } \\
\text { Duncan Chessell, } \\
\text { David Tingay (base } \\
\text { camp doctor) }\end{array}$ & $\begin{array}{l}\text { Auricht and Chessell } \\
\text { reached summit of } \\
\text { Lhakpa Ri in late } \\
\text { April. Chessell and } \\
\text { Tshering Sherpa } \\
\text { reached summit of } \\
\text { Mt Everest on } 23 \\
\text { May using oxygen. } \\
\text { Auricht reached } \\
\text { above Third Step } \\
\text { before turning back. }\end{array}$ & $\begin{array}{l}\text { First Australian } \\
\text { ascent of } \\
\text { trekking peak } \\
\text { near Mt Everest } \\
\text { Advanced Base } \\
\text { Camp. Auricht } \\
\text { died at Camp } \\
\text { III (7900 m) } \\
\text { on Mt Everest } \\
\text { on } 24 \text { May. }\end{array}$ \\
\hline & $\begin{array}{l}\text { Mt Everest } \\
\text { (8850 m) } \\
\text { N Ridge, Tibet }\end{array}$ & $\begin{array}{l}\text { Tanya Bylart, } \\
\text { Mike Cook, } \\
\text { David Donaldson, } \\
\text { Roger Grose, } \\
\text { Jamie Hackett, } \\
\text { Carl Johnson, } \\
\text { Bob Killip, Peter } \\
\text { Lambert, Brian } \\
\text { Laursen, Adrian } \\
\text { McCallum, } \\
\text { Tim Robathan, } \\
\text { Chewang Sherpa, } \\
\text { Nima Nuru Sherpa, } \\
\text { Jungbu Sherpa } \\
\text { (sirdar), Pasang } \\
\text { Sherpa, Peter } \\
\text { Szypula, Mark } \\
\text { Whetu (NZ), } \\
\text { Zac Zaharias }\end{array}$ & $\begin{array}{l}\text { Laursen reached } \\
\text { summit on } 25 \text { May } \\
\text { using oxygen, with } \\
\text { Sherpas Chewang } \\
\text { and Nima. Cook and } \\
\text { Zaharias reached } \\
8700 \mathrm{~m} \text {, above the } \\
\text { Third Step. Ten } \\
\text { climbers reached } \\
8500 \text { m or higher. }\end{array}$ & $\begin{array}{l}\text { Cameraman } \\
\text { Peter Szypula } \\
\text { killed by ice } \\
\text { avalanche during } \\
\text { acclimatisation } \\
\text { trek in the } \\
\text { Annapurna } \\
\text { Sanctuary on } 24 \\
\text { March along with } \\
\text { family members } \\
\text { Michelle and } \\
\text { Kathleen (KC) } \\
\text { Hackett. }\end{array}$ \\
\hline & $\begin{array}{l}\text { Mt Everest } \\
\text { (8850 m) } \\
\text { N Ridge, Tibet }\end{array}$ & $\begin{array}{l}\text { Scott Ferris, Paul } \\
\text { Karis (South } \\
\text { Africa), Theo } \\
\text { Kossart (leader) }\end{array}$ & $\begin{array}{l}\text { Ferris reached high } \\
\text { point of } 7900 \mathrm{~m} .\end{array}$ & $\begin{array}{l}\text { Karis returned } \\
\text { early due to } \\
\text { pneumonia. }\end{array}$ \\
\hline
\end{tabular}




\begin{tabular}{|c|c|c|c|c|}
\hline & \begin{tabular}{|l} 
Mt Everest \\
$(8850 \mathrm{~m})$ \\
N Ridge, Tibet
\end{tabular} & $\begin{array}{l}\text { John Dunlop on } \\
\text { UK commercial } \\
\text { expedition }\end{array}$ & Reached $6800 \mathrm{~m}$. & $\begin{array}{l}\text { Left after } \\
\text { contracting a } \\
\text { chest infection. } \\
\text { Guided climb. }\end{array}$ \\
\hline & $\begin{array}{l}\text { Spantik } \\
\text { (7027 m) } \\
\text { SE Ridge, } \\
\text { Pakistan }\end{array}$ & $\begin{array}{l}\text { Mike Dunjey, Dave } \\
\text { Hancock (guide), } \\
\text { Kyle Richardson, } \\
\text { Mark Sheen } \\
\text { on Australian } \\
\text { commercial } \\
\text { expedition sharing } \\
\text { British permit }\end{array}$ & $\begin{array}{l}\text { High point of } 6400 \mathrm{~m} \\
\text { reached in August. }\end{array}$ & $\begin{array}{l}\text { Climb abandoned } \\
\text { due to deep } \\
\text { snow and } \\
\text { dangerous } \\
\text { conditions. } \\
\text { Guided climb. }\end{array}$ \\
\hline & $\begin{array}{l}\text { Annapurna IV } \\
\text { (7525 m) } \\
\text { NW Ridge, } \\
\text { Nepal }\end{array}$ & $\begin{array}{l}\text { Simon Fitzclarence, } \\
\text { Jenni Fraser, } \\
\text { Andrew Mitchell, } \\
\text { Martin Pocock, } \\
\text { Bridget Quince, } \\
\text { David Ridley, lan } \\
\text { Rutherford plus } \\
\text { four climbing } \\
\text { Sherpas on } \\
\text { commercial } \\
\text { expedition led } \\
\text { by Gary Hayes }\end{array}$ & $\begin{array}{l}\text { High point of } 7000 \\
\mathrm{~m} \text { reached on } 22 \\
\text { September by Ridley } \\
\text { and Mitchell. }\end{array}$ & $\begin{array}{l}\text { Camp I hit by } \\
\text { avalanche with } \\
\text { loss of gear. } \\
\text { Expedition } \\
\text { abandoned due } \\
\text { to strong winds } \\
\text { and threatening } \\
\text { storms. Guided } \\
\text { climb. }\end{array}$ \\
\hline & $\begin{array}{l}\text { Cho Oyu } \\
\text { (8201 m) } \\
\text { NW Face, Tibet }\end{array}$ & $\begin{array}{l}\text { John Taske and } \\
\text { Dietmar Voss } \\
\text { on commercial } \\
\text { expedition led by } \\
\text { Dean Staples (NZ) }\end{array}$ & $\begin{array}{l}\text { Unsuccessful. High } \\
\text { point of } 7700 \mathrm{~m} \\
\text { reached on } 1 \text { October. }\end{array}$ & Guided climb. \\
\hline & \begin{tabular}{|l|} 
Passu Sar \\
(7492 m) \\
NE Face to East \\
Ridge, Batura \\
Massif, Hunza, \\
Pakistan
\end{tabular} & $\begin{array}{l}\text { Colin Chaplin, } \\
\text { Damien Gildea } \\
\text { (leader), Ian } \\
\text { Hibbert, Paul } \\
\text { Hudson and } \\
\text { Ken Hutt }\end{array}$ & $\begin{array}{l}\text { Climbed abandoned } \\
\text { just above } 4700 \mathrm{~m} \\
\text { due to dangerous } \\
\text { and difficult icefall. }\end{array}$ & \\
\hline & $\begin{array}{l}\text { Ama Dablam } \\
\text { (6854 m) } \\
\text { SW Ridge, } \\
\text { Nepal }\end{array}$ & $\begin{array}{l}\text { Duncan Chessell } \\
\text { (guide) and } \\
\text { Peter Weeks } \\
\text { on commercial } \\
\text { expedition }\end{array}$ & $\begin{array}{l}\text { Summit reached } \\
\text { late October. }\end{array}$ & Guided climb. \\
\hline & $\begin{array}{l}\text { Pumori } \\
\text { (7161 m) } \\
\text { SE Ridge, Nepal }\end{array}$ & $\begin{array}{l}\text { Steve Janssen } \\
\text { on five-member } \\
\text { international } \\
\text { expedition }\end{array}$ & High point of $6500 \mathrm{~m}$. & \\
\hline 2002 & $\begin{array}{l}\text { Annapurna IV } \\
\text { (7525 m) } \\
\text { NW Ridge, } \\
\text { Nepal }\end{array}$ & $\begin{array}{l}\text { Robert Fox, } \\
\text { Anthony Jamison, } \\
\text { Stephen Patrikios, } \\
\text { Matthew Rolfe } \\
\text { and Allan Wright }\end{array}$ & $\begin{array}{l}\text { High point of } 5470 \\
\mathrm{~m} \text { reached on } 30 \\
\text { March by Rolfe. }\end{array}$ & $\begin{array}{l}\text { Base camp } \\
\text { buried on } 29 \\
\text { April. Expedition } \\
\text { abandoned } \\
\text { on } 4 \text { May due } \\
\text { to constant } \\
\text { avalanche } \\
\text { danger. }\end{array}$ \\
\hline
\end{tabular}




\begin{tabular}{|c|c|c|c|}
\hline $\begin{array}{l}\text { Manaslu } \\
\text { (8163 m) } \\
\text { NE Face, Nepal }\end{array}$ & $\begin{array}{l}\text { Tracje Aleksov } \\
\text { (Alex), Andrew } \\
\text { Lock }\end{array}$ & $\begin{array}{l}\text { Lock reached summit } \\
\text { on } 21 \text { April with } \\
\text { Norwegians Jan and } \\
\text { Sven Gangdal. }\end{array}$ & $\begin{array}{l}\text { First Australian } \\
\text { ascent. }\end{array}$ \\
\hline $\begin{array}{l}\text { Manaslu } \\
\text { (8163 m) } \\
\text { NE Face, Nepal }\end{array}$ & $\begin{array}{l}\text { Brian Laursen, } \\
\text { George Lloyd, Greg } \\
\text { Mortimer (leader), } \\
\text { Andrew Peacock, } \\
\text { Geoff Robb, } \\
\text { Nawang Sherpa, } \\
\text { Nima Sherpa }\end{array}$ & $\begin{array}{l}\text { Laursen, Mortimer, } \\
\text { Peacock, Robb and } \\
\text { Nawang Sherpa } \\
\text { reached summit } \\
\text { on } 13 \text { May. }\end{array}$ & $\begin{array}{l}\text { Second } \\
\text { Australian } \\
\text { ascent. Laursen's } \\
\text { fourth } 8000 \\
\text { m peak. }\end{array}$ \\
\hline $\begin{array}{l}\text { Shisha Pangma } \\
\text { (Central } \\
\text { Summit) } \\
\text { (8026 m) } \\
\text { N Ridge, Tibet }\end{array}$ & $\begin{array}{l}\text { Sue Fear and Nima } \\
\text { Tamang sharing } \\
\text { permit with Belgian } \\
\text { expedition }\end{array}$ & $\begin{array}{l}\text { Fear reached Central } \\
\text { Summit on } 15 \\
\text { May with Pasang } \\
\text { Sherpa and Belgian } \\
\text { Johan de Bruyn. }\end{array}$ & $\begin{array}{l}\text { First attempt } \\
\text { abandoned at } \\
7300 \mathrm{~m} \text { on } \\
7 \text { May. Nima } \\
\text { Tamang became } \\
\text { sick on } 12 \text { May. }\end{array}$ \\
\hline $\begin{array}{l}\text { Lhotse }(8516 \mathrm{~m}) \\
\text { W Face, Nepal }\end{array}$ & Andrew Lock & $\begin{array}{l}\text { Lock reached summit } \\
\text { on } 16 \text { May climbing } \\
\text { solo by way of direct } \\
\text { West Face route } \\
\text { from } 7100 \mathrm{~m} \text {. }\end{array}$ & $\begin{array}{l}\text { Second } \\
\text { Australian ascent } \\
\text { and ninth } 8000 \\
\mathrm{~m} \text { peak for Lock. }\end{array}$ \\
\hline $\begin{array}{l}\text { Mt Everest } \\
\text { (8850 m) } \\
\text { SE Ridge, Nepal }\end{array}$ & $\begin{array}{l}\text { Tashi Tenzing on } \\
\text { Swiss Everest } \\
\text { 50th Anniversary } \\
\text { Expedition led by } \\
\text { Stephane Schaffter }\end{array}$ & $\begin{array}{l}\text { Tenzing reached } \\
\text { summit on } 16 \text { May } \\
\text { using oxygen along } \\
\text { with Yves Lambert } \\
\text { (Switzerland) and } \\
\text { Apa Sherpa. }\end{array}$ & $\begin{array}{l}\text { Tenzing's second } \\
\text { ascent of Mt } \\
\text { Everest. Yves } \\
\text { Lambert is the } \\
\text { son of Raymond } \\
\text { Lambert. }\end{array}$ \\
\hline $\begin{array}{l}\text { Mt Everest } \\
\text { (8850 m) } \\
\text { SE Ridge, Nepal }\end{array}$ & $\begin{array}{l}\text { Robert Geir on } \\
\text { international } \\
\text { commercial } \\
\text { expedition led by } \\
\text { Guillermo Benegas }\end{array}$ & $\begin{array}{l}\text { Reached summit } \\
\text { on } 16 \text { May guided } \\
\text { by Scott Woolums } \\
\text { using oxygen. }\end{array}$ & \\
\hline $\begin{array}{l}\text { Mt Everest } \\
\text { (8850 m) } \\
\text { SE Ridge, Nepal }\end{array}$ & $\begin{array}{l}\text { Robert Meluish } \\
\text { and John Taske } \\
\text { on commercial } \\
\text { expedition led by } \\
\text { Bill Crouse (USA) }\end{array}$ & $\begin{array}{l}\text { Successful. } \\
\text { Meluish and Taske } \\
\text { reached Camp II. }\end{array}$ & Guided climb. \\
\hline $\begin{array}{l}\text { Kangchenjunga } \\
\text { (8586 m) } \\
\text { SW Face, Nepal }\end{array}$ & $\begin{array}{l}\text { Christine Boskov } \\
\text { (USA) and } \\
\text { Andrew Lock }\end{array}$ & $\begin{array}{l}\text { High point of } 7700 \\
m \text { reached. }\end{array}$ & $\begin{array}{l}\text { Climb abandoned } \\
\text { due to poor } \\
\text { conditions. }\end{array}$ \\
\hline $\begin{array}{l}\text { Kedar Dome } \\
\text { (6831 m) } \\
\text { NW Face, } \\
\text { Gangotri, India }\end{array}$ & $\begin{array}{l}\text { Guides Lindsay } \\
\text { Abbots (UK), } \\
\text { Peter Allen, } \\
\text { Mick Chapman } \\
\text { (UK; leader), } \\
\text { Leonie Berger, } \\
\text { Rob Sellers, } \\
\text { Gregg Wells } \\
\text { plus five others } \\
\text { on commercial } \\
\text { expedition }\end{array}$ & $\begin{array}{l}\text { Unsuccessful. High } \\
\text { point of } 6100 \mathrm{~m} \\
\text { reached in June. }\end{array}$ & $\begin{array}{l}\text { Christian Marxt } \\
\text { (Austria) skied } \\
\text { down from } 6000 \\
\text { m. Guided climb. }\end{array}$ \\
\hline
\end{tabular}




\begin{tabular}{|c|c|c|c|c|}
\hline & $\begin{array}{l}\text { Ama Dablam } \\
\text { (6854 m) } \\
\text { SW Ridge, } \\
\text { Nepal }\end{array}$ & $\begin{array}{l}\text { Jay Reilly on } \\
\text { 30-member } \\
\text { international } \\
\text { commercial } \\
\text { expedition led by } \\
\text { Dan Mazur (USA) }\end{array}$ & $\begin{array}{l}\text { Reached summit } \\
22 \text { October. }\end{array}$ & Guided climb. \\
\hline \multirow[t]{6}{*}{2003} & $\begin{array}{l}\text { Pumori } \\
\text { (7161 m) } \\
\text { SE Face, E } \\
\text { Ridge, Nepal }\end{array}$ & $\begin{array}{l}\text { Jay Reilly on } \\
\text { international } \\
\text { commercial } \\
\text { expedition led by } \\
\text { Dan Mazur (USA) }\end{array}$ & $\begin{array}{l}\text { Reached summit } \\
8 \text { April. }\end{array}$ & Guided climb. \\
\hline & $\begin{array}{l}\text { Cho Oyu } \\
\text { (8201 m) } \\
\text { NW Face, Tibet }\end{array}$ & $\begin{array}{l}\text { Jo Gambi (UK) } \\
\text { and Robert Gambi } \\
\text { on international } \\
\text { commercial } \\
\text { expedition led by } \\
\text { Russell Brice (NZ) }\end{array}$ & $\begin{array}{l}\text { Husband and wife } \\
\text { team of Robert and Jo } \\
\text { Gambi reached summit } \\
\text { on } 27 \text { September. }\end{array}$ & Guided climb. \\
\hline & $\begin{array}{l}\text { Annapurna IV } \\
\text { (7525 m) } \\
\text { NW Ridge, } \\
\text { Nepal }\end{array}$ & $\begin{array}{l}\text { Kate Carlin, Matt } \\
\text { Carlin, Andrew } \\
\text { Reilly, David Ridley } \\
\text { and Gareth Turner } \\
\text { on international } \\
\text { commercial } \\
\text { expedition led } \\
\text { by Gary Hayes }\end{array}$ & $\begin{array}{l}\text { Matt Carlin and } \\
\text { Ridley reached high } \\
\text { point of } 6380 \mathrm{~m} \text { on } \\
3 \text { October; Reilly } \\
\text { also reached high } \\
\text { point, on } 4 \text { October. }\end{array}$ & $\begin{array}{l}\text { Avalanche took } \\
\text { out Camp II on } \\
21 \text { September. } \\
\text { Expedition } \\
\text { abandoned due } \\
\text { to impassable } 10 \\
\text { m-wide crevasse. } \\
\text { Guided climb. }\end{array}$ \\
\hline & \begin{tabular}{|l} 
Shisha \\
Pangma(Central \\
Summit) \\
(8026 m) \\
N Ridge, Tibet
\end{tabular} & Nicola Tsang & $\begin{array}{l}\text { Reached summit } \\
\text { on } 6 \text { October. }\end{array}$ & Guided climb. \\
\hline & $\begin{array}{l}\text { Ama Dablam } \\
(6854 \mathrm{~m}) \\
\text { SW Ridge, } \\
\text { Nepal }\end{array}$ & $\begin{array}{l}\text { David Chiew } \\
\text { (leader), Annabelle } \\
\text { Cochrane (NZ) } \\
\text { and Brett Moule } \\
\text { with three Sherpas } \\
\text { on Australian } \\
\text { commercial } \\
\text { expedition }\end{array}$ & $\begin{array}{l}\text { Summit reached by } \\
\text { Chiew, Cochrane and } \\
\text { Moule on } 1 \text { November. }\end{array}$ & Guided climb. \\
\hline & $\begin{array}{l}\text { Ama Dablam } \\
\text { (6854 m) } \\
\text { SW Ridge, } \\
\text { Nepal }\end{array}$ & $\begin{array}{l}\text { Chris Kinney, } \\
\text { Tony Kinney and } \\
\text { Camille Kinney } \\
\text { on 29-member } \\
\text { international } \\
\text { commercial } \\
\text { expedition led } \\
\text { by Dan Mazur } \\
\text { (USA); Jay Reilly } \\
\text { deputy leader }\end{array}$ & $\begin{array}{l}\text { Summit reached } \\
\text { by father, son and } \\
\text { daughter team on } \\
23 \text { October. }\end{array}$ & $\begin{array}{l}\text { Camille Kinney } \\
\text { youngest woman } \\
\text { to summit } \\
\text { Ama Dablam. } \\
\text { Guided climb. }\end{array}$ \\
\hline
\end{tabular}




\begin{tabular}{|c|c|c|c|}
\hline $\begin{array}{l}\text { Cho Oyu } \\
\text { (8201 m) } \\
\text { NW Face and } \\
\text { Labchi Kang } \\
\text { (7367 m) } \\
\text { Tibet }\end{array}$ & $\begin{array}{l}\text { Duncan Chessell } \\
\text { (guide), Robert } \\
\text { Jackson, Steve } \\
\text { Jansen, Anna } \\
\text { Svasadotiar } \\
\text { (Iceland), Peter } \\
\text { Weeks, Sherpas } \\
\text { Tshering Pande } \\
\text { Bhote and } \\
\text { Jamyang Bhote } \\
\text { on commercial } \\
\text { expedition }\end{array}$ & $\begin{array}{l}\text { Chessell, Jackson, } \\
\text { Jansen, Svasadotiar } \\
\text { and Weeks summit } \\
\text { Labchi Kang in late } \\
\text { April. Chessell and } \\
\text { Jackson summit Cho } \\
\text { Oyu on } 11 \text { May. }\end{array}$ & $\begin{array}{l}\text { Oxygen used } \\
\text { for the ascent } \\
\text { of Cho Oyu. } \\
\text { Guided climbs. }\end{array}$ \\
\hline $\begin{array}{l}\text { Cho Oyu } \\
\text { (8201 m) } \\
\text { NW Face, Tibet }\end{array}$ & $\begin{array}{l}\text { Geoff Robb } \\
\text { on commercial } \\
\text { expedition with } \\
\text { nine other clients } \\
\text { and seven Sherpas } \\
\text { led by Terry } \\
\text { Moore (UK) }\end{array}$ & $\begin{array}{l}\text { Robb reached } \\
\text { summit on } 11 \text { May } \\
\text { with Torre Sunde- } \\
\text { Rasmussen (Norway) } \\
\text { and two Sherpas. }\end{array}$ & $\begin{array}{l}\text { Robb's fourth } \\
8000 \text { m peak. } \\
\text { Guided climb. }\end{array}$ \\
\hline $\begin{array}{l}\text { Ama Dablam } \\
\text { ( } 6854 \mathrm{~m}) \\
\text { SW Ridge, } \\
\text { Nepal }\end{array}$ & $\begin{array}{l}\text { Hayen Brotchie, } \\
\text { Jon Castley, Neil } \\
\text { Lefevre, Garth } \\
\text { Rickert, Alan } \\
\text { Silva (leader), } \\
\text { Jangbu Sherpa, } \\
\text { Grace Tang and } \\
\text { Penny Troy }\end{array}$ & $\begin{array}{l}\text { Summit reached by } \\
\text { Castley and Tang } \\
\text { on } 11 \text { May, Brotchie } \\
\text { and Silva } 12 \text { May, } \\
\text { Lefevre and Rickert } \\
13 \text { May and Castley } \\
\text { and Troy on } 18 \text { May. }\end{array}$ & $\begin{array}{l}\text { Sydney } \\
\text { Rockclimbing } \\
\text { Club expedition. } \\
\text { Jungbu Sherpa } \\
\text { summited three } \\
\text { times, on 10, } 11 \\
\text { and } 18 \text { May. }\end{array}$ \\
\hline $\begin{array}{l}\text { Mt Everest } \\
\text { ( } 8850 \mathrm{~m}) \\
\text { N Ridge, Tibet }\end{array}$ & $\begin{array}{l}\text { Sue Fear on } \\
\text { Russell Brice } \\
\text { (NZ) commercial } \\
\text { expedition }\end{array}$ & $\begin{array}{l}\text { Reached summit } \\
\text { on } 31 \text { May. }\end{array}$ & $\begin{array}{l}\text { Self-guided } \\
\text { ascent. }\end{array}$ \\
\hline $\begin{array}{l}\text { Mt Everest } \\
\text { (8850 m) } \\
\text { N Ridge, Tibet }\end{array}$ & $\begin{array}{l}\text { Peter Madew on } \\
\text { UK commercial } \\
\text { expedition }\end{array}$ & $\begin{array}{l}\text { Madew reached } 8500 \\
\text { m. Attempt abandoned } \\
\text { to assist Conan } \\
\text { Harrod (UK) after a } \\
\text { US climber fell on him } \\
\text { and broke his leg. }\end{array}$ & $\begin{array}{l}\text { Madew suffered } \\
\text { third-degree } \\
\text { frostbite on } \\
\text { both hands. } \\
\text { Guided climb. }\end{array}$ \\
\hline $\begin{array}{l}\text { Mt Everest } \\
(8850 \mathrm{~m}) \\
\text { SE Ridge, Nepal }\end{array}$ & $\begin{array}{l}\text { Nick Dyer on } \\
\text { commercial } \\
\text { expedition led by } \\
\text { Bill Crouse (USA) }\end{array}$ & $\begin{array}{l}\text { Unsuccessful. High } \\
\text { point of south summit } \\
(8750 \mathrm{~m} \text { ) reached } \\
\text { by the expedition } \\
\text { on } 23 \text { May. }\end{array}$ & Guided climb. \\
\hline $\begin{array}{l}\text { Cho Oyu } \\
\text { (8201 m) } \\
\text { NW Face, Tibet }\end{array}$ & $\begin{array}{l}\text { Blair Falahey } \\
\text { and two Spanish } \\
\text { climbers on self- } \\
\text { guided expedition }\end{array}$ & $\begin{array}{l}\text { Falahey reached } \\
7700 \text { m. Spanish } \\
\text { climbers abandoned } \\
\text { the expedition. }\end{array}$ & $\begin{array}{l}\text { Falahey suffered } \\
\text { third-degree } \\
\text { frostbite to } \\
\text { all fingers on } \\
13 \text { May. }\end{array}$ \\
\hline $\begin{array}{l}\text { Cho Oyu } \\
\text { (8201 m) } \\
\text { NW Face, Tibet }\end{array}$ & $\begin{array}{l}\text { Jack Carmody, } \\
\text { Paul Carr, Nick } \\
\text { Farr, Mick Harvey } \\
\text { with Sherpas Tika } \\
\text { and Yodha on } \\
\text { Victorian Police } \\
\text { expedition }\end{array}$ & $\begin{array}{l}\text { High point and top } \\
\text { camp at } 7400 \mathrm{~m} \\
\text { reached by Carr, Farr, } \\
\text { Tika and Yodha. }\end{array}$ & $\begin{array}{l}\text { Paul Carr died } \\
\text { of a blocked } \\
\text { cardiovascular } \\
\text { artery in tent } \\
\text { at top camp. }\end{array}$ \\
\hline
\end{tabular}




\begin{tabular}{|c|c|c|c|c|}
\hline & $\begin{array}{l}\text { Kangchenjunga } \\
\text { (8586 m) } \\
\text { Nepal }\end{array}$ & $\begin{array}{l}\text { Mick Parker, Paul } \\
\text { Walters and Roland } \\
\text { Hunter (UK) }\end{array}$ & Unsuccessful. & \\
\hline & $\begin{array}{l}\text { Ama Dablam } \\
(6854 \mathrm{~m}) \\
\text { SW Ridge, } \\
\text { Nepal }\end{array}$ & $\begin{array}{l}\text { Anthony Baldry } \\
\text { on commercial } \\
\text { expedition led by } \\
\text { Dean Staples (NZ) }\end{array}$ & Unsuccessful. & Guided climb. \\
\hline & $\begin{array}{l}\text { Gasherbrum } \\
\text { IV (7925 m) } \\
\text { W Face, } \\
\text { Pakistan }\end{array}$ & $\begin{array}{l}\text { Andrew Lindblade } \\
\text { and Athol } \\
\text { Whimp (NZ) }\end{array}$ & Unsuccessful. & $\begin{array}{l}\text { Acclimatisation } \\
\text { climb to } 7000 \mathrm{~m} \\
\text { on NW Ridge. }\end{array}$ \\
\hline & \begin{tabular}{|l|} 
Gasherbrum \\
II (8035 m) \\
SE Ridge, \\
Pakistan \\
\end{tabular} & $\begin{array}{l}\text { Darren Scott } \\
\text { on commercial } \\
\text { expedition led by } \\
\text { Mike Roberts (NZ) }\end{array}$ & $\begin{array}{l}\text { Scott reached high } \\
\text { point of } 7000 \mathrm{~m} \\
\text { on } 22 \text { July. }\end{array}$ & Guided climb. \\
\hline & $\begin{array}{l}\text { Cho Oyu } \\
\text { (8201 m) } \\
\text { NW Face, Tibet }\end{array}$ & $\begin{array}{l}\text { Anthony Baldry, } \\
\text { Ed Bradley, } \\
\text { Piers Buck, } \\
\text { Lewis Gomes } \\
\text { on commercial } \\
\text { expedition led by } \\
\text { Mike Roberts (NZ) }\end{array}$ & $\begin{array}{l}\text { Baldry, Buck and } \\
\text { Gomes reached } \\
\text { summit on } 27 \\
\text { September along with } \\
\text { eight other members. }\end{array}$ & $\begin{array}{l}\text { Oxygen used } \\
\text { during summit } \\
\text { climb. Guided } \\
\text { climb. }\end{array}$ \\
\hline & $\begin{array}{l}\text { Cho Oyu } \\
\text { (8201 m) } \\
\text { NW Face, Tibet }\end{array}$ & Mick Parker & $\begin{array}{l}\text { Parker reached summit } \\
\text { on } 5 \text { October, climbing } \\
\text { alone from Camp II. }\end{array}$ & \\
\hline & $\begin{array}{l}\text { Shisha Pangma } \\
\text { (Central } \\
\text { Summit) } \\
\text { (8026 m) } \\
\text { N Ridge, Tibet }\end{array}$ & $\begin{array}{l}\text { Andrew Lock (solo) } \\
\text { except with Italians } \\
\text { Silvio Mondinelli } \\
\text { and Mario on } \\
\text { summit day only }\end{array}$ & $\begin{array}{l}\text { Reached summit } \\
\text { on } 6 \text { October. }\end{array}$ & $\begin{array}{l}\text { Main summit not } \\
\text { attempted due to } \\
\text { poor conditions. } \\
\text { Lock's tenth } \\
8000 \text { m peak. }\end{array}$ \\
\hline & $\begin{array}{l}\text { Peak } 6417 \\
\text { (6417 m) } \\
\text { Damodar } \\
\text { Himal, Nepal }\end{array}$ & $\begin{array}{l}\text { Anna Brooks, } \\
\text { Ken McConnell, } \\
\text { Dendi Sherpa and } \\
\text { Ongdi Sherpa }\end{array}$ & $\begin{array}{l}\text { Successful. } \\
\text { Summit reached } \\
\text { on } 21 \text { October. }\end{array}$ & \\
\hline \multirow[t]{3}{*}{2004} & $\begin{array}{l}\text { Pumori } \\
\text { (7161 m) } \\
\text { SE Face, E } \\
\text { Ridge, Nepal }\end{array}$ & $\begin{array}{l}\text { Dan Marino on } \\
\text { international } \\
\text { commercial } \\
\text { expedition led by } \\
\text { Dan Mazur (USA) } \\
\text { with Jay Reilly as } \\
\text { deputy leader }\end{array}$ & $\begin{array}{l}\text { Reilly and Marino } \\
\text { reached the summit } \\
\text { on } 23 \text { March. }\end{array}$ & $\begin{array}{l}\text { Reilly's second } \\
\text { ascent of Pumori. } \\
\text { Guided climb. }\end{array}$ \\
\hline & \begin{tabular}{|l|} 
Baruntse \\
(7168 m) \\
SE Ridge, Nepal
\end{tabular} & $\begin{array}{l}\text { George Lloyd } \\
\text { on five-member } \\
\text { international } \\
\text { commercial } \\
\text { expedition led by } \\
\text { Neville Taylor (UK) }\end{array}$ & $\begin{array}{l}\text { Lloyd reached the } \\
\text { expedition high } \\
\text { point of } 6800 \mathrm{~m} \text {. } \\
\text { Expedition frustrated } \\
\text { by complicated } \\
\text { crevasse system } \\
\text { breaking the SE Ridge. }\end{array}$ & $\begin{array}{l}\text { Second } \\
\text { Australian } \\
\text { attempt on } \\
\text { Baruntse. } \\
\text { Guided climb. }\end{array}$ \\
\hline & $\begin{array}{l}\text { Cho Oyu } \\
\text { (8201 m) } \\
\text { NW Face, Tibet }\end{array}$ & $\begin{array}{l}\text { Catherine Carlyle } \\
\text { on international } \\
\text { commercial } \\
\text { expedition } \\
\text { led by Jamie } \\
\text { McGuinness (NZ) }\end{array}$ & $\begin{array}{l}\text { Reached summit } \\
\text { on } 14 \text { May. }\end{array}$ & $\begin{array}{l}\text { Carlyle used } \\
\text { supplementary } \\
\text { oxygen from } \\
\text { Camp III. } \\
\text { Guided climb. }\end{array}$ \\
\hline
\end{tabular}




\begin{tabular}{|c|c|c|c|}
\hline $\begin{array}{l}\text { Mt Everest } \\
\text { ( } 8850 \mathrm{~m}) \\
\text { SE Ridge, Nepal }\end{array}$ & $\begin{array}{l}\text { Andrew Lock on } \\
\text { Discovery Channel } \\
\text { filming expedition } \\
\text { led by Ben Webster } \\
\text { (Canada) with } \\
\text { Shaunna Bourke } \\
\text { (Canada) and } \\
\text { Hector Ponce de } \\
\text { Leon (Mexico) }\end{array}$ & $\begin{array}{l}\text { Lock reached summit } \\
\text { on } 16 \text { May. }\end{array}$ & $\begin{array}{l}\text { Lock's second } \\
\text { ascent of Mt } \\
\text { Everest. }\end{array}$ \\
\hline $\begin{array}{l}\text { Mt Everest } \\
\text { (8850 m) } \\
\text { N Ridge, Tibet }\end{array}$ & $\begin{array}{l}\text { Robert Gambi, } \\
\text { Andrew Marquis } \\
\text { and Paul Hockey } \\
\text { on international } \\
\text { commercial } \\
\text { expedition led by } \\
\text { Bill Crouse (USA) }\end{array}$ & $\begin{array}{l}\text { Gambi and Marquis } \\
\text { reached summit on } \\
24 \text { May. Hockey } \\
\text { reached } 8600 \text { m. }\end{array}$ & $\begin{array}{l}\text { Hockey, a } \\
\text { disabled climber, } \\
\text { lost his right } \\
\text { arm to cancer } \\
\text { as a child. } \\
\text { Guided climb. }\end{array}$ \\
\hline $\begin{array}{l}\text { Mt Everest } \\
\text { ( } 8850 \mathrm{~m}) \\
\text { SE Ridge, Nepal }\end{array}$ & $\begin{array}{l}\text { Anthony Baldry } \\
\text { and Ed Bradley } \\
\text { on international } \\
\text { commercial } \\
\text { expedition led by } \\
\text { Luis Benitez (USA) }\end{array}$ & $\begin{array}{l}\text { Baldry reached summit } \\
\text { on } 27 \text { May. Bradley } \\
\text { reached the south } \\
\text { summit }(8750 \mathrm{~m}) \text {. }\end{array}$ & Guided climb. \\
\hline $\begin{array}{l}\text { Makalu } \\
\text { (8481 m) } \\
\text { Nepal }\end{array}$ & $\begin{array}{l}\text { Mick Parker on } \\
\text { international } \\
\text { expedition }\end{array}$ & $\begin{array}{l}\text { Parker turned around } \\
\text { at high camp. }\end{array}$ & $\begin{array}{l}\text { Expedition leader } \\
\text { reached summit } \\
\text { using oxygen. }\end{array}$ \\
\hline $\begin{array}{l}\text { Gasherbrum } \\
\text { II (8035 m) } \\
\text { SE Ridge, } \\
\text { Pakistan }\end{array}$ & $\begin{array}{l}\text { Ernestine Tjepkema } \\
\text { and Steve Hay } \\
\text { on international } \\
\text { commercial } \\
\text { expedition led } \\
\text { by Sue Fear }\end{array}$ & $\begin{array}{l}\text { Fear reached summit } \\
\text { on } 26 \text { July. High } \\
\text { point of } 6000 \text { m for } \\
\text { Tjepkema and Hay. }\end{array}$ & $\begin{array}{l}\text { Fear's fourth } \\
8000 \text { m peak. } \\
\text { First Australian } \\
\text { female ascent. }\end{array}$ \\
\hline $\begin{array}{l}\text { Broad Peak } \\
\text { (8047 m) } \\
\text { W Face, } \\
\text { Pakistan }\end{array}$ & $\begin{array}{l}\text { Malte Hagge } \\
\text { on international } \\
\text { commercial } \\
\text { expedition } \\
\text { led by Jamie } \\
\text { McGuinness (NZ) }\end{array}$ & $\begin{array}{l}\text { Hagge reached } 7700 \\
\text { m on } 26 \text { July. }\end{array}$ & $\begin{array}{l}\text { Hagge returned } \\
\text { to Broad } \\
\text { Peak after an } \\
\text { unsuccessful } \\
\text { attempt in } 2003 . \\
\text { Guided climb. }\end{array}$ \\
\hline $\begin{array}{l}\text { Broad Peak } \\
\text { (8047 m) } \\
\text { W Face, } \\
\text { Pakistan }\end{array}$ & $\begin{array}{l}\text { John Dunlop, } \\
\text { Mick Parker and } \\
\text { Paul Walters } \\
\text { on international } \\
\text { expedition led by } \\
\text { Roland Hunter (UK) }\end{array}$ & $\begin{array}{l}\text { Parker and Walters } \\
\text { reached summit } \\
\text { on } 27 \text { July. }\end{array}$ & $\begin{array}{l}\text { Third Australian } \\
\text { ascent of } \\
\text { Broad Peak. } \\
\text { Walters's fifth } \\
8000 \text { m peak. }\end{array}$ \\
\hline $\begin{array}{l}\text { Spantik } \\
\text { (7027 m) } \\
\text { SE Ridge, } \\
\text { Pakistan }\end{array}$ & $\begin{array}{l}\text { Rob Findlay, Dave } \\
\text { Jackson, Tony } \\
\text { Breen and Patrick } \\
\text { Hollingworth } \\
\text { on 20-member } \\
\text { international } \\
\text { commercial } \\
\text { expedition led } \\
\text { by Gary Hayes }\end{array}$ & $\begin{array}{l}\text { Unsuccessful. } \\
\text { Expedition high } \\
\text { point of Camp II. }\end{array}$ & $\begin{array}{l}\text { Expedition } \\
\text { abandoned due } \\
\text { to steep and } \\
\text { unstable snow. } \\
\text { Guided climb. }\end{array}$ \\
\hline
\end{tabular}




\begin{tabular}{|c|c|c|c|}
\hline $\begin{array}{l}\text { Cho Oyu } \\
\text { (8201 m) } \\
\text { NW Face, Tibet }\end{array}$ & $\begin{array}{l}\text { Michael Dunjey } \\
\text { on international } \\
\text { commercial } \\
\text { expedition led by } \\
\text { Ron Holt (UK) }\end{array}$ & $\begin{array}{l}\text { Reached advanced } \\
\text { base camp }(5500 \mathrm{~m}) .\end{array}$ & $\begin{array}{l}\text { Dunjey left } \\
\text { due to illness. } \\
\text { Guided climb. }\end{array}$ \\
\hline $\begin{array}{l}\text { Cho Oyu } \\
\text { (8201 m) } \\
\text { NW Face, Tibet }\end{array}$ & $\begin{array}{l}\text { John Cook with } \\
\text { two Sherpas }\end{array}$ & $\begin{array}{l}\text { Reached } 6400 \mathrm{~m} \\
\text { on } 20 \text { September. }\end{array}$ & $\begin{array}{l}\text { Cook abandoned } \\
\text { climb due to } \\
\text { cerebral oedema. }\end{array}$ \\
\hline $\begin{array}{l}\text { Cho Oyu } \\
\text { (8201 m) } \\
\text { NW Face, Tibet }\end{array}$ & Bruce Gibbens & $\begin{array}{l}\text { Reached advanced } \\
\text { base camp. }\end{array}$ & $\begin{array}{l}\text { Gibbens got } \\
\text { chest infection } \\
\text { and left } A B C \text { on } \\
22 \text { September. }\end{array}$ \\
\hline $\begin{array}{l}\text { Cho Oyu } \\
\text { (8201 m) } \\
\text { NW Face, Tibet }\end{array}$ & Andrew Lock & $\begin{array}{l}\text { Lock reached summit } \\
\text { on } 25 \text { September } \\
\text { from Camp II. }\end{array}$ & $\begin{array}{l}\text { Lock's eleventh } \\
8000 \text { m peak. } \\
\text { Solo climb. }\end{array}$ \\
\hline $\begin{array}{l}\text { Cho Oyu } \\
\text { (8201 m) } \\
\text { NW Face, Tibet }\end{array}$ & $\begin{array}{l}\text { Nic Bendeli, Mick } \\
\text { Vander Vlist, } \\
\text { George Lloyd, } \\
\text { Chris Warner and } \\
\text { Zac Zaharias }\end{array}$ & $\begin{array}{l}\text { Zaharias reached } \\
\text { summit on } 1 \text { October } \\
\text { climbing solo from } \\
\text { Camp II. Warner } \\
\text { reached } 8100 \mathrm{~m} \\
\text { on } 2 \text { October. }\end{array}$ & \\
\hline $\begin{array}{l}\text { Shisha } \\
\text { Pangma(Central } \\
\text { Summit) } \\
(8026 \mathrm{~m}) \\
\text { N Ridge, Tibet }\end{array}$ & $\begin{array}{l}\text { Colin Pacey on } \\
\text { seven-person } \\
\text { international } \\
\text { commercial } \\
\text { expedition } \\
\text { led by David } \\
\text { Hamilton (UK) }\end{array}$ & $\begin{array}{l}\text { Pacey reached Central } \\
\text { Summit on } 8 \text { October. }\end{array}$ & Guided climb. \\
\hline $\begin{array}{l}\text { Ama Dablam } \\
\text { (6854 m) } \\
\text { SW Ridge, } \\
\text { Nepal }\end{array}$ & $\begin{array}{l}\text { Adam Shepard, } \\
\text { Anthony Truscott } \\
\text { on international } \\
\text { commercial } \\
\text { expedition led by } \\
\text { Dan Mazur (USA) } \\
\text { with Jay Reilly as } \\
\text { deputy leader }\end{array}$ & $\begin{array}{l}\text { Shepard reached } \\
\text { summit on } 23 \text {, Reilly } \\
\text { on } 24 \text { and Truscott } \\
\text { on } 25 \text { October. }\end{array}$ & Guided climb. \\
\hline $\begin{array}{l}\text { Lobuje East } \\
(6119 \mathrm{~m}) \text { and } \\
\text { Pumori } \\
(7161 \mathrm{~m}) \\
\text { Nepal }\end{array}$ & $\begin{array}{l}\text { Owen Davis, } \\
\text { Anthony Smailes } \\
\text { and Whiteway }\end{array}$ & $\begin{array}{l}\text { Davis, Smailes and } \\
\text { Whiteway reached } \\
\text { summit of Lobuje } \\
\text { East on } 28 \text { October. }\end{array}$ & $\begin{array}{l}\text { Smailes killed } \\
\text { on } 30 \text { October } \\
\text { en route to } \\
\text { Pumori base } \\
\text { camp. Expedition } \\
\text { abandoned. }\end{array}$ \\
\hline $\begin{array}{l}\text { Ama Dablam } \\
(6854 \mathrm{~m}) \\
\text { SW Ridge, } \\
\text { Nepal }\end{array}$ & $\begin{array}{l}\text { Jan Anderson, } \\
\text { Robert Gambi and } \\
\text { Louis Koszteiny } \\
\text { on international } \\
\text { commercial } \\
\text { expedition led by } \\
\text { Luis Benitez (USA) }\end{array}$ & $\begin{array}{l}\text { Gambi reached summit } \\
\text { on } 2 \text { November. }\end{array}$ & Guided climb. \\
\hline
\end{tabular}




\begin{tabular}{|c|c|c|c|c|}
\hline & $\begin{array}{l}\text { Ama Dablam } \\
(6854 \mathrm{~m}) \\
\text { SW Ridge, } \\
\text { Nepal }\end{array}$ & $\begin{array}{l}\text { Daniel Bull } \\
\text { and Brendan } \\
\text { O'Mahoney on } \\
\text { international } \\
\text { commercial } \\
\text { expedition } \\
\text { led by Tarn } \\
\text { Pilkington (NZ) }\end{array}$ & $\begin{array}{l}\text { Bull and O'Mahoney } \\
\text { reached summit } \\
\text { on } 4 \text { November. }\end{array}$ & Guided climb. \\
\hline & $\begin{array}{l}\text { Ama Dablam } \\
\text { (6854 m) } \\
\text { SW Ridge, } \\
\text { Nepal }\end{array}$ & $\begin{array}{l}\text { Tim Colquhoun } \\
\text { and Mic Rofe } \\
\text { on a range of } \\
\text { commercial } \\
\text { expeditions }\end{array}$ & $\begin{array}{l}\text { Colquhoun reached } \\
\text { summit on } 1 \\
\text { November and Rofe } \\
\text { on } 5 \text { November. }\end{array}$ & Guided climbs. \\
\hline \multirow[t]{6}{*}{2005} & $\begin{array}{l}\text { Pumori } \\
\text { (7161 m) } \\
\text { SE Face, E } \\
\text { Ridge, Nepal }\end{array}$ & $\begin{array}{l}\text { Philip Ling and } \\
\text { Kirk Morely on } \\
\text { international } \\
\text { commercial } \\
\text { expedition led by } \\
\text { Dan Mazur (USA) } \\
\text { with Jay Reilly as } \\
\text { deputy leader }\end{array}$ & $\begin{array}{l}\text { Unsuccessful. High } \\
\text { point of } 6150 \mathrm{~m} \\
\text { reached on } 23 \text { March. }\end{array}$ & Guided climb. \\
\hline & $\begin{array}{l}\text { Kula Kangri } \\
\text { (7554 m) } \\
\text { W Ridge and } \\
\text { Jiexiang } \\
\text { (6676 m) } \\
\text { E Ridge, } \\
\text { Tibet }\end{array}$ & $\begin{array}{l}\text { Damien Gildea, } \\
\text { Steve Chaplin } \\
\text { (UK), Lars Svens } \\
\text { (Sweden) and Laila } \\
\text { Ojefelt (Sweden) }\end{array}$ & $\begin{array}{l}\text { Unsuccessful. Reached } \\
6200 \text { m on Kula } \\
\text { Kangri and } 6300 \\
\text { m on Jiexiang. }\end{array}$ & $\begin{array}{l}\text { Continual poor } \\
\text { weather thwarted } \\
\text { progress. }\end{array}$ \\
\hline & $\begin{array}{l}\text { Cho Oyu } \\
\text { (8201 m) } \\
\text { NW Face, Tibet }\end{array}$ & $\begin{array}{l}\text { Tashi Tensing } \\
\text { guiding an } \\
\text { international } \\
\text { commercial } \\
\text { expedition }\end{array}$ & $\begin{array}{l}\text { Camp I }(6300 \\
\text { m) reached. }\end{array}$ & \\
\hline & $\begin{array}{l}\text { Mt Everest } \\
\text { (8850 m) } \\
\text { N Ridge, Tibet }\end{array}$ & $\begin{array}{l}\text { Mick Parker and } \\
\text { one other climber }\end{array}$ & $\begin{array}{l}\text { Unsuccessful, } \\
\text { reached } 7700 \text { m. }\end{array}$ & \\
\hline & $\begin{array}{l}\text { Mt Everest } \\
\text { (8850 m) } \\
\text { SE Ridge, Nepal }\end{array}$ & $\begin{array}{l}\text { Victorian Police } \\
\text { team of Nick Farr, } \\
\text { Greg Linsdell } \\
\text { and John Taylor } \\
\text { on commercial } \\
\text { expedition led by } \\
\text { Kenton Cool (UK) }\end{array}$ & $\begin{array}{l}\text { Farr, Linsdell and } \\
\text { Taylor reached the } \\
\text { summit on } 31 \text { May. }\end{array}$ & Guided climb. \\
\hline & $\begin{array}{l}\text { Mt Everest } \\
\text { ( } 8850 \mathrm{~m}) \\
\text { SE Ridge, Nepal }\end{array}$ & $\begin{array}{l}\text { Rex Pemberton } \\
\text { on international } \\
\text { commercial } \\
\text { expedition led by } \\
\text { Eric Simonsen } \\
\text { (USA) }\end{array}$ & $\begin{array}{l}\text { Reached summit } \\
\text { on } 31 \text { May. }\end{array}$ & $\begin{array}{l}\text { Guided climb. } \\
\text { Pemberton } \\
\text { (20) youngest } \\
\text { Australian to } \\
\text { climb Mt Everest. }\end{array}$ \\
\hline
\end{tabular}




\begin{tabular}{|c|c|c|c|}
\hline $\begin{array}{l}\text { Mt Everest } \\
(8850 \mathrm{~m}) \\
\text { SE Ridge, Nepal }\end{array}$ & $\begin{array}{l}\text { Piers Buck and } \\
\text { Gerrard Gosens } \\
\text { on New Zealand } \\
\text { commercial } \\
\text { expedition led by } \\
\text { Mike Roberts (NZ) }\end{array}$ & $\begin{array}{l}\text { Buck and Gosens } \\
\text { climbed to Camp III. } \\
\text { Expedition abandoned } \\
\text { on } 29 \text { May due } \\
\text { to high winds. }\end{array}$ & $\begin{array}{l}\text { Gosens is a } \\
\text { congenitally blind } \\
\text { climber. Buck left } \\
\text { for Tibet on } 25 \\
\text { May for attempt } \\
\text { from north side. } \\
\text { Guided climb. }\end{array}$ \\
\hline $\begin{array}{l}\text { Mt Everest } \\
\text { ( } 8850 \mathrm{~m}) \\
\text { N Ridge, Tibet }\end{array}$ & $\begin{array}{l}\text { Paul Hockey } \\
\text { and Piers Buck } \\
\text { on international } \\
\text { commercial } \\
\text { expedition led } \\
\text { by Dean Staples } \\
\text { (NZ) and guide } \\
\text { Duncan Chessell }\end{array}$ & $\begin{array}{l}\text { Hockey and Buck } \\
\text { reached summit } \\
\text { on } 5 \text { June. }\end{array}$ & $\begin{array}{l}\text { Hockey is the } \\
\text { first Australian } \\
\text { disabled climber } \\
\text { to climb Everest. } \\
\text { Buck joined } \\
\text { the expedition } \\
\text { in late May. } \\
\text { Guided climb. }\end{array}$ \\
\hline $\begin{array}{l}\text { Annapurna I } \\
\text { (8091 m) } \\
\text { North face } \\
\text { (French route), } \\
\text { Nepal }\end{array}$ & $\begin{array}{l}\text { Andrew Lock, } \\
\text { Brendan Cusick } \\
\text { (USA) and Charlie } \\
\text { Mace (USA). } \\
\text { Lock also teamed } \\
\text { up with Italians } \\
\text { Christian Kuntner, } \\
\text { Abele Blanc and } \\
\text { Silvio Mondinelli } \\
\text { for summit push }\end{array}$ & $\begin{array}{l}\text { Lock reached high } \\
\text { point of } 6000 \text { m. } \\
\text { Expedition abandoned } \\
\text { on } 18 \text { May after } \\
\text { avalanche hit the } \\
\text { group above Camp II, } \\
\text { injuring four Italians. } \\
\text { Kuntner died in Lock's } \\
\text { arms at Camp II. }\end{array}$ & $\begin{array}{l}\text { First Australian } \\
\text { attempt on } \\
\text { Annapurna I. }\end{array}$ \\
\hline $\begin{array}{l}\text { Cho Oyu } \\
\text { (8201 m) } \\
\text { NW Face, Tibet }\end{array}$ & $\begin{array}{l}\text { Simon Andrade } \\
\text { on New Zealand } \\
\text { commercial } \\
\text { expedition led by } \\
\text { Mike Roberts (NZ) } \\
\end{array}$ & $\begin{array}{l}\text { Andrade left on } \\
14 \text { September for } \\
\text { medical reasons. }\end{array}$ & Guided climb. \\
\hline $\begin{array}{l}\text { Lhotse(8516) } \\
\text { W Face, Nepal }\end{array}$ & Blair Falahey & $\begin{array}{l}\text { Unsuccessful. } \\
\text { Reached } 7800 \text { m. }\end{array}$ & \\
\hline $\begin{array}{l}\text { K2 }(8611 \mathrm{~m}) \\
\text { Pakistan }\end{array}$ & $\begin{array}{l}\text { Mick Parker and } \\
\text { Banjo Bannon } \\
\text { (Ireland) }\end{array}$ & $\begin{array}{l}\text { Unsuccessful. } \\
\text { Reached } 8100 \mathrm{~m} \text { but } \\
\text { abandoned climb due } \\
\text { to poor weather. }\end{array}$ & \\
\hline $\begin{array}{l}\text { Gasherbrum } \\
\text { II (8035 m) } \\
\text { SE Ridge, } \\
\text { Pakistan }\end{array}$ & $\begin{array}{l}\text { Geoff Robb, Zac } \\
\text { Zaharias and Ali } \\
\text { Shimshal (Pakistan) }\end{array}$ & $\begin{array}{l}\text { Zaharias reached } \\
\text { summit on } 23 \text { July } \\
\text { in whiteout; Robb } \\
\text { reached } 7800 \mathrm{~m} . \\
\text { Both climbed from } \\
\text { Camp III at } 7000 \mathrm{~m} \text {. }\end{array}$ & $\begin{array}{l}\text { Zaharias's fifth } \\
8000 \text { m peak. }\end{array}$ \\
\hline $\begin{array}{l}\text { Cho Oyu } \\
\text { (8201 m) } \\
\text { NW Face, Tibet }\end{array}$ & $\begin{array}{l}\text { Jen Peedom and } \\
\text { Christopher Hallam } \\
\text { on international } \\
\text { commercial } \\
\text { expedition led by } \\
\text { Russell Brice (NZ) } \\
\end{array}$ & $\begin{array}{l}\text { Peedom reached } \\
\text { summit on } 22 \\
\text { September; Hallam } \\
\text { reached } 7300 \mathrm{~m} .\end{array}$ & $\begin{array}{l}\text { Peedom used } \\
\text { bottled oxygen } \\
\text { from } \\
\text { Camp III. } \\
\text { Guided climb. }\end{array}$ \\
\hline $\begin{array}{l}\text { Shisha Pangma } \\
\text { (Central } \\
\text { Summit) } \\
\text { (8026 m) } \\
\text { N Ridge, Tibet }\end{array}$ & $\begin{array}{l}\text { Warwick Barnes } \\
\text { on a international } \\
\text { commercial } \\
\text { expedition } \\
\text { led by Jamie } \\
\text { McGuinness (NZ) }\end{array}$ & $\begin{array}{l}\text { Reached summit on } 4 \\
\text { October with Pasang } \\
\text { Gyelu Sherpa. }\end{array}$ & Guided climb. \\
\hline
\end{tabular}




\begin{tabular}{|c|c|c|c|c|}
\hline & $\begin{array}{l}\text { Cho Oyu } \\
\text { (8201 m) } \\
\text { NW Face and } \\
\text { Shisha Pangma } \\
\text { (Central } \\
\text { Summit) } \\
\text { (8026m) } \\
\text { N Ridge, } \\
\text { Tibet }\end{array}$ & $\begin{array}{l}\text { Andrew Lock } \\
\text { guiding Spaniard } \\
\text { Inigo de Pineda }\end{array}$ & $\begin{array}{l}\text { Lock reached summit } \\
\text { of Cho Oyu on } 25 \\
\text { September and Shisha } \\
\text { Pangma Central } \\
\text { on } 8 \text { October. }\end{array}$ & $\begin{array}{l}\text { Lock's second } \\
\text { ascent of } \\
\text { Cho Oyu } \\
\text { and Shisha } \\
\text { Pangma Central. }\end{array}$ \\
\hline & $\begin{array}{l}\text { Amin Brakk } \\
(4900 \mathrm{~m}) \text { and } \\
\text { Denbour Tower } \\
(4900 \mathrm{~m}) \\
\text { Hushe Valley, } \\
\text { Pakistan }\end{array}$ & $\begin{array}{l}\text { Chris Fitzgerald } \\
\text { and Nathan } \\
\text { Kukuthas }\end{array}$ & $\begin{array}{l}\text { Fitzgerald and } \\
\text { Kukuthas reached } \\
\text { summit of Denbour } \\
\text { Tower on } 29 \\
\text { September. Climb } \\
\text { took six days } \\
\text { including descent. }\end{array}$ & $\begin{array}{l}\text { New route, } \\
\text { One Degree } \\
\text { of Separation } \\
\text { (17, A5, } 12 \\
\text { pitches). }\end{array}$ \\
\hline & $\begin{array}{l}\text { Ama Dablam } \\
\text { (6854 m) } \\
\text { SW Ridge, } \\
\text { Nepal }\end{array}$ & $\begin{array}{l}\text { Andrew McDonald } \\
\text { on international } \\
\text { commercial } \\
\text { expedition led by } \\
\text { Dan Mazur (USA) } \\
\text { with Jay Reilly as } \\
\text { deputy leader }\end{array}$ & $\begin{array}{l}\text { Reilly reached summit } \\
\text { on } 20 \text { October } \\
\text { and McDonald on } \\
22 \text { October. }\end{array}$ & $\begin{array}{l}\text { Reilly's third } \\
\text { ascent of } \\
\text { Ama Dablam. } \\
\text { Guided climb. }\end{array}$ \\
\hline & $\begin{array}{l}\text { Ama Dablam } \\
\text { ( } 6854 \mathrm{~m}) \\
\text { SW Ridge, } \\
\text { Nepal }\end{array}$ & $\begin{array}{l}\text { David Ridley and } \\
\text { Daniel Fisher } \\
\text { on commercial } \\
\text { expedition }\end{array}$ & $\begin{array}{l}\text { Ridley and Fisher } \\
\text { reached summit } \\
\text { on } 25 \text { October. }\end{array}$ & Guided climb. \\
\hline & $\begin{array}{l}\text { Ama Dablam } \\
\text { (6854 m) } \\
\text { SW Ridge, } \\
\text { Nepal }\end{array}$ & $\begin{array}{l}\text { Shaun McLauchlan } \\
\text { and Brian } \\
\text { McLauchlan }\end{array}$ & $\begin{array}{l}\text { Unsuccessful. Shaun } \\
\text { McLauchlan suffered } \\
\text { frostbite on eight toes. } \\
\text { Brian McLauchlan had } \\
\text { altitude problems. }\end{array}$ & $\begin{array}{l}\text { Father and } \\
\text { son team. }\end{array}$ \\
\hline & $\begin{array}{l}\text { Ama Dablam } \\
\text { (6854 m) } \\
\text { SW Ridge, } \\
\text { Nepal }\end{array}$ & $\begin{array}{l}\text { Anthony } \\
\text { Geoghegan, Brad } \\
\text { Jackson and } \\
\text { Vanessa Wills } \\
\text { on 13-member } \\
\text { international } \\
\text { commercial } \\
\text { expedition } \\
\text { led by Stuart } \\
\text { Remensnyder } \\
\text { (USA) }\end{array}$ & $\begin{array}{l}\text { Wills reached } \\
\text { summit on } 29 \\
\text { October, Jackson } \\
\text { on } 4 \text { November } \\
\text { and Geoghegan } \\
\text { on } 7 \text { November. }\end{array}$ & Guided climb. \\
\hline & $\begin{array}{l}\text { Kyajo Ri } \\
\text { (6186 m) } \\
\text { SE Ridge, Nepal }\end{array}$ & $\begin{array}{l}\text { Armando Corvini } \\
\text { (leader), Fil Giles, } \\
\text { Graham Franklin- } \\
\text { Browne, Cheryl } \\
\text { Woods and } \\
\text { Adam Liddyard }\end{array}$ & $\begin{array}{l}\text { Unsuccessful. High } \\
\text { point of Camp I } \\
(5400 \mathrm{~m}) \text { reached. }\end{array}$ & $\begin{array}{l}\text { Expedition } \\
\text { abandoned } \\
\text { due to lack of } \\
\text { time and poor } \\
\text { weather. }\end{array}$ \\
\hline 2006 & $\begin{array}{l}\text { Mt Everest } \\
\text { (8850 m) } \\
\text { N Ridge, Tibet }\end{array}$ & $\begin{array}{l}\text { Blair Falahey with } \\
\text { two Sherpas }\end{array}$ & $\begin{array}{l}\text { Reached summit } \\
\text { on } 18 \text { May. }\end{array}$ & $\begin{array}{l}\text { Smallest } \\
\text { Australian } \\
\text { expedition. }\end{array}$ \\
\hline
\end{tabular}




\begin{tabular}{|c|c|c|c|c|}
\hline & \begin{tabular}{|l} 
Mt Everest \\
$(8850 \mathrm{~m})$ \\
N Ridge, Tibet
\end{tabular} & $\begin{array}{l}\text { Mike Dillon, } \\
\text { Lincoln Hall, } \\
\text { Christopher Harris } \\
\text { and Richard Harris }\end{array}$ & $\begin{array}{l}\text { Hall reached } \\
\text { summit on } 25 \text { May. } \\
\text { Christopher Harris } \\
\text { reached } 7300 \mathrm{~m} \text {. }\end{array}$ & $\begin{array}{l}15 \text {-year-old } \\
\text { Christopher } \\
\text { Harris attempted } \\
\text { to become the } \\
\text { youngest person } \\
\text { to climb Everest. } \\
\text { Hall 'died' } \\
\text { and revived } \\
\text { at } 8700 \mathrm{~m}- \\
\text { rescued by large } \\
\text { ground party. }\end{array}$ \\
\hline & \begin{tabular}{|l} 
Manaslu \\
(8163 m) \\
NE Face, Nepal
\end{tabular} & $\begin{array}{l}\text { Sue Fear and } \\
\text { Bishnu Gurung }\end{array}$ & \begin{tabular}{|l|} 
Summit reached \\
28 May. Died in \\
crevasse fall at 7600 \\
$\mathrm{~m}$ during descent. \\
\end{tabular} & $\begin{array}{l}\text { Fear's fifth } \\
\text { summit over } \\
8000 \text { m. }\end{array}$ \\
\hline & $\begin{array}{l}\text { Kangchenjunga } \\
\text { (8586 m) } \\
\text { SW Face Nepal }\end{array}$ & $\begin{array}{l}\text { Ralf Dujmovits } \\
\text { (Germany), } \\
\text { Gerlinde } \\
\text { Kaltenbrunner } \\
\text { (Austria), Veikka } \\
\text { Gustafsson } \\
\text { (Finland), Hirotaka } \\
\text { Takeuchi (Japan), } \\
\text { Joao Garcia } \\
\text { (Portugal) and } \\
\text { Andrew Lock }\end{array}$ & $\begin{array}{l}\text { Lock reached summit } \\
\text { on } 14 \text { May. }\end{array}$ & \\
\hline & $\begin{array}{l}\text { Saribung } \\
\text { (6328 m) } \\
\text { Damodar } \\
\text { Himal, Nepal }\end{array}$ & $\begin{array}{l}\text { Peter Allen, Mick } \\
\text { Chapman, Nima } \\
\text { Lama, Mingma } \\
\text { Sherpa and Pasang } \\
\text { Nima Sherpa }\end{array}$ & $\begin{array}{l}\text { Successful. Summit } \\
\text { reached on } 19 \text { May } \\
2006 \text { by Allen, } \\
\text { Nima, Mingma and } \\
\text { Pasang Nima. }\end{array}$ & $\begin{array}{l}\text { First Australian } \\
\text { ascent. }\end{array}$ \\
\hline & $\begin{array}{l}\text { Broad Peak } \\
(8047 \mathrm{~m}) \\
\text { W Face, } \\
\text { Pakistan }\end{array}$ & Terry Tremble & Reached $7500 \mathrm{~m}$. & \\
\hline & $\begin{array}{l}\text { Broad Peak } \\
(8047 \mathrm{~m}) \\
\text { W Face, } \\
\text { Pakistan }\end{array}$ & $\begin{array}{l}\text { Nic Barcley, } \\
\text { Mark Sheen and } \\
\text { Mick Parker }\end{array}$ & $\begin{array}{l}\text { Sheen reached } \\
\text { Camp IV. }\end{array}$ & \\
\hline & \begin{tabular}{|l} 
Cho Oyu \\
(8201 m) \\
NW Face, Tibet
\end{tabular} & Blair Falahey & $\begin{array}{l}\text { Successful. Falahey } \\
\text { reached summit } \\
\text { on } 20 \text { October. }\end{array}$ & \\
\hline 2007 & \begin{tabular}{|l} 
Dhaulagiri I \\
(8167 m) \\
NE Ridge, Nepal
\end{tabular} & Mick Parker & $\begin{array}{l}\text { Unsuccessful. Reached } \\
7000 \text { m. Parker fell } \\
\text { into crevasse. }\end{array}$ & $\begin{array}{l}\text { Avalanche killed } \\
\text { two Spaniards at } \\
\text { Camp II, Parker } \\
\text { abandoned } \\
\text { expedition. }\end{array}$ \\
\hline & $\begin{array}{l}\text { Lhotse }(8516 \mathrm{~m}) \\
\text { W Face, Nepal }\end{array}$ & Blair Falahey & $\begin{array}{l}\text { Summit reached on } \\
21 \text { May } 2007 .\end{array}$ & $\begin{array}{l}\text { Used oxygen } \\
\text { from Camp IV. }\end{array}$ \\
\hline & $\begin{array}{l}\text { Annapurna I } \\
\text { (8091 m) } \\
\text { N Face (French } \\
\text { route), Nepal }\end{array}$ & Andrew Lock & $\begin{array}{l}\text { Reached summit } \\
\text { on } 24 \text { May. }\end{array}$ & $\begin{array}{l}\text { First Australian } \\
\text { ascent. }\end{array}$ \\
\hline
\end{tabular}




\begin{tabular}{|c|c|c|c|c|}
\hline & $\begin{array}{l}\text { Chamser Kangri } \\
\text { (6622 m) } \\
\text { Ladakh, India }\end{array}$ & $\begin{array}{l}\text { Lindsay Abbotts } \\
\text { (UK), Silvana } \\
\text { Adams, Peter } \\
\text { Allen, Elizabeth } \\
\text { Armitage, } \\
\text { Bryan Atkins, } \\
\text { Mick Chapman, } \\
\text { Christine Clarence, } \\
\text { Bryan Fruish (UK), } \\
\text { Kevin Harkins, } \\
\text { Alan Johnston, } \\
\text { Bett Koch, Francis } \\
\text { Lawrence, Neil } \\
\text { Pilling, David } \\
\text { Rae and Rahul } \\
\text { Sharma (India) }\end{array}$ & $\begin{array}{l}\text { Successful. Summit } \\
\text { reached on } 23 \text { July } \\
2007 \text { by Harkins } \\
\text { and Allen, on } 26 \\
\text { July by Harkins, } \\
\text { Atkins, Fruish and } \\
\text { Lawrence, on } 27 \text { July } \\
\text { by Allen, Armitage, } \\
\text { Haala, Johnston and } \\
\text { Pilling and on } 28 \\
\text { July by Chapman, } \\
\text { Abbotts, Adams, } \\
\text { Koch and Clarence. }\end{array}$ & $\begin{array}{l}\text { First Australian } \\
\text { ascent. Peregrine } \\
\text { Adventures } \\
\text { expedition. }\end{array}$ \\
\hline & $\begin{array}{l}\text { Gasherbrum } \\
\text { I ( } 8068 \mathrm{~m}) \\
\text { Japanese } \\
\text { Couloir, Pakistan }\end{array}$ & $\begin{array}{l}\text { Mike Cook, Lesley } \\
\text { Gidding, Damien } \\
\text { Gildea, Brian } \\
\text { Laursen, Mick } \\
\text { Parker, Geoff } \\
\text { Robb, Dr James } \\
\text { Strohfeldt, Mick } \\
\text { Vander Vlist, Chris } \\
\text { Warner and Zac } \\
\text { Zaharias (leader) }\end{array}$ & $\begin{array}{l}\text { Mick Parker reached } \\
\text { summit on } 29 \text { July. } \\
\text { Zaharias, Robb and } \\
\text { Warner reached } 7400 \\
\text { m on } 20 \text { July. }\end{array}$ & $\begin{array}{l}\text { Second } \\
\text { Australian } \\
\text { ascent of G1. }\end{array}$ \\
\hline & $\begin{array}{l}\text { Gasherbrum } \\
\text { II (8035 m) } \\
\text { SE Ridge, } \\
\text { Pakistan }\end{array}$ & $\begin{array}{l}\text { Mary Adams, } \\
\text { Catherine } \\
\text { Carlyle and Blair } \\
\text { Falahey (guide) } \\
\text { on commercial } \\
\text { expedition }\end{array}$ & $\begin{array}{l}\text { Falahey reached } \\
7500 \mathrm{~m} .\end{array}$ & $\begin{array}{l}\text { Expedition } \\
\text { abandoned } \\
\text { due to poor } \\
\text { weather and } \\
\text { two avalanche } \\
\text { deaths (from } \\
\text { another team). }\end{array}$ \\
\hline & $\begin{array}{l}\text { Manaslu } \\
\text { (8163 m) } \\
\text { NE Face, Nepal }\end{array}$ & Mick Parker & Unsuccessful. & \\
\hline & $\begin{array}{l}\text { Shisha Pangma } \\
\text { (Central } \\
\text { Summit) } \\
\text { (8026 m) } \\
\text { N Ridge, Tibet }\end{array}$ & Blair Falahey & $\begin{array}{l}\text { Reached } 7400 \mathrm{~m} \text {. } \\
\text { Climb abandoned after } \\
\text { climbing partner died. }\end{array}$ & \\
\hline & $\begin{array}{l}\text { Shivling } \\
\text { (6543m) } \\
\text { W Ridge, India }\end{array}$ & $\begin{array}{l}\text { Noel Eatough, John } \\
\text { Morrison, Sean } \\
\text { Parkes, Shannon } \\
\text { Parkinson, Max } \\
\text { Pemberton, Mark } \\
\text { Raymond, Matt } \\
\text { Rogerson (leader), } \\
\text { Shane Saltmarsh, } \\
\text { Liam Scarlett and } \\
20 \text { Indian climbers }\end{array}$ & $\begin{array}{l}\text { Rogerson and } \\
\text { Pemberton summited } \\
\text { on } 3 \text { October, plus } \\
\text { five Indian climbers. }\end{array}$ & $\begin{array}{l}\text { Indo-Australian } \\
\text { military } \\
\text { expedition. }\end{array}$ \\
\hline 2008 & $\begin{array}{l}\text { Manaslu } \\
\text { (8163 m) } \\
\text { NE Face, Nepal }\end{array}$ & $\begin{array}{l}\text { Mick Parker and } \\
\text { Ben Grayling }\end{array}$ & $\begin{array}{l}\text { Parker reached summit } \\
\text { on } 14 \text { May; Grayling } \\
\text { reached } 7800 \mathrm{~m} .\end{array}$ & \\
\hline
\end{tabular}




\begin{tabular}{|c|c|c|c|}
\hline $\begin{array}{l}\text { Lhotse }(8516 \mathrm{~m}) \\
\text { W Face, Nepal }\end{array}$ & $\begin{array}{l}\text { Margaret } \\
\text { Watroba on } \\
\text { DCXP commercial } \\
\text { expedition }\end{array}$ & $\begin{array}{l}\text { Watroba reached } \\
6000 \mathrm{~m} .\end{array}$ & \\
\hline $\begin{array}{l}\text { Makalu } \\
\text { ( } 8463 \mathrm{~m}) \\
\text { Nepal }\end{array}$ & Andrew Lock & $\begin{array}{l}\text { Summited on } 21 \\
\text { May } 2008 .\end{array}$ & \\
\hline $\begin{array}{l}\text { Bhrikuti } \\
\text { (6372m) } \\
\text { Damodar } \\
\text { Himal, Nepal }\end{array}$ & $\begin{array}{l}\text { Mick Chapman, } \\
\text { Peter Allen, } \\
\text { Elizabeth Armitage, } \\
\text { Bett Koch, Bryan } \\
\text { Fruish (UK) } \\
\text { and Lindsay } \\
\text { Abbotts (UK) }\end{array}$ & $\begin{array}{l}\text { Successful. Summit } \\
\text { reached on } 14 \\
\text { May } 2008 .\end{array}$ & $\begin{array}{l}\text { First Australian } \\
\text { ascent. Group } \\
\text { exited through } \\
\text { Mustang. }\end{array}$ \\
\hline $\begin{array}{l}\text { Makalu } \\
\text { (8463 m) } \\
\text { Nepal }\end{array}$ & Blair Falahey & $\begin{array}{l}\text { Unsuccessful. } \\
\text { Reached } 8000 \mathrm{~m} .\end{array}$ & \\
\hline $\begin{array}{l}\text { K2 }(8611 \mathrm{~m}) \\
\text { Abruzzi Ridge, } \\
\text { Pakistan }\end{array}$ & $\begin{array}{l}\text { Chris Warner } \\
\text { and Paul Walters } \\
\text { on international } \\
\text { expedition led by } \\
\text { Mike Farris (USA) }\end{array}$ & $\begin{array}{l}\text { Chirring Dorje Sherpa } \\
\text { reached summit on } \\
1 \text { August. Walters } \\
\text { reached } 8000 \mathrm{~m} \text { and } \\
\text { Warner } 6800 \mathrm{~m} .\end{array}$ & $\begin{array}{l}\text { Climb abandoned } \\
\text { after serac } \\
\text { collapse on the } \\
\text { bottleneck saw } \\
11 \text { climbers } \\
\text { perish. }\end{array}$ \\
\hline $\begin{array}{l}\text { K2 }(8611 \mathrm{~m}) \\
\text { Abruzzi Ridge, } \\
\text { Pakistan }\end{array}$ & $\begin{array}{l}\text { Mark Sheen on a } \\
\text { Dutch expedition }\end{array}$ & Reached $8000 \mathrm{~m}$. & $\begin{array}{l}\text { Delayed } \\
\text { his summit } \\
\text { attempt due to } \\
\text { overcrowding } \\
\text { at Camp IV } \\
\text { then abandoned } \\
\text { climb after } \\
\text { serac collapse. }\end{array}$ \\
\hline $\begin{array}{l}\text { Dhaulagiri I } \\
\text { (8167 m) } \\
\text { NE Spur, Nepal }\end{array}$ & Mick Parker & $\begin{array}{l}\text { Reached } 6500 \mathrm{~m} . \\
\text { Abandoned due to } \\
\text { poor weather. }\end{array}$ & \\
\hline $\begin{array}{l}\text { James Point } \\
(4965 \text { m), } \\
\text { Nazomi Peak } \\
(5300 \mathrm{~m}) \text { and } \\
\text { Triple Crown } \\
(5800 \mathrm{~m}) \\
\text { NW Ridge, } \\
\text { Chhudong } \\
\text { Valley, Himachal } \\
\text { Pradesh, India }\end{array}$ & $\begin{array}{l}\text { Gemma } \\
\text { Woldendorp and } \\
\text { Natasha Sebire }\end{array}$ & $\begin{array}{l}\text { Successful. New route } \\
\text { on James Point and } \\
\text { first ascent of Nazomi } \\
\text { Peak and Triple Crown. }\end{array}$ & $\begin{array}{l}\text { Ascent of Triple } \\
\text { Crown involved } \\
1000 \mathrm{~m} \text { of } \\
\text { mixed climbing } \\
\text { on snow, ice } \\
\text { and rock, AD + } \\
70 \text { degrees. }\end{array}$ \\
\hline $\begin{array}{l}\text { Kyajo Ri } \\
\text { (6186 m) } \\
\text { SE Route, Nepal }\end{array}$ & $\begin{array}{l}\text { Armando Corvini } \\
\text { (leader), Chris } \\
\text { Brown, Graham } \\
\text { Franklin-Browne, } \\
\text { Kerry Flanagan, } \\
\text { Greg Holland and } \\
\text { Adam Lyddiard }\end{array}$ & $\begin{array}{l}\text { Unsuccessful. Franklin- } \\
\text { Browne and Holland } \\
\text { reached } 5500 \mathrm{~m} \text {. }\end{array}$ & \\
\hline
\end{tabular}




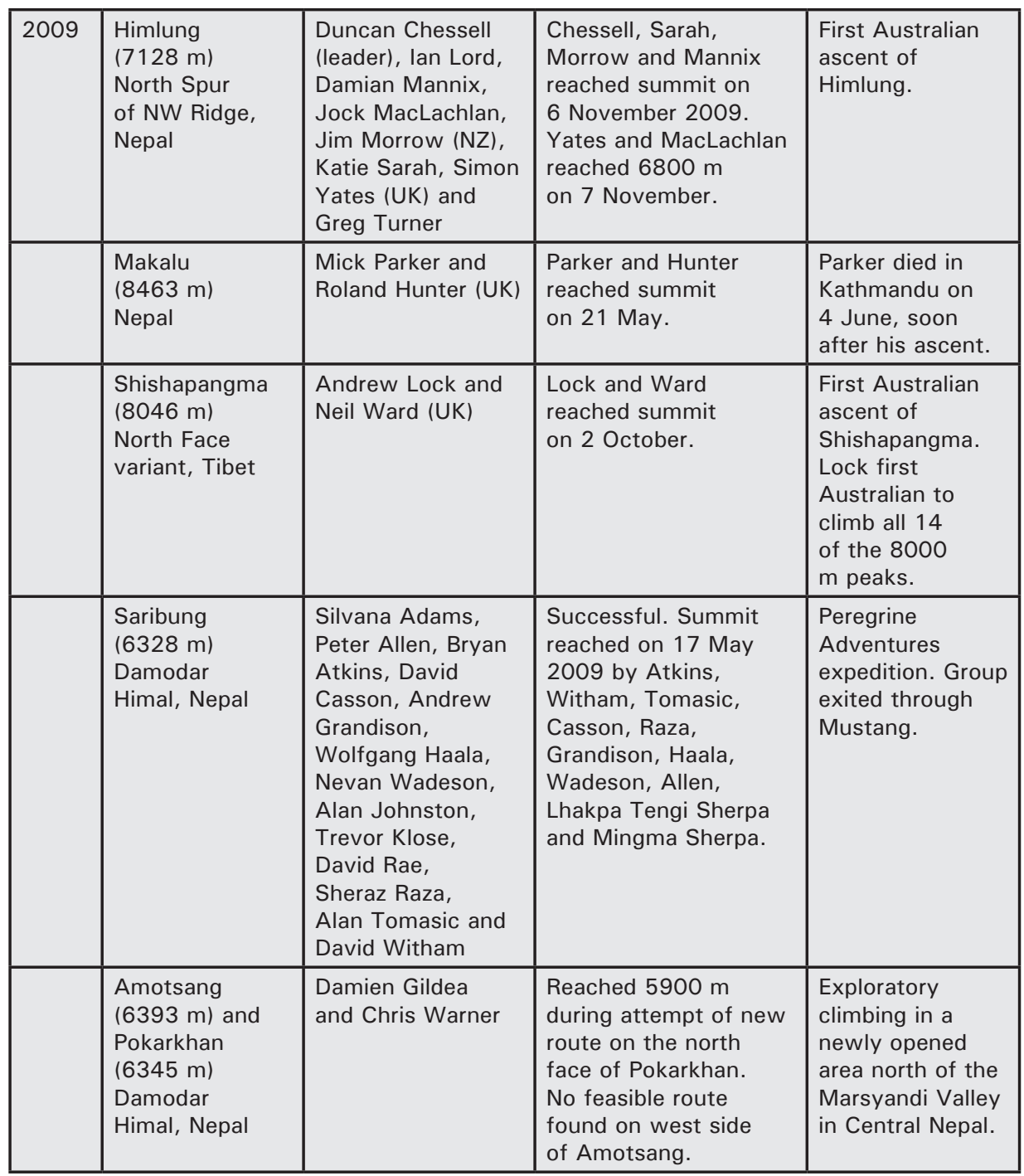

Notes: This and the following two tables are based on surveys of Australian Himalayan climbs that have been published in Wild magazine (nos 40 [Autumn 1991], 55 [Summer 1995], 80 [Autumn 2001], 92 [Autumn 2004] and 100 [Autumn 2006]). The first two surveys were compiled by Will Steffen and the remainder by Zac Zaharias. This table includes all successful Australian ascents of significant Himalayan peaks (generally considered to be above $5500 \mathrm{~m}$ ), but only first Australian ascents of 'trekking peaks' in Nepal and Tibet. It also includes near ascents on major Himalayan peaks and other unsuccessful attempts, which are considered noteworthy for any reason (for example, technical difficulty, unclimbed peak, death). Where possible, differentiation is made between those summiting as clients on commercial expeditions and those who participate in a commercial expedition in an unguided or free-climbing capacity. Climbers of other nationalities have been listed only when they are notable, have done something of interest, are Sherpas climbing with Australians or are guides. Ascents of Shisha Pangma Central Summit are recognised as an ascent of an 8000-m summit in this survey. From 2006, the table does not include commercial expeditions to Mt Everest, Cho-Oyu, Shisha Pangma and Ama Dablam. 
Table 2 Australian ascents of 8000 metre Himalayan peaks, 1984-2009

\begin{tabular}{|c|c|c|c|}
\hline Peak & $\begin{array}{l}\text { Date of first } \\
\text { Australian } \\
\text { ascent }\end{array}$ & $\begin{array}{l}\text { First Australian(s) } \\
\text { to summit }\end{array}$ & $\begin{array}{l}\text { Total number of } \\
\text { Australians to } \\
\text { reach summit\# }\end{array}$ \\
\hline $\begin{array}{l}\text { Mt Everest } \\
(8850 \mathrm{~m})\end{array}$ & 3 October 1984 & $\begin{array}{l}\text { Tim Macartney-Snape, } \\
\text { Greg Mortimer }\end{array}$ & 49 \\
\hline K2 (8611 m) & 20 August 1990 & $\begin{array}{l}\text { Greg Child, Greg } \\
\text { Mortimer }\end{array}$ & 4 \\
\hline $\begin{array}{l}\text { Kangchenjunga } \\
(8586 \mathrm{~m})\end{array}$ & $\begin{array}{l}10 \text { October } \\
1987\end{array}$ & $\begin{array}{l}\text { John Coulten, } \\
\text { Mike Groom }\end{array}$ & 3 \\
\hline Lhotse $(8516 \mathrm{~m})$ & 6 May 1995 & Mike Groom & 3 \\
\hline Makalu $(8463 \mathrm{~m})$ & 8 May 1995 & $\begin{array}{l}\text { Mark Auricht, } \\
\text { David Hume* }\end{array}$ & 6 \\
\hline Cho Oyu (8201 m) & 11 May 1990 & Mike Groom & 36 \\
\hline $\begin{array}{l}\text { Dhaulagiri I } \\
(8167 \mathrm{~m})\end{array}$ & 25 May 1997 & $\begin{array}{l}\text { Andrew Lock, Matt } \\
\text { Rogerson, Zac Zaharias }\end{array}$ & 4 \\
\hline Manaslu (8163 m) & 21 April 2002 & Andrew Lock & 7 \\
\hline $\begin{array}{l}\text { Nanga Parbat } \\
(8126 \mathrm{~m})\end{array}$ & 21 July 1998 & Andrew Lock & 1 \\
\hline $\begin{array}{l}\text { Annapurna I } \\
(8091 \mathrm{~m}) \\
\end{array}$ & 24 May 2007 & Andrew Lock & 1 \\
\hline $\begin{array}{l}\text { Gasherbrum I } \\
(8068 \mathrm{~m})\end{array}$ & 17 July 1999 & Andrew Lock & 2 \\
\hline $\begin{array}{l}\text { Broad Peak } \\
(8047 \mathrm{~m})\end{array}$ & 16 August 1986 & $\begin{array}{l}\text { Brian Agnew, Pat } \\
\text { Cullinan, Jon Chester, } \\
\text { Peter Lambert, Terry } \\
\text { McCullagh, Mike } \\
\text { Rheinberger, Jim van } \\
\text { Gelder, Zac Zaharias }\end{array}$ & 11 \\
\hline $\begin{array}{l}\text { Shishapangma } \\
(8046 \mathrm{~m})\end{array}$ & 2 October 2009 & Andrew Lock & 1 \\
\hline $\begin{array}{l}\text { Shishapangma } \\
\text { Central }(8024 \mathrm{~m})\end{array}$ & 26 May 1990 & Mark Lemaire & 30 \\
\hline $\begin{array}{l}\text { Gasherbrum } \\
\text { II (8035 m) }\end{array}$ & 16 August 1987 & Geoff Little & 5 \\
\hline
\end{tabular}

* Died during the descent

\# Does not include multiple ascents 
Table 3 Australian Himalayan climbing deaths, 1972-2009*

\begin{tabular}{|l|l|l|l|}
\hline Name & Mountain & Year & Cause \\
\hline Tony Tighe & Mt Everest & 1972 & Serac collapse \\
\hline Lynne Griffith & Dhaulagiri I & 1980 & Avalanche \\
\hline Stafford Morse & Annapurna III & 1980 & Avalanche \\
\hline Nicholas Reeves & Annapurna III & 1980 & Avalanche \\
\hline Richard Schmidt & Annapurna III & 1980 & Avalanche \\
\hline David Sloane & Ganesh IV & 1981 & Avalanche \\
\hline Mark Moorhead & Makalu & 1983 & Fall \\
\hline Fred From & Mt Everest & 1984 & Fall \\
\hline Craig Nottle & Mt Everest & 1984 & Fall \\
\hline Keith Egerton & Jannu & 1986 & Altitude illness \\
\hline Mike Rheinberger & Mt Everest & 1994 & Cerebral oedema \\
\hline David Hume & Makalu & 1995 & Fall \\
\hline Mark Auricht & Mt Everest & 2001 & Cerebral oedema \\
\hline Paul Carr & Cho Oyu & 2003 & Blocked artery \\
\hline Sue Fear & Manaslu & 2006 & Fall in crevasse \\
\hline
\end{tabular}

* Deaths that occurred at or above the base camp while on a mountaineering expedition. The table does not include deaths that occurred while trekking in or out of an expedition. 
